

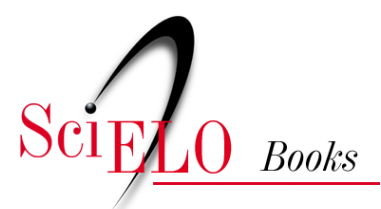

\title{
Rede de frio gestão, especificidades e atividades
}

\author{
Marileide do Nascimento Silva \\ Regina Fernandes Flauzino \\ (orgs.)
}

SILVA, M.N., and FLAUZINO, R.F., eds. Rede de frio: gestão, especificidades e atividades [online]. Rio de Janeiro: CDEAD/ENSP/EPSJV/Editora FIOCRUZ, 2017, 348 p. ISBN: 978-65-5708-096-2. https://doi.org/10.7476/9786557080962.

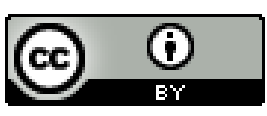

All the contents of this work, except where otherwise noted, is licensed under a Creative Commons Attribution 4.0 International license.

Todo o conteúdo deste trabalho, exceto quando houver ressalva, é publicado sob a licença Creative Commons Atribição 4.0. 


\section{Fundação Oswaldo Cruz - Fiocruz}

PRESIDENTE

Nísia Trindade Lima

VICE-PRESIDENTE DE EDUCAÇÃO, INFORMAÇÃO E COMUNICAÇÃO

Manoel Barral Netto

\section{Editora Fiocruz}

DIRETOR

Manoel Barral Netto

EDITOR EXECUTIVO

João Carlos Canossa Mendes

EDITORES CIENTÍFICOS

Carlos Machado de Freitas

Gilberto Hochman

CONSELHO EDITORIAL

Denise Valle

José Roberto Lapa e Silva

Kenneth Rochel de Camargo Jr.

Ligia Maria Vieira da Silva

Marcos Cueto

Maria Cecília de Souza Minayo

Marilia Santini de Oliveira

Moisés Goldbaum

Rafael Linden

Ricardo Ventura Santos
Escola Nacional de Saúde Pública Sergio Arouca

DIRETOR

Hermano Albuquerque de Castro

VICE-DIRETORA DE ENSINO

Lúcia Maria Dupret

COORDENADOR DE DESENVOLVIMENTO EDUCACIONAL

E EDUCAÇÃO A DISTÂNCIA

Mauricio De Seta

Escola Politécnica de Saúde Joaquim Venâncio

DIRETORA

Anakeila de Barros Stauffer 
Copyright (C2017 dos autores

Todos os direitos de edição reservados à Fundação Oswaldo Cruz - Editora Fiocruz e ENSP/CDEAD

SUPERVISORA EDITORIAL

Maria Leonor de M. S. Leal

ASSESSORAS PEDAGÓGICAS

Ana Paula Abreu-Fialho

Henriette dos Santos

ASSESSORAS TÉCNICAS

Ana Catarina de Melo Araújo

Maria de Fatima Guirra

REVISORA METODOLÓGICA

Ana Paula Abreu-Fialho
REVISORAS E NORMALIZADORAS

Christiane Abbade

Maria Auxiliadora Nogueira

Selma Monteiro Correia

Simone Teles

CAPA E PROJETO GRÁFICO

Jonathas Scott

EDITORAÇÃO ELETRÔNICA E TRATAMENTO DE IMAGEM

Robson Lima - Obra Completa Comunicação

ILUSTRADOR

Wagner Magalhães Paula

\section{S586r Silva, Marileide do Nascimento (Org.)}

Rede de frio: gestão, especificidades e atividades. / organizado por Marileide do Nascimento Silva e Regina Fernandes Flauzino. - Rio de Janeiro, RJ: CDEAD/ENSP/EPSJV/Editora FIOCRUZ, 2017.

348 p. ; il.

ISBN: 978-85-8432-019-6

1. Planejamento em Saúde. 2. Programas de Imunização. 3. Sistemas de Informação. 4. Refrigeração. 5.Rede de Frio. 6. Gerenciamento de Resíduos. 7. Saúde do Trabalhador. I.Flauzino, Regina Fernandes (Org.).II. Título.

$$
\text { CDD - 22.ed. }-615.372
$$

2017

\section{Editora Fiocruz}

Avenida Brasil, 4.036 - Sala 112

Manguinhos - Rio de Janeiro - RJ

CEP 21041-210

Tels.: (21) 3882-9039 ou 3882-9041

Telefax: (21) 3882-9006

www.fiocruz.br/editora
Coordenação de Desenvolvimento Educacional e Educação a Distância da Escola Nacional de Saúde Pública Sergio Arouca

Rua Leopoldo Bulhões, 1.480

Prédio Professor Joaquim Alberto Cardoso de Melo Manguinhos - Rio de Janeiro - RJ

CEP 21041-210

Tel.: (21) 2598-2996

www.ead.fiocruz.br 
Não é suficiente você fazer o seu melhor; primeiro você precisa saber exatamente o que fazer, para depois dar o seu melhor.

W. Edwards Deming 



\section{Autores}

\section{Alexandre Moreno Azevedo}

Economista graduado pela Universidade Estácio de Sá. Especialista em educação profissional em saúde pela Escola Politécnica de Saúde Joaquim Venâncio (EPSJV/ Fiocruz). Coordenador do Laboratório de Educação Profissional em Manutenção de Equipamentos de Saúde (EPSJV/Fiocruz).

\section{André Silva Cardoso}

Especialista técnico em rede de frio em imunobiológicos pela Escola Politécnica de Saúde Joaquim Venâncio (EPSJV/Fiocruz). Supervisor de almoxarifado do Setor de Distribuição da Central Nacional de Armazenagem e Distribuição de Imunobiológicos (Cenadi).

\section{Cláudia Othero Nunes Abreu}

Enfermeira referência técnica em imunização da SRS-BH da Secretaria de Estado da Saúde de Minas Gerais.

\section{Clayton Bernardo da Costa}

Especialista técnico em rede de frio de imunibiológicos pela Escola Politécnica de Saúde Joaquim Venâncio (EPSJV/Fiocruz). Tecnólogo em logística e responsável pelo Setor de Distribuição de imunobiológicos da Central Nacional de Armazenagem e Distribuição de Imunobiológicos (Cenadi).

\section{Cristiane Pereira de Barros}

Enfermeira. Especialista em saúde pública. Atualmente, é consultora técnica especialista do Ministério da Saúde.

\section{Evelin Plácido dos Santos}

Enfermeira. Mestre em ciências da saúde da Escola de Enfermagem da Universidade de São Paulo (USP). Especialista em saúde indígena pela Universidade Federal de São Paulo (Unifesp). Coordenadora da área de imunização do Projeto Xingu (Unifesp).

Felipe da Silva Furtado

Especialista técnico em rede de frio de imunibiológicos pela Escola Politécnica de Saúde Joaquim Venâncio (EPSJV/Fiocruz). Tecnólogo responsável pelo Setor de Recebimento e Armazenamento de Imunobiológicos da Central Nacional de Armazenagem e Distribuição de Imunobiológicos (Cenadi).

Irai Borges de Freitas

Pedagogo graduado pela Faculdade São Judas Tadeu. Mestre em desenvolvimento local pela Suam. Especialista em ergonomia pela Coppe/UFRJ e pela PUC. Especialista em saúde do trabalhador e ecologia humana pela Escola Nacional de Saúde Pública Sergio Arouca (ENSP/Fiocruz). Professor pesquisador do Laboratório de Educação Profissional em Manutenção de Equipamentos de Saúde da Escola Politécnica de Saúde Joaquim Venâncio (EPSJV/Fiocruz).

\section{João Leonel Batista Estery}

Médico; farmacêutico; advogado. Especialista em saúde pública pela UFRGS.

Coordenador de logística de imunobiológicos do Ministério da Saúde (MS) e consultor da produção do Manual de Rede de Frio, do Programa Nacional de Imunizações (MS).

\section{Luis Cláudio Bernardo Colacio}

Biólogo. Analista da qualidade em Bio-Manguinhos (Fiocruz). Atua na área de treinamentos em BPF e desenvolve auditorias internas da qualidade e auditorias em fornecedores. 
Katia Butter Leão de Freitas

Administradora. Mestre em ciências pela Escola Nacional de Saúde Pública Sergio Arouca (ENSP/Fiocruz). Especialista em ergonomia pela Coppe/UFRJ e em saúde do trabalhador e ecologia humana pela ENSP/Fiocruz. Professora pesquisadora do Laboratório de Educação Profissional em Manutenção de Equipamentos de Saúde da Escola Politécnica de Saúde Joaquim Venâncio (EPSJV/Fiocruz).

Marcello de Moura Coutinho

Bacharel e licenciado em ciências sociais pela Universidade Federal Fluminense (UFF). Mestre em políticas públicas e saúde pela Escola Nacional de Saúde Pública Sergio Arouca (ENSP/Fiocruz). Professor pesquisador da Escola Politécnica de Saúde Joaquim Venâncio (EPSJV/ Fiocruz). Coordenador do curso técnico de nível médio em gerência em saúde. Participa de projetos de pesquisa vinculados a políticas de saúde, qualificação de trabalhadores técnicos de saúde no Brasil, saúde do trabalhador e gestão em saúde.

Maria Luiza Silva Cunha

Psicóloga. Doutoranda em saúde pública pela Escola Nacional de Saúde Pública Sergio Arouca (ENSP/Fiocruz). Professora pesquisadora do Laboratório de Educação Profissional em Gestão em Saúde, da Escola Politécnica de Saúde Joaquim Venâncio (EPSJV/Fiocruz). Pesquisadora dos Grupos de Pesquisa Currículo e Processos de Formação em Saúde e Núcleo de Estudos em Democratização e Sociabilidades em Saúde.

Marileide do Nascimento Silva Enfermeira. Mestre em ensino de biociências em saúde do Instituto Oswaldo Cruz/ Fiocruz. Especialista em educação profissional em saúde pela Escola Politécnica de Saúde Joaquim Venâncio (EPSJV/Fiocruz). Auditora em serviços de saúde e professora pesquisadora na área de vigilância em saúde e imunizações da EPSJV/Fiocruz.

Marta Casagrande Koehler

Médica graduada pela Universidade Federal do Espírito Santo. Especialista em pediatria e pós-graduada em saúde pública pela Universidade de São Paulo (USP). Coordenadora do Programa Estadual de Imunizações e Vigilância dos Eventos Adversos Pós-Vacinação do estado do Espírito Santo, no período de 2001 a 2013.

Paulo Roberto de Carvalho

Químico. Doutor em ciências. Mestre em sistemas de gestão de segurança. Especialista em gestão ambiental. Professor pesquisador em biossegurança da Escola Politécnica de Saúde Joaquim Venâncio (EPSJV/Fiocruz). Professor orientador em programas de pósgraduação em biossegurança em unidades técnico-científicas da Fiocruz.

Pedro Luiz da Silva Moura

Engenheiro eletrônico pela Universidade Federal Fluminense (UFF). Técnico de gestão e planejamento em saúde do Ministério da Saúde. Professor pesquisador da Escola Politécnica de Saúde Joaquim Venâncio (EPSJV/Fiocruz).

Sarita de Oliveira Ferreira Lopes

Pedagoga graduada pela Faculdade São Judas Tadeu. Mestre em educação profissional em saúde pela Escola Politécnica de Saúde Joaquim Venâncio (EPSJV/ Fiocruz). Especialista em ergonomia pela Coppe/UFRJ e em saúde do trabalhador e ecologia humana pela Escola Nacional de Saúde Pública Sergio Arouca (ENSP/Fiocruz). Professora pesquisadora do Laboratório de Educação Profissional em Manutenção de Equipamentos de Saúde (EPSJV/Fiocruz).

Sergio Ricardo de Oliveira

Licenciado em física. Doutor em ensino de ciências e mestre em ciências na área de radiologia. Professor pesquisador do Laboratório de Educação Profissional em Manutenção de Equipamento de Saúde da Escola Politécnica de Saúde Joaquim Venâncio (EPSJV/Fiocruz). Atualmente é Vice-Diretor de Pesquisa e Desenvolvimento Tecnológico da EPSJV. 
Tereza Cristina Ramos Paiva

Psicóloga. Mestre em saúde pública pela Escola Nacional de Saúde Pública Sergio Arouca (ENSP/Fiocruz). Tecnologista em saúde do Laboratório de Educação Profissional em Gestão em Saúde da Escola Politécnica de Saúde Joaquim Venâncio (EPSJV/Fiocruz).

Valéria Cristina Gomes de Castro

Graduada em serviço social pela Universidade Federal Fluminense (UFF). Mestre em ciências, na área de saúde pública, pela Escola Nacional de Saúde Pública Sergio Arouca (ENSP/Fiocruz). Atualmente é docente e pesquisadora na Coordenadoria de Cooperação Social/Presidência Fiocruz. Experiência na área de saúde coletiva, com ênfase em saúde mental, gestão do trabalho, educação popular e participação social em saúde.

\title{
Yeda Célia Silva Eugênio
}

Enfermeira. Especialista em enfermagem de saúde pública. Atua na Coordenação de Vigilância Epidemiológica da Secretaria de Estado da Saúde (SESA/ES), no Programa Estadual de Imunizações e Doenças Imunopreveníveis.

\section{Walkyria Hercilia Carneiro}

Enfermeira. Especialista em enfermagem de saúde pública. Diretora técnica de Saúde ॥ da Rede de Frio da Secretaria de Estado da Saúde de São Paulo, desde maio 2002 até a presente data.

Walquíria Gonçalves dos Santos Teles

Enfermeira. Especialista em enfermagem de saúde pública. Técnica assessora do Programa Nacional de Imunizações, de 1999 a 2014. Atualmente, é auditora do Ministério da Saúde do Departamento Nacional de Auditoria do SUS.

\section{Organizadoras}

\author{
Marileide do Nascimento Silva
}

Regina Fernandes Flauzino

Enfermeira sanitarista. Doutora e mestre em saúde pública/epidemiologia pela Escola Nacional de Saúde Pública Sergio Arouca (ENSP/Fiocruz). Professora adjunta de epidemiologia do Instituto de Saúde Coletiva (ISC) da Universidade Federal Fluminense (UFF).

\section{Colaboradores}

\section{Andréa Pereira Laranjeira}

Biomédica. Mestre em biologia celular e molecular. Tecnologista em saúde pública do Instituto Nacional de Controle de Qualidade em Saúde (INCQS/Fiocruz).

Daniele Bessler

Enfermeira da Maternidade Leila Diniz (RJ). Conselheira do Conselho Regional de Enfermagem (RJ) e docente especialista em resíduos dos serviços de saúde.

Dilson dos Santos Oliveira

Especialista técnico em rede de frio de imunobiológicos pela Escola Politécnica de Saúde Joaquim Venâncio (EPSJV/Fiocruz). Tecnólogo responsável pelo Setor de Kits e Diagnóstico da Central Nacional de Armazenagem e Distribuição de Imunobiológicos (Cenadi). 
Eduardo Jorge Rabelo Netto

Biólogo. Mestre em vigilância sanitária. Coordenador dos núcleos técnicos do Instituto Nacional de Controle de Qualidade em Saúde (INCQS/Fiocruz).

Gladys Miyashiro Miyashiro

Médica. Mestre em saúde pública pela Escola Nacional de Saúde Pública Sergio Arouca (ENSP/Fiocruz). Especialista em educação profissional em saúde pela Escola Politécnica de Saúde Joaquim Venâncio (EPSJV/Fiocruz). Tecnologista em saúde pública da EPSJV/Fiocruz.

\section{Guaracemyr Matos}

Especialista técnico em rede de frio de imunobiológicos pela Escola Politécnica de Saúde Joaquim Venâncio (EPSJV/Fiocruz). Tecnólogo responsável pelo Setor de Almoxarifado da Central Nacional de Armazenagem e Distribuição de Imunobiológicos (Cenadi).

leda da Costa Barbosa

Enfermeira. Mestre em políticas públicas pela Universidade do Estado do Rio de Janeiro (Uerj). Especialista em educação profissional em saúde pela Escola Politécnica de Saúde Joaquim Venâncio (EPSJV/Fiocruz). Tecnologista em saúde pública da EPSJV/Fiocruz.

\section{Jaline Alves Cabral da Costa}

Farmacêutica industrial e bioquímica. Mestre em ciências biológicas pelo Instituto de Microbiologia Paulo de Goés - UFRJ. Tecnologista em saúde pública do Instituto Nacional de Controle de Qualidade em Saúde (INCQS/Fiocruz).

Márcia Danieluk

Enfermeira. Atualmente lotada na Secretaria Estadual de Saúde da Bahia.

\section{Muriel Silva Moura}

Médica graduada pela Universidade Federal de Alagoas (Ufal). Especialista em clínica médica (Hospital Santa Marcelina-SP), hematologia, unidade de terapia intensiva e transplante de medula (Unicamp). Em exercício no Centro de Hematologia da Santa Casa de Misericórdia de Maceió e no Hospital Cliom.

\section{Nadja Greffe}

Enfermeira. Especialista em saúde pública pela Universidade Federal do Estado do Rio de Janeiro (UniRio). Coordenadora do Programa de Imunizações da Superintendência de Vigilância em Saúde da Subsecretaria de Promoção, Atenção Primária e Vigilância em Saúde da SMS do Rio de Janeiro. 


\section{Sumário}

Prefácio

Apresentação

\section{Imunização: especificidades e as bases para a compreensão} da rede de frio de imunobiológicos

1. Planejamento em saúde

Maria Luiza Silva Cunha e Tereza Cristina Ramos Paiva

2. O calendário de vacinação brasileiro e as estratégias para imunização da população Marta Casagrande Koehler e Evelin Plácido dos Santos

3. Vigilância epidemiológica em eventos adversos pós-vacinação.

Cláudia Othero Nunes Abreu e Marileide do Nascimento Silva

4. Avaliação da vacinação

Cláudia Othero Nunes Abreu

5. Sistemas de Informações do Programa Nacional de Imunizações (SI-PNI)

Walkyria Hercilia Carneiro e Marileide do Nascimento Silva

\section{A gestão da rede de frio de imunobiológicos e seu processo de trabalho}

6. A rede de frio e a importância da temperatura dos imunobiológicos. Alexandre Moreno Azevedo, Clayton Bernardo da Costa, Luis Cláudio Bernardo Colacio, Pedro Luiz da Silva Moura e Sergio Ricardo de Oliveira

7. Refrigeração e equipamentos da rede de frio

Alexandre Moreno Azevedo e Pedro Luiz da Silva Moura

8. Gestão da rede de frio de imunobiológicos André Silva Cardoso, Clayton Bernardo da Costa, Cristiane Pereira de Barros, Felipe da Silva Furtado, João Leonel Batista Estery, Walquíria Gonçalves dos Santos Teles e Yeda Célia Silva Eugênio

9. Gerenciamento de resíduos na rede de frio

Cristiane Pereira de Barros e Walquiria Gonçalves dos Santos Teles

\section{Organização do trabalho em saúde e a rede de frio de imunobiológicos}

10. Organização do trabalho

Marcello de Moura Coutinho e Valéria Cristina Gomes de Castro

11. Organizações públicas e o processo de trabalho em saúde Marcello de Moura Coutinho, Maria Luiza Silva Cunha

12. Saúde e segurança do trabalhador na rede de frio de imunobiológicos Irai Borges de Freitas, Katia Butter Leão de Freitas, Marcello de Moura Coutinho,

Sarita de Oliveira Ferreira Lopes 
13. Arquitetura, ambiência, ergonomia e saúde nos locais de trabalho Irai Borges de Freitas, Katia Butter Leão de Freitas e Sarita de Oliveira Ferreira Lopes

14. Noções gerais sobre biossegurançae a questão do incêndio .... 


\section{Prefácio}

A iniciativa de publicar um livro sobre rede de frio é de alta relevância para o Programa Nacional de Imunizações e, portanto, para a saúde da população brasileira.

Todos conhecemos exemplos de surtos de doenças infecciosas em que a má conservação de vacinas, especialmente as de vírus vivos, foi identificada como fator relevante para essa ocorrência. Mesmo que a termoestabilidade de vacinas tenha sido melhorada nos últimos anos, e as respectivas apresentações tenham agora muito menos doses, a manutenção adequada da rede de frio continua sendo fator essencial para que as vacinações possam atingir seu objetivo: imunizar as pessoas contra doenças infecciosas de grande relevância, que, por isso, demandam ações específicas de prevenção.

Sabemos também, pelas experiências negativas, que a conscientização e a preparação dos profissionais encarregados da rede de frio são indispensáveis. Por mais simples que sejam as ações, se as pessoas não souberem a razão que baseia a forma de organização, a logística de distribuição, os procedimentos, bem como seu fundamento teórico básico, a execução ficará comprometida. Os profissionais da rede de frio devem compreender que fazem parte de um conjunto articulado, que visa obter imunizações bem-sucedidas. Para isso, devem conservar a vacina, um produto muito sensível e delicado, de forma correta. A rede de frio adequada evitará perdas de vacinas e, portanto, contribuirá para a efetiva diminuição de custos e a redução de desperdício.

A apresentação didática dos fundamentos das ações de manutenção de rede de frio e de seu papel dentro do Sistema Único de Saúde visa mais do que formar técnicos, é sim ter profissionais comprometidos com a saúde da população e conscientes de que fazem parte de uma grande equipe integrada, em que tudo e todos são importantes. 
Outro aspecto essencial dentro da organização e articulação da rede de frio é a sua gestão, qualificada e profissional, focada detalhadamente neste livro. Bio-Manguinhos/Fiocruz tem orgulho de ter contribuído com a organização e operação do embrião inicial da, hoje, altamente complexa rede de frio do Programa Nacional de Imunizações.

As organizadoras, os autores e os colaboradores do livro são pessoas com grande conhecimento e experiência na área, garantindo a qualidade e pertinência da obra, que será uma fonte básica para busca de informações, treinamento e formação de pessoal especializado.

\section{Akira Homma}

Assessor científico sênior de Bio-Manguinhos/Fiocruz; membro do Comitê Executivo da Rede de Fabricantes de Vacinas dos Países em Desenvolvimento (DCVMM).

Reinaldo de Menezes Martins

Assessor do Comitê Técnico em Imunizações do Programa Nacional de Imunizações do Ministério da Saúde (PNI/MS); consultor científico de Bio-Manguinhos/Fiocruz. 


\section{Apresentação}

A imunização é uma das intervenções em saúde pública de maior efetividade na redução das mortes, das doenças, no Brasil e no mundo inteiro. As vacinas, junto com a vigilância, foram responsáveis pela eliminação de diversas doenças como, por exemplo, a varíola, obtendo, indiscutivelmente, o reconhecimento da população por sua efetividade e importância.

A oferta à população de imunobiológicos em condições de conferir proteção é assegurada por um eficiente processo de conservação, armazenamento e distribuição, denominado rede de frio. Esse processo logístico é complexo e exige padrões rígidos, preestabelecidos, e padrões técnicos de utilização e gestão dos imunobiológicos, em todos os níveis de gestão do sistema de saúde, a fim de garantir a qualidade dos imunobiológicos que chegam às diversas salas de vacinas do país.

O governo brasileiro, visando manter a qualidade e segurança desses produtos, tem investido, cada vez mais, na estruturação e/ou construção de centrais de armazenamento e distribuição de imunobiológicos em todo país.

O Programa Nacional de Imunizações tem empenhado esforços nessa direção, de modo a ofertar imunobiológicos de qualidade, por meio da construção de novas centrais e, também, da compra de equipamentos específicos, de sistema de informação próprio e de padrões de referência e rotinas que assegurem o correto funcionamento da rede de frio.

Se, por um lado, podemos comemorar as iniciativas de investimento na construção de novas centrais de armazenamento, que ocorrem de forma dinâmica e crescente, por outro, observamos que as capacitações de profissionais não ocorrem na mesma proporção, visto que inexistem ofertas para a formação específica nessa área bem como materiais didáticos que abordem a temática de forma ampla, e não apenas técnica, de modo a atender a demanda cada vez maior da imunização/rede de frio no Sistema Único de Saúde. 
É fundamental que a formação desses profissionais esteja em consonância com a proposta da vigilância em saúde, baseada na atenção básica e na reorganização das práticas sanitárias, com ênfase na integralidade do cuidado, sem perder o foco da importância do conhecimento técnico, que deve estar associado às demais questões da saúde.

Com essa convicção é que o livro Rede de Frio: gestão, especificidades e atividades foi concebido, organizado e produzido pela Fiocruz, por meio da Escola Politécnica Joaquim Venâncio e da Escola Nacional de Saúde Pública Sergio Arouca/Coordenação de Desenvolvimento Educacional e Educação a Distância, em parceria com a Editora Fiocruz. A obra contou com a participação de especialistas das Secretarias Estadual e Municipal de Saúde do Rio de Janeiro, da Central Nacional de Armazenagem e Distribuição de Imunobiológicos (Cenadi), do Ministério da Saúde, da Universidade Federal Fluminense (UFF) e da Universidade Federal do Estado do Rio de Janeiro (UniRio). Ele é, portanto, fruto do compartilhamento de ideias entre parceiros com perfis diversificados e objetivos bem definidos.

Com o propósito de colaborar para o aperfeiçoamento dos processos formativos, o livro discorre sobre temas relacionados às atividades de imunização que balizam a existência e compreensão da rede de frio para a garantia dos imunobiológicos, com base no trabalho realizado na Cenadi. Destaca a necessidade do trabalho compartilhado e do planejamento para gestão eficiente da rede; ressalta o papel estratégico que o trabalhador da rede de frio desempenha nesse processo; debate assuntos que vão desde o calendário vacinal até o gerenciamento dos resíduos resultantes das atividades desenvolvidas na imunização e na rede de frio de imunobiológicos.

Da forma como está organizado, em três partes, o livro propõe ao conjunto de trabalhadores da área de saúde reflexões sobre o processo de trabalho em saúde com enfoque na atenção básica e no conhecimento dos aspectos fundamentais das estruturas de gestão da rede de frio de imunobiológicos, nas diversas instâncias e níveis de gestão.

Essa proposta reflexiva, em que teoria e prática se articulam e se complementam, torna a publicação valorosa para os profissionais de saúde, à medida que suscita a análise de conceitos e debates à luz de suas experiências, tanto nos serviços como no meio acadêmico, conferindo-lhes o papel de atores em seus processos formativos ou de trabalho. Desse modo, os estudos apresentados contribuem para a qualificação de profissionais com uma visão ampla das questões que perpassam as atividades da rede de frio e para uma atuação crítica e inovadora no seu cotidiano. 
I Imunização: especificidades e as bases para a compreensão da rede de frio de imunobiológicos

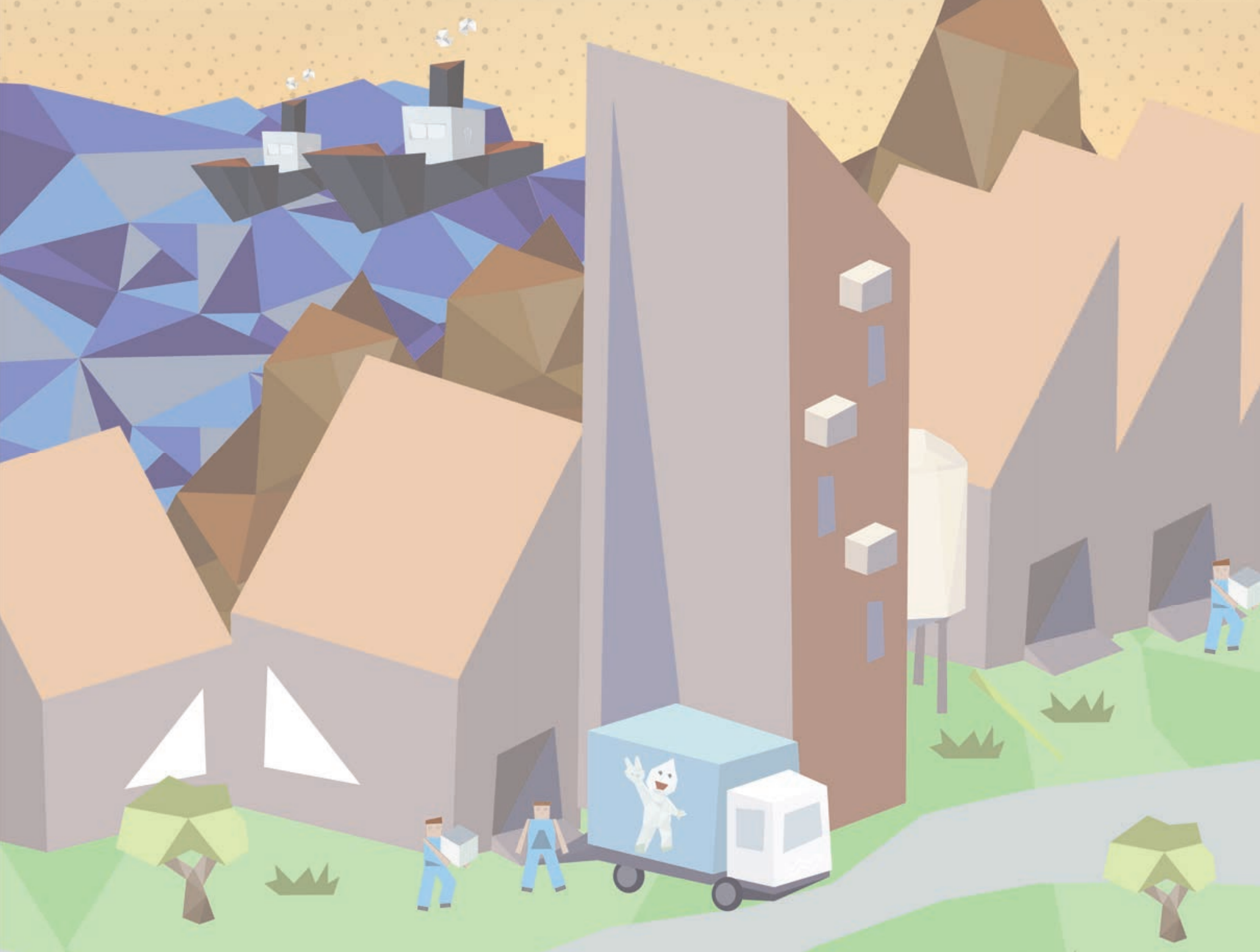





\title{
1. Planejamento em saúde
}

\author{
Maria Luiza Silva Cunha e Tereza Cristina Ramos Paiva
}

A garantia da proteção da população por meio da imunização contra as doenças passíveis de vacinação envolve um conjunto de procedimentos prévios que incluem, até chegar à imunização, de fato, e cumprir com o objetivo proposto:

* planejamento do calendário de vacinação;

*organização das unidades e centrais de rede de frio com recursos materiais e humanos, em quantitativos suficientes;

* adequação e preparação dos centros de referência para aplicação dos imunobiológicos especiais;

* infraestrutura e equipe capacitada para manuseio, conservação, preparo, administração, registro e descarte dos resíduos resultantes das ações de vacinação.

Essa gama de atividades deve ser realizada com o máximo de organização para que haja o mínimo de risco e interferências possíveis. Assim, as ações necessitam de ser pensadas, previstas, monitoradas e avaliadas, ou seja, precisam, antes de qualquer ato, ser planejadas! O dimensionamento do que é necessário e de como poderá ser realizado, a partir dos objetivos traçados, somente será efetivo com um planejamento cuidadoso das atividades e uma avaliação contínua e sistemática dessas ações.

Ao longo deste capítulo, buscamos apresentar o planejamento em saúde como fator determinante e propulsor das atividades de imunização e da rede de frio de imunobiológicos. Inicialmente, destacamos algumas concepções que reforçam a importância de se planejar ações para obter

No Capítulo 8," Gestão da rede de frio de imunobiológicos", demonstraremos a aplicação prática da discussão sobre planejamento nessa rede. 
êxito e alcançar metas. Em seguida, propomos algumas reflexões sobre a relação intrínseca entre o planejamento e os processos de trabalho na rede de frio, utilizando o planejamento estratégico como referência. Esperamos, ainda, fornecer subsídios que o ajudem a entender sobre o planejamento e seu papel na organização das atividades de vacinação e da rede de frio.

\section{Conceito de planejamento}

Planejar em saúde não é um modismo ou uma opção de gestão, mas uma necessidade! Em imunização e em rede de frio, o planejamento é elemento fundamental, especialmente porque ambas as situações envolvem um complexo sistema logístico, executado em diversos níveis ou instâncias, com atuação de inúmeros profissionais, de níveis e conhecimentos diversos, todos trabalhando em comum para levar as vacinas a cada recanto ou região deste imenso país que é o Brasil.

Como fazer para que a vacina esteja disponível e em condições de conferir proteção e/ou imunizar cada uma das pessoas nas mais diversas regiões e diferentes realidades sociopolíticas, econômicas e culturais? Como garantir que as vacinas cheguem às unidades de saúde em temperatura adequada para serem aplicadas?

Reconhecemos não ser tarefa fácil. Por isso, precisamos que as atividades sejam planejadas adequadamente e acompanhadas em cada etapa, realizando-se os ajustes necessários, as readequações e/ou reorganizações, para que se possa garantir sua realização com a máxima eficácia e o mínimo de risco.

Figura 1 - Reunião de planejamento

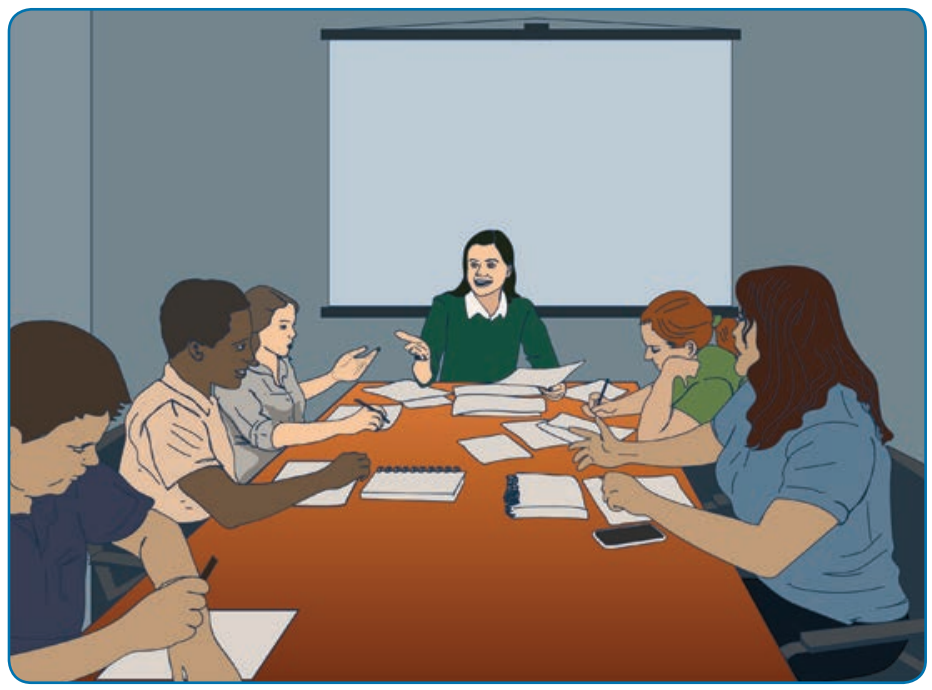

O planejamento se constitui em poderosa ferramenta para as atividades da saúde, especialmente para a vacinação e para a rede de frio. Para iniciarmos uma reflexão acerca do planejamento como importante ferramenta no processo de gestão, precisamos entender como ele é conceituado.

Analise a Figura 1: observe que há um grupo de pessoas realizando um trabalho sistemático de planejamento.

Podemos, em algumas situações, agir de forma não planejada, realizando ou marcando nossas ações pelo improviso. 
O planejamento das ações passa a ser uma alternativa à não improvisação, usando-se métodos, pensamento sistemático e traçando-se objetivos a fim de criar um futuro (HUERTAS, 1996).

Algumas pessoas podem ponderar, no entanto, que o futuro é complexo, incerto, repleto de surpresas, não sendo possível realizar uma predição do que ocorrerá.

Devemos, então, ficar no imobilismo e esperar para ver o que o destino nos reserva?

A resposta é não! Porque "quem planeja influi nos resultados futuros, ainda que não tenha total controle sobre os resultados de sua ação", conforme cita HUERTAS (1996, p. 15). Em outras palavras, significa que, se não podemos predizer o que irá acontecer no futuro, podemos, sim, prevê-lo e influenciar os fatos que se seguirão, através do planejamento das ações.

Conforme essa concepção, o planejamento se opõe à visão determinística e de condução pelo destino (como na música Deixa a vida me levar, de Serginho Meriti (PAGODINHO, 2002)), e se configura como uma possibilidade de escolha e uma ferramenta de liberdade.

No setor de saúde, em geral, e na rede de frio de imunobiológicos, em particular, existem importantes motivos para que tais ações baseadas no improviso sejam evitadas. Consequências dessa ação não planejada podem levar a problemas sérios. Um exemplo é na própria imunização e na rede de frio, em que a falta ou a inadequação de planejamento na aquisição e distribuição dos imunobiológicos pode acarretar desabastecimento desses produtos, levando à insuficiência ou à inexistência de vacinas para atender à população. Tal equívoco interfere no controle epidemiológico das doenças e, consequentemente, nas mortes evitáveis pela vacinação.

Em outras palavras, ações não planejadas podem levar ao desperdício e ao mau uso dos recursos, além de interferirem no alcance dos objetivos.

“O planejamento então precede a ação, sendo inseparável desta como as faces de uma mesma moeda. Podemos dizer que o planejamento e ação são indissociáveis" (MATUS, 1996). Em síntese, nas palavras de Carlos Matus, importante autor do planejamento em saúde na América Latina, o "planejamento é o cálculo que precede e preside a ação" (MATUS, 1996, p. 57).

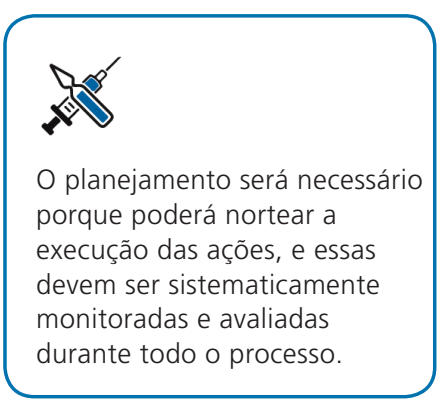


No Anexo A, "Contribuições de Carlos Matus e Mário Testa no planejamento estratégico", deste capítulo, apresentamos algumas informações sobre esses autores.

\section{Podemos então afirmar:}

Planejamento é um processo que busca transformar uma situação em outra tendo em vista uma dada finalidade. Para isso, precisaremos recorrer ao uso de instrumentos (meios de trabalho tais como técnicas e saberes), desenvolvendo atividades (trabalho propriamente dito), sob determinadas relações sociais, em uma dada organização (PAIM, 2002). Essa prática social, técnica, política, econômica e ideológica pode se apresentar de modo estruturado, por meio de políticas, planos, programa e projetos, ou não estruturado, isto é, como um cálculo (MATUS, 1996) ou um pensamento estratégico (TESTA, 1995).

Fonte: Paim (2006, p. 770).

A partir dessas concepções, por que é importante planejar na saúde?

Em saúde, o uso dos recursos deve ser racionalizado, e os diferentes atores envolvidos precisam ser ouvidos e contemplados de alguma forma. Isso só é possível com planejamento constante das ações a serem realizadas. Vale destacar que o planejamento é uma ferramenta também muito utilizada em outras áreas, mas, em saúde, é imprescindível, em função dos fatores já mencionados e de outros, como a própria complexidade do setor de saúde. Necessidades da população, perfil de adoecimento, concentração de oferta de serviços, disponibilização desses serviços, crescentes inovações tecnológicas são exemplos de questões constantes que precisam ser superadas. Alguns desses aspectos tornam-se pontos de gargalo perante a escassez de recursos para resolvê-los ou equacioná-los de forma a garantir a equidade da atenção.

Outro fator a ser considerado é o próprio processo de trabalho em saúde, que é complexo e envolve aspectos dinâmicos e relacionais, sendo este último um aspecto delicado, porque prevê a interação dos profissionais da saúde com múltiplos sujeitos, entre eles, gestores, usuários, lideranças comunitárias, trabalhadores de outros setores sociais, fornecedores etc. Todos podem apresentar explicações distintas da realidade e possuir diferentes interesses e valores, tornando o planejamento essencial e necessário para que se possam traçar objetivos compartilhados e ações coerentes em um processo participativo e democrático.

\section{Para refletir}

Pense, então: como se dá o planejamento em seu local de trabalho? Existem fóruns deliberativos e de planejamento? Quem participa? Na sua opinião, ele é considerado importante para seu trabalho e/ou de seus colegas? 
Com base no que vimos até agora, podemos afirmar que o planejamento é uma etapa fundamental na organização de qualquer atividade, mas, para realizá-lo e melhor compreender sua importância, precisamos conhecer como surgiu e quais as concepções adotadas ao longo do tempo.

\section{Planejamento em saúde: origem e concepções}

As origens do planejamento estão associadas à própria existência humana, ao adquirir a capacidade de pensar antes de agir e de transformar a realidade a partir do processo de trabalho. Essa é uma condição inerente à vida humana (GIOVANELLA, 1991).

A literatura faz referência ao fato de que, no início do século $\mathrm{XX}$, no contexto de organização dos serviços previsto pelo modelo campanhista de saúde pública, já se utilizavam noções, métodos e técnicas da Teoria Geral da Administração. No entanto, foi a partir da década de 1960 que emergiu na América Latina e no Brasil a reflexão teórica e metodológica voltada às questões específicas do setor de saúde, com o movimento pelo Planejamento em Saúde (PAIM, 1983 apud TEIXEIRA; SÁ, 1996). Naquela época, surgiram as duas concepções mais importantes de planejamento: a normativa e a estratégica.

\section{Concepção normativa: uma breve síntese}

Em 1961, o Conselho Interamericano Econômico e Social, em reunião especial, formulou a Carta de Punta del Este, marco histórico na perspectiva do desenvolvimento mediante a associação do econômico com o social. Esse documento "reconhecia a saúde como componente essencial do desenvolvimento, enfatizando a necessidade do planejamento, sob a condução do Estado, para a consecução dos objetivos nacionais de bem-estar, democracia e segurança" (LIMA, 2002, p. 82). Esse enfoque foi dado à concepção normativa, que se relaciona com a busca pelo desenvolvimento econômico dos países periféricos, visando alcançar os mesmos patamares dos países centrais.

No ano de 1963, na reunião de ministros da saúde promovida pela Opas, se estabeleceu o Plano Decenal de Saúde Pública para as Américas. A associação estabelecida com o Banco Interamericano de Desenvolvimento permitiu o investimento em programas de saúde nos anos de 1960 e 1970 (LIMA, 2002).

Para cumprir as exigências relativas ao recebimento dos investimentos oferecidos pelos organismos internacionais, os países periféricos
Os modelos de atenção foram apresentados no Capítulo 2, "Políticas públicas de saúde e a organização do SUS", do livro Rede de Frio: fundamentos para a compreensão do trabalho (SILVA; FLAUZINO; GONDIM, 2016). Já as concepções normativa e estratégica serão apresentadas no Anexo A, "Contribuições de Carlos Matus e Mário Testa no planejamento estratégico", deste capítulo. 
deveriam realizar um plano nos moldes metodológicos desenvolvidos pelo Centro de Estudos do Desenvolvimento da Universidade Central da Venezuela (Cendes), a partir da solicitação da Organização Pan-Americana da Saúde (Opas). Esse método, conhecido como Método Cendes-Opas, é a expressão da concepção normativa do planejamento e caracteriza-se, entre outros aspectos:

* pela preocupação com a eficiência;

* pela centralidade da técnica;

* pelo distanciamento do planejador da realidade social planejada; e velo fato de tomar essa realidade como um objeto estático e sujeita à predição.

Fotos 1 e 2 - Planejamento distante da realidade social planejada é uma característica da concepção normativa
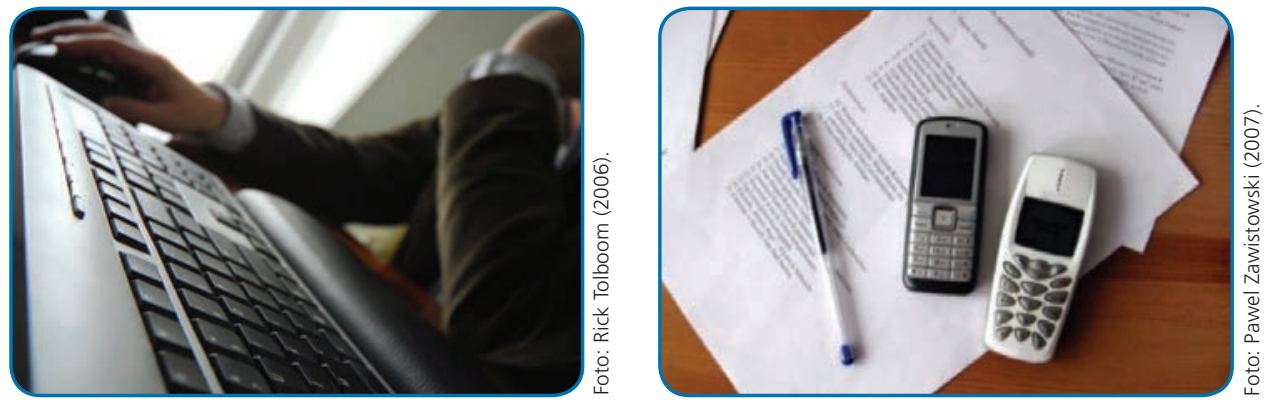

A crítica ao Método Cendes-Opas foi referente à "omissão dos aspectos políticos inerentes à problemática institucional do setor, como o financiamento, a falta de coordenação dos serviços, a baixa capacidade de regulação do Estado, a baixa capacidade de governo, o nível de privatização etc."(RIVERA, 2009, p. 313).

Outra concepção de planejamento, a concepção estratégica, em particular a do Planejamento Estratégico Situacional (PES), tem grande aplicação no campo da saúde.

\section{Concepção estratégica}

Surgiu a partir do fim dos anos 1970, tendo em vista a crítica ao método normativo. A concepção estratégica propôs uma reformulação do planejamento, incorporando o aspecto político. Um marco, nessa

Microeconomia é o ramo da economia que se ocupa dos diferentes agentes econômicos, entre os quais as empresas e os consumidores (MICROECONOMIA, [200-]). perspectiva, foi a publicação, no ano de 1975, de "Formulación de Políticas de Salud", pelo Centro Pan-Americano de Planejamento em Saúde (CPPS-Opas). Esse documento significou um passo fundamental na direção do deslocamento da discussão do planejamento em saúde do âmbito da microeconomia para o âmbito político. 
O enfoque estratégico parte do pressuposto da existência de sistemas sociais históricos, caracterizados pela complexidade e incerteza. As vertentes da corrente estratégica do planejamento em saúde são: o Planejamento Situacional, de Carlos Matus, o Pensamento Estratégico, de Mário Testa, e a Escola de Medellin (ORGANIZAÇÃO PAN-AMERICANA DA SAÚDE, 1995).

Antes de continuarmos, entendemos que uma situação ilustrativa pode ajudar a compreender a diferença entre as duas concepções mencionadas. Leia com atenção o trecho a seguir.

\section{Diálogo entre a prática e a teoria cujo tema é o verbo planejar}

A professora, Dona Prática, pede à Senhorita Teoria Normativa:

- Conjugue o verbo "planejar".

A Senhorita Teoria Normativa obedece: - Eu planejo.

- Continue, está indo bem - diz a Dona Prática.

- Já terminei, professora - responde a Senhorita Teoria Normativa.

Perplexa, Dona Prática olha suas alunas. A Senhorita Situacional está ansiosa para falar e conjuga o verbo antes que Ihe peçam: - Eu planejo, tu planejas, ele planeja etc.

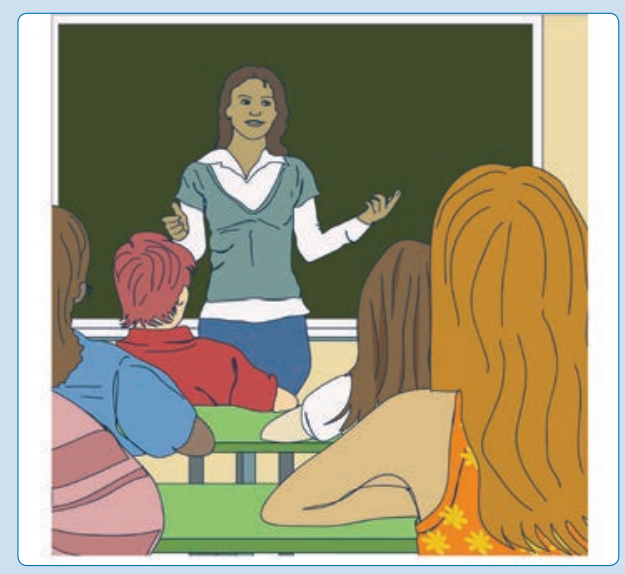

O primeiro princípio do planejamento moderno é: "Ninguém detém o monopólio do cálculo sistemático sobre o futuro" (MATUS, 1996, p. 52-53). Todos podemos planejar e todos fazemos algum tipo de análise sobre o amanhã antes de, hoje, tomar uma decisão. Eu planejo, tu planejas. Se não compreendermos pelo menos isso, não poderemos resgatar o planejamento do mar de confusões em que navega.

Fonte: Matus (1996, p. 52-53). 


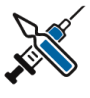

Ao considerar todos esses atores participantes no planejamento em saúde, conforme a concepção estratégica, avançamos em um dos princípios organizativos do SUS, que é a participação social contribuindo para a democratização da saúde.
Com base na situação ilustrada, podemos observar que a prática (professora Dona Prática) espera da teoria normativa (Senhorita Teoria Normativa) respostas que esta não dá? Ficou mais nítido que existem diferenças em tais concepções em relação a quem planeja?

Percebemos, a partir dessas concepções, que o planejamento na área da saúde precisa ser realizado de forma mais operativa, dadas as especificidades do setor, e deve envolver todos os aspectos e atores que participam do processo. Acredita-se, então, que a visão do planejamento na concepção estratégica tenha maior possibilidade de lidar com a complexidade do setor de saúde.

Vimos, anteriormente, que o próprio trabalho em saúde e também na rede de frio de imunobiológicos engloba um conjunto amplo de envolvidos, sejam trabalhadores, gestores, profissionais das centrais de armazenamento e usuários. Como planejar com esse conjunto de atores é um desafio apresentado pela concepção estratégica, que, na saúde (e, consequentemente, na rede de frio e imunização), se expressa pela metodologia do Planejamento Estratégico Situacional (PES).

\section{Enfoque sobre a metodologia do Planejamento Estratégico Situacional, de Carlos Matus}

O enfoque situacional de planejamento reconhece a existência de várias visões sobre determinada situação e, consequentemente, de conflitos na realidade. A situação pode ser percebida ou compreendida diferentemente, dependendo de quem e de como ela é observada. Um exemplo é a clássica figura a seguir (Figura 2). Este enfoque visa oferecer instrumentos ou subsídios que possam ajudá-lo a planejar na sua realidade de trabalho.

O que você vê? Dois rostos ou um cálice? Podemos dizer que as respostas podem ser distintas, embora a figura seja única. Ao planejar com base no enfoque do PES, é preciso considerar as diversas visões sobre a realidade e debater sobre essas opiniões com o intuito de construir consensos sobre ações estratégicas que possam auxiliar na resolução ou diminuição de problemas e, assim, propiciar mudanças em determinada realidade. Planejar, portanto, precede uma ação, exige participação e visão dinâmica permanente durante suas fases ou momentos.
Figura 2 - São rostos ou um cálice?

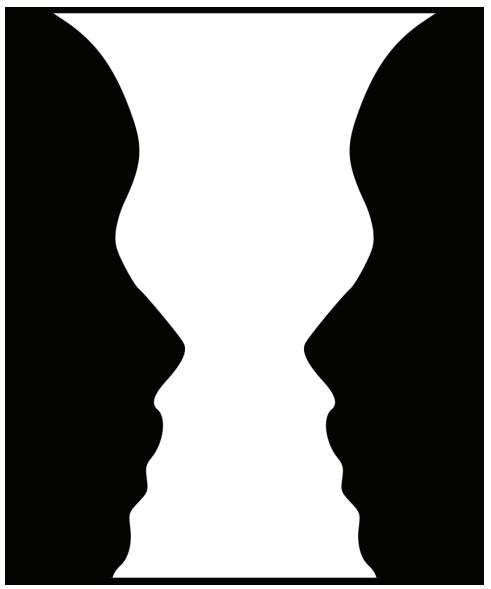

Fonte: Wikimedia Commons (user: Bryan Derksen, 2007) 
Apresentaremos quatro noções que são importantes para a aplicação da metodologia do PES: situação, ator social, poder e problema.

\section{Situação}

É o conjunto de problemas identificados, descritos e analisados sobre determinada realidade na qual se quer intervir. Por exemplo, quando conversa com uma pessoa sobre as principais dificuldades encontradas em seu processo de trabalho, sejam elas operacionais, relacionais, financeiras, políticas, você está apresentando a sua visão sobre a situação em questão.

Situação, portanto, é o lugar social onde estão presentes o ator e a ação.

\section{Ator social}

Pode ser uma personalidade, uma organização ou um agrupamento humano que tenha capacidade organizativa, um projeto e controle de variáveis para produzir fatos na situação.

Ator, portanto, pode ser você, sua equipe de trabalho, representantes de sua instituição, desde que possuam capacidade e governabilidade para intervir em determinado problema presente na realidade.

\section{Poder}

É uma relação social que se refere às forças sociais em conflito. É a capacidade de fazer, de influenciar o que os outros fazem. Está relacionado à governabilidade de determinado ator ao intervir numa determinada ação, por exemplo, a influência que o gestor da rede de frio exerce sobre os processos de trabalho nessa rede.

\section{Problema}

É algo considerado fora dos padrões de normalidade para os atores sociais que estão analisando a situação. Esses padrões são definidos a partir do conhecimento, do interesse e da capacidade de agir sobre dada situação.

O problema é a distância entre o que é (situação atual) e o que deveria ser (situação-objetivo) para determinado ator social.

Os problemas podem ser classificados em problemas estruturados, quase ou semiestruturados e mal estruturados.
O PES é bastante potente, principalmente diante de problemas mal estruturados e quase estruturados, muito frequentes no campo da saúde. 
Essas definições de problema bem como uma introdução ao PES são brevemente abordadas no Capítulo 3, "Introdução à vigilância em saúde: vigilância epidemiológica, vigilância sanitária, ambiental e saúde do trabalhador", do livro Rede de Frio: fundamentos para a compreensão do trabalho (SILVA; FLAUZINO; Gondim, 2016). Lá, o foco está na análise das condições de vida e situação de saúde de uma população; aqui, discutimos com vistas ao processo de trabalho em saúde.
Os problemas estruturados respondem às regras já estabelecidas, e suas causas podem ser claramente identificadas, o que possibilita, de forma óbvia, a sua solução. Esses problemas podem ser resolvidos de forma normativa, como, por exemplo, erros na estocagem de imunobiológicos, torneira com vazamentos, ou outros que você pode conhecer.

Os problemas quase ou semiestruturados possuem características intermediárias, pressupõem certo grau de incerteza. O enfrentamento desse tipo de problema pode gerar dificuldades em outro problema, o que demanda forte abordagem sociopolítica. Eles dependem de um enfoque multissetorial, do contexto em que se inserem. Não são consensuais e necessitam da atuação estratégica de vários atores para o seu enfrentamento. A definição de como chegar a uma solução não é muito clara, pois pode haver várias soluções com graus diferentes de eficácia.

Um exemplo: como melhorar a cobertura vacinal em menores de 1 ano de idade, no município de Morro Alto? A solução depende não somente dos profissionais que trabalham no setor de imunização. Para resolver o problema, pode ser necessária a adesão de diversos outros profissionais e setores, como agentes comunitários de saúde, equipe da saúde da criança, até mesmo profissionais das escolas, associação de moradores.

Em contrapartida, os problemas mal estruturados estão relacionados à situação de incerteza e só podem ser tratados por meio de modelos probabilísticos, visto que nem todas as suas causas podem ser identificadas. Como melhorar os serviços de saúde é um exemplo de problema mal estruturado, visto que envolve muitas variáveis (social, política, econômica, cultural), que nem sempre são conhecidas, e está relacionado a situações de incerteza, que não são facilmente controladas por protocolos ou normas.

A metodologia do PES é aplicada para intervir sobre problemas quase ou semiestruturados ou, principalmente, em problemas pouco estruturados.

A partir do entendimento sobre os três tipos de problema, como podemos planejar estrategicamente as atividades, considerando o cotidiano de trabalho em saúde, caracterizado por diversas dificuldades, e a complexidade logística que envolve as atividades de vacinação e da rede de frio?

Certamente, não há uma resposta pronta, mas planejar essas ações pode auxiliar, e muito, a equacionar ou dirimir parte dos riscos e problemas 
que poderiam vir a ocorrer, caso elas não fossem planejadas. Vale lembrar que, associados ao planejamento, o monitoramento e a avaliação das atividades deverão ser realizados como forma de controle, acompanhamento, revisão e reorganização do trabalho, das ações.

\section{Para refletir}

Pense em seu local de trabalho: quais os problemas que você identifica?

Quais os atores sociais que poderiam planejar mudanças? Quais foram os critérios de sua escolha?

Para auxiliá-lo a resolver determinados problemas em seu local de trabalho, apresentamos no Quadro 1, de forma resumida, os principais momentos que compõem a metodologia do PES para a elaboração de um plano de ação.

A palavra momentos tem o objetivo de ressaltar a noção de que o planejamento se constitui em um processo dinâmico, construído permanentemente; portanto, tem sentido distinto da palavra etapas.

Quadro 1 - Momentos do Planejamento Estratégico Situacional

\begin{tabular}{|c|c|c|}
\hline Momentos do PES & O que é & O que o compõe \\
\hline $\begin{array}{l}\text { Explicativo (o que } \\
\text { foi, é, tende a ser) }\end{array}$ & $\begin{array}{l}\text { É o momento da análise da situação } \\
\text { inicial (SI), para fundamentar a ação. }\end{array}$ & $\begin{array}{l}\text { - Identificação dos problemas } \\
\text { - Priorização } \\
\text { - Explicação do problema }\end{array}$ \\
\hline $\begin{array}{l}\text { Normativo (o que } \\
\text { deve ser) }\end{array}$ & $\begin{array}{l}\text { É o momento de desenhar as ações } \\
\text { necessárias e suficientes para atacar as } \\
\text { causas fundamentais dos problemas } \\
\text { (nós críticos). }\end{array}$ & $\begin{array}{l}\text { - Elaboração dos objetivos } \\
\text { - Definição das ações do plano }\end{array}$ \\
\hline $\begin{array}{l}\text { Estratégico (o que } \\
\text { pode ser) }\end{array}$ & $\begin{array}{l}\text { É o momento para discutir a } \\
\text { viabilidade estratégica das ações do } \\
\text { plano para garantir sua realização com } \\
\text { máxima eficácia. }\end{array}$ & $\begin{array}{l}\text { - Análise de cenários } \\
\text { - Construção da viabilidade } \\
\text { estratégica para se atingir a } \\
\text { situação-objetivo }\end{array}$ \\
\hline $\begin{array}{l}\text { Tático-operacional } \\
\text { (o fazer) }\end{array}$ & $\begin{array}{l}\text { É o momento de fazer, de finalmente } \\
\text { agir sobre a realidade concreta. }\end{array}$ & - Execução e avaliação do plano \\
\hline
\end{tabular}

Fonte: Matus (1996).

Sendo conhecedor desses momentos do PES, veja agora como operacionalizá-los. Para efeito de ilustração, tomemos, como exemplo, um dos problemas que começamos a formular anteriormente neste capítulo, agora com acréscimo de alguns dados: "cobertura vacinal abaixo da meta, em menores de 1 ano de idade, no município de Morro Alto, no ano de 2013".

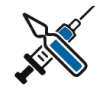

Vale lembrar que, ao se aplicar uma metodologia com enfoque situacional, conforme já mencionado, é preciso conhecer a complexidade dos problemas, a governabilidade de intervir sobre determinado problema e o nível de organização da instituição onde se planeja. Para atender a essas questões, é necessário, em algumas situações, combinar métodos de planejamento.
O momento explicativo é abordado com maior detalhamento no Anexo B, "Dinâmica do PES e o momento explicativo", deste capítulo. 


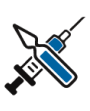

Árvore de Problemas é uma versão simplificada do Fluxograma Situacional. Essas ferramentas visam definir o conteúdo do problema a partir de descritores que possam demonstrar a existência do problema. São compostas pelo conjunto de descritores e identificação das causas do problema.
Ele poderia ser explicado na árvore de problemas da seguinte forma:

䠌Problema (encontra-se no tronco):

- Cobertura vacinal abaixo da meta, em menores de 1 ano de idade, no município de Morro Alto, no ano de 2013.

Causas (representam os determinantes, a raiz do problema):

- pouca divulgação sobre a importância da vacinação;

- número reduzido de profissionais para a busca ativa dos faltosos;

- desconhecimento dos responsáveis.

* Consequências (encontra-se na copa):

- aumento do número de internações entre menores de 1 ano de idade;

- ocorrência de óbitos em menores de 1 ano de idade por causas preveníveis;

- aumento de número de faltas ao trabalho por parte dos responsáveis pela criança;

- aumento de doenças;

- aumento de gastos com internações e tratamentos.
Figura 3 - Árvore de problemas

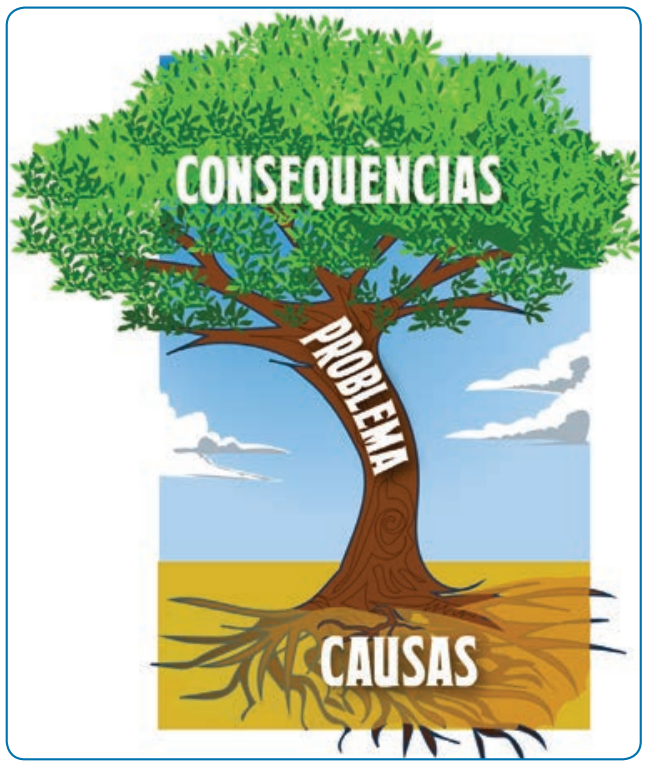

Como já assinalado, a explicação do problema deve considerar, também, maior conhecimento sobre ele. É importante que o problema seja estudado, investigado, para que se possam identificar todas as suas prováveis causas e consequências.

As causas relacionam-se aos determinantes do problema, que se expressam de forma simples ou complexa, conhecida ou desconhecida. Entre as causas, existem aquelas que são denominadas causas críticas ou nós críticos, isto é, causas que, se trabalhadas, poderão modificar as demais e o problema em questão.

Em nosso exemplo, qual a causa que você definiria como nó crítico?

O nó crítico pode ter relação com várias causas. Poderia ser a pouca divulgação sobre a importância da vacinação. Por quê? Se houver maior 
divulgação acerca da importância da vacinação, os responsáveis terão conhecimento sobre o assunto; isso poderá aumentar a procura pelo serviço na unidade, e os profissionais não precisarão realizar a busca ativa de tantas crianças. Assim, esta causa trabalhada poderá diminuir as demais, além de ser algo possível de ser realizado.

A outra questão a ser vista são as consequências do problema: os condicionantes do problema, os elementos que o constituem e os demais problemas e fatores que ele desencadeia.

Identificado e priorizado o problema com suas causas e nós críticos, devemos passar ao momento normativo, que é o momento propositivo do plano, em que são estabelecidos os objetivos e as ações necessárias para atacar os nós críticos do problema, na busca de se atingir o objetivo.

Nesse momento, são elaborados os objetivos (geral e específicos), bem como as ações que irão compor o plano:

* objetivo geral refere-se à proposição positiva do

problema, considera a situação-objetivo, isto é, onde se quer chegar com o plano;

os objetivos específicos devem estar relacionados ao(s) nó(s) crítico(s).

Foto 3 - A definição dos objetivos visa atacar os nós críticos de um problema

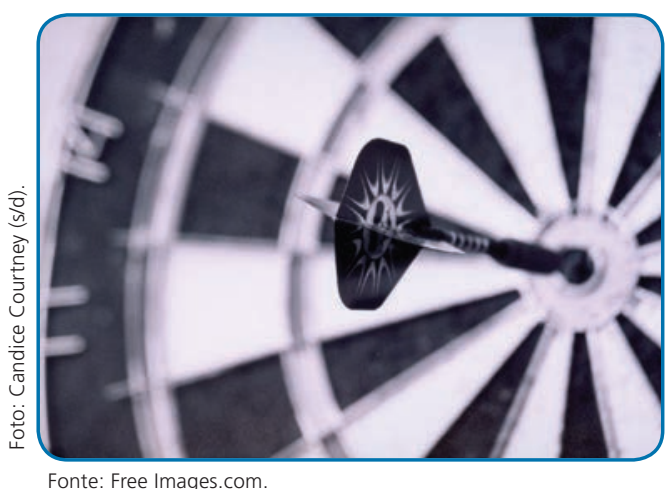

Fonte: Free Images.com.

A explicação do problema é a base para a construção dos objetivos.

Tanto o objetivo geral como os objetivos específicos devem expressar uma intenção de transformação da situação-problema.

Voltemos ao exemplo anterior para entender como podemos construir os objetivos de um plano:

* Problema: cobertura vacinal abaixo da meta, em menores de 1 ano de idade, no município de Morro Alto, no ano de 2013.

O objetivo geral deve expressar aonde se quer chegar, por exemplo: aumentar a cobertura vacinal em menores de 1 ano de idade, no município de Morro Alto, no ano de 2013.

O mesmo deverá acontecer com o objetivo específico, que está relacionado com o nó crítico selecionado:

* Nó crítico: pouca divulgação acerca da importância da vacinação.

* Objetivo específico: aumentar a divulgação acerca da importância da vacinação em menores de 1 ano de idade, no município de Morro Alto, no ano de 2013.

Note que o objetivo geral é o oposto do problema apresentado.

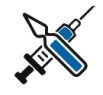

Vários nós críticos podem ser selecionados e, nesse caso, haverá vários objetivos específicos. 
Sabendo o que se quer atingir com o plano, será possível, então, discutir que ações devem ser realizadas.

\section{Para refletir}

Quais as ações que você e sua equipe de trabalho descreveriam para efetivar o objetivo específico do exemplo anterior?

Chegamos ao momento de como fazer o plano de ações: o momento estratégico.

Ocorre quando há a análise sobre a viabilidade das ações propostas no plano. Após escolher as ações, elas devem ser analisadas considerando-se as facilidades e dificuldades para a sua execução, bem como as estratégias de enfrentamento para superar as dificuldades. Assim, o momento estratégico é a ocasião de se analisar a viabilidade das ações, já que, embora possam ser muito importantes, algumas delas podem ser inviáveis em determinado momento.

Após a análise da viabilidade, é elaborado o plano operativo com as atividades que serão realizadas, os recursos necessários, os responsáveis e o tempo necessário para a execução de cada uma delas. Para melhor entendimento e visualização, apresentamos o Plano Operativo no Quadro 2:

Quadro 2 - Conteúdos necessários para a elaboração do plano operativo

\begin{tabular}{|l|l|}
\hline \multicolumn{2}{|c|}{ Plano operativo } \\
\hline Atividades & Referem-se ao detalhamento das ações. \\
\hline Recursos & $\begin{array}{l}\text { Dizem respeito aos dispositivos necessários para a realização das } \\
\text { atividades, sejam eles humanos, materiais, financeiros ou políticos. }\end{array}$ \\
\hline Responsáveis & $\begin{array}{l}\text { Devem ser nomeados, isto é, não colocar o cargo, e sim os nomes } \\
\text { daqueles que estarão à frente de cada atividade. }\end{array}$ \\
\hline Prazos & $\begin{array}{l}\text { Devem ser expressos preferencialmente na forma DD/MM/AAAA, } \\
\text { para melhor acompanhamento e avaliação do plano. }\end{array}$ \\
\hline
\end{tabular}

Um planejamento com base na metodologia do PES não termina aqui. A execução, o acompanhamento e a avaliação são partes importantes do processo e estão descritos no quarto momento, que é o momento tático-operacional.

Esse momento corresponde à execução do plano, o agir sobre a realidade, isto é, o fazer. Para garantir a eficácia do plano, será preciso acompanhar, avaliar e monitorar o desenvolvimento das ações propostas e a situação dos problemas iniciais, seja através do desempenho das 
metas propostas, seja do sistema de prestação de contas ou do conteúdo da participação democrática na condução do plano.

Para o acompanhamento e a avaliação do plano, é preciso detalhar:

* Metas: objetivos quantitativos que se pretende atingir.

Exemplo: realizar a distribuição de imunobiológicos em 100\% das unidades de saúde, no município de Morro Alto, no ano de 2014.

* Indicadores: medidas usadas para verificar um resultado.

Exemplo: número de unidades com entrega de imunobiológicos em dia.

* Fontes de verificação: descrição de onde será verificado o cumprimento de determinada ação ou objetivo.

Exemplo: sistemas de informação, planilhas, folhas de recebimento, boletim diário, entre outros.

* Periodicidade da coleta: o tempo previsto para verificar o resultado.

Exemplo: diário, quinzenal, mensal, anual, entre outros.

* Formas de divulgação: onde serão divulgadas as informações sobre o acompanhamento das ações do plano.

Exemplo: mural da unidade, boletim informativo, imprensa local etc.
Participação democrática pode ser entendida como a participação popular nas decisões políticas do país em referendos, plebiscitos e projetos de iniciativa da população.

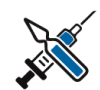

Como o plano é flexível, todo o processo deve ser avaliado criticamente e, se preciso, reformulado.

Esses são os momentos do PES, presentes na metodologia aqui apresentada.

Para encerrar a discussão sobre essa metodologia relacionada ao PES, selecionamos um exemplo para que você observe como pode ser elaborado um plano com base nessa proposta. Para efeito didático, consideramos melhor apresentar esse exemplo no Anexo C, “Construindo um plano de ação a partir de exemplo hipotético", deste capítulo. Nele, você encontrará também detalhamentos sobre diversos aspectos e conceitos apresentados ao longo da nossa discussão, bem como o relato de como José e sua equipe elaboraram um plano para resolver um problema em seu processo de trabalho.

Tente fazer o mesmo! Entendendo que o planejamento

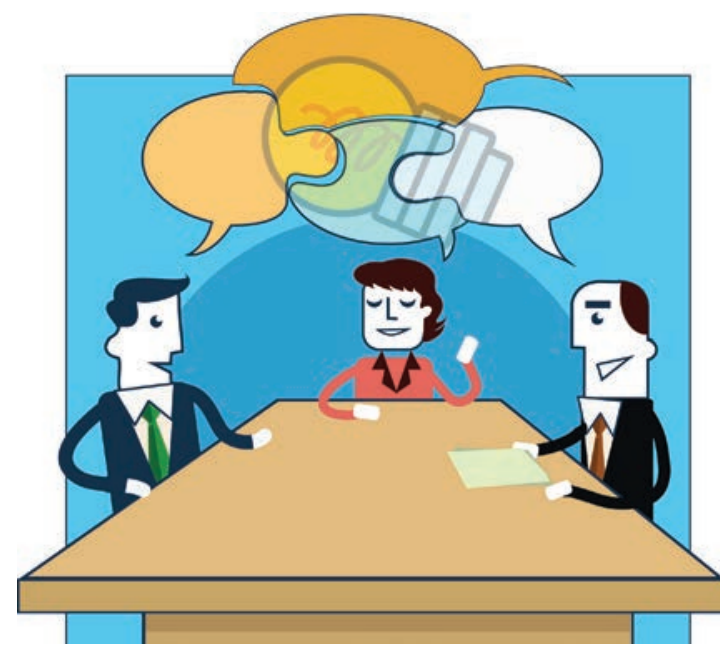
deve ser participativo, junte seus parceiros, pensem os 
seus processos de trabalho e tentem elaborar um plano para enfrentar um dos problemas encontrados. Esse pode ser um passo importante quando se busca melhorar as práticas cotidianas. Bom trabalho!

\section{Considerações finais}

Neste capítulo, você encontrou elementos para melhor compreender o planejamento associado à complexidade do setor de saúde, entendendo as diferentes concepções do planejamento em saúde que foram construídas ao longo da história.

Buscamos fornecer alguns subsídios para você lidar com essa complexidade, especificamente no que se refere ao trabalho em imunização e em rede de frio. Além desses subsídios, você precisará de outros elementos e conhecimentos que o ajudem a refletir, organizar e planejar suas atividades, que serão abordados nos demais capítulos deste livro. A ideia é possibilitar não somente a reflexão, mas uma atuação baseada em conceitos sólidos e consistentes que permitam a você, trabalhador e leitor, entender criticamente seu trabalho, de modo a se constituir, efetivamente, em um dos elos desta rede, que é a rede de frio de imunobiológicos!

\section{Referências}

ARTMANN, E. O planejamento estratégico situacional: a trilogia matusiana e uma proposta para o nível local de saúde (uma abordagem comunicativa). 1993. Tese (Mestrado) - Escola Nacional de Saúde Pública, Fiocruz, Rio de Janeiro.

CECÍLIO, L. C. O. Uma sistematização e discussão de tecnologia leve de planejamento estratégico aplicada ao setor governamental. In: MERHY, Emerson Elias. Agir em saúde: um desafio para o público. São Paulo: Hucitec, 1997. p. 151-167.

GIOVANELLA, L. As origens e as correntes atuais do enfoque estratégico em planejamento em saúde na América Latina. Cadernos de Saúde Pública, Rio de Janeiro, v. 7, n. 1, p. 26-44, jan./mar. 1991.

HUERTAS, F. O método PES: entrevista com Matus. São Paulo: Fundap, 1996.

LIMA, N. T. O Brasil e a Organização Pan-Americana da Saúde: uma história em três dimensões. In: FINELMAN, J. (Org.). Caminhos da saúde pública no Brasil. Rio de Janeiro: Ed. Fiocruz, 2002.

MATUS, C. Adeus, senhor presidente: governantes governados. São Paulo: Fundap, 1996.

MATUS, C. Fundamentos da planificação situacional. In: RIVERA, F. J. U. (Org.). Planejamento e programação em saúde: um enfoque estratégico. Rio de Janeiro: Cortez: Abrasco, 1989. p. 107-123. 
MATUS, C. Política, planejamento e governo. 2. ed. Brasília: IPEA, 1993. p. 297-554.

MATUS, C. Los tres cinturones del gobierno: gestión, organización e reforma. Caracas: Fundación ALTADIR, 1997.

MICROECONOMIA. [S.I.]: Economia.net, [200-]. Disponível em: <http://www.economiabr.net/ teoria_escolas/microeconomia.html>. Acesso em: 1 ago. 2016.

OLIVEIRA, V. C. et al. Conservação de vacina em unidades públicas de saúde: uma revisão integrativa. Revista de Enfermagem Referência, 3. série, n. 9, p. 45-54, 2013. Disponível em $<$ http://www.scielo.gpeari.mctes.pt/scielo.php?script=sci_pdf\&pid=S0874-02832013000100005\&ln

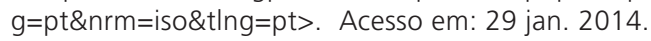

ORGANIZAÇÃO PAN-AMÉRICANA DA SAÚDE. Desenvolvimento gerencial de unidades básicas de saúde do distrito sanitário: Projeto Gerus. Brasília, DF: Ministério da Saúde: Fundação Nacional de Saúde, 1995.

PAGODINHO, Zeca. Deixa a vida me levar. Rio de Janeiro: Universal Music, 2002. 1 CD-Rom, faixa 3.

PAIM, J. S. Planejamento em saúde para não especialistas. In: CAMPOS, G.W. S. et al. Tratado de saúde coletiva. São Paulo: Hucitec; Rio de Janeiro: Ed. Fiocruz, 2006.

RIVERA, F. J. U. Planejamento de saúde. In: PEREIRA, I. B.; LIMA, J. C. Dicionário da educação profissional em saúde. 2. ed. rev. ampl. Rio de Janeiro: EPSJV, 2009.

SÁ, M. C.; ARTMANN, E. Planejamento estratégico em saúde: desafios e perspectivas para o nível local. In: MENDES, E. V. Planejamento e Programação Local da Vigilância da Saúde no Distrito Sanitário. Brasília, DF: Organização Pan-Americana de Saúde, 1994. p. 19-44.

SILVA, M. N.; FLAUZINO, R. F.; GONDIM, G. M. M. (Org.). Rede de frio: fundamentos para a compreensão do trabalho. Rio de Janeiro: Ed. Fiocruz, 2016.

TEIXEIRA, C. F. Enfoques teórico-metodológicos do planejamento em saúde. In: TEIXEIRA, C. F. (Org.). Planejamento em saúde: conceitos, métodos e experiências. Salvador: EDUFBA, 2010. p. 17-31.

TEIXEIRA, C. F.; SÁ, M. C. Planejamento \& gestão em saúde: situação atual e perspectivas para a pesquisa, o ensino e a cooperação técnica na área. Ciência e Saúde Coletiva, Rio de Janeiro, v. 1, n. 1, p. 82-103, 1996.

TESTA, M. Pensamento estratégico e lógica de programação: o caso da saúde. São Paulo: Hucitec; Rio de Janeiro: Abrasco, 1995. p. 5-103. 


\section{Anexo A - Contribuições de Carlos Matus e Mário Testa no planejamento estratégico}

Análise resumida das contribuições de dois importantes autores vinculados ao planejamento estratégico e que influenciaram fortemente o planejamento em saúde no Brasil.

\section{Carlos Matus}

Formulou um modelo de planejamento estratégico baseado nas teorias da situação, da produção social e da ação interativa. O seu método para o processamento de problemas e soluções prevê quatro momentos: explicativo, normativo, estratégico e tático-operacional. Propõe elementos de cálculo de cenários e um instrumental de análise estratégica. Esse autor contribuiu, ainda, com uma proposta de direção estratégica para a administração pública a partir da formulação da teoria das macro-organizações. Esta prevê a reforma vertical da administração com base em subsistemas de gestão, que se voltam ao "planejamento criativo, à descentralização dos sistemas de condução e uma abordagem de gestão por objetivos ou operações e, por fim, a alta responsabilidade decorrente do monitoramento, da cobrança e a prestação de contas" (MATUS, 1996, p.314).

\section{Mário Testa}

Um dos autores do Método Cendes-Opas, ele partiu da crítica a essa metodologia para formular uma proposta de natureza estratégica de explicação da problemática do setor de saúde, composta por diferentes diagnósticos: administrativo, estratégico e ideológico. Adota um enfoque com um componente fortemente comunicacional, com base na teoria do agir comunicativo de Rivera (2009).

Como crítico das formas institucionais autoritárias, enfatiza as ações capazes de acentuar os traços democráticos. Desse modo, prevê um tipo de planejamento com centralidade nas práticas dialógicas, na formação de consensos e de compromissos. Evita um excesso de formalização política, o que critica em Matus, levando à proposição de um método pouco estruturado (RIVERA, 2009).

A seguir, apresentamos uma síntese dos pressupostos do planejamento normativo e do planejamento estratégico, com base na obra de Carlos Matus (1996). 


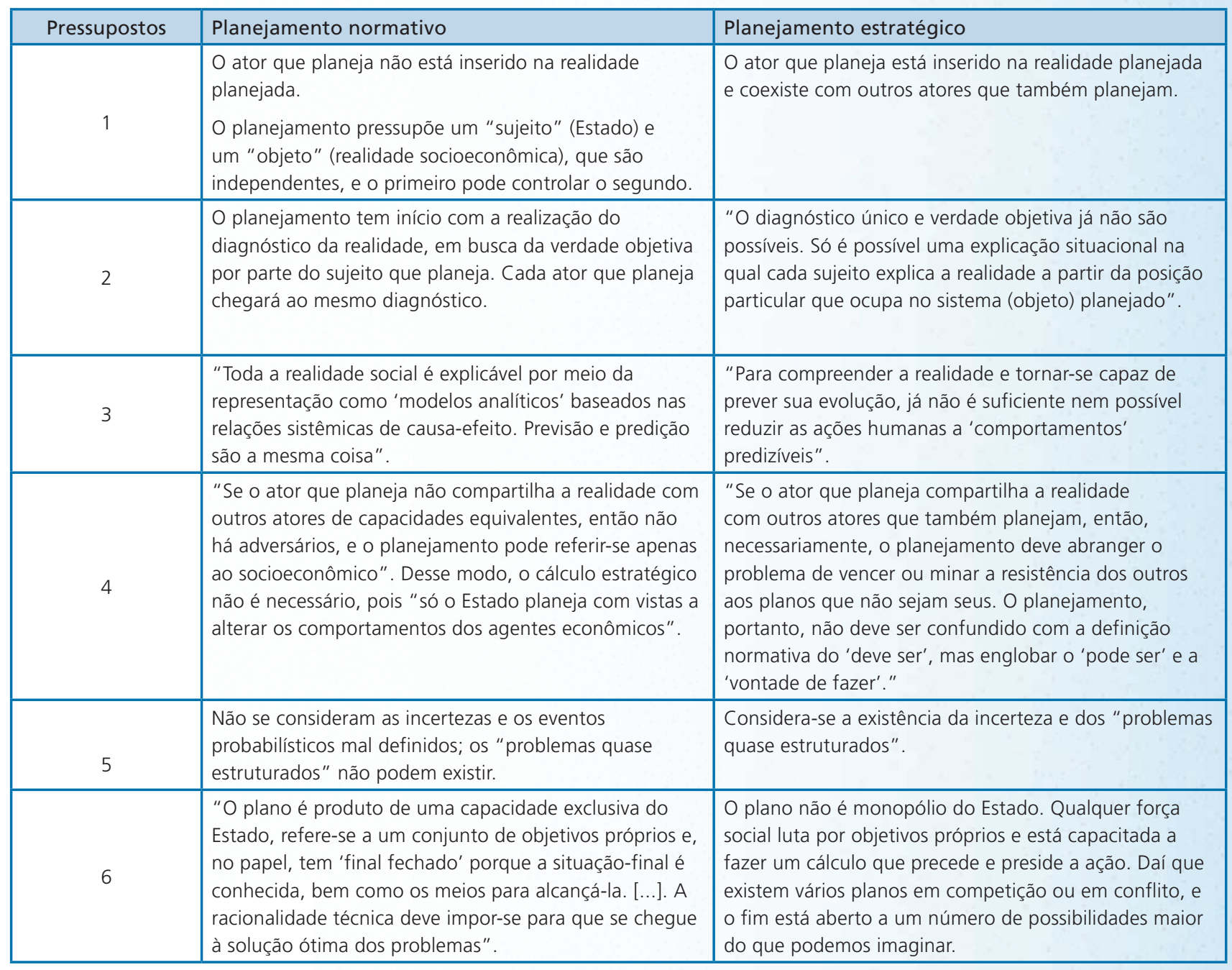

Fonte: Matus (1996, p. 66-69). 


\section{Anexo B - Dinâmica do PES e o momento explicativo}

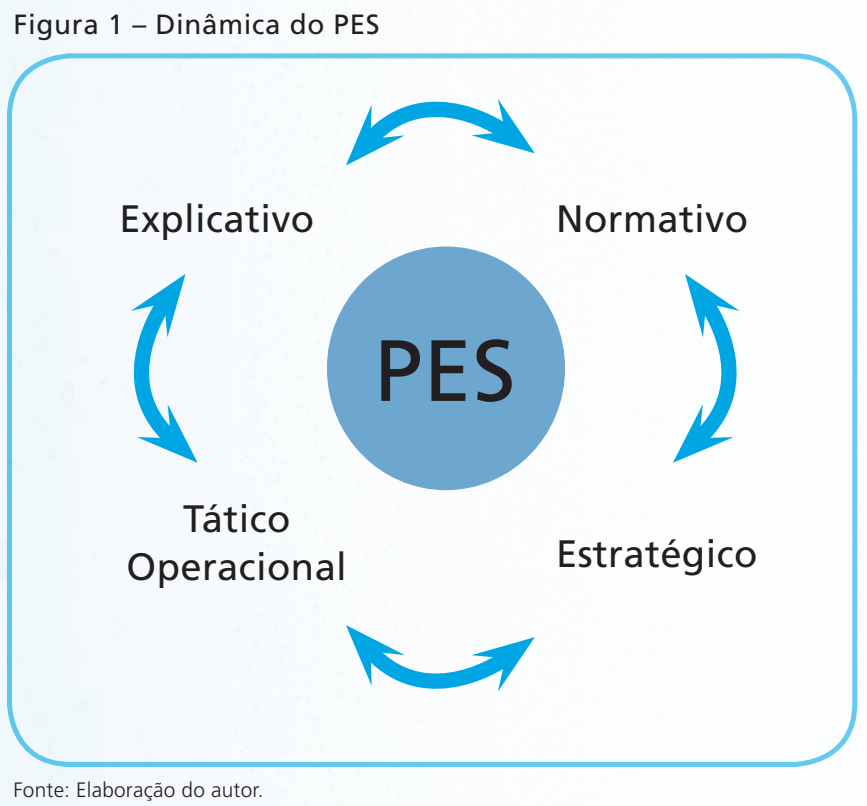

Momento explicativo - o que foi, é, tende a ser

Esse momento refere-se ao reconhecimento da existência de problemas mal estruturados ou semiestruturados e à análise da situação. A análise da situação envolve o processo coletivo de identificação, priorização e explicação de problemas.

Para a identificação, é importante reunir o maior número de informantes, tanto dos sistemas existentes como dos atores envolvidos com a situação que se quer transformar, para que se garanta uma importante qualidade do PES, a de ser participativo.

A partir da identificação dos problemas, é necessário priorizar os que serão enfrentados, levando-se em consideração a governabilidade para intervir no problema, como também outros critérios, como o tamanho do problema (sua magnitude), o valor que é dado ao problema, a tecnologia disponível e o custo para enfrentá-lo. 
Os critérios podem ser pontuados, por exemplo, de 0 a 3, considerando para cada um deles os seguintes aspectos:

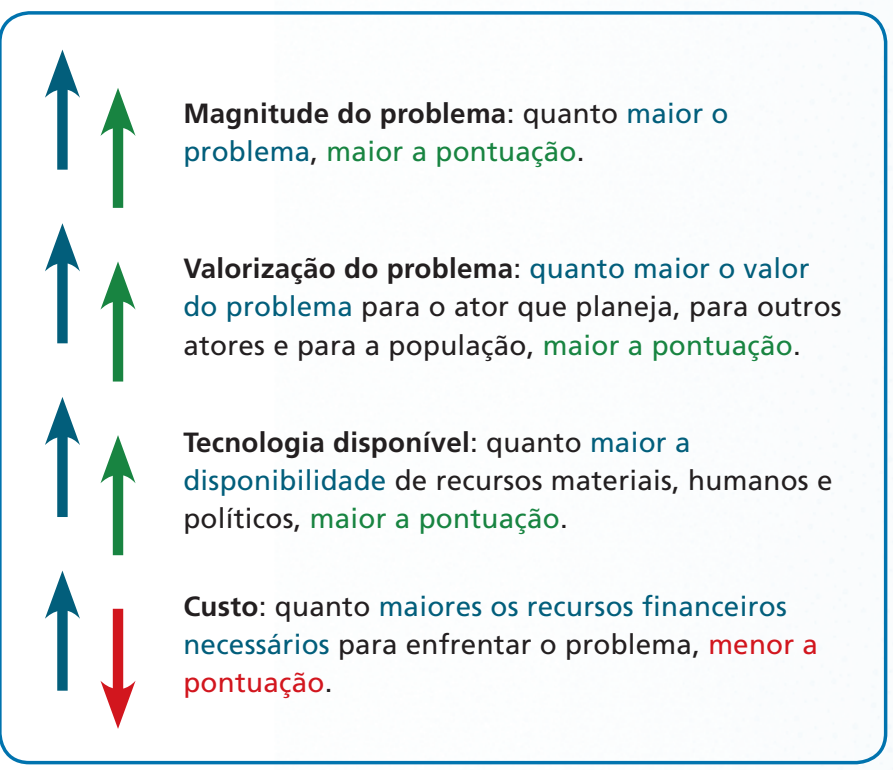

\section{Importante!}

A priorização de problemas deve considerar a capacidade do ator de intervir sobre eles. Ao olhar para sua realidade (situação), ele poderá identificar vários problemas, mas será preciso selecionar aqueles nos quais ele pode interferir e que são estratégicos para o alcance dos objetivos.

Após a priorização, é necessário explicar o problema. Para isso, é necessário formulá-lo de forma clara e pesquisar sobre o tema central deste.

Na área da saúde, os problemas, frequentemente, são de duas naturezas:

* problemas referentes à saúde de determinada população;

problemas referentes à organização dos sistemas e serviços de saúde.

Para cada natureza do problema, a formulação deverá responder às seguintes perguntas:

* problemas referentes à saúde de determinada população: o que é o problema? Em quem ocorre? Onde ocorre? Quando ocorre? 
* problemas referentes à organização dos sistemas e serviços de saúde: o que é o problema? Onde ocorre? Quando ocorre?

A formulação contribui para a explicação do problema e a busca de possíveis soluções. Vejamos, em exemplos, a diferença na formulação de determinados problemas:

* Problema 1: distribuição de imunobiológicos

- problema formulado: atraso na distribuição de imunobiológicos (o que é o problema) pelo órgão central (onde ocorre), no primeiro trimestre de 2013 (quando ocorre).

* Problema 2: cobertura vacinal abaixo da meta

- problema formulado: cobertura vacinal abaixo da meta (o que é o problema) em menores de 1 ano de idade (em quem ocorre), no município de Morro Alto (onde ocorre), no ano de 2013 (quando ocorre).

Como já assinalado, a explicação do problema deve considerar, também, maior conhecimento sobre ele. É importante que o problema seja estudado, investigado, para que seja possível identificar todas as suas prováveis causas e consequências.

As causas relacionam-se aos determinantes do problema, que se expressam de forma simples ou complexa, conhecida ou desconhecida. Entre as causas, existem aquelas denominadas causas críticas ou nós críticos, que respondem afirmativamente às seguintes questões:

* Os atores que irão realizar o plano possuem governabilidade para intervir nas causas?

* Essas causas geram ações que podem ser gerenciadas?

As causas, se trabalhadas, podem contribuir para diminuir as demais?

As consequências são os condicionantes do problema, os elementos que o constituem e os demais problemas e fatores que ele desencadeia. Existem dois instrumentos que podem ser utilizados para a explicação da cadeia causal do problema:

o fluxograma situacional;

a árvore de problemas. 
O fluxograma situacional é um método que exige grande rigor conceitual ao operar as categorias explicativas. A árvore de problemas, apresentada no Capítulo 1, é um instrumento mais simples, o qual precisa ser bem aplicado para não se tornar pouco eficiente na explicação da cadeia causal.

Por exigir maior rigor que a árvore de problemas, o fluxograma apresenta uma vantagem, mas isso também é um fator que inibe o grupo e dificulta a sua autonomia, pois, quase sempre, é necessária a presença de um coordenador para auxiliar nesse processo. 


\section{Anexo $\mathrm{C}$ - Construindo um plano de ação a partir de exemplo hipotético}

A partir do exemplo adiante, você poderá entender como pode ser construído um plano de ação baseado na metodologia do Planejamento Estratégico Situacional e na trilogia matusiana.

\section{Atenção!}

Este é apenas um exemplo, o problema pode não existir em sua realidade. No entanto, mesmo que haja um problema semelhante, causas diferentes poderão ser apontadas e, com isso, outras consequências também.

\section{Exemplo:}

José trabalha no setor de imunização de uma unidade básica de saúde. Como está sempre buscando aperfeiçoar o seu processo de trabalho e conhecendo a metodologia do PES, resolveu reunir os demais integrantes da equipe e representantes da comunidade (atores sociais) para discutir sobre o que estava dificultando o bom funcionamento do setor (problemas) naquela realidade (situação), tendo em vista a elaboração de um plano de intervenção.

Após vários encontros e discussões, o grupo identificou os seguintes problemas:

* número reduzido de trabalhadores qualificados;

* pequeno espaço físico para armazenamento de insumos estratégicos;

* refrigeradores de armazenamento de insumos estratégicos

utilizados, frequentemente, para guarda de alimentos dos funcionários;

* número reduzido de refrigeradores.

Diante desse cenário, resolveram então selecionar um problema no qual seria possível intervir. Para isso, consideraram alguns critérios, com pontuação de 0 a 3, e elaboraram uma planilha com o registro da avaliação (Quadro 1). 
Quadro 1 - Planilha com o registro da avaliação

\begin{tabular}{|l|c|c|c|c|}
\hline Problema & Magnitude & Valorização & $\begin{array}{c}\text { Tecnologia } \\
\text { disponível }\end{array}$ & $\begin{array}{c}\text { Custo } \\
\text { estimado }\end{array}$ \\
\hline $\begin{array}{l}\text { Número reduzido de trabalhadores } \\
\text { qualificados. }\end{array}$ & 2 & 1 & 2 & 0 \\
\hline $\begin{array}{l}\text { Pequeno espaço físico para } \\
\text { armazenamento de insumos estratégicos. }\end{array}$ & 2 & 1 & 2 & 1 \\
\hline $\begin{array}{l}\text { Uso não exclusivo do refrigerador para } \\
\text { conservação de imunobiológicos. }\end{array}$ & 3 & 1 & 1 & 3 \\
\hline Número reduzido de refrigeradores. & 3 & 2 & 1 & 8 \\
\hline
\end{tabular}

Com o problema selecionado com base na priorização, a equipe trabalhou na sua formulação, isto é, buscou, com palavras, tornar o problema claro e seu enunciado passível de responder às seguintes questões: o que ocorre, onde ocorre e quando ocorre.

O problema foi assim formulado:

"Uso não exclusivo do refrigerador para conservação de imunobiológicos na unidade de saúde do bairro de Boa Vista, no município de Serra Velha, no ano de 2013".

Após analisar e pesquisar sobre o problema, a equipe utilizou o instrumento árvore de problemas para detalhar a cadeia causal do problema e selecionar um nó crítico, a ser trabalhado para modificar a situação.

Veja a árvore de problemas elaborada pelo grupo:

Causas:

- Falta de refrigerador para outros fins.

- Desconhecimento de parte dos trabalhadores sobre a utilização correta dos refrigeradores.

- Deficiência no monitoramento e na avaliação do processo de trabalho diário, no princípio, no meio e no fim do expediente.

- Inexistência de ações educativas sobre conservação de imunobiológicos para os profissionais.

\section{*onsequências:}

- Comprometimento da imunogenicidade.

- Perdas desnecessárias de vacinas.

- Aumento dos custos do PNI.

- Aumento de morbimortalidade por doenças imunopreveníveis. 
Como o problema selecionado foi "Uso não exclusivo do refrigerador para conservação de imunobiológicos na unidade de saúde do bairro de Boa Vista, no município de Serra Velha, no ano de 2013", o objetivo geral foi assim formulado:

* Objetivo geral: utilizar exclusivamente o refrigerador para imunobiológicos na unidade de saúde do bairro de Boa Vista, no município de Serra Velha.

Considerando nó crítico a "inexistência de ações educativas sobre conservação de imunobiológicos para os profissionais", a formulação de um dos objetivos específicos do plano foi:

* Objetivo específico: realizar ações educativas sobre conservação de imunobiológicos para os profissionais da unidade de saúde do bairro de Boa Vista, no município de Serra Velha, no ano de 2014.

Com esse objetivo definido, a equipe descreveu várias ações e realizou a análise da viabilidade destas. No Quadro 2, apresentamos apenas a análise de viabilidade de uma delas.

Quadro 2 - Análise de viabilidade de uma ação educativa sobre conservação de imunobiológicos

\begin{tabular}{|l|l|l|l|}
\hline Ações & Facilidades & Dificuldades & $\begin{array}{l}\text { Estratégias (para enfrentar } \\
\text { as dificuldades) }\end{array}$ \\
\hline $\begin{array}{l}\text { Realizar rodas de conversa } \\
\text { para discutir e informar sobre a } \\
\text { importância da conservação de } \\
\text { imunobiológicos. }\end{array}$ & $\begin{array}{l}\text { - Profissionais e usuários } \\
\text { sensibilizados para o encontro. }\end{array}$ & $\begin{array}{l}\text { Tempo dos profissionais } \\
\text { para participar das rodas de } \\
\text { conversa. } \\
\text { unidade de saúde. }\end{array}$ & $\begin{array}{l}\text { Aproveitar o período já existente } \\
\text { das reuniões semanais da } \\
\text { equipe. }\end{array}$ \\
\hline
\end{tabular}

\section{Importante!}

Não esqueça que estamos apresentando um exemplo, com apenas um objetivo específico. Um plano pode possuir vários objetivos específicos, e as planilhas de análise de viabilidade do plano operativo e o acompanhamento e a avaliação devem conter e analisar todas as ações possíveis e necessárias para o alcance de cada objetivo.

Após analisar a viabilidade e traçar estratégias para superar as dificuldades de execução das ações, foi então elaborado o plano operativo. Veja como ficou estruturado o plano para uma das ações no Quadro 3. 
Quadro 3 - Plano operativo

\begin{tabular}{|c|c|c|c|c|c|}
\hline Objetivo específico & Ações & Atividades & Recursos & Responsáveis & Prazos \\
\hline $\begin{array}{l}\text { Realizar ações } \\
\text { de educação } \\
\text { permanente sobre } \\
\text { conservação de } \\
\text { imunobiológicos } \\
\text { para os profissionais } \\
\text { na unidade de saúde } \\
\text { do bairro de Boa } \\
\text { Vista, no município } \\
\text { de Serra Velha. }\end{array}$ & $\begin{array}{l}\text { Realizar rodas } \\
\text { de conversa } \\
\text { para discutir e } \\
\text { informar sobre a } \\
\text { importância da } \\
\text { conservação de } \\
\text { imunobiológicos. }\end{array}$ & $\begin{array}{l}\text { - Preparar um questionário para avaliar } \\
\text { o conhecimento dos profissionais e } \\
\text { usuários sobre o assunto. } \\
\text { - Aplicar e analisar os questionários. } \\
\text { - Contatar o responsável técnico da } \\
\text { UBS para agendar o dia do encontro } \\
\text { com os profissionais. } \\
\text { - Preparar material e sala no dia do } \\
\text { encontro. }\end{array}$ & $\begin{array}{l}\text { Materiais: } \\
\text { papel, } \\
\text { computador, } \\
\text { impressora. } \\
\text { - Humanos: } \\
\text { equipe do setor } \\
\text { de imunização. }\end{array}$ & $\begin{array}{l}\text { José, Luís, Ana } \\
\text { e Lia } \\
\text { José e Ana } \\
\text { Luís } \\
\text { Lia }\end{array}$ & $\begin{array}{l}02 / 05 / 2014 a \\
30 / 05 / 2014 \\
01 / 06 / 2014 a \\
20 / 06 / 2014 \\
10 / 06 / 2014 a \\
17 / 06 / 2014 \\
01 / 07 / 2014\end{array}$ \\
\hline
\end{tabular}

Quadro 4 - Planilha de acompanhamento e avaliação

\begin{tabular}{|c|c|c|c|c|c|c|}
\hline $\begin{array}{l}\text { Objetivo } \\
\text { específico }\end{array}$ & Ação & Meta & Indicador & Fonte & $\begin{array}{l}\text { Periodicidade } \\
\text { da coleta }\end{array}$ & $\begin{array}{l}\text { Formas de } \\
\text { divulgação }\end{array}$ \\
\hline $\begin{array}{l}\text { Realizar ações } \\
\text { de educação } \\
\text { permanente sobre } \\
\text { conservação de } \\
\text { imunobiológicos } \\
\text { para os } \\
\text { profissionais } \\
\text { na unidade de } \\
\text { saúde do bairro } \\
\text { de Boa Vista, } \\
\text { no município de } \\
\text { Serra Velha. }\end{array}$ & $\begin{array}{l}\text { Realizar rodas } \\
\text { de conversa com } \\
\text { profissionais } \\
\text { da unidade } \\
\text { para discutir e } \\
\text { informar sobre a } \\
\text { importância da } \\
\text { conservação de } \\
\text { imunobiológicos. }\end{array}$ & $\begin{array}{l}\text { - Realizar } 12 \text { rodas } \\
\text { de conversa. } \\
\text { - } \text { Quinzenalmente. } \\
\text { - Realizar } \\
\text { monitoramento e } \\
\text { avaliação diários. }\end{array}$ & $\begin{array}{l}\text { - Número de } \\
\text { participantes } \\
\text { nas rodas. } \\
\text { Número de } \\
\text { monitoramento } \\
\text { e avaliação } \\
\text { diários. }\end{array}$ & $\begin{array}{l}\text { - Folha de } \\
\text { frequência. } \\
\text { - Mapa de } \\
\text { monitoramento } \\
\text { e avaliação. }\end{array}$ & $\begin{array}{l}\text { - Quinzenal } \\
\text { - Diário }\end{array}$ & $\begin{array}{l}\text { - Mural da } \\
\text { UBS e na } \\
\text { Associação de } \\
\text { Moradores. } \\
\text { - Mural da } \\
\text { UBS. }\end{array}$ \\
\hline
\end{tabular}

Mapa é uma ferramenta do planejamento que permite identificar, acompanhar/monitorar e avaliar processos de trabalho e execução de ações no campo da gestão em saúde. 



\section{O calendário de vacinação brasileiro e as estratégias para imunização da população}

Marta Casagrande Koehler e Evelin Plácido dos Santos

Hoje, no mundo, existem dezenas de vacinas disponíveis e algumas em desenvolvimento. São disponibilizadas nas unidades de saúde das redes pública e privada do país e organizadas para serem administradas conforme grupos etários, constituindo uma importante estratégia de saúde pública. Você já se perguntou como as vacinas são organizadas para serem administradas nas unidades de saúde? Qual o critério de escolha da vacina? Qual delas deve ser aplicada nessa ou naquela pessoa? Em que faixas etárias, quantas doses são necessárias e por quê?

A escolha das vacinas, a faixa etária recomendada na organização dos calendários de vacinação, que obedecem a critérios de sequência cronológica, tipo de vacina, pessoa a ser vacinada, número de doses etc., bem como as diversas estratégias utilizadas pelo governo para alcançar e vacinar a população são conhecimentos essenciais, que irão balizar a atuação dos profissionais envolvidos nas atividades da rede de frio de imunobiológicos e de vacinação.

Neste capítulo, serão apresentadas algumas questões referentes à vacinação dos diversos grupos etários, constantes do Calendário Nacional de Vacinação do Programa Nacional de Imunizações (PNI) brasileiro, as principais características dos esquemas vacinais da rede pública, com destaque para o calendário de vacinação do trabalhador de saúde, e algumas características relacionadas ao calendário da rede privada. Outras estratégias diferenciadas da rotina, como vacinação de bloqueio, vacinação extramuros e as campanhas, serão, também, abordadas, assim como ações de equidade no favorecimento do acesso à imunização de grupos populacionais em maior situação de vulnerabilidade. A ideia é, através da apresentação desses temas, colaborar na construção de 
A avaliação das atividades de vacinação e da cobertura vacinal é discutida no Capítulo 4, "Avaliação da vacinação", deste livro.

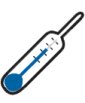

Para saber mais sobre o monitoramento de coberturas vacinais, consulte: http://bvsms saude.gov.br/bvs/politicas/ livro_30_anos_pni.pdf e http://tabnet.datasus.gov.br/ cgi/pni/cpnidescr.htm conhecimentos sobre a estratégia de vacinação adotada no país, assim como permitir que o trabalhador da rede de frio reflita sobre a importância do seu trabalho para a garantia da qualidade e da segurança das vacinas administradas nas diversas unidades de saúde, de toda a rede federativa.

\section{O Programa Nacional de Imunizações}

O Programa Nacional de Imunizações (PNI) foi criado em 1973, com o objetivo de promover o controle das principais doenças infectocontagiosas da época: sarampo, poliomielite, tuberculose, tétano, difteria e coqueluche. Ao instituir o PNI, o Ministério da Saúde buscava:

a integralidade das ações de imunização realizadas no país, que eram então fortemente marcadas pela atuação de programas nacionais de controle de doenças específicas. Assim, o PNI passou a coordenar as atividades de imunização desenvolvidas rotineiramente na rede de serviços e, para tanto, traçou diretrizes pautadas na experiência da Fundação Serviços de Saúde Pública (FSESP), com a prestação de serviços integrais de saúde por intermédio de sua rede própria (FUNDAÇÃO NACIONAL DE SAÚDE, 1998).

A atividade de imunização, antes da instituição do PNI, não se concretizava como uma ação continuada, e as coberturas vacinais, geralmente, ficavam aquém do esperado. A melhoria das coberturas vacinais, ao longo dos 40 anos do PNI, tem contribuído para o declínio acelerado das doenças imunopreveníveis.

O PNI desenvolve suas atividades mediante o estabelecimento do calendário de vacinação, normatizado em nível federal por meio de portarias do Ministério da Saúde. É de sua responsabilidade elaborar normas e procedimentos para aquisição, armazenamento e distribuição dos imunobiológicos nos níveis nacional, estadual e municipal, atuando de acordo com o modelo descentralizado de gestão do SUS, em parceria com os estados e municípios.

O calendário é dinâmico e alterado de acordo com a situação epidemiológica do país e o avanço da tecnologia para a disponibilização de vacinas. Cada vez que ele é modificado, o Ministério da Saúde o faz através de portarias.

As ações do PNI de prevenção e controle de doenças transmissíveis têm logrado êxito, ganhando cada vez mais a confiança da população. O PNI tem acompanhado as transformações demográficas e epidemiológicas 
registradas no país e no mundo, estabelecendo metas que contemplem o controle, a eliminação e/ou a erradicação de doenças. O controle da raiva humana, a eliminação do tétano neonatal e a manutenção da erradicação da poliomielite nas Américas são exemplos do sucesso desse programa.

As ações de vacinação desenvolvidas pelo PNI são estabelecidas com base em critérios para o alcance de seus objetivos, como:

*alcançar e manter coberturas vacinais em torno de $95 \%$ em todos os municípios brasileiros;

* assegurar a qualidade e o quantitativo das vacinas necessários para o cumprimento do calendário de vacinação, garantindo a proteção do indivíduo por meio de controle rigoroso da qualidade dos imunobiológicos oferecidos.

Para alcance dos seus objetivos, o Programa Nacional de Imunizações estabelece metas, sendo que a meta básica é vacinar, o mais precocemente possível, $100 \%$ das crianças que nascem. Todas as metas estabelecidas pelo programa estão relacionadas com as coberturas vacinais, visando atingir coberturas entre $90 \%$ e $95 \%$ para todos os imunobiológicos como percentual mínimo de alcance para controle, eliminação e erradicação das doenças imunopreveníveis, meta principal do PNI.

O alcance dessas coberturas de forma homogênea em todo o país permitiu e tem permitido, cada vez mais, avanços e benefícios incalculáveis para toda a população, tais como os que podemos observar em 2015:

Esquema 1 - Coberturas vacinais, avanços e benefícios para a população em 2015

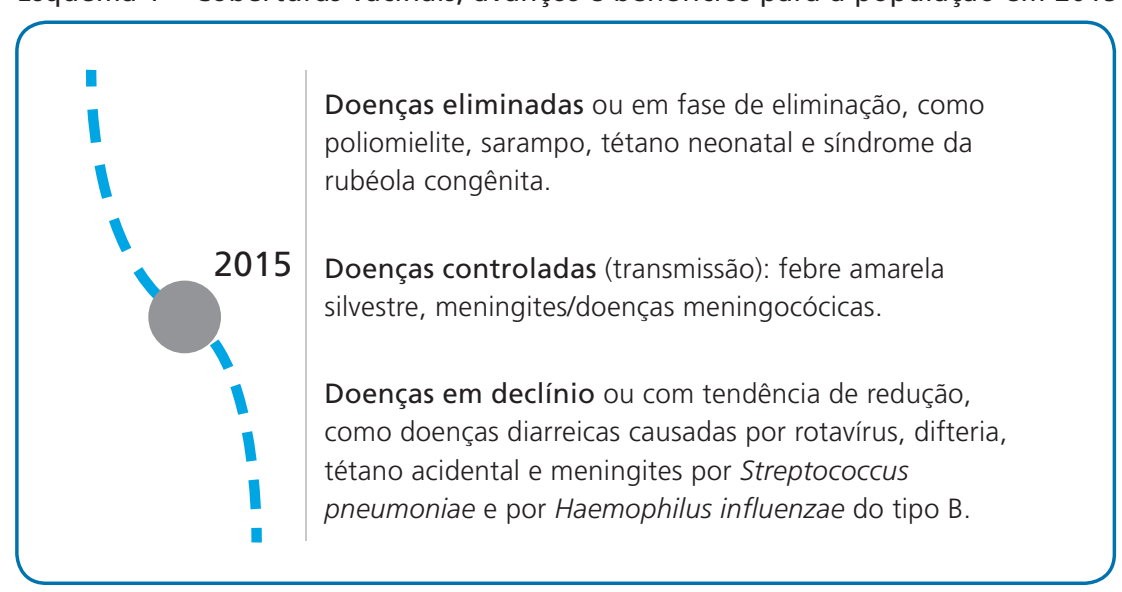

Desde a sua criação, o PNI sempre primou pela qualidade dos imunobiológicos oferecidos para uso humano. Produtos nacionais ou importados passam por rigorosos controles de qualidade. Com a criação do Instituto Nacional de Controle de Qualidade em Saúde (INCQS), em 1981, o país passou a contar com uma infraestrutura laboratorial capaz de avaliar os requisitos de qualidade dos imunobiológicos a serem aplicados na população, atuando em parceria com a Agência Nacional de Vigilância Sanitária (Anvisa). O INCQS é uma das unidades técnico-científicas da Fundação Oswaldo Cruz.

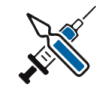

Todos esses avanços foram obtidos com a implementação de um eficaz calendário de vacinação e imunobiológicos disponíveis na rede pública para toda a população. 


\section{Calendários de vacinação}

As estratégias de vacinação adotadas nos países como ações de saúde pública têm, em linhas gerais, a finalidade de diminuir a carga de doenças, com redução do número de hospitalizações, casos graves e óbitos, por meio de atividades de controle, eliminação e erradicação das doenças imunopreveníveis. Os calendários de vacinação são instrumentos fundamentais para implementação dessas estratégias.

Calendário de vacinação corresponde ao conjunto de vacinas consideradas de interesse prioritário à saúde pública do país, recomendadas à população desde o nascimento até a terceira idade. Tem por finalidade obter imunização adequada da população contra doenças para as quais existam vacinas seguras e eficazes. O calendário pode ser compreendido, então, como a relação de vacinas recomendadas com a(s) idade(s) e faixa(s) etária(s) em que devem ser aplicadas.

A escolha da faixa etária guarda relação direta com os riscos da doença, a resposta do sistema imune a cada vacina e as possíveis complicações que podem advir de sua administração. É fundamental que todos os grupos previstos no calendário de vacinação sejam corretamente vacinados, recebendo todas as doses necessárias e completando seu esquema vacinal. Por isso, é importante que as vacinas estejam organizadas no calendário de forma a viabilizar o menor número de idas à unidade de vacinação, o máximo de aplicações possíveis, de acordo com o preconizado, evitando, assim, oportunidades perdidas de vacinação e otimizando os recursos humanos e materiais.

Embora possam existir diferenças de calendário entre os países, todos terão em comum um elenco básico de vacinas que são consideradas essenciais pela Organização Mundial da Saúde.
De acordo com as recomendações da Organização Mundial da Saúde (OMS), cada país deve possuir autonomia para adotar seus próprios calendários de vacinação. Estes irão refletir, além do contexto epidemiológico local, as condições socioeconômicas, políticas e culturais daquele país. As ações de imunização serão coordenadas por meio de programas nacionais de imunizações, com metas definidas.

A OMS vem, ao longo do tempo, indicando o acréscimo de novas vacinas ao calendário básico, à medida que avançam as colaborações e o suporte financeiro de outras organizações, como as não governamentais. Dependendo do contexto epidemiológico de cada país, a OMS tem recomendado, também, a inclusão de outras vacinas, como febre amarela, encefalite japonesa, febre tifoide etc.

As vacinas do calendário que serão administradas rotineiramente têm uma sequência cronológica e uma previsão de início e término para sua 
administração. À medida que cresce o número de vacinas, amplia-se o calendário, estendendo suas faixas etárias para diferentes momentos de vida, o que acarreta calendários específicos para determinados grupos. Com isso, torna-se necessária a divisão do calendário de vacinação em, no mínimo, três grupos com faixas etárias distintas do calendário infantil: o calendário do adolescente, do adulto e do idoso.

Outros grupos específicos são também contemplados com um calendário de vacinação, como viajantes, gestantes e profissionais de saúde etc., por causa dos riscos profissionais ou de exposição a agentes causadores de doenças a que estão expostos, seja por atividades laborais ou de lazer.

Qualquer calendário deverá estar adequado à situação do contexto local. Entretanto, exceções e variações poderão ser necessárias na prática diária, sendo fundamental que todos os grupos recebam todas as vacinas recomendadas e completem o esquema básico, de forma a garantir a imunização e proteção da saúde da coletividade. Cabe ao profissional de saúde estimular, orientar e incentivar a vacinação por meio de diversas estratégias disponíveis, assim como manter seu esquema vacinal atualizado.

\section{O calendário de vacinação brasileiro}

No Brasil, a Coordenação Geral do Programa Nacional de Imunizações do Ministério da Saúde (CGPNI/MS) é responsável pela elaboração de normas, aquisição e distribuição dos imunobiológicos a serem utilizados pelas demais instâncias de governo. Além da responsabilidade de elaborar normas e procedimentos, cabe também ao PNI, pela sua Coordenação Geral (CGPNI/MS), o estabelecimento do Calendário Nacional de Vacinação para os diferentes ciclos de vida do indivíduo, que se configura em calendários voltados para as populações infantil, adolescente, adulta e idosa.

Normatizado em nível federal, por meio de portarias do Ministério da Saúde, o calendário brasileiro dispõe de um elenco de vacinas que são ofertadas, gratuitamente, na rotina das salas de vacinação da rede pública de todo o país. Para viabilizar essa oferta, o Brasil necessita de infraestrutura adequada para aquisição, armazenamento e distribuição de imunobiológicos, bem como de laboratórios produtores. A autossuficiência desses laboratórios aumenta as possibilidades de ampliação das vacinas do calendário brasileiro. Atualmente, o país dispõe de um complexo nacional produtor de imunobiológicos composto por sete laboratórios. 


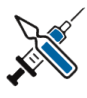

É importante que os profissionais de saúde, em especial os da sala de vacinação e os da rede de frio, estejam atentos às novas publicações e/ou recomendações sobre vacinas!

Além das vacinas incluídas no calendário público, existem outras disponíveis nos Centros de Referência para Imunobiológicos Especiais (Crie). Elas são abordadas mais adiante, neste capítulo.
Algumas informações sobre publicações e recomendações relativas a calendários de vacinação

- O primeiro calendário nacional básico, com as vacinas obrigatórias para menores de 1 ano de idade (tuberculose, poliomielite, sarampo, difteria, tétano e coqueluche/DTP), foi oficializado em 1977, pela Portaria MS n. 452/1977. Além dessas vacinas, existia a TT (Toxoide Tetânico), indicada para uso em adultos, totalizando sete vacinas disponíveis no país naquela época.

- A Portaria GM n. 597 criou, em 12 de abril de 2004, os três calendários básicos de vacinação: da criança, do adolescente e do adulto e idoso.

- A Portaria n. 1.498, em vigor, em 22 de julho de 2013, revoga as portarias anteriores e redefine o Calendário Nacional de Vacinação e institui o Calendário Nacional de Vacinação dos Povos Indígenas no âmbito do Programa Nacional de Imunizações (PNI), em todo o território nacional.

- O Calendário Nacional de Vacinação do PNI/MS e o Calendário Nacional de Vacinação dos Povos Indígenas estão disponíveis no site http://goo.gl/jB4FHd.

- A introdução de novas vacinas e a alteração de faixa etária geram a publicação de novas portarias, revogando as anteriores.

Em 2015, o calendário de vacinação público e gratuito do Brasil foi considerado o mais completo do mundo, pelo elenco de vacinas disponíveis na rotina de mais de 35 mil salas de vacinação, distribuídas em todo o território nacional.

Ao longo dos anos, outras vacinas têm sido acrescidas àquelas introduzidas no calendário de vacinação brasileiro, instituído pela Portaria MS n. 452/1977(BRASIL, 1977), o que tem permitido manter atualizada a vacinação de rotina no país. 
Esquema 2 - Ampliação da oferta de vacinas pelo PNI

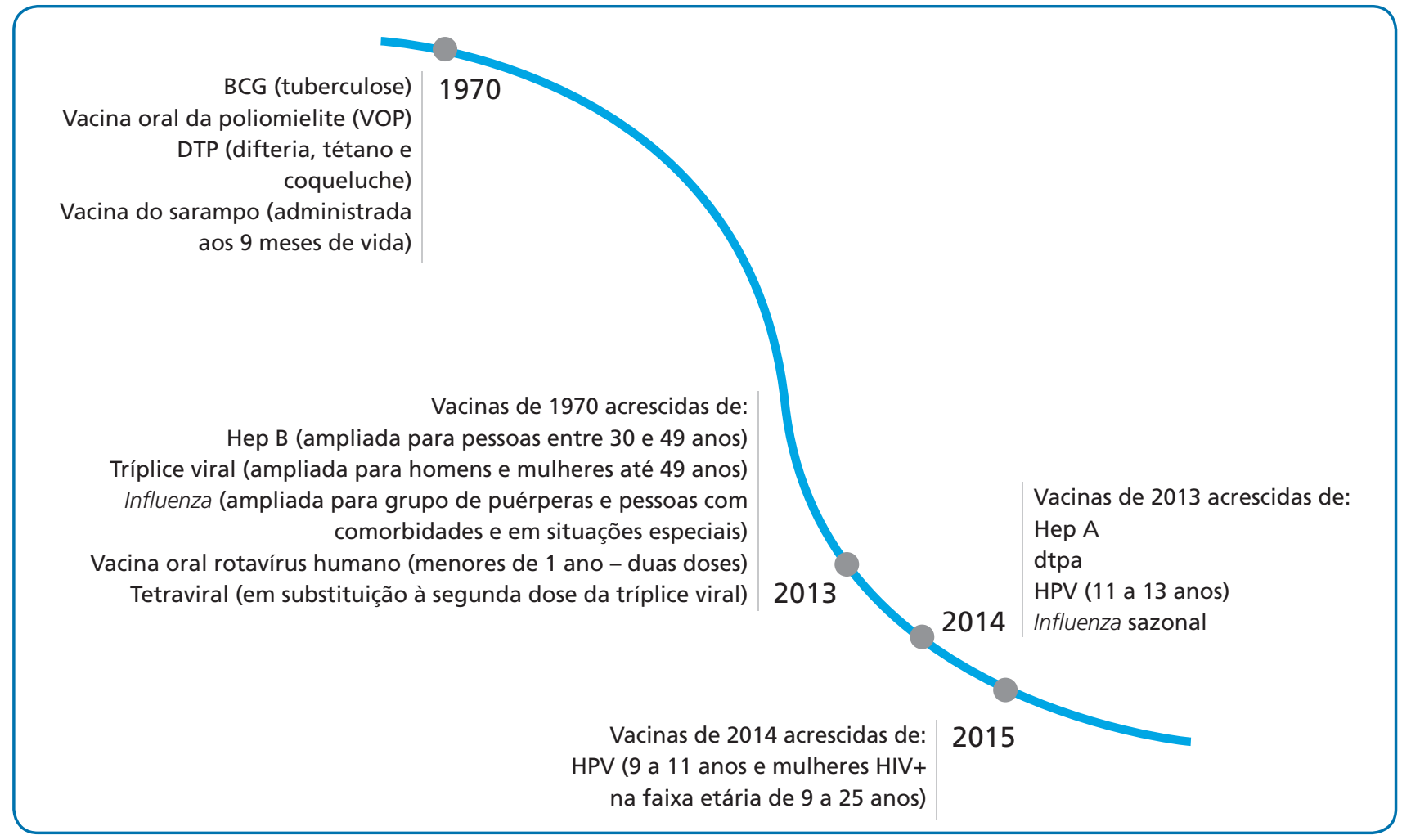

O calendário de vacinação brasileiro dispõe, em 2015, de 15 vacinas destinadas à população infantil, seis para adolescentes e adultos e cinco para idosos.

Em 2016, foram redefinidos o calendário nacional de vacinação, o calendário dos povos indígenas e as campanhas nacionais de vacinações no âmbito do Programa Nacional de Imunizações (PNI), em todo território nacional, por meio da publicação da Portaria n. 1.533, de 18 de agosto de 2016.

Além do calendário público oficial, existem, também, os da rede privada, apresentados pelas organizações/sociedades médicas e científicas do país, como a Sociedade Brasileira de Imunizações (SBIM) e a Sociedade Brasileira de Pediatria (SBP).

O calendário da SBIM, em 2016, assim como o da rede pública, sofreu mudanças, buscando atender a diversos grupos, tais como crianças, prematuros, adolescentes, adultos, idosos e outros. Inclui, também, um calendário de vacinação ocupacional, com indicação de vacinas de acordo com os riscos ocupacionais específicos de cada atividade profissional. 
Nesses calendários constam algumas vacinas que ainda não estão contempladas no PNI, ou que possuem esquemas vacinais diferenciados, ficando sua utilização a critério dos usuários e do médico assistente.

Para saber mais sobre a atuação da SBIM e da SBP, consulte:

http://www.sbim.org.br e http://www.sbp.com.br/pdfs/ calendario_vacinal 2014.

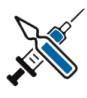

Em relação à vacina da varicela, devem ser observadas as indicações dos Crie.

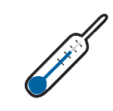

Se você quiser saber mais sobre o assunto, sugerimos consultar - Manual de recomendações para controle da tuberculose no Brasil, 2011, disponível no portal www.saude.gov.br/svs.
Vale ressaltar que as instituições que aplicam vacinas na rede privada devem possuir registro no órgão regulador responsável (Anvisa), bem como profissionais capacitados e rede de frio adequada, para a garantia de qualidade dos imunobiológicos e a prática de vacinação segura.

Cada vacina tem seu esquema vacinal específico: o volume a ser aplicado, o número de doses necessárias e oportunas para a efetiva proteção e as idades para aplicação. O calendário nacional de vacinação apresenta esquemas diferenciados para criança, adolescente, adulto, idoso, gestante e populações específicas, como a dos povos indígenas.

Dos calendários mencionados, será destacado, neste capítulo, o calendário ocupacional, como forma de conhecimento e incentivo à vacinação dos profissionais da saúde, de modo geral.

\section{Vacinação do profissional de saúde}

Os trabalhadores da saúde se expõem constantemente a doenças contagiosas, muitas delas preveníveis por vacinação. De acordo com os riscos ocupacionais, existem vacinas especialmente indicadas para eles.

Com o objetivo de proteção individual ou de pessoas no ambiente de trabalho e no domicílio, os profissionais da saúde devem manter seu calendário de vacinação rigorosamente em dia.

Na rede pública, integram o calendário ocupacional vacinas como hepatite B, tríplice viral-SCR, dT (difteria e tétano adulto) e influenza (gripe), entre outras. Em algumas situações, a vacina da varicela é recomendada. Além dessas, algumas poderão ser acrescentadas em decorrência do risco ocupacional para o indivíduo, sua clientela, ou mesmo do risco de disseminação de doenças na comunidade.

A vacina BCG não está indicada para os profissionais da saúde, independentemente do resultado da prova tuberculínica. Isso porque não existem evidências de que a revacinação com BCG traga benefícios para o profissional de saúde no que se refere à proteção contra a tuberculose, além de dificultar, também, o monitoramento das medidas de controle de infecção na interpretação de novas provas tuberculínicas.

Na rede privada, além das vacinas citadas anteriormente, o calendário ocupacional relativo aos profissionais da saúde recomenda as vacinas 
varicela, meningocócica conjugada e hepatite A. Para os cuidadores de crianças, em especial trabalhadores de centros de neonatologia, a vacina tríplice acelular do adulto (dTpa) está recomendada, com o objetivo de interrupção da transmissão da coqueluche.

O calendário ocupacional da SBIM, de 2015, sofreu algumas alterações relacionadas à área de atuação, como a de coletores de lixo, que foram agrupados em "Profissionais que lidam com dejetos e águas contaminadas entre outros". Foram introduzidas, também, novas áreas de atuação, como: profissionais ou voluntários que trabalham em campos de refugiados, em situações de catástrofes, em regime de confinamento e atletas profissionais.

Para você, profissional da área de saúde e atuante na rede de frio, por que é importante estar adequadamente vacinado?

Se você trabalha no almoxarifado ou no armazenamento e distribuição, por exemplo, manipula caixas, papéis, máquinas, equipamentos de refrigeração, veículos, entre outros, e está sujeito a acidentes que podem expô-lo ao bacilo do tétano. Já na sala de vacina, existe a possibilidade de acidente com material perfurocortante, que coloca o profissional em risco de contrair, entre outras doenças, a hepatite $\mathrm{B}$.

No seu dia a dia, o profissional também mantém contato com pessoas que podem lhe transmitir doenças respiratórias, como sarampo, gripe, e outras, como caxumba, rubéola, varicela, coqueluche etc. Além de ficar doente, pode transmitir a enfermidade para outras pessoas e ser responsável por iniciar um surto em seu ambiente de trabalho, ou para onde se deslocar.

Alguns grupos de trabalhadores necessitam de avaliação especial pelo risco aumentado de doenças infecciosas como os trabalhadores idosos, em função de outras patologias de base, trabalhadores que viajam ou têm contato constante com viajantes, devido aos riscos de contagio, trabalhadores do sexo, pela vulnerabilidade a que são expostos e por se constituírem potencial reservatório de agentes infecciosos, com risco elevado de contaminação dos clientes. Em qualquer que seja a atividade laboral, o trabalhador deve conhecer os riscos relacionados à sua atividade e as vacinas disponíveis.

Por isso, é imprescindível que o profissional cuide da sua saúde, mantendo a vacinação em dia, e também da saúde das pessoas de seu convívio.
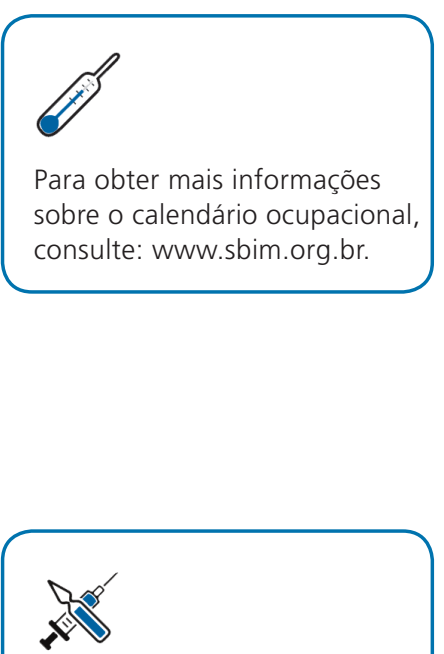

Além da hepatite $B$, que pode ser prevenida pela vacinação, o profissional está exposto ao risco de contrair outras doenças, como hepatite $C$ e HIV, contra as quais ainda não existem vacinas. 
O Planejamento Estratégico Situacional foi apresentado no Capítulo 1, "Planejamento em saúde", deste livro.

\section{Planejamento dos calendários de vacinação}

Vimos anteriormente que é imprescindível planejar na área da saúde, em função da própria complexidade do setor; na rede de frio de imunobiológicos, é um fator determinante e propulsor das atividades de imunização e da própria rede. Vimos também que o trabalho em saúde e na rede de frio engloba um conjunto amplo de atores e que planejar com esse conjunto é um desafio estratégico. Para superarmos esse desafio, podemos nos apoiar na metodologia de Planejamento Estratégico Situacional (PES).

Ao planejar com o enfoque do PES, é preciso considerar diversas visões sobre determinada realidade no intuito de construir consensos sobre ações estratégicas que possam auxiliar na resolução ou diminuição de problemas naquela realidade. Os problemas contribuem para elucidar uma situação de saúde e as condições de vida de uma população. Eles irão se juntar aos dados de mortalidade e morbidade e com as necessidades de saúde para configurar um cenário (contexto local) ou situação-problema ( se podem desenhar várias soluções (ações intersetoriais) ou situações-objetivo - onde se deseja chegar. Os problemas podem conter riscos, vulnerabilidades, doenças e mortes, elementos com capacidade para gerar explicações e intervenções da melhor maneira possível.

É importante ressaltar que o planejamento de calendários de vacinação é uma estratégia que envolve ações que devem ser realizadas com o máximo de escuta dos atores envolvidos, organização, ajustes necessários, readequações e/ou reorganizações, para que se possa garantir sua realização com a máxima eficácia e o mínimo risco. Essas ações necessitam de ser pensadas, previstas, monitoradas e avaliadas. O dimensionamento do que é necessário e de como poderá ser realizado, a partir dos objetivos traçados, somente será efetivo com um planejamento cuidadoso das atividades e por meio de avaliação contínua e sistemática dessas ações.

Os calendários de vacinação são atualizados permanentemente, tendo em vista o desenvolvimento de novas vacinas, o surgimento, a reemergência ou a eliminação de doenças, e são sempre adaptados às necessidades da população e às suas características socioeconômicas, demográficas e epidemiológicas. Por isso, podem ocorrer alterações em relação à idade, ao número de doses, à inclusão ou à exclusão de vacinas. 
Com as constantes modificações no fornecimento e produção de vacinas em nível mundial, surgem, a cada ano, novas recomendações para certos imunobiológicos, assim como se expande o uso deles para grupos cada vez mais abrangentes, tornando o calendário vacinal ainda mais dinâmico. É essencial que essas mudanças sejam conhecidas e acompanhadas pelos profissionais de saúde para a decisão correta na hora de vacinar.

Para tomada de decisão de alterações no calendário de vacinação, são consideradas características como o tamanho das faixas etárias da população, o tipo, o local onde ocorrem as doenças, o momento em que ocorrem, os diferentes climas das regiões, entre outras. Ao serem analisadas em conjunto, essas caraterísticas vão compor o padrão sanitário de uma população, possibilitar análises e definir ações específicas, como prioridades relativas ao uso de imunobiológicos.

Estudos criteriosos são realizados previamente, quando se planeja a inclusão de novas vacinas em um calendário. Esses estudos observam:

* Aspectos epidemiológicos relativos ao comportamento da doença: baseiam-se em estudos de incidência (casos novos) ou prevalência (casos novos e antigos) de uma doença que impacta a saúde da população, com elevados números de casos (morbidade) ou de mortalidade.

Relação custo e efetividade na introdução do imunobiológico: que compara os gastos com a aquisição ou produção da vacina com as despesas resultantes da doença, naquele momento.

* Resultados de impacto na doença: avaliam a eficácia da vacina no controle, na eliminação e/ou erradicação da doença e na promoção de imunidade prolongada ou duradoura, levando em consideração os estudos de efetividade e experiências de outros países, onde a vacina faz parte do calendário.

* Sustentabilidade financeira: analisa o custo de produção ou de importação da vacina, caso ela não seja produzida no país. O critério se baseia no planejamento orçamentário para a aquisição da vacina sem o pressuposto de qualquer interrupção por falta de recursos financeiros após sua implantação no calendário.

* Disponibilidade de aquisição ou produção de vacinas: avalia a capacidade e a tecnologia disponível no país para a produção da vacina. Caso não seja possível produzi-la, avalia a disponibilidade no mercado internacional para importação.
No Capítulo 4, "Conhecendo a epidemiologia", do livro Rede de Frio: fundamentos para a compreensão do trabalho (SILVA; FLAUZINO; GONDIM, 2016), são apresentados alguns dos elementos necessários para se analisar adequadamente a situação de saúde de determinada população.

A interrupção de oferta de um produto já implantado ocasiona prejuízos à saúde da população, além da quebra de credibilidade do programa de imunizações.

Um exemplo dessa situação é a vacina varicela, que entrou no calendário do PNI somente em 2014, pois não havia produção nacional nem vacinas suficientes para serem adquiridas no mercado internacional, até então. 


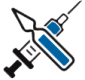

O critério estrutura da rede de frio é fundamental, pois não adianta haver disponibilidade e possibilidade de aquisição de novos imunobiológicos se não houver estrutura, insumos e equipe técnica especializada suficientes para a execução das atividades de armazenamento e transporte dos produtos.

Podemos citar, como exemplos, a vacina oral de rotavírus humano, importada em 2006 (ano da implantação) do laboratório Glaxo Smith Kline Biologicals (GSK) e que, hoje, é produzida pela Fiocruz/Bio-Manguinhos; e a mais recente, a vacina hepatite A. Para se efetivar a implantação dessa vacina no calendário, em 2014, houve a Parceria de Desenvolvimento Produtivo (PDP) entre o Ministério da Saúde e - laboratório produtor Merck Sharp \& Dohme Farmacêutica, que irá transferir, gradualmente, para o laboratório público Instituto Butantã, a tecnologia e a fórmula do princípio ativo do imunobiológico.
Novos conhecimentos técnicos e científicos: atentam para o desenvolvimento de novos produtos, que vão sendo produzidos a partir de recomendações baseadas em estudos científicos e pela incorporação de novas tecnologias.

* Estrutura da rede de frio: considera a capacidade instalada da rede de frio para avaliar a possibilidade e planejar a inclusão de mais imunobiológicos no calendário de imunizações.

\section{* Transferência de tecnologia entre laboratórios produtores} nacionais e internacionais: este último critério para incorporação de vacinas ao calendário nacional de vacinação é especialmente relevante. Inicialmente, os imunobiológicos utilizados pelo PNI eram todos importados. Há alguns anos, o Ministério da Saúde adotou a prática de firmar acordos com os laboratórios produtores internacionais. Estes transferem a tecnologia de produção das vacinas para os laboratórios nacionais, como o Instituto Butantã e a Fiocruz/Bio-Manguinhos. À medida que se ampliou o parque nacional de produção de imunobiológicos e se consolidou o processo de transferência de tecnologia de produção com laboratórios internacionais, o calendário público de vacinação tornou-se mais completo, e as coberturas vacinais se elevaram e se tornaram mais homogêneas em todo o país.

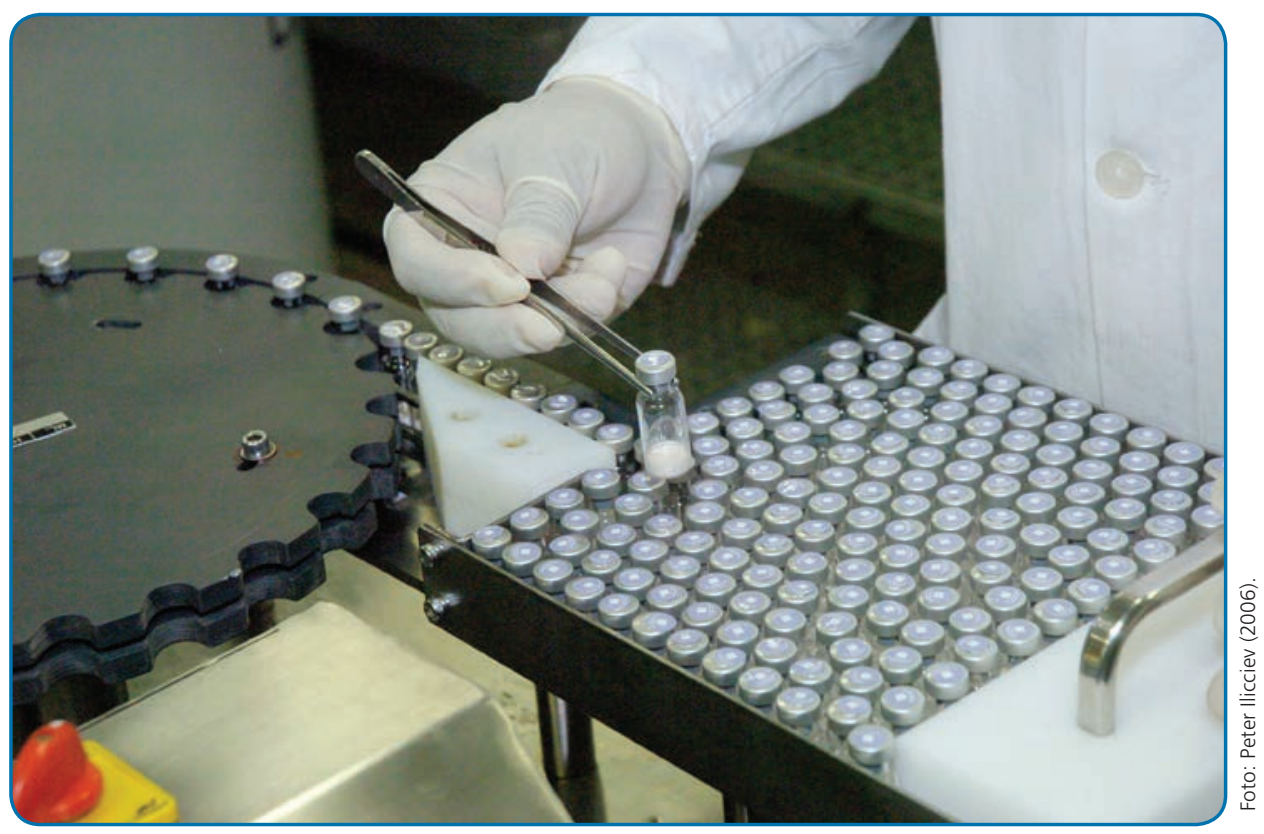

Laboratório de produção de vacinas: Bio-Manguinhos. O Instituto de Tecnologia em Imunobiológicos (Bio-Manguinhos), da Fundação Oswaldo Cruz, é uma das unidades responsáveis pela produção das vacinas utilizadas no Programa Nacional de Imunizações. 


\section{O calendário e a caderneta de vacinação}

A realização dos esquemas vacinais completos nos indivíduos deve ser registrada em documentos conhecidos como cadernetas de vacinação. O ideal é que uma pessoa tenha sua caderneta de vacinação para toda a vida, pois nela estará registrado o histórico de sua imunização desde o nascimento.

Todos devem guardar o registro de vacinação. Qualquer pessoa que procurar a unidade vacinadora deve comprovar sua condição vacinal com o cartão/caderneta de vacina ou o registro vacinal, seja público ou privado. Caso contrário, será considerada não vacinada. Nesse caso, deve recomeçar a vacinação, apesar do risco de ocorrência de eventos adversos pós-vacinação, em consequência de vacinações sucessivas e uso desnecessário de doses da mesma vacina.

A unidade de saúde, por sua vez, realizará o registro das doses aplicadas no Sistema de Informações do PNI (SI-PNI). O SI-PNI está em processo de implantação em todo o país; nele é possível o resgate dos cartões, pois a inclusão das doses aplicadas no sistema é feita por nome do usuário.

A produção e a distribuição da Caderneta de Saúde da Criança são responsabilidade do Programa Nacional de Saúde Materno-Infantil, do Ministério da Saúde, sendo entregue já na maternidade. Nela são registradas todas as vacinas administradas na população infantil.

O Quadro 1 reproduz uma das páginas em que são registradas as doses de vacinas aplicadas. 
Quadro 1 - Registro das vacinas do calendário básico

\begin{tabular}{|c|c|c|c|c|c|c|}
\hline Doses/vacinas & BCG-ID & Hepatite B & Pólio & Tetravalente & Rotavírus & Pneumocócica \\
\hline $1^{\text {a }}$ dose & $\begin{array}{l}\text { Data: / / } \\
\text { Lote: } \\
\text { Unid: }\end{array}$ & $\begin{array}{l}\text { Data: / / } \\
\text { Lote: } \\
\text { Unid: }\end{array}$ & $\begin{array}{l}\text { Data: / / } \\
\text { Lote: } \\
\text { Unid: }\end{array}$ & $\begin{array}{l}\text { Data: / / } \\
\text { Lote: } \\
\text { Unid: }\end{array}$ & $\begin{array}{l}\text { Data: / / } \\
\text { Lote: } \\
\text { Unid: }\end{array}$ & $\begin{array}{l}\text { Data: / / } \\
\text { Lote: } \\
\text { Unid: }\end{array}$ \\
\hline $2^{\mathrm{a}}$ dose & $\begin{array}{l}\text { Data: / / } \\
\text { Lote: } \\
\text { Unid: }\end{array}$ & $\begin{array}{l}\text { Data: / / } \\
\text { Lote: } \\
\text { Unid: }\end{array}$ & $\begin{array}{l}\text { Data: / / } \\
\text { Lote: } \\
\text { Unid: }\end{array}$ & $\begin{array}{l}\text { Data: / / } \\
\text { Lote: } \\
\text { Unid: }\end{array}$ & $\begin{array}{l}\text { Data: / / } \\
\text { Lote: } \\
\text { Unid: }\end{array}$ & $\begin{array}{l}\text { Data: / / } \\
\text { Lote: } \\
\text { Unid: }\end{array}$ \\
\hline \multirow{2}{*}{$3^{\mathrm{a}}$ dose } & \multirow{2}{*}{ Meningocócica } & \multirow{2}{*}{ Tríplice } & \multirow{2}{*}{$\begin{array}{l}\text { Febre Amarela } \\
\text { Dose inicial }\end{array}$} & \multicolumn{3}{|l|}{ Reforço } \\
\hline & & & & DTP & $P$ & Pneumocócica \\
\hline $\begin{array}{l}1^{\text {a }} \text { dose ou } \\
\text { reforço }\end{array}$ & $\begin{array}{l}\text { Data: / / } \\
\text { Lote: } \\
\text { Unid: }\end{array}$ & $\begin{array}{l}\text { Data: / / } \\
\text { Lote: } \\
\text { Unid: }\end{array}$ & $\begin{array}{l}\text { Data: / / } \\
\text { Lote: } \\
\text { Unid: }\end{array}$ & $\begin{array}{l}\text { Data: / / } \\
\text { Lote: } \\
\text { Unid: }\end{array}$ & $\begin{array}{l}\text { Data: / / } \\
\text { Lote: } \\
\text { Unid: }\end{array}$ & $\begin{array}{l}\text { Data: / / } \\
\text { Lote: } \\
\text { Unid: }\end{array}$ \\
\hline $2^{a}$ dose & $\begin{array}{l}\text { Data: / / } \\
\text { Lote: } \\
\text { Unid: }\end{array}$ & $\begin{array}{l}\text { Data: / / } \\
\text { Lote: } \\
\text { Unid: }\end{array}$ & $\begin{array}{l}\text { Data: / / } \\
\text { Lote: } \\
\text { Unid: }\end{array}$ & $\begin{array}{l}\text { Data: / / } \\
\text { Lote: } \\
\text { Unid: }\end{array}$ & $\begin{array}{l}\text { Data: / / } \\
\text { Lote: } \\
\text { Unid: }\end{array}$ & $\begin{array}{l}\text { Data: / / } \\
\text { Lote: } \\
\text { Unid: }\end{array}$ \\
\hline
\end{tabular}

Fonte: Programa Nacional de Saúde Materno-Infantil do MS. Quadro de Edson Alves de Moura Filho (1994).

É fundamental que o registro das doses aplicadas contenha as seguintes informações:

nome da vacina;

燐 data em que foi realizada a vacinação;

número do lote, validade;

慗laboratório produtor;

unidade vacinadora;

nome legível do vacinador.

Isso garante a confiabilidade das informações para consultas futuras ou para investigação de possíveis eventos adversos pós-vacinação.

\section{Estratégias de vacinação}

Estratégia pode ser definida como o caminho escolhido para se atingir determinada meta. É o "como fazer". No caso da vacinação, a estratégia é o caminho escolhido para se conseguir oferecer o imunobiológico ao público-alvo que dele necessita, no menor prazo, alcançando a proteção e, em consequência, o controle, a eliminação ou a erradicação da doença. 
Como já dissemos, o PNI tem como meta básica vacinar 100\% da população infantil, o mais precocemente possível. Diversas estratégias são utilizadas para o alcance dessa meta, como vacinação de rotina (calendário), extramuros, campanhas etc.

As estratégias de vacinação podem ser utilizadas de forma isolada ou combinadas, já que não existe uma solução única. A escolha de uma ou outra forma de trabalhar leva em conta as características do território e da população, assim como a capacidade instalada e o percentual de cobertura que vêm sendo alcançados (FUNDAÇÃO NACIONAL DE SAÚDE, 2001).

São estratégias básicas de vacinação:

* a vacinação de rotina realizada no serviço de saúde;

* campanhas de vacinação;

* vacinação de bloqueio;

atividades de vacinação extramuros.

Ao se propor a realização de qualquer uma dessas estratégias, é fundamental considerar a necessidade de capacitação dos recursos humanos (treinamento, atualização) e de ações para mobilização e envolvimento dos diversos segmentos da comunidade, seja para divulgar informações, seja para participar da vacinação.

Segundo o Planejamento Estratégico Situacional (PES), diversas visões e opiniões sobre a realidade devem ser consideradas para se construir consensos sobre ações estratégicas que possam auxiliar na resolução ou diminuição dos chamados problemas semi ou quase estruturados, para propiciar mudanças em determinada realidade.

A discussão da estratégia para aumentar a cobertura vacinal de determinado território é um exemplo desse tipo de problema, e a sua solução não depende somente dos profissionais que trabalham no setor de imunização. Para resolvê-lo, pode ser necessária a adesão de diversos profissionais e setores, como agentes comunitários de saúde, equipes da saúde da família, até mesmo profissionais das escolas, associação de moradores etc. Planejar essas ações pode auxiliar a equacionar ou dirimir parte dos riscos e problemas que poderão ocorrer, caso elas não tenham sido planejadas.

\section{Vacinação de rotina}

A vacinação de rotina consiste no atendimento da população no dia a dia do serviço de saúde. Essa estratégia permite o acompanhamento 
contínuo e programado das metas previstas, facilitando o monitoramento sistemático (mensal ou trimestral), de forma a identificar, em tempo oportuno, se as metas estão sendo alcançadas, que áreas merecem atenção, ou grupos que necessitam ser priorizados.

$\mathrm{Na}$ rotina, é fundamental que se aproveitem todas as oportunidades para vacinar as pessoas que pertencem aos grupos-alvo, em qualquer situação de contato da equipe com o usuário do serviço. A articulação e a mobilização das instituições e organizações da comunidade podem, também, favorecer o trabalho da equipe de saúde para alcançar o público-alvo (BAHIA, 2011).

Quando são detectadas coberturas vacinais aquém dos percentuais estabelecidos, é necessário identificar mecanismos para sua superação. Um desses mecanismos é a chamada "intensificação da rotina", que consiste em trabalhar o dia a dia de forma mais dinâmica, tornando a vacinação mais acessível à população suscetível, o que inclui, certamente, a vacinação extramuros.

\section{Vacinação extramuros}

As atividades extramuros são adotadas em função de uma necessidade operacional ou epidemiológica que exige colocar a vacinação mais acessível e próxima da população. Seu principal objetivo é eliminar bolsões de suscetíveis, sobretudo na realização da prática de vacinação nas residências e instituições em geral, como escolas, creches, empresas, orfanatos etc. Essa atividade tem como finalidade alcançar pessoas que não são vacinadas na rotina; população em situação de rua; acampada; boias-frias etc. Essa prática possibilita, também, atender populações com maior dificuldade de ser vacinadas, em especial pessoas que vivem em áreas rurais de difícil acesso: populações indígenas, ribeirinhos, quilombolas (AGÊNCIA NACIONAL DE VIGILÂNCIA SANITÁRIA; FUNDAÇÃO NACIONAL DE SAÚDE, 2000; BAHIA, 2011 ).

Muitas pessoas e grupos vivem em condições de grande vulnerabilidade social em locais insalubres e sem infraestrutura adequada, cujas formas de viver, além de influenciar na imunidade, Ihes atribui maior suscetibilidade em adoecer.

O conhecimento do lugar onde ocorre determinada doença é muito importante, em epidemiologia, para a caracterização do evento. A análise dos agravos à saúde, com ênfase nas diferenças geográficas, constitui uma preocupação fundamental para se entender o processo de manutenção da saúde e de adoecimento das pessoas. 
Distinguir onde as pessoas moram, as características geográficas do lugar, a sua forma de ocupação, os poluentes existentes e até a existência de alimentos contaminados ajudam a apontar os riscos a que o indivíduo está sujeito pelo fato de viver em certas regiões ou visitá-las. Assim, conhecer as condições de vida e a situação de saúde de territórios (determinantes, riscos e vulnerabilidades) onde os eventos de doença ocorrem é fundamental para a tomada de decisão e ação no sentido de proteger pessoas e grupos e controlar a ocorrência de doenças.

As atividades extramuros podem ser realizadas tanto pelo setor público quanto pelo privado. No caso de estabelecimentos privados, estão liberados somente aqueles licenciados pela vigilância sanitária e credenciados pela vigilância epidemiológica, desde que sigam rigorosamente as orientações da Portaria Conjunta Anvisa/Funasa n. 1, de 2 de agosto de 2000, e as regulamentações locais, que podem variar em cada estado e município.

O trabalho de imunização extramuros reúne uma série de peculiaridades e especificidades desafiadoras, tais como:

* falta de energia elétrica em tempo constante;

* manutenção dos equipamentos da rede de frio;

* grande dispersão geográfica;

dificuldades de acesso;

* dificuldade de acompanhamento de possíveis eventos adversos

relacionados à vacinação, por causa da curta permanência da equipe de saúde local, sendo necessária, ainda, maior atenção na conservação das vacinas (SANTOS, 2010);

* condições ambientais adversas;

* diversidade das características culturais, como as dos povos indígenas, quilombolas e ribeirinhos.

Para a conservação das vacinas nessas condições, as ações de imunização necessitam de uma série de cuidados para manutenção de uma rede de frio, que tem características próprias, que se diferencia da manutenção dos imunobiológicos na rotina (geladeiras).

O custo para a realização das atividades extramuros pode ser alto, especialmente quando envolve transporte por longas distâncias, em áreas rurais e indígenas, por exemplo. Por isso, é importante que esses momentos sejam aproveitados para se realizar outras ações de atenção básica, de forma integrada com a imunização.

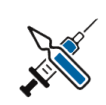

No Brasil, Santa Catarina é o único estado que regulamenta, de forma mais detalhada, a atividade de vacinação extramuros, por meio da Instrução Normativa Conjunta n. 001/DIVS/DVE/2012, retificada e ratificada pela Instrução Normativa Conjunta n. 003/DIVS/DVE/2013 (SANTA (ATARINA, 2013).

Para conhecer o teor das Instruções Normativas Conjuntas n. 001/DIVS/ DVE/2012 e n. 003/DIVS/ DVE/2013, consulte:

http://www.dive.sc.gov. br/conteudos/imunizacao/ publicacoes/Instrucao_ Normativa_Vacinacao_ Extramuro.pdf 
Um planejamento cuidadoso das atividades extramuros possibilita a realização de ações de vigilância à saúde, a atualização de cadernetas de vacinação, de censos da população atendida, além de fortalecer o vínculo entre a comunidade e a equipe de saúde. Para tanto, na elaboração de estratégias de imunização extramuros, devem ser consideradas a extensão do território e as distâncias a serem percorridas, a população, a realidade de saúde local, o perfil epidemiológico e a infraestrutura do local, bem como as seguintes medidas:

* vacinação simultânea de toda a população suscetível, visando à melhoria contínua dos indicadores vacinais, por meio da busca ativa de suscetíveis;

* vigilância permanente para as doenças imunopreveníveis e capacitação da equipe local para intervenção imediata nas formas de bloqueio, manutenção e varredura, entre outras;

* parcerias com as diferentes instituições participantes do Programa Nacional de Imunizações (PNI) e avaliação imediata do trabalho, após cada ação de imunização, por todos os envolvidos, subsidiando o planejamento das ações subsequentes;

* valorização e inserção dos agentes de saúde nas atividades de imunização, considerando os propósitos de formação profissional e a interação educativa com as comunidades;

* integração do trabalho de imunização com as demais atividades multiprofissionais de assistência e vigilância à saúde;

* estabelecimento de rotinas no trabalho do programa de imunizações, contendo regras e fluxos programáticos para as ações e especificidades operacionais de cada local;

* elaboração de padronização de condutas e ações técnicas sobre a prática de imunização.

A vacinação extramuros, quando bem programada em termos de recursos humanos e materiais e realizada de forma sistemática, apresenta resultados proveitosos para a cobertura vacinal dessas populações.

\section{Vacinação de bloqueio}

A vacinação de bloqueio é uma atividade executada quando há ocorrência de um ou mais casos de doença prevenível pela vacinação. Ela visa interromper a cadeia de transmissão de doença mediante a vacinação de todos os suscetíveis, em curto espaço de tempo. 
Essa atividade pode ser limitada à moradia do doente, ao seu local de trabalho ou de estudo; abranger as residências vizinhas, ou estender-se a um ou mais quarteirões, ou mesmo a todo um bairro, vila ou município.

Os critérios para definição da área de cobertura de uma vacinação de bloqueio estão definidos no Guia de vigilância epidemiológica, publicado pela Secretaria de Vigilância em Saúde (SVS), ou por notas e informes técnicos do Ministério da Saúde (BRASIL, 2010).

\section{Campanhas de vacinação}

As campanhas de vacinação são estratégias diferenciadas da rotina, com abrangência limitada e que visam ao controle de doenças de maneira intensiva, com vacinação em massa da população-alvo, ou a extensão da cobertura vacinal, para complementação do serviço de rotina. São estratégias que visam ao controle de pandemias, epidemias e surtos, ou à manutenção da eliminação/erradicação de determinada doença imunoprevenível.

Ações de intensa mobilização da comunidade, principalmente por meio dos veículos de comunicação de massa e da ampliação do número de postos, contribuem para o sucesso das campanhas, permitindo que a população fique mais próxima da vacina, possibilitando o alcance de maiores contingentes e a obtenção de altos índices de cobertura.

O alto custo financeiro e a grande mobilização de recursos (humanos, institucionais) e da comunidade são fatores a serem considerados, mas que não devem impossibilitar a realização da campanha. A oportunidade da campanha deve ser aproveitada para se administrarem todas as vacinas em crianças ou em outros grupos de risco, iniciando ou completando o esquema de vacinação estabelecido.

As campanhas nacionais, a vacinação de rotina e outras estratégias têm possibilitado a melhoria das coberturas vacinais ao longo dos anos de existência do PNI, com efetiva contribuição no declínio das doenças imunopreveníveis (BAHIA, 2011 ; FUNDAÇÃO NACIONAL DA SAÚDE, 2001).

\section{Breve histórico das campanhas de vacinação realizadas pelo PNI}

Foram muitas as ações realizadas no país que lograram êxito no controle e na eliminação de doenças como a poliomielite, o sarampo, a rubéola e a influenza pandêmica (gripe). Algumas permanecem até hoje. Vejamos um pouco desse histórico.
No Capítulo 3 do livro Rede de Frio: fundamentos para a compreensão do trabalho, a estratégia de campanha de vacinação é exemplificada na discussão da importância das ações de saúde pautadas em base territorial. São as informações sobre o território que irão apontar como irá se desenvolver a campanha: qual o público-alvo a ser vacinado; a quantidade necessária de vacinas; os locais de vacinação; a forma de comunicação sobre a campanha; as formas de distribuição e acondicionamento das vacinas e a duração da campanha, entre outros (SILVA; FLAUZINO; GONDIM, 2016).

As campanhas nacionais de vacinação realizadas pelo PNI, publicadas na Portaria n. 1.489/2013, estão listadas no Anexo A deste capítulo.

O Anexo A deste capítulo apresenta as campanhas nacionais de vacinação e relaciona os grupos-alvos. 
Autóctone, diz-se daquilo que é natural da região onde ocorre (DICIO, 2009).
1980: foi realizada a $1^{\text {a }}$ Campanha Nacional de Vacinação contra a poliomielite, com a meta de vacinar todas as crianças menores de 5 anos de idade em um só dia. Graças aos resultados obtidos ao longo dos anos, em 1989 foi notificado o último caso de poliomielite no Brasil. Em setembro de 1994, junto com os demais países das Américas do Norte, Central e Sul, o Brasil recebeu da Comissão Internacional para a Certificação da Ausência de Circulação Autóctone do Poliovírus Selvagem nas Américas o certificado de que a doença e o vírus foram eliminados do continente.

Com o objetivo de sensibilizar o público, especialmente o infantil, para a importância da vacinação, em 1986 foi criado o personagem Zé Gotinha, pelo artista Darlan Rosa. Utilizado pela primeira vez na campanha contra a pólio da década de 1980, o Zé Gotinha tornou-se uma referência e é utilizado, até hoje, em diversas campanhas de vacinação, passando por adaptações ao longo do tempo.

* 1999: iniciou-se a campanha de vacinação contra influenza para a população idosa, hoje ampliada para outros grupos prioritários.

2000: com campanhas nacionais de seguimento contra sarampo e boas coberturas vacinais na rotina, houve a confirmação do último caso de sarampo autóctone no país, graças a essas estratégias. Os casos confirmados posteriormente foram importados de outros países.

* 2008: houve grande mobilização nacional para eliminar, no país, a rubéola e a síndrome da rubéola congênita e fortalecer a eliminação do sarampo, com a execução da maior campanha de vacinação realizada no mundo, em tão curto espaço de tempo. Cerca de 67 milhões de pessoas foram vacinadas entre os meses de agosto e dezembro do referido ano (dados nacionais disponíveis no site do DATASUS (2016)).

* 2010: a campanha contra o vírus influenza A (H1Nl) foi o maior desafio enfrentado pelo PNI até então, em virtude da vacinação de mais de 89 milhões de brasileiros, durante a pandemia de gripe.

\section{Outros produtos disponibilizados pelo PNI}

A vacinação é a principal estratégia de imunização da população. No entanto, em alguns casos, é necessário associá-la a outras ações. Dependendo da gravidade da ocorrência de uma infecção, muitas vezes existe a necessidade de se associar a vacinação ao uso de um soro específico, pois, como a vacina demora de 14 a 21 dias, em média, para produzir anticorpos protetores e o soro já possui imunoglobulinas prontas, este 
irá proteger a pessoa, temporariamente, até que a ação da vacina se inicie. É mais ou menos assim: quando a ação do soro está terminando, começa a da vacina. Exemplos mais comuns são os casos de profilaxia da raiva, tétano, difteria e hepatite $B$.

Outra situação é a imunização contra acidentes por animais peçonhentos ou por botulismo, em que não existe vacina, só o soro. Nesse caso, quando a pessoa se cura, pode ficar vulnerável, novamente, diante de uma nova exposição ao agente.

Considerando sua atuação nas diferentes estratégias de imunização da população, além das vacinas disponíveis na rotina e nas campanhas, cabe ainda ao PNI a aquisição e distribuição de soros heterólogos e homólogos, utilizados nas unidades hospitalares e de pronto atendimento. Os soros mais comumente utilizados e que fazem parte da administração do PNI são: antitetânicos, antidiftéricos e antirrábicos.

Conhecemos, anteriormente, os dois tipos de soros: os heterólogos e os homólogos. Agora, iremos conhecer a diferença entre os tipos de soros.

\section{Soros heterólogos}

São soluções injetáveis de imunoglobulinas específicas, purificadas e concentradas, obtidas de soros de equinos hiperimunizados com venenos de animais peçonhentos, ou produtos de microrganismos que protegem o indivíduo mais rapidamente do que as vacinas, pois são anticorpos já prontos. Têm durabilidade limitada, com vida média em torno de 14 dias. São utilizados em caso de acidentes com animais peçonhentos, para os quais não existem vacinas, ou em risco eminente de doenças como o tétano, a raiva e a difteria, em pessoas não imunizadas.

Os soros heterólogos podem induzir reações alérgicas, em algumas pessoas, ou depósitos de imunocomplexos que levam à doença do soro, em resposta a proteínas estranhas oriundas do animal. Em virtude disso, existe a recomendação de se administrar esses soros em ambiente onde o paciente possa receber assistência imediata, caso alguma reação anormal ocorra (ambiente hospitalar, Unidades de Pronto Atendimento).

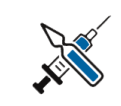

Essas condutas para proteção da população dependem diretamente da sua atuação, profissional da rede de frio. Por meio do trabalho adequado na conservação, no armazenamento e na distribuição dos imunobiológicos, você garantirá a manutenção da qualidade e eficácia do produto, conferindo imunidade às pessoas.
O Anexo B deste capítulo lista os soros heterólogos distribuídos pelo $\mathrm{PNI} / \mathrm{MS}$.
Imunocomplexos são antígenos ligados a IgG e IgM que causam uma reação de hipersensibilidade, ao se depositarem na parede dos vasos, e provocam uma reação inflamatória que lesiona o tecido celular, prejudicando o seu funcionamento. 
Figura 1 - Esquema de produção de soros heterólogos

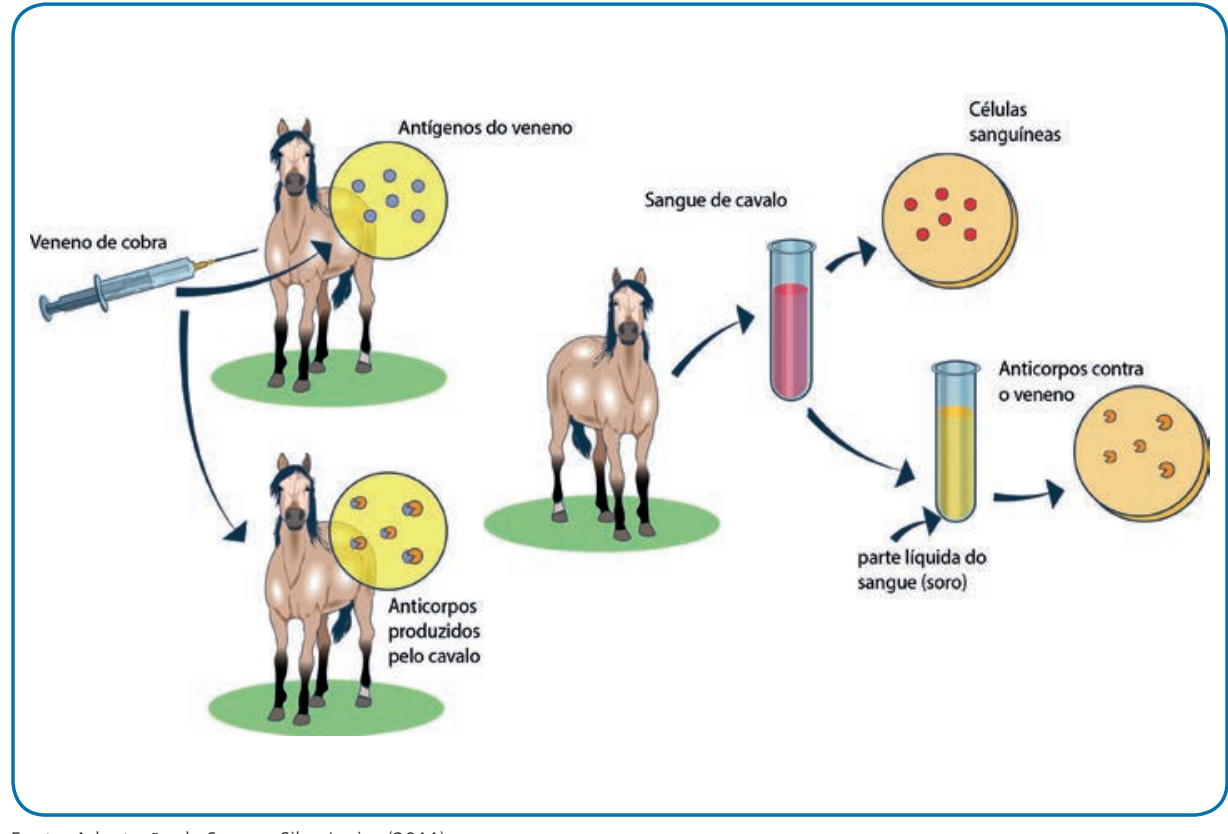

Fonte: Adaptação de Sasson; Silva Junior (2011).

\section{Soros homólogos (imunoglobulinas de origem humana)}

São soluções obtidas de doadores humanos, com altos títulos de anticorpos contra determinado microrganismo, obtidos tanto por infecção natural como por vacinação anterior.

Por não conterem proteínas de origem animal em sua formulação, apresentam menor incidência de reações alérgicas ou por depósito de complexos imunes (doença do soro).

Em virtude das particularidades no processo de produção, os soros homólogos, em geral, têm custo mais elevado e são utilizados em pessoas que já apresentaram reações adversas anteriormente, após o uso de soros heterólogos, ou com necessidades especiais, de acordo com os protocolos de indicação dos Crie. Atualmente, as imunoglobulinas contra tétano, raiva, varicela-zóster e hepatite B estão disponíveis nos Crie.

Com base no que foi apresentado, agora você é capaz de entender por que, em algumas situações, se utiliza a vacina, em outras, a vacina e o soro, e em outras mais, só o soro. 


\section{Imunobiológicos especiais}

Os imunobiológicos especiais (vacinas e imunoglobulinas hiperimunes) são adquiridos pelo Ministério da Saúde para atender pessoas que, por motivos biológicos, são impedidas de receber os produtos que se encontram na rotina e disponibilizados na rede pública. Esses produtos são administrados em locais específicos, como os Centros de Referência para Imunobiológicos Especiais (Crie).

\section{Sobre os Crie}

Em 1993, iniciou-se no Brasil a implantação dos Crie, que são salas públicas de vacinação, geralmente localizadas em instituições hospitalares, onde são disponibilizados imunobiológicos não contemplados na rotina, chamados de imunobiológicos especiais.

Os Crie disponibilizam imunobiológicos especiais e imunoglobulinas de origem humana, cujos critérios de inclusão estão referidos no Manual de referência para imunobiológicos especiais do Ministério da Saúde (BRASIL, 2014).

Por se tratar de estrutura direcionada ao atendimento diferencial, os Crie contam com produtos imunobiológicos de moderna tecnologia e alto custo, com a finalidade de proporcionar melhor qualidade de vida à população brasileira. A vacinação nos Crie se faz mediante indicação e prescrição médica.

Para receber os imunobiológicos especiais, os indivíduos devem apresentar uma sensibilidade aumentada às doenças, ou risco de complicações para si ou para outros, decorrentes de:

- motivos biológicos, como imunodepressão, asplenia (falta do baço), transplante, Aids;

- convívio com pessoas imunodeprimidas, como profissionais da área da saúde e parentes de imunodeprimidos;

- intolerância aos imunobiológicos, em virtude de alergia ou evento adverso grave após recebê-los;

- exposição inadvertida a agentes infecciosos por motivos profissionais ou violência contra a pessoa.

Os Crie têm, ainda, a função de investigar, notificar e atender os casos de Eventos Adversos Pós-Vacinação (EAPV) e representam importantes centros de informações e pesquisas.

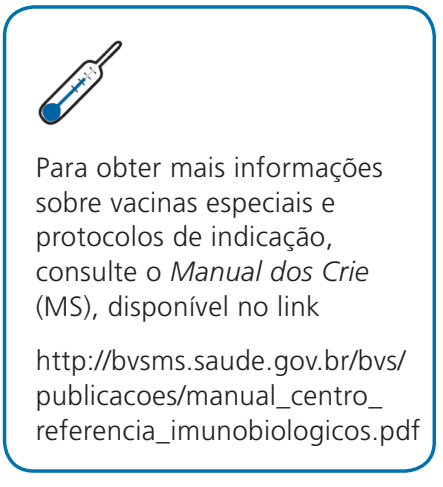

Os imunobiológicos especiais disponibilizados pelo PNI são apresentados no Anexo $C$ deste capítulo. Os EAPV serão apresentados e discutidos no próximo capítulo deste livro. 


\section{Considerações finais}

Neste capítulo foi possível conhecer um pouco sobre o Programa Nacional de Imunizações e as diferentes estratégias de vacinação, as quais visam alcançar o principal objetivo do PNI, qual seja, vacinar $100 \%$ da população brasileira.

Ao ser formulado, o PNI tinha, como missão inicial, coordenar as ações de imunização no país, antes organizadas em programas de controle de doenças. Sua criação possibilitou a organização e a coordenação das ações de vacinação e um conjunto de avanços, como a erradicação da varíola, a eliminação da poliomielite, do sarampo e da rubéola, o processo de eliminação do tétano neonatal, a redução e o controle da meningite por Haemophilus influenzae e meningococo C, entre outros.

Hoje o programa dispõe de um conjunto de vacinas disponíveis para toda a população, de forma gratuita, com perspectivas de introdução de novas vacinas e ampliação do uso de algumas já existentes. Está prevista a ampliação da oferta da vacina hepatite B (Hep B) a toda a população, bem como alteração do esquema vacinal de algumas vacinas, como a vacina meningocócica C conjugada, entre outras, tornando o calendário de vacinação brasileiro cada vez mais efetivo no controle das doenças preveníveis e na proteção de toda a população.

Aliados a esses fatores, a capacidade do programa em mobilizar a população para adesão à vacinação nas campanhas e o crescente aumento do número das salas de vacinação de rotina tornam o PNI um exemplo de política pública bem-sucedida, com o fortalecimento do Ministério da Saúde.

Todas essas atividades estão fundamentadas e orientadas na discussão permanente sobre normas, metas e resultados, o que propicia a modernização de sua infraestrutura e a operacionalização entre as três esferas de governo. As ações do PNI são desenvolvidas no Sistema Único de Saúde (SUS), por intermédio de uma rede descentralizada, articulada, hierarquizada e integrada.

É inegável a contribuição do PNI para a redução das desigualdades regionais e sociais, ao viabilizar a vacinação para todos os brasileiros, em todas as localidades de fácil ou difícil acesso. Sua forma de atuação garante a implementação de todas as estratégias de ação, definidas segundo os princípios do SUS: universalidade, integralidade e participação da comunidade, estabelecidos no artigo $7^{\circ}$, da Lei n. 8.080, de 19 de setembro de 1990 (BRASIL, 1990). 
O programa é protagonista de um novo momento, no qual a complexidade do quadro epidemiológico e o desenvolvimento de novas vacinas passaram a exigir adequada e inédita maneira de organização das ações de vacinação. Sem o conhecimento e a participação efetiva do profissional de saúde, o PNI não alcançaria o êxito que hoje o coloca entre um dos programas de maior sucesso no mundo.

\section{Referências}

AGÊNCIA NACIONAL DE VIGILÂNCIA SANITÁRIA (Brasil); FUNDAÇÃO NACIONAL DE SAÚDE (Brasil). Portaria Conjunta Anvisa/Funasa n. 1, de 2 de agosto de 2000. Estabelece as exigências para o funcionamento de estabelecimentos privados de vacinação, seu licenciamento, fiscalização e controle, e dá outras providências. Diário Oficial da União, Brasília, DF, 3 ago. 2000. Seção 1, p. 15.

ALMEIDA FILHO, N.; ROUQUAYROL, M. Z. Elementos de metodologia epidemiológica. Rio de Janeiro: Medsi, 2003.

ARANDA, C. M. S. S. et al. Rede de frio para a conservação de vacinas em unidades públicas do município de São Paulo: conhecimento e prática. Revista Brasileira de Epidemiologia, São Paulo, v. 9, n. 2, p. 172-185, 2006.

AUSTRALIA. National vaccine storage guidelines. Strive for 5. 2nd. Edition. Canberra, 2013. Disponível em: <http://immunise.health.gov.au>. Acesso em: 20 abr. 2010.

BAHIA. Secretaria da Saúde. Coordenação do Programa Estadual de Imunizações. Manual de procedimento para vacinação. Salvador, 2011.

BRASIL. Lei n. 8.080, de 19 de setembro de 1990. Dispõe sobre as condições para a promoção, proteção e recuperação da saúde, a organização e o funcionamento dos serviços correspondentes e dá outras providências. Diário Oficial da União, Brasília, DF, 20 set. 1990 b.

BRASIL. Ministério da Saúde. Manual de rede de frio do Programa Nacional de Imunizações. Brasília, DF, 2013.

BRASIL. Ministério da Saúde. Portaria n. 597, de 8 de abril de 2004. Diário Oficial da União, Brasília, DF, 12 abr. 2004. Seção 1, p. 46.

BRASIL. Ministério da Saúde. Portaria n. 1.498, de 19 de julho de 2013. Revoga as anteriores e redefine o Calendário Nacional de Vacinação, o Calendário Nacional de Vacinação dos Povos Indígenas e as Campanhas Nacionais de Vacinação, no âmbito do Programa Nacional de Imunizações (PNI), em todo o território nacional. Diário Oficial da União, Brasília, DF, 22 jul. 2013. Seção 1, p. 31-32.

BRASIL. Ministério da Saúde. Programa Nacional de Imunizações, 30 anos. Brasília, DF, 2003.

BRASIL. Ministério da Saúde. Secretaria de Vigilância em Saúde. Departamento de Vigilância das Doenças Transmissíveis. Manual de rede de frio do Programa Nacional de Imunizações. 4. ed. Brasília, DF, 2013. Disponível em: <http://portalsaude.saude.gov.br/images/pdf/2014/julho/03/ manual-rede-frio.pdf>. Acesso em: 20 abr. 2014. 
BRASIL. Ministério da Saúde. Secretaria de Vigilância em Saúde. Departamento de Vigilância das Doenças Transmissíveis. Manual dos Centros de Referência para Imunobiológicos Especiais. 4. ed. Brasília, DF, 2014.

BRASIL. Ministério da Saúde. Secretaria de Vigilância em Saúde. Departamento de Vigilância das Doenças Transmissíveis. 40 anos do Programa Nacional de Imunizações. Brasília, DF, 2013.

BRASIL. Ministério da Saúde. Secretaria de Vigilância em Saúde. Departamento de Vigilância Epidemiológica. Guia de vigilância epidemiológica. 7. ed. Brasília, DF, 2009.

BRASIL. Ministério da Saúde. Secretaria de Vigilância em Saúde. Departamento de Vigilância Epidemiológica. Informe técnico de introdução da vacina meningocócica C (conjugada) no calendário de vacinação da criança: incorporação agosto-2010. Brasília, DF, fev. 2010.

BRASIL. Ministério da Saúde. Secretaria de Vigilância em Saúde. Departamento de Vigilância Epidemiológica. Informe técnico de implantação da vacina pentavalente no calendário de vacinação da criança. Brasília, DF, 2012.

BRASIL. Ministério da Saúde. Secretaria de Vigilância em Saúde. Departamento de Vigilância Epidemiológica. Informe técnico de implantação da vacina poliomielite inativada no calendário de vacinação da criança. Brasília, DF, 2012.

BRASIL. Ministério da Saúde. Secretaria de Vigilância em Saúde. Departamento de Vigilância Epidemiológica. Informe técnico de introdução da vacina sarampo, rubéola, caxumba e varicela no calendário de vacinação da criança. Brasília, DF, set. 2013.

BRASIL. Ministério da Saúde. Secretaria de Vigilância em Saúde. Departamento de Vigilância Epidemiológica. Informe técnico da introdução da vacina adsorvida hepatite A (inativada). Brasília, DF, set. 2013

BRASIL. Ministério da Saúde. Secretaria de Vigilância em Saúde. Departamento de Vigilância Epidemiológica. Informe técnico sobre a vacina papilomavírus humano (HPV) na atenção básica. Brasília, DF, nov. 2013.

BRASIL. Ministério da Saúde. Secretaria de Vigilância em Saúde. Departamento de Vigilância Epidemiológica. Manual de recomendações para controle da tuberculose no Brasil. 2011.

BRASIL. Ministério da Saúde. Secretaria de Vigilância em Saúde. Departamento de Vigilância Epidemiológica. Manual dos Centros de Referência para Imunobiológicos Especiais. 3. ed. Brasília, DF, 2006.

BRASIL. Ministério da Saúde. Secretaria de Vigilância em Saúde. Departamento de Vigilância Epidemiológica. Proposta para introdução da vacina pneumocócica 10-valente (conjugada) no calendário básico de vacinação da criança: incorporação março-2010. Brasília, DF, fev. 2010.

CENTERS FOR DISEASE CONTROL AND PREVENTION. National Center for Immunization and Respiratory Diseases. Vaccine storage and handling toolkit. Washington, DC, May 2014. Disponível em: <http://www.cdc.gov/vaccines/recs/storage/toolkit/storage-handling-toolkit.pdf>. Acesso em: 5 jul. 2014.

DATASUS. Sistema de informações do PNI. Brasília, DF, 2016. Disponível em: <pni.DATASUS.gov. br>. Acesso em: 1 ago. 2016. 
DICIO: dicionário online de português. [S.I.]: 7 Graus, 2009. Disponível em: <www.dicio.com.br>. Acesso em: 18 set. 2016.

DOMINGUES, C. M. A. S.; TEIXEIRA, A. M. S. Coberturas vacinais e doenças imunopreveníveis no Brasil no período 1982-2012: avanços e desafios do Programa Nacional de Imunizações. Epidemiologia e Serviços de Saúde, Brasília, DF, v. 22, n. 1, p. 9-27, 2013.

FUNDAÇÃO NACIONAL DE SAÚDE (Brasil). Manual de normas de vacinação. 3. ed. Brasília, 2001.

FUNDAÇÃO NACIONAL DE SAÚDE (Brasil). Manual de procedimentos para vacinação. 4. ed. rev. atual. e ampl. Brasília, DF, 2001.

FUNDAÇÃO NACIONAL DE SAÚDE (Brasil). Programa Nacional de Imunizações: PNI - 25 anos. 2. ed. Brasília, DF, 1998. Disponível em: <http://bvsms.saude.gov.br/bvs/publicacoes/cd03_10.pdf>. Acesso em: 1 ago. 2016.

GUTHRIDGE, S. L.; MILLER, N. C. Cold chain in a hot climate. Australian and New Zealand Journal of Public Health, v. 20, p. 657-660, 1997.

HAZELTON, K. et al. The immunisation cold chain. Why is it so hard to get it right? Australian Family Physician, v. 31, p. 939-942, 2002.

KENDAL, A. P.; SNYDER, R.; GARRISON, P. J. Validation of cold chain procedures suitable for distribution of vaccines by public health programs in the USA. Vaccine, v. 15, p. 1459-1465, 1997.

MOLINA, P. O. et al. Cadena del frío para conservacíon de las vacunas em los centros de atención primaria de um área de Madrid: Mantenimento y nivel de conocimentos. Revista Española de Salud Pública, v. 76, n. 4, p. 333-346, jul./ago. 2002.

MORAES, J. C. et al. Qual é a cobertura vacinal real?. Epidemiologia e Serviços de Saúde, Brasília, DF, v. 12, n. 3, p. 147-153, 2003.

NATIONAL guidelines for vaccine storage and distribution. Wellington, New Zealand: Ministry of Health, Sept. 2012.

OLIVEIRA, S. et al. Avaliação das condições de estocagem da vacina contra o sarampo nas unidades sanitárias dos municípios de Niterói e São Gonçalo, Estado do Rio de Janeiro. Revista do Instituto de Medicina Tropical, São Paulo, v. 33, p. 313-318, 1991.

SANTA CATARINA. Secretaria de Estado da Saúde. Superintendência de Vigilância em Saúde. Diretoria de Vigilância Sanitária. Diretoria de Vigilância Epidemiológica. Instrução normativa conjunta n. 001/DIVS/DVE/2012. Diário Oficial do Estado de Santa Catarina, Florianópolis, 10 abr. 2013. Retificado e ratificado pela Instrução Normativa conjunta n. 003/DIVS/DVE/2013.

SANTOS, E. P. Estrutura e operacionalização da imunização em uma área de difícil acesso. Trabalho de conclusão de curso (Pós-graduação lato sensu em Saúde Indígena) - Universidade Federal de São Paulo, EAD, São Paulo, 2010.

SASSON, S.; SILVA JUNIOR, C. Biologia celular. 5. ed. Rio de Janeiro: Saraiva, 2011. 
SILVA, M. N.; FLAUZINO, R. F.; GONDIM, G. M. M. (Org.). Rede de frio: fundamentos para a compreensão do trabalho. Rio de Janeiro: Ed. Fiocruz, 2016.

TREGNAGHI, Miguel W.; CEBALloS, Ana. Manual de vacinas da América Latina. [S.I.]: Associação Pan-Americana de Infectologia, 2005.

WIRKAS, T. et al. A vaccine cold chain freezing study in PNG highlights technology needs for hot climate countries. Vaccine, v. 25, n. 4, p. 691-697, 2007 Jan 8.

WORLD HELTH ORGANIZATION. Global programme for vaccines and immunization expanded programme on immunization: safe vaccine handling, cold chain and immunizations: a manual for the newly independent states. Geneva, 1998. Disponível em: <http://www.who.int/vaccinesdocuments/DocsPDF/www9825.pdf>. Acesso em: 20 abr. 2010.

\section{Sites}

www.sim-gsk.com.br;

www.brasilsus.com.br;

http://portalsaude.saude.gov.br;

http://pni.datasus.gov.br;

http://www.sbim.org.br

http://www.sbp.com.br 


\section{Anexo A - Campanhas nacionais de vacinação}

\begin{tabular}{|l|l|}
\hline Campanha nacional de vacinação & População-alvo \\
\hline Influenza & $\begin{array}{l}\text { Crianças de } 6 \text { meses a menores de } 2 \text { anos de idade, } \\
\text { gestantes, puérperas até 45 dias após o parto, pessoas } \\
\text { com } 60 \text { anos de idade e mais, trabalhadores da saúde, } \\
\text { população privada de liberdade, povos indígenas e } \\
\text { indivíduos com comorbidades. }\end{array}$ \\
\hline Poliomielite & Crianças de 6 meses a menores de 5 anos de idade. \\
\hline $\begin{array}{l}\text { Multivacinação } \\
\text { (todas as vacinas do calendário } \\
\text { básico de vacinação da criança para } \\
\text { atualização de esquema vacinal) }\end{array}$ & Crianças menores de 5 anos de idade. \\
\hline $\begin{array}{l}\text { Seguimento contra o sarampo } \\
\text { (a cada cinco anos ou de acordo } \\
\text { com a situação epidemiológica) }\end{array}$ & Crianças menores de 5 anos de idade. \\
\hline
\end{tabular}

Fonte: Portaria n. 1.498, de 19 de julho de 2013 (BRASIL, 2013). 


\section{Anexo B - Soros heterólogos distribuídos pelo $\mathrm{PNI} / \mathrm{MS}$}

1. Soro anticrotálico (SACR): acidentes com serpentes do gênero Crotalus (cascavel).

2. Soro antibotrópico (SABR): acidentes com serpentes do gênero Bothrops (jararaca, jararacussu, urutu, cotiara e outras

3. Soro antibotrópico-crotálico (SABC): acidentes com serpentes do gênero Crotalus e Bothrops.

4. Soro antielapídico (Sael): acidentes com serpentes do gênero Micrurus (corais verdadeiras).

5. Soro antibotrópico-laquético (SABL): acidentes com serpentes do gênero Bothropse lachesis (surucucus).

6. Soro antiaracnídico (Saares): acidentes com aranhas do gênero Phoneutria (aranha armadeira) e do gênero Loxosceles (aranha marrom). Pode ser utilizado na falta do soro antiescorpiônico, uma vez que contém, em sua formulação, a imunoglobulina do escorpião Tityusserrulatus (Tr).

7. Soro antiescorpiônico (Saes): tratamento dos envenenamentos provocados por picadas de escorpião do gênero Tityus.

8. Soro antilonômico (Salo): acidentes com lagarta Lonomia obliqua (taturana).

9. Soro antibotulínico (SAB): visa eliminar uma potente toxina produzida pela bactéria Clostridium botulinum, que causa o botulismo.

10. Soro antiloxoscélico (SALX): acidentes com aranhas das espécies Loxosceles laeta, Loxosceles gaucho e Loxosceles intermedia (aranha marrom).

11. Soro antitetânico (SAT): imunoglobulinas específicas e purificadas obtidas de plasma de equinos hiperimunizados pela toxina do bacilo Clostridium tetani.

12. Soro antidiftérico (SADF): imunoglobulinas específicas e purificadas obtidas de plasma de equinos hiperimunizados pela toxina do bacilo Corinebacterium diphtheriae.

13. Soro antirrábico (SARH): imunoglobulinas específicas obtidas do plasma de equinos vacinados contra a raiva. 


\section{Anexo C - Imunobiológicos especiais distribuídos pelo PNI/MS}

1. Vacina hepatite B (recombinante) - HB

2. Vacina poliomielite 1, 2 e 3 (inativada) - VIP

3. Vacina varicella - Varc

4. Vacina influenza - FLU

5. Vacina adsorvida meningocócica C (conjugada) - Meningo Conj C

6. Vacina pneumocócica 10-valente (conjugada) - PnccloV

7. Vacina pneumocócica 23-valente (polissicarídica) - Pncc23V

8. Vacina haemophilus influenzae B (conjugada) - Hib

9. Vacina adsorvida difteria, tétano, pertussis (acelular) - tríplice acelular - DTPa

10. Vacina adsorvida difteria e tétano infantil - dupla infantil - DT

11. Vacina adsorvida hepatite A (inativada) - HA

12. Vacina adsorvida difteria, tétano, pertussis, hepatite B (recombinante) e haemophilus influenzae B (conjugada) - Penta (pentavalente) - DTP-HB/Hib

13. Vacina febre tifoide (polissacarídica) - FTp

14. Imunoglobulina anti-hepatite B - IGHB

15. Imunoglobulina antivaricela-zóster - IGVZ

16. Imunoglobulina antirrábica humana - IGRH

17. Imunoglobulina antitetânica - IGAT.

Para obter mais informações sobre as vacinas especiais e os protocolos de indicação, consulte o Manual dos Centros de Referência para Imunobiológicos Especiais (Crie) do Ministério da Saúde, disponível na parte de Publicações do endereço eletrônico:

http://bvsms.saude.gov.br/bvs/ publicacoes/manual_centro_ referencia_imunobiologicos.pdf 



\section{Vigilância epidemiológica em eventos adversos pós-vacinação}

Cláudia Othero Nunes Abreu e Marileide do Nascimento Silva

Com o crescente aumento do número de pessoas vacinadas, a ampliação do calendário de vacinação introduzindo novas vacinas e, consequentemente, a diminuição do risco de algumas doenças que antes eram causas de morte, é natural que, hoje, parte da preocupação dos usuários esteja mais voltada para a segurança das vacinas do que somente para a proteção que elas possam determinar.

Apesar de, no passado, ter havido diversas ocorrências relacionadas à aplicação de algumas vacinas, ou a alguns lotes de determinados fabricantes, sabemos que, atualmente, os imunobiológicos são fabricados com um bom perfil de tolerabilidade e segurança, e os riscos de eventos indesejáveis pós-vacinação não devem superar os seus benefícios. Vale ressaltar que hoje em dia testes rigorosos de segurança são exigidos para qualquer vacina, desde seu planejamento até seu licenciamento, independentemente do laboratório produtor. Entretanto, como qualquer produto farmacêutico-biológico para profilaxia ou tratamento, a vacina pode desencadear alguns eventos indesejáveis, denominados eventos adversos pós-vacinação (EAPV). Alguns deles já são esperados e, em sua maioria, são leves, de evolução rápida e regridem sem necessidade de tratamento.

Este capítulo apresenta o que são eventos adversos, fatores relacionados ao seu acontecimento, sua classificação, bem como a vigilância dos EAPV, realizada por meio de notificação e investigação. 
Muitos dos EAPV que são temporalmente associados à vacinação podem ser consequências de doenças intercorrentes que aparecem ou se exacerbam no momento da vacinação, ou mesmo causados por fatores neurológicos prévios etc.
Eficácia é a capacidade de alcançar o efeito esperado ou desejado por meio da realização de uma ação. Resulta em atingir o objetivo proposto, em executar algo de acordo com o determinado.

\section{Eventos adversos pós-vacinação e a atividade de vacinação}

Entende-se como eventos adversos pós-vacinação (EAPV) qualquer ocorrência ou intercorrência clínica indesejável em indivíduo que tenha recebido um imunobiológico, independentemente de ser decorrente ou não da vacinação, ou seja, de estar associada ou não à vacina!

É importante que os eventos adversos pós-vacinais sejam entendidos como uma ocorrência possível, que deve ser tratada e que contribui para o aperfeiçoamento das vacinas e para a qualidade destas, uma vez que a maioria desses eventos significa apenas associações temporais com a vacina (coincidências), sem confirmação de serem decorrentes de sua aplicação.

Tais associações são inevitáveis e ocorrem em função de diversos fatores. No entanto, até a finalização de um processo de investigação (calcado em avaliação clínica e laboratorial criteriosa), que discutiremos mais adiante, não se pode afirmar que haja relação de causa e efeito entre a ocorrência de um evento e a vacinação. Por isso, usa-se a expressão evento adverso, e não reação, pois esta última implicaria uma relação de causa e efeito ainda não determinada.

Em relação à frequência de ocorrência de EAPV, é importante fazermos uma avaliação histórica. Com a evolução das pesquisas e da tecnologia, novas vacinas foram desenvolvidas e implementadas na rotina, obtendo-se um número cada vez maior de indivíduos vacinados e, com isso, maior número de ocorrências de eventos adversos. Embora a maioria dos eventos pós-vacinação seja local e de leve intensidade, eventos graves, ainda que raros, podem ocorrer, crescendo a importância de sua investigação e acompanhamento.

1. O monitoramento dos eventos adversos sempre foi uma preocupação mundial.

2. Para minimizar seus riscos, o desenvolvimento de uma vacina é cercado de cuidados com a segurança e qualidade, com o objetivo de obter um produto com maior grau de proteção/eficácia e o mais inócuo possível, ou seja, com menor potencial de causar eventos indesejáveis.

3. Caso ocorra EAPV, sua investigação é fundamental para que o evento não seja atribuído à vacina, sem a devida comprovação científica, e se possa manter a confiabilidade das vacinas na proteção da população. 
4. Como qualquer produto, a vacina não está livre de causar um evento adverso. No entanto, a análise comparativa entre risco e benefício demonstra que a probabilidade de uma vacina causar um evento grave é muito menor do que o risco de adoecer, caso o indivíduo não seja imunizado. Assim, é preciso muito cuidado ao tratar dessa questão, principalmente no que diz respeito à contraindicação de uma vacina baseada nos eventos que esta pode causar. Uma pessoa não vacinada representa um risco de adoecimento para ela mesma e para a população.

\section{Fatores relacionados aos EAPV}

Ainda que todos os cuidados necessários ao desenvolvimento e à atividade de vacinação sejam tomados, há possibilidade de ocorrência de eventos associados à composição das vacinas, produtos com propriedades farmacológicas específicas. Por isso, é fundamental conhecer suas características, como:

tipo de antígeno, se é vivo, atenuado, inativado, ou constituído de produtos como toxoides, polissacarídeos, ou produzido por DNA recombinante;

* aditivos utilizados na produção, como agentes de suspensão (água, solução salina);

presença de conservantes como o timerosal;

橉 uso de estabilizantes como sorbitol e gelatina hidrolisada;

* uso de adjuvante como sais de alumínio;

outras substâncias que podem estar presentes, por exemplo, subprodutos residuais de meio de cultivo e antibióticos (neomicina).

Alguns dos termos mencionados nos tópicos anteriores são de uso bastante recorrente, quer na rede de frio, quer na sala de vacinação. Por isso, sistematizamos algumas definições para ajudá-lo no dia a dia de trabalho, caso ainda não conheça seus significados.

Vacina viva atenuada: preparação composta de microrganismos vivos atenuados em laboratório, capazes de se multiplicar no organismo (não causando doença) e estimular uma resposta imune. Essa resposta é idêntica à produzida pela infecção natural.

Vacina inativada: preparação contendo microrganismos mortos ou suas frações, possuidores de propriedades antigênicas para induzir, em um indivíduo, a imunidade ativa e específica contra um microrganismo. 
Comorbidade é um termo utilizado para descrever a ocorrência simultânea de dois ou mais problemas de saúde em um mesmo indivíduo.

Eventos inusitados são aqueles decorrentes de algum erro ou falha no preparo ou na administração da vacina (dose, via, local etc.).

Abcesso é uma coleção de pus (secreção amarelada) que se forma no local da ferida, localizada em qualquer parte do corpo.

Supuração é a eliminação ou o escorrimento de pus de um abcesso

Abcesso séptico é o abcesso decorrente da contaminação do local, no momento da administração de uma injeção; no nosso caso, de uma vacina.
Essa vacina tem a desvantagem de induzir uma baixa resposta imunitária, o que, por vezes, requer a necessidade de se associar adjuvantes e de administrar várias doses de reforço.

Aditivos: substâncias utilizadas como agentes de suspensão na produção da vacina.

Conservantes: substâncias utilizadas para preservar os componentes da vacina.

Estabilizantes: nutrientes contidos nas vacinas atenuadas para estabilizar e prolongar a vida útil da vacina.

Adjuvante: substância que potencializa, de forma inespecífica, a resposta imunológica a um antígeno.

Em relação aos vacinados, fatores como idade, sexo, antecedentes alérgicos, comorbidade devem ser considerados em casos de EAPV. Merecem, também, atenção especial aqueles relacionados à preparação e/ ou à aplicação dos imunobiológicos, como agulha e seringa utilizadas, contaminação no ato da preparação ou aplicação, técnica de aplicação incorreta etc. São esses procedimentos técnicos que, quando inadequados, causam eventos inusitados, conforme apresenta o Exemplo 1, a seguir.

\section{Exemplo 1 - Evento adverso associado à aplicação de vacina}

J. C. M., com 6 meses de vida, recebeu a $3^{a}$ dose da vacina contra hepatite $B$, na unidade de saúde do distrito rural de Caracóis, município de Esmeraldas, Minas Gerais. Após 20 dias, a criança apresentou como manifestações no local da aplicação:

- dor, edema (inchaço), calor e rubor;

- abcesso com secreção purulenta;

- supuração do abcesso.

Concluímos que, diante das manifestações apresentadas, o aparecimento do evento adverso estava diretamente associado ao procedimento executado no ato da vacinação, e não às características propriamente ditas da vacina. Isso porque havia:

- abcesso quente, geralmente associado a infecção secundária e erros na técnica de aplicação (contaminação no local de inoculação);

- tumoração no local da aplicação, com sinais inflamatórios (dor, edema, calor e rubor), sugerindo um abcesso séptico. 


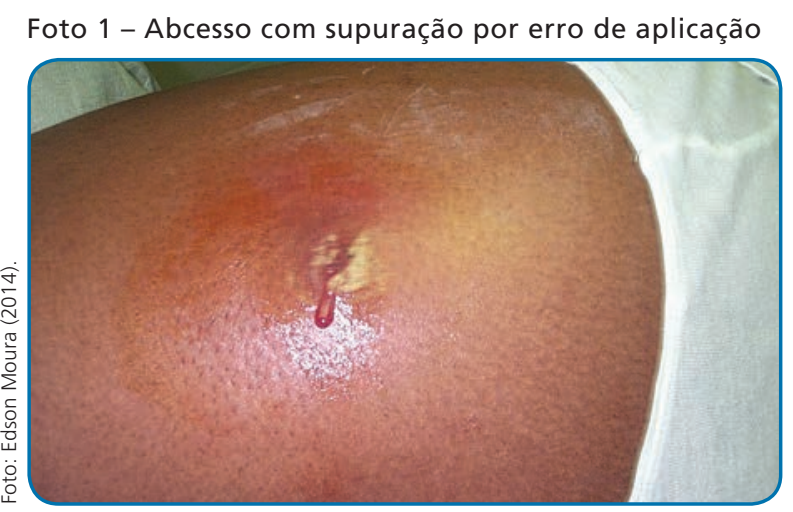

\section{Classificação dos EAPV}

Um evento adverso pode ser classificado em decorrência da causa que o originou, ou seja:

* induzido pelo imunobiológico: quando o evento não teria ocorrido, se a vacina não tivesse sido aplicada. Pode estar relacionado à característica intrínseca dos componentes, ou à forma de constituição do imunobiológico, ou ainda à resposta individual do vacinado;

potencializado pelo imunobiológico: quando o evento ocorreria de qualquer maneira, mas foi precipitado pela vacinação (por exemplo, primeira convulsão febril em uma criança);

* erros programáticos: quando o evento está relacionado à técnica incorreta na preparação, aplicação e/ou no manuseio do produto;

* coincidente: associado temporalmente à vacinação, por acaso ou pela existência de um quadro clínico subjacente, não manifesto ou não valorizado no momento da vacinação.

\section{Para refletir}

Com base nessa classificação, que eventos adversos você relacionaria como os mais prováveis de acontecer e que fatores estariam envolvidos para desencadeá-los? Quais medidas poderiam ser adotadas para minimizá-los?

Há eventos adversos, em geral brandos, que ocorrem com maior frequência, e, por isso, sua ocorrência é mais esperada que outros. Estes são classificados como:

* locais - são os mais comuns, de início agudo, e ocorrem com a aplicação dos imunobiológicos por via parenteral. Manifestam-se
Via parenteral é a via em que substâncias são aplicadas diretamente nos tecidos por injeção, com emprego de seringas, agulhas ou cateteres. 
Cianose é um quadro de coloração azul-violácea da pele e das mucosas devida à oxigenação insuficiente do sangue. com dor, edema, eritema (vermelhidão) na área da injeção do produto;

sistêmicos - manifestam-se, geralmente, com febre, mal-estar generalizado, irritabilidade, cefaleia, náuseas, vômitos e sonolência.

De acordo com os dados sobre os eventos adversos pós-vacinação, além dos eventos locais, os sistêmicos leves (aqueles que não necessitam de exames complementares e tratamento médico) são os mais frequentes. Eles evoluem e desaparecem naturalmente, como o caso apresentado no Exemplo 1, "Evento adverso associado à aplicação de vacina". Por isso, as ações de vigilância estão basicamente voltadas para os eventos graves.

Os eventos graves são os que requerem hospitalização por, no mínimo, 24 horas; resultam em disfunção ou incapacidade significativa, sequelas, anomalias, risco de morte, óbito e exigem intervenção imediata para evitar a morte. Diante de um evento grave, a instância de sua ocorrência deverá notificar, de imediato, a instância superior por e-mail ou telefone. Para ilustrar um evento adverso pós-vacinação do tipo grave, vamos ao Exemplo 2.

\section{Exemplo 2 - EAPV grave}

Criança de 2 meses de vida, trazida pelos pais de volta à unidade de saúde, meia hora após a administração das vacinas pentavalente (DTP, Hib e hepatite B), poliomielite inativada (VIP), pneumococo 10-valente e rotavírus humano (VORH), com diminuição de resposta aos estímulos, palidez e redução do tônus muscular.

Ao ser examinada, constatou-se quadro de episódio hipotônicohiporresponsivo (EHH), também chamado de síndrome hipotônicahiporresponsiva, de instalação súbita, com os seguintes sintomas: palidez seguida de cianose, diminuição do tônus muscular (hipotonia) e diminuição de resposta a estímulos externos (hiporresponsividade).

Podemos, então, caracterizar o evento como grave, do tipo sistêmico, decorrente de fatores relacionados ao imunobiológico. Por quê?

No exame, foi constatada reação sistêmica, inflamatória e exagerada a componentes vacinais, em especial à endotoxina, que existe, principalmente, na vacina celular contra coqueluche. Estudos demonstraram que a ocorrência de EHH tem sido documentada após a administração de vacinas contendo o componente pertussis. É observado mais frequentemente após o uso de vacinas antipertussis de células inteiras do que após vacinas acelulares (BRIGHTON COLLABORATION HHE WORKING GROUP, 2004; VAERS WORKING GROUP, 2000).

Outra constatação foi o quadro clínico da criança, com limitação das funções, que a levou à hospitalização e ao tratamento. 
$\mathrm{Na}$ atualidade, novas classificações para evento adverso podem ser encontradas na literatura, entretanto, adotaremos, para efeito desta publicação, a classificação dos eventos adversos pós-vacinação apresentada neste item.

\section{Vigilância dos EAPV}

Qualquer EAPV, independentemente de sua classificação e dos inúmeros fatores que podem tê-los provocado (aqueles referentes ao vacinado, à vacinação, às características do imunobiológico, à técnica de preparo e/ou de aplicação das vacinas etc.), deve ser notificado e investigado.

Para tal, é necessário um conjunto de ações que propiciem a identificação, o monitoramento e acompanhamento desses eventos, ou seja, a vigilância dos eventos adversos pós-vacinação.

A vigilância do evento adverso faz parte da farmacovigilância dos imunobiológicos e é definida como as atividades relativas a detecção, avaliação, compreensão e prevenção de eventos supostamente atribuíveis à vacinação. Foi instituída pelo PNI, em 1993, considerando o crescente número de imunobiológicos disponíveis e o aumento das exigências em relação a sua qualidade e segurança. O propósito principal é investigar qualquer ocorrência indesejada após a aplicação de uma vacina e/ou de um soro, mesmo que a manifestação clínica, local ou sistêmica, seja uma associação temporal, uma suspeição (suspeita).

\section{Arcabouço legal relacionado à vacinação}

As atividades de imunização são realizadas de acordo com um exigente perfil de segurança e sustentadas por arcabouços legal e jurídico, que atendem não somente à produção de vacinas, mas também à vigilância de eventos adversos pós-vacinais. Essas legislações devem ser rigorosamente seguidas, contribuindo para a notificação e o acompanhamento dos EAPV, bem como para o aumento dos benefícios da vacinação. Para melhor compreensão do arcabouço legal relacionado aos EAPV, recomendamos como fonte de pesquisa e consulta algumas portarias e decretos:

- Portaria Conjunta n. 92, de 9 de outubro de 2008, que dispõe sobre Resolução da Diretoria Colegiada - RDC n. 306, de 7 de dezembro de 2004, e a Resolução do Conama n. 358, de 29 de abril de 2005. Disponíveis em: http://goo.gl/zM8ljr.

- Portaria n. 1.271, de 6 de junho de 2014, que define a lista nacional de notificação compulsória de doenças, agravos e eventos de saúde pública nos serviços de saúde públicos e privados, em todo o território nacional. Disponível em: http://goo.gl/Jml60d.
Farmacovigilância refere-se a um conjunto de procedimentos relacionados a detecção, avaliação, compreensão e prevenção de reações adversas a medicamentos ou quaisquer outros possíveis problemas relacionados a fármacos.

A farmacovigilância de vacinas e outros produtos, por exemplo, é regulamentada pela Portaria Conjunta n. 92, de 9 de outubro de 2008 (BRASIL, 2008), que dispõe sobre a articulação entre a Agência Nacional de Vigilância Sanitária (Anvisa), a Secretaria de Vigilância em Saúde (SVS/MS) e o Instituto Nacional de Controle de Qualidade (INCQS/Fiocruz/MS). 
Além destas, recomendamos que os profissionais se atualizem constantemente sobre as publicações de portarias e notas técnicas que incluem vacinas no calendário básico de vacinação.

A vigilância de eventos adversos pós-vacinação está encarregada de normatizar:

* notificação e investigação dos eventos;

* a consolidação e análise dos casos;

* divulgação das informações;

* as condutas e as ações a serem adotadas para controlar e prevenir eventos adversos, objetivando, principalmente, maior conhecimento sobre a natureza dos EAPV;

* a identificação de eventos novos ou raros;

* as possíveis falhas na cadeia de frio, no manuseio e na administração dos imunobiológicos (erros programáticos); além disso, possibilita a identificação de lotes com desvios de qualidade na produção, resultando em lotes mais reatogênicos.

Dentre esses itens, a notificação e a investigação são fundamentais, pois é a partir delas que são geradas e compartilhadas as informações sobre EAPV. Por isso, a seguir, nos deteremos no detalhamento dessas duas ações.

\section{Notificação dos EAPV}

Após a identificação da ocorrência de um evento adverso, o passo seguinte é assegurar, em tempo real, a notificação, ou seja, a comunicação do evento ao serviço ou à unidade de saúde. Isso é fundamental para prover regularmente informação pertinente à segurança dos imunobiológicos disponíveis, contribuindo para a manutenção da credibilidade das ações de vacinação junto à população e aos profissionais da saúde. A notificação deve ser realizada, preferencialmente, na unidade de saúde onde foi administrada a vacina ou o soro, mas pode ser feita em qualquer estabelecimento de saúde em que o vacinado buscar atendimento em razão das condições clínicas que apresenta, seja unidade básica ou hospital.

\section{Importante!}

Todo(a) trabalhador(a) da saúde, em especial o(a) da sala de vacina, seja de qualquer nível de escolaridade (médio ou superior), pode e deve fazer a notificação de EAPV! 
I Quais eventos adversos pós-vacinação devem ser notificados?

Atualmente, os eventos adversos são considerados de notificação compulsória, conforme Portaria SVS n. 33, de 14 de julho de 2005, independentemente de sua classificação (BRASIL, 2005). É por meio da notificação que se tornam possíveis o monitoramento e a vigilância de tais eventos.

Devem ser notificados todos os sinais e sintomas (queixas) da pessoa vacinada, denominados eventos adversos temporais, com retorno à unidade de saúde por demanda espontânea ou não. Para garantir esse retorno, é fundamental que, na triagem, o usuário da vacina ou seu responsável seja esclarecido sobre os eventos possíveis e orientado sobre como proceder em caso de:

* evento adverso comum ou esperado - retornar à sala de vacina, caso o evento (por exemplo, uma reação local) ocorra de maneira mais intensa, ou demore muito a passar;

outros eventos (raros ou EAPV moderados - buscar uma unidade de saúde de emergência, caso observe eventos deste tipo, por exemplo, episódio hipotônico-hiporresponsivo (EHH), convulsão etc.

\section{Recomendações ao profissional de saúde}

Em qualquer evento adverso pós-vacinação, refletir sobre alguns pontos, como os apresentados a seguir, ajuda a compreender a situação e tomar decisões adequadas:

- Esse evento é possível?

- Foi possível neste caso?

- Repetir-se-á no próximo caso?

- A causa precede o efeito?

- A exposição ao fator de risco antecede o aparecimento dos EAPV?

- O evento é compatível com o respectivo imunobiológico?

\section{Como notificar os eventos adversos pós-vacinação?}

A notificação do evento adverso pós-vacinação é feita pelo preenchimento da Ficha de Notificação, disponível nas unidades de saúde. O formulário tende, com o tempo, a não ser mais utilizado, visto que a notificação deverá ser realizada por meio do SI-EAPV on-line.

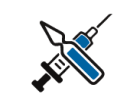

Atenção!

- Frequência ou intensidade dos EAPV aumentada é sinal de alerta para a equipe da saúde. Essas ocorrências devem ser investigadas.

- Eventos adversos graves devem ser notificados imediatamente.

EAPV moderados são eventos que necessitam apenas de avaliação médica e exames complementares e/ou tratamento médico.

O sistema de informação voltado para eventos adversos pósvacinação (SI-EAPV) será abordado no próximo capítulo. 


\section{Recomendações ao profissional de saúde}

Na presença de quaisquer EAPV, o profissional deve, independentemente de sua categoria profissional na equipe, realizar as seguintes condutas:

- registro do evento adverso;

- orientação ao paciente/família;

- notificação do evento adverso;

- investigação;

- fechamento do caso.

\section{Investigação dos EAPV}

É por meio da investigação que se torna possível esclarecer se há relação de causalidade ou não entre o evento observado e a vacina. $\mathrm{O}$ SI-EAPV é um aliado fundamental nesse processo, visto que coleta e sistematiza dados que permitem a identificação, a avaliação e o monitoramento dos EAPV. Somente conhecendo a ocorrência de um conjunto de eventos adversos pós-vacinação é possível analisar se o evento-alvo de investigação ocorreu dentro da frequência esperada, se tem relação com a vacinação (componente da vacina ou técnica de aplicação), ou se é apenas uma associação temporal.

O monitoramento dos EAPV e a adoção das medidas cabíveis somente serão possíveis pela notificação desses eventos. Ainda que haja dúvida se a ocorrência foi informada, deve-se fazer a notificação. Alguns eventos, por serem de maior gravidade, embora sejam raros, precisam, além da notificação imediata, que se inicie rapidamente a investigação.

A investigação é o procedimento que determinará se o evento adverso teve ou não relação com a vacina. Em geral, é realizada por médico, e/ ou enfermeiro, podendo envolver também profissionais dos Crie para

Não preencher uma informação na Ficha de Notificação, ou preenchê-la de maneira errada, pode resultar em conclusões não verdadeiras durante a investigação da causa do evento adverso pós-vacinação. o caso de acompanhamento e orientações em futuras vacinações. A investigação envolve as etapas: evolução, fechamento do caso e conduta a ser adotada para o cumprimento do esquema vacinal. Todas essas etapas correspondem a atividades específicas, que irão requerer informações clínicas e exames laboratoriais minuciosos para o fechamento da investigação, podendo esta ser continuada em outros níveis do serviço.

Os conhecimentos sobre os eventos ocorridos, sua frequência, a associação ou não à vacina e a adoção de condutas para prevenir e monitorar os EAPV somente serão possíveis por meio de um eficiente Sistema 
Nacional de Vigilância de Eventos Adversos, responsável pela normatização das atividades de notificação e investigação, consolidação e análise dos casos e divulgação das informações.

Outra questão que deve ser considerada e que vem ganhando destaque na atualidade é a dor causada pela vacinação, entendida como um evento que pode levar à recusa de vacinação. Estima-se que 10\% da população mundial tem medo de agulhas e injeções, conforme cita Gavura (2010 apud MOREIRA; OLIVEIRA, 2015) ao estabelecer a relação entre dor e aplicação de vacinas.

Alguns trabalhos desenvolvidos no Canadá e nos Estados Unidos da América apontam que mais de $85 \%$ dos pais acreditam que a dor causada pela vacinação é responsabilidade do profissional de saúde, que deve administrar a vacina de forma menos dolorosa. E a preocupação com a dor, revelada por mais de $25 \%$ dos pais, é um fator que interfere na aceitação da vacinação. Essa recusa influi negativamente na prevenção das doenças evitáveis pela vacinação.

Por esse motivo, estudos vêm sendo realizados em escala mundial, e diversos países já se preocupam com o manejo da dor no momento da vacinação como um evento passível de ser controlado. Estratégias como a utilização de soluções orais de glicose, a amamentação antes e durante a vacinação têm sido recomendadas. Alguns países, embora já adotem um conjunto de recomendações para redução da dor, não dispõem ainda de protocolos específicos para esses casos específicos como, por exemplo, a Inglaterra, o Canadá e os Estados Unidos. Por isso, é fundamental que o profissional conheça os estudos que estão sendo desenvolvidos nessa área e as recomendações dos programas nacionais de vacinação, para que possa adotar medidas que visem prevenir ou minimizar quaisquer eventos que possam prejudicar ou interferir na aceitação da vacinação.

\section{Considerações finais}

A tarefa da vigilância epidemiológica dos eventos adversos pós-vacinação é realizar o monitoramento desses eventos de forma a permitir que os benefícios alcançados com a utilização das vacinas sejam sempre superiores a seus possíveis riscos.

Diversos países mantêm sistemas de vigilância e investigação de eventos adversos pós-vacinação, considerando que o monitoramento adequado e a investigação oportuna e competente são de fundamental importância para a manutenção da confiança nos programas de 
imunizações. Essa confiança se pauta no cumprimento de seus objetivos, que orientam a tomada de medidas que asseguram a melhor relação de risco-benefício para a população vacinada.

A vigilância dos eventos adversos mantém, desse modo, a confiabilidade dos imunobiológicos utilizados no PNI junto à população e aos profissionais da saúde, procurando usar vacinas cada vez mais seguras e menos reatogênicas.

O papel do profissional de saúde é essencial nesse processo, visto que a identificação e o monitoramento dos eventos são atividades fundamentais para o funcionamento do Sistema Nacional de Vigilância de Eventos Adversos Pós-Vacinais, um sistema em construção cujo aperfeiçoamento ocorre dia a dia, com a contribuição dos profissionais envolvidos com a vacinação. É por tudo isso que você, trabalhador da saúde, é tão importante no processo!

\section{Referências}

ARAUJO, T. M. E. Análise dos eventos adversos pós-vacinais ocorridos em Teresina. Revista Brasileira de Enfermagem, Brasília, DF, v. 60, jul./ago. 2007.

BAHIA. Secretaria da Saúde. Coordenação do Programa Estadual de Imunizações. Manual de procedimento para vacinação. Salvador, 2011.

BALLALAI, Isabella. Manual prático de imunizações. São Paulo: Ac. Farmacêutica, 2013.

BISETTO, L. H. L. et al. A prática da enfermagem frente aos eventos adversos pós-vacinação. Revista da Escola de Enfermagem da USP, São Paulo, v. 45, n. 5, p. 1128-1134, 2011.

BRASIL. Ministério da Saúde. Portaria GM n. 1.271, de 6 de junho de 2014. Diário Oficial da União, Brasília, DF, 9 jun. 2014. Seção 1, p. 67.

BRASIL. Ministério da Saúde. Secretaria de Vigilância em Saúde. Portaria n. 33, de 14 de julho de 2005. Inclui doenças à relação de notificação compulsória, define agravos de notificação imediata e a relação dos resultados laboratoriais que devem ser notificados pelos Laboratórios de Referência Nacional ou Regional. Diário Oficial da União, Brasília, DF, 15 jul. 2005. Seção 1, p. 111.

BRASIL. Ministério da Saúde. Secretaria de Vigilância em Saúde. Departamento de Vigilância das Doenças Transmissíveis. Curso de atualização para trabalhador da sala de vacinação: manual do aluno. 3. ed. rev. e ampl. Brasília, DF, 2013.

BRASIL. Ministério da Saúde. Secretaria de Vigilância em Saúde. Departamento de Vigilância Epidemiológica. Manual de vigilância epidemiológica de eventos adversos pós-vacinação. 2. ed. Brasília, DF, 2008. Disponível em: <http://portal.saude.gov.br/portal/saude/gestor/visualizar texto> Acesso em: 9 nov. 2015. 
BRASIL. Ministério da Saúde. Secretaria de Vigilância em Saúde. Departamento de Vigilância Epidemiológica. Manual dos centros de referência para imunobiológicos especiais. 3. ed. Brasília, DF, 2006. Disponível em: <http://bvsms.saude.gov.br/bvs/publicacoes/manual_centro_referencia_ imunobiologicos.pdf>. Acesso em: 9 nov. 2015.

BRASIL. Ministério da Saúde. Secretaria de Vigilância em Saúde. Departamento de Vigilância Epidemiológica. Vigilância dos eventos adversos pós-vacinação: cartilha para trabalhadores de sala de vacinação. Brasília, DF, 2003.

BRASIL. Ministério da Saúde. Secretaria de Vigilância Sanitária. Portaria conjunta n. 92, de 9 de outubro de 2008. Dispõe sobre o estabelecimento de mecanismo de articulação entre a Agência Nacional de Vigilância Sanitária, a Secretaria de Vigilância em Saúde e o Instituto Nacional de Controle de Qualidade em Saúde da Fundação Oswaldo Cruz sobre Farmacovigilância de Vacinas e outros Imunobiológicos no âmbito do Sistema Único de Saúde e define suas competências. Diário Oficial da União, Brasília, DF, 10 out. 2008. Seção 1, p. 112.

BRIGHTON COLLABORATION THE WORKING GROUP. Hypotonic-Hyporesponsive (HHE) as an adverse event following immunization: case definition and guidelines for data collection, analysis, and presentation. Vaccine, v. 22, p. 563-568, 2004.

BRITO, G. S. Eventos adversos e segurança de vacinas. In: FARHAT, C. K. et al. Imunizações: fundamentos e práticas. São Paulo: Atheneu, 2000. p. 43-45.

BRITO, G. S. Eventos adversos e segurança de vacinas. In: FARHAT, C. K. et al. Imunizações: fundamentos e práticas. 5. ed. São Paulo: Atheneu, 2007. p. 43-64.

BRITO, G. S.; SATO, H. K. Eventos adversos pós-vacinais: a prevenção e o controle: um radar sobre nossas crianças. Imunizações, v. 1, n. 1, p. 15-20, 1997.

FARHAT, C. K. et al. Imunizações: fundamentos e prática. 5. ed. São Paulo: Atheneu, 2008.

FREITAS, F. R. M. et al. Eventos adversos pós-vacinais contra difteria, coqueluche e tétano e fatores associados à sua gravidade. Revista Saúde Pública, São Paulo, v. 41, n. 6, p. 1032-1041, 2007.

LEVI, G. et al. Controvérsias em imunizações. São Paulo: Ed. Farma, 2014.

MARTINS, R. M.; MAIA, M. L. S. Eventos adversos pós-vacinais e resposta social. História, Ciências, Saúde Manguinhos, Rio de Janeiro, v. 10, n. 2, p. 807-825, 2006.

MOURA, M. M; OLIVEIRA, M. M. M. Reducing pain at the time of vaccination: WHO position paper. Weekly Epidemiological Record, v. 90, n. 39, p. 505-516, 2015.

MONTEIRO, S. A. et al. Avaliação do sistema brasileiro de vigilância de eventos adversos pósvacinação. Revista Brasileira de Epidemiologia, São Paulo, v. 14, n. 3, set. 2011.

NOVADZKI, I.; ROSARIO FILHO, N. Anafilaxia associada à vacina contra sarampo, caxumba e rubéola. Revista Saúde Pública, São Paulo, v. 44. n. 2, p. 372-376, abr. 2010. 
NOVADZKI, I.; ROSARIO FILHO, N. Reações adversas à gelatina em imunobiológicos. Revista Brasileira Alergia Imunopatologia, v. 29, n. 1, p. 2-8, jan./fev. 2006.

RIO DE JANEIRO. Secretaria Municipal de Saúde. Superintendência de Vigilância em Saúde. Guia prático de normas e procedimentos de vacinação. Ed. rev. Rio de Janeiro, 2013.

SÃO PAULO. Secretaria de Estado da Saúde. Centro de Vigilância Epidemiológica Prof. Alexandre Vranjac. Norma técnica do programa de imunização. São Paulo, 2008. Disponível em: <http://www. cve.saude.sp.gov.br/dtm/imuni/imuni_doc.htm>. Acesso em: 9 nov. 2015.

VAERS WORKING GROUP. Hypotonic-hyporesponsive episodes reported to the Vaccine Adverse Event Reporting System (VAERS), 1996-1998. Pediatrics, v. 106, n. 4, p. 52, Oct. 2000.

WALDMAN, E. A. et al. Vigilância de eventos adversos pós-vacinação e segurança de programas de imunização. Revista de Saúde Pública, São Paulo, v. 45, n. 1, fev. 2011.

WORLD HEALTH ORGANIZATION. Adverse events following imunnization (AEFI): causality assessment. Geneve, 2013 


\title{
4. Avaliação da vacinação
}

\author{
Cláudia Othero Nunes Abreu
}

Indiscutivelmente, hoje a vacinação constitui-se na principal estratégia de prevenção e combate às doenças imunopreveníveis. Para que ela aconteça, uma série de procedimentos é necessária e deve ser executada, de forma organizada e articulada, em todos os níveis ou instâncias que envolvem esta atividade, desde a unidade básica de saúde/instância local até as municipais, estaduais e nacional. Uma forma de assegurar que isso ocorra é a realização de monitoramento e avaliação sistemática dos procedimentos que envolvem as atividades de vacinação.

O monitoramento e a avaliação irão fornecer elementos sobre essas atividades, permitindo que sejam ajustadas, reorganizadas, ou até mesmo adotados outros procedimentos/ações, de modo que a vacinação ocorra de forma segura e eficaz e contribua, efetivamente, para a melhoria do quadro de saúde pública brasileira. Através da avaliação será possível verificar e acompanhar os resultados e o impacto do trabalho desenvolvido, de modo que sejam realizados os ajustes necessários e estabelecidas as estratégias para o alcance dos objetivos.

Este capítulo visa apresentar os principais aspectos relacionados ao monitoramento e à avaliação das atividades de vacinação, os indicadores mais usados no PNI, sua importância para a elaboração das estratégias de vacinação e forma de utilização, em cumprimento aos objetivos e às metas propostas pelo Programa Nacional de Imunizações (PNI). 


\section{Processo de avaliação das ações de imunização}

A avaliação como uma forma de julgamento e de análise diagnóstica para detecção de problemas é realizada nas ações de vacinação tendo por base e diretriz os objetivos e metas do PNI, a saber:

* vacinar o maior número de pessoas com qualidade e segurança,

contribuindo para a redução da morbimortalidade; e

* vacinar $100 \%$ da população infantil o mais precocemente possível, buscando, como objetivo geral, a proteção universal (BRASIL, 2014).

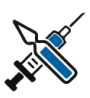

Como a estimativa é alcançar o mais alto nível de cobertura e de forma homogênea, os profissionais da saúde devem atentar para o fato de que obter um percentual de $90 \%$ a $95 \%$ não significa atender à meta pretendida, mas sim o percentual mínimo a ser alcançado para controle, erradicação ou eliminação das doenças imunopreveníveis.
O registro dos dados relacionados à vacinação e aos imunobiológicos é concentrado, atualmente, no Sistema de Informações do Programa Nacional de Imunizações (SI-PNI), que é abordado no próximo capítulo.
Para que esses objetivos sejam alcançados, são estabelecidas metas. Meta é a quantificação do objetivo e deve ser perseguida em todas as etapas e instâncias do sistema de vacinação, especialmente no que se refere ao trabalho articulado entre os profissionais da vacinação e os da rede de frio. Em vacinação, as metas principais são definidas em percentuais de cobertura, os quais, por sua vez, são estabelecidos com base nas características epidemiológicas das doenças e nas características da vacina.

Embora sejam produzidas com alto grau de segurança e confiabilidade, as vacinas necessitam de uma rede de procedimentos que funcione, em todas as suas etapas, de forma eficiente e articulada, para garantir a proteção desejada e atingir outras metas, como redução da ocorrência de eventos adversos pós-vacinação (EAPV), satisfação dos usuários etc.

Para se atingir as metas da vacinação, é necessário realizar o registro dos dados e proceder ao monitoramento, por meio de métodos e da construção e análise de indicadores. A seguir, serão apresentadas essas etapas, de forma mais detalhada.

\section{Registro}

O registro das atividades de vacinação deve ser realizado em todas as instâncias do programa de imunizações, principalmente para fornecer dados que auxiliem o acompanhamento, a análise e a consequente avaliação do trabalho desenvolvido e de seus resultados. É realizado por meio de instrumentos específicos, que servem de base de dados para alimentar o sistema de informação (SI) e podem ser de diversos tipos: formulários, fichas, boletins, mapas, gráficos etc., dispostos em meio físico ou on-line. Depois de consolidados pelos municípios, os dados são encaminhados para as demais esferas de gestão, até o nível nacional. Como exemplo, no Anexo A, temos a ficha de registro do vacinado. 
É fundamental registrar todas as atividades de vacinação, sejam elas diárias, mensais, campanhas, busca de faltosos, monitoramento rápido de cobertura vacinal etc. As informações e/ou relatórios gerados pelos variados registros permitem o acompanhamento e a avaliação das ações, com consequente definição/redefinição das estratégias de vacinação.

São os registros que fornecem dados para avaliação e subsidiam a aquisição de imunobiológicos e insumos necessários para a execução adequada das atividades do programa. Por isso, as consequências de um registro mal realizado são graves.

\section{Monitoramento e avaliação}

Monitorar significa seguir, acompanhar. O monitoramento das atividades de vacinação, portanto, objetiva o acompanhamento dessas atividades e da cobertura vacinal, verificando:

* se as metas foram alcançadas;

* em que medida a população-alvo foi atendida;

* se resultado está de acordo com o planejado e preconizado, incluindo a utilização de todos os recursos: materiais e humanos.

Avaliar, por sua vez, significa fazer um julgamento, uma comparação ou julgamento de valor (BAHIA, 2011); comparar um serviço, uma ação/atividade/procedimento com algo considerado ideal, ou com algum referencial. A avaliação detecta problemas que interferem na execução das atividades e redefine novas estratégias.

A avaliação deve ser executada em todas as instâncias do Programa Nacional de Imunizações, porque oferece subsídio para a programação das atividades de vacinação. No processo de avaliação em saúde, considera-se, entre outros aspectos, a situação de saúde da população, as condições socioeconômicas, o grau de organização dos serviços e sua capacidade e resolutividade.

Para os profissionais da rede de frio, a avaliação é fundamental e deve ser desenvolvida nas diversas etapas do seu trabalho (armazenamento, conservação, distribuição etc.). Essas etapas se relacionam e se complementam, devendo ocorrer com total precisão para que o resultado esperado seja alcançado: a manutenção da propriedade e qualidade do imunobiológico oferecido à população, garantindo o controle e a redução das doenças imunopreveníveis. 
Todas essas ações deverão ser registradas, conforme discutido no item anterior.
No processo de monitoramento e avaliação da vacinação, também são utilizados indicadores, como cobertura vacinal, homogeneidade, taxa de abandono, registro das doses aplicadas etc. Eles são abordados mais adiante.
O monitoramento e a avaliação devem ser realizados de forma contínua e sistemática. Para tanto, é necessário dispor de métodos, instrumentos e indicadores precisos, que expressem o conjunto das atividades da vacinação em todas as instâncias. A partir dos resultados do monitoramento e da avaliação é que os profissionais irão verificar a necessidade de elaborar e desenvolver novas estratégias, como campanhas, vacinação de bloqueio, atividades extramuros, vacinação casa a casa e/ou de grupo específicos etc.

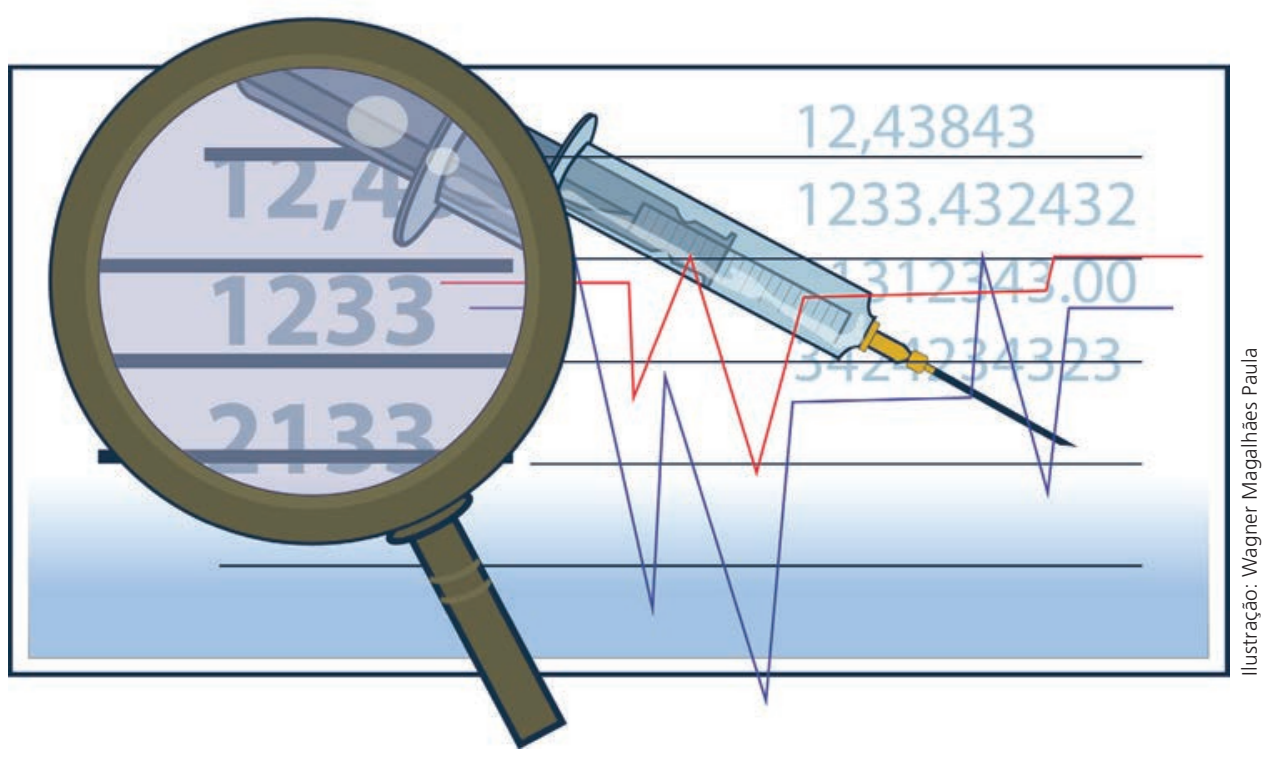

\section{Métodos de avaliação}

Diversos mecanismos/métodos de avaliação são utilizados nas atividades de vacinação. Abordaremos alguns deles a seguir.

\section{Supervisão}

É um instrumento gerencial para o acompanhamento, o levantamento dos problemas e a orientação das ações e atividades. No âmbito do PNI, o processo de supervisão pode, também, monitorar:

a disponibilidade de imunobiológicos - necessidades, falta dos produtos, controle e descarte;

* as coberturas vacinais das campanhas e da vacinação de rotina, identificando, assim, bolsões de suscetíveis;

* a adequação dos equipamentos e dos materiais para a conservação das vacinas etc. 
O profissional da rede de frio, nas instâncias local, municipal e regional ou estadual, frequentemente está envolvido com atividades de supervisão. Exemplos disso são a verificação semanal, quinzenal ou mensal do estoque e da organização dos imunobiológicos, bem como o acompanhamento sistemático do estado geral dos equipamentos de refrigeração etc. Tais ações permitem o levantamento de possíveis problemas no estoque de imunobiológicos e nas condições dos equipamentos, assim como a detecção precoce da necessidade de solicitar mais ou transferir imunobiológicos, ou de realizar reparos ou trocas nos equipamentos. Como consequência da supervisão, evitam-se, respectivamente, perdas de vacinas e falhas na conservação da temperatura dos imunobiológicos.

\section{Para refletir}

Como você avalia que possa contribuir para uma supervisão eficaz no seu processo de trabalho, considerando o objetivo final de manter a qualidade dos imunobiológicos e contribuir para uma boa cobertura vacinal da população?

\section{Importante!}

A supervisão, como um dos métodos de avaliação, deve ser realizada de forma cooperativa, conjunta e planejada; seus resultados devem ser sistematizados em relatórios objetivos e sucintos, de acordo com o propósito para a qual foi planejada.

\section{Monitoramento rápido de cobertura (MRC)}

É uma importante estratégia de vigilância das doenças imunopreveníveis, visto que sua metodologia permite obter dados reais sobre a cobertura vacinal, por meio de inquérito ou levantamento de campo. Ocorre escolhendo-se, inicialmente, por meio de sorteio aleatório, uma microárea de um território para ser visitada. No local, é verificada a situação vacinal das crianças residentes. Caso alguma delas não esteja com o cartão vacinal em dia, a administração da vacina é realizada naquele momento.

O MRC é de fundamental importância para as áreas de difícil acesso, onde o registro é deficiente, a caracterização da população-alvo por área de abrangência é inexistente, e onde haja movimentos migrató-

rios ou processos de imigração/emigração. Nesse contexto, constitui,

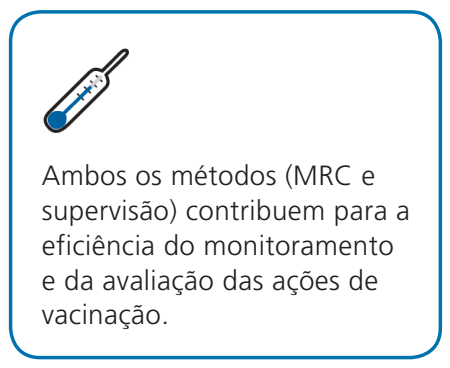


Outro método sensível e prático para o acompanhamento contínuo dos indicadores de cobertura vacinal, em determinado período, é o registro gráfico de cobertura vacinal. Para conhecê-lo, acesse: http:// tabnet.datasus.gov.br/tabdata/ livroidb/Com2007/Com_F13. pdf e http://bvsms.saude.gov. br/bvs/publicacoes/livro_30_ anos_pni.pdf
A definição de indicadores é apresentada no Capítulo 5, "Indicadores de saúde e sistemas de informação em saúde: instrumentos para analisar a saúde da população", do livro Rede de Frio: fundamentos para a compreensão do trabalho (Silva; Flauzino; Gondim, 2016). portanto, importante estratégia, para o gestor e a equipe, obter dados sobre a população vacinada, bem como proceder à vacinação, garantindo proteção daquele grupo/comunidade.

Para a realização do MRC, temos que observar alguns pontos como:

* determinação da composição da amostra representativa da população a ser avaliada;

* elaboração do instrumento para a coleta das informações;

* estabelecimento das regras para aplicá-lo corretamente;

* preparação dos mapas da localidade;

detalhamento dos quarteirões ou aglomerados rurais;

*acilidade na localização dos domicílios sorteados na amostra

(território em saúde);

capacitação da equipe que fará as entrevistas;

* definição da equipe que analisará os dados coletados;

estimativa da cobertura vacinal da área sorteada etc.

Como todo método, o MRC apresenta aspectos positivos e negativos. Vantagens da sua utilização estão na ausência de sub-registro e rapidez na obtenção dos dados. Entretanto, é de elevado custo operacional, requer pessoal especializado para formular o inquérito, coordenar a execução e analisar os dados.

\section{Exemplos de questões da prática respondidas pelo MRC}

1. A atividade de vacinação está em conformidade com as normas e os procedimentos recomendados?

2. A equipe está utilizando todos os recursos disponíveis para superar dificuldades e transpor obstáculos?

3. Até que ponto o trabalho de vacinação está atingindo a população-alvo?

\section{Indicadores}

No contexto do PNI, utilizamos indicadores buscando analisar os resultados obtidos e o impacto causado pelas ações do programa. Em vacinação, o principal indicador é o índice de cobertura vacinal que, associado aos demais, permite o alcance do principal objetivo: aumentar a cobertura vacinal de forma homogênea e reduzir a morbimortalidade dos diversos grupos suscetíveis. A seguir detalharemos um pouco mais esse 
indicador, bem como outros também utilizados pelo PNI para monitorar as ações de vacinação.

\section{Indicador de cobertura vacinal}

É expresso pelo percentual de pessoas vacinadas (com uma vacina específica), em determinado espaço geográfico e em determinado período. Por meio desse indicador, pode ser estimado o nível de proteção da população contra doenças evitáveis pela imunização, mediante o cumprimento dos esquemas de vacinação específicos. Por exemplo, para vacinas de apresentação unidose (vacinados com uma dose), considera-se o único evento de vacinação existente, enquanto, para vacinas multidose, considera-se o quantitativo de vacinados com a última dose preconizada no esquema.

A construção do indicador de cobertura vacinal é feita por meio das doses aplicadas e a população-alvo a vacinar.

\section{Como fazer o cálculo da cobertura vacinal?}

Após verificar, no Sistema de Informações SI-PNI, o número de doses administradas em uma população-alvo específica (grupo/faixa etária), de determinado local e período, e também o total da população desse mesmo grupo, aplicar os dados na seguinte fórmula:

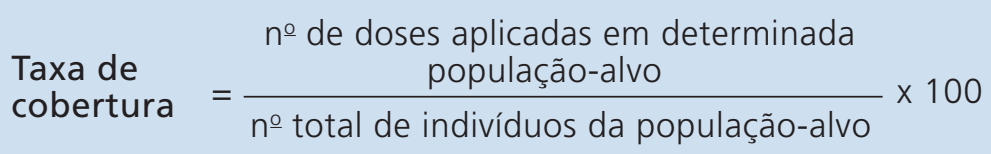

Por exemplo: o número de doses da vacina tríplice viral administrada na população de determinado município, em 2014, foi 245. Esse município tem 246 habitantes na faixa etária de 1 ano, que é alvo de vacinação. Nesse caso, a taxa de cobertura de vacinação é:

Taxa de cobertura $=\frac{245}{246} \times 100=99,5 \%$

Nota: o denominador para o cálculo da cobertura vacinal é diferente quando se trata de grupo menor de 1 ano de idade. Nesse caso, devem-se utilizar dados do sistema de informação sobre nascidos vivos (Sinasc), do último ano disponível.

Outros métodos podem ser utilizados para avaliação da cobertura, como, por exemplo, a titulagem de anticorpos, que permite saber a situação imunológica, e o levantamento do registro individual, reali-

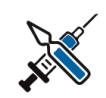

Sejam quais forem os indicadores, é preciso conhecê-los, compreender como são utilizados e a forma de calculá-los para que as ações de vacinação possam ser corretamente planejadas, monitoradas e avaliadas.

Esse é o caso da hepatite $B$, cujo esquema completo corresponde à aplicação de três doses.
Titulagem de anticorpos referese à medição de concentração de anticorpos no sangue. 

ser alcançada para vacinação é universal e deve ser de $100 \%$, tendo como meta mínima estabelecida o percentual de $95 \%$ !

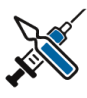

Os bolsões de não vacinados se formam pela falta de acesso à vacinação ou pelo abandono dos esquemas vacinais. É importante cobrar dos responsáveis a garantia do acesso à vacinação e investigar as razões do abandono da vacinação, para se adotar medidas que evitem o acúmulo de suscetíveis e a formação desses grandes bolsões, que possam comprometer o controle epidemiológico da doença. zado com base no arquivo das informações sobre o vacinado, existente nas unidades de saúde.

\section{Indicador homogeneidade}

De acordo com o Manual de procedimentos para vacinação (FUNDAÇÃO NACIONAL DA SAÚDE, 2001), “a redução da morbidade e da mortalidade por doenças imunopreveníveis somente será possível se os indicadores de cobertura forem mantidos elevados e homogêneos".

Tal como o de cobertura vacinal, o indicador de homogeneidade desempenha importante papel no monitoramento e na avaliação das ações de imunização, porque permite identificar grupos ou áreas de risco. É expresso pela proporção de unidade territorial (municípios, bairros, territórios ou área abrangente) que atingiu a cobertura vacinal. Em outras palavras, o quanto (em percentual) determinado lugar teve de cobertura vacinal. Podemos afirmar que houve homogeneidade quando $70 \%$ ou mais das unidades territoriais avaliadas alcançaram a cobertura estabelecida para aquelas áreas.

\section{Como fazer o cálculo do indicador de homogeneidade? \\ no de municípios com coberturas \\ Homogeneidade $=\frac{\text { para determinada vacina }}{\mathrm{n}^{\circ} \text { total de municípios }} \times 100$}

Fonte: Manual de normas e procedimentos para vacinação (BRASIL, 2014).

Este indicador é uma ferramenta de avaliação fundamental, pois permite que equipe e gestores possam:

* identificar, em caso de baixa homogeneidade, os grupos de suscetíveis (bolsões de não vacinados), as áreas de risco e/ou de exclusão e as pessoas com dificuldade de acessar os serviços de saúde (maior concentração da população em estado de pobreza, de migração);

* realizar as intervenções necessárias para redução ou eliminação do problema por meio de várias estratégias (busca de faltosos, campanhas de vacinação extramuros, monitoramento domiciliar etc.). 


\section{Indicador de utilização das vacinas}

Avaliar a utilização do imunobiológico no nível local, verificando se houve desperdício/perdas pela alteração de temperatura ou procedimento incorreto, demonstra como o trabalho vem sendo realizado na rede de frio e nas salas e demais locais de vacinação, possibilitando intervenção.

Este indicador é expresso pela seguinte fórmula matemática:

\section{Cálculo do indicador de utilização de vacinas}

Taxa de aproveitamento $=\frac{\mathrm{n} \text { o de doses administradas }}{\mathrm{n} \text { - de doses distribuídas }} \times 100$

O indicador de utilização das vacinas é importante instrumento de avaliação das atividades e pode sofrer interferência de alguns fatores, por exemplo, a perda das vacinas. As perdas podem ser de dois tipos:

萍 técnicas, quando decorrentes da abertura de frasco de multidose, em que vence o prazo de uso depois de aberto, como BCG, poliomielite etc.;

藩 físicas, quando decorrentes de quebra de frasco, vencimento de prazo de validade do fabricante ou por problemas na rede de frio.

\section{Alguns cuidados para evitar perdas de vacinas}

As perdas podem ser diminuídas ou eliminadas pela aplicação e zelo de normas e padrões técnicos estabelecidos pelo PNI. Vejamos alguns cuidados que podem ser tomados:

- O profissional de saúde deve conhecer o prazo de validade dos imunobiológicos, bem como as recomendações dos laboratórios produtores. Deve utilizar sempre, primeiramente, os imunobiológicos com prazos mais curtos.

- No próprio frasco da vacina devem ser registrados data e horário de sua abertura, abrindo-o no momento de recebimento do primeiro cliente e sempre de acordo com a demanda.

- Quando não for possível obter dados confiáveis sobre a população a vacinar, o quantitativo de vacinas necessário deve ser levantado utilizando-se o cálculo de percentuais de população, conforme os parâmetros estabelecidos pela Organização Pan-Americana da Saúde (Opas).
Aproveitar $100 \%$ das vacinas recebidas é uma meta difícil de alcançar, mas que deve ser permanentemente perseguida.
Para melhor conhecer a forma de realizar os cálculos e as normas e os procedimentos técnicos para evitar perdas de vacinas, consulte o Manual de normas e procedimentos para vacinação (BRASIL, 2014), disponível em: http://bvsms. saude.gov.br/bvs/publicacoes/ manual_procedimentos_ vacinacao.pdf 


\section{Taxa de abandono}

Possibilita a avaliação da proporção de vacinas aplicadas que não completaram o esquema básico. É expressa pelo percentual de pessoas que não chegaram a completar o mínimo de doses do esquema para uma vacina específica. Seu cálculo pode ser realizado diretamente pelo SI-PNI, com uso da seguinte fórmula:

\section{Cálculo da taxa de abandono}

Taxa de abandono $=\frac{\mathrm{n} \text { - de primeiras doses }-\mathrm{n} \text { - de terceira dose }}{\mathrm{n}^{\circ} \text { de terceira dose }}$

Para permitir o acompanhamento e a análise da taxa de abandono, alguns parâmetros foram estabelecidos:

粼 taxas maiores que $10 \%$ são consideradas altas;

de $5 \%$ a $10 \%$, taxa média;

menor que 5\%, parâmetro aceitável.

Diversos fatores podem contribuir para que as pessoas estejam incompletamente vacinadas, como desinformação, receio de ocorrência de eventos adversos causados pelas vacinas, dificuldade de acessar a unidade de saúde nos horários estabelecidos, enfim, uma gama de situações às quais a equipe deve estar atenta. $\mathrm{O}$ acompanhamento por meio deste indicador permite intervir precocemente nas causas, evitando acúmulo de suscetíveis e formação de bolsões, os quais comprometem o controle epidemiológico das doenças preveníveis por vacinação.

\section{Indicadores de qualidade}

Permitem avaliar vários aspectos como:

* acessibilidade: revela a quantidade dos serviços disponíveis à população, as dificuldades financeiras e de acesso aos serviços, as barreiras físicas e geográficas, as questões estruturais etc. que impedem o usuário de receber a vacina; a análise desse indicador deve ser realizada com base nas necessidades da população e nas condições de utilização dos serviços de saúde;

* satisfação do usuário: demonstra a percepção da população sobre o serviço prestado, no que diz respeito à relação entre o profissional de saúde e o paciente, à infraestrutura do serviço e ao significado de saúde e doença; para o gestor, importa conhecer o que pensa 
o usuário porque a decisão de se vacinar ou não depende de sua vontade e interesse e, caso não esteja satisfeito com o serviço oferecido, pode não aderir à vacinação;

* resolutividade: se expressa em duas dimensões - a quantitativa (capacidade de resolver quantitativamente serviços requeridos pela população) e a capacidade de solução do problema o mais próximo de onde ele acontece. Esse indicador está diretamente relacionado com a capacidade de gestão da rede regionalizada, da sua organização, do funcionamento do sistema de referência e contrarreferência etc.

Outros parâmetros podem ser utilizados na avaliação das atividades, como o grau de eficiência e eficácia. A eficácia é verificada pelo grau alcançado por uma ação em relação ao resultado proposto, isto é, resultados X efeitos (por exemplo, eficácia da vacina). Já a eficiência refere-se a atingir o resultado com um mínimo de perda de recursos, isto é, fazer o melhor uso possível do dinheiro, do tempo, de materiais e pessoas.

Os estudos sobre custo-benefício e custo-eficácia são importantes, porque comparam os pontos positivos e negativos das estratégias adotadas. Quando se realiza a análise custo-benefício, as consequências positivas (benefícios) são avaliadas, e seus custos são medidos em unidades monetárias. Já na análise do custo-eficácia, o resultado também é medido pelas consequências positivas, mas o custo é medido em elementos como dias de doença evitados, anos de vida poupados, óbitos evitados etc.

Para uma avaliação da vacinação é importante realizar a análise de custos, por exemplo, levar em consideração o custo de implantação de novas salas de vacinação em relação ao custo de montagem de equipes móveis, o custo das estratégias adotadas em relação ao impacto alcançado. Na análise do custo, o maior objetivo é a redução do gasto sem perder a eficácia. A análise de custos ajuda a estabelecer a quantidade dos recursos necessários para o alcance das metas. Em ambas, serão avaliados os resultados alcançados, constituindo-se em um importante instrumento de avaliação (BAHIA, 2011).

\section{Considerações finais}

A avaliação é de fundamental importância para as atividades de vacinação, devendo ser realizada sistematicamente no conjunto das ações da atenção básica. 
Configura-se como um poderoso instrumento no julgamento e na análise das atividades de vacinação, contribuindo para que as ações adotadas sejam revisadas, bem como novas estratégias sejam implementadas. A partir dos seus resultados, todos os envolvidos e responsáveis pelas atividades de vacinação, como profissionais, gestores etc. poderão melhor conduzir as ações. Isso significa escolher as estratégias mais indicadas para aquela população-alvo da área ou do território específico e adequar as ações às especificidades locais, permitindo, assim, a manutenção de coberturas acima do mínimo preconizado.

A avaliação deve ser entendida como uma ferramenta de uso contínuo, aplicável em todas as instâncias, a partir da premissa de que a avaliação não deve ser realizada somente no fim das atividades, mas durante todo o processo. Dessa forma, fornece elementos que permitem ajustes e construção de parâmetros que balizem escolha de caminhos e diretrizes adequadas aos objetivos da vacinação e do Programa Nacional de Imunizações: imunizar toda a população, garantindo a vacinação universal, em consonância com um dos princípios do SUS.

Para subsidiar a avaliação e fornecer as informações necessárias para a construção e o cálculo dos indicadores, temos um importante instrumento: o Sistema de Informações do PNI (SI-PNI), que será apresentado no capítulo seguinte.

\section{Referências}

BAHIA. Secretaria da Saúde. Coordenação do Programa Estadual de Imunizações. Manual de procedimento para vacinação. Salvador, 2011.

BRASIL. Ministério da Saúde. Sistema de planejamento do SUS (PlanejaSUS): uma construção coletiva: trajetória e orientações de operacionalização. Brasília, DF: Organização Pan-Americana da Saúde, 2009. Disponível em: <http://bvsms.saude.gov.br/bvs/publicacoes/planejaSUS_livro_1a6. pdf.> Acesso em: 9 nov. 2015.

BRASIL. Ministério da Saúde. Secretaria de Vigilância em Saúde. Departamento de Vigilância das Doenças Transmissíveis. Curso de atualização para trabalhador da sala de vacinação: manual do aluno. 3. ed. rev. e ampl. Brasília, DF, 2013.

BRASIL. Ministério da Saúde. Secretaria de Vigilância em Saúde. Departamento de Vigilância das Doenças Transmissíveis. Manual de normas e procedimentos para vacinação. Brasília, DF, 2014.

BRASIL. Ministério da Saúde. Secretaria de Vigilância em Saúde. Departamento de Vigilância Epidemiológica. Manual técnico-operacional: campanha nacional de vacinação para eliminação da rubéola, no Brasil. Brasília, DF, 2008. 
LUHM, K. R.; WALDMAN, E. A. Sistemas informatizados de registro de imunização: uma revisão com enfoque na saúde infantil. Epidemiologia e Serviços de Saúde, Brasília, DF, v. 18, n. 1, p. 65-78, jan./mar. 2009.

MORAES, J. C. et al. Qual é a cobertura vacinal real? Epidemiologia e Serviços de Saúde, Brasília, DF, v. 12, n. 3, p. 147-153, set. 2003.

MOTA, E. Inquérito domiciliar de cobertura vacinal: a perspectiva do estudo das desigualdades sociais no acesso à imunização básica infantil. Revista Brasileira de Epidemiologia, São Paulo, v. 11, p. 125-128, maio 2008. Suplemento 1.

SILVA, M. N.; FLAUZINO, R. F.; GONDIM, G. M. M. (Org.). Rede de frio: fundamentos para a compreensão do trabalho. Rio de Janeiro: Ed. Fiocruz, 2016. 


\section{Anexo A - Ficha de registro do vacinado}

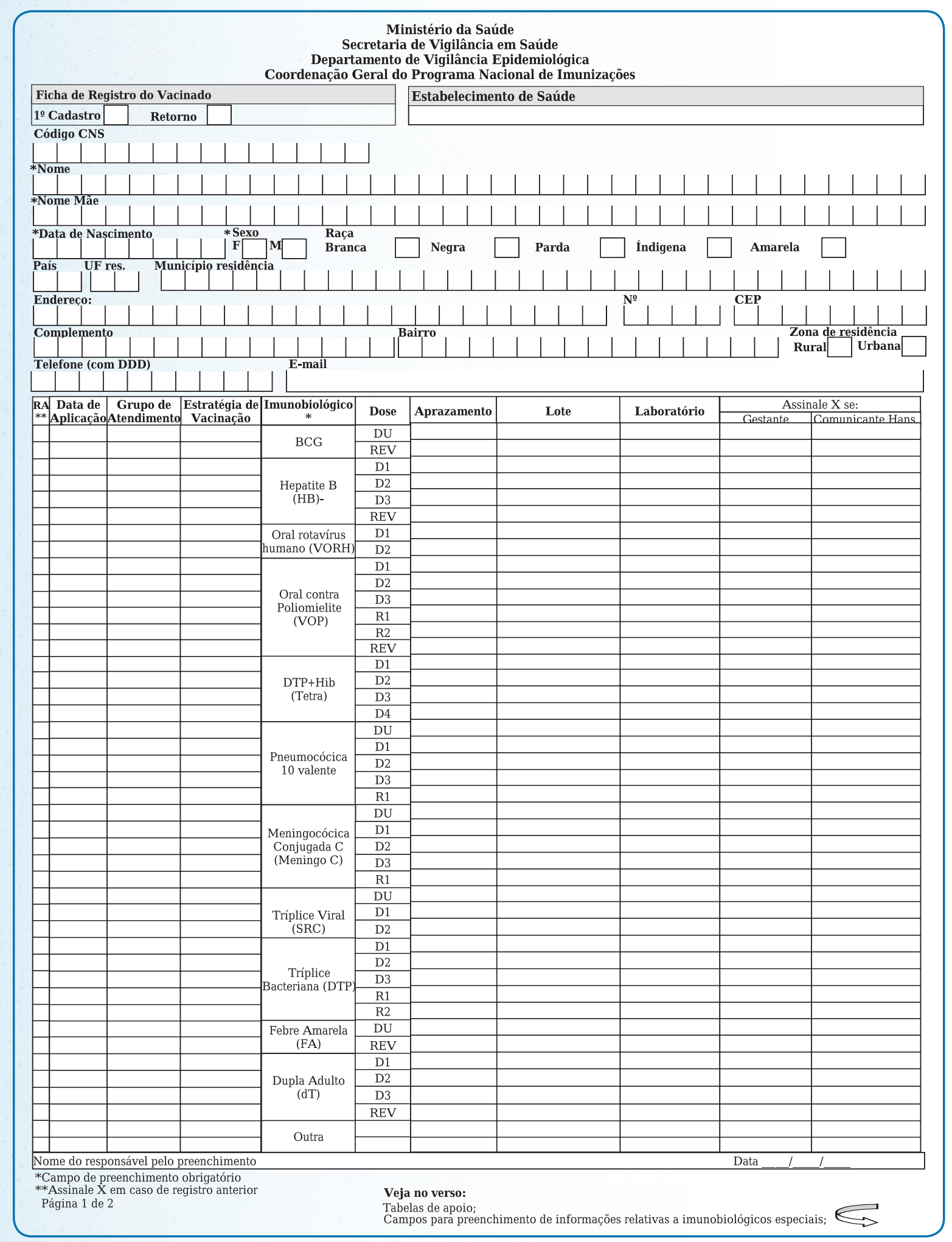




\begin{tabular}{|c|c|c|c|c|c|c|c|c|c|}
\hline \multicolumn{10}{|c|}{ Imunobiológicos especiais } \\
\hline $\begin{array}{c}\text { Data de } \\
\text { Aplicação* }\end{array}$ & $\begin{array}{c}\text { Grupo de } \\
\text { Atendimento* }\end{array}$ & Imunobiológico* & Aprazamento & Dose* & Laboratório* & Lote & $\begin{array}{l}\text { Motivo da } \\
\text { Indicação* }\end{array}$ & \begin{tabular}{|c|}
$\begin{array}{c}\text { Especialidade do } \\
\text { solicitante* }\end{array}$ \\
\end{tabular} & $\begin{array}{l}\text { Marcar (X) } \\
\text { se Gestante }\end{array}$ \\
\hline & & & & & & & & & \\
\hline & & & & & & & & & \\
\hline & & & & & & & & & \\
\hline & & & & & & & & & \\
\hline & & & & & & & & & \\
\hline & & & & & & & & & \\
\hline & & & & & & & & & \\
\hline & & & & & & & & & \\
\hline & & & & & & & & & \\
\hline & & & & & & & & & \\
\hline & & & & & & & & & \\
\hline & & & & & & & & & \\
\hline & & & & & & & & & \\
\hline & & & & & & & & & \\
\hline & & & & & & & & & \\
\hline & & & & & & & & & \\
\hline Nome do resp & onsável pelo pree & nchimento & & & & & & Data & \\
\hline
\end{tabular}

\section{Tabelas de apoio}

\begin{tabular}{|c|l|}
\hline \multicolumn{2}{|c|}{ Raça } \\
\hline 1 & Branca \\
\hline 2 & Negra \\
\hline 3 & Parda \\
\hline 4 & Indígena \\
\hline 5 & Amarela \\
\hline
\end{tabular}

\begin{tabular}{|c|c|}
\hline País & Estratégia \\
\hline 1 Brasil & 1 Rotina \\
\hline 2 Argentina & \begin{tabular}{l|l}
2 & Especial
\end{tabular} \\
\hline 3 Bolívia & \begin{tabular}{l|l}
3 & Bloqueio
\end{tabular} \\
\hline \begin{tabular}{|l|l|}
4 & Chile \\
\end{tabular} & 4 Intensificação \\
\hline 5 Paraguai & \begin{tabular}{l|l}
5 & Campanha indiscriminada \\
\end{tabular} \\
\hline 6 Uruguai & $\begin{array}{ll}6 & \text { Campanha seletiva } \\
\end{array}$ \\
\hline 7 Colombia & 7 Soroterapia \\
\hline
\end{tabular}

\begin{tabular}{|l|l|}
\hline \multicolumn{2}{|c|}{ Grupo de atendimento } \\
\hline 1 & Indígenas \\
\hline 2 & Assentados \\
\hline 3 & Acampados \\
\hline 4 & Militares \\
\hline 5 & Quilombolas \\
\hline 6 & População privada de liberdade \\
\hline 7 & População geral \\
\hline
\end{tabular}

8 Equador

9 Outros países

10 Perú

11 Venezuela

12 Suriname

13 Guiana Francesa

14 Guiana Inglesa

\begin{tabular}{|l|l|}
\hline \multicolumn{2}{|c|}{ Dose } \\
\hline D1 & $1^{\text {a }}$ Dose \\
\hline D2 & $2^{2}$ Dose \\
\hline D3 & $3^{3}$ Dose \\
\hline D4 & $4^{a}$ Dose \\
\hline D5 & $5^{\text {a }}$ Dose \\
\hline R1 & $1^{\circ}$ Reforço \\
\hline R2 & $2^{\circ}$ Reforço \\
\hline D & Dose \\
\hline DU & Dose Única \\
\hline REV & Revacinação \\
\hline T1 & Tratamento c/ 1 dose até T 24 \\
\hline T24 & Tratamento c/ 24 doses \\
\hline
\end{tabular}




\begin{tabular}{|c|c|c|c|}
\hline \multicolumn{2}{|c|}{ Motivo de indicação } & \multicolumn{2}{|r|}{ Continuação Motivo de indicação } \\
\hline 1 & Abuso sexual & 55 & Prematuridade \\
\hline \multirow{2}{*}{2} & \multirow{2}{*}{$\begin{array}{l}\text { Acidente c/ mat. biológico positivo/fortemente suspeito de infecção } \\
\text { por VHB }\end{array}$} & 56 & Prevenção da infecção perinatal pelo vírus HB \\
\hline & & 57 & Profilaxia após exposição de risco \\
\hline 3 & Adultos com HIV/AIDS portadores do VHB ou VHC & 58 & Profissional de saúde \\
\hline 4 & Asma grave & 59 & Receptores de transplante de medula óssea \\
\hline 5 & Asma moderada & 60 & Risco de tétano neonatal \\
\hline 6 & Asplenia anatômica ou funcional e doenças relacionada & \begin{tabular}{|l|l|}
60 \\
61
\end{tabular} & síndrome nefrótica \\
\hline 7 & Candidatos a transplante de órgão sólido & \begin{tabular}{|l|l}
62 \\
62
\end{tabular} & Subst. de vacinas bacterianas por DTPa+Hib \\
\hline$\frac{8}{9}$ & Cardiopatias crônicas & \begin{tabular}{|l|l|l}
03 \\
63
\end{tabular} & $\begin{array}{l}\text { Suscetibilidade à doença e imunocompetentes em convívio } \\
\text { imunodeprimidos }\end{array}$ \\
\hline$\frac{9}{10}$ & Coagulopatias & 64 & trabalhadores de campanhas de esgoto sanitário \\
\hline 11 & comunicantes domiciliares de imunodeprimidos & 65 & Transplante de medula óssea \\
\hline 12 & comunicantes sexuais de portadores de HVB & 66 & Transplante de órgão sólido \\
\hline 13 & Contato domiciliar & 67 & Trissomias \\
\hline 14 & contato hospitalar & 68 & Uso crônico AC Acetil Salicilico \\
\hline 15 & controle de surto de varicela em ambiente hospitalar & 69 & Viajante \\
\hline 16 & convívio com portadores de VHB & 70 & Processo jurídico \\
\hline 17 & Crianças $<13$ anos com HIV/AIDS & 71 & Não informado \\
\hline 18 & Deficiência isolada de imunidade humoral e celular preservada & Esp & ecialidade do Solicitante \\
\hline 19 & Dermatopatias graves & \begin{tabular}{|l|l|}
1 & \\
1 &
\end{tabular} & Cirurgião dentista \\
\hline 20 & Diabetes mellitus & 2 & Cirurgião dentista odontopediatria \\
\hline 21 & Doadores de órgãos sólidos ou de medula óssea & 3 & Clinica geral \\
\hline 22 & Doadores de sangue & 4 & Dermatologia \\
\hline 23 & Doença convulsiva crônica & 5 & Enfermeiro \\
\hline 24 & Doença de depósito & \begin{tabular}{|l|l}
6 \\
6
\end{tabular} & Geriatria \\
\hline 25 & doença neurológica crônica incapacitante & \begin{tabular}{|l}
7 \\
\end{tabular} & Gerontologia \\
\hline 26 & Encefalopatia (7 dias subsequentes à vacinação com vacina bacteriana) & \begin{tabular}{|l|l}
8 \\
\end{tabular} & \begin{tabular}{|l|l} 
Ginecologia \\
\end{tabular} \\
\hline 27 & Evento adverso prévio & \begin{tabular}{|l|l|l}
9 & \\
\end{tabular} & Hansenologia \\
\hline 28 & Fibrose cística (mucoviscidose) & \begin{tabular}{|l|l}
10 & \\
\end{tabular} & Hematologia \\
\hline 29 & \begin{tabular}{|l|} 
filho de mãe HIV+exposto \\
\end{tabular} & \begin{tabular}{|l|l|l}
11 \\
\end{tabular} & \begin{tabular}{|l|} 
Infectologia \\
\end{tabular} \\
\hline 30 & Fístula liquórica & 12 & Médico residente \\
\hline 31 & Hemoglobinopatias & 13 & Nefrologia \\
\hline 32 & Hepatopatias crônicas e portadores de Hepatite C & 14 & Neonatologia \\
\hline 33 & HIV/AIDS & \begin{tabular}{|l|l}
17 \\
15
\end{tabular} & Neurocirurgia \\
\hline 34 & Hospitalizado & 16 & Neurologia \\
\hline 35 & Implante de clóquea & \begin{tabular}{|l|l}
17 \\
\end{tabular} & Obstetrícia \\
\hline 36 & Himunocompetente $>1$ ano contato hospitalar & \begin{tabular}{|l|l|l}
18 \\
18
\end{tabular} & Otorrinoralingologia \\
\hline 37 & Imunodeficiência adquirida & 19 & Pneumologia \\
\hline 38 & Imunodeficiência congênita & 20 & Reumatologia \\
\hline 39 & $\begin{array}{l}\text { Imunodeficiência congênita da unidade humoral (particularmente do } \\
\text { complemento de lectina fixadora de mamose) }\end{array}$ & 21 & Saúde da família \\
\hline 41 & Imunodeficiência devido a câncer ou imunossupressão terapêutica & 22 & Serviço de alergista \\
\hline 42 & Imunodepressão terapêutica & 23 & Serviço de atend. ao diabético \\
\hline 43 & Imunodepressão terapêutica ou devido a câncer & 24 & Serviço de atend. de hanseníase \\
\hline 44 & Imunodeprimidos & 25 & Serviço de cardiologia \\
\hline 45 & Infectados pelo HIV/Aids (se suscetíveis a varicela, assintomáticos ou & 26 & Serviço de cirurgia cabeça e pescoço \\
\hline & oligossintomáticos) & 27 & Serviço de cirurgia aparelho digestivo \\
\hline 46 & Leucemia linfócita aguda e tumores sólidos & 28 & Serviço de cirurgia geral \\
\hline 47 & Hão soro conversão & \begin{tabular}{|l|l}
20 \\
29
\end{tabular} & Serviço de cirurgia ginecológica \\
\hline 48 & Hefropatias crônicas/dialisados/síndrome nefrótica & 230 & Serviço de cirurgia pediátrica \\
\hline 49 & Pneumopatias crônicas & 31 & Serviço de endocrinologia \\
\hline 50 & $\begin{array}{l}\text { Pneumopatias crônicas em }<2 \text { anos de idade (risco de descompensação } \\
\text { em vigência de febre) }\end{array}$ & \begin{tabular}{|l|l|}
32 \\
32 \\
\end{tabular} & Serviço de imunologia \\
\hline 51 & Politransfundidos & 33 & Serviço de pediatria \\
\hline 52 & Portadores crônicos do VHB & & \\
\hline 53 & Potenciais receptores de múltiplas transfusões de sangue & & \\
\hline 54 & Pré-quimioterapia (protocolos) & & \\
\hline
\end{tabular}

Fonte: http://pni.datasus.gov.br/Download//IIPNI/ficha_registro_vacinado.pdf 


\section{Sistemas de Informações do Programa Nacional de Imunizações}

Walkyria Hercilia Carneiro e Marileide do Nascimento Silva

Para que os objetivos e metas do Programa Nacional de Imunizações sejam alcançados, as atividades de imunização devem ser planejadas e sistematicamente monitoradas e avaliadas, sendo o registro dessas atividades fundamental nesse processo. Tal registro é realizado em um sistema informatizado, que facilita o acompanhamento das atividades por todos os gestores relacionados às ações do Programa Nacional de Imunizações.

Neste capítulo, apresentaremos o Sistema de Informações do Programa Nacional de Imunizações (SI-PNI), sua história, funcionamento e sua utilização em imunização. Além dele, por sua importância para o funcionamento da rede de frio, também abordaremos o Sistema de Informações de Insumos Estratégicos (Sies), que fornece dados referentes a solicitação, distribuição e estoque dos insumos imunobiológicos e seringas.

\section{Criação do Sistema de Informações do PNI}

Desde o início das atividades do Programa Nacional de Imunizações, detectou-se a necessidade de sistematizar as informações sobre vacinação, de forma a se ter dados que possibilitassem a melhor tomada de decisão no planejamento das ações de imunização. Em 1975, após a criação do PNI, alguns estados iniciaram essa sistematização com a implantação de registro de doses de vacinas aplicadas, através do preenchimento de planilhas impressas, que eram posteriormente encaminhadas para a instância nacional de gestão do PNI, o PNI Nacional.

Em 1984, foi introduzido o boletim mensal impresso de doses aplicadas, e cada estado realizava a consolidação dos dados e enviava, por 
malote, ao PNI Nacional. Posteriormente, foi necessário fazer o mesmo para a gestão dos produtos utilizados pelo programa, sistematizando a movimentação de estoques dos imunobiológicos, o que possibilitou o planejamento das necessidades e a definição de cronogramas de distribuição dos produtos.

As primeiras iniciativas de informatização dos registros de vacinação datam de 1990, na Região Nordeste, apoiadas pelo Fundo das Nações Unidas para a Infância (Unicef), que não avançaram por causa da insuficiência de recursos financeiros. Entre 1993 e 1994, essas iniciativas foram retomadas com o apoio do Departamento de Informática do Sistema Único de Saúde (DATASUS), de modo que, em 1997, o registro informatizado das informações sobre imunização estava implantado em todas as unidades federadas.

Até 2012, o registro das informações do Programa Nacional de Imunizações era realizado via subsistemas, que funcionavam isoladamente. Eles forneciam informações sobre as principais atividades de vacinação. Os subsistemas eram:

* SI-API: Sistema de Informações de Avaliação do Programa de Imunizações, destinado ao registro das doses de imunobiológicos aplicadas, possibilitando construir o indicador de coberturas vacinais. No âmbito municipal, as informações são desagregadas ao nível de salas de vacinas. A versão web deste sistema API-WEB está sendo utilizada como etapa para a implementação do SI-PNI (Sistema de Informações do PNI).

* Sies: Sistema de Informações de Insumos Estratégicos, que substituiu o SI-EDI (Sistema de Informações de Estoque e Distribuição de Imunobiológicos). Registra doses de imunobiológicos distribuídas e em estoque. É o sistema utilizado na rede de frio.

* SI-AIU: Sistema de Informações de Apuração dos Imunobiológicos Utilizados. Permite registrar a utilização e perda de imunobiológicos.

* SI-EAPV: Sistema de Informações de Eventos Adversos PósVacinação. Registra os eventos adversos notificados.

* SI-Crie: Sistema de Informações dos Centros de Referência para Imunobiológicos Especiais, utilizado para o registro das doses aplicadas nos usuários desses centros.

* SI-Pais: Sistema de Informações do Programa de Avaliação de Instrumento. Registra as supervisões que são realizadas pelos profissionais atuantes no PNI.

Apesar de todos esses sistemas possibilitarem a avaliação regular e sistemática dos dados das coberturas vacinais (campanha e rotina), con- 
forme faixa etária, grupo-alvo e imunobiológicos específicos, não havia dados sobre os vacinados, o que se tornou uma necessidade ao longo dos anos do programa. Por isso, posteriormente, em 2010, foi desenvolvido, pelo DATASUS-RJ, um sistema com entrada individual de dados e por procedência, o Sistema de Informações do Programa Nacional de Imunizações, o SI-PNI.

\section{O Sistema de Informações do PNI}

O SI-PNI é um sistema que permite, através dos dados cadastrais do vacinado, acompanhá-lo em qualquer lugar do país, além de viabilizar uma análise mais consistente dos indicadores das áreas de imunizações das unidades federativas. Possibilita, também, que todos os subsistemas já mencionados possam ser consolidados em um único banco de dados.

O SI-PNI tem, entre outros, o objetivo de coletar os dados referentes às atividades de vacinação de forma a gerar informação individualizada, a partir da instância local, para subsidiar as decisões/ações no âmbito da esfera de gestão. Visa, também, fornecer dados sobre a movimentação dos imunobiológicos disponíveis na sala de vacinação, proporcionando aos gestores uma avaliação ágil dos insumos utilizados, subsidiando o planejamento das ações de vacinação e a alocação de recursos gerenciais (de pessoas, financeiros, materiais). A coordenação, a supervisão e a atualização desse sistema estão sob a responsabilidade da CGPNI.

Atualmente, os gestores podem utilizar o SI-PNI sem qualquer custo. O sistema também pode ser instalado em diferentes sistemas operacionais, por conta da tecnologia que é utilizada. Para que possa ser usado por qualquer gestor da rede pública ou privada, é necessário comunicar à coordenação de imunizações e elaborar e informar o fluxo de transmissão dos dados ao PNI, uma vez que essa função está sob a responsabilidade da coordenação municipal.

\section{Implantação do SI-PNI}

O SI-PNI foi implantado em 2010, mas somente a partir de 2012 foi possível expandir o sistema, com a disponibilização de recursos para compra de equipamentos de informática para as salas de vacina. Todos os estados e municípios que aderiram à Portaria n. 2.363/2012 receberam o recurso para a compra dos equipamentos, tendo, como prazo final, o ano de 2014 para implantação do SI-PNI (Ofício Circular n. 123/2013- GAB/SVS/MS).

A Figura 1 demonstra os subsistemas que integram o SI-PNI e as principais informações disponibilizadas por ele.

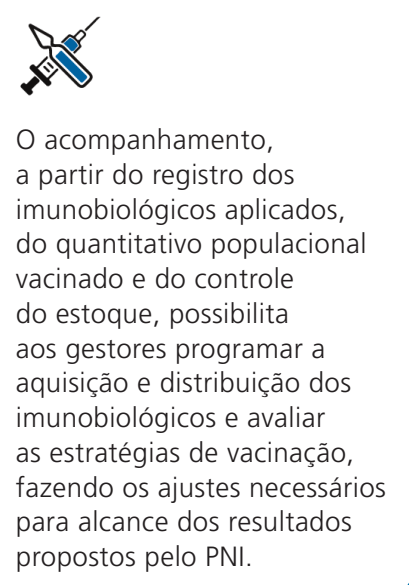

propostos pelo PNI.

Lembramos que, durante a fase de implantação do SI-PNI, foi utilizado um sistema intermediário, o Sistema de Informações de Avaliação do Programa de Imunizações (API-WEB). A compra dos equipamentos necessários para a implantação do SI-PNI nas salas de vacina foi viabilizada por recursos alocados pela Portaria n. 2.363/2012 (BRASIL, 2012). 
Figura 1 - O SI-PNI

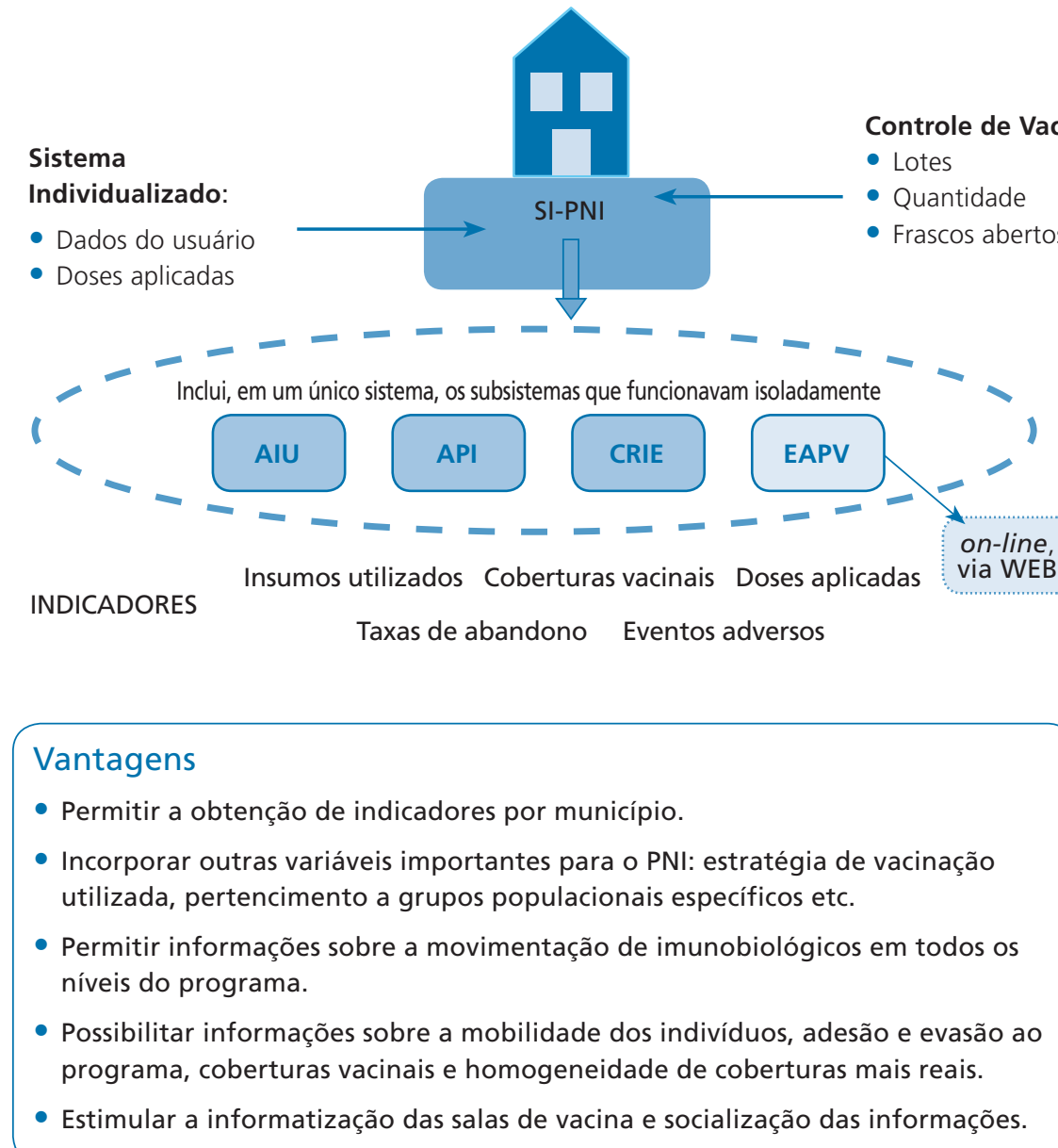

Fonte: Elaboração do autor.

O SI-PNI foi se modificando ao longo de sua existência, procurando acompanhar o crescimento do próprio Programa Nacional de Imunizações, o que resultou em várias versões do software.

Em 2010, o DATASUS-RJ desenvolveu o Sistema de Informações do Programa Nacional de Imunizações, o SI-PNI, colocando-o em funcionamento. No entanto, a expansão de utilização desse novo sistema não pôde ser impulsionada pela falta de equipamentos de informática em todas as salas de vacina do país.

Em outubro de 2012, com o intuito de auxiliar/subsidiar a compra de computadores para todas as salas de vacina cadastradas no SI-API e favorecer a implementação/utilização do SI-PNI, o Programa Nacional de Imunizações repassou, por meio da Portaria n. 2.363/2012 e do Piso Variável 
de Vigilância e Promoção da Saúde (PVVPS), o valor de R\$1.500,00 para as unidades de saúde da rede básica. O objetivo, além da compra de computadores, era facilitar o entendimento e apoiar a utilização do SI-PNI. Para auxiliar na capacitação dos profissionais na utilização do novo sistema de informação, o PNI produziu videoaulas. As videoaulas estão disponíveis no canal do Ministério da Saúde, no YouTube, pelo link: https://www. youtube.com/watch?v=UnX--qKPPLk

\section{Funcionamento do SI-PNI}

O sistema utiliza dois instrumentos de coleta de dados: um para o registro de doses aplicadas na sala de vacinação (ficha do vacinado) e outro para o registro da movimentação das doses de imunobiológicos em todas as esferas de gestão do PNI.

O sistema permite a entrada de dados por:

* indivíduo: sua procedência, estratégia de vacinação utilizada (rotina, intensificação, bloqueio, campanha, especial);

grupos populacionais específicos (quilombolas, privados de liberdade, indígenas, assentados, população geral);

* mobilidade dos indivíduos;

* adesão ao programa de imunizações e evasão, oportunidade perdida de vacinação;

* movimentação de imunobiológicos (laboratório produtor, fornecedor do imunobiológico);

lotes disponíveis e utilizados;

utilização de imunobiológicos, inclusive perdas físicas e técnicas;

*aprazamento de vacinação etc.

Além disso, o SI-PNI possibilita que, durante a entrada de dados, o usuário identifique e corrija inconsistências antes do processamento da informação e, com isso, permite uma análise qualitativa/quantitativa mais consistente do programa de imunizações. Tem caráter descentralizado, uma vez que não somente a coleta, mas também a digitação dos dados, são realizadas no domínio do município.

\section{Disponibilização para o uso do SI-PNI}

Como apresentado, uma das vantagens do SI-PNI é a coleta de informações na esfera municipal pelas pessoas que estão diretamente envolvidas 


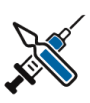

O SI-PNI permite que qualquer pessoa interessada nos dados de imunização do país tenha acesso aos relatórios emitidos. com a vacinação. Para utilizar o sistema nas unidades públicas de saúde, é necessário, apenas, obter autorização das instâncias superiores de vacinação e dispor dos equipamentos de informática.

Figura 2 - Fluxo de informação do SI-PNI

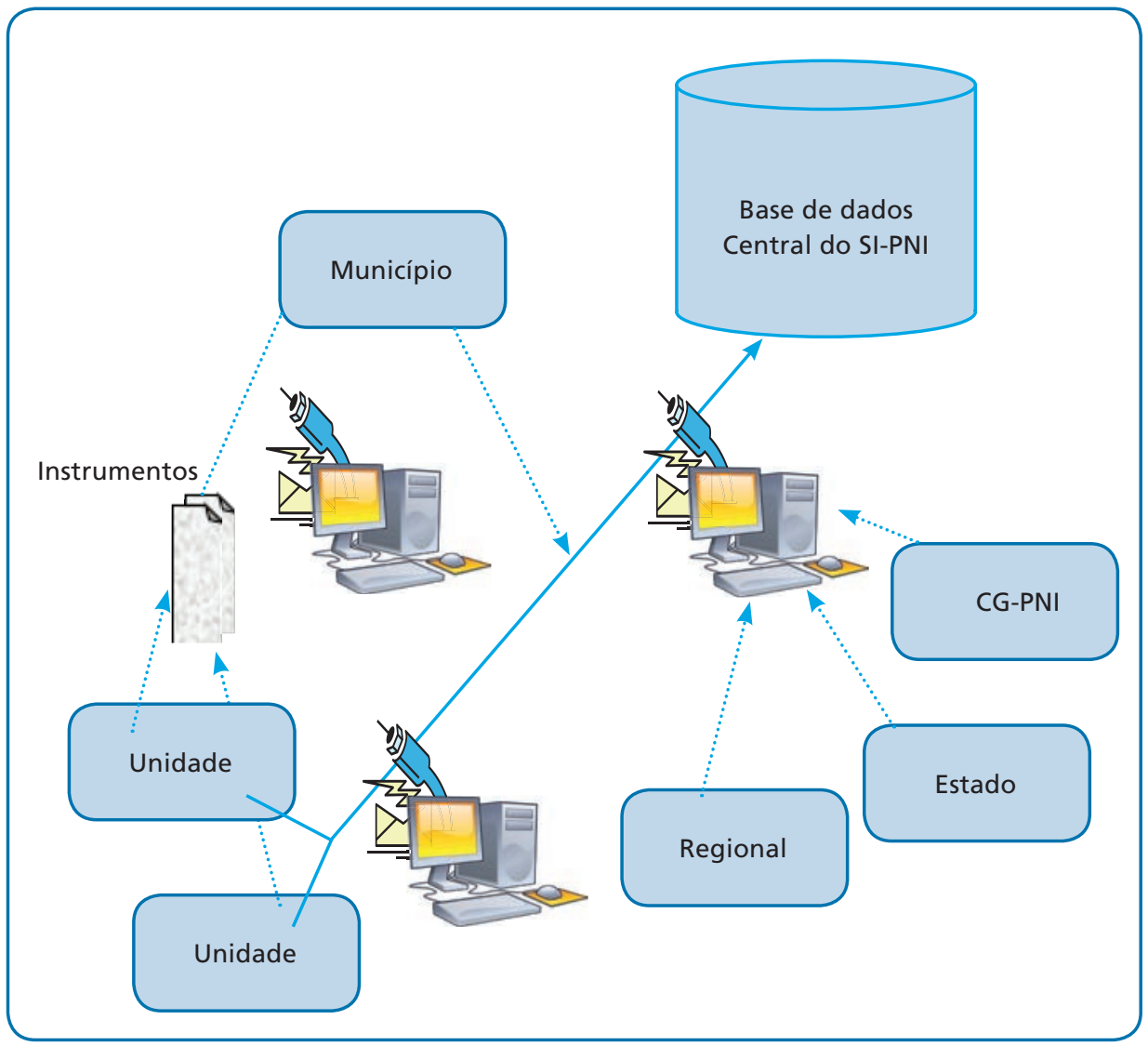

Fonte: Elaboração do autor.

\section{Instalação do SI-PNI}

O processo de instalação do SI-PNI é bastante simples; é possível acessar o pacote de instalação, esclarecer dúvidas sobre como importar dados para outros sistemas nominais, desinstalar ou reinstalar o sistema, a partir do site do DATASUS dedicado ao sistema. Pode ser instalado em rede, com vários computadores interligados, compartilhando os registros do SI-PNI.

Como é de fácil instalação, não requer equipamentos sofisticados; entretanto, recomenda-se o uso de computadores modernos e velozes, pelo volume de informações gerenciadas pelo sistema. A instalação do software pode ser feita desde a sala de vacina até o nível central da gestão do município. 
Ao ser instalado o SI-PNI nas unidades de saúde, todos os sistemas antigos não devem mais ser utilizados, pois o SI-PNI substitui os sistemas antigos relacionados à vacinação (apresentados na Figura 1). É importante que a substituição seja realizada de imediato, para evitar a duplicidade de informações e o prejuízo da análise dos dados e dos resultados.

Para maior compreensão do funcionamento do sistema, é preciso conhecer cada etapa de sua utilização e como é feito o registro dos dados.

\section{Utilização do SI-PNI}

A utilização do sistema e a entrada de dados são possíveis, somente, por usuários cadastrados. Portanto, para utilizá-lo, o primeiro passo deve ser o cadastro de todos os operadores, incluindo o usuário com perfil de administrador, que pode cadastrar os demais operadores, conforme o nível de habilitação (administrador, digitador, vacinador etc.). Para cadastrar cada usuário, devem ser informados:

dados pessoais;

login e senha;

* tipo de habilitação;

status (ativo ou inativo);

*ível de instância onde ocorrerá o registro.

O sistema permite a inserção do cadastro de vacinadores por estabelecimento, gerando uma tabela de vacinadores por sala de vacina ou instituição de saúde. O vacinador poderá ser, também, o operador (aquele que registra no sistema), visto que o sistema identifica quem vacinou e quem registrou. Fornece, também, a opção de pesquisar antes da inserção dos dados do usuário, evitando cadastro em duplicidade dentro de um mesmo estabelecimento.

Em relação aos dados registrados, o SI-PNI dispõe de um módulo específico que visa fornecer informações sobre o vacinado, tais como:

橉 dados básicos;

* histórico de vacinação com informações sobre todas as vacinas que foram e serão aplicadas;

qualidade do registro (se foi realizado corretamente);

* intercorrências na vacinação ou erros de imunização;

*avaliação da caderneta;

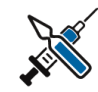

O mesmo vacinador pode ser cadastrado em mais de um estabelecimento de saúde. 


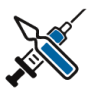

O uso correto da terminologia evita erros no cálculo dos imunobiológicos disponíveis e em estoque. Lembre-se: frasco aberto é considerado frasco utilizado!
* estratégias utilizadas: de acordo com a estratégia selecionada, o sistema disponibiliza, no campo imunobiológico, uma vacina específica. Essa inter-relação da estratégia com a vacina ocorre porque o sistema foi criado para atender a população em geral e, também, grupos específicos, como indígenas, quilombolas, Centros de Referência para Imunobiológicos Especiais (Crie) etc.

\section{Utilização do SI-PNI para registro de movimentação do imunobiológico}

O movimento dos imunobiológicos é observado através de um módulo específico, que registra e disponibiliza os dados para as redes pública e privada. Isso permite conhecer como o imunobiológico está sendo utilizado nas salas de vacina, ou seja, se há perdas técnicas ou físicas, se há controle de doses existentes e em estoque, o saldo disponível anterior e atual, a quantidade distribuída pela rede de frio ou movimentada na sala de vacina etc. É um módulo completo, que visa registrar toda a movimentação do imunobiológico, subsidiando o planejamento, o acompanhamento e a avaliação da programação do PNI, em todas as esferas ou instâncias de gestão do programa.

A alimentação do módulo é feita pelo preenchimento de boletins de movimentação dos imunobiológicos. Ao preenchê-los, o profissional deve estar atento ao uso correto da terminologia:

* utilizado - frasco aberto para uso;

recebido - frasco fechado;

remanejado - transferência de frascos para outro local;

* perda - frasco fechado que não pôde ser usado em função de alguma ocorrência, como quebra, procedimento ou manuseio inadequado.

Com o exposto até o momento, podemos indagar: como o profissional poderia registrar corretamente as inúmeras ocorrências na sala de vacinas e na rede de frio considerando suas especificidades?

Inicialmente, vamos analisar algumas situações e verificar como proceder ao registro de forma adequada. 


\section{Exemplos de ocorrências}

Em determinada unidade básica de saúde (UBS), foram recebidos da rede de frio local, no mês de fevereiro, 1.000 frascos da vacina hepatite $B, 300$ doses do BCG e 1.500 frascos da poliomielite atenuada, por solicitação da enfermeira responsável pelo setor de imunização.

No início do mês, na mesma UBS, havia 200 frascos de hepatite B, 200 de BCG e 500 da poliomielite. E no dia do recebimento mencionado, a UBS tinha três frascos de hepatite, um de BCG (além dos 300) e um de pólio em uso. Destes, um frasco de hepatite foi quebrado durante o manuseio e outro, contaminado na hora de abrir. Por necessidade, outra UBS solicitou a essa unidade 40 frascos de pólio, que foram enviados.

No fim da tarde, durante o processo de limpeza da sala, a tomada do refrigerador onde os imunobiológicos estavam armazenados foi desligada. O fato foi comunicado à coordenação da instância superior, que orientou para manter o refrigerador com as vacinas fechado, aguardando avaliação.

Com base nas ocorrências apresentadas, podemos verificar:

1. Saldo disponível de imunobiológicos da UBS: corresponde à quantidade de frascos fechados existentes e os recebidos no início do mês de movimentação de cada tipo de imunobiológico.

No exemplo:

$$
B C G=300+200=500 \text { frascos }
$$

\section{Importante!}

No SI-PNI, o campo saldo disponível é aberto somente no primeiro acesso, após a inclusão do primeiro mês de movimentação, tal informação aparece automaticamente para o usuário do sistema.

2. Frascos recebidos: corresponde à quantidade de frascos recebidos da rede de frio, do laboratório produtor e outros durante o mês a que se refere a movimentação.

No exemplo:

$$
B C G=300 \text { frascos }
$$

3. Frascos transferidos: corresponde à quantidade de frascos de cada imunobiológico que foi remanejada para outro serviço.

No exemplo:

Poliomielite $=40$ frascos 


\section{Importante!}

A unidade que enviou a vacina deve registrar como frasco transferido, e a que recebeu a vacina, frasco recebido.

4. Frascos utilizados: corresponde ao número de frascos/ampolas de cada tipo de imunobiológico aberto para uso. A retirada de, pelo menos, uma dose já o caracteriza como frasco utilizado.

No exemplo:

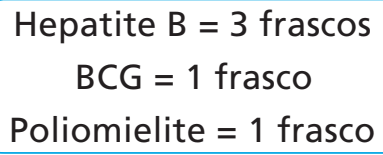

Se houver alguma intercorrência no processo de preparo, manuseio, acondicionamento, ou qualquer outra irregularidade, sem que nenhuma dose tenha sido utilizada, o frasco não pode ser registrado como utilizado. Seu registro deve ser feito como perda. Isso se aplica às unidades e/ou salas de vacina e às centrais de rede de frio (problemas no acondicionamento, transporte etc.).

5.Perdas de frascos: o registro de perda de frasco deve ser feito conforme o tipo de ocorrência - quebra de frasco, procedimento inadequado, validade vencida, falta de energia ou falha no equipamento.

No exemplo:

Hepatite $B=2$ frascos

\section{Importante!}

- Só podem ser registrados como perda os frascos ou ampolas quebrados antes de serem utilizados.

- O frasco aberto, com retirada de uma única dose e que veio a quebrar, é registrado como utilizado, e não quebrado.

6. Falta de energia ou falha no equipamento: refere-se à exposição do imunobiológico a uma temperatura inadequada, em consequência da interrupção no fornecimento da energia elétrica ou por ocorrência de falha mecânica no equipamento que acondiciona os imunobiológicos (salas de vacina ou centrais de rede de frio). 
Em ambos os casos, a orientação é, primeiramente, comunicar a ocorrência à instância imediatamente superior, conforme consta no exemplo apresentado.

Se a orientação for devolvê-lo à instância imediatamente superior, em condição de temperatura ideal, o registro deve ser frasco remanejado. Se for para desprezar o imunobiológico, o registro deve ser perda, seja por falha no equipamento ou por falta de energia elétrica.

7. Procedimento inadequado: relacionado com a quantidade de imunobiológicos perdida por erros nos procedimentos técnicos.

Em nosso exemplo de ocorrências, o desligamento acidental da tomada do refrigerador é considerado perda por procedimento inadequado. Outros exemplos são: acondicionamento incorreto para o transporte, quebra do frasco por acondicionamento incorreto, imunobiológico exposto ao sol durante o transporte ou a distribuição, acondicionamento em refrigerador sem controle de temperatura.

Podem ser registrados como perda os imunobiológicos com aspecto alterado (alteração na cor, presença de elementos ou corpos estranhos etc.), frascos sem rótulo etc. Nesses casos, o registro no sistema deve ser realizado no campo outros motivos.

Há outra situação importante que não foi contemplada em nosso exemplo de ocorrências:

8. Validade vencida: refere-se aos imunobiológicos cujo prazo de validade expirou. Não devem ser registrados como validade vencida os frascos que, por recomendação do laboratório produtor, têm seu tempo de validade alterado depois de abertos!

\section{Utilização para registro de doses aplicadas}

Nos municípios em que o SI-PNI está implantado, o registro dos dados sobre as doses aplicadas é feito por usuário, na ficha de registro do vacinado, processada na própria sala de vacinação ou na Secretaria Municipal de Saúde. As fichas processadas são armazenadas em um banco de dados, do qual é possível extrair o numerador da cobertura vacinal. O banco pode ser acessado no município, no estado e no Ministério da Saúde pela equipe que trabalha no Programa de Imunizações, das diferentes instâncias.
Naqueles municípios em que o SI-PNI ainda não tenha sido totalmente implantado, o registro das doses aplicadas pode ser realizado no API-WEB.

A ficha de registro do vacinado encontra-se no Anexo A do Capítulo 4, "Avaliação da vacinação". 


\section{Utilização para análise de dados}

O SI-PNI permite a emissão de relatórios de imunizações com dados sobre as pessoas que foram vacinadas e os imunobiológicos administrados. Essas informações podem ser individualizadas, por pessoa ou imunobiológico, em período e local determinados e por instância. Inclui-se, também, o relatório sobre os imunobiológicos especiais, com informações sobre os motivos da indicação de tal vacina e, até mesmo, a especialidade do solicitante. Esses relatórios são fundamentais para planejamento, monitoramento, avaliação e adoção das estratégias de vacinação e se constituem em poderosos instrumentos para o gestor.

Mas como são repassados os dados que subsidiam a tomada de decisão?

O SI-PNI possui um módulo denominado utilitário, composto por duas funções: transferência (exportação e importação dos dados) e segurança (backup). Os dados (sobre os vacinados e a movimentação dos imunobiológicos) são registrados diretamente no sistema e exportados, de forma segura (por meio de CD, pen-drive, e-mail institucional), pela instância ou pelo estabelecimento de saúde para a esfera ou instância municipal, a qual, posteriormente, os envia à instância nacional.

A instituição municipal concentra os dados de todo o município e faz a exportação por meio de um aplicativo (transmissor) disponível no site do DATASUS, exclusivo para transmissão de dados do sistema. O acompanhamento da transmissão dos dados pode ser realizado pelo gestor, por meio de relatórios emitidos pelo sistema, que permitem visualizar as informações de todos os estabelecimentos cadastrados no SI-PNI. A transferência é, portanto, uma etapa fundamental e deve ser feita com todo o cuidado, pois é somente dessa forma que os dados poderão chegar ao Ministério da Saúde. A Coordenação Geral do Programa Nacional de Imunizações (CGPNI), da Secretaria de Vigilância em Saúde do Ministério da Saúde (SVS/MS), depende desses dados para analisar, elaborar e reorganizar as atividades de vacinação, objetivando alcançar os objetivos e as metas propostas pelo programa.

O SI-PNI, como qualquer sistema, deve ser atualizado, de modo a acompanhar as inovações e mudanças na área de imunizações e no cotidiano do processo de trabalho. É fundamental que os estabelecimentos de saúde que trabalham com o SI-PNI utilizem sempre as versões mais atualizadas do sistema e dados, como tabelas de bairro, fornecidos pelos órgãos competentes, evitando erros de importação e exportação, com consequente prejuízo na análise e nos resultados da vacinação. 
A análise, o acompanhamento e a interpretação dos dados do sistema, nas diferentes instâncias, servirão de parâmetro para a compreensão da realidade de saúde e doença da população, possibilitando a intervenção nos processos de gestão das unidades e salas de vacina e na reorganização da cadeia de frio.

\section{Sistema de Informações de Insumos Estratégicos (Sies)}

Outro sistema utilizado no PNI é o Sies, de grande utilidade nas centrais e/ou coordenações de rede de frio, para solicitação e dispensação de insumos. Esse sistema foi desenvolvido com base em outro, que o antecedeu, o Sistema de Informações de Insumos Distribuídos e em Estoque (SI-EDI), utilizado anteriormente para o registro das doses dos imunobiológicos distribuídos e em estoque nas centrais de armazenamento.

O Sies se encontra na versão on-line, permitindo que o PNI possa visualizar toda a movimentação de entrada e saída dos imunobiológicos de todas as unidades federadas, em tempo real. Tem como objetivo o gerenciamento dos imunobiológicos, no que se refere a entradas e saídas, controle de pedidos em tempo real, controle de estoque, emissão de relatórios etc.

O pedido de imunobiológicos às centrais de rede de frio pelas unidades de saúde inclui as demandas de todas as estratégias, como ações de rotina, campanhas e vacinação extramuros (veja a tela de pedido na Figura 3). Deve ser realizado de acordo com o cronograma preestabelecido e com a concordância do PNI, de forma a evitar o desabastecimento de vacinas. A instância nacional avalia os pedidos dos estados e adequa a distribuição conforme o estoque disponível, informando e liberando a distribuição pela Central Nacional de Armazenamento e Distribuição de Imunobiológicos (Cenadi).

A utilização desse sistema permite conhecimento específico das demandas e grande otimização dos recursos disponíveis, de forma a garantir o atendimento às metas do PNI de máxima cobertura vacinal possível.
Além de atender ao PNI, esse sistema atende, também, a outras instâncias; é empregado para o gerenciamento de insumos não utilizados pelo $\mathrm{PNI}$, tais como medicamentos, inseticidas, kits laboratoriais etc. 
Figura 3 - Tela de solicitação de imunobiológicos do Sies

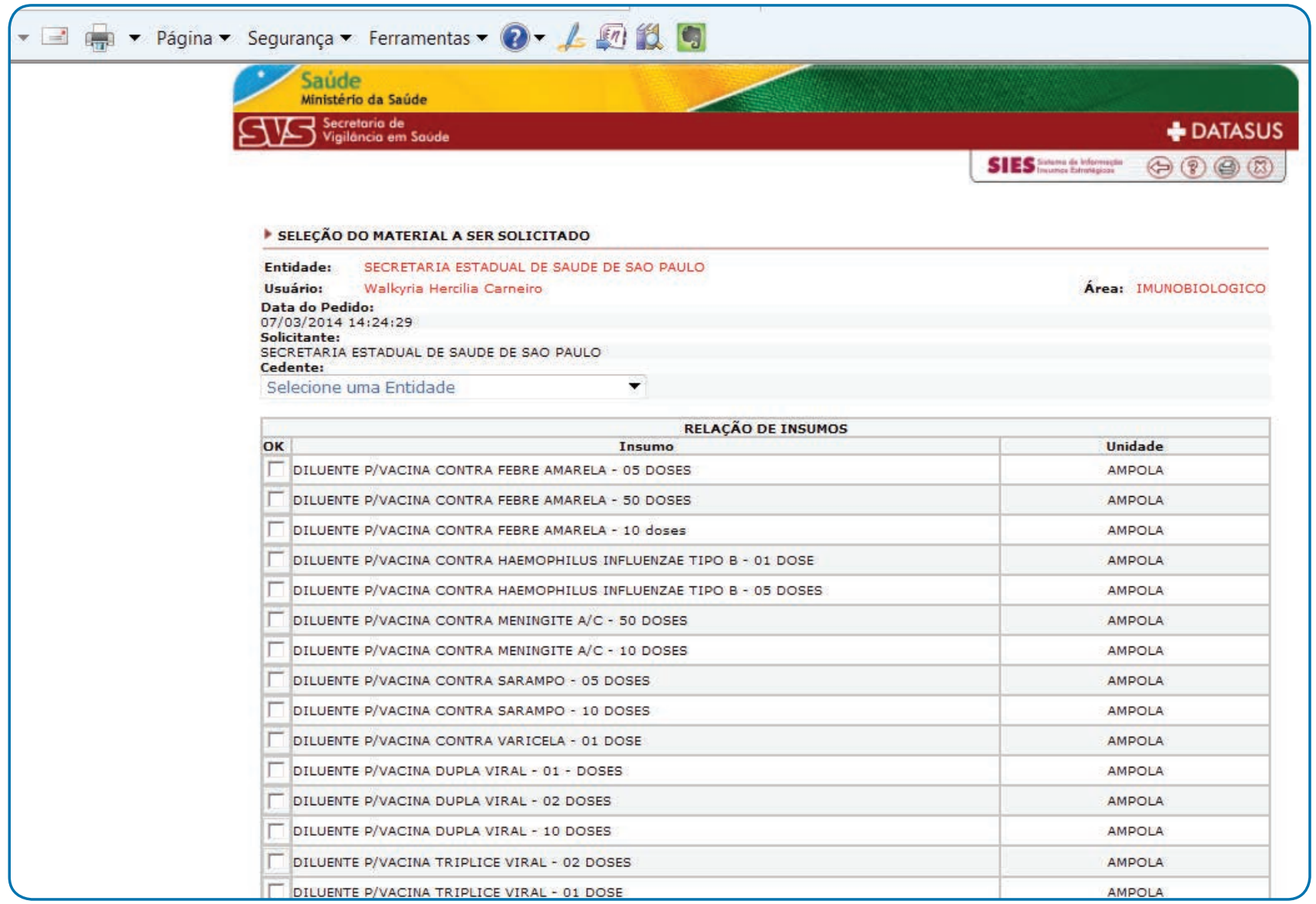

Fonte: DATASUS (acesso restrito)

\section{Considerações finais}

O conhecimento e a atualização técnica da equipe, a adequação da rede de frio, os registros confiáveis, o sistema de informações eficiente, a disponibilidade de imunobiológicos e insumos e a participação da comunidade são pontos fundamentais para o bom desenvolvimento das ações de vacinação, em qualquer instância do Programa Nacional de Imunizações.

Para o melhor desempenho dos serviços de saúde, as ações de vacinação exigirão planejamento, infraestrutura adequada e avaliação, visando a um bom resultado. A utilização adequada dos sistemas que apresentamos (SI-PNI e Sies) pelos profissionais da rede de frio fornecerá ao Programa de Imunizações informações precisas para uma adequada tomada de decisão na aquisição de imunobiológicos e demais insumos, garantindo êxito nas atividades de vacinação. 
É uma responsabilidade compartilhada. De um lado, gestores e o governo devem permitir que os profissionais envolvidos nas atividades, em qualquer instância do sistema, sejam capacitados e informados; devem adotar políticas que incentivem e possibilitem a formação e a capacitação dos profissionais, investindo e equipando os locais de trabalho ou as unidades de saúde. De outro, é necessário, também, que o profissional envolvido com as atividades de rede de frio e vacinação tenha clareza da importância da atuação qualificada e comprometida em relação aos registros dos dados.

\section{Referências}

BRASIL. Ministério da Saúde. Manual do sistema de informação do Programa Nacional de Imunizações. Brasília, DF, 2012.

BRASIL. Ministério da Saúde. Portaria n. 2.363, de 18 de outubro de 2012. Diário Oficial da União, Brasília, DF, 19 out. 2016.

BRASIL. Ministério da Saúde. Secretaria de Vigilância em Saúde. Manual do sistema de informação do Programa Nacional de Imunizações: SI-PNI. Brasília, DF, fev. 2014.

BRASIL. Ministério da Saúde. Secretaria de Vigilância em Saúde. Manual para registro de doses aplicadas no sistema de informação on-line de avaliação do programa de imunização: APIWEB. Brasília, DF, jul. 2013.

BRASIL. Ministério da Saúde. Secretaria de Vigilância em Saúde. Ofício circular n. 123/2013 GAB/SVS/MS. Enviado aos Secretários de Estaduais de Saúde, estabelece como prazo final, para implantação do SIPNI aos municípios e estados que aderiram à Portaria n. 2.363, o dia 31 de dezembro de 2013. Brasília, DF, 2013.

BRASIL. Ministério da Saúde. Secretaria de Vigilância em Saúde. Manual para registro de doses aplicadas no sistema de informação on-line de avaliação do programa de imunização: APIWEB. Brasília, DF, fev. 2014.

BRASIL. Ministério da Saúde. Secretaria de Vigilância em Saúde. Programa Nacional de Imunizações: 30 anos. Brasília, DF, 2003.

BRASIL. Ministério da Saúde. Secretaria de Vigilância em Saúde. Departamento de Vigilância das Doenças Transmissíveis. Curso de atualização para trabalhador da sala de vacinação: manual do aluno. 3. ed. rev. e ampl. Brasília, DF, 2013.

BRASIL. Ministério da Saúde. Secretaria de Vigilância em Saúde. Departamento de Vigilância Epidemiológica. Manual do usuário do SI-EAPV. Brasília, DF: DATASUS, 2003.

BRASIL. Ministério da Saúde. Secretaria de Vigilância em Saúde. Departamento de Vigilância Epidemiológica. SI-AIU Sistema de apuração de imunobiológicos utilizados: manual do usuário. Versão preliminar. Brasília, DF: DATASUS, 2004. Disponível em: <http://pni.datasus.gov.br/ Download/Aiu/Manual_AlU.pdf>. Acesso em: 10 nov. 2015. 
FUNDAÇÃO NACIONAL DE SAÚDE (Brasil). Manual de procedimentos para vacinação. Brasília, DF, 1993.

FUNDAÇÃO NACIONAL DE SAÚDE (Brasil). Manual do usuário SI-PNI/API: avaliação do Programa de Imunizações. Brasília, DF, 2001.

\section{Sites}

http://pni.datasus.gov.br/inf_estatistica_cobertura.asp

www.datasus.saude.gov.br/index

http://pni.datasus.gov.br

http://sipni.datasus.gov.br 
II A gestão da rede de frio de imunobiológicos e seu processo de trabalho

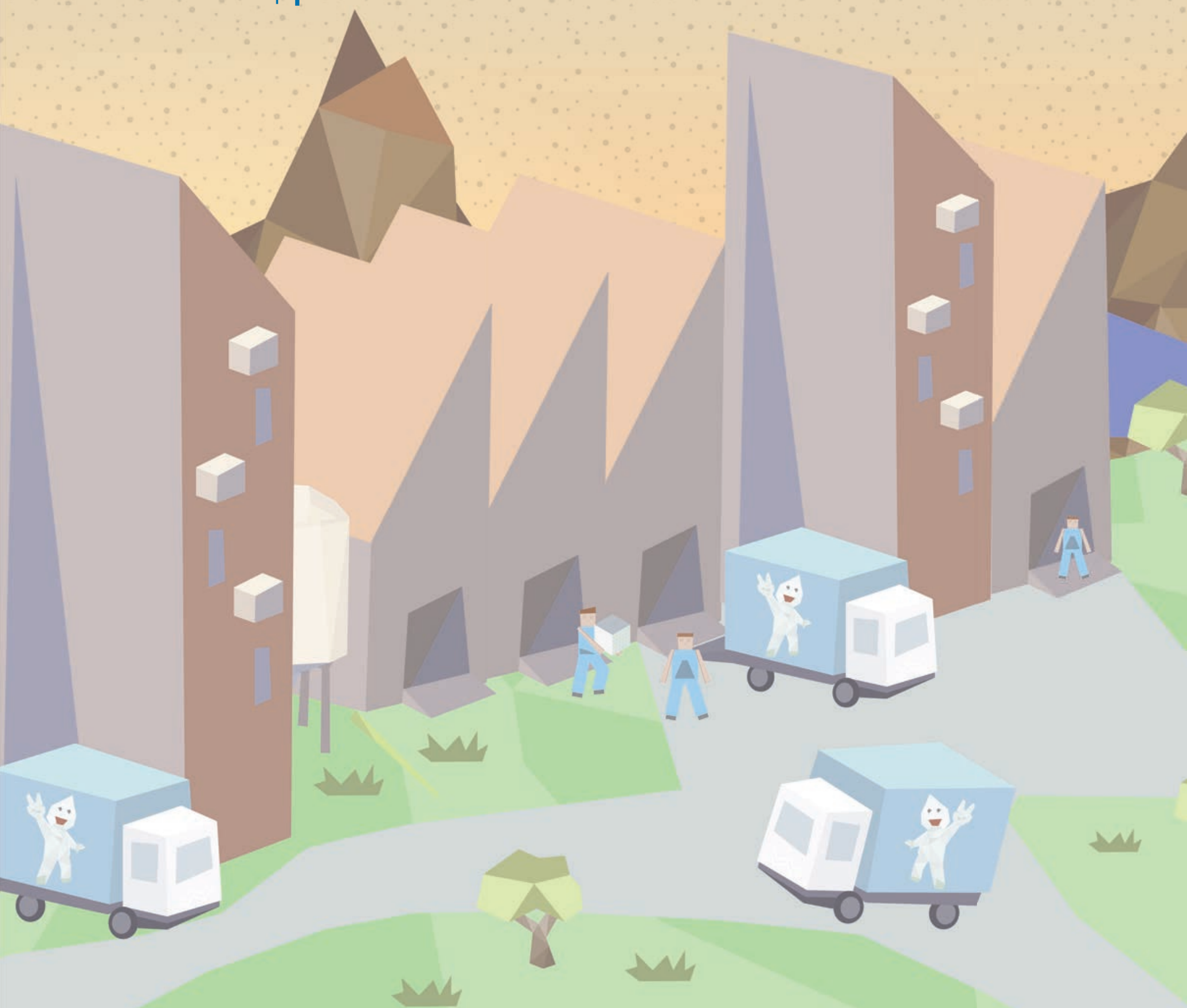





\section{A rede de frio}

\section{e a importância da temperatura dos imunobiológicos}

Alexandre Moreno Azevedo, Clayton Bernardo da Costa, Luis Cláudio Bernardo Colacio, Pedro Luiz da Silva Moura e Sergio Ricardo de Oliveira

O funcionamento correto da rede de frio (RF), em todas as etapas, é essencial para que os imunobiológicos e produtos termolábeis preservem suas características iniciais e princípios ativos até serem administrados - condição indispensável para garantir imunidade a todos que os recebam.

Para assegurar a potência das vacinas, é necessária atenção cuidadosa nas práticas de produção, conservação, armazenamento e distribuição dos imunobiológicos, em qualquer nível ou instância no país. Essas ações e cuidados incluem o armazenamento e transporte das vacinas das câmaras frias, do nível nacional até o usuário final, no estabelecimento de saúde, incluindo os locais de atividades extramuros e as campanhas de vacinação.

Ao percorrermos as instâncias da rede de frio, percebemos que a base que sustenta todo o processo é a manutenção da temperatura, dentro de parâmetros preconizados, condição essencial para se preservar a eficácia dos produtos imunobiológicos.

Portanto, não podemos pensar em conservação de vacinas sem considerar os conhecimentos da termologia. Devemos, também, conhecer princípios básicos de refrigeração, transmissão de calor por condução, por convecção e por radiação. Esses princípios fornecem subsídios para se trabalhar com segurança no gerenciamento da rede de frio, em qualquer instância.

Este capítulo aborda os principais aspectos relacionados à manutenção da temperatura dos imunobiológicos, destacando os princípios, as bases 


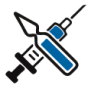

O conhecimento da estabilidade de uma vacina é importante para todos os profissionais que atuam nessa área, principalmente no que se refere à perda de sua estabilidade e suas características, ao ser submetida a temperaturas fora da faixa de $+2^{\circ} \mathrm{C}$ a $+8^{\circ} \mathrm{C}$. Esse conhecimento pode auxiliar os gestores e a equipe no planejamento e na operacionalização das atividades, garantindo segurança e efetividade das vacinas utilizadas.
Os átomos são compostos, ainda, por partículas menores, como prótons, nêutrons, elétrons etc. e as recomendações fundamentais da termologia, de modo a contribuir no entendimento sobre os processos físicos envolvidos na conservação dos imunobiológicos.

A ênfase sobre a gestão das vacinas para protegê-las do calor e do frio vem aumentando a cada dia, com a incorporação de novos instrumentos e equipamentos. Certamente, muitos outros estão por vir. Por isso, não é nossa pretensão esgotar o assunto, mas fornecer subsídios para a manipulação segura dos imunobiológicos e a gestão eficiente da rede de frio.

\section{Fundamentos da termologia}

A exposição das vacinas a variações de temperatura, desde calor até temperaturas mais baixas que o estabelecido (ou congelamento), pode acarretar problemas com a termoestabilidade destas. Isso pode interferir tanto em sua qualidade e eficácia, impedindo que o sistema imunológico da pessoa vacinada produza anticorpos e gere imunidade, como também na segurança do paciente, já que podem ocorrer reações locais após administração de uma vacina incorretamente armazenada, como já destacamos nos capítulos anteriores.

Para melhor entendermos os princípios que se aplicam à temperatura dos imunobiológicos e sua estabilidade, vamos analisar algumas questões relativas à termologia, iniciando com as definições de calor e frio.

\section{Calor e temperatura}

Olhando à sua volta, você pode notar que há uma grande quantidade de objetos parados ou em movimento, em relação ao solo. Escolha um, especificamente, que esteja parado e o observe por alguns segundos. O que se percebe é que ele permanece imóvel. No entanto, isso é apenas aparente!

Os objetos, de uma forma geral, são compostos por pequenas porções de matérias que chamamos de átomos. Os átomos, por sua vez, se juntam e formam moléculas que, de acordo com sua organização e a energia presente, podem constituir estruturas sólidas.

O que se sabe é que a molécula, independentemente da sua complexidade, possui alguma energia que a mantém em constante agitação (movimentação). É esse movimento interno da estrutura molecular que constituiu a base de estudos da física sobre termologia. 
Nossa vida está diretamente ligada a uma forma de energia que agita as moléculas: a energia térmica, ou calor. Essa forma de energia está relacionada às variações de temperatura, à mudança de estados físicos das substâncias e da estrutura dos corpos. Dada a sua importância, começaremos conhecendo os conceitos fundamentais que servirão de base para melhor compreendermos os fenômenos que estão relacionados a esse tipo de energia. Tais conhecimentos nos permitirão entender melhor a importância da temperatura na rede de frio.

O primeiro conceito importante para compreender o calor é o de energia, algo constante na natureza, que pode se apresentar de diferentes formas e se transferir de um corpo para outro. No caso do calor, por exemplo, isso implica a existência de uma fonte térmica. Trata-se de um dispositivo natural ou artificial que, por meio da utilização da queima de um combustível, ou mesmo de outras formas de energia, como a eletricidade, produz uma quantidade esgotável de energia térmica.

\section{Faça um teste!}

Coloque água em uma panela pequena e leve-a à chama do fogão. Com o passar do tempo, observe que a água começa a formar bolhas, e, em seguida, tem início o processo de fervura. Note que a água se encontra em processo de agitação constante. Esse efeito está relacionado com o ganho de calor (energia) fornecido pela chama do fogo (fonte térmica, nesse caso).

Com essas informações, podemos, então, construir um conceito básico de calor:

Calor é uma forma de energia em trânsito, que passa sempre do corpo mais quente para o corpo menos quente (HEWITT, 2011).

Essa transferência de energia aumenta o grau de agitação das moléculas do corpo que recebeu calor. Observa-se, também, que, enquanto a fonte térmica permanece em contato com o corpo, transferindo calor a ele, a temperatura deste aumenta, transmitindo ao corpo maior grau de agitação das moléculas. Dessa forma, podemos concluir que, quanto maior a agitação de um corpo, maior sua energia térmica.
Alguns exemplos de diferentes formas de energia são: energia luminosa, que faz um corpo emitir luz; energia cinética, relacionada ao movimento dos corpos; energia elétrica, que se converte em energia luminosa, quando acendemos uma lâmpada em casa, por exemplo, etc. 


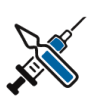

Atenção!

Cuidado para não tocar a panela que abriga o recipiente em banho-maria. E, claro, não permaneça com a mão na água, quando ela começar a causar sensação de desconforto térmico.
Observe o seguinte...

Ao retirarmos água da geladeira e, imediatamente, a colocarmos em um recipiente em banho-maria, aquecendo em fogo brando, se colocarmos a mão na água, verificaremos que haverá alterações de temperatura. Você poderá ter as seguintes sensações:

Muito fria

Fria

Morna

Quente - Atenção, não ultrapassar esta fase!

Muito quente - Cuidado! Não recomendamos manter a mão na água nesta fase!

Ao se transferir calor para um corpo, percebe-se, na verdade, um aumento da quantidade de energia nesse corpo, composto basicamente por pequenas partículas atômicas que começam a se agitar em virtude do ganho de energia cinética (movimento). Assim, podemos definir outro conceito básico, isto é, o de temperatura:

Temperatura é a grandeza física que mede o grau de agitação das moléculas (HEWITT, 2011).

Agora que já sabemos que calor e temperatura não são a mesma coisa, é fundamental diferenciá-los da sensação térmica, que é a capacidade que temos de observar se um corpo está quente ou frio. Essa capacidade, porém, não pode servir de parâmetro, pois o que para uns seria quente, para outros pode ser frio.

Se considerarmos, por exemplo, a temperatura da cidade do Rio de Janeiro, que, com frequência, atinge mais de $35^{\circ} \mathrm{C}$, veremos que a temperatura é extremamente quente e desagradável para povos que vivem em regiões mais frias do planeta e amena e tolerável para os que vivem em regiões tropicais.

Outra situação que demonstra bem esse fenômeno é quando, em uma sala com ar-condicionado ligado, algumas pessoas estão confortáveis com a temperatura enquanto outras sentem muito frio. A sensação térmica depende de quem a está sentindo. No entanto, a temperatura da sala é a mesma para todos, por exemplo, $25^{\circ} \mathrm{C}$.

Vimos, nos dois exemplos, que sempre haverá certa subjetividade nesse tipo de análise. 
A forma de medir a temperatura de um lugar ou de um corpo é por meio de termômetros. Quando calibrados, informam com precisão as temperaturas reais dos corpos, por intermédio de escalas termométricas conhecidas. Por isso, é o principal instrumento para medição da temperatura. Para efetuarmos essa verificação, contudo, temos que considerar um princípio fundamental denominado lei zero da termodinâmica.

A lei zero da termodinâmica estabelece que, se dois corpos estiverem em equilíbrio com um terceiro, eles estarão em equilíbrio entre si.

Em outras palavras, a lei da termodinâmica está relacionada com um fundamento básico físico, que é o do equilíbrio térmico. Isso significa que, quando dois ou mais corpos, em temperaturas inicialmente diferentes, são colocados em contato térmico, irão trocar calor até que, depois de certo tempo, tenham a mesma temperatura.

É possível observar esse efeito quando retiramos um frasco de imunobiológico da geladeira. Após algum tempo fora do refrigerador, observamos a formação de gotículas de água na superfície externa do frasco. Esse efeito é provocado pela troca de calor entre o ar externo e o frasco, que possui temperatura menor do que a do ambiente. Nessa situação, o ar sofre redução de temperatura, condensando-se sobre a superfície do frasco, o qual, ao mesmo tempo, tem a sua temperatura elevada, comprometendo sua utilização. Esse princípio é o mesmo que nos possibilita compreender como uma vacina, em contato com materiais congelados ou em temperatura fora dos padrões, pode vir a congelar ou perder calor e diminuir sua temperatura.

\section{Medição de temperatura: termômetros}

Para medir a temperatura dos corpos, o termômetro é o instrumento mais seguro e preciso. Em geral, o fundamento do equilíbrio térmico é usado para medir a temperatura dos corpos por meio do termômetro.

Existem vários tipos de termômetros, que possuem características distintas quanto à funcionalidade e à precisão. Basicamente, em relação a sua constituição, eles são do tipo analógico (que utiliza dispositivos mecânicos) ou digital (que utiliza dispositivos elétricos) e devem ser capazes de verificar com precisão a temperatura dos corpos.

Os termômetros analógicos são dispositivos que utilizam diversos tipos de produtos para monitorar as temperaturas. Os produtos utilizados nesse tipo de termômetro podem ser mercúrio (metal líquido com alto coeficiente de dilatação térmica), álcool (que tem baixo custo e menor

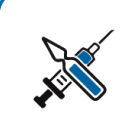

Todo e qualquer corpo, independente da sua temperatura, é uma fonte térmica, pois transmite energia na forma de calor para corpos com temperaturas abaixo da sua.

Condensando refere-se à condensação, que significa a passagem do estado gasoso para o líquido. No exemplo, a umidade que está no ar e as gotículas que se formam em volta do frasco.

A redução da temperatura do ar pela troca de calor com um frasco de imunobiológico que estava gelado não é perceptível, pois o frasco e o calor trocado são muito pequenos em relação ao volume de ar em uma sala.

A rede de frio utiliza, com frequência, um termômetro analógico, conhecido como capelinha ou "de máxima e mínima". 
risco que o mercúrio), gás (medido por pressão), ou mesmo dispositivos mecânicos, como lâminas bimetálicas.

Figura 1 - Termômetro analógico de mercúrio do tipo capelinha

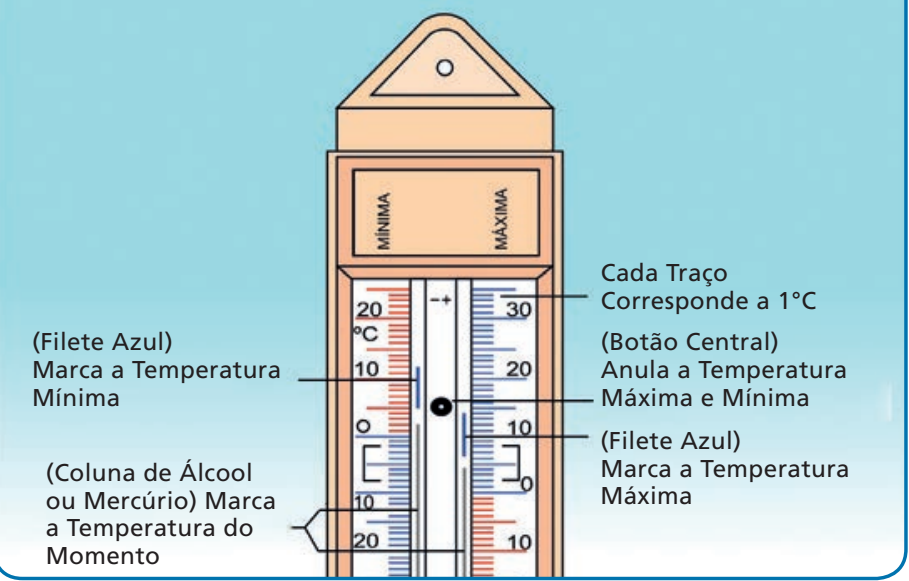

Fonte: Elaboração de Edson Moura (2001).

Outros termômetros, como os digitais, são baseados em propriedades elétricas e eletrônicas de alguns materiais. A medida da temperatura é feita a partir de variações nas características elétricas do sensor de temperatura. O dispositivo utilizado para indicar variação ou medir a temperatura, nesses casos, é o termopar, ou simplesmente par termoelétrico, que responde com uma corrente elétrica diferenciada, de acordo com a temperatura do corpo.

A diferença básica entre os termômetros digitais e analógicos está na precisão da medida que se quer obter. Quando se pretende acondicionar um produto em uma temperatura que não pode sofrer grandes variações (de $1{ }^{\circ} \mathrm{C}$, por exemplo), como no caso dos imunobiológicos, o ideal é utilizar termômetros digitais, para garantir que a temperatura do ambiente seja uniforme. O termômetro analógico é indicado para verificar a temperatura de determinado ambiente ou local de acondicionamento, quando pequenas variações de temperatura não forem relevantes. Nesse caso, deve-se alocar

Foto 1 - Termômetro digital

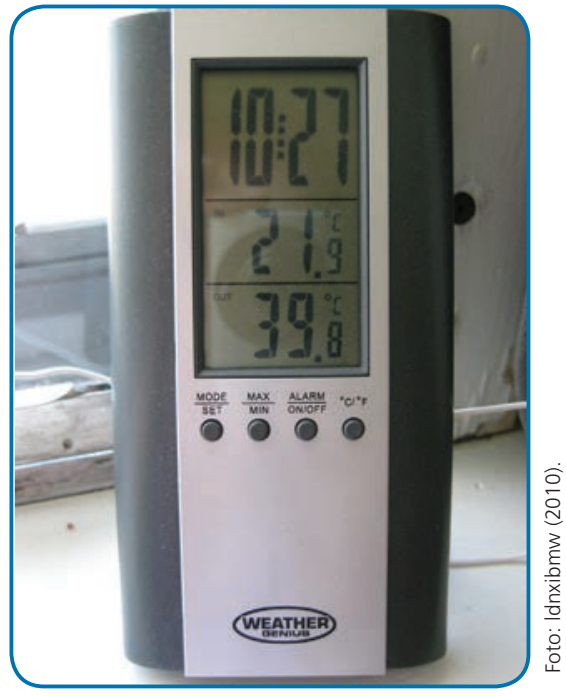

Fonte: Flickr.com 
o termômetro nas regiões consideradas mais críticas (de maior e menor temperatura), aguardar o equilíbrio térmico entre o ambiente e o instrumento e manter a observação constante do ambiente, de forma a garantir sua temperatura.

Há, ainda, outro tipo de termômetro, conhecido como de radiação. Utilizado para medir a distância, ou seja, sem contato com o objeto; seu princípio se baseia em captar a radiação eletromagnética da fonte de calor.

Foto 2 - Termômetro de radiação

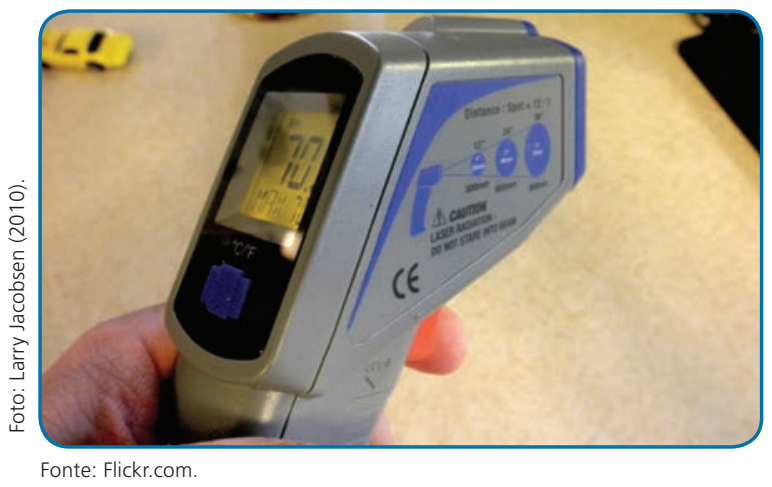

Agora que conhecemos mais sobre temperatura e como devemos medi-la, a pergunta é: por que há mais de uma escala de medida da temperatura? Para respondê-la, apresentaremos um pouco da história das escalas termométricas.

\section{Escalas termométricas}

Desde que o homem se preocupou, realmente, em medir temperaturas, percebeu que, para isso, deveria criar escalas numéricas e instrumentos menos subjetivos do que seus próprios sentidos. As primeiras tentativas remontam ao início da Era Cristã, quando alguns médicos (motivados, talvez, pela necessidade de quantificar a febre de seus pacientes) procuraram representar numericamente as diversas gradações entre frio e quente. No entanto, foi somente a partir do século XVI que começaram a surgir aparelhos e escalas com um mínimo de precisão e confiabilidade. Pelo que se sabe, o primeiro desses aparelhos foi construído por Galileu (1564-1642), em 1592. O próprio Newton (1643-1727) também criou uma escala para medir temperaturas (MÁXIMO; ALVARENGA, 2006).

Para se ter uma ideia da "febre" que acometeu os cientistas, mesmo sem estes terem a noção do que ocorria com os corpos quando mudavam de temperatura, no fim do século XVIII já havia mais de 60 escalas termométricas registradas! De todas as existentes, apenas duas chegaram até os dias de hoje: a escala Celsius, utilizada na maioria dos países, e a Fahrenheit, ainda utilizada em países de língua inglesa (MÁXIMO; ALVARENGA, 2006). 
Se você quiser se aprofundar mais sobre o assunto ou obter informações sobre os cientistas responsáveis pelas escalas, visite as páginas: http://www.if.ufrgs. br/ dschulz/web/escalas_term. htm e http://www.if.ufrgs. $\mathrm{br} / \sim \mathrm{dschulz/web/escalas}$ term_a.htm
É importante conhecer a lógica da conversão entre as escalas. Caso necessite realizar essa operação, consulte a internet, onde é possível encontrar sítios que fazem a conversão de escalas Celsius, Fahrenheit e Kelvin. Um deles: http:// www.convertworld.com/pt/ temperatura/Fahrenheit.html
Quando realizamos uma medida, ela deve obedecer a algum referencial, critério ou padrão, ou então o valor obtido não pode ser considerado válido. Para isso, utilizamos, além das escalas Celsius e Fahrenheit, outra escala considerada absoluta e que não possui valores negativos, a escala Kelvin.

A escala Kelvin, por ser absoluta, tem como valor mínimo o 0 (zero), que corresponde ao repouso (falta de movimentação) total das moléculas de um corpo. Além disso, a Kelvin também é utilizada em estudos científicos e em laboratórios para, principalmente, aferir e calibrar os termômetros em outras escalas.

Contudo, há uma relação direta entre as escalas, e qualquer temperatura registrada em uma delas pode ser calculada para as demais. Na Figura 2, podemos observar a relação entre as escalas termométricas.

Figura 2 - Relação entre as escalas termométricas

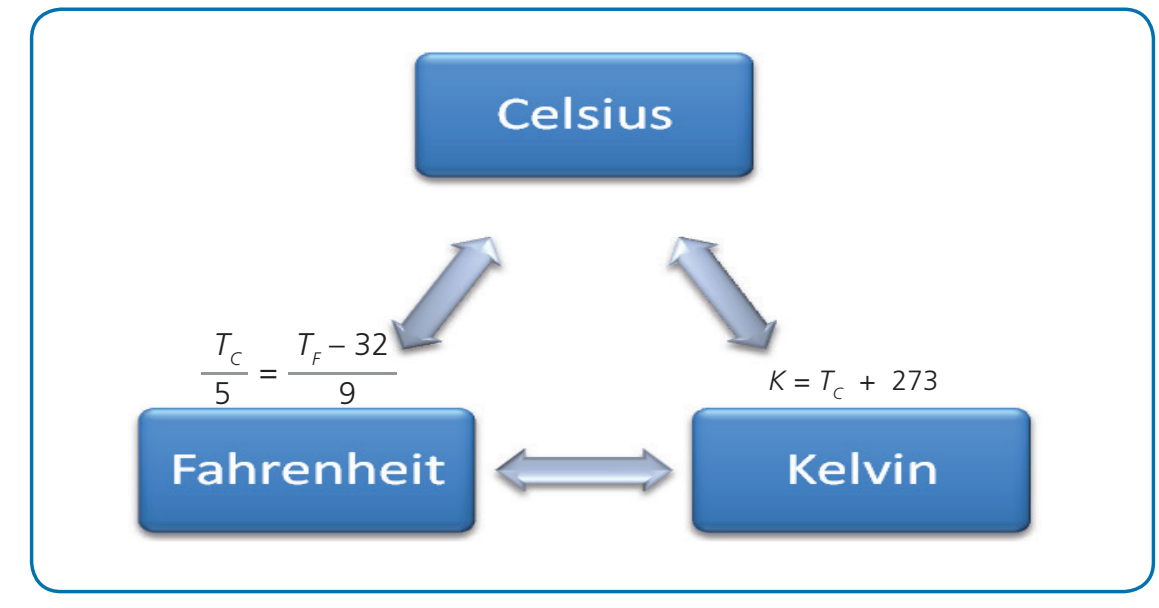

$T_{C}$ : Temperatura na escala Celsius; $T_{F}$ : temperatura na escala Fahrenheit; $K$ : temperatura na escala Kelvin.

Fonte: Elaboração do autor.

Eis um exemplo. Digamos que determinado produto da rede de frio seja importado de um país de língua inglesa e apresente, no rótulo, a indicação para ser acondicionado em temperatura de $-4^{\circ} \mathrm{F}$ (graus Fahrenheit). Qual seria sua correspondente aqui no Brasil?

A solução é simples; basta utilizar a relação que há entre as escalas Celsius e Fahrenheit, substituindo o valor $-4^{\circ} \mathrm{F}$ no lugar de $\mathrm{T}_{\mathrm{F}}$.

$$
\frac{T_{C}}{5}=\frac{-4-32}{9}
$$


Fazendo as contas, você conclui que o produto deve ser acondicionado a $-20^{\circ} \mathrm{C}$ (graus Celsius).

\section{Trocas de calor}

Vimos, há pouco, que corpos em contato tendem a trocar calor até atingirem o equilíbrio, ou seja, a mesma temperatura. No entanto, alguns materiais podem ganhar ou perder calor mais rapidamente que outros. Em outras palavras, diferentes materiais absorvem diferentes quantidades de calor, mesmo tendo a mesma massa e independentemente do seu tamanho.

Por exemplo, imagine que é colocada a mesma quantidade de água, a temperatura ambiente, em duas canecas, uma de vidro e outra de alumínio. Espera-se um pouco para que as duas atinjam a mesma temperatura e, depois disso, as canecas são colocadas no congelador de uma geladeira. Minutos depois, retiram-se as duas canecas do congelador (de modo que as duas porções de água não estejam totalmente congeladas). O que se observa é que há uma pequena camada de gelo na parede da caneca de alumínio, enquanto na parede de vidro esse efeito não é percebido.

Isso acontece porque o vidro troca calor mais rápido que o alumínio, e o processo de congelamento passa a ser de dentro para fora, ou seja, o congelamento no vidro é de dentro para fora. No entanto, na caneca de alumínio o congelamento da água se dá de fora para dentro, por isso congela a parte em contato com a caneca, antes da parte interna.

Esse experimento é bastante simples e permite visualizar a diferença das trocas de calor de diferentes materiais (vidro e alumínio). O que explica essa diferença é a capacidade que cada material tem de ganhar ou perder calor com rapidez. A essa relação denominamos de calor específico. Quanto menor o calor específico do material, mais rápida é a troca de calor entre ele e o meio ou outro corpo.

O vidro, material sólido utilizado no envase dos imunobiológicos, possui um calor específico muito baixo e, por isso, troca calor com muita facilidade. Prova disso é a mudança rápida de sensação térmica quando seguramos um frasco de vidro que está em baixa temperatura: o vidro esquenta pela troca de calor com a mão. Por isso, é importante que, nas atividades de vacinação extramuro ou de campanhas, os profissionais não permaneçam com o frasco nas mãos durante todo o processo de vacinação, para que o produto imunobiológico não sofra alteração de temperatura em contato permanente com o calor das mãos. O vacinador deve colocar o frasco no recipiente, isopor ou caixa térmica, a cada pessoa vacinada. 
O isopor é uma espuma de poliestireno expandido, ou seja, um polímero que contém inúmeras e minúsculas bolhas de ar. O ar é um excelente isolante térmico, e essas minúsculas bolsinhas de ar são as responsáveis por absorver o calor entre as faces do isopor. O verdadeiro isolante térmico do isopor é o ar retido nele.
A temperatura do gelo empregado na conservação das vacinas é de grande importância. Caso se utilize gelo em temperaturas muito baixas $\left(-20^{\circ} \mathrm{C}\right.$, por exemplo) e em grande quantidade ("ilhando" as vacinas), corre-se o risco de, em determinado momento, a temperatura das vacinas ficar próxima à temperatura do gelo. Em consequência, as vacinas ficarão congeladas, o que inativará alguns tipos específicos, como a DTP (FUNDAÇÃO NACIONAL DE SAÚDE, 2001).
Se fizermos uma analogia com uma lata de bebida, iremos reparar que, se retirarmos a lata do sistema de refrigeração, ela rapidamente trocará calor, absorvendo energia do meio ambiente. Para reduzir esse efeito, as latas podem ser colocadas em dispositivos individuais de isopor, que funcionam como isolante térmico. Esse tipo de material, que impede a troca de calor com o meio, ou mesmo com outros corpos, é utilizado na produção de calorímetros, que nada mais são do que recipientes com alta capacidade térmica. A capacidade térmica de um corpo está relacionada à capacidade de receber ou ceder calor, quando o corpo sofre uma variação de temperatura.

O calor específico é a característica da substância (água, óleo, alumínio, vidro), não muda com a massa (por exemplo, o calor específico de um ou dois litros de água é o mesmo). E a capacidade térmica é a característica do corpo, isto é, muda com a massa (por exemplo, a massa de um litro de água é diferente da de dois litros de água).

Em nosso dia a dia, utilizamos vários recipientes que não deixam a temperatura do seu interior variar muito, ou seja, possuem grande capacidade térmica, como garrafa térmica, caixa de isopor, a água (banho-maria), recipiente para garrafas de cerveja etc. Esses objetos são denominados de calorímetros. Então, as caixas térmicas, os isopores usados nas atividades de imunização e de rede de frio são também denominados de calorímetros!

\section{Tipos de calor}

Uma das preocupações com os imunobiológicos é a conservação da sua temperatura durante o transporte. Como é possível que produtos sensíveis como os imunobiológicos não sofram pequenas variações de temperatura em longos períodos? Como fazer para que não percam ou ganhem calor, e também não congelem?

A caixa de isopor (calorímetro), utilizada no transporte, é fundamental nesse processo, pois evita bastante a troca de calor do meio interno com o externo. Entretanto, há outro fator que também impede o aumento de temperatura no interior da caixa. Esse fator está ligado à mudança de estado físico dos produtos que se encontram no interior da caixa (os próprios imunobiológicos ou mesmo o líquido das bobinas). 
Para entender melhor o que acontece, observe que, durante a preparação das caixas de imunobiológicos, as bobinas a serem utilizadas no interior da caixa devem estar "climatizadas" com o meio externo, ou seja, devem estar no processo de mudança de estado físico (sólido para líquido) com o propósito de evitar a diminuição da temperatura dos imunobiológicos. Dessa forma, quando as bobinas forem acondicionadas no interior da caixa, devem estar frias o suficiente para criar uma "atmosfera" que mantenha os imunobiológicos em temperatura constante, mas não frias demais de modo que possam provocar o congelamento destes. Esse efeito pode ocorrer por conta da troca de calor entre as bobinas e os imunobiológicos, em razão da diferença de capacidade térmica entre os objetos no interior da caixa.

Isso acontece porque, no momento de mudança de estado, o corpo não sofre variação de temperatura; logo, a temperatura de todo o conjunto permanece constante, e a quantidade de calor absorvido ou cedido pelo corpo é apenas para a mudança de estado. Esse tipo de calor, que se refere à mudança de estado, é chamado de calor latente.

Há, também, outra forma de ganho ou perda de calor, que é aquela perceptível, pois ocorre variação de temperatura. A esse tipo damos o nome de calor sensível. É importante perceber que este só ocorre enquanto o material se encontrar em um único tipo de estado da matéria.

Para que se compreenda melhor os diversos tipos de calor, temos de relembrar alguns conceitos básicos sobre os diferentes estados da matéria. Você lembra o nome dos estados da matéria e de seus processos de transformação?

No diagrama a seguir, representamos as diferentes mudanças de estados da matéria e seus respectivos nomes. Vale ressaltar que a maioria das substâncias passa pelos três estados da matéria, o que caracteriza dois calores latentes. Na sequência, podemos observar a descrição de cada uma das mudanças de fase. 
Diagrama 1 - Estados da matéria

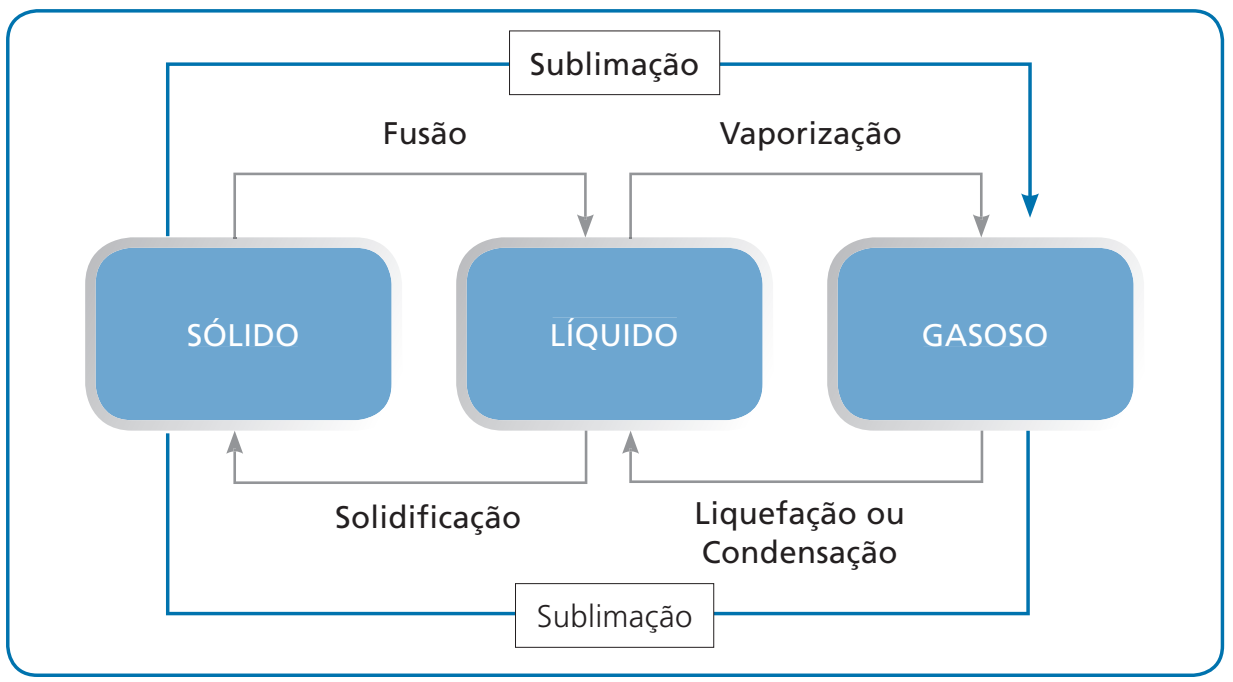

Fonte: Adaptado de João Neto ([20--]).

\section{Notas}

- Fusão: passagem do estado sólido para o estado líquido (por exemplo, gelo virando água, bobina de conteúdo líquido quando não mantida sob refrigeração permanente).

- Vaporização: passagem do estado líquido para o estado gasoso. Pode ocorrer de três maneiras:

- Calefação: passagem do estado líquido para o gasoso, de modo muito rápido (por exemplo, gotas d'água derramadas numa chapa metálica aquecida).

- Ebulição: passagem forçada do estado líquido para o estado gasoso (por exemplo, água fervendo no fogo).

- Evaporação: passagem do estado líquido para o gasoso, que envolve apenas a superfície do líquido (por exemplo, gota d'água sobre a pele secando sozinha, poça de água evaporando).

- Liquefação ou condensação: passagem do estado gasoso para o estado líquido, por contato do vapor com uma superfície fria (por exemplo, os espelhos do banheiro embaçados depois de um banho quente, nuvem que se transforma em chuva).

- Solidificação: passagem do estado líquido para o estado sólido (por exemplo, água congelando).

- Sublimação: passagem do estado sólido para o gasoso, ou o processo inverso, sem passar pelo estado líquido (por exemplo, a sublimação do gás carbônico sólido, conhecido como gelo seco, usado algumas vezes pela Central Nacional de Armazenamento no transporte de grandes volumes de imunobiológicos, e a temperatura ambiente). 
Podemos perceber, pelos exemplos descritos, os diversos estados da matéria, seja nas atividades domésticas ou na própria atividade da rede de frio. O conhecimento acerca dos estados da matéria das substâncias e de suas propriedades é fundamental para se entender o processo físico do sistema de refrigeração, sua importância e utilização em todo o processo da rede de frio.

\section{Propagação de calor}

Agora que já sabemos que o calor é uma forma de energia em trânsito e que os processos de trocas de calor dependem da capacidade térmica dos produtos, é necessário saber, então, a forma como se transmite.

\section{Para refletir}

Você tem alguma ideia de como o calor pode ser transmitido entre os corpos?

O calor pode se propagar por meio de condução, convecção e irradiação. Vejamos cada uma dessas formas a seguir.

\section{Condução térmica}

É o processo de transporte de energia sem transporte de matéria que ocorre, geralmente, em materiais sólidos. Nesse processo, a energia é transferida de partícula a partícula, sem que nenhuma delas seja deslocada. Um exemplo de condução térmica é o calor que sentimos ao utilizar uma colher metálica para cozinhar um alimento. O calor que a colher recebe, por estar em contato com o alimento quente, é conduzido pelas partículas que a formam até a ponta do cabo, onde estamos segurando, e, por isso, a sentimos esquentar.

De todos os tipos de substâncias, os metais são os materiais que melhor conduzem o calor, razão pela qual são chamados de condutores térmicos. Os materiais não condutores de calor são denominados de isolantes térmicos, como o isopor usado na conservação dos imunobiológicos, o ar, a madeira, o plástico e o vidro. Por isso, utensílios de cozinha que vão ao fogo, como panelas e espetos de churrasco, possuem uma base metálica, para aquecer mais rápido, e, nos cabos, materiais isolantes, para não queimar a mão de quem os segura.
Mais detalhes sobre o sistema de refrigeração podem ser obtidos no Capítulo 7, "Refrigeração e equipamentos da rede de frio", deste livro. 
Os trabalhadores que atuam na rede de frio utilizam roupas confeccionadas com materiais que funcionam como isolantes térmicos. Mais detalhes sobre esses materiais são apresentados no Capítulo 14, "Noções gerais sobre biossegurança e a questão do incêndio", deste livro.

É por isso que no Polo Norte, por exemplo, os esquimós constroem suas casas (iglus) com gelo, material que dificulta a condução térmica.

As caixas de isopor utilizadas na conservação dos imunobiológicos devem ter sua densidade cuidadosamente verificada, para que cumpram a função de manutenção da temperatura de forma eficaz.

Por isso, é importantíssimo que o gestor/trabalhador, no momento da compra desse tipo de insumo, atente para as especificações que garantam as necessidades de manutenção da temperatura requerida pelas vacinas, em todas as atividades de imunização e na rede de frio.

As roupas de lã ou de materiais similares também são isolantes térmicos. Elas retêm o calor que o corpo emite, por causa do ar que fica retido entre suas fibras. Esse ar é que dificulta a condução do calor. O mesmo ocorre com os pelos dos animais e a serragem, que são bons isolantes porque retêm o calor, ou seja, impedem a troca de calor interno com o meio externo.

Outro material que dificulta a condução térmica é o gelo. Um exemplo simples é verificado no inverno: em localidades com frio intenso, os lagos congelam, mas apenas em sua parte superior, onde se forma uma camada isolante entre o frio do ar e a água do lago; abaixo do gelo, a vida marinha continua!

\section{Convecção térmica}

É o processo de transferência de calor através do transporte de matéria, por causa de uma diferença de densidade e da ação da gravidade. Acontece, apenas, em fluidos, isto é, em líquidos ou em gases.

Para entender esse processo, observe o aquecimento de um líquido, a água, por exemplo. Assim, quando o recipiente é aquecido, as porções inferiores recebem maior quantidade de calor e aquecem primeiro. Como elas se tornam menos densas, sobem; enquanto isso, as porções superiores descem, por serem mais frias e densas, e também por ação da gravidade. Esse movimento chama-se corrente de convecção.
Figura 3 - Corrente de convecção

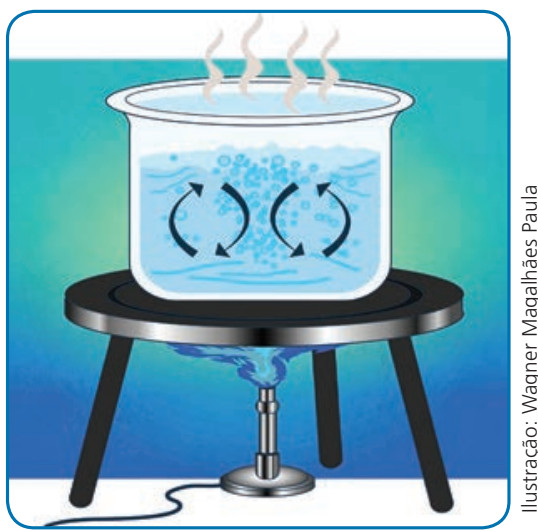

$\mathrm{Na}$ figura, as setas para cima representam o fluxo de água quente que sobe, enquanto as setas para baixo representam o de água fria, que desce para ser aquecido. Esse mesmo fluxo é percebido no interior das caixas de acondicionamento dos imunobiológicos, que, ao trocar calor, mantêm o ar mais quente na parte superior (abaixo da tampa). Uma das formas de evitar essas trocas de calor é manter as bobinas na parte inferior das caixas, para conservar o ar frio sempre no fundo da caixa. 
Outro exemplo de convecção e movimento cíclico entre o ar quente, menos denso, e o ar frio, mais denso, é o funcionamento do ar-condicionado. O aparelho deve ser colocado na parte superior da habitação para possibilitar que o ar frio, mais denso, que sai do aparelho desça e desloque o ar quente, menos denso, que deve subir. Isso possibilita a criação de correntes de convecção e o resfriamento do ambiente.

O mesmo acontece na geladeira, em que a refrigeração dos alimentos é feita através da convecção. $\mathrm{O}$ ar em contato com os alimentos se aquece e sobe até o congelador, onde é resfriado, e volta para os alimentos. Por isso, o congelador fica na parte superior da geladeira.

Com esses exemplos, podemos entender, também, porque não se recomendam, em imunização, refrigeradores com o congelador separado: neles, o "ar resfriado" não descerá para o local (parte separada) onde se encontram as vacinas.

Vejamos, agora, o processo de convecção térmica nos gases, tendo, como exemplo, uma praia. Durante o dia, o ar próximo da superfície do continente aquece mais rápido que o ar próximo à superfície do mar. Isso ocorre porque a água tem uma capacidade térmica maior que a areia. Então, o ar aquecido do continente fica mais leve e sobe, enquanto o ar mais frio do mar se desloca em direção ao continente, formando a brisa marinha.

Figura 4 - Formação da brisa marinha

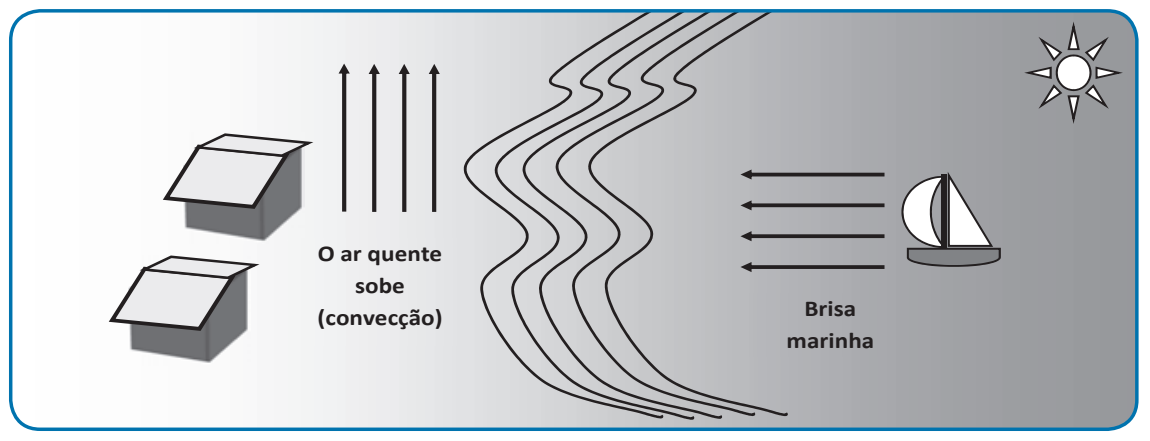

Fonte: Elaboração do autor.

Durante a noite, acontece o inverso: o ar próximo ao mar permanece aquecido por mais tempo do que o ar próximo ao continente, então o ar próximo ao mar sobe, e ocorre o deslocamento de ar do continente para o mar, dando origem à brisa terrestre. 
Figura 5 - Formação da brisa terrestre

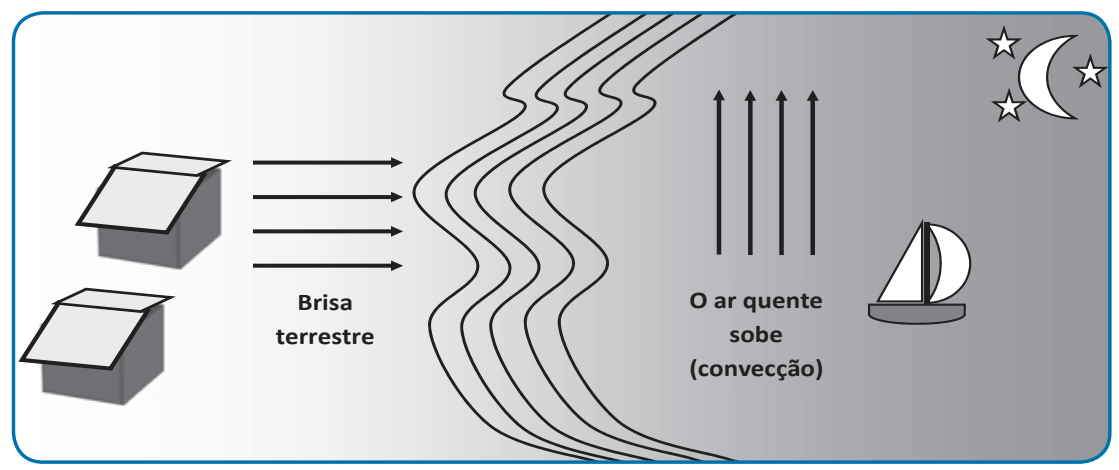

Fonte: Elaboração do autor

\section{Você sabia?}

- Quando um grupo de aves sobrevoa uma região, em círculos, está planando em uma corrente de convecção. O ar quente sobe em um fluxo de corrente sempre ascendente. Por exemplo: aves, como os urubus, percebem que uma corrente de ar aquecido ascendente (de baixo para cima) está ocorrendo em determinado ponto. As aves vão até esse ponto e aproveitam essa propriedade para flutuar, economizando energia. As correntes giram, por isso as aves voam em círculo. Esse mesmo princípio é aproveitado pelos praticantes de voo livre.

- As correntes de convecção são importantes para a dispersão de poluentes. Nas grandes cidades, a grande quantidade de poluentes suspensos no ar dificulta a dispersão; em dias quentes, ela é mais eficiente. Já no inverno, quando a superfície da Terra esfria muito, principalmente à noite, ocorre o fenômeno da inversão térmica. Isso porque as camadas de ar mais próximas da superfície da Terra ficam mais frias, e o Sol nem sempre consegue aquecer o solo para reverter esse processo, o que provoca interrupção das correntes de convecção e permanência dos poluentes junto ao solo, não se dispersando na atmosfera.

\section{Irradiação térmica}

Enquanto a condução e a convecção ocorrem em meios materiais, a irradiação pode acontecer tanto em meios materiais quanto no vácuo (ausência de matéria). A irradiação térmica é o processo de transferência de calor por meio de ondas magnéticas. Como exemplo, podemos citar o calor de uma fogueira, a luz do Sol etc.

As ondas são geradas pela agitação da matéria, que, por sua vez, é produzida pela quantidade de calor que contém; ou seja, as ondas dependem da temperatura do corpo. O Sol, cuja temperatura em sua super- 
fície é de aproximadamente 6.000K (temperatura na escala Kelvin), é o principal irradiador de calor para a Terra. A Terra recebe o calor do Sol diretamente no solo, que o reflete para a atmosfera e aquece nosso planeta às temperaturas que temos.

Assim como o Sol, as lâmpadas incandescentes também emitem calor luminoso (ondas eletromagnéticas). Dessa forma, podemos entender por que as caixas ou os equipamentos onde estão acondicionadas as vacinas não devem estar em locais em que incida a luz solar direta, ou mesmo sob luz/lâmpadas incandescentes.

De um modo geral, podemos afirmar que todos os corpos emitem uma energia radiante, uns mais e outros menos, em virtude de sua temperatura. A maioria, no entanto, emite calor obscuro (não acompanhado de luz), inclusive nós, seres humanos.

Agora, vamos comentar sobre algumas aplicações de formas de propagação de calor que, de algum modo, contribuem para estudos ou manutenção da temperatura dos corpos, em especial, o efeito estufa.

Uma estufa pode ser definida, dentre outras formas, como um ambiente fechado onde se colocam plantas que precisam de condições climáticas especiais. O teto é feito de vidro ou outro material similar. É transparente à radiação que chega do Sol e opaco às ondas de calor emitidas pela Terra. Desse modo, o interior da estufa se mantém com uma temperatura maior do que a do exterior.

Um automóvel exposto aos raios solares, com os vidros fechados, reproduz as condições de uma estufa. Caso situação semelhante ocorra com veículos de transporte de vacinas, os valores de temperatura indicados para manutenção da integridade dos imunobiológicos serão alterados, provocando inadequação do produto para uso e consequente descarte. Para evitar prejuízos desse porte, somente veículos climatizados são recomendados para o transporte de imunobiológicos.

No caminho percorrido pela termologia, conhecemos diversos aspectos que nos fizeram compreender o calor e o frio, como eles se propagam e as diversas formas de condução. Todas essas informações são importantes para vocês, profissional da saúde e trabalhadores da imunização e da rede de frio, visto que, com base nesses princípios e nas experiências aqui demonstradas, associadas à leitura dos próximos capítulos, será possível compreender os processos envolvidos na rede de frio e como eles estão convenientemente aplicados à conservação de imunobiológicos.

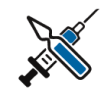

Convecção térmica também ocorre em uma estufa.

$\mathrm{Na}$ atmosfera terrestre também ocorre o efeito estufa. Em virtude do aumento considerável do número de veículos (automóveis, caminhões, ônibus), indústrias e fontes poluidoras em geral, os níveis de gás carbônico $\left(\mathrm{CO}_{2}\right)$, monóxido de carbono (CO), dióxido de enxofre $\left(\mathrm{SO}_{2}\right)$ e outros gases têm aumentado expressivamente, contribuindo para o aumento da temperatura do planeta. 


\section{Considerações finais}

Sabemos que a rede de frio tem, como base, a manutenção da temperatura dos imunobiológicos em todas as fases. Pela própria exigência dos órgãos reguladores, todos os produtores de imunobiológicos devem realizar diversos estudos de estabilidade, visando demonstrar que seus produtos mantêm suas características e a sua imunogenicidade quando expostos a condições adversas, por determinado período de tempo (AGÊNCIA NACIONAL DE VIGILÂNCIA SANITÁRIA, 2010).

Vimos que, além desse controle da produção, temos de estar atentos a quaisquer mudanças ou alteração de temperatura que possam influir na estabilidade dos produtos, tendo sido demonstrada, neste capítulo, a base para entendermos como ocorrem as perdas e transmissão de calor de uma matéria para outra, incluindo os princípios físicos envolvidos na termologia. Esses princípios precisam ser conhecidos e aplicados, obrigatoriamente, em todas as etapas da rede de frio, porque assim estaremos agindo em prol da qualidade das vacinas e, consequentemente, do controle, da eliminação ou erradicação das doenças imunopreveníveis no país.

Equipes bem treinadas e instrumentos de medição disponíveis são fundamentais, mas as condições em que os imunobiológicos são armazenados e transportados são determinantes para garantir a qualidade dos produtos e evitar prejuízos de consequências incalculáveis. Considerando a vasta dimensão territorial do nosso país, as áreas de difícil acesso e outras situações que os profissionais da saúde, em especial os da rede de frio, enfrentam para que os imunobiológicos, em todas as instâncias, sejam mantidos nas temperaturas ideais preconizadas, percebemos a importância das informações aqui apresentadas e os desafios impostos a esses profissionais na manutenção da temperatura dos produtos em todos os recantos do país.

\section{Referências}

AGÊNCIA NACIONAL DE VIGILÂNCIA SANITÁRIA (Brasil). Resolução da Diretoria Colegiada RDC n. 17, de 16 de abril de 2010. Dispõe sobre as boas práticas de fabricação de medicamentos. Diário Oficial da União, Brasília, DF, 19 abr. 2010. Seção 1, p. 94.

DOCA, R. H.; BISCUOLA, G. J.; VILLAS BOAS, N. Tópicos de física. São Paulo: Saraiva, 2003. v. 2. 
JOÃO NETO, Prof. Química: estados físicos e mudanças de estado. [S.I., 20--]. Disponível em: <http://www.profjoaoneto.com/quimicag/estadex.htm>. Acesso em: 18 set. 2016.

MÁXIMO, A.; AlVAGEngA, B. Física ensino médio. São Paulo: Scipione, 2006. v. 2.

PIRES, D. P. L.; AFONSO, J. C.; CHAVES, F. A. B. Do termoscópio ao termômetro digital: quatro séculos de termometria. Química Nova, São Paulo, v. 29, n. 6, p. 1393-1400, 2006. Disponível em: <http://www.scielo.br/pdf/qn/v29n6/40.pdf>. Acesso em: 3 ago. 2016.

RAMALHO JUNIOR, F.; FERRARO, N. G.; SOARES, P. A. T. Os fundamentos da física: $2^{\circ}$ ano. São Paulo: Moderna, 2006. 



\title{
7. Refrigeração e equipamentos da rede de frio
}

\author{
Alexandre Moreno Azevedo e Pedro Luiz da Silva Moura
}

Como vimos, os imunobiológicos têm sua potência e sua eficácia garantidas pela conservação em temperaturas ideais, preestabelecidas pelos órgãos competentes. Para a conservação desses produtos e de outros, o gelo é o elemento de escolha, sendo amplamente utilizado desde a Antiguidade. Em 1806, Frederick Tudor (1783-1864) iniciou o comércio de blocos de gelo retirados do rio Hudson, Nova York, vendendo-os a preços acessíveis à população, para serem utilizados na conservação de alimentos. Eles eram armazenados nas chamadas casas de gelo, que utilizavam a serragem como elemento térmico para a sua conservação.

O gelo era utilizado sem que se entendesse direito o porquê de ele ser capaz de conservar os alimentos. Foi o químico francês Louis Pasteur (1822-1895) quem demonstrou que alguns tipos de bactérias eram responsáveis pela deterioração dos alimentos, e que sua reprodução poderia ser impedida pela aplicação de baixa temperatura. Essa descoberta incentivou o desenvolvimento e a expansão da indústria de refrigeração, porque possibilitou a conservação dos alimentos durante um período de tempo maior. Com a descoberta de Louis Pasteur, o homem buscou processos que permitissem a obtenção artificial de gelo.

Foi a partir de 1834, nos Estados Unidos, que se desenvolveu o primeiro sistema mecânico (por ciclo de evaporação e condensação de fluidos) de fabricação de gelo artificial, patenteado por Jacob Perkins (1766-1894). Em 1859, o francês Ferdinand Carré (1824-1900) patenteou outro tipo de mecanismo para a fabricação do gelo artificial, baseado no princípio da absorção. Eram, portanto, dois processos diferentes.

O sistema mecânico por ciclo de evaporação e condensação de fluidos é apresentado mais adiante, neste capítulo. 
Atualmente, inúmeros equipamentos utilizados no nosso dia a dia se beneficiam desses princípios de fabricação de gelo artificial, mantendo os produtos de consumo doméstico sob refrigeração e/ou congelados. No nosso cotidiano, vemos diversos equipamentos, como refrigeradores/câmara refrigerada, freezers, câmara frigorífica e outros. No que se refere à rede de frio, equipamentos como câmaras refrigeradas, freezers ou geladeiras domésticas são utilizados na conservação das vacinas, para manter suas propriedades e características imunogênicas.

Esses equipamentos são, portanto, essenciais na rede de frio, e seu funcionamento deve ser conhecido por todos os profissionais que atuam na área. Por isso, este capítulo apresenta alguns desses equipamentos, destacando a importância de se conhecer como funcionam, as formas de monitorá-los, além de demonstrar as especificidades de cada um para o seu aproveitamento máximo, com menor custo. Apresenta, também, o papel da manutenção preventiva e corretiva no aumento da vida útil dos equipamentos de refrigeração, de modo que tenham um bom funcionamento e, consequentemente, garantam a conservação e a preservação da qualidade do imunobiológico.

\section{Princípios da gestão segura no armazenamento de vacinas}

A rede de frio utiliza diversos equipamentos de refrigeração para conservação dos imunobiológicos, desde caminhão frigorífico até geladeira alimentada por energia solar. A escolha desses equipamentos é essencial para o bom funcionamento da rede.

Sabemos que as tecnologias para o armazenamento de vacinas estão evoluindo a cada dia, e a compra dos equipamentos para a rede de frio deve ser criteriosa e cuidadosa. Recomenda-se, então, que o gestor, antes de efetuar a compra, investigue sobre o equipamento que será adquirido, ou forneça informações à sua chefia imediata ou demais gestores, de modo que os produtos comprados atendam, de fato, às necessidades das ações de imunização, evitando custos e problemas desnecessários.

A ruptura da cadeia de frio, ou seja, quando a temperatura de armazenamento das vacinas está fora da faixa recomendada (de $+2{ }^{\circ} \mathrm{C}$ a $+8^{\circ} \mathrm{C}$ ), pode ocorrer em função de um problema no equipamento de refrigeração. Dessa forma, além dos cuidados na escolha das câmaras refrigeradas/refrigeradores, é necessário também adotar alguns princípios para a gestão segura no armazenamento de vacinas, que serão apresentados a seguir: 
escolher/adquirir um refrigerador adequado para a armazenagem das vacinas;

designar um profissional habilitado/capacitado para ser responsável pela gestão das vacinas;

adotar políticas de capacitação permanente, assegurando que todas as pessoas envolvidas no transporte, armazenamento e na administração de vacinas estejam capacitadas na gestão de imunobiológicos;

(Q) realizar supervisão periódica nos equipamentos, atentando para a forma de armazenamento das vacinas;

elaborar protocolos/procedimento operacional-padrão (Pop) para armazenamento, remanejamento ou suspensão do uso de vacinas, conforme as recomendações do PNl;

realizar o monitoramento da temperatura dos refrigeradores de vacinas duas vezes ao dia, assegurando que os protocolos (Pop) estejam atualizados, especialmente nos casos de rotura da rede de frio ou de falha no fornecimento de energia-elétrica;

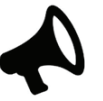

informar à chefia imediata temperaturas fora da faixa de $+2^{\circ} \mathrm{C} \mathrm{a}+8^{\circ} \mathrm{C}$, adotando os procedimentos adequados conforme protocolos;

seguir as recomendações para o uso de bobinas de gelo reutilizáveis, caixas térmicas, refrigeradores e termômetros;

realizar o monitoramento e o ajuste do equipamento e demais instrumentos de verificação da temperatura, como data logger, termômetro,

periodicamente;

realizar as manutenções preventiva e corretiva dos equipamentos, incluindo refrigerador e data logger, procedendo à troca das baterias do data logger e do termômetro;

verificar a precisão dos termômetros e realizar a calibração;

realizar a limpeza periódica do refrigerador conforme as recomendações e os protocolos da unidade e do PNI.

A adoção dos princípios minimiza, ou mesmo impede, a ocorrência de problemas na temperatura e conservação das vacinas, evitando o risco de se administrar uma vacina ineficaz. A seguir, discutiremos alguns desses princípios, buscando ampliar seus conhecimentos sobre equipamentos refrigeradores.

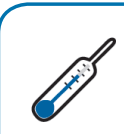

Para saber mais sobre limpeza periódica de refrigeradores na rede de frio, consulte 0 Manual da rede de frio, do PNI (BRASIL, 2013), disponível em: http://bvsms.saude.gov.br/ bvs/publicacoes/manual_rede_ frio4ed.pdf 


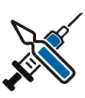

O tamanho de um refrigerador deve ser dimensionado considerando as necessidades diárias e outras, como é o caso de campanhas, quando é necessário o acondicionamento de maiores volumes de imunobiológicos.

\section{Aspectos a serem considerados quando da aquisição do refrigerador de vacinas}

Ao adquirir uma câmara refrigerada/refrigerador para armazenar vacinas, o profissional/gestor deve, inicialmente, refletir sobre o valor do equipamento, relacionando custo-benefício, avaliando se o equipamento atenderá suas expectativas (capacidade $\mathrm{X}$ número de atendimentos), verificando o tamanho da câmara refrigerada/refrigerador, a dimensão e a estrutura física da sala onde será alocado, assegurando espaço em torno deste para circulação do ar, conforme recomendações do fabricante.

Além desses cuidados, o gestor ou especialista em rede de frio deve escolher uma câmara refrigerada/refrigerador que apresente algumas características fundamentais, em virtude da especificidade do produto a ser armazenado, tais como:

dispositivo, monitor/termômetro ou logger embutido para temperatura;

* sistema de alarme, que possa identificar "porta aberta" e/ou permitir a notificação por discagem telefônica automática a alguém sobre qualquer problema no fornecimento de energia ou falha no equipamento, devendo ser escolhido o sistema de alarme que melhor se adeque às suas necessidades;

* sistema de registro de temperatura embutido, que permita a leitura fácil da temperatura (máxima e mínima). Alguns sistemas de registro gráfico apresentam a possibilidade de serem colocados na parte inferior do gabinete do refrigerador.

O passo seguinte é atentar para os aspectos referentes ao fabricante. Nessa hora, algumas questões precisam ser respondidas, como:

* Por quanto tempo o refrigerador permanecerá dentro da faixa de temperatura, no caso de falha na energia elétrica?

*uais diferenças os refrigeradores com portas tradicionais (sólidas) apresentam em relação às câmaras refrigeradas com portas de vidro, no que se refere à manutenção da temperatura?

* O refrigerador terá necessidade de dispositivos que reforcem seu funcionamento, como alarmes, recursos de monitoramento da temperatura etc. Nesse caso, qual o custo adicional?

* O custo com a assistência técnica inclui a manutenção e os reparos em áreas mais distantes (particularmente em áreas rurais etc.)? 
Qual a duração da garantia e suas condições?

*ual é a eficiência energética do equipamento? Ele necessita de suporte de "massa fria" para ajudar na manutenção da temperatura interna, como garrafas com água resfriada?

O avanço da tecnologia tem permitido uma gama variada de refrigeradores, sejam domésticos ou câmaras refrigeradas. Existem vários tipos de refrigeradores domésticos no mercado, dispondo, cada um, de recursos que devem ser avaliados no momento de sua compra e, também, de seu uso.

De modo geral, os refrigeradores domésticos são os equipamentos utilizados nas atividades de imunização no nível local. Entretanto, não possuem precisão no controle da temperatura e, por isso, sua utilização tem sido paulatinamente reduzida, por orientação do PNI, em virtude da existência de outros equipamentos mais apropriados ao acondicionamento de vacinas. Considerando essa situação, tem sido recomendada a aquisição de câmaras refrigeradas, desenvolvidas especificamente para a conservação de imunobiológicos, e esses equipamentos devem ter registro na Anvisa.

Apesar da recomendação, o refrigerador doméstico ainda é muito presente e, por esse motivo, vale ressaltar alguns cuidados para os casos em que esse equipamento for usado para armazenagem das vacinas, de forma a reduzir o risco de alterações drásticas na manutenção da temperatura.

Inicialmente, o gestor ou especialista em rede de frio deve seguir as recomendações do PNI em relação à forma de acondicionamento e disposição das vacinas no refrigerador e conhecer as características principais do equipamento. Algumas questões, então, devem ser levantadas, como:

Onde estão localizadas as áreas frias e quentes no refrigerador?

* Onde ocorre maior variação de temperatura da área de cima para baixo e da frente para o fundo?

* Como são as oscilações da temperatura do refrigerador em clima muito quente ou muito frio? (Alguns refrigeradores domésticos se tornam mais quentes em clima mais quente e mais frio em climas mais frios, podendo também ocorrer o inverso.)

É fundamental, também, seguir as recomendações preconizadas pelo programa de imunizações para conservação e controle da temperatura dos imunobiológicos. Convém destacar alguns cuidados:
Suportes de "massa fria" serão discutidos mais adiante neste capítulo.

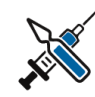

Mesmo que somente seja possível adquirir um refrigerador doméstico para armazenagem de imunobiológicos, as características das câmaras refrigeradas projetadas especificamente para acondicionar vacinas devem ser consideradas.

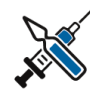

Refrigeradores projetados para bar, suscetíveis ao congelamento, ou com ciclo de degelo não devem ser utilizados para o acondicionamento de vacinas. 
*assegurar que o refrigerador tenha um termômetro de mínima/ máxima e um mapa/livro de registro das temperaturas, e que o bulbo do termômetro possa ser colocado corretamente no interior do equipamento onde fica a vacina, de modo que informe a temperatura mais próxima possível da que a vacina se encontra, e não do recipiente de acondicionamento;

粰 não encostar as vacinas nas paredes do refrigerador ou próximo às entradas de ar frio, pois há risco de congelamento;

茦 usar garrafas com água colorida nas portas, deixando espaço de ar entre elas;

* colocar garrafas com água ou bobinas de gelo na parte de baixo do refrigerador.

\section{Contribuindo para a manutenção da temperatura do} refrigerador

O uso de garrafas com água resfriada auxilia a estabilizar a temperatura, no interior do refrigerador, pelo aumento da "massa fria", reduzindo os períodos de aquecimento quando o equipamento é aberto, ou retardando o aquecimento quando ocorre interrupção da energia elétrica ou falha no refrigerador.

Para evitar que essa água seja consumida e, consequentemente, a massa fria seja retirada do refrigerador, recomenda-se colocar sal ou corantes para torná-la não potável. As garrafas devem ser rotuladas para informar o que contêm.

Outro cuidado é em relação ao congelamento das vacinas. Não é possível assegurar que as vacinas tenham sido congeladas usando apenas a observação da aparência física, pois o congelamento pode ter ocorrido mesmo que as vacinas ou garrafas com água estejam descongeladas no momento da observação. Essa aparência de "descongelada" não indica, necessariamente, que a temperatura do refrigerador não alcançou $0^{\circ} \mathrm{C}$.

\section{Para refletir}

Que pontos positivos e negativos você identifica em relação às condições de armazenamento e à conservação de imunobiológicos em seu local de trabalho?

Considerando os aspectos mencionados para aquisição dos equipamentos de refrigeração, é importante entendermos os princípios envolvidos no seu funcionamento. Vamos conhecê-los? 


\section{O princípio de funcionamento e os componentes de um refrigerador}

As câmaras refrigeradas/refrigeradores são aparelhos que funcionam continuamente, dia e noite, para manter a temperatura baixa, seguindo a calibragem determinada (por exemplo, câmara fria de $4^{\circ} \mathrm{C}$ ou de $\left.-20^{\circ} \mathrm{C}\right)$.

O princípio de funcionamento de uma câmara refrigerada/refrigerador é muito simples: ela usa a evaporação de um líquido refrigerante para absorver calor (calor latente). Para compreender melhor, vamos a um exemplo mais cotidiano: ao colocar água fria em sua pele, você normalmente sente um frescor. Isso porque a água troca calor com a pele e "rouba" calor, que a faz evaporar; quando evapora, levando calor consigo, cria a sensação de frio. O líquido refrigerante usado em uma geladeira evapora a uma temperatura mais baixa do que a do ponto de congelamento da água, que é de $0^{\circ} \mathrm{C}$, nas condições normas de temperatura e pressão ambiente; ao evaporar, ele cria temperaturas baixas dentro da câmara refrigerada/refrigerador. Se você colocar o fluido refrigerante (líquido refrigerante) em sua pele, ele irá congelá-la enquanto evapora.

O sistema básico de funcionamento de uma câmara refrigerada/refrigerador apresentado, a seguir, é conhecido também como unidade selada (um sistema lacrado, em que somente o técnico ou o mecânico de refrigeração podem intervir, caso haja uma falha no funcionamento). Recebe esse nome porque seus componentes são ligados por tubos soldados, formando um circuito hermético e que tem por finalidade realizar o ciclo fundamental da refrigeração, ou seja, a retirada da energia térmica do interior da câmara refrigerada/ refrigerador, transportando-a para seu trocador de calor externo (condensador). A Figura 1 demonstra como esse sistema básico é composto.

Figura 1 - Sistema básico de uma câmara refrigerada/refrigerador

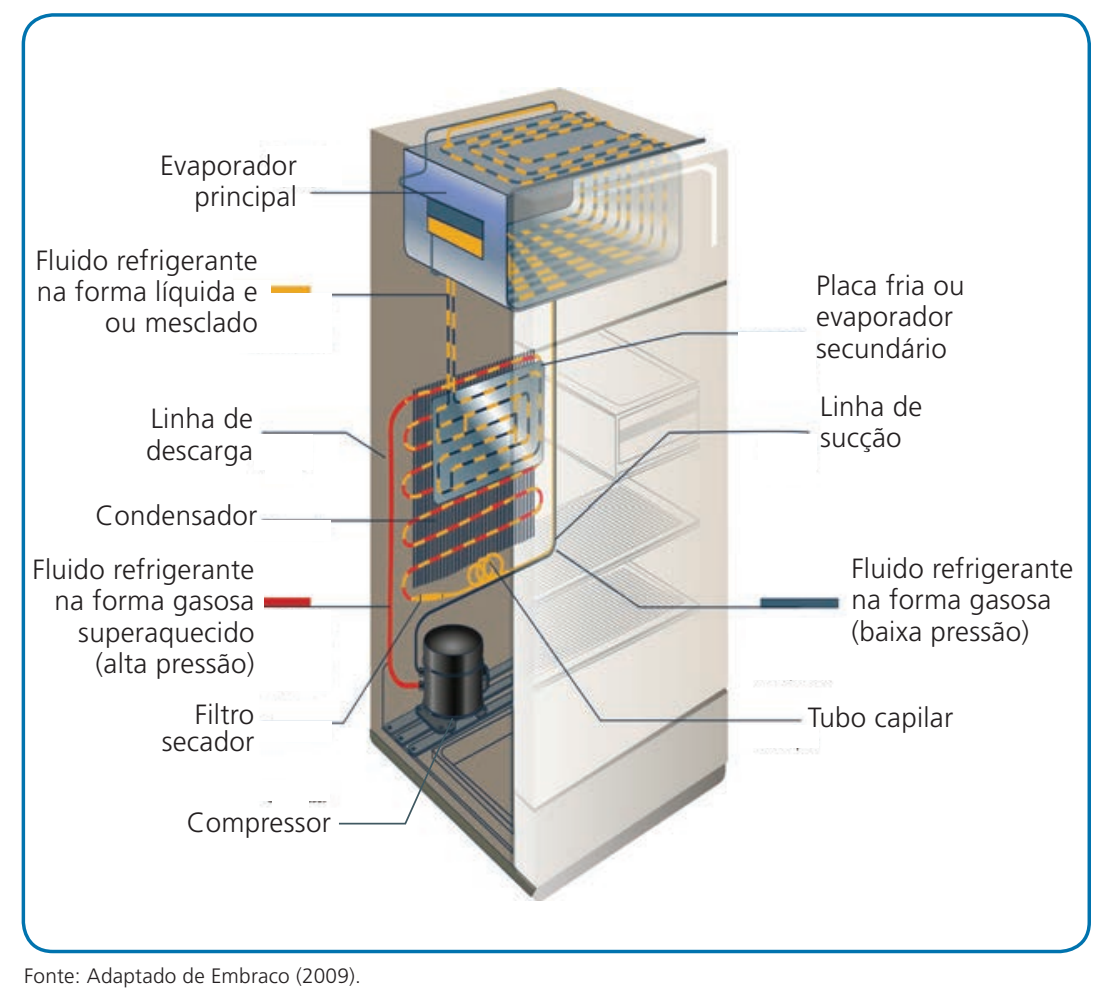


A seguir, podemos ver como funciona e para que serve cada um dos componentes do refrigerador, já que demonstramos o mecanismo geral.

\section{Compressor}

É o dispositivo responsável pela sucção e compressão do fluido refrigerante, fazendo com que este circule por toda a unidade selada. É responsável, também, pelas transformações físicas (evaporação e condensação) para a realização da refrigeração. Os compressores, dispositivos eletromecânicos responsáveis pela transformação da energia elétrica em energia mecânica, estão localizados, geralmente, na parte inferior traseira da câmara de conservação, ligando-se aos outros componentes por tubos soldados. Os compressores possuem, em seu interior, óleo lubrificante para os componentes mecânicos, diminuindo o desgaste por atrito entre as partes mecânicas.

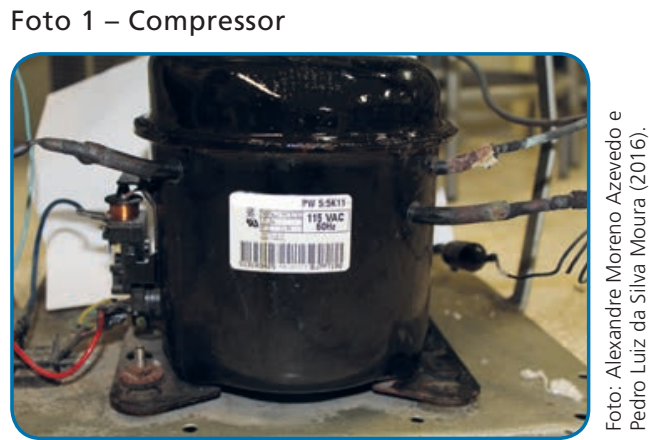

Os compressores são herméticos e constituídos por carcaça, sistema mecânico e sistema elétrico. Do lado de fora do compressor, existem quatro dispositivos elétricos. Abordaremos cada parte do compressor.

* Relé de partida: responsável por fornecer energia adicional ao motor do compressor no instante da partida, visando vencer a inércia inicial do próprio motor.

Figura 2 - Relé de partida

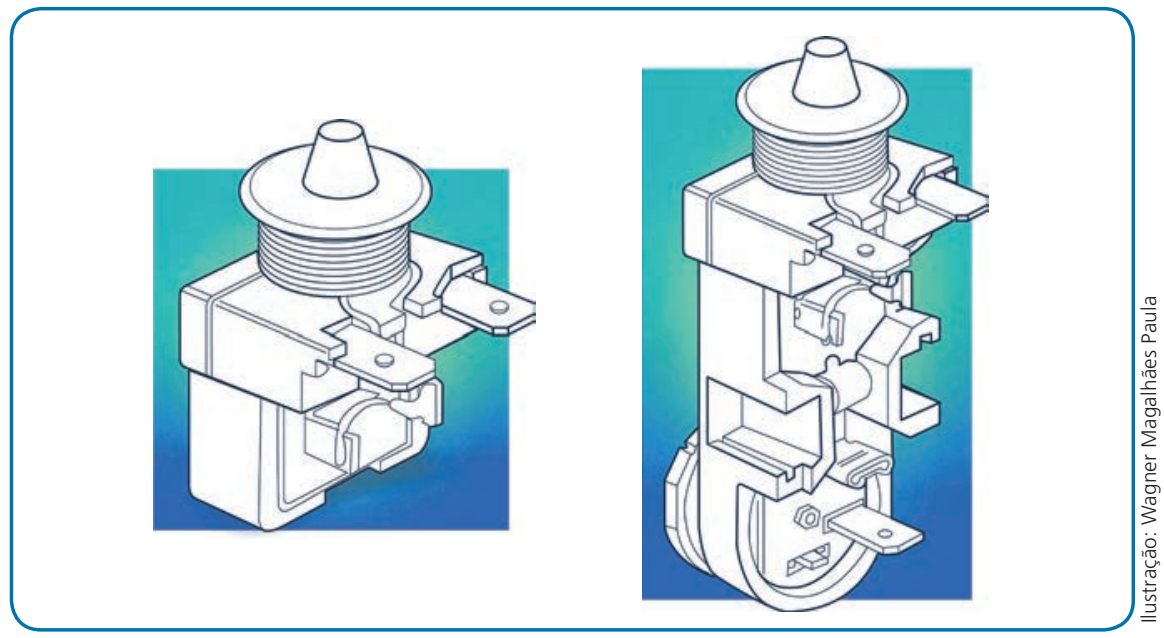

Fonte: Adaptado de Embraco (2009) 
* Protetor térmico ou de sobrecarga: sua função principal é atuar como "anjo da guarda" do motor do compressor, evitando sua queima caso ocorra alguma falha que o obrigue a trabalhar para além dos limites para o qual foi projetado.

Figura 3 - Protetor térmico

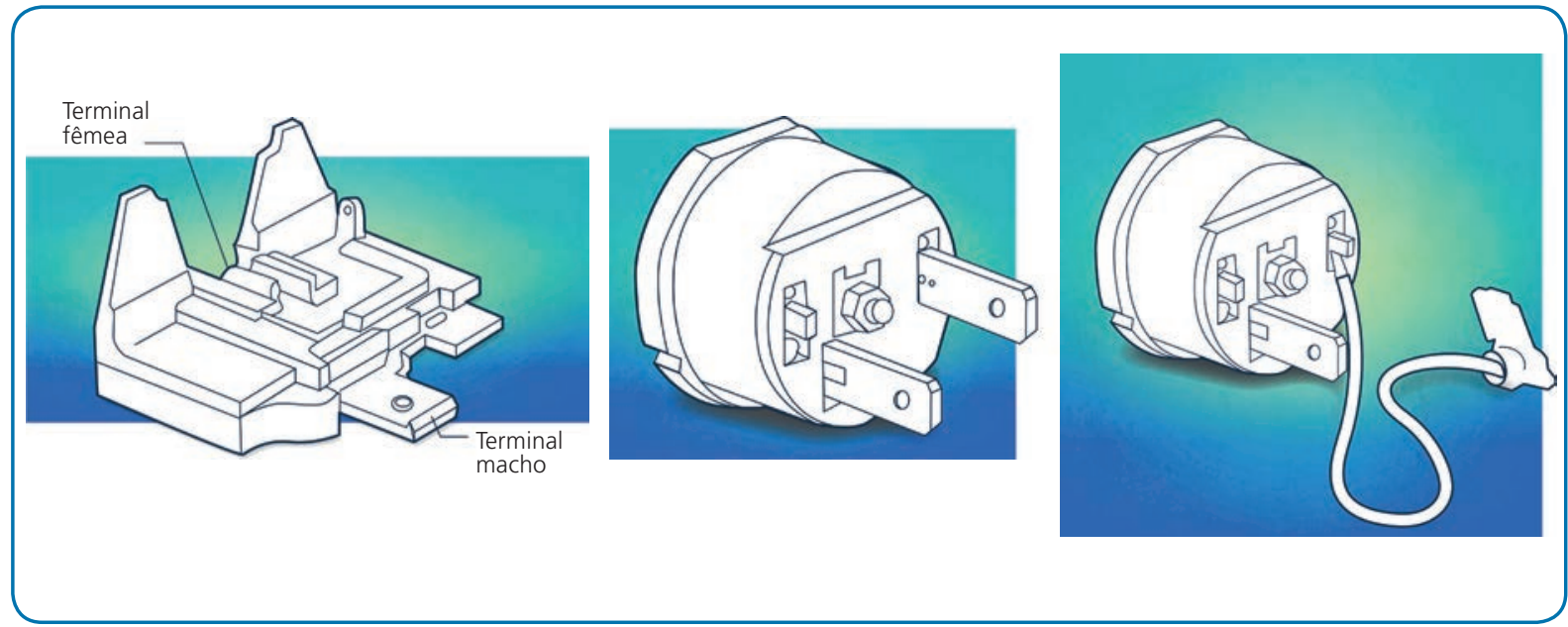

Fonte: Embraco (2009).

* Termostato: dispositivo que regula temperatura. Ao identificar a temperatura elevada em relação à desejada, ele aciona o relé que liga o compressor, fazendo com que todo o sistema de refrigeração seja acionado para que a temperatura retorne ao preestabelecido. Quando atinge a temperatura preestabelecida, o compressor desliga, evitando o desperdício de energia elétrica.

Figura 4 - Termostato

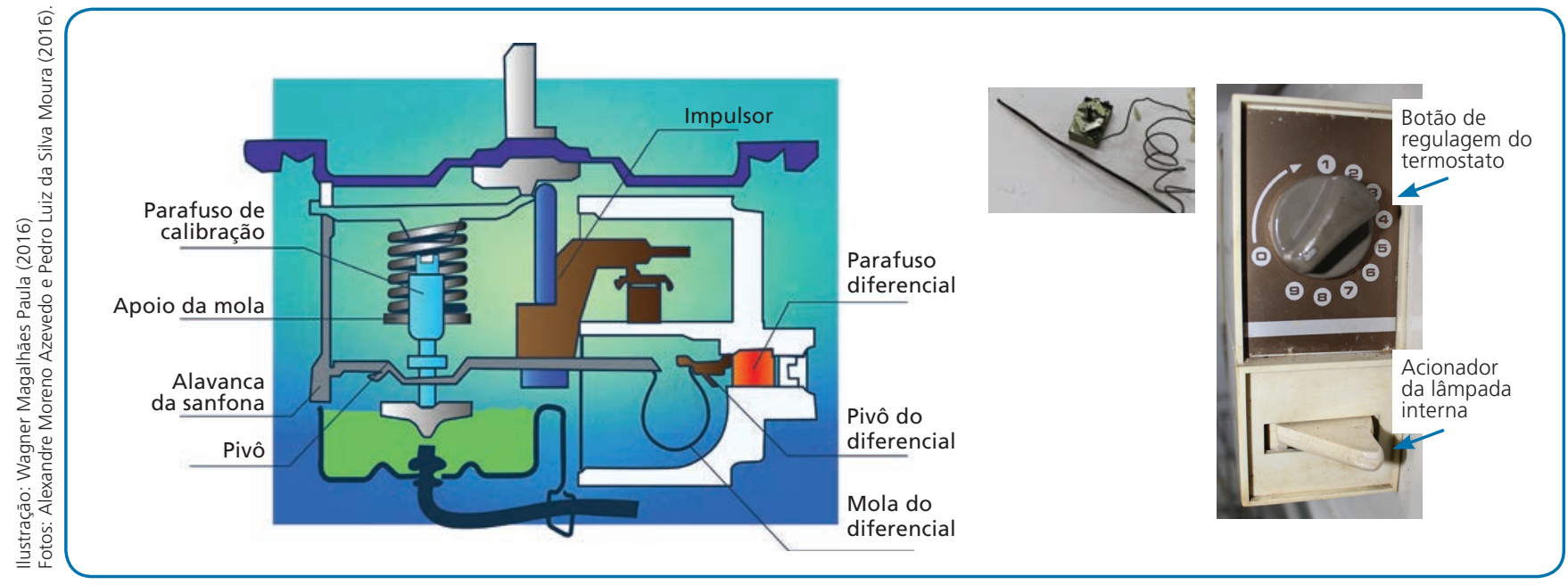


Vale ressaltar que, na ausência do condensador na parte traseira do equipamento de refrigeração, o trabalhador saberá que o condensador estará entre o corpo de metal externo lateral e a placa de isolamento térmico, não sendo visível.

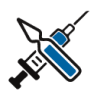

O condensador que trabalha com a circulação natural do ar possui aletas que passam na tubulação com o fluido refrigerante. Essas aletas têm a função de aumentar a área de troca de calor do fluido refrigerante com o ar ambiente. Por isso nunca pendure nada na parte traseira da câmara refrigerada/refrigerador.
* Capacitor: tem por finalidade armazenar carga elétrica e descarregá-la para dar partida no compressor, que necessita de força adicional para funcionar. Esse dispositivo só é instalado em locais de baixa tensão.

Figura 5 - Capacitor

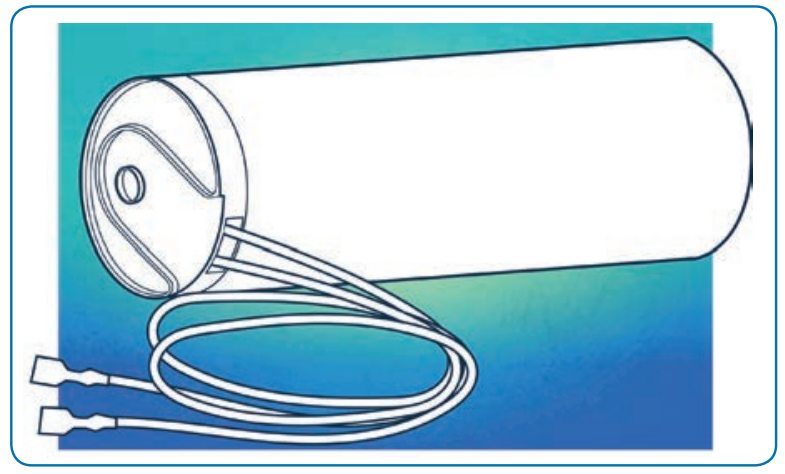

Fonte: Adaptado de Embraco (2009).

\section{Condensador}

Outro componente da câmara refrigerada/refrigerador é o condensador, localizado na parte externa traseira na maioria dos equipamentos, conforme o representado na Figura 1. Em algumas câmaras refrigeradas/refrigeradores, dependendo do modelo, o condensador pode ser instalado, também, entre o corpo de metal externo lateral e a placa de isolamento térmico. O condensador da câmara refrigerada/refrigerador é fabricado com liga de aço cobreado, curvado em forma de serpentina, preso por chapas de aço.

A função do condensador, independentemente do local da sua instalação, é sempre a mesma. Ele realiza mudança de fase do fluido refrigerante, ou seja, faz com que este passe de vapor para líquido, isto é, perca calor latente na mudança de estado para o ambiente, transformando-se em líquido. Para que isso ocorra, o condensador precisa de um meio para se resfriar, que permita a retirada de calor. Geralmente, o meio utilizado é o ar.

É importante lembrar que a câmara refrigerada/refrigerador de uso industrial ou Comercial, por ser demasiadamente exigida e ter seu uso prolongado, necessita de ventilação
Foto 2 - Condensador

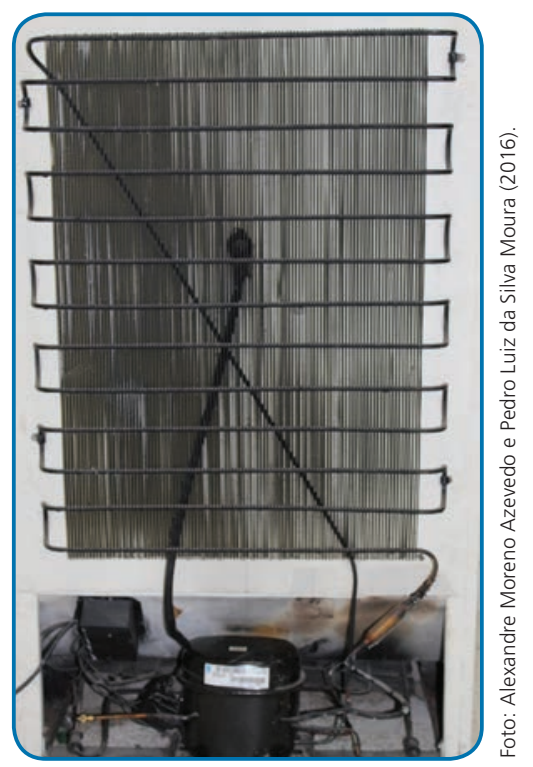


forçada (pequenos ventiladores), que atuam para retirar calor do condensador mais rapidamente. O esquema a seguir apresenta o funcionamento do condensador.

Figura 6 - Etapas de funcionamento do condensador

$1^{\text {a }}$ etapa - $O$ condensador recebe fluido refrigerante em forma gasosa, em alta pressão e alta temperatura vindo do compressor.

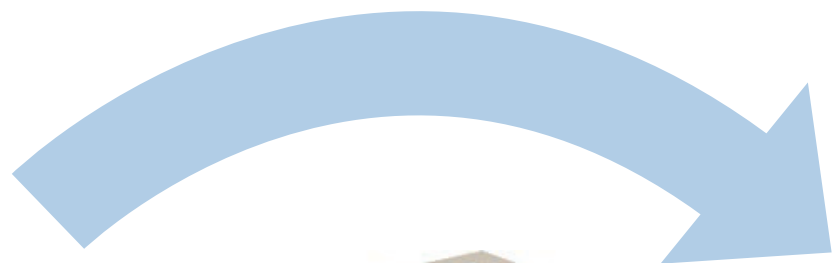

$2^{a}$ etapa - o evaporador libera calor, facilitando a troca entre o fluido refrigerante em seu interior e o ar do ambiente. A partir dessa troca ocorre a liquefação do fluido refrigerante.

\section{Evaporador principal}

\section{Fluido refrigerante} na forma líquida e ou mesclado

Linha de descarga

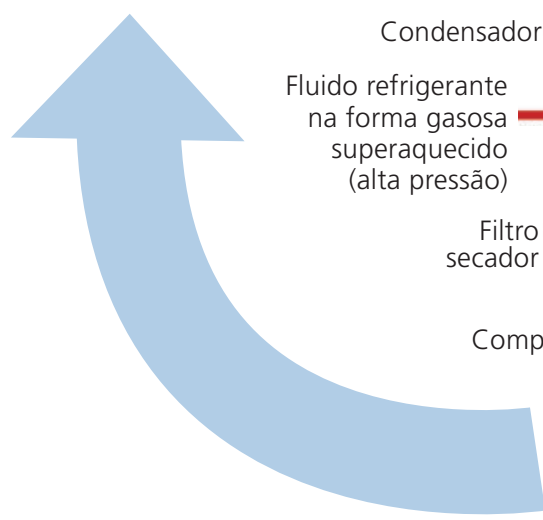

$3^{a}$ etapa - O fluido refrigerante no estado gasoso no condensador, ao acumular-se no último tubo do condensador, esfria mais um pouco, segue para o filtro secador, passa pelo tubo capilar e vai para o evaporador (componentes que apresentaremos na sequência do capítulo) e transforma-se em gás, resfriando rapidamente; em seguida, é sugado pelo compressor, que fornece energia mecânica (pressão) e transforma-o em líquido.

Podemos observar, na Figura 7, um esquema do filtro secador. Ele é fabricado em latão ou cobre, sua entrada é maior que a saída. É utilizado em câmara refrigerada/refrigerador e tem duas telas de malhas de níquel ou bronze; entre essas telas, há um dessecante, que tem a finalidade de remover a umidade residual da fabricação do fluido refrigerante, evitando que essa umidade entre no tubo capilar e 
ocasione entupimento. Esse dispositivo é instalado no final do condensador, na posição vertical, com a saída para baixo, possibilitando melhor filtragem.

Figura 7 - Filtro secador

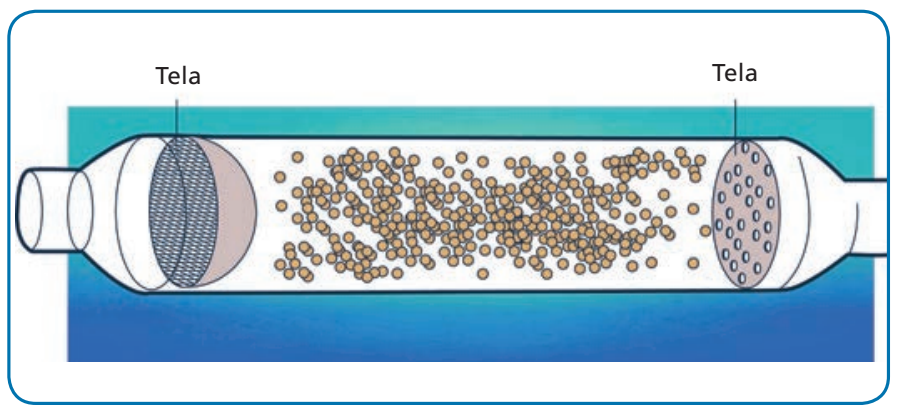

Fonte: Portal da refrigeração (2008).
Foto 3 - Filtro secador

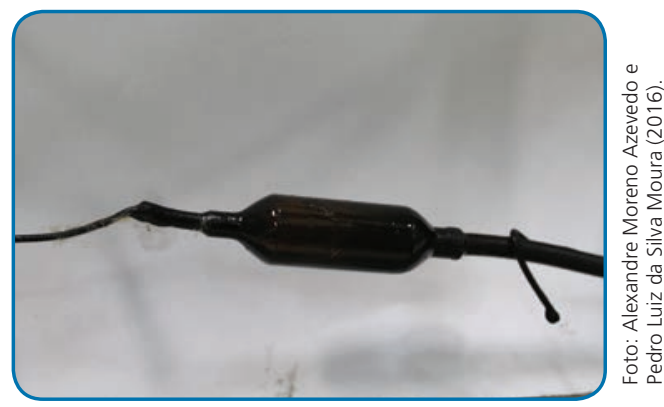

\section{Tubo capilar}

Outro componente do sistema básico de refrigeração da câmara refrigerada/refrigerador é o tubo capilar, feito de cobre, com diâmetro interno muito pequeno. Localiza-se entre a saída do condensador e a entrada do evaporador. Sua função é manter a diferença de pressão entre o lado de alta pressão do condensador e o de baixa pressão do evaporador, possibilitando a mudança de fase do fluido refrigerante de líquido para gasoso, no evaporador.

Foto 4 - Tubo capilar com filtro secador

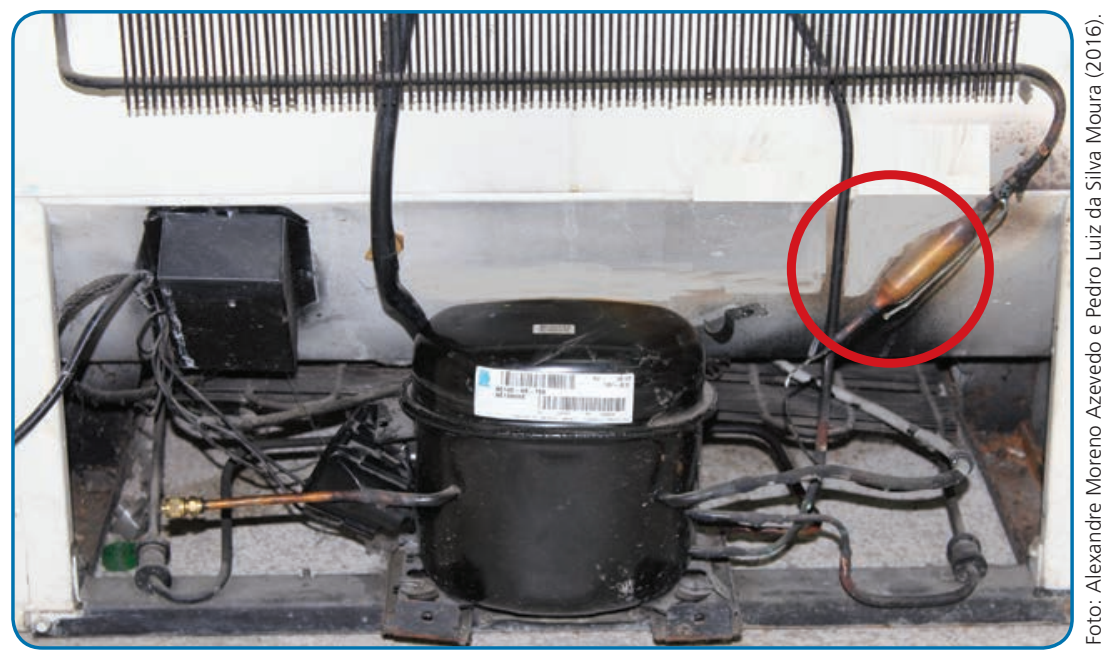




\section{Evaporador}

Tem a função de possibilitar a transformação do fluido refrigerante do estado líquido para o gasoso, absorvendo, nessa mudança de fase, a energia térmica do interior da câmara refrigerada/refrigerador e reduzindo a temperatura dos materiais armazenados em seu interior. No refrigerador da sua casa, é provável que o evaporador esteja localizado na parte de cima, onde

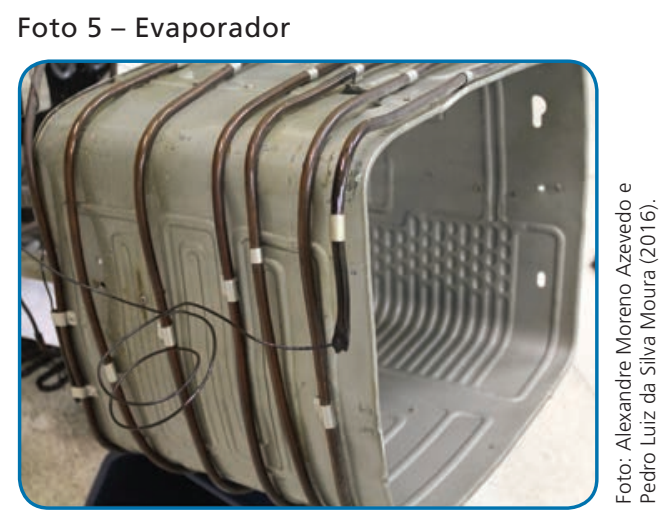
você congela os alimentos, tanto nos equipamentos de uma porta como no de duas portas. No entanto, hoje existem também refrigeradores em que o evaporador se localiza na parte inferior do equipamento.

\section{Descrição do processo de funcionamento dos componentes}

Agora que já conhecemos as partes vedadas do sistema, podemos descrevê-lo. Todo o processo ocorre da seguinte forma:

* O compressor suga do evaporador o fluido refrigerante, na forma de vapor, em baixas pressão e temperatura.

Em seguida, o compressor comprime o fluido refrigerante para o condensador; nesse momento, sua pressão e temperatura se elevam, o fluido refrigerante se condensa no condensador e troca calor com o ambiente.

* Quando o fluido refrigerante sai do condensador, em estado líquido, passa pelo filtro secador e entra no tubo capilar, sofre atrito, em virtude do diâmetro reduzido do tubo capilar, e com isso sua pressão e temperatura diminuem.

O fluido refrigerante, ao sair do tubo capilar e ainda líquido, entra no evaporador que está com baixa pressão. O fluido refrigerante absorve calor, evapora e esfria (assim o evaporador realiza a sua função de resfriamento do equipamento), voltando a ser sugado pelo compressor, repetindo o ciclo.

Entendemos a base de funcionamento dos componentes de um refrigerador ou câmara refrigerada, mas um elemento muito utilizado nos equipamentos da rede de frio, geralmente manipulado de forma inadequada, é o termostato. 


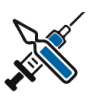

Todo sistema em que há troca de calor necessita de um tempo para alcançar o equilíbrio térmico; porém, levantamentos empíricos demonstram que é recomendável um tempo mínimo de dez minutos entre cada sessão, até que a temperatura atinja o valor desejado. Isso é de grande importância, pois o sistema requer um período de tempo para estabilizar a temperatura.

Manter o compressor ligado por mais tempo significa maior gasto de energia e maior desgaste para o equipamento.

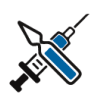

Alguns modelos de refrigerador não permitem que seja trocada somente a gaxeta, em caso de defeito, sendo necessário trocar toda a porta. Para saber se o refrigerador permite ou não a troca da gaxeta apenas, deve-se verificar o número do modelo e consultar o site do fabricante, que fornece toda a informação necessária.

\section{Qual é a função do termostato no sistema de refrigeração?}

Trata-se de um dispositivo de controle automático de temperatura. Tem sua calibragem específica em cada câmara de conservação/refrigerador e pode ser instalado internamente no lado direito ou no console externo. Conforme as variações de temperatura, o termostato detecta se a temperatura da câmara refrigerada/refrigerador está no mínimo ou no máximo estipulados e arma ou desarma o compressor, em resposta. Isso permite o controle da temperatura interna no evaporador e a regulagem manual da temperatura.

Para regular a temperatura, deve-se colocar um termômetro aferido e calibrado dentro da câmara de conservação/refrigerador, efetuando-se, a seguir, os ajustes do termostato, movendo-se o botão de regulagem para mais $(+)$ ou para menos $(-)$, segundo a temperatura desejada. Esses ajustes devem ser realizados antes de o equipamento receber as vacinas.

A câmara refrigerada/refrigerador possui outra parte que necessita de cuidado especial: as portas. Elas possuem dobradiças, nas partes supe-
Foto 6 - Botão de regulagem do termostato

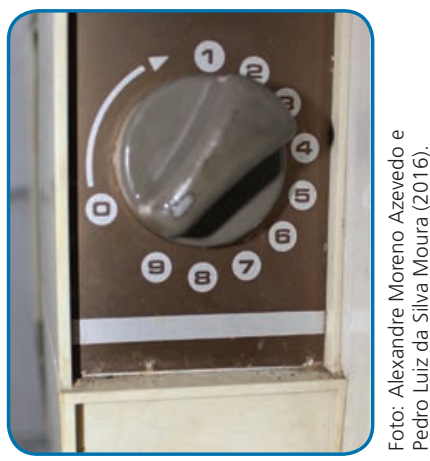
rior e inferior, que, ao longo do tempo, sofrem desgastes e necessitam ser trocadas. Em alguns casos, a simples inversão do lado em que a porta se abre já é o suficiente para que o equipamento volte a funcionar normalmente, reduzindo o custo e o tempo de manutenção.

As dobradiças com defeito causam um desnivelamento da porta. Esse defeito, quando ocorre, permite a entrada de ar quente no interior da câmara refrigerada/refrigerador, causando elevação da temperatura, formação excessiva de gelo e gotas d'água, além de forçar o compressor a ligar várias vezes para compensar a perda de refrigeração.

Outro componente da porta é a gaxeta, que é mais comumente conhecida como borracha da porta ou borracha de vedação. Os problemas causados na câmara refrigerada/refrigerador pelo desgaste da gaxeta são os mesmos provocados pelas dobradiças defeituosas; sua integridade é fundamental para evitar a saída de ar frio e a entrada de ar quente no interior da câmara refrigerada. Essa borracha é de fácil manutenção: ao apresentar desgaste, basta trocá-la, pois é de encaixe, em sua maioria, permitindo a retirada e colocação de nova borracha, facilmente. 


\section{Câmara frigorífica negativa ou positiva}

São ambientes construídos, na rede de frio, com a finalidade específica de armazenar grandes quantidades de imunobiológicos nas instâncias central e estadual, tanto em temperatura negativa como positiva.

A câmara frigorífica tem o seu princípio de funcionamento igual ao do das câmaras refrigeradas/refrigeradores; porém, todo o seu sistema hermético fica em local separado da câmara de armazenagem, em virtude do seu tamanho.

Essas câmaras têm contrato de manutenção terceirizada, com controle rígido de manutenção preventiva, além de possuírem alarmes de identificação de falhas automáticos, que acionam o(s) responsável(eis) pela manutenção via SMS ou outro sistema de comunicação remota. Também possui um gerador acionado automaticamente, em caso de falta de fornecimento de energia elétrica (BRASIL, 2013).

Todos os sistemas de refrigeração apresentados até o momento utilizam a energia elétrica para seu funcionamento. Entretanto, em virtude das diferenças regionais, culturais, econômicas etc. do nosso país, é importante aqui referenciar outra forma de refrigeração: a energia solar, apresentada a seguir.

\section{Sistema de refrigeração fotovoltaico}

Nos locais em que o fornecimento de energia elétrica inexiste ou é muito precário e irregular, caso típico de comunidades servidas por pequenos geradores locais ou regiões remotas, recomenda-se a utilização de sistemas de refrigeração autossuficiente. Na rede de frio, uti-

Foto 7 - Sistema de refrigeração fotovoltaico

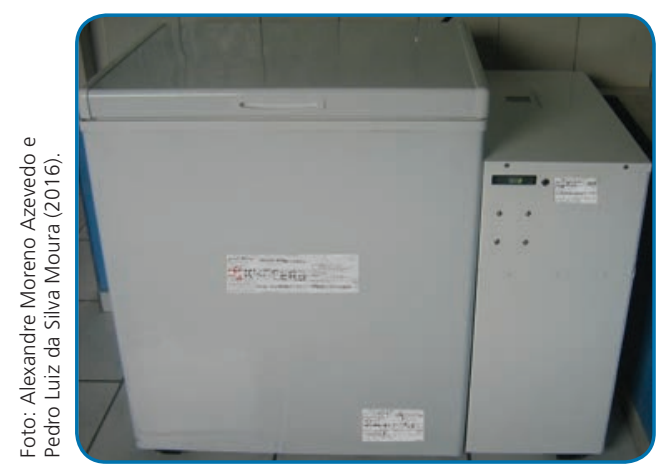

liza-se o sistema de refrigeração com energia gerada por células fotovoltaicas.

O sistema fotovoltaico é composto por um conjunto de células fotovoltaicas, o qual é capaz de fornecer energia elétrica a partir da luz solar. Esta é transformada em energia elétrica por painéis solares (célula fotovoltaica), criados especificamente para essa função. 


\section{Células fotovoltaicas}

São elementos capazes de converter energia luminosa (preferencialmente solar) em energia elétrica. Apresentam algumas vantagens em sua utilização, como:

- baixa necessidade de manutenção;

- ser uma fonte de energia ambientalmente limpa;

- possibilidade de utilização mesmo em localidades com precária infraestrutura.

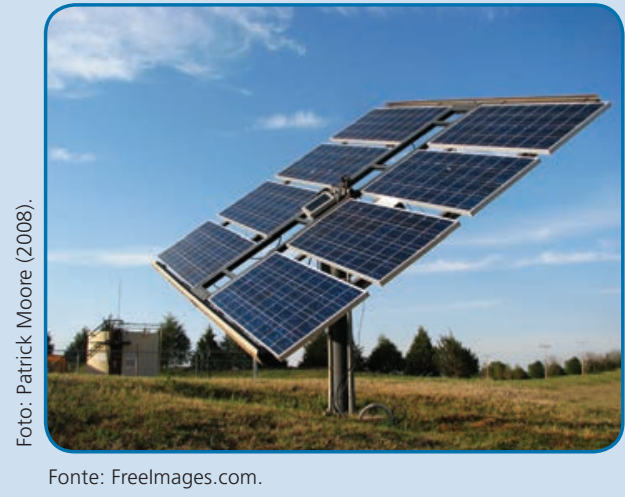

As células fotovoltaicas são feitas de material semicondutor. Ao absorver a luz, esse dispositivo produz uma pequena corrente elétrica, que pode ser aproveitada. Os semicondutores feitos de silício são os mais usados na construção de células fotovoltaicas, e sua eficiência em converter luz solar (que é branca) em eletricidade chega a $10 \%$.
Corrente alternada está presente em nossas casas, nas tomadas em que ligamos os nossos eletrodomésticos.

Corrente contínua é aquela presente nas pilhas, nas baterias, utilizadas em nossos celulares, carros, rádios.

\section{Funcionamento do sistema de refrigeração alimentado por células fotovoltaicas}

O sistema dos refrigeradores/câmaras refrigeradas "comuns" é alimentado por energia elétrica de $127 \mathrm{~V}$ (corrente alternada); já o sistema de refrigeração gerado por células fotovoltaicas é alimentado por energia elétrica de $12 \mathrm{v}$ ou $24 \mathrm{v}$ (corrente contínua).

Assim, o sistema de refrigeração fotovoltaico consiste, basicamente, em um sistema de refrigeração convencional (visto anteriormente), no qual o circuito elétrico de corrente alternada (rede elétrica existente em nossas casas) é substituído por uma corrente contínua (12v a 24v), alimentado por um sistema fotovoltaico e armazenado em baterias.

I Mas, e à noite, quando não há luz solar?

A fim de prover energia durante o período noturno, o excedente de energia gerado pelas células fotovoltaicas, não utilizado imediatamente pelo compressor, é armazenado em uma bateria. As baterias têm a capacidade de armazenar energia elétrica, que será utilizada em períodos de 
falhas no fornecimento pela concessionária, ou durante translado de câmaras de conservação portáteis de imunobiológicos.

As baterias do sistema de refrigeração fotovoltaico são as de chumbo ácidas, constituídas, basicamente, por placas de chumbo metálico (ânodo polo negativo), placas de óxido de chumbo (cátodo polo positivo); ambas as placas são imersas em uma solução (líquida) de ácido sulfúrico, ou em um gel pastoso (baterias seladas), e todo o conjunto é acondicionado em uma embalagem plástica.

Figura 8 - Constituição das baterias

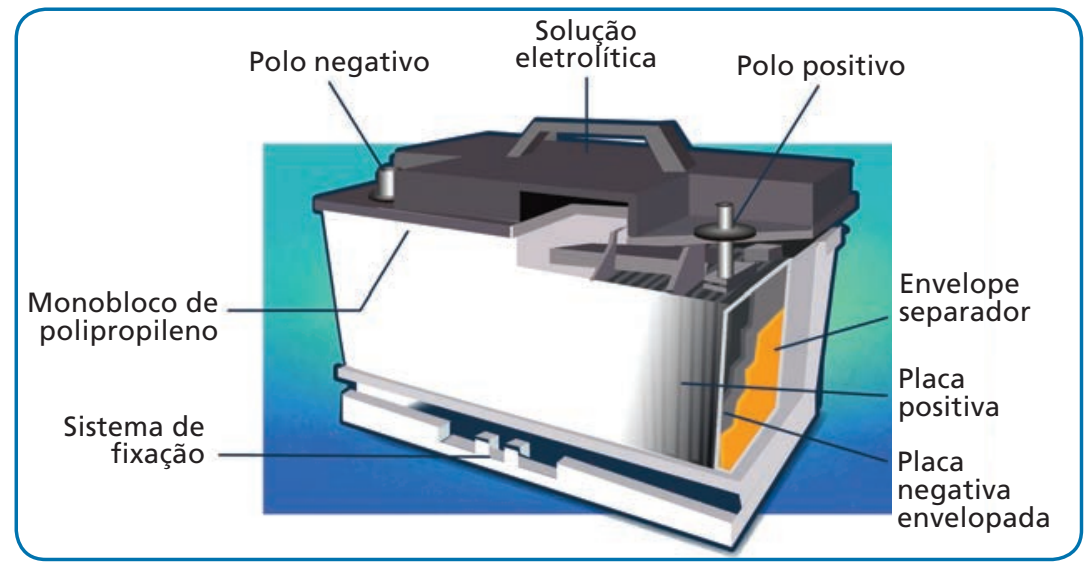

O sistema fotovoltaico é composto basicamente por:

1. compressor com alimentação por corrente contínua;

2. bateria, cuja função é armazenar energia fornecida pela célula fotovoltaica durante o dia para, à noite, suprir o compressor da energia elétrica necessária para manter a temperatura dos imunobiológicos, evitando sua deterioração;

3. circuito regulador/controlador de carga, cujo objetivo é controlar tensões elétricas fornecidas à bateria e ao compressor;

4. célula fotovoltaica, elemento capaz de transformar energia luminosa do Sol em energia elétrica;

5. condensador, que passa o fluido refrigerante de seu estado gasoso para o líquido;

6.fusível, que protege o sistema contra eventuais sobrecargas;

7.painel de controle luminoso, que fornece informações visuais, conforme o manual do operador;

8. filtro secador;

9.tubo capilar. 
Foto 8 - Refrigerador fotovoltaico

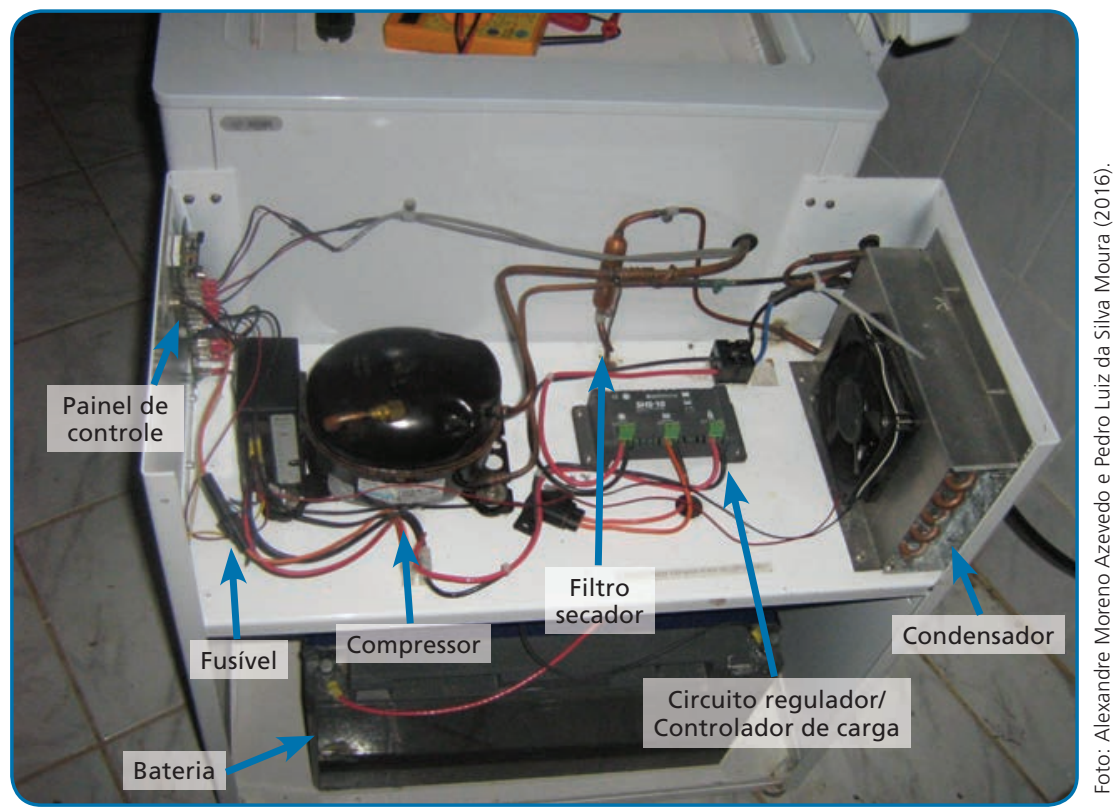

Vimos que os refrigeradores ou os equipamentos de refrigeração são importantes aliados na conservação dos imunobiológicos, mas outros materiais também são utilizados com o mesmo propósito. São eles: caixas térmicas e monitores de registro de temperatura.

\section{Caixas térmicas}

Embora não possuam os mesmos elementos de um sistema de refrigeração, as caixas térmicas são bastante utilizadas nas atividades cotidianas de vacinação. Elas podem ser de dois tipos: de poliestireno e poliuretano.

Por sua baixa confiabilidade, precário controle de temperatura e ausência de registros das variações internas de temperatura, tem-se reco-

Figura 9 - Câmara de conservação portátil

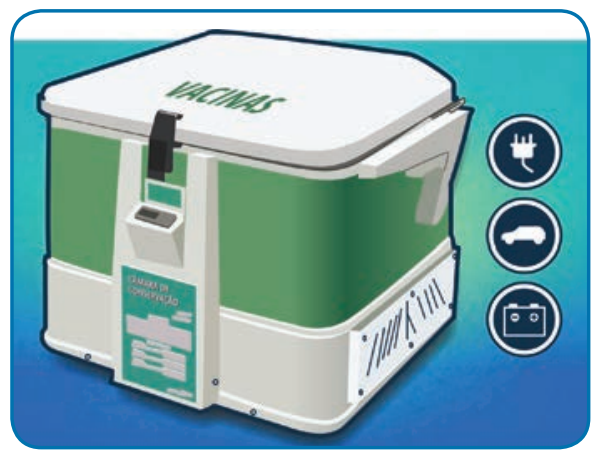
mendado que as caixas de poliestireno expandido (isopor) sejam substituídas pelas de poliuretano, já que estas são mais duráveis, resistentes e de fácil higienização (BRASIL, 2013).

As caixas térmicas têm papel importante na manutenção da temperatura do imunobiológico, seja nas atividades diárias ou durante seu transporte. No entanto, atualmente, já existe alternativa para 
substituí-las, em virtude dos problemas que podem apresentar. Está disponível no mercado brasileiro a câmara de conservação portátil, com registro na Anvisa, para transporte de termolábeis. Ela é dotada de controle e registradores adequados ao armazenamento de vacinas e possui bateria para falta de energia ou instabilidade na rede; alguns modelos podem ser ligados em veículos automotores com saída de 12 volts e/ou à rede elétrica convencional.

\section{Lembre-se!}

A escolha de quaisquer desses equipamentos dependerá da atividade a ser realizada, do tempo necessário para realização, do quantitativo dos imunobiológicos etc. Não podemos esquecer que a escolha também deve levar em conta o tipo de material, a densidade e especificidade, conforme já apresentado no capítulo anterior sobre termologia. Precisamos associar aqueles conhecimentos às informações sobre refrigeração para uma atuação consciente e calcada em bases técnicas sólidas.

\section{Monitores de registro de temperatura para refrigeradores de vacinas}

Além dos refrigeradores e derivados, outros equipamentos são utilizados na conservação dos imunobiológicos. Como mencionado anteriormente, os monitores de temperatura (data loggers) e os termômetros são importantes aliados para a manutenção, o monitoramento e o controle da temperatura dos imunobiológicos. Precisamos, assim como fizemos com os refrigeradores, conhecer a base de seu funcionamento e as principais características e recomendações durante sua utilização.

\section{Data loggers}

São pequenos dispositivos eletrônicos que mensuram as temperaturas em intervalos preestabelecidos, apresentando os resultados durante um período de tempo. Eles podem ter forma e tamanhos variados. Cada data logger contém uma miniatura de computador, devendo ser configurado e programado para registrar as temperaturas em intervalos de acordo com o que se deseja.

Alguns refrigeradores específicos para vacinas têm um data logger embutido, e seus registros devem ser realizados de acordo com as orientações do fabricante. Os loggers precisam ser programados por intermédio do computador. Uma vez programados, são desconectados do computador 
e colocados no refrigerador de vacinas, onde funcionarão independentemente, com sua própria bateria, até que o registro seja baixado para o computador. O objetivo dos loggers é fornecer uma série ou um mapa das temperaturas do equipamento e das vacinas.

Avanços na tecnologia têm permitido a confecção de inúmeros tipos de loggers. Entretanto, todos fornecem informações básicas, como:

* indicação precisa das temperaturas do refrigerador e das vacinas.

Podem ser usados para mapear "pontos frios" ou investigar problemas, identificando as áreas seguras para o armazenamento de vacinas;

*egistro e armazenamento dos dados de temperatura para serem consultados oportunamente;

* monitoramento da temperatura dos equipamentos e produtos; * identificação das áreas onde as vacinas podem congelar.

\section{Atenção!}

- As temperaturas mínima/máxima devem ser registradas duas vezes ao dia, de forma manual, independentemente do data logger, como forma de segurança e de detecção precoce de qualquer rotura na rede de frio.

- Caso o data logger seja usado para o monitoramento rotineiro das temperaturas, em lugar de um termômetro de mínimo-máxima, ele deve ter um display visual de temperaturas mínimo-máxima para permitir os registros em tempo real. Visando, também, à segurança das vacinas, os data loggers podem ser programados para acionar o alarme quando a temperatura estiver fora da faixa de $+2^{\circ} \mathrm{C} \mathrm{a}+8^{\circ} \mathrm{C}$.

\section{Considerações para aquisição dos data loggers}

Antes de efetuar a compra de data loggers, assim como de qualquer outro equipamento, os profissionais da saúde ou gestores devem obter todas as informações a respeito do produto com os fabricantes. É importante que esteja claro o tipo de uso do logger, ou seja, se será usado como método permanente de monitoramento das temperaturas; se pode ser configurado para registros de temperatura em intervalos, conforme desejado; se é de fácil uso, especialmente em relação ao registro e ao download dos dados; se a temperatura corrente é visível; se tem display para visualização das temperaturas máxima e mínima etc.

A precisão do logger, bem como informações sobre a vida média da bateria são também importantes para a aquisição do monitor, pois permite 
que o gestor obtenha um equipamento adequado às necessidades do serviço, evitando desgastes por mau uso e, consequentemente, gastos desnecessários. Recomenda-se data logger preciso, com variação máxima de $\pm 0,1{ }^{\circ} \mathrm{C}$, e que sua precisão possa ser verificada pelo usuário, além do técnico. Esses são aspectos que devem ser considerados no momento da compra.

\section{Termômetros}

Os termômetros são, também, essenciais no monitoramento da temperatura de um refrigerador e do próprio imunobiológico. Requerem verificações anuais, para assegurar precisão em sua mensuração. Visando essa precisão, é importante verificar as baterias, evitando que fiquem descarregadas, e proceder à troca destas, quando necessário, ou, no mínimo, a cada 12 meses. Avaliar possíveis danos também no cabo extensor, em caso de termômetro digital, pode contribuir para a precisão do termômetro, uma vez que danos desse tipo podem afetar a leitura dos valores fornecidos pelo instrumento.

A precisão dos monitores de temperatura como logger e termômetros deve ser uma preocupação constante do especialista ou gestor da rede de frio. Em ambos, o grau aceitável de precisão deve variar entre $\pm 0,1^{\circ} \mathrm{C}$, devendo ser sempre verificada com o fabricante a precisão esperada para aquele tipo de logger ou termômetro. Recomenda-se a verificação da precisão do termômetro após a troca da bateria ou em situações de problemas na rede de frio, conforme avaliação do gestor.

\section{Aspectos a considerar na localização do refrigerador de vacinas}

A escolha do refrigerador e o conhecimento sobre seu funcionamento, juntamente com uma equipe capacitada, são elos determinantes da eficiência na rede de frio. Além de conhecermos a base de funcionamento dos equipamentos, é preciso considerar as condições do ambiente em que serão instalados, uma vez que isso influenciará seu rendimento e funcionamento.

Vários aspectos devem ser considerados ao se instalar um refrigerador na sala de vacinas, e alguns já são bem conhecidos dos profissionais de saúde que atuam na imunização. O objetivo será sempre o mesmo: permitir que o refrigerador funcione adequadamente, com o mínimo possível de desgaste e em condições que permitam a manutenção da temperatura interna. É sempre recomendado que o refrigerador:

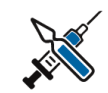

É fundamental que toda a equipe seja capacitada para o manuseio do data logger e para interpretação de seus registros, pois os dados fornecidos auxiliarão os profissionais da rede de frio ou da vacinação a conhecer o funcionamento de seus refrigeradores. 


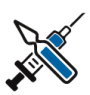

Os refrigeradores/câmaras refrigeradas necessitam de espaço livre dos lados e atrás deles para prevenir acúmulo de calor. Consulte o fabricante para conhecer as dimensões recomendadas.
* seja instalado em locais fora do alcance da luz solar direta ou de lâmpadas incandescentes e que permitam a circulação do ar;

* não fique encostado nas paredes da sala, para não estar em contato direto com as mudanças de temperatura do ambiente;

* esteja localizado em áreas seguras, para reduzir riscos como: desligamento da tomada, abertura desnecessária da porta do refrigerador, locais/salas de grandes flutuações da temperatura ambiente (que podem afetar a temperatura do refrigerador) etc.

A desconexão acidental do refrigerador de sua fonte de energia pode causar dano à vacina, se não for notada imediatamente. Uma forma de evitar a situação é colocar um adesivo acima do interruptor e da tomada. Outro recurso que pode ser usado é um dispositivo que previna o desligamento de refrigeradores da fonte de energia. Qualquer que seja o recurso utilizado, o profissional deve estar atento a esses possíveis riscos, uma vez que as grandes perdas de vacinas estão relacionadas com falhas desse tipo.

\section{Estabilização da temperatura do refrigerador de vacinas}

O profissional de saúde da rede de frio ou de imunização é elemento essencial na manutenção da temperatura das vacinas. Sua ação é decisiva!

Por isso, a equipe deve estar familiarizada com o refrigerador de vacinas e registrar as temperaturas em várias seções do equipamento, como: cada prateleira, de cima a baixo, da frente para o fundo e de lado a lado. A estabilização do refrigerador antes da armazenagem das vacinas minimiza a probabilidade de elas serem expostas a variações de temperatura, que afetam a sua eficácia. É importante lembrar que, em alguns refrigeradores, a área mais fria é a prateleira de cima e, em outros, a frente da prateleira inferior. Por isso, o profissional deve ter atenção, pois os modelos de refrigeradores podem diferir de pontos ou áreas de maior ou menor frio, mesmo que sejam do mesmo fabricante.

A identificação dos "pontos frios" pode ser feita pelo monitoramento detalhado do refrigerador, por exemplo, colocando data loggers ou termômetros em todas as áreas do equipamento e observando as temperaturas diferentes, antes de usar o refrigerador para armazenar vacinas. Recomenda-se monitorar cada área por, pelo menos, 24 horas. Essa conduta permite capturar todas as flutuações que ocorram. 
Dependendo do tipo e do número de monitores que se tenha na unidade, o monitoramento abrangente da temperatura pode levar algum tempo para ser concluído. Durante a avaliação dos "pontos frios", indica-se usar uma "massa fria", por exemplo, garrafas com água, imitando um lote de vacina, uma vez que os refrigeradores se comportam diferentemente quando estão vazios.

A verificação e o registro das temperaturas de um refrigerador de vacinas permitem que sejam identificados problemas ou falhas no funcionamento do equipamento e flutuações da temperatura ao longo da jornada de trabalho, evitando perdas de vacina ou de sua potência.

\section{Manutenção dos refrigeradores e equipamentos de armazenagem de vacinas}

A maioria das falhas que ocorrem na câmara refrigerada/refrigerador tem, como consequência, variação da temperatura interna para mais ou para menos, o que alterará a conservação do que estiver em seu interior. O controle constante da temperatura interna, por meio de um termômetro, se faz necessário.

Atualmente, recomenda-se não só o uso do termômetro, mas também o de termorregistradores, que têm como principal característica registrar as variações de temperatura ao longo do tempo. Esses equipamentos indicam se o sistema de refrigeração apresenta alguma falha.

Ao apresentarem falhas, alguns componentes do sistema de refrigeração podem levar ao desligamento total da câmara refrigerada/refrigerador. Quando isso ocorre, em pouco tempo a temperatura se elevará em seu interior, inutilizando os imunobiológicos. Portanto, prevenir a ocorrência de falhas é o objetivo que devemos almejar.

- É importante lembrar que o gestor da rede de frio deve buscar sempre o auxílio do técnico para a resolução do problema. Isso não impede que o profissional usuário conheça o funcionamento dos equipamentos e de seus elementos.

- A manutenção adequada é outra forma de segurança do uso dos equipamentos. 
Para saber mais sobre manutenção de equipamentos, consulte a NBR 5.462, de 1994, que versa sobre confiabilidade e mantenabilidade. Verifique, em seu serviço, se há um exemplar da norma.
Na rede de frio, para os equipamentos câmara refrigerada/refrigerador, destacamos três tipos de manutenção: preventiva, corretiva e preditiva.

1. Manutenção preventiva: realizada em períodos predeterminados ou de acordo com o manual do fabricante, respeitando-se componentes a serem substituídos ou verificados, conforme utilização e frequência de uso do equipamento. Por exemplo, teste de efetividade de compressão do compressor.

Para que possamos manter a câmara refrigerada/refrigerador em perfeitas condições de uso, por um período prolongado de tempo, evitando que se percam imunobiológicos, alguns cuidados devem ser tomados periodicamente, tais como:

* verificar a borracha da porta do refrigerador/câmara refrigerada;

* verificar as dobradiças da porta do refrigerador/câmara refrigerada;

verificar o nivelamento do refrigerador/câmara refrigerada;

verificar se o cabo de alimentação está íntegro;

verificar se as tomadas (parede e cabo) estão em bom estado;

* observar se há oscilação excessiva de energia elétrica no local; em caso positivo, instalar um nobreak adequado à potência da câmara refrigerada/refrigerador, ou solicitar verificação na instalação elétrica;

* não utilizar a câmara refrigerada/refrigerador para outros fins; * não instalar a câmara refrigerada/refrigerador sem pés;

*ão instalar a câmara refrigerada/refrigerador em locais de piso instável; * evitar arrastar a câmara refrigerada/refrigerador;

* instalar a câmara refrigerada/refrigerador em local abrigado do tempo (nem muito frio, nem muito quente);

*ão colocar a câmara refrigerada/refrigerador muito próximo à parede, nem uma de costas para a outra;

* abrir a porta somente quando necessário.

2. Manutenção corretiva: realizada após a ocorrência do defeito, restaurando suas condições originais de funcionamento. Por exemplo, troca da borracha (gaxeta) de vedação da porta.

3. Manutenção preditiva: realizada através do acompanhamento de indicadores previamente estabelecidos, cujos limites e tolerâncias admissíveis não devem ser ultrapassados. Por exemplo, limites de vibrações, desgaste de componentes, alterações na temperatura etc. 
Na rede de frio, consideram-se limites e tolerâncias admissíveis para

imunobiológicos as temperaturas entre $+2^{\circ} \mathrm{C} \mathrm{e}+8^{\circ} \mathrm{C}$.

\section{Para refletir}

Quais tipos de manutenção são realizados no seu trabalho?

Se não acontecem todos eles, você saberia o motivo? Em que você

pode contribuir para a manutenção adequada dos refrigeradores do

seu serviço?

\section{O Quadro 1 apresenta pequenos problemas e soluções que podem} ocorrer no dia a dia com os equipamentos de refrigeração utilizados na rede de frio.

Quadro 1 - Problemas frequentes com refrigeradores

\begin{tabular}{|c|c|c|}
\hline Problema & Causa & Solução \\
\hline Não liga. & Falta de energia/voltagem da rede baixa. & $\begin{array}{l}\text { Verificar o fusível, a tomada, o cabo, } \\
\text { o disjuntor; verificar se a voltagem da } \\
\text { concessionária local está de acordo com o } \\
\text { padrão local. }\end{array}$ \\
\hline $\begin{array}{l}\text { Compressor que } \\
\text { liga e desliga com } \\
\text { frequência anormal. }\end{array}$ & Voltagem muito alta ou muito baixa. & $\begin{array}{l}\text { Verificar se a voltagem da concessionária local } \\
\text { está de acordo com o padrão local. }\end{array}$ \\
\hline $\begin{array}{l}\text { Compressor com } \\
\text { zumbido e que não } \\
\text { liga. }\end{array}$ & Baixa voltagem. & $\begin{array}{l}\text { Verificar se a voltagem da concessionária local } \\
\text { está de acordo com o padrão local; na tomada } \\
\text { utilizada, não deve haver outros aparelhos } \\
\text { ligados. }\end{array}$ \\
\hline $\begin{array}{l}\text { Compressor ligado } \\
\text { excessivamente. }\end{array}$ & $\begin{array}{l}\text { Frequente abertura de porta; borracha da porta danificada; } \\
\text { lâmpada interna acesa continuamente (a maioria das } \\
\text { lâmpadas usadas nos refrigeradores é incandescente, gera } \\
\text { calor, o que eleva a temperatura interna do equipamento, } \\
\text { ocasionando a armação do compressor); material impedindo } \\
\text { a circulação de ar no condensador; material quente } \\
\text { colocado repentina e excessivamente na câmara refrigerada/ } \\
\text { refrigerador. Dobradiças da porta com defeito, o que } \\
\text { ocasiona desnivelamento da porta, permitindo entrada de ar } \\
\text { quente e acionando o compressor. }\end{array}$ & $\begin{array}{l}\text { Evitar abrir a porta desnecessariamente; } \\
\text { verificar interruptor da porta; não utilizar } \\
\text { materiais que impeçam a circulação de } \\
\text { ar na parte de trás do equipamento; não } \\
\text { colocar materiais em grande quantidade e } \\
\text { de uma única vez no equipamento. Trocar as } \\
\text { dobradiças. }\end{array}$ \\
\hline Ruído anormal. & Desnivelado/encostado na parede. & $\begin{array}{l}\text { Regular os pés; afastar da parede; colocar } \\
\text { calço, se necessário; verificar se o piso é estável. }\end{array}$ \\
\hline Interior muito quente. & $\begin{array}{l}\text { Temperatura ambiente muito alta; excesso de gelo no } \\
\text { evaporador; material encostado no bulbo do termostato; } \\
\text { termostato na posição errada. }\end{array}$ & $\begin{array}{l}\text { Instalar equipamento em local arejado; degelar } \\
\text { periodicamente; afastar material do bulbo do } \\
\text { termostato; colocar termostato compatível com } \\
\text { a temperatura externa. }\end{array}$ \\
\hline
\end{tabular}


Quadro 1 - Problemas frequentes com refrigeradores (cont.)

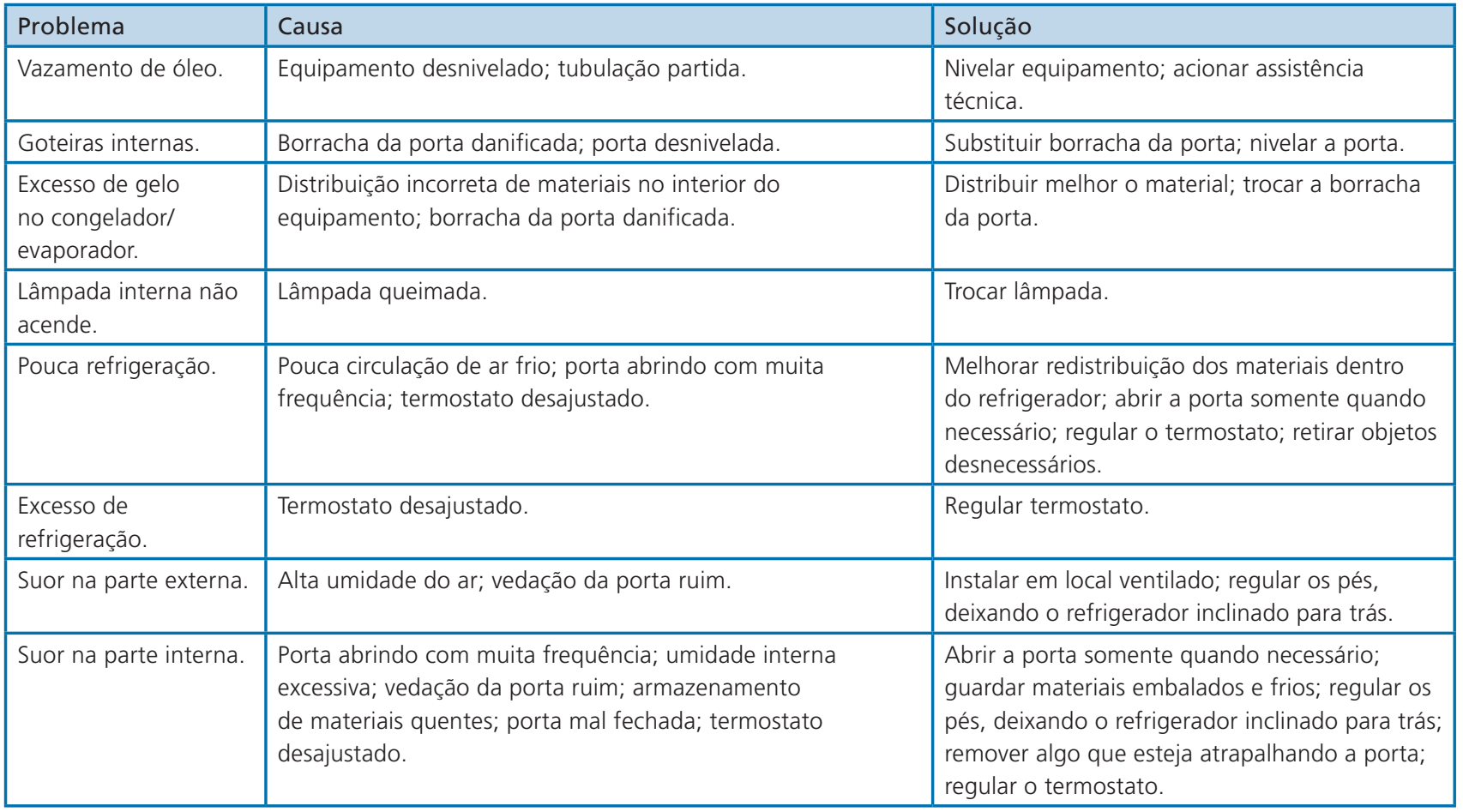

\section{Considerações finais}

Ao longo deste capítulo, entendemos que o controle da temperatura dos diversos equipamentos de conservação de imunobiológicos é de fundamental importância para que os produtos mantenham a sua potência em todas as etapas da rede de frio, até o seu destino final. Aprendemos que os cuidados com esses equipamentos incluem: seguir as recomendações do manual do fabricante, acompanhar o seu funcionamento e comunicar imediatamente qualquer defeito, por mais simples que seja, ao responsável pelo contato com a equipe técnica.

São procedimentos como esses que garantem a manutenção dos equipamentos em perfeitas condições de operação. Possivelmente, você será a primeira pessoa que identificará um indício de mau funcionamento em uma câmara refrigerada/refrigerador; quanto mais rápida for essa identificação e a comunicação do indício, mais rapidamente poderá ser efetuado o conserto. A demora em informar um mau funcionamento só agravará o problema. Portanto, você é parte fundamental de todo esse processo! E para garantir o êxito, contamos com você na busca do conhecimento que fundamente sua ação! 


\section{Referências}

ASSOCIAÇÃO BRASILEIRA DE NORMAS TÉCNICAS. NBR 5.462:1994: confiabilidade e mantenabilidade. Rio de Janeiro, 1994.

BRASIL. Ministério da Saúde. Secretaria de Vigilância em Saúde. Departamento de Vigilância das Doenças Transmissíveis. Manual de rede de frio do Programa Nacional de Imunizações. 4. ed. Brasília, DF, 2013. Disponível em: <http://portalsaude.saude.gov.br/images/pdf/2014/julho/03/ manual-rede-frio.pdf>. Acesso em: 20 abr. 2014.

EMBRACO. Componentes elétricos dos compressores de revenda. Joinville, 2009. Disponível em: <http://www.embraco.com/DesktopModules/DownloadsAdmin/Arquivos/01019.pdf >. Acesso em: 3 ago. 2016.

FERRAZ, F. Refrigeração. Salvador: Centro Federal de Educação Tecnológica da Bahia, 2008. Apostila.

LAUAND, C. A. Manual prático de geladeiras: refrigeração industrial e residencial. São Paulo: Hemus, 2004.

MENDES, L. M. O. Refrigeração e ar-condicionado: teoria, prática, defeitos. São Paulo: Ediouro, 1994.

MENEZES, M. S. Refrigeração e ar-condicionado. Passo Fundo: Universidade de Passo Fundo/ Faculdade de Engenharia e Arquitetura, 2005.

PORTAL DA REFRIGERAÇÃO. Filtro secador. [S.I.], 2008. Disponível em: <http://www.refrigeracao. net/Topicos/filtro_seca.htm>. Acesso em: 3 ago. 2016.

SENAI. Curso de refrigeração mecânica. São Paulo, 2003. Apostila.

SILVA, J. G. Introdução à tecnologia da refrigeração e da climatização. São Paulo: Artliber, 2003. 



\section{Gestão da rede de frio de imunobiológicos}

André Silva Cardoso, Clayton Bernardo da Costa, Cristiane Pereira de Barros, Felipe da Silva Furtado, João Leonel Batista Estery, Walquíria Gonçalves dos Santos Teles e Yeda Célia Silva Eugênio

Os imunobiológicos precisam ser mantidos em determinada temperatura para lhes conferir proteção. Para tal, são conservados por meio de um sistema que envolve diversos procedimentos, executados de forma sincrônica e articulada, denominado cadeia ou rede de frio. Para entendermos esse sistema, várias informações foram apresentadas ao longo deste livro, de modo a favorecer a compreensão sobre a rede de frio e sua importância, os fundamentos que balizam essa rede, tais como os princípios da física relacionados à temperatura dos imunobiológicos, o efeito da temperatura sobre esses produtos e o papel da refrigeração para a garantia da manutenção da temperatura apropriada e, consequentemente, de sua qualidade.

O sistema, portanto, envolve um complexo logístico em que os imunobiológicos, para atingirem seu destino, precisam percorrer um longo trajeto, cercado de cuidados indispensáveis até chegarem com segurança à população, conservando suas propriedades imunogênicas. O conjunto de procedimentos que integram esse sistema inclui armazenamento, transporte, distribuição e manipulação das vacinas em condições adequadas de refrigeração, contando, para isso, com equipamentos e equipe técnica especializada.

Todos esses procedimentos visam, essencialmente, garantir a manutenção da temperatura dos imunobiológicos, visto que são termolábeis e/ ou fotossensíveis e, obrigatoriamente, necessitam de armazenamento adequado para que suas características sejam mantidas.

Para que possamos conhecer e entender melhor a rede de frio de imunobiológicos, abordamos, neste capítulo, a forma de sua organização 
e estruturação, as etapas envolvidas no processo e os insumos utilizados, demonstrando a importância do planejamento e do trabalho em equipe para a manutenção da termoestabilidade dos imunobiológicos, que depende, em sua essência, do funcionamento eficiente de cada elemento ou elo dessa complexa rede.

\section{Definindo a rede de frio}

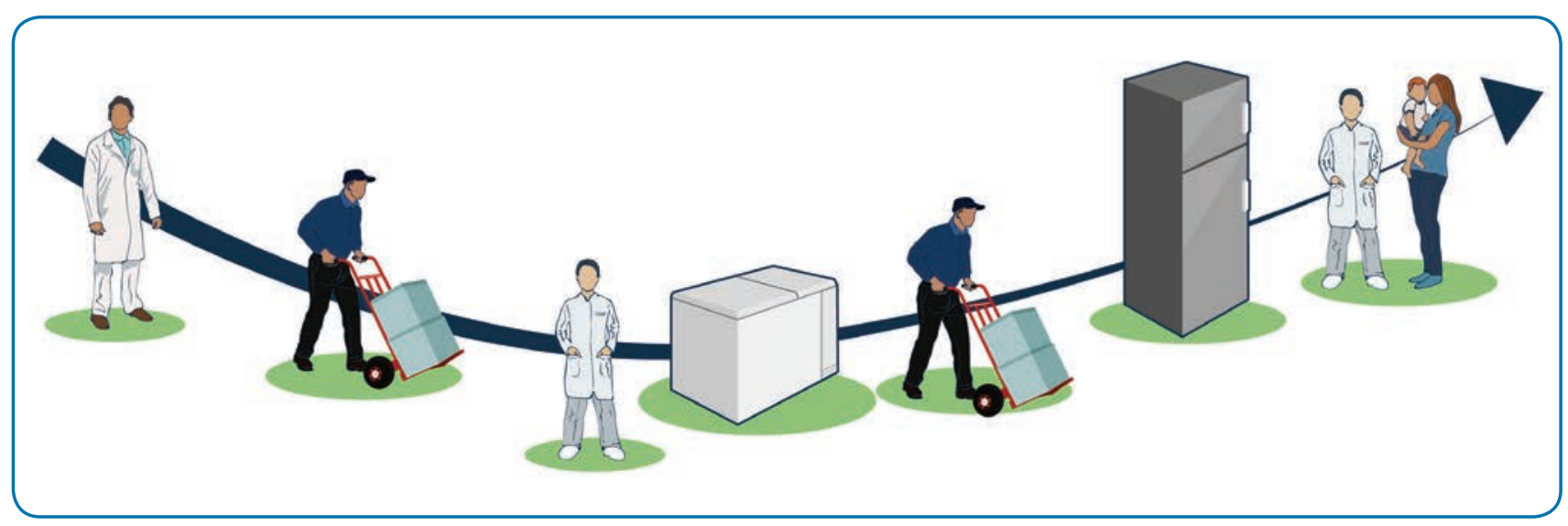

Prosseguindo, precisamos, inicialmente, compreender o que significa rede de frio de imunobiológicos.

Rede de frio é o processo de recebimento, armazenamento, conservação, manipulação, distribuição e transporte dos imunobiológicos (AGÊNCIA NACIONAL DE VIGILÂNCIA SANITÁRIA, 2007). Em outras palavras, podemos entendê-la como um processo logístico, composto por um conjunto de procedimentos destinados à conservação dos imunobiológicos, em temperatura ideal para que possam, de fato, imunizar.

Para isso, deve funcionar de forma integrada e articulada como os elos ou as tramas que se interligam e formam uma rede, garantindo a temperatura dos imunobiológicos desde sua fabricação até a chegada ao destino final (usuário).

Qualquer alteração ou quebra na rede ou em parte dela (como manuseio inadequado, equipamento com defeito, ou falta de energia elétrica) interrompe o processo de refrigeração, comprometendo a potência dos imunobiológicos. Essa quebra, ou rompimento, pode ocorrer em qualquer etapa e é denominada de rotura. Isso significa que, a qualquer quebra na temperatura ou condição inadequada de manipulação do imunobiológico, haverá "rotura na rede de frio", conforme apresenta a Figura 1, influenciando de forma decisiva a qualidade da vacina. Em 
alguns países, como, por exemplo, na Austrália, a rotura é conhecida como "rotura da cadeia de frio".

Figura 1 - Rotura da rede de frio

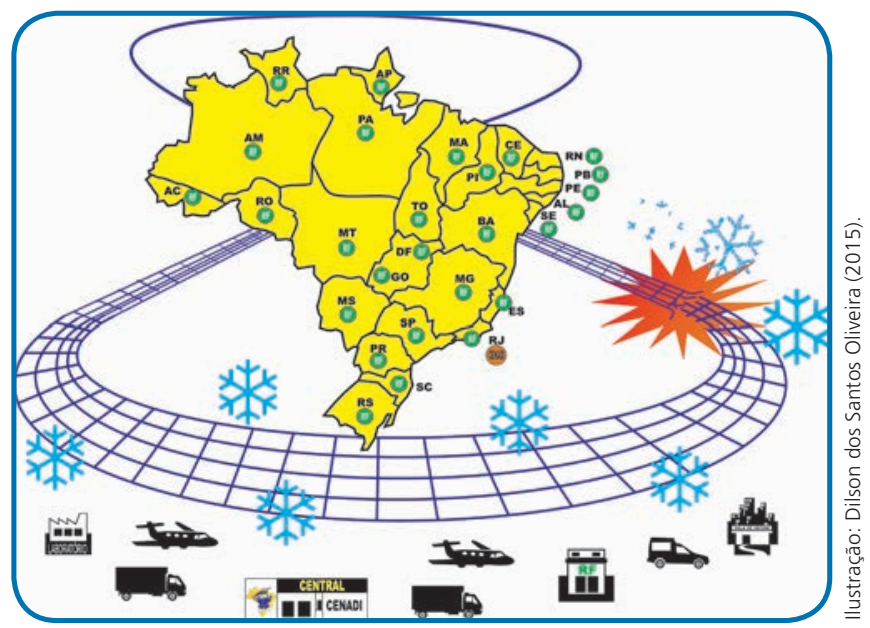

\section{Importante!}

Na ocorrência de uma rotura da rede de frio, devem-se seguir as recomendações do Ministério da Saúde e/ou das secretarias estaduais e municipais de saúde e/ou os protocolos estabelecidos, conforme constam nas publicações desses órgãos.

Para que se tenha uma rede de frio confiável (portanto, sem roturas) e se possa garantir a qualidade dos imunobiológicos, alguns elementos são necessários, como:

equipamentos em condições de armazenar, transportar e distribuir com segurança;

* trabalhadores da rede de frio devidamente capacitados, que gerenciem o armazenamento, façam o transporte e a distribuição adequadamente;

* instalações apropriadas e adequadas ao armazenamento nos diferentes níveis: nacional, estadual, regional, municipal e unidade local.

Além dessas questões, é preciso considerar que as vacinas, substâncias biológicas delicadas, podem se tornar menos eficazes ou destruídas se forem: congeladas, expostas ao calor, ou à luz solar direta ou luz UV, incluindo a fluorescente. Quando expostas, repetidamente, a temperaturas fora da faixa recomendada, terão perda de potência acumulativamente, sem que se possa reverter esse processo.

\section{se?}

Garantia de qualidade da vacina é sinônimo de controle rigoroso das condições de conservação, transporte, armazenamento e distribuição. Sendo assim, a manutenção das condições da rede de frio e a correta avaliação dos fatores que podem afetar a qualidade dos imunobiológicos são fundamentais.

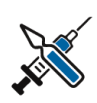

Por isso, se não protegermos nossas vacinas, elas não protegerão nossa comunidade! 
O efeito das variações de temperatura sobre as vacinas é discutido no Capítulo 6, "A rede de frio e a importância da temperatura dos imunobiológicos", deste livro.
A depender de situações epidemiológicas e/ou emergenciais específicas, os fluxos podem ocorrer de forma horizontalizada. Por necessidade, um estado pode realizar algumas atividades diretamente com outro estado ou, na mesma perspectiva, um município com outro município (por exemplo, no caso de necessidade excepcional de envio de imunobiológicos de um local para o outro). Qualquer que seja o fluxo, este deverá ser feito sob orientação geral do órgão imediatamente superior.
Portanto, todas as vacinas devem ser armazenadas e transportadas dentro da faixa de temperatura recomendada, em todos os momentos; todas as pessoas responsáveis pelo seu manuseio, em qualquer fase, devem entender a importância de uma gestão eficiente dos imunobiológicos, perseguindo sempre os $5^{\circ} \mathrm{C}$.

\section{Por que perseguir os $5^{\circ} \mathrm{C}$ ?}

Porque 5 graus Celsius $\left({ }^{\circ} \mathrm{C}\right)$ é o ponto médio entre $+2^{\circ} \mathrm{C}-+8^{\circ} \mathrm{C}$, que é a faixa de temperatura recomendada para o armazenamento de vacinas. Muitas são danificadas ou destruídas em temperaturas fora dessa faixa, lembrando que algumas são sensíveis ao calor, e outras não suportam o congelamento. Mantendo-se a temperatura a $5^{\circ} \mathrm{C}$, garante-se uma faixa de segurança, evitando aquecimento (mais de $8^{\circ} \mathrm{C}$ ) ou congelamento (menos de $2^{\circ} \mathrm{C}$ ).

Consolidados esses conceitos, vamos entender como a rede está estruturada.

\section{Estrutura da rede de frio de imunobiológicos}

Para que se possa garantir a manutenção da qualidade das vacinas, é necessário contar com uma rede estruturada. Com esse objetivo, a rede de frio de imunobiológicos permeia as cinco esferas administrativas, organizando-se em instâncias, com fluxos de distribuição e armazenamento basicamente verticalizados (BRASIL, 2013), mas que devem trabalhar de maneira articulada. As instâncias da rede de frio de imunobiológicos são as mesmas das esferas administrativas: nacional, estadual, regional, municipal e local.

\section{Instância ou nível nacional}

A instância nacional é representada pelo Ministério da Saúde, no qual está inserido o Programa Nacional de Imunizações (PNI), que tem como atribuição, por meio da sua Coordenação Geral (CGPNI), a definição de normas e parâmetros técnicos para utilização e distribuição dos imunobiológicos.

A CGPNI está organizada por áreas técnicas, com um coordenador geral. Cada área é responsável por atividades específicas. Em 2014, essas áreas se organizavam da seguinte forma:

* Gerência Técnica Científica e Normatização; 
* Gerência Técnica Gestão de Insumos;

* Gerência Técnica de Apoio à Gestão;

* Gerência Técnica de Apoio Administrativo.

A área responsável por todas as ações relativas à gestão e ao funcionamento da rede de frio é a Gerência Técnica Gestão de Insumos. Entre suas atribuições estão o planejamento, a aquisição e a distribuição dos imunobiológicos para as 27 unidades federadas, bem como o acompanhamento sistemático do controle de qualidade dos produtos adquiridos e distribuídos.

Para a operacionalização da logística de distribuição dos imunobiológicos às demais instâncias, a CGPNI conta com um complexo logístico, que representa a instância nacional, denominado Central Nacional de Armazenagem e Distribuição de Imunobiológicos (Cenadi). Mais adiante, trataremos especificamente dessa instância.

Diferentes vias (terrestre, aérea etc.) são usadas para o transporte dos imunobiológicos do laboratório produtor até a Cenadi. Em geral, a via aérea é utilizada para o imunobiológico produzido fora do país; no caso de laboratório nacional, são usuais tanto a via terrestre como a aérea. Em qualquer das vias, o controle da temperatura durante todo o trajeto é fundamental, como também a logística utilizada, os equipamentos, os tipos de embalagens usados etc., e a cada instância compete a responsabilidade pelo cumprimento e monitoramento de todos esses aspectos e/ou condições para o transporte correto.

O caminho dos imunobiológicos se inicia na instância nacional, representada pelo Ministério da Saúde (MS-CGPNI), que libera a distribuição. A partir do momento que saem dos laboratórios produtores e são armazenados na Cenadi, ela se torna responsável pela qualidade e segurança dos imunobiológicos no que se refere a organização, distribuição, controle de temperatura e transporte, até estes serem entregues às centrais estaduais de imunização.

\section{Instância ou nível estadual}

Esse nível de gestão é representado pelas Secretarias Estaduais de Saúde, por meio da Coordenação Estadual de Imunizações, responsável pela rede de frio no nível estadual. O transporte dos imunobiológicos da instância central até a estadual depende da disponibilidade da malha aérea e das condições relacionadas ao percurso e ao local do destino, 
Foto 1 - Cenadi

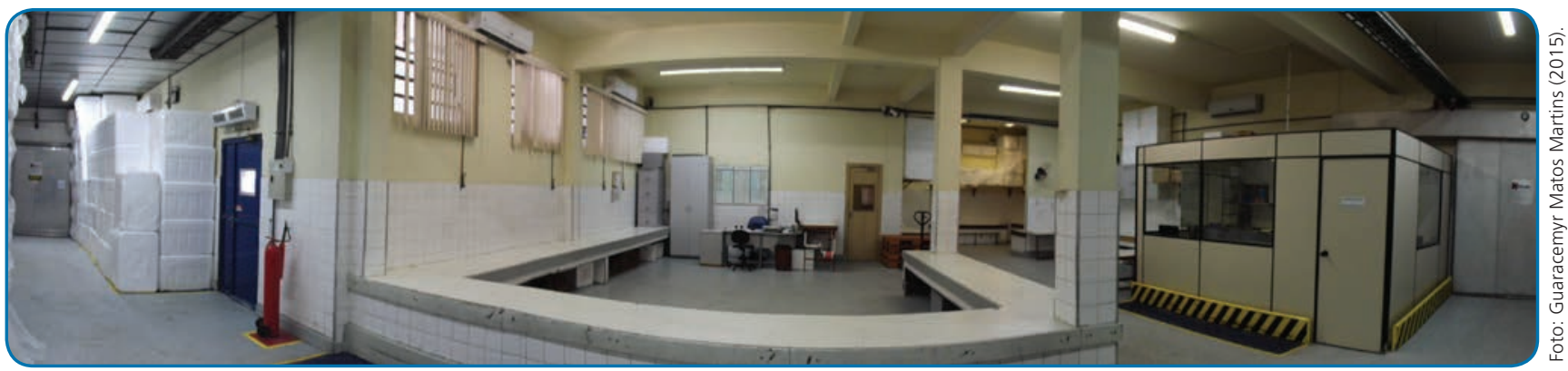

que deve apresentar condições adequadas para o armazenamento dos produtos.

Para se construir uma rede de frio nesse nível ou instância, é necessária uma estrutura mínima em que sejam previstas áreas físicas que disponham de (BRASIL, 2013):

* espaço para armazenagem e distribuição, com câmaras frigoríficas positivas e negativas. Dependendo da demanda, poderá ter almoxarifado, sala de preparo, área de recebimento, inspeção e distribuição de imunobiológicos;

Foto 2 - Acesso à câmara fria na Cenadi

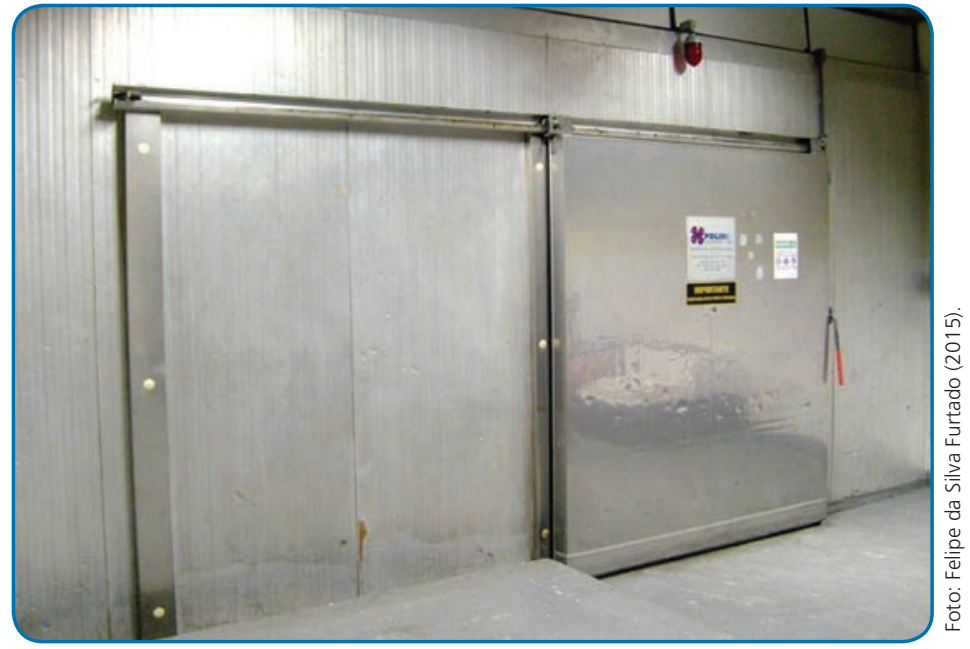

* área com previsão de espaços adequados às atividades de gestão e administração, bem como sala para realização de reuniões, planejamento, educação em saúde, formação e capacitação de recursos humanos; 
Foto 3 - Sala de reunião da Cenadi

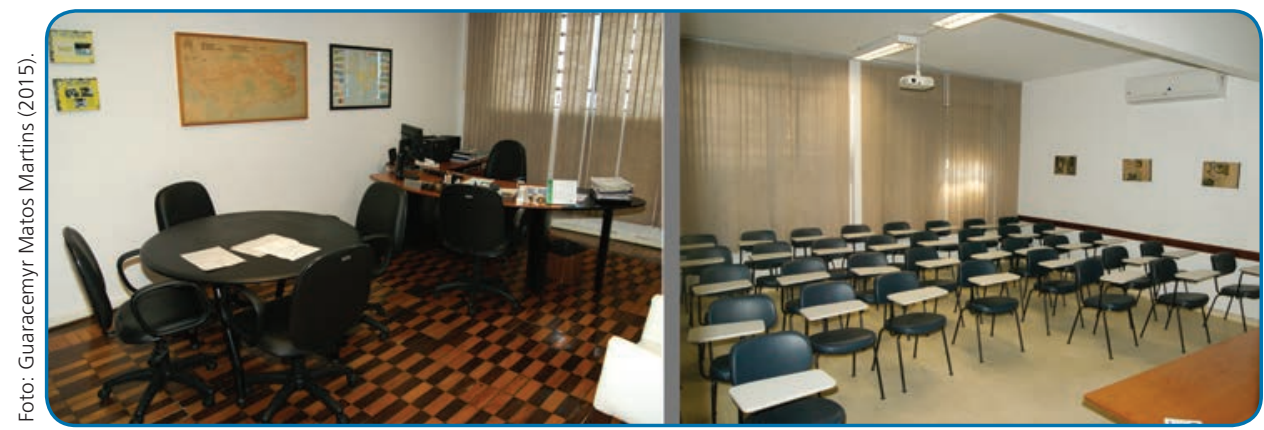

* estrutura adequada à carga e descarga de imunobiológicos; área para gerador, para garantia do sistema back up de geração de energia elétrica; espaço para instalação de equipamentos condensadores, depósito de material de limpeza e higiene; e ambiente para seleção e guarda temporária de resíduos, além de espaços para copa, recepção/espera e banheiros.
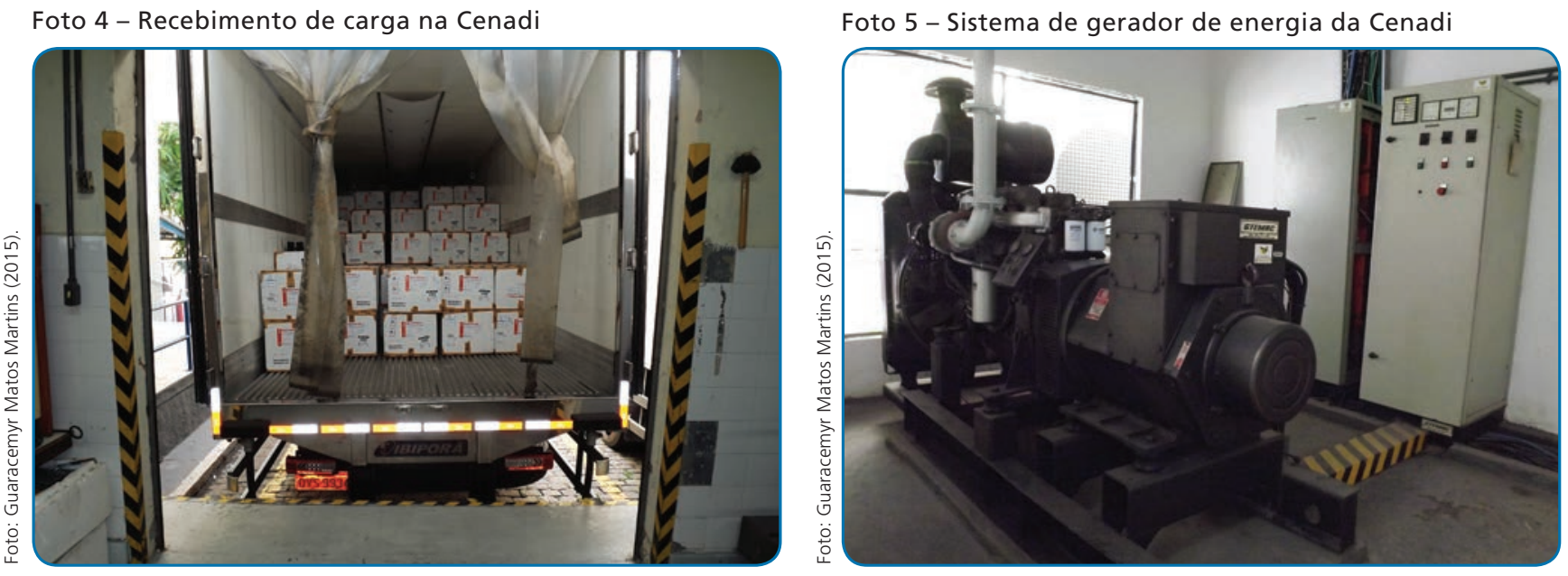

Esse nível ou instância é composto de estruturas existentes nas 27 unidades federativas do país, havendo, portanto, 27 centrais estaduais de armazenamento e distribuição de imunobiológicos, que estão geralmente localizadas nas capitais e sob a responsabilidade técnico-administrativa das coordenações estaduais de imunizações das Secretarias Estaduais de Saúde (BRASIL, 2013). A coordenação estadual é responsável por distribuir os imunobiológicos para os municípios, por meio da instância regional, quando existir.

A partir do momento em que o estado recebe os imunobiológicos enviados pela Cenadi, ele se torna responsável por toda a logística que 
os envolve, ou seja, recebimento, armazenamento, distribuição, e pela qualidade e segurança dos produtos.

A CGPNI trabalha articulada com a instância estadual no planejamento das atividades de vacinação, considerando o Calendário Nacional de Vacinação e a situação epidemiológica vivenciada. Esse planejamento visa ao abastecimento de todas as salas de vacina do estado, atendendo às demandas específicas de cada localidade, respeitando as condições adequadas e o processo logístico necessário para a conservação dos imunobiológicos, seja no nível municipal ou local.

\section{Instância ou nível regional}

A instância regional é representada pelas centrais regionais de rede de frio, subordinadas às Secretarias Estaduais de Saúde, e tem, como função, distribuir os imunobiológicos aos municípios de sua abrangência. Para realizar essa tarefa, de forma adequada, deve possuir estrutura com área para armazenamento dos imunobiológicos, almoxarifado para guarda de insumos como seringas, agulhas, caixas térmicas etc.

Deve ter, também, área de acesso para os veículos de carga, destinada ao recebimento, à preparação e à distribuição dos imunobiológicos, e outras que possibilitem a realização de atividades administrativas, técnicas e de ensino/pesquisa, sendo o último desejável e não obrigatório. Seu dimensionamento deve estar de acordo com as funções/atribuições citadas, devendo dispor, ainda, de gerador, como sistema de segurança para os casos de falta de energia elétrica, muito comum em determinadas regiões do país.

O transporte dos imunobiológicos e todo o processo que envolve seu recebimento e distribuição em temperatura adequada devem ser realizados por técnico especializado/capacitado desde a instância estadual, de modo a garantir que todos os procedimentos sejam realizados conforme o preconizado pelo PNI, no Manual de rede de frio do Programa Nacional de Imunizações (BRASIL, 2013).

\section{Instância ou nível municipal}

A central municipal de rede de frio desse nível ou instância (CMRF) está incluída na estrutura organizacional da Secretaria Municipal de Saúde e tem como atribuição o planejamento integrado das ações realizadas nesse nível de gestão, além do armazenamento e distribuição dos imunobiológicos (BRASIL, 2013). 
Como no nível regional, a instância municipal deve dispor de estrutura e equipamentos que comportem todos os procedimentos já mencionados, especialmente aqueles destinados ao armazenamento de imunobiológicos que, posteriormente, serão distribuídos e utilizados na sala de vacinação, do nível local. Por isso, o gestor da instância municipal deve planejar as atividades zelando para que todos os insumos e imunobiológicos necessários estejam disponíveis, bem como dispor, também, de um plano de contingência, com todos os fluxos e procedimentos detalhados para o caso de qualquer problema com os equipamentos da rede de frio. A equipe deve estar devidamente treinada e orientada quanto cada procedimento constante desse plano de contingência.

Seja na instância regional ou municipal, os imunobiológicos deverão ser conservados em câmaras frias, freezers $\left(-20^{\circ} \mathrm{C}\right)$, ou em refrigeradores $\left(+2^{\circ} \mathrm{C} a+8^{\circ} \mathrm{C}\right)$ específicos para vacina, conforme a temperatura indicada para cada produto. Nessas instâncias, a instalação da câmara fria, a quantidade de freezers e refrigeradores comerciais e domésticos dependem do volume a ser estocado, do tempo de armazenamento e da rotatividade dos produtos. Atualmente, o uso de refrigeradores domésticos está em desuso, sendo indicado o uso de equipamentos específicos para vacina. É fundamental que todos os trabalhadores saibam manuseá-los, disponham de um plano de contingência para o caso de qualquer avaria nesses refrigeradores, e possam estabelecer rotinas que incluam as manutenções preventivas e corretivas desses equipamentos.

Quando o município recebe os imunobiológicos, passa a ser responsável pela qualidade e segurança desses produtos em quaisquer dos procedimentos, seja no transporte, na distribuição, no controle de temperatura etc. Por isso, é fundamental que gestores e trabalhadores de qualquer nível ou instância estejam devidamente orientados e capacitados para atuar de forma correta em todas as etapas.

O controle de temperatura, as orientações técnicas e capacitações dos profissionais que trabalham na rede de frio, seja em nível regional ou municipal, estão sob a responsabilidade do nível estadual, não invalidando a iniciativa dos municípios para elaboração de processos de capacitação de sua equipe e de outros municípios.

\section{Instância ou nível local}

A instância local, representada pela sala de vacinação (SV), é a instância final da rede de frio, exclusivamente responsável pelos procedimentos ou estratégias de vacinação de rotina, campanhas, bloqueios e intensificações e vacinações extramuros (BRASIL, 2013).

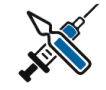

Por isso, enfatiza-se sempre a necessidade de profissional devidamente capacitado para as atividades de rede de frio, em qualquer instância. Somente um técnico qualificado poderá estar atento às características e condições necessárias dos equipamentos e ao acondicionamento dos produtos imunobiológicos. 
O papel dos Crie, no caso de eventos adversos pós-vacinação, foi discutido no Capítulo 3,

"Vigilância epidemiológica em eventos adversos pós-vacinação".
Em 2014, foram referenciadas pelo PNI, aproximadamente, 36 mil salas de vacina em funcionamento à disposição da população. Todas elas estão localizadas em unidades/serviços da rede de saúde, policlínicas e hospitais, ocupando posição estratégica na atenção básica.

Nas instâncias local e municipal, a rede de frio deve armazenar os imunobiológicos em câmeras de armazenamento específicas para vacinas, refrigeradores do tipo doméstico (não são mais indicados) ou em caixas térmicas (para transporte e uso diário), com temperatura na faixa de $+2^{\circ} \mathrm{C} \mathrm{a}+8^{\circ} \mathrm{C}$. O transporte dos imunobiológicos da instância municipal para a local deve ser realizado em veículos climatizados, utilizando-se caixas térmicas apropriadas para garantir a manutenção da temperatura. No caso de transporte por longas distâncias, do município para o nível local, o PNI recomenda que seja realizado, preferencialmente, em veículos frigoríficos específicos (BRASIL, 2013).

O planejamento e a escolha dos equipamentos utilizados em nível local devem levar em consideração a capacidade de armazenamento de imunobiológicos em quantitativo suficiente para vacinar a população de sua abrangência durante um mês e, também, para a programação de abastecimento das demais salas de vacinação daquele território adstrito.

Recomenda-se o uso de freezers exclusivos para a guarda das bobinas reutilizáveis, em número suficiente às demandas locais, assim como a climatização da sala de vacinação por meio de aparelhos de ar-condicionado. Desse modo, a temperatura ambiente ajuda a manter a dos imunobiológicos, minimizando os riscos indesejados de alterações de temperatura dos produtos (BRASIL, 2013).

Fazem parte, também, da instância local os Centros de Referência para Imunobiológicos Especiais (Crie). Neles, são realizados procedimentos de vacinação com imunobiológicos, geralmente, não disponíveis nas salas de vacinação da rede básica de saúde, os quais são destinados à clientela específica. O funcionamento e a operacionalização desses centros devem prever facilidade de acesso da população e também garantir investigação, acompanhamento e elucidação nos casos de eventos adversos pós-vacinação (BRASIL, 2013).

Conhecido o percurso realizado pelos imunobiológicos nas diversas instâncias, destacaremos a RF de nível central ou nacional, a Cenadi. Isso porque, apesar desta não se caracterizar formalmente como uma instância, como aquelas apresentadas até o momento, ela retrata bem todos os procedimentos realizados na rede de frio, sendo expressão fiel de todos os elos e etapas que compõem a rede. 


\section{A Central Nacional de Armazenamento e Distribuição de Imunobiológicos (Cenadi)}

A Cenadi representa o nível nacional da rede de frio e é responsável pelo recebimento, armazenamento e pela distribuição de todos os imunobiológicos disponibilizados pelo Programa Nacional de Imunizações. Portanto, todas as vacinas liberadas e disponibilizadas pelo PNI, adquiridas em laboratórios nacionais (públicos e privados) e internacionais, são armazenadas na Cenadi, a quem compete a responsabilidade de distribuí-las às Secretárias Estaduais de Saúde (SES), para serem utilizadas em todo o país.

Foto 6 - Fachada da Cenadi

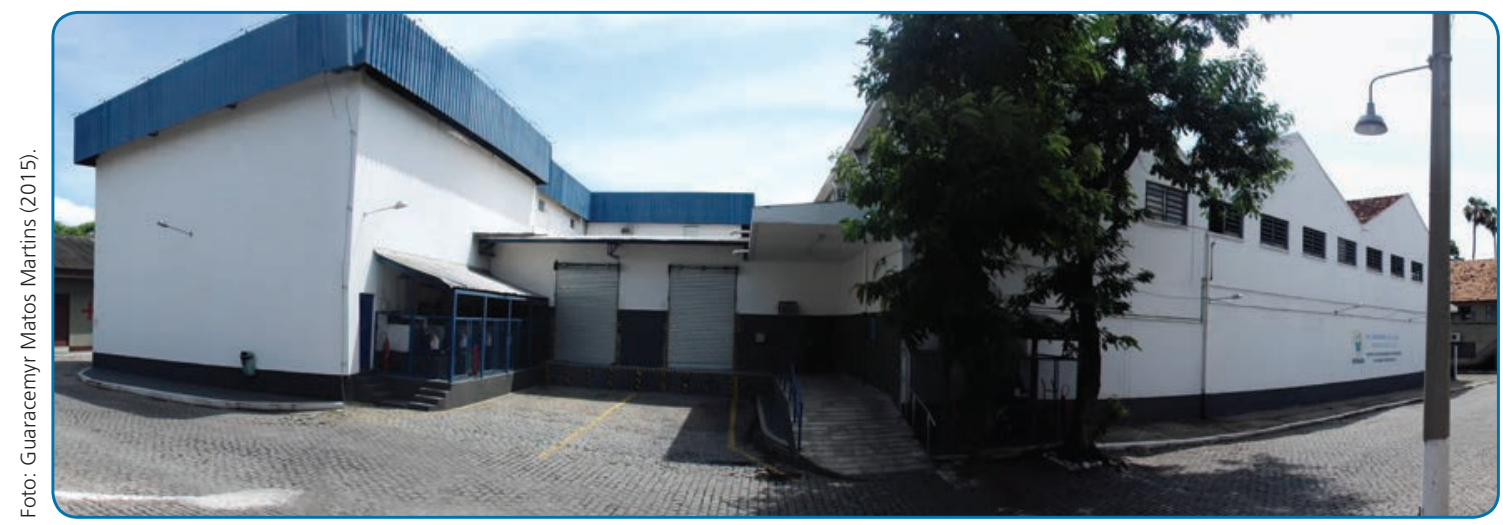

Para refletir

Você tem ideia da quantidade de imunobiológicos que chegam à Cenadi para serem armazenados e distribuídos para todo o Brasil?

A Cenadi é composta por duas áreas: uma no bairro Rocha (a sede) e outra no bairro Irajá, ambas no Rio de Janeiro. Somadas, as duas unidades dispunham, em 2015, de sete câmaras de armazenamento, sendo quatro com temperatura positiva e três com temperatura negativa. Juntas, essas câmaras têm ampla capacidade de armazenamento, em torno de uma média anual de 25.324 .773 doses de vacinas, possibilitando garantir a qualidade da imunização para milhões de brasileiros. 
Foto 7 - Interior da câmara

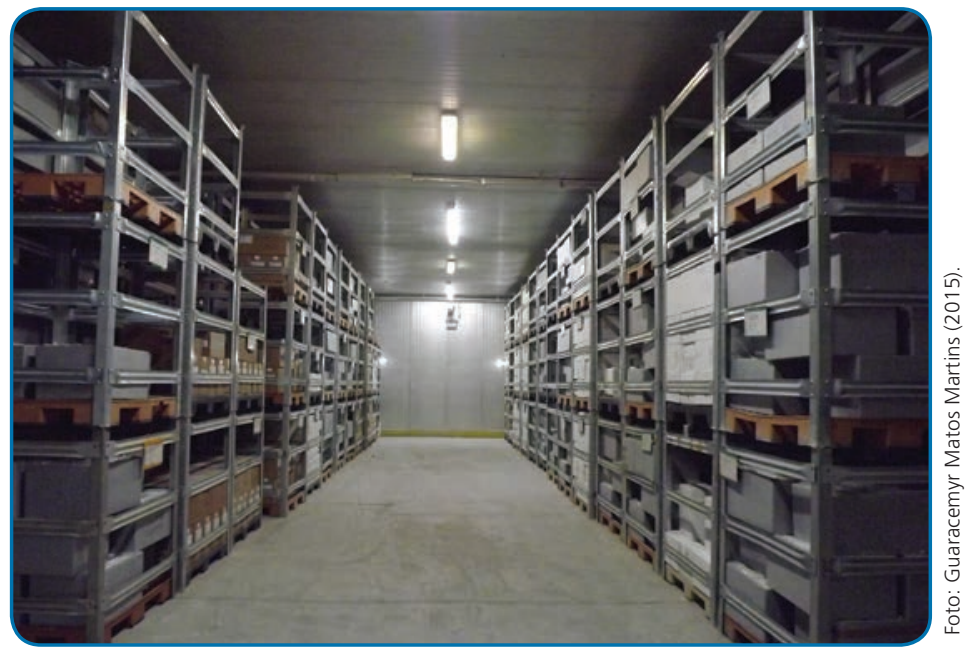

Em relação à capacidade refrigerada, o complexo logístico da Cenadi possui $19.600 \mathrm{~m}^{3}$ de área em temperatura de $+2^{\circ} \mathrm{C} \mathrm{a}+8^{\circ} \mathrm{C}$, e $2.646 \mathrm{~m}^{3}$ de área em temperatura de $-20^{\circ} \mathrm{C}$, além de $800 \mathrm{~m}^{2}$ de área de temperatura controlada entre $+16^{\circ} \mathrm{C}$ e $+17^{\circ} \mathrm{C}$. Essa última área é utilizada para atividades de preparo, recebimento e distribuição. Dispõe, também, de sistema de gestão e manutenção automatizado, moderno e eficiente, com controle qualificado dos equipamentos de refrigeração e alarmes, além de geração de energia emergencial, para casos de desabastecimento da energia elétrica pela concessionária de rede elétrica, garantindo sempre a manutenção da temperatura dos imunobiológicos ali armazenados.

Para operacionalizar o volume de imunobiológicos, a Cenadi conta com uma equipe capacitada e qualificada em processos sistemáticos de educação continuada e de um rigoroso planejamento de suas atividades, etapa esta estratégica para o bom funcionamento de uma rede de frio e para o sucesso do Programa Nacional de Imunizações.

\section{Planejamento da rede de frio}

Existem importantes motivos para que ações de vacinação não sejam baseadas no improviso. O principal deles é que estamos lidando com um produto que impacta diretamente a saúde e a vida das pessoas.

Uma ação não planejada pode ter diversas consequências. Para que a logística da rede de frio seja eficiente, faz-se necessário um planejamento que envolva um conjunto amplo de atores, como os profissionais envolvidos nas diferentes instâncias da rede de frio, gestores e usuários. 
A realização do planejamento na RF irá nortear o desenvolvimento das ações, garantindo o controle e o monitoramento de todos os procedimentos, desde o início. O planejamento deve conter também um plano de contingência. Este será de grande utilidade no caso de eventuais problemas que possam ocorrer nos equipamentos e interferir na manutenção da temperatura dos imunobiologicos, causando a perda de vacinas, prejuízos econômicos e possíveis desabastecimentos, em virtude do grande volume de imunobiológicos armazenados na Central Nacional de Armazenamento e Distribuição de Imunobiológicos.

A seguir, apresentamos os itens que compõem o planejamento de uma rede de frio em cada etapa do seu processo de funcionamento, destacando os procedimentos realizados na Cenadi.

\section{Aquisição dos imunobiológicos}

Nesta etapa da RF, é importante, inicialmente, conhecer o quantitativo de imunobiológicos necessário para o cumprimento do calendário nacional de vacinação do PNI, de modo a atender as estratégias de rotina e outras, como as campanhas.

O planejamento da aquisição de imunobiológicos é realizado pela Coordenação Geral do Programa Nacional de Imunizações (CGPNI), que tem total responsabilidade sobre o processo. Entretanto, ainda que de forma indireta, as demais instâncias também participam desse planejamento, em caráter complementar. Cada uma possui atribuições e competências específicas. A seguir, no Quadro 1, apresentamos, de forma esquemática, as atividades e responsabilidades de cada nível da rede de frio na aquisição dos imunobiológicos.

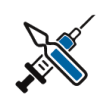

É importante lembrar que o monitoramento e a avaliação das ações de vacinação e da rede de frio podem apontar a necessidade de novo planejamento para adequação das ações e reorganização de novas necessidades.

Quadro 1 - Níveis da rede de frio e suas responsabilidades/competências no planejamento para aquisição de imunobiológicos

\begin{tabular}{|l|l|}
\hline $\begin{array}{l}\text { Níveis da rede de frio de } \\
\text { imunobiológicos }\end{array}$ & Responsabilidades/competências \\
\hline Unidades de saúde/salas de vacina & $\begin{array}{l}\text { Informar os estoques existentes, mensalmente, por meio de formulário próprio, às Secretárias } \\
\text { Municipais de Saúde ou Regionais e Distritos Sanitários, a depender da organização dos municípios. }\end{array}$ \\
\hline Secretarias Municipais de Saúde & $\begin{array}{l}\text { Receber os formulários encaminhados pelas unidades de saúde, assim como analisar, consolidar e } \\
\text { elaborar a programação municipal e encaminhá-la à instância regional ou estadual. }\end{array}$ \\
\hline $\begin{array}{l}\text { Regionais das Secretarias Estaduais } \\
\text { de Saúde }\end{array}$ & $\begin{array}{l}\text { Após o recebimento da programação municipal ou regionais, analisar, consolidar e elaborar a } \\
\text { programação macrorregional. }\end{array}$ \\
\hline $\begin{array}{l}\text { Centros de Referência para } \\
\text { Imunobiológicos Especiais (Crie) }\end{array}$ & $\begin{array}{l}\text { Elaborar a programação dos imunobiológicos especiais utilizados no centro e informar às } \\
\text { Secretarias Estaduais ou Municipais de Saúde, a depender da organização do estado. }\end{array}$ \\
\hline Secretarias Estaduais de Saúde & $\begin{array}{l}\text { Após o recebimento da programação dos municípios, regionais e Crie, analisar, consolidar e } \\
\text { elaborar a programação estadual. }\end{array}$ \\
\hline
\end{tabular}

Fonte: Elaborado por André Silva Cardoso, Clayton Bernardo da Costa, Felipe da Silva Furtado e João Leonel Batista Estery, em 2014. 
Os sistemas de informação ligados ao Programa Nacional de Imunizações são apresentados no Capítulo 5, "Sistemas de Informações do Programa Nacional de Imunizações (SI-PNI)", deste livro.
Todas essas informações permitirão saber o quantitativo de imunobiológico a ser adquirido. Baseada nos informes repassados pelas instâncias estadual, municipal, local e Cenadi, a Coordenação Geral do Programa Nacional de Imunizações (CGPNI) realiza uma série de procedimentos visando chegar ao quantitativo real de vacinas necessário naquele ano e à normatização do seu uso. Assim, cabe à CGPNI:

* analisar e consolidar as programações a ela encaminhadas pelos estados e pela Cenadi;

* elaborar programação nacional de aquisição, definindo quantitativos e cronograma de recebimento;

* elaborar especificações técnicas por produto;

emitir parecer técnico, justificando a compra;

* elaborar o Termo de Referência (TR) de aquisição, tomando por base as necessidades programadas e os valores correspondentes à última aquisição (salvo se houver informação mais recente);

* elaborar programação orçamentária para o próximo ano, visando à garantia dos recursos;

* enviar para a Cenadi os imunobiológicos necessários para atender o país.

Considerando todos esses aspectos, fica a questão: como a Cenadi se organiza para atender a toda essa demanda?

Inicialmente, participando do processo de planejamento, prestando informações que auxiliem na elaboração do quantitativo a ser comprado/adquirido, bem como do planejamento da estrutura necessária ao armazenamento dos imunobiológicos na Cenadi. Precisará obter informações sobre:

volume ocupado por cada tipo de imunobiológico;

validade dos estoques;

* quantidade e capacidade de armazenagem;

* consumo médio mensal do ano anterior por estado e por imunobiológico, utilizando como base o Sistema de Informação do PNI, o Sistema de Informações de Insumos Estratégicos (Sies).

A partir das questões respondidas, a Cenadi poderá se organizar para receber os imunobiológicos, e, com base nas informações fornecidas pela Cenadi, caberá ao Departamento de Logística (DLOG) da Secretaria Executiva do Ministério da Saúde efetuar a aquisição dos diversos imunobiológicos. Para isso, precisa organizar as informações técnicas 
que caracterizam cada imunobiológico a ser adquirido e realizar licitações nacionais e/ou internacionais, conforme o tipo de imunobiológico.

A partir da aquisição, outros procedimentos que compõem a logística da RF são desencadeados, como recebimento, armazenamento e distribuição dos imunobiológicos, todos comuns a qualquer rede de frio.

Para ilustrar essas etapas/procedimentos, apresentamos na Figura 2 o fluxo do trabalho na Cenadi, desde a aquisição dos imunobiológicos até sua distribuição à instância estadual.

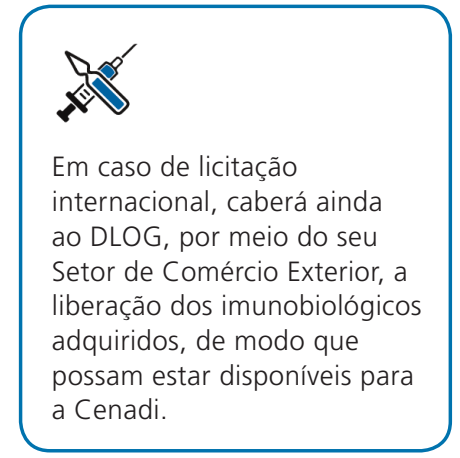

Figura 2 - Fluxograma da rede de frio de imunobiológicos da Cenadi

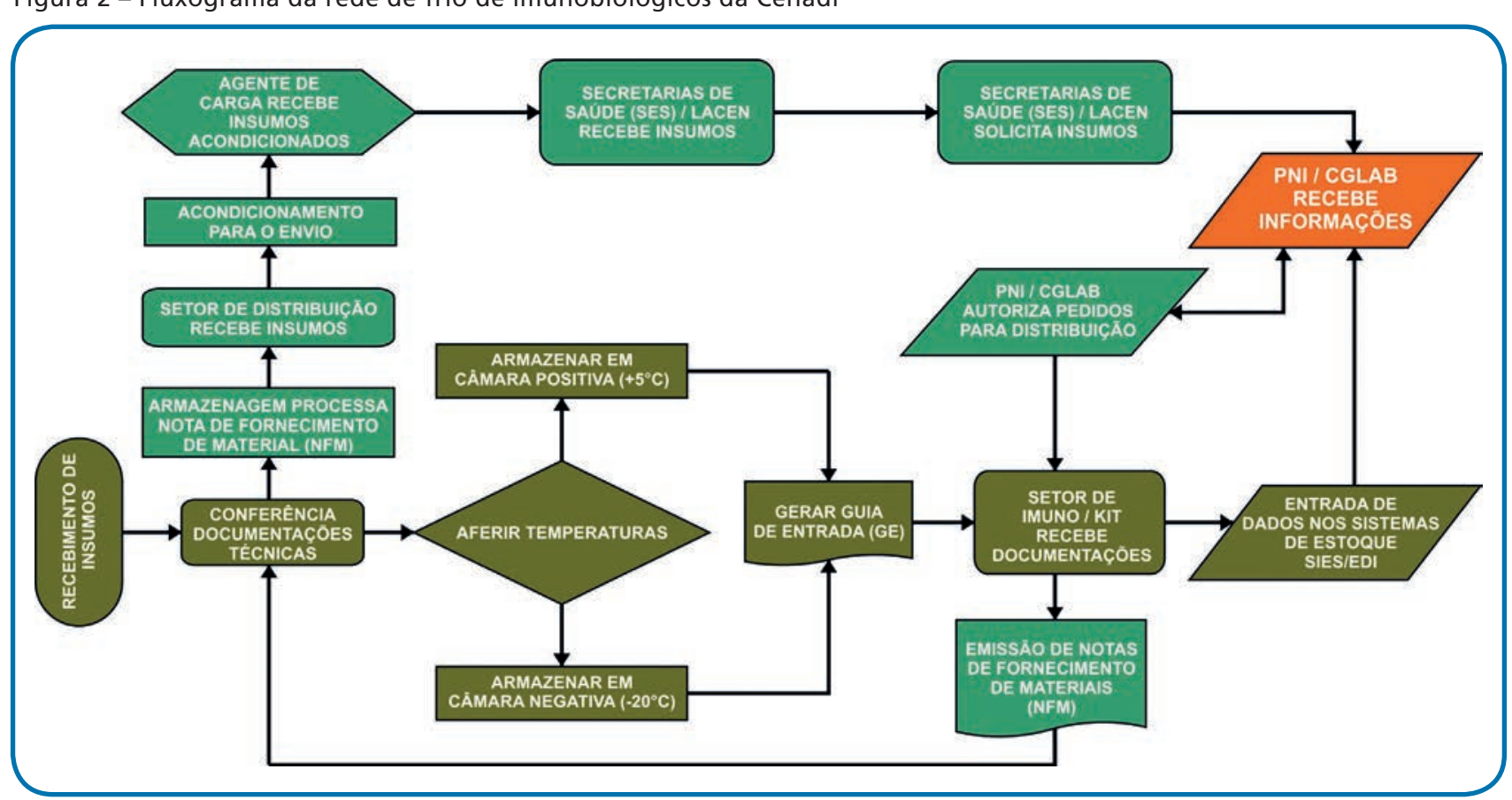

Fonte: Adaptado por Felipe da Silva Furtado, em 2014.

As etapas ou os elos/tramas da rede de frio são apresentados a seguir, caracterizando todo o complexo logístico que a envolve através do trabalho realizado na Cenadi.

\section{Procedimentos de recebimento de imunobiológicos na Cenadi}

Inicialmente, a Cenadi deve ser informada, com antecedência, sobre a chegada dos imunobiológicos. Na chegada à central, uma comissão ou equipe de recebimento confere se a entrega dos imunobiológicos está em conformidade com o estabelecido no Contrato e no Termo de Referência de Aquisição. 
Invoice é um documento administrativo semelhante à nota fiscal, utilizado em caso de produtos importados.
Paletes são estruturas de madeira, ferro ou plástico. Sua função na rede de frio é viabilizar a otimização do transporte de cargas de imunobiológicos, através do uso de paleteiras manuais ou elétricas e empilhadeiras. Os paletes de madeira devem ser evitados pela possibilidade de desprendimento de partículas e propagação dos microrganismos, em face da dificuldade de desinfecção na rotina do serviço.
Além desses, outros pontos devem ser observados e registrados, especialmente aqueles relacionados às condições do veículo transportador e de acondicionamento do imunobiológico na chegada. Para efetuar o registro, utilizam-se formulários específicos, disponíveis em cada central. A Cenadi, por exemplo, possui o formulário Protocolo de recebimento de insumos (Anexo A) e o documento formal Ata de recebimento de vacina (Anexo B).

Destacamos, a seguir, alguns dados que devem ser registrados.

\section{Condições do veículo de transporte do imunobiológico}

* lacre do baú, para verificar o nível de segurança do baú refrigerado a que a carga (imunobiológicos) foi submetida;

* estado de conservação e limpeza do baú do caminhão de transporte; * temperatura exibida no painel do equipamento do transporte;

磷 temperatura do baú no momento;

dados dispostos na nota fiscal eletrônica (NFe) ou invoice;

*xistência e entrega dos documentos técnicos (protocolo de produção, protocolo de produto acabado, controle de inspeção, certificado de análise e liberação).

Foto 8 - Aferição da temperatura do baú do transporte

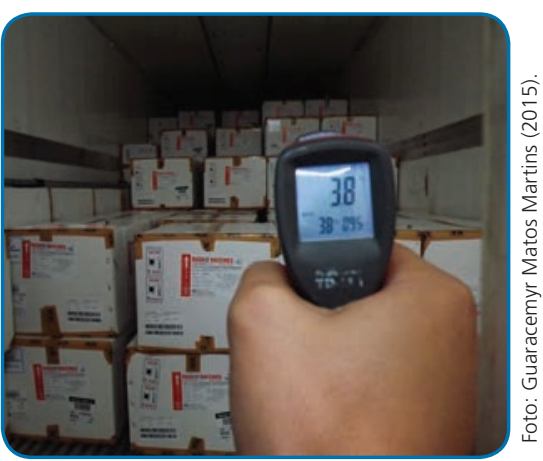

\section{Condições dos imunobiológicos}

Envolvem, essencialmente, a temperatura e a disposição do imunobiológico no baú refrigerado. O técnico responsável pelo recebimento deve atentar para a:

* disposição dos imunobiológicos no baú e a distância entre:

- os paletes onde foram dispostos os imunobiológicos e o equipamento de refrigeração;

- o imunobiológico e o sistema de proteção contra umidades elevadas que existe no baú refrigerado (espécie de filme); * qualidade e disposição das embalagens, quantidade, lote, prazo de validade;

* temperatura do momento dos imunobiológicos recebidos; * identificação correta dos produtos imunobiológicos. 
Foto 9 - Paletes

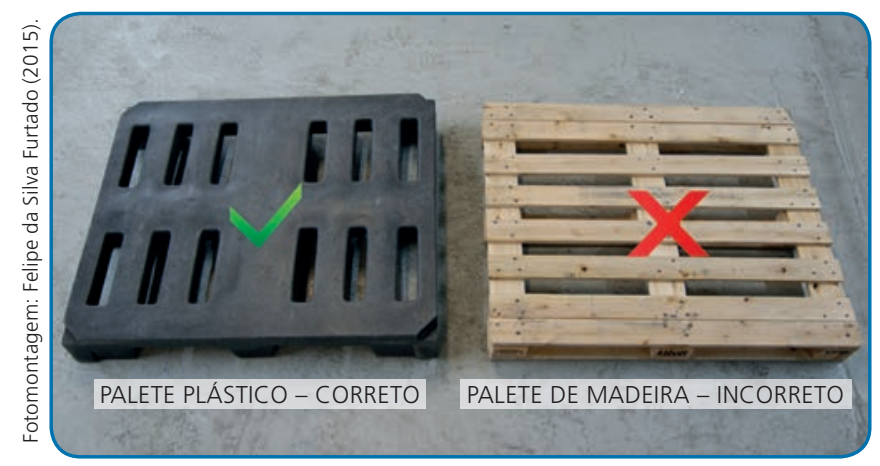

Foto 10 - Aferição da temperatura quando do recebimento dos imunobiológicos

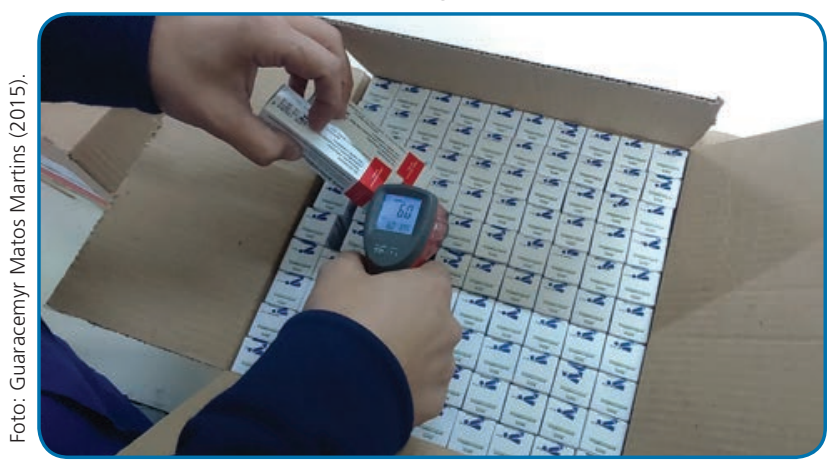

Após a conferência, caso os imunobiológicos cheguem com temperatura em desacordo com as normas técnicas preconizadas pelo produtor ou com o estabelecido no Termo de Referência, a equipe técnica de recebimento, através do formulário Protocolo de recebimento de insumos (Anexo A), faz constar essas observações na Ata de recebimento de vacina (Anexo B), a fim de que sejam tomadas as providências necessárias junto à equipe técnica do órgão requisitante (CGPNI), ou da área administrativa de aquisição (DLOG/SE/MS).

\section{O que fazer quando a temperatura dos imunobiológicos não está de acordo com as normas estabelecidas pelo fabricante?}

Nesse caso, todo o lote é armazenado em local predeterminado dentro das especificações; em seguida, o fabricante é contatado e informado acerca das variações de temperatura fora dos limites estabelecidos. O fabricante, então, realiza uma análise da variação da temperatura do lote, baseado no estudo de estabilidade e de acordo com as normas e os protocolos de produção. Caso o lote não apresente nenhum problema, o fabricante emite um laudo certificando a garantia de uso. Caso não possa mais ser utilizado, o próprio fabricante recolhe o imunobiológico e o substitui por outro lote com as mesmas especificações. Durante o período de espera do recolhimento, o imunobiológico sob suspeita deve permanecer na temperatura indicada pelo fabricante.

Se estiver tudo correto, os imunobiológicos seguem o fluxo normal, ou seja, uma vez paletizados e devidamente identificados, são encaminhados para o armazenamento nas câmaras frigoríficas de acordo com a faixa de temperatura preconizada, que pode ser de $+2^{\circ} \mathrm{C}$ a $+8^{\circ} \mathrm{C}$ nas câmaras positivas ou $-20^{\circ} \mathrm{C}$ nas negativas.

Os dados do recebimento dos imunobiológicos são encaminhados e registrados nos sistemas de controle de estoque (Sies/EDI), por meio 
do formulário Guia de entrada de imunobiológicos (GEI) (Anexo C). Nesse formulário constam o registro do insumo recebido e as principais informações do protocolo de recebimento; pode também ser registrado no formulário o quantitativo de saída do produto, por ocasião do envio para controle de qualidade no INCQS.

\section{Registros relacionados ao recebimento}

Alguns procedimentos são necessários para o registro dos imunobiológicos na central de rede de frio na ocasião de seu recebimento. Em geral, referem-se a conferência e inserção dos dados descritos na nota de recebimento, no sistema de informação local. Como a Cenadi é uma central nacional, existem outros cuidados que devem ser preservados, como:

* O responsável pelo registro deve fazer uma reconferência entre as informações constantes na guia de entrada e na nota fiscal eletrônica, procedendo, em seguida, à alimentação das informações nos sistemas de controle de estoque (Sies).

* Depois do registro de entrada, o profissional responsável deve imprimir uma cópia da nota de lançamento (NL) e anexá-la à nota fiscal.

* O ateste da nota fiscal deve ser efetuado no verso da própria nota, configurando o recebimento definitivo do imunobiológico pelo setor responsável da Cenadi. A nota fiscal, a cópia de registro no sistema de controle de estoque e a ata original da comissão de recebimento devem ser encaminhadas por memorando ao DLOG/SE/MS, para os trâmites administrativos de contabilização e pagamento do laboratório fornecedor.

Após esses procedimentos, os imunobiológicos têm seus lotes, validade e quantidade conferidos e, em seguida, são armazenados na Cenadi nas câmaras com temperaturas positivas ou negativas, conforme estabelecido pelo produtor.

\section{Acondicionamento dos imunobiológicos na central de rede de frio}

De acordo com o espaço físico disponível, as vacinas recebidas são organizadas nas câmaras frigoríficas. Na Cenadi, a organização obedece a uma lógica própria: os imunobiológicos são dispostos nas câmaras frias por blocos, setores e lotes. Essa organização visa facilitar a localização no momento da retirada e/ou do manuseio. Posteriormente, dados sobre estoque poderão ser inseridos em planilhas eletrônicas para controle dos insumos recebidos e para o serviço de transporte. 


\section{Armazenagem}

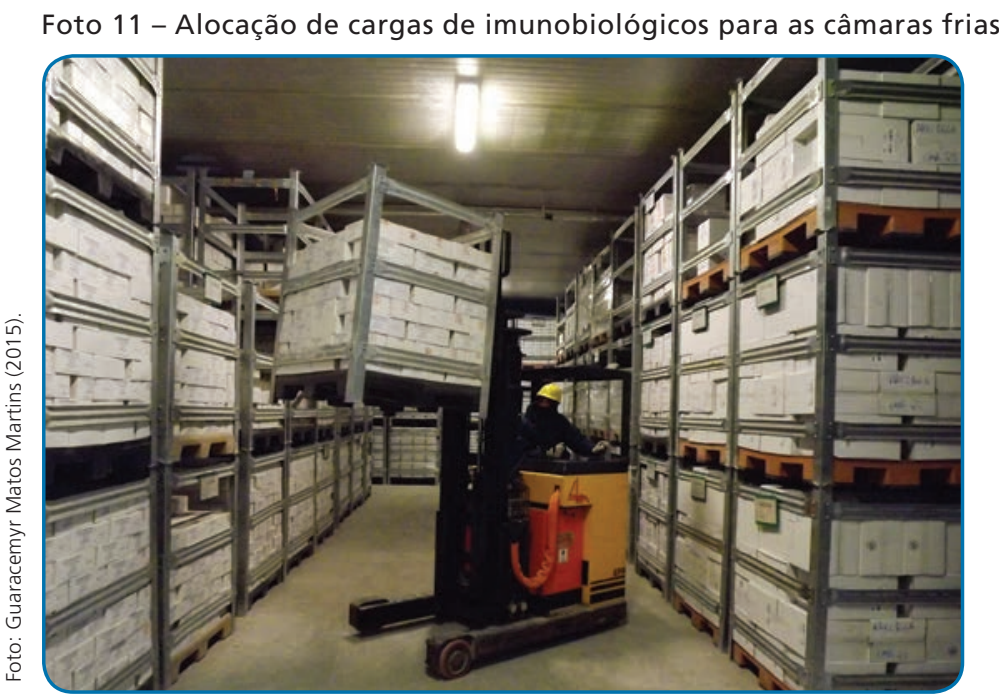

O armazenamento é uma etapa intermediária entre a produção e a etapa final da rede de frio, que é o transporte do imunobiológico até o seu destino. Por isso, requer, também, tratamentos específicos para garantir a integridade dos produtos e a eficiência da rede, exigindo movimentação ou manuseio dos mesmos por meio de práticas específicas para cada tipo de imunobiológico. O local da armazenagem deve possuir instalações de acordo com a legislação e regras dos órgãos oficiais: Ministério da Agricultura, Agência Nacional de Vigilância Sanitária (Anvisa) etc.

O setor de armazenagem deve dispor de câmaras frigoríficas em temperaturas positivas e negativas, em número compatível com o tipo de central e instância. Deve possuir também ferramentas de controle e gerenciamento da movimentação dos produtos dentro das câmaras. No caso da Cenadi, essa movimentação é realizada por meio de sistemas de endereçamento dinâmicos. Nas centrais de RF, o uso de ferramentas ou mecanismos como esses proporciona otimização do tempo das operações e maior confiança e segurança no serviço que está sendo executado.

O armazenamento dos imunobiológicos nas câmaras frias deve observar as normas de armazenagem e as temperaturas preconizadas pelo produtor. Nessa ação logística, a armazenagem deve, necessariamente, obedecer aos critérios de estocagem do material, em concordância com os lotes e validades. Esse procedimento é de fundamental importância para a racionalização do trabalho no que tange a localização, separação e posterior distribuição. Cada central de RF adota sistema próprio de 
O controle de qualidade dos imunobiológicos é apresentado mais adiante, neste capítulo. localização do imunobiológico; no entanto, todas devem seguir a regra de colocar na frente os primeiros lotes a vencer e atrás os que possuem maior período de validade.

Na Cenadi, o processo de estocagem está baseado em um tipo de estudo logístico conhecido como sistema Peps (primeiro que entra, primeiro que sai). É adotada uma ordem que funciona da seguinte forma: saída sempre da esquerda para direita, de cima para baixo e de frente para trás. A aplicação do sistema Peps em qualquer central auxilia no gerenciamento e na distribuição do imunobiológico, porque permite que sejam utilizados inicialmente aqueles que foram recebidos primeiro. Isso evita inutilização de produtos por validade vencida e contribui para diminuição de desperdícios.

No setor de armazenagem, além das câmaras de refrigeração, é necessário que existam áreas climatizadas com controle de temperatura, utilizadas para recebimento e expedição dos imunobiológicos. Nas câmaras, os imunobiológicos são identificados por um código de cores registrado em placas de acrílico, conforme seu status ou situação:

* Vermelha: reprovado ou vencido;

* Amarela: em processo de análise no controle de qualidade;
Foto 12 - Produtos identificados de acordo com seu status

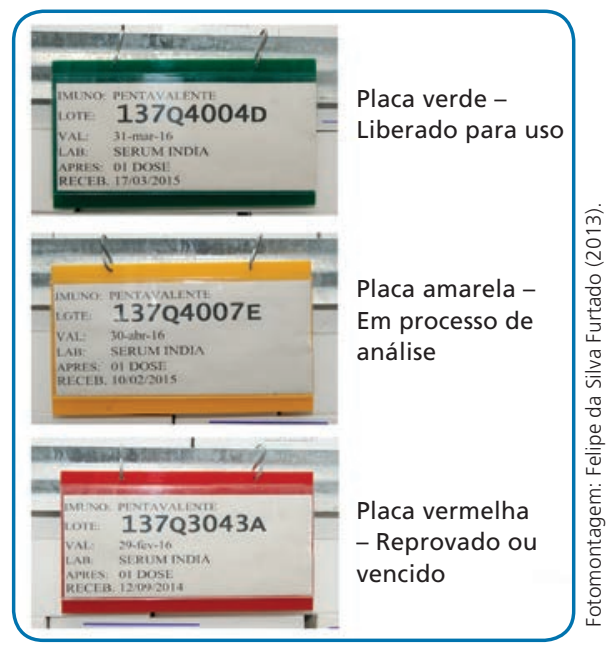

粰Verde: liberado para uso.

Os imunobiológicos são retirados do estoque de acordo com a sinalização das fotos. Na Cenadi, são retirados primeiro aqueles que estão na parte de cima de cada bloco, obedecendo ao sentido vertical. Quando todos os imunobiológicos daquele bloco são retirados, passa-se para a coluna seguinte, observando sempre a retirada de cima para baixo, como visualizado na Figura 3. 
Figura 3 - Ordem de saída das caixas do estoque

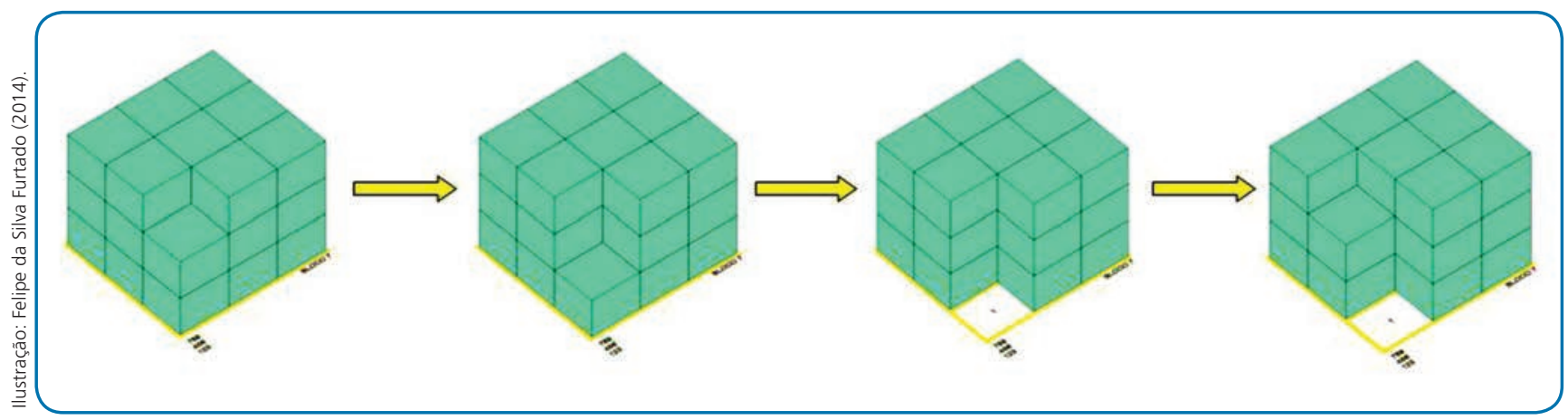

A etapa seguinte é o envio de lotes de todos os imunobiológicos para o controle de qualidade.

\section{Envio dos imunobiológicos para o controle de qualidade}

Como mencionado anteriormente, todos os imunobiológicos disponibilizados pelo PNI passam por um controle de qualidade, que se inicia no momento pós-recebimento e armazenagem na Cenadi. A central nacional é a única responsável pelo envio de amostras ao Instituto Nacional de Controle de Qualidade em Saúde (INCQS), vinculado à Fundação Oswaldo Cruz (Fiocruz), para testes e controle de qualidade.

O envio dos imunobiológicos para o INCQS segue a orientação do próprio órgão, por amostragem aleatória de lotes de cada vacina. Em algumas situações, um mesmo lote pode ser analisado duas vezes ou mais, caso apresente qualquer alteração ou circunstância cujas condições ou qualidade sejam colocadas sob suspeita. Nesse caso, novas amostras são enviadas ao INCQS para análise.

Foto 13 - Fachada do INCQS no campus de Manguinhos, Fiocruz

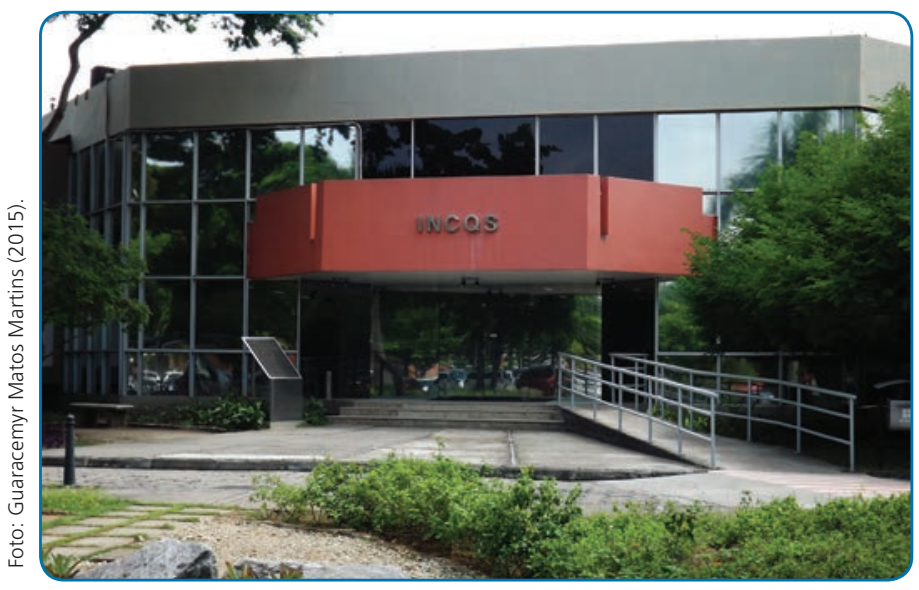


Amostras de todos os lotes dos imunobiológicos adquiridos, sejam eles nacionais ou importados, são enviadas pela Cenadi para o Instituto Nacional de Controle de Qualidade em Saúde (INCQS). Somente após a aprovação da análise de qualidade é que a Cenadi inicia a distribuição às instâncias estaduais.

\section{Distribuiç̧ão dos imunobiológicos}

É importante ressaltar que a logística da distribuição dos imunobiológicos no Brasil é bastante complexa, envolvendo uma verdadeira rede que deve se intercomunicar para que os imunobiológicos possam chegar, com a qualidade necessária, até a população.

Figura 4 - Distribuição dos imunobiológicos no Brasil

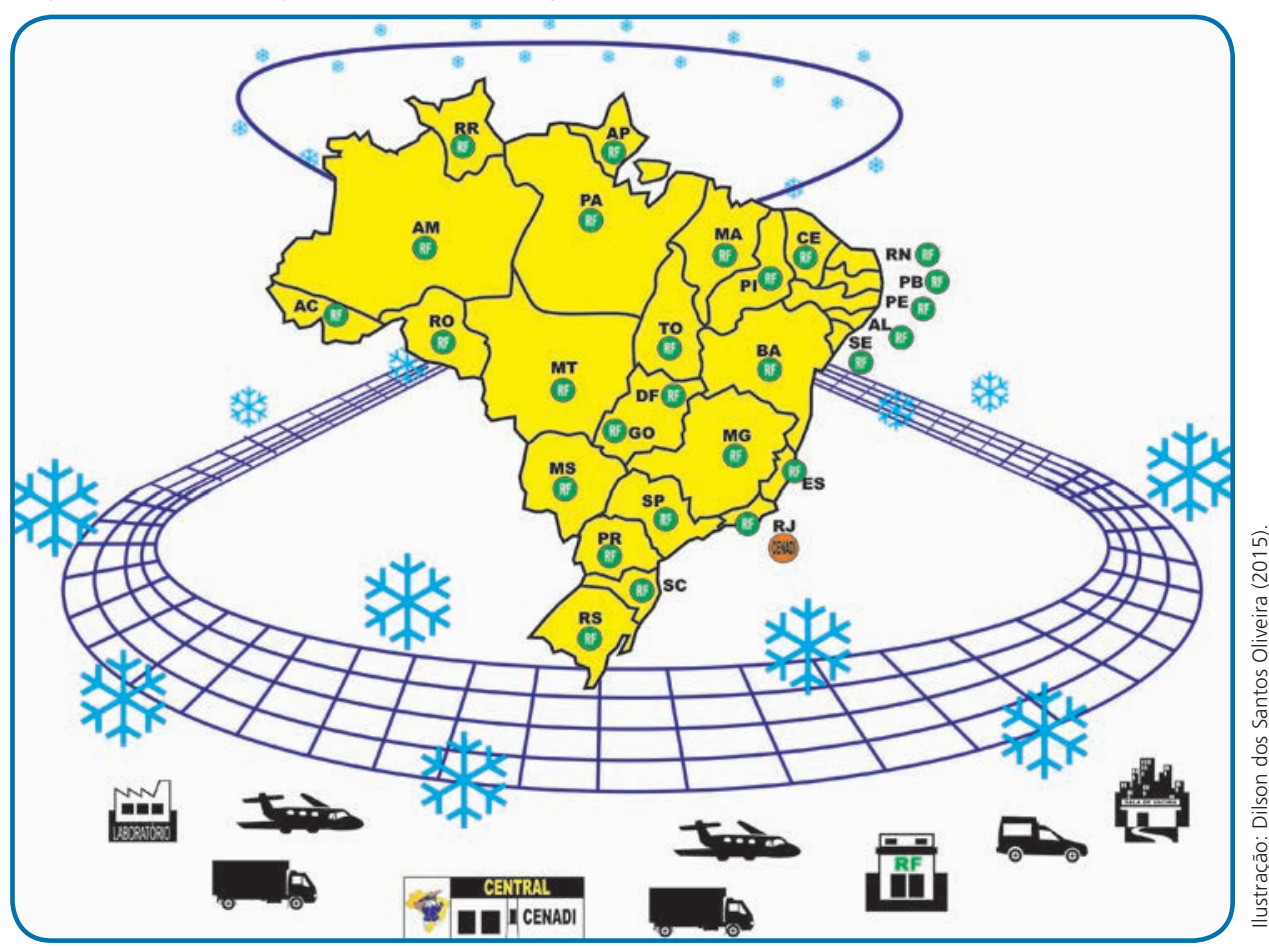

A Cenadi distribui os imunobiológicos para os estados que, por sua vez, os redistribuem aos municípios, de onde seguem para o nível local. A fim de manter a qualidade do produto, faz-se necessário garantir, em toda a rede, o controle da temperatura dos imunobiológicos. Caso ocorram falhas no sistema, estas devem ser notificadas por meio do formulário de avaliação de imunobiológicos sob suspeita, que deve ser encaminhado às instâncias responsáveis, junto com os dados sobre o controle diário de temperatura. 
A articulação e o compromisso dos profissionais da imunização, da rede de frio e gestores são fundamentais para que todas as ações relacionadas à vacinação sejam garantidas, desde a aquisição até a oferta dos imunobiológicos nas salas de vacina, em condições e tempo hábil. Para tanto, é um requisito haver centrais de rede de frio funcionando de forma eficiente, nas diversas instâncias.

Para que seja viabilizada a distribuição de rotina dos imunobiológicos, é necessário o cumprimento de um cronograma acordado entre o PNI e os estados: estes encaminham ao PNI, por meio do Sies, os quantitativos e a especificação dos imunobiológicos necessários para o atendimento de sua rotina mensal. No início de cada mês, o PNI consolida as informações encaminhadas pelos estados. A partir dos quantitativos e da especificação dos imunobiológicos, inicia a análise da pertinência das demandas e providencia as devidas autorizações de distribuição pela Cenadi, por meio do sistema on-line (Sies).

Após a análise do pedido, o PNI autoriza a Cenadi a distribuir para os estados. A distribuição é realizada mensalmente, ocorre segundo cronograma próprio da central e de acordo com a disponibilidade de estoque. Todo processo de distribuição deve ocorrer até o último dia do mês, podendo haver, excepcionalmente, distribuição fora do calendário proposto, atendendo a demandas extraordinárias ou emergenciais.

Os imunobiológicos seguirão em caixas térmicas devidamente preparadas, considerando o local e o tempo de chegada no destino. Os estados devem garantir a distribuição dos imunobiológicos nas centrais regionais ou municipais.

Foto 14 - Conferência para distribuição

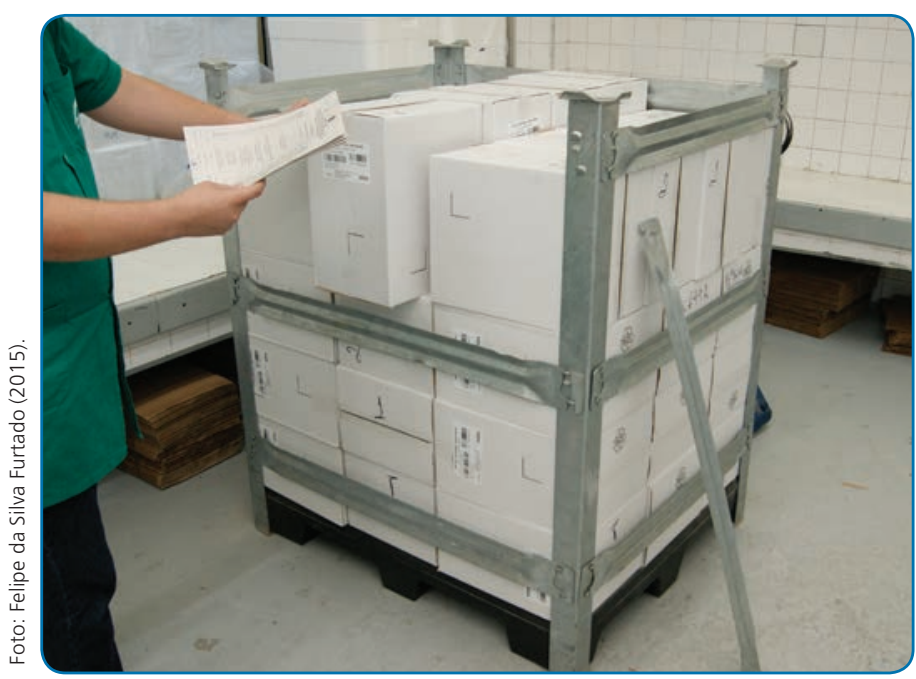

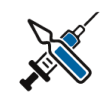

Vale ressaltar novamente que, para garantir a qualidade da vacina, a temperatura durante o transporte deve ser mantida entre $+2^{\circ} \mathrm{C} \mathrm{e}+8^{\circ} \mathrm{C}$ e/ou $-20^{\circ} \mathrm{C}$, dependendo do tipo de vacina, seguindo sempre as recomendações dos laboratórios produtores. 
Quando há evidência de que a vacina foi submetida a uma variação da temperatura diferente da preconizada pelo produtor (descrita na bula), a OMS orienta procedimentos específicos para análise da estabilidade das vacinas. Tais procedimentos estão disponíveis para conhecimento no Manual de Rede de Frio (BRASIL, 2013), disponível em http://bvsms. saude.gov.br/bvs/publicacoes/ manual_rede_frio4ed.pdf
Os critérios utilizados pelo PNI para análise das solicitações mensais feitas pelos estados estão baseados em:

- estoques disponíveis na Cenadi para a distribuição;

- média de distribuição mensal nacional;

- estoque estadual;

- cota mensal estadual;

- validade do imunobiológico disponível para distribuição, em consonância com os quantitativos planejados na aquisição;

- cumprimento do cronograma de entrega pelo laboratório produtor;

- doses aplicadas.

Fonte: André Silva Cardoso, Clayton Bernardo da Costa, Felipe da Silva Furtado e João Leonel Batista Estery, em 2013.

Para que a distribuição ocorra com segurança, uma série de cuidados é necessária para a manutenção da temperatura durante todo o processo, assim como no recebimento e armazenamento dos imunobiológicos.

Nesta etapa de distribuição, muitos erros podem ocorrer, interferindo na qualidade e propriedade dos produtos. A OMS apresenta estudos que apontam erros recorrentes no manuseio da vacina, que afetam substancialmente a sua potência. Em geral, são em decorrência de condições insatisfatórias de acondicionamento na distribuição e no armazenamento. Dentre as deficiências mais comuns relatadas por diversos países desenvolvidos, destacam-se: altas temperaturas durante a armazenagem ou o transporte; exposição da vacina a temperaturas de congelamento; equipamentos de refrigeração sem controle de temperatura; falhas nas leituras e nos registros da temperatura etc.

Condições ideais na armazenagem/distribuição, como estrutura adequada, são outro cuidado necessário para garantia da qualidade das vacinas. Por exemplo, os imunobiológicos são recebidos ou distribuídos em um setor específico, que, na Cenadi, é denominado de expedição. Nele, os imunobiológicos são preparados para serem armazenados ou distribuídos. Esse local deve ser climatizado, com temperatura monitorada constantemente; em caso de qualquer alteração que exceda o limite tolerável, deve ser acionado um alarme, para que se realize o ajuste necessário.

Outro cuidado é a conferência e o acondicionamento dos imunobiológicos em caixas apropriadas para serem transportados com segurança. Conferida a validade e quantidade dos lotes que serão expedidos, os 
imunobiológicos devem ser inseridos, imediatamente, nas caixas isotérmicas com núcleo (berço) para, em seguida, as bobinas de gelo serem adicionadas (que estarão a $-15^{\circ} \mathrm{C}$ ). O uso do berço, nesse caso, é para a manutenção térmica dos imunobiológicos (que precisam ser mantidos em temperatura positiva, de $+2{ }^{\circ} \mathrm{C} \mathrm{a}+8^{\circ} \mathrm{C}$, evitando contato direto com a bobina congelada e, consequentemente, seu congelamento).

Os imunobiológicos que precisam ser mantidos em temperatura negativa deverão ser acondicionados em caixas isotérmicas sem o núcleo (berço), uma vez que já se encontram em temperatura negativa, não necessitando de proteção para isso. Para ajudar, também, na manutenção da temperatura durante o transporte, poderá ser inserido gelo seco.

\section{Cuidados para organização das caixas térmicas na Cenadi}

Como mencionado, deve-se ter precaução com os recipientes ou as caixas nos quais os imunobiológicos serão acondicionados para o transporte. As caixas utilizadas devem ser de material apropriado, como recomendado pelo PNI, e utilizadas conforme critérios específicos, sendo fundamental manter-se atualizado sobre as novas recomendações de caixas a serem utilizadas.

A Cenadi, conforme já referido, utiliza um recurso de proteção denominado de núcleo ou berço no transporte de alguns imunobiológicos. A finalidade do "berço" é manter a estabilidade da temperatura (entre $+2^{\circ} \mathrm{C}$ $\mathrm{e}+8^{\circ} \mathrm{C}$ ) dos imunobiológicos por um intervalo de tempo maior e evitar o congelamento pelo contato com bobinas em temperatura negativa.

A Cenadi passou a utilizar o berço depois de observar as condições em que chegavam embalados/acondicionados os imunobiológicos de outros países. Percebeu, então, que poderia desenvolver uma proteção semelhante à dos produtos importados, que permitisse a utilização de bobinas de gelo reutilizáveis em temperatura negativa usando um núcleo separador ou berço, com o mesmo material da caixa de isopor onde são acondicionados os imunobiológicos para transporte. Assim, poderia utilizar, nas caixas térmicas, as bobinas retiradas diretamente do freezer, sem precisar de aclimatação e sem congelar o produto imunobiológico, tornando a logística segura e mais ágil. Após inúmeros testes e análises, a Cenadi adotou o núcleo ou berço no processo de transporte dos imunobiológicos armazenados em temperatura positiva. 
Data loggers são apresentados no Capítulo 7, "Refrigeração e equipamentos da rede de frio", deste livro.

Foto 15 - Berço e caixa térmica com berço para transporte

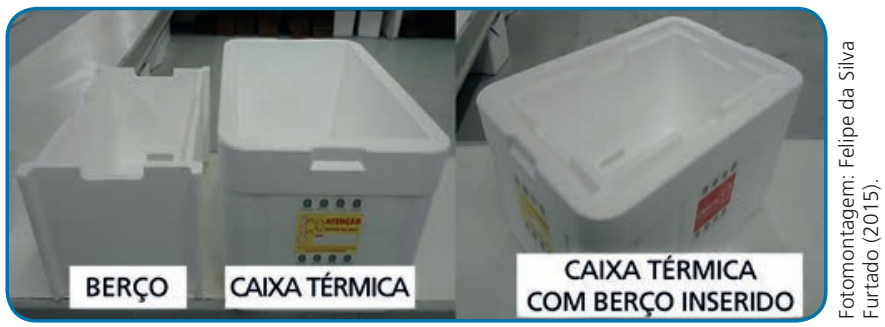

Escolhida a caixa apropriada, o passo seguinte é acondicionar os imunobiológicos no interior das caixas isotérmicas com "berço".

Como se organiza esse tipo de caixa?

1. As bobinas reutilizáveis de gelo, congeladas à temperatura de até $-15^{\circ} \mathrm{C}$, devem circundar as paredes internas da caixa (entre a caixa e o berço).

2. Os imunobiológicos devem ser organizados no interior da caixa posicionando-se o instrumento de medida de temperatura (data logger) no centro.

3. Os imunobiológicos devem ser cobertos com uma lâmina de papelão dupla face, impermeável e coberta com bobinas reutilizáveis à temperatura de até $-15^{\circ} \mathrm{C}$.

4. A caixa deve ser lacrada com fita adesiva e identificada externamente, conforme especificação e padrão local.

5. Flocos de poliestireno podem ser colocados nas caixas térmicas sem núcleo separador, no caso de ser necessário preencher espaços vazios, que não tenham sido ocupados com imunobiológicos.

O objetivo dessa ação é diminuir a quantidade de ar em seu interior e assegurar que o ambiente da caixa permaneça na temperatura recomendada.

6. A temperatura deve ser monitorada durante o transporte.

Foto 16 - Caixa organizada com bobinas e o berço

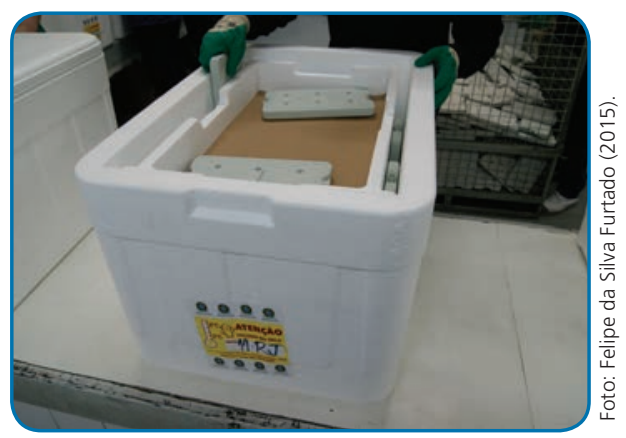

Foto 17 - Caixa pronta, fechada, com a fita identificadora do produto

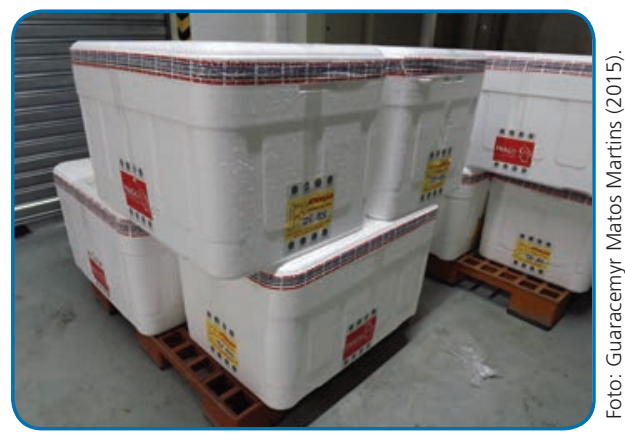




\section{Reforçando!}

- O uso de flocos de poliestireno ou de outros materiais (papelão, jornais etc.) entre os frascos avulsos, nas caixas dos imunobiológicos, tem por finalidade diminuir os espaços vazios, reduzir a quantidade de ar em seu interior e evitar deslocamento dos produtos e impactos mecânicos que, muitas vezes, levam a quebras e microfissuras dos frascos durante 0 transporte.

- O ideal é utilizar caixas com capacidade adequada para cada volume a ser transportado, para não ser necessário o uso desses artifícios.

- Conhecer os diversos tipos de embalagens dos imunobiológicos

é importante para a escolha das caixas mais adequadas ao acondicionamento das vacinas.
A partir do momento em que as caixas estiverem prontas, serão transportadas em caminhões frigoríficos da Cenadi ao aeroporto do Rio de Janeiro e embarcadas em aviões comerciais, até o aeroporto de destino. Nos estados, seguirão transportadas em caminhão frigorífico até as centrais estaduais de imunizações. Nas centrais, ao receber a carga, o profissional de rede de frio, idealmente o técnico/especialista, deve conferir a temperatura interna das caixas isotérmicas, o lote, a quantidade e a validade dos imunobiológicos. Em seguida, deve preencher o documento Comprovante de recebimento de insumos (Anexo F), assinar e enviar uma cópia à Cenadi. Caso exista alguma divergência nas informações, a SES comunica à Cenadi para realização dos ajustes.

Outros formulários são utilizados no transporte dos imunobiológicos da central nacional para os estados. A Nota de fornecimento de material (Anexo D), o formulário Detalhamento da carga (Anexo E) e o Comprovante de recebimento de insumos (Anexo F) são utilizados pela Cenadi e acompanham a carga de imunobiológicos durante sua entrega. O gestor deve prever, no planejamento e na organização da central, o número de formulários suficientes para atender à demanda, bem como um local visível para guarda dos imunobiológicos. Cada central de RF pode dispor de impressos específicos, desde que contenham todos os dados que atendam e detalhem o recebimento dos imunobiológicos.

Vale ressaltar que as vacinas, ao chegarem no nível local ou na sala de vacinação, devem ser rigorosamente mantidas em temperatura entre $+2^{\circ} \mathrm{C}$ e $+8^{\circ} \mathrm{C}$, de preferência, entre $+4^{\circ} \mathrm{C}$ e $+5^{\circ} \mathrm{C}$, como medida de segurança, evitando mudanças bruscas de temperatura e, em consequência, possível alteração ou perda de potência. Para tal, é necessário que a temperatura durante o transporte das vacinas seja assegurada!
As embalagens dos imunobiológicos são abordadas mais adiante, neste capítulo.
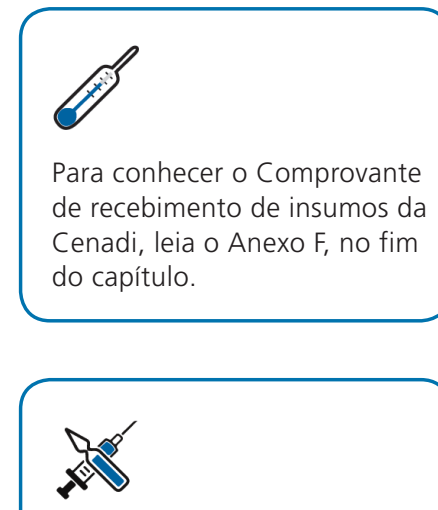

No caso de ausência do especialista ou técnico em RF, a pessoa que receber o material deve chamar o responsável da central pela realização dos procedimentos de recebimento necessários. 


\section{Transporte dos imunobiológicos}

Todas as etapas da RF são importantes. Uma delas é o transporte, durante o qual todos os cuidados tomados para a manutenção e segurança das vacinas, por ocasião do recebimento, armazenamento e distribuição, poderão ser perdidos, caso ocorra qualquer procedimento incorreto no momento em que se transportam os imunobiológicos.

Durante o deslocamento, os imunobiológicos são expostos a riscos que podem comprometer sua qualidade. Os riscos variam desde o tipo de transporte utilizado até o recipiente escolhido. Por isso, algumas regras devem ser observadas na escolha do recipiente onde serão colocados os imunobiológicos. Condições das caixas, como espessura, densidade e qualidade, devem ser rigorosamente observadas e respeitadas durante a sua aquisição e utilização.

Para o transporte adequado das vacinas, é necessário observar:

tempo a ser gasto com o transporte (considerar distância, tipo de transporte utilizado, condições do tempo, condições das estradas etc.);

tipos de termômetro a serem utilizados no transporte;

* quantidade e temperatura do gelo reciclável colocado dentro da caixa;

temperatura ambiente em torno da caixa térmica;

* colocação do termômetro na parte externa da caixa e do bulbo no interior da caixa térmica, no centro dos recipientes das vacinas, para garantir o monitoramento contínuo da temperatura, entre outros.

Além de adotar os cuidados fundamentais para garantir a manutenção das temperaturas de armazenamento durante o transporte, conforme as recomendações preconizadas em todas as instâncias, é preciso, ainda, estar alerta em relação a vários aspectos que podem interferir decisivamente na qualidade das vacinas e na manutenção de suas propriedades imunogênicas, tais como:

* instalações adequadas;

* equipe técnica bem treinada e atualizada;

equipamentos confiáveis;

* calendário preestabelecido de manutenção preventiva;

* garantia de manutenção corretiva, quando necessária. 
Foto 18 - Caixas dentro do caminhão para transporte

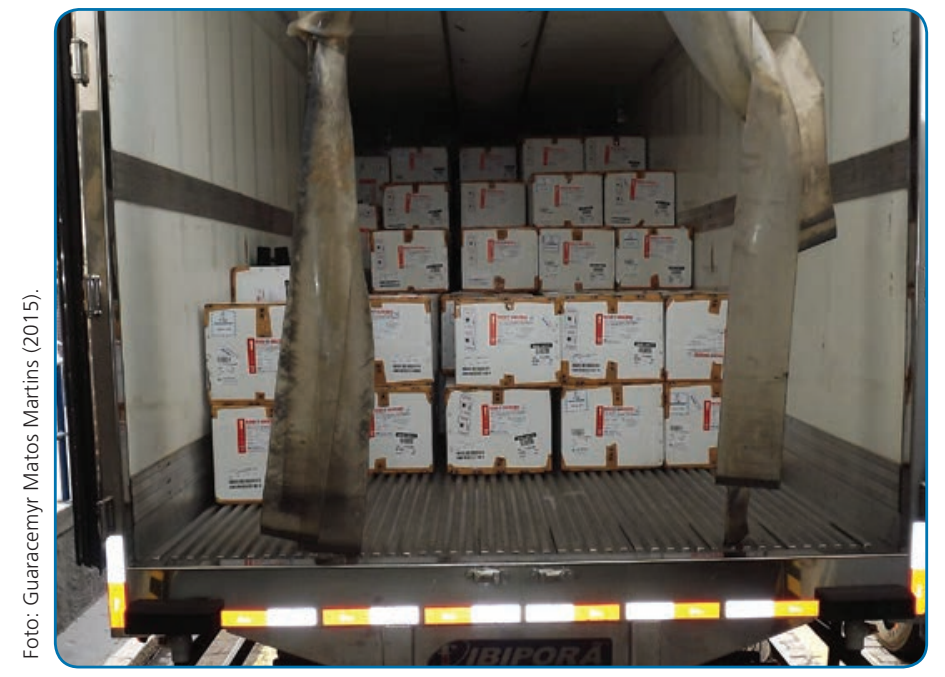

Sabemos que o tipo e a qualidade dos insumos utilizados são elementos que impactam tanto a armazenagem quanto a distribuição ou o transporte dos imunobiológicos na rede de frio e, consequentemente, o planejamento da rede. Os recipientes, como as caixas térmicas; os invólucros para acondicionar e proteger os imunobiológicos de interferências da temperatura externa (embalagens, berços etc.); os impactos ou danos durante sua manipulação e transporte são fundamentais para garantir eficiência no funcionamento de toda rede de frio. Por isso, apresentamos, a seguir, algumas informações sobre os principais insumos utilizados e os tipos de embalagens onde são acondicionados os imunobiológicos, visando auxiliar o gestor ou técnico especialista da rede de frio na aquisição e gestão apropriada dos insumos, otimizando os recursos e evitando perdas desnecessárias.

Além dos imunobiológicos, são também considerados insumos necessários à gestão da rede de frio os materiais de acondicionamento, como caixas térmicas, isopores, equipamentos de proteção, manuseio e transporte dos imunobiológicos. Por isso, é necessário planejar não somente a aquisição das vacinas, mas também a desses materiais, a fim de evitar o desabastecimento e a descontinuidade de uso destes.

Vejamos, a seguir, de forma breve, as embalagens e os principais insumos usados na RF. 


\section{Embalagens}

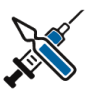

É importante salientar que as caixas térmicas são utilizadas para acondicionamento dos produtos imunobiológicos e, em geral, são consideradas embalagens do tipo terciária em diante. É mais comum serem quaternárias, destinadas a abrigar e proteger as embalagens primárias ou secundárias. As caixas isotérmicas devem ser escolhidas conforme o tipo de uso (vacinação, transporte etc.), a quantidade de imunobiológicos etc.

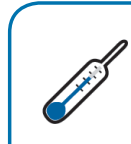

Para obter mais informações sobre outras embalagens usadas pelos laboratórios e respectivas especificações, leia:

- Consulta Pública n. 81, de 29 de agosto de 2007, da Anvisa, que dispõe sobre a criação do "Vocabulário controlado de formas farmacêuticas e embalagens";

- "Vocabulário controlado de formas farmacêuticas e embalagens", da Anvisa, disponível em http://www. anvisa.gov.br/medicamentos/ seminario_III/informe_6.pdf
Em todo o processo de gestão da RF, a embalagem é um dos fatores a serem considerados para o acondicionamento adequado. As formas de quantificação, uso e preservação dos imunobiológicos por meio de embalagens apropriadas irão determinar a proteção desses produtos e a forma de organização nas caixas isotérmicas. Por isso, é importante que o gestor e os demais profissionais da RF conheçam as formas e os tipos de embalagens que serão utilizados em todas as atividades desenvolvidas na rede, uma vez que eles impactam as etapas de logística e os planos de dimensionamento para armazenamento, distribuição, transporte dos produtos imunobiológicos e o planejamento dos insumos a serem adquiridos. Um exemplo é o planejamento da quantidade de bobinas necessárias para se colocar nas caixas térmicas. Dependendo de qual seja o tipo de embalagem (primária, secundária), poderá ser necessária maior ou menor quantidade de bobinas para a manutenção da temperatura indicada dos imunobiológicos dentro das caixas ou da embalagem quaternária.

Para melhor entendimento, é importante reforçar que as embalagens que contêm ou envolvem os imunobiológicos recebem uma denominação específica. Podem ser dos tipos primária, secundária, terciária (BRASIL, 2013), e assim sucessivamente. A embalagem primária é aquela que contém o produto ou tem contato direto com ele. Por exemplo, o frasco da vacina pentavalente ou a bisnaga da vacina poliomielite oral.

A embalagem secundária é o invólucro que envolve a primária, protegendo-a. Pode ser removível ou não e conter outras embalagens primárias. A embalagem terciária é a que envolve ou protege a secundária, e assim, sucessivamente, todas são usadas conforme a necessidade de proteção do produto.

Além das embalagens, outros materiais, equipamentos e insumos são utilizados na rede de frio para conservação da temperatura dos imunobiológicos e para aplicação nas salas de vacina. Vejamos alguns deles que influem no planejamento e na gestão da RF.
Foto 19 - Embalagens primária, secundária e terciária

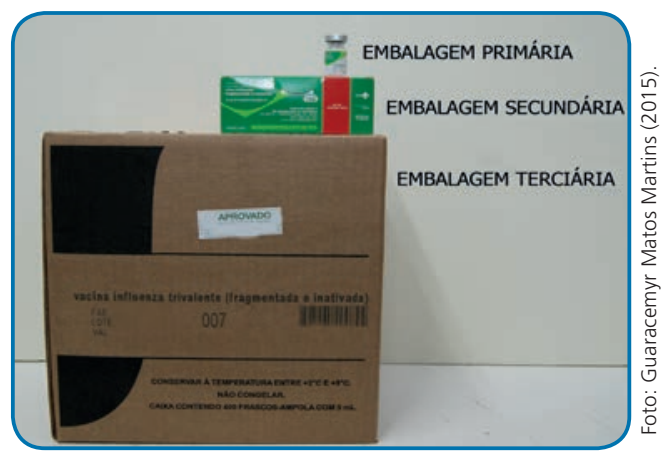




\section{Materiais, equipamentos e insumos utilizados na rede de frio de imunobiológicos}

A manipulação de materiais e equipamentos utilizados na RF requer conhecimento sobre como funcionam e os cuidados específicos recomendados. O planejamento para aquisição desses materiais é, também, importante etapa na gestão e precisa ser rigorosamente pensado pelo gestor em todo o percurso que o imunobiológico fará na rede de frio, desde o recebimento na central até seu transporte para as demais instâncias.

Apresentamos, a seguir, as principais informações acerca dos insumos usados durante a conservação e o transporte dos imunobiológicos, já que a maioria dos materiais ou equipamentos já foi explicitada em capítulos anteriores.

Abordamos, de forma resumida, cuidados a serem adotados na manipulação de: bobinas de gelo reutilizáveis, gelo seco, caixas térmicas, termômetros, câmara refrigerada, refrigerador e freezer.

\section{Bobinas de gelo reutilizáveis}

As bobinas de gelo são materiais de plástico, em geral de polietileno, que podem conter, em seu interior, água ou gel de concentração não tóxica. Sua função é manter a estabilidade da temperatura na caixa térmica onde estão os imunobiológicos e criar uma barreira que impeça a troca de calor do meio ambiente com o interior da caixa e vice-versa.

A aquisição das bobinas para as atividades da RF deve considerar o quantitativo necessário para armazenamento e distribuição aos diversos estados, incluindo o envio de amostras ao INCQS e outras instituições, se necessário. É importante que o gestor calcule um quantitativo que permita também a reserva de bobinas para situações de emergência e estoque, com finalidade de uso diário na central de RF, onde se necessita de bobinas congeladas.

No mercado, há bobinas de diferentes modelos, dimensões e capacidades (em litros), as quais devem ser selecionadas conforme as necessidades. No caso da rede de frio, por exemplo, as dimensões das bobinas devem ser de acordo com o tamanho das caixas térmicas (altura e largura) e com a capacidade das caixas de receber bobinas em número suficiente para acondicionar adequadamente o imunobiológico, mantendo-o na temperatura recomendada. 
Precipitação é um fenômeno que se verifica quando um corpo insolúvel se forma num líquido e se deposita, como sedimento, no fundo de um recipiente.
Entre os cuidados que se deve ter com as bobinas, é preciso observar suas condições, conservá-las limpas e descartar as que se apresentam estragadas ou danificadas. Se forem usadas bobinas danificadas, não será possível garantir a manutenção da temperatura dos imunobiológicos e, portanto, de suas propriedades e qualidade, podendo ocorrer congelamento ou outras situações que comprometam a conservação do imunobiológico.

Além dessas precauções, o trabalhador deve se certificar sempre que a temperatura da bobina está correta antes de armazená-la na caixa térmica, seja na atividade de vacinação ou no uso do transporte dos imunobiológicos. Esse é um importante cuidado a ser tomado, já que os diferentes conteúdos que compõem as bobinas possuem pontos de congelamento distintos. Assim, quando a bobina que contém água atinge $0^{\circ} \mathrm{C}$, começa, fisicamente, o processo de descongelamento, com a presença de líquido em seu interior e ausência de "névoa" na superfície externa. Ao contrário, a bobina com gel pode, ainda, se encontrar em temperatura abaixo de $0^{\circ} \mathrm{C}$, estar totalmente descongelada, em estado líquido e apresentar externamente "névoa", dando a "falsa impressão" de que atingiu a temperatura apropriada para acondicionamento nas caixas térmicas. Todo o processo para que a bobina chegue a $0^{\circ} \mathrm{C}$ é denominado de "aclimatação ou ambientação". No nível local, esse processo precisa ser realizado sempre, enquanto na Cenadi esses insumos são utilizados sem aclimatação

É importante salientar que centrais de rede de frio que não disponham de núcleo ou berço para o transporte de vacinas em temperatura positiva devem usar bobinas aclimatadas antes de colocar na caixa térmica.

Isso porque existe o risco de congelamento e consequente comprometimento da qualidade das vacinas. Um dos problemas que pode decorrer do congelamento de uma vacina é a sua precipitação.

A precipitação de uma vacina ocorre em função de sua permanência em temperatura inferior a $0^{\circ} \mathrm{C}$ por um período de vários dias ou acúmulo de períodos parciais de tempo.

Todo trabalhador da sala de vacina ou rede de frio precisa se certificar acerca da temperatura das bobinas antes de colocá-las nas caixas térmicas, usando, além da observação, termômetro devidamente calibrado para aferição e garantia da temperatura apropriada. Isso deve ser feito independentemente do tipo de atividade que será realizada, seja imunização ou na rede de frio.

Após a ambientação das bobinas, elas devem ser arrumadas no interior da caixa, em posição vertical. A quantidade depende da atividade a ser 
realizada (transporte, vacinação de rotina, extramuros etc.), da distância entre o local de saída e o local de chegada, do tempo de transporte, entre outras situações. Por exemplo, se for um trabalho extramuro ou em uma sala que não tenha climatização, pode ser colocada uma bobina extra no assoalho da caixa (posição horizontal). Quando a temperatura da caixa atingir o recomendado, os imunobiológicos poderão ser organizados no interior da caixa. Outros cuidados com as bobinas envolvem limpeza, conservação, congelamento apropriado, verificação do prazo de validade e da presença de resíduos ou outras substâncias que possam contaminá-la.

Frascos e ampolas dos imunobiológicos não podem entrar em contato direto com as bobinas; por isso, devem ficar acondicionados em recipientes. Dentro do recipiente com vacinas, deve ser colocado o bulbo do termômetro, e na parte externa da caixa térmica deve ficar o termômetro (a depender do tamanho da caixa, podem ser colocados mais de um termômetro). Esse cuidado proporciona segurança no monitoramento e controle da temperatura.

Foto 20 - Bobina de gelo reutilizável

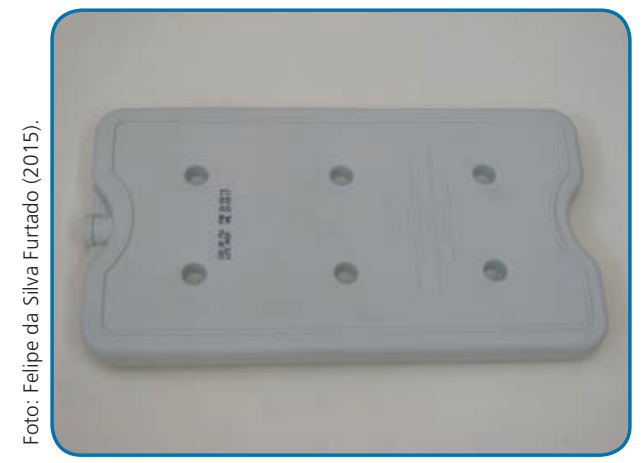

Nas atividades de vacinação em nível local, não se devem colocar bobinas no fundo da caixa térmica e em contato direto com o recipiente de vacinas, para evitar que congelem. Para as atividades extramuros (em que a vacina estará em trânsito por um tempo determinado) ou no transporte desses produtos, recomenda-se o uso de bobinas de gelo reutilizáveis no fundo da caixa, em função da maior exposição da vacina à temperatura do meio externo ou do meio ambiente.

\section{Gelo seco}

O gelo seco é utilizado na rede de frio no transporte de imunobiológicos, com especificação de manutenção em temperatura negativa (abaixo de $0^{\circ} \mathrm{C}$ ). A finalidade de seu uso é a manutenção dessa temperatura até o destino final. A quantidade a ser usada será de acordo com o tempo e a distância a ser percorrida.

O mercado dispõe de várias formas de gelo seco, em escamas, barras ou nuggets. Apesar de auxiliar na manutenção do produto em temperatura negativa, tem sido cada vez menos utilizado na Cenadi, porque

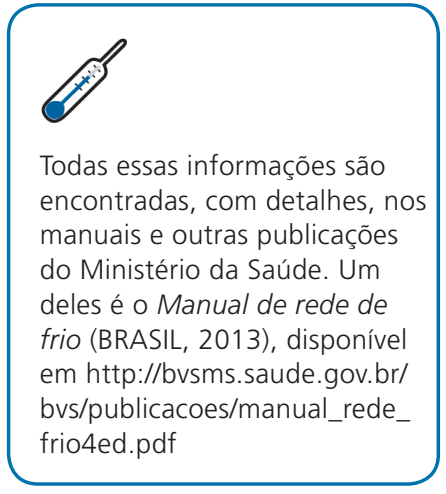

Todas essas informações são encontradas, com detalhes, nos manuais e outras publicações do Ministério da Saúde. Um deles é o Manual de rede de frio (BRASIL, 2013), disponível em http://bvsms.saude.gov.br/ bvs/publicacoes/manual_rede frio4ed.pdf 
O uso de gelo seco no transporte de imunobiológicos por via aérea pode oferecer risco, porque o gelo seco é composto de $\mathrm{CO}_{2}$ em estado sólido. Quando este entra em contato com a água ou umidade relativa do ar, pode se expandir e provocar explosões, fato possível de ocorrer com as caixas isotérmicas que acondicionam o imunobiológico transportado em aeronaves. estudos realizados demonstram a existência de outros produtos mais adequados ao transporte de imunobiológicos e com capacidade similar de manutenção de temperatura. Como exemplo, pode ser citado o ice foam, composto por bobinas de gel em espuma que permitem manter os imunobiológicos em temperaturas negativas por longo tempo, durante o transporte, sem necessidade de uso do gelo seco, principalmente no transporte aéreo.

Foto 21 - Vacina para febre amarela acondicionada com gelo seco

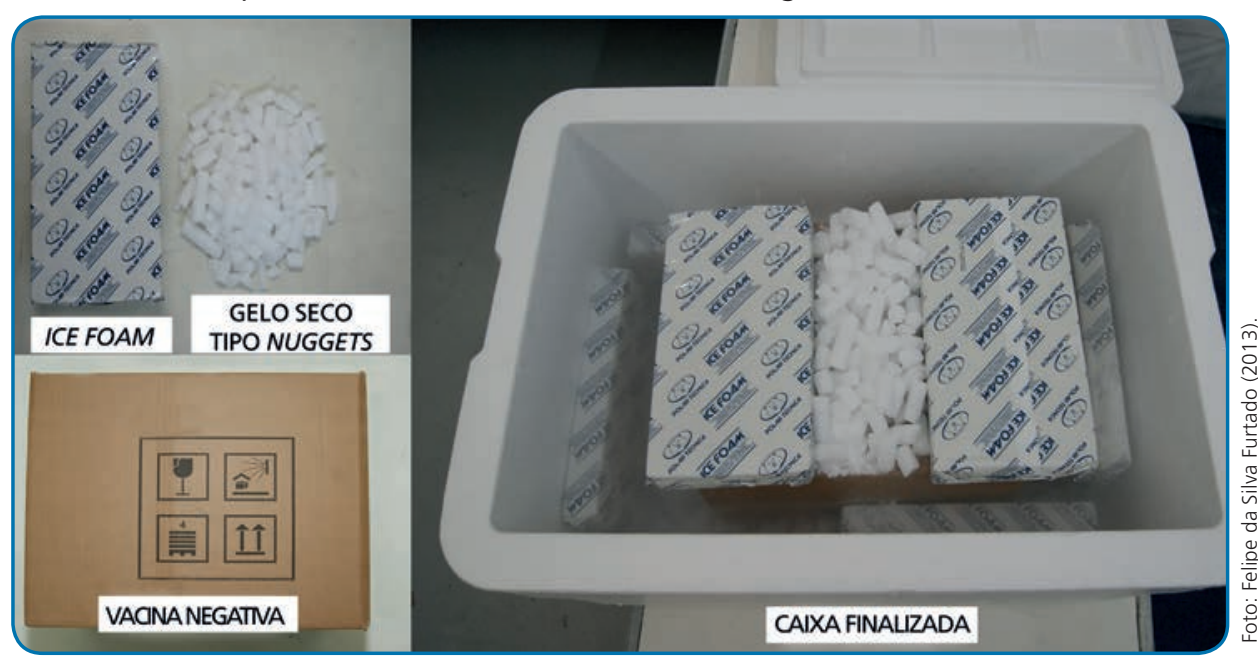

\section{Atenção!}

1. Não se deve confundir e substituir bobinas de gel ou água reutilizáveis por gelo seco, pois têm aplicações diferentes. As bobinas devem ser utilizadas para conservação dos imunobiológicos de $+2^{\circ} \mathrm{C}$ a $+8^{\circ} \mathrm{C}$, e o gelo seco, para o transporte em $-20^{\circ} \mathrm{C}$, como no caso das vacinas víricas, quando são transportadas do laboratório produtor para a Cenadi e desta para os estados.

2. Vale destacar que, atualmente, a Cenadi tem utilizado, no máximo, $5 \mathrm{~kg}$ de gelo seco por caixa térmica, complementando com bobinas do tipo ice foam, para casos de transporte em temperaturas negativas. Tem sido observado, na prática da central nacional, que somente bobinas desse tipo (sem o gelo seco) têm mantido a temperatura dos imunobiológicos, mas são necessários mais estudos e pesquisas para substituir definitivamente o gelo seco pelas bobinas ice foam.

3. A utilização de gelo em barra ou escama não é recomendada para atividades de rotina, em função do risco de congelamento dos imunobiológicos. 


\section{Caixas térmicas}

Esse material é utilizado amplamente nas atividades de imunização ou de RF para acondicionar os imunobiológicos, sendo elemento essencial no transporte e nas atividades de vacinação. As caixas podem ser encontradas no comércio sob duas formas de apresentação: como caixa de isopor, composta de material isotérmico do tipo poliestireno expandido, ou sob a forma de caixa feita de poliuretano.

De acordo com o tipo de atividade, uma ou outra poderá ser mais apropriada. Por exemplo, a caixa de isopor, em geral, é mais utilizada no transporte dos imunobiológicos entre laboratórios, central nacional e desta para a instância estadual, ao passo que a caixa de poliuretano é mais usada nas atividades de vacinação de rotina.

Foto 22 - Modelos de caixa térmica de poliuretano e poliestireno expandido

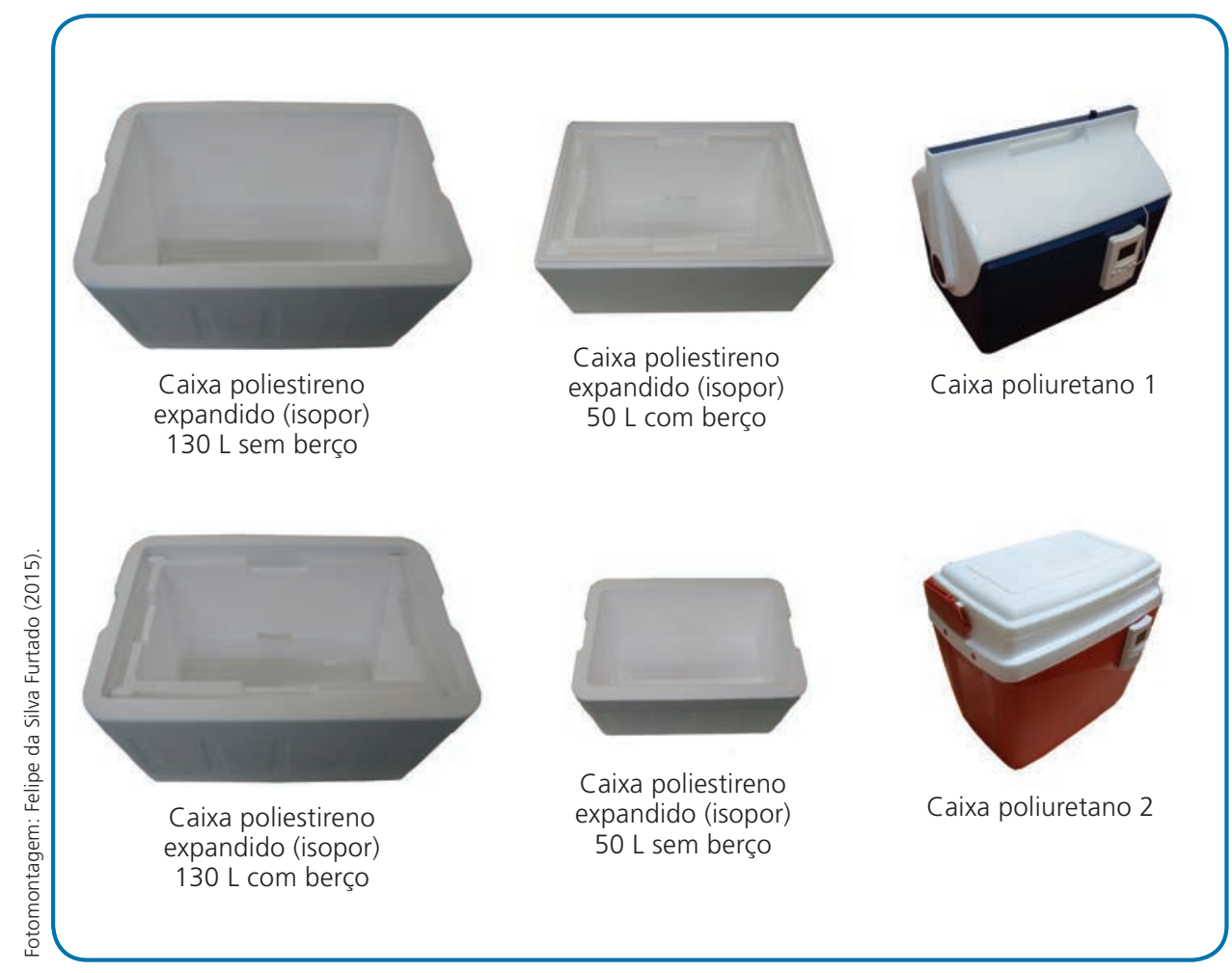

Seja qual for o tipo de caixa térmica escolhido, esta não pode estar danificada ou fora dos padrões preconizados. Assim, no planejamento da aquisição de caixas, o gestor da RF deve levar em consideração as especificações do fabricante, a propriedade e a característica térmica do produto, sua densidade, capacidade etc. É fundamental que o tipo de caixa seja escolhido de acordo com o tipo de atividade ou uso a que
Poliestireno é o que, popularmente, conhecemos como isopor.

Poliuretano refere-se a um tipo de plástico que permite o isolamento térmico.

Em função da facilidade de limpeza, durabilidade e resistência, o uso das caixas de poliuretano está recomendado pelo PNI, nas atividades de rotina. 
se destina, especialmente em relação a sua capacidade, resistência a impactos e espessura. Caso não sejam seguidas essas recomendações, as caixas poderão não resistir ao manuseio e às circunstâncias do dia a dia de vacinação ou transporte, bem como não manter a temperatura adequada, por terem estrutura e espessuras impróprias ao uso previsto.

Alguns cuidados devem ser tomados na organização das caixas térmicas, além dos já mencionados, em função das diversas variáveis envolvidas. Tais cuidados se aplicam, especialmente, ao acondicionamento dos imunobiológicos para o transporte. Nesse caso, é fundamental considerar:

a temperatura ambiente do local de origem e de destino;

* a distância até o destino, tempo em trânsito, via e condições de transporte e o quantitativo de imunobiológicos a ser transportado;

o isolamento da caixa térmica (deve ser preservado);

* a quantidade e o tipo de bobina reutilizável (as bobinas devem ser verificadas e monitoradas);

* a padronização e as recomendações do PNI para a organização das vacinas nas caixas térmicas;

o volume da caixa a ser transportada;

* a posição dos imunobiológicos na caixa térmica (não devem ficar soltos no interior da caixa).

Em todas as atividades, a previsão do quantitativo de caixas é indispensável, devendo-se considerar sempre a relação atividade $\mathrm{X}$ capacidade da caixa; quantidade de vacinas para atender a população X volume de caixas para transporte $\mathrm{X}$ quantidade de bobinas necessárias etc.

Os gestores das centrais de RF e as instituições de saúde que dispõem de salas de vacina devem planejar o orçamento considerando a aquisição do quantitativo de caixas térmicas, bobinas e gelo necessário às atividades, de acordo com o padrão e o preconizado pelo PNI.

Para saber mais detalhes sobre a forma e as recomendações para organização das caixas e utilização de bobinas, consulte as publicações referentes ao tema no site do Ministério da Saúde (www.saude.gov.br).

\section{Termômetros}

Como regra geral, os imunobiológicos devem permanecer rigorosamente em temperaturas entre $+2^{\circ} \mathrm{C} \mathrm{e}+8^{\circ} \mathrm{C}$ na Central Nacional de Rede 
de Frio, na central ou coordenação estadual de imunizações, nas regionais de saúde, nas salas de vacinação, nos postos volantes (por ocasião de campanhas, intensificações e bloqueios), bem como durante todo o percurso do transporte. Excepcionalmente, e mediante estrita orientação do PNI e/ou do laboratório produtor, algumas vacinas podem ser armazenadas em temperaturas negativas, mas apenas nas instâncias superiores (nacional, estadual ou regional), e nunca na municipal ou local. Isso significa dizer que a temperatura ideal de acondicionamento das vacinas para posterior utilização será sempre de $+2^{\circ} \mathrm{C} a+8^{\circ} \mathrm{C}$.

Em qualquer das instâncias ou locais, o instrumento utilizado no monitoramento da temperatura é o termômetro. Existe uma variedade de tipos e modelos, com diferentes princípios de funcionamento, tais como termômetro de momento, máxima e mínima digital com cabo extensor, analógico, de radiação infravermelha visível, de registro gráfico e termorregistradores, como já apresentado em capítulos anteriores. Procuramos tratar aqui dos principais cuidados no uso desse instrumento na rede de frio ou nas salas de vacina. Vale destacar que a instalação e a medição dos equipamentos utilizados nas salas de vacina podem ser encontradas, de forma vasta, na literatura sobre imunização. Por isso, neste capítulo serão apresentados os termômetros mais utilizados na rede de frio e os cuidados necessários para usá-los de forma segura.

\section{Termômetro de momento, máxima e mínima digital com cabo extensor}

É utilizado em grande parte das atividades de vacinação. Atualmente, na Cenadi, tem sido utilizado em determinadas situações, como para medição da temperatura das caixas durante o transporte (embora deva ser feito o uso preferencial de data loggers). Pode, também, ser utilizado para auxiliar na medição de temperatura, quando há dúvidas na leitura realizada por outro equipamento como o laser.

Dado seu amplo uso na sala de vacinação, a aquisição desse tipo de insumo deve ser realizada com bastante rigor pelo gestor, devendo-se planejar um quantitativo de reserva para estoque e recursos para verificação sistemática da calibração do equipamento, visto que sua utilização é diária na rotina das unidades.

Para o correto uso, alguns cuidados devem ser tomados no seu manuseio, como:

燐 verificação e seguimento das recomendações do fabricante;

*ata de instalação da pilha com identificação do período para troca;
Termômetros são abordados nos Capítulos 6 e 7, respectivamente, "A rede de frio e a importância da temperatura dos imunobiológicos" e "Refrigeração e equipamentos da rede de frio". 
* adequação do termômetro na escala apropriada: verificar a presença de botão de controle de leitura em ${ }^{\circ} \mathrm{F}$ (Fahrenheit) ou ${ }^{\circ} \mathrm{C}$ (Celsius), para posicioná-lo na escala utilizada no Brasil, que é o ${ }^{\circ} \mathrm{C}$;

* calibração conforme especificações do fabricante ou normas, entre outros.

A instalação desse tipo de termômetro no refrigerador doméstico da sala de vacina ou nas caixas térmicas deve seguir as instruções dos manuais do Ministério da Saúde, observando-se, principalmente, que a maioria dos modelos digitais é importada e desenhada para o registro de temperatura ambiente dentro e fora da sala. Por isso, o visor identificado com Out (fora) corresponde à temperatura do ambiente em que se encontra o refrigerador ou caixa térmica, e o visor identificado com In (dentro), à temperatura do interior do refrigerador.

Para a verificação da temperatura, deve-se pressionar o botão uma vez, e será dada a temperatura máxima atingida, surgindo a sigla Max (máxima); pressionando-o mais uma vez, surgirá a sigla Min (mínima); pressionando-o pela terceira vez, a temperatura do momento. Recomenda-se que, após cada leitura e registro das temperaturas, seja pressionado o botão Reset, para iniciar um novo ciclo de medição.

Também existe disponível um modelo que permite a leitura das temperaturas de momento, máxima, mínima e do ambiente externo, com dispositivo de alarme, que é acionado quando a variação de temperatura ultrapassa os limites configurados, ou seja, menor que $+2^{\circ} \mathrm{C}$ e maior que $+8^{\circ} \mathrm{C}$ (set point).

\section{Importante!}

A Organização Mundial da Saúde (OMS) recomenda que a utilização do termômetro de momento, máxima e mínima digital com cabo extensor deve restringir-se às caixas de uso diário, na instância local. O deslocamento pode comprometer a calibração e, consequentemente, a confiabilidade da medição.

Por ser bastante utilizado, a sua instalação e forma de leitura devem ser conhecidas pelo profissional da saúde que trabalha com o equipamento, em qualquer instância da rede de frio ou unidade de saúde.

\section{Termômetro analógico}

É indicado para refrigeradores domésticos da sala de vacina ou em câmara frigorífica, não sendo recomendado seu uso nas caixas tér- 
micas. Isso porque é um termômetro de dilatação constituído de um reservatório, preenchido com líquido, soldado a um tubo capilar de vidro graduado e fechado na parte superior, que precisa ser mantido na posição vertical para que não haja fragmentação do líquido utilizado no seu interior, o que impossibilita sua instalação no interior das caixas térmicas.

Outro fator que contraindica seu uso nas caixas térmicas é a possibilidade de quebra do vidro que o reveste em situação de impacto, como nas atividades de rotina na sala de vacina e no transporte na RF. O capítulo anterior aborda com detalhes os usos e as restrições do termômetro digital, não sendo necessários mais detalhes sobre o assunto.

\section{Termômetro de radiação infravermelha ou pirômetro}

É recomendado para medições rápidas e grandes volumes de cargas; por isso, tem amplo uso na rede de frio e na instância estadual. É um instrumento composto por sensores de temperatura, tem formato de pistola, e a temperatura é verificada a partir do acionamento do gatilho do aparelho. Possui alta tecnologia, funciona por meio de sensores que utilizam radiação térmica. A medição da temperatura é feita por laser, ao ser acionado o gatilho. Seu medidor possui display LCD iluminado, com tampa protetora para o sensor, e chave de seleção ${ }^{\circ} \mathrm{C} /{ }^{\circ} \mathrm{F}$.

Foto 23 - Termômetro de radiação infravermelha visível

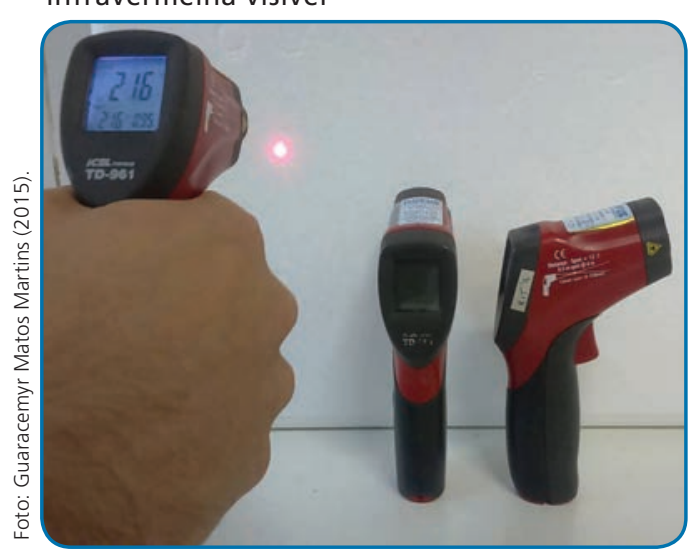

A distância mínima e o tempo de pressão do gatilho para medição da temperatura diária na RF devem ser rigorosamente seguidos pelo profissional, que deve ser capacitado ou informado sobre a forma correta de uso do equipamento. Para que o registro desse termômetro seja confiável, é preciso observar e seguir os procedimentos descritos pelo fabricante do produto.

\section{Importante!}

Por causa da emissão de raio laser, recomenda-se não utilizar esse equipamento diretamente na pele e, em especial, em direção aos olhos. 


\section{Termômetro de registro gráfico}

É utilizado em câmaras e freezers, nas centrais de rede de frio, para a conservação de imunobiológicos. Registra temperaturas em um intervalo de tempo, geralmente de sete dias, e os discos devem ser trocados após esse período. O planejamento para sua aquisição deve levar em consideração a necessidade de estoque de discos para registro, de forma que a observação do comportamento da temperatura não seja interrompida ou impedida pela falta de material. O registro gráfico das temperaturas

Foto 24 - Termógrafo

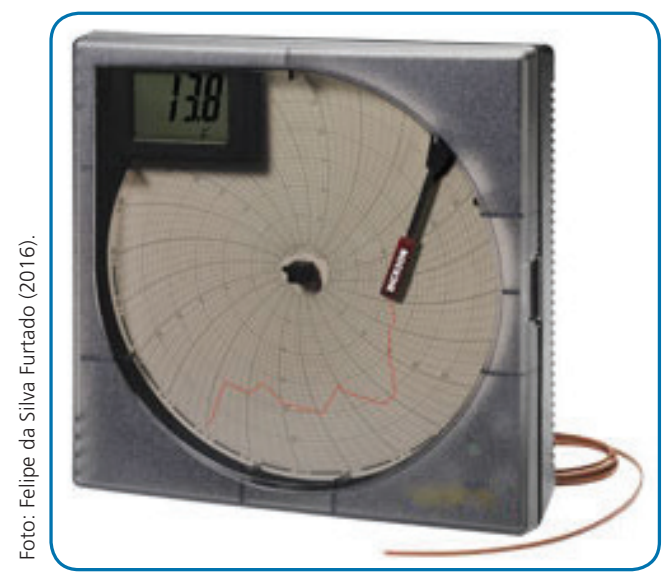

medidas por esse aparelho deve ser avaliado diariamente para detecção de possíveis oscilações de temperatura.

O termômetro de registro gráfico é utilizado pela Cenadi em situações excepcionais, como na medição da temperatura para verificar a eficiência e/ou condição de funcionamento do sistema de automação; serve, portanto, como um instrumento de avaliação periódica.
Informações sobre os demais instrumentos de medição de temperatura poderão ser encontradas nas publicações do Programa Nacional de Imunizações, em portarias e manuais do Ministério da Saúde.

Segundo orientações da Organização Mundial da Saúde, os data loggers são indicados para uso em caixas de transporte e câmara refrigerada para imunobiológicos.

\section{Termorregistradores: os data loggers}

Eles podem ser de diversos tipos: data loggers, registrador eletrônico frigorífico e indicador de congelamento. Aqui, abordamos apenas o data logger, por sua ampla utilização na rede de frio.

Como a descrição sobre a forma de utilização desse instrumento de medição da temperatura já foi apresentada no capítulo anterior, vamos abordar apenas as informações relativas aos cuidados com o equipamento na central de rede de frio.

Data loggers são pequenos registradores de temperatura utilizados nas atividades de transporte dos imunobiológicos das centrais de RF, em geral. É um importante insumo, porque permite o monitoramento da temperatura durante o transporte, indicando quando ela está fora da faixa adequada, assim como o tempo em que é mantida na faixa ideal, demonstrando, também, o intervalo de tempo durante o qual o imunobiológico pode ter sido submetido a alterações de temperatura.

Além de seguir as especificações do fabricante, o principal cuidado a ser tomado pelo profissional da RF é a calibração desse termômetro, que deve ser realizada anualmente. 
Por serem muito utilizados, o gestor precisa planejar sua aquisição considerando o uso, a capacidade instalada da rede, a movimentação e o volume de transporte das vacinas na central de rede de frio sob sua responsabilidade. É importante que, na capacitação da equipe da rede de frio, sejam consultadas e informadas as orientações do fabricante em relação ao uso e às calibrações desse registrador de temperatura.

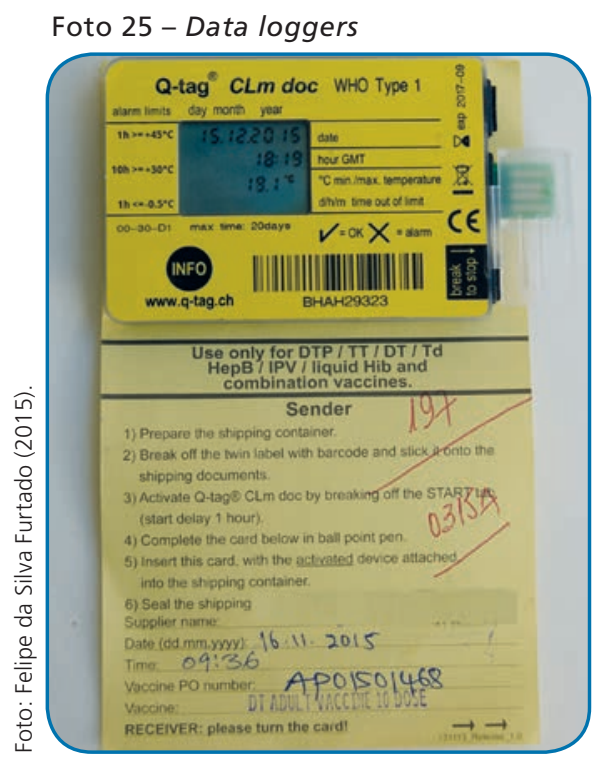

Vale, por fim, reforçar que, independentemente do tipo de termômetro utilizado, o manejo, a calibração, a fixação e o monitoramento de seus registros são fundamentais para a correta medição e o funcionamento do equipamento.

Convém, ainda, reiterar outros dois pontos. O primeiro refere-se à exigência de que todos os equipamentos de refrigeração e de transporte utilizados na rede de frio tenham algum tipo de instrumento para medir e monitorar quantitativamente a temperatura. E o segundo diz respeito à adequação desse instrumento aos equipamentos como câmara frigorífica, refrigerador doméstico, freezer, caixas térmicas de uso diário ou para transporte.

\section{Câmara refrigerada/refrigeradores}

Os refrigeradores/câmaras refrigeradas e as câmaras frigoríficas (negativas ou positivas) são equipamentos destinados ao armazenamento de imunobiológicos nas instâncias locais e nas centrais de RF, respectivamente.

Nas atividades de vacinação no nível local, são comumente usados a câmara refrigerada ou os refrigeradores domésticos. Entretanto, no mercado, já existem tipos de câmara refrigerada/refrigeradores próprios para armazenar imunobiológicos que poderão substituir, gradualmente, os refrigeradores domésticos, conforme já mencionado no capítulo anterior, em que é mostrado, com detalhes, como esses equipamentos funcionam e os cuidados na sua instalação e aquisição.

O planejamento para aquisição desses equipamentos deve considerar, principalmente, o tipo de uso, a capacidade de armazenamento, o espaço disponível para o refrigerador, a garantia de assistência técnica 
Esses são cuidados que todo gestor deve tomar na aquisição de qualquer equipamento.
Como discutido no capítulo anterior, as garrafas de água visam criar uma massa fria dentro do equipamento. O uso do corante serve para alertar que aquela água não é própria para consumo. e o registro do produto. O gestor deve conhecer os diversos tipos disponíveis no mercado, escolher o mais apropriado às atividades a que se destina e só então proceder a ou encaminhar o pedido de aquisição do equipamento. Ao efetuar a compra, o gestor deve assegurar, também, a instalação, a assistência técnica e o treinamento da equipe pelo fabricante, efetuando, ainda, a capacitação da equipe de acordo com a nova estruturação da rede de frio.

Em relação aos cuidados com os refrigeradores, para que mantenham com qualidade e segurança os imunobiológicos armazenados, alertamos, principalmente, para os seguintes procedimentos:

* fazer uso exclusivo da câmara refrigerada/refrigerador para os imunobiológicos;

* localizar a câmara refrigerada/refrigerador a uma distância em torno de $20 \mathrm{~cm}$ da parede e, se houver mais de um equipamento, de $20 \mathrm{~cm}$ entre eles;

* instalar tomada a 1,30 m (um metro e trinta centímetros) do piso;

* usar tomada exclusiva para o equipamento;

* evitar a colocação de qualquer objeto sobre o equipamento;

* não colocar qualquer objeto dentro da geladeira que possa dificultar a circulação de ar;

* realizar a verificação de rotina do fechamento das portas do equipamento, no fim de cada dia de trabalho;

* fazer a limpeza periódica do equipamento, de preferência a cada 15 a 20 dias, antes de a camada de gelo ultrapassar $0,5 \mathrm{~cm}$.

Em relação à arrumação interna da câmara refrigerada/refrigerador, devem ser observadas algumas normas, como:

* no evaporador, devem ser colocadas as bobinas reutilizáveis arrumadas na posição vertical; quando colocadas no evaporador, devem estar congeladas, com uma consistência firme;

* na porta da câmara refrigerada/refrigerador, não deve ser armazenado nenhum produto, assim como na parte inferior, local da gaveta de frutas. A tampa deve ser retirada, e a gaveta deve permanecer, por constituir uma barreira para a saída do ar frio. É o processo de convecção que rege a transferência de energia no interior do equipamento. A colocação de garrafas de mais ou menos 1 litro, contendo água e um corante, também vai favorecer esse processo;

* os imunobiológicos, depois de retirados das caixas, devem ser armazenados em bandejas, tipo guarda-talheres, perfuradas ou não, 
com um espaço de mais ou menos $1 \mathrm{~cm}$ da parede do equipamento de refrigeração;

o termômetro deve ficar em local central, entre a primeira e a segunda prateleira, equidistante de todos os pontos do interior do equipamento;

* se o termômetro utilizado no equipamento for um modelo com o bulbo, deve-se ter o cuidado para que essa parte permaneça na posição central. O bulbo do termômetro deve ser colocado na parte central da prateleira do meio, onde se encontram armazenados os frascos dos imunos; com isso, se garante a medição exata da temperatura das vacinas por meio da medida do ar que circula em torno desses produtos;

* após a fixação do termômetro digital na parte externa da câmara refrigerada/refrigerador, é necessário introduzir o cabo no gabinete interno, através do espaço entre a porta e o interior do gabinete da câmara refrigerada/refrigerador, próximo às dobradiças.

Logo após a aquisição do equipamento, ou durante o processo de capacitação da equipe, é fundamental identificar a localização do evaporador ou do local de entrada do ar-refrigerado, que são diferentes conforme o modelo do equipamento, a fim de evitar a colocação de vacinas próximo a esses pontos, durante a arrumação dos produtos, e resguardá-las de oscilações de temperatura que comprometam suas propriedades e segurança.

Reiteramos, ainda, outros procedimentos tratados no capítulo anterior: planejar e executar as manutenções preventivas, preditivas e corretivas, dispor de um plano de contingência e equipe devidamente treinada. O gestor e o especialista em RF devem estar atentos a esses pontos e seguir as recomendações propostas para cada equipamento, conforme orientações do fabricante e do Programa Nacional de Imunizações.

O cumprimento das recomendações e dos cuidados aqui apresentados irá garantir o perfeito funcionamento do equipamento, aumentando sua vida útil e assegurando a qualidade e conservação dos produtos imunobiológicos.

\section{Freezers}

São equipamentos destinados ao armazenamento das bobinas que precisam ser congeladas para uso no transporte dos imunobiológicos entre as instâncias e centrais de RF e na realização dos procedimentos de vacinação nas unidades de saúde, nas ações extramuro etc.

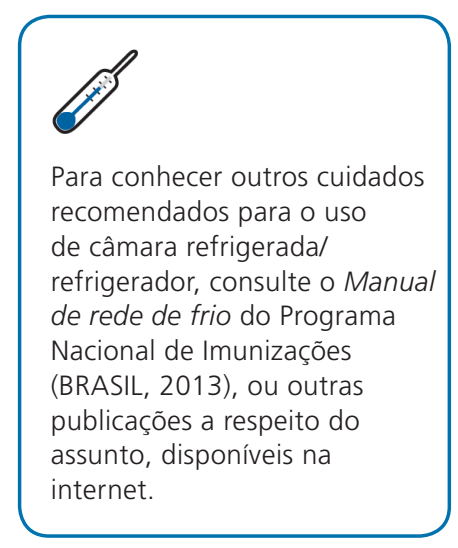

Para conhecer outros cuidados recomendados para o uso de câmara refrigerada/ refrigerador, consulte o Manual de rede de frio do Programa Nacional de Imunizações (BRASIL, 2013), ou outras publicações a respeito do internet. 


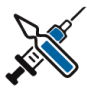

É importante que o gestor esteja sempre atento às recomendações do laboratório produtor, bem como às portarias e notas técnicas do Programa Nacional de Imunizações (PNI).

Apresentamos, no Anexo G, "Cuidados com seringas e agulhas", os principais cuidados para que o profissional possa atuar de forma segura, evitando acidentes durante a execução dos procedimentos de vacinação.
Os cuidados com esse equipamento são os mesmos aplicados aos refrigeradores. No planejamento para aquisição do produto, o gestor da rede de frio deve dar preferência aos freezers do tipo horizontal, com isolamento de suas paredes, evaporador e condensador localizado em áreas abaixo do gabinete, com selo do Inmetro e sistema de refrigeração selado. Outras especificações podem ser encontradas nos modelos disponíveis, devendo o especialista da RF ou o gestor conhecerem os existentes para realizar a escolha apropriada, sempre considerando a capacidade do equipamento para atender a sua demanda de armazenamento, a compatibilidade com a rede elétrica local, entre outros aspectos.

Devem ser adotados pelo profissional especialista as mesmas orientações e cuidados na aquisição, instalação e manutenção dos demais equipamentos de refrigeração.

Existem outros insumos necessários, especialmente para as atividades de imunização, que apresentamos a seguir, de forma resumida. São eles: seringas, agulhas e caixas coletoras de resíduos.

\section{Seringas e agulhas}

Seringas e agulhas são amplamente utilizadas nas atividades de vacinação, configurando-se como o principal insumo para a administração dos imunobiológicos.

O uso de seringas descartáveis trouxe grandes benefícios ao trabalho de vacinação, tanto em termos da segurança quanto da esterilização e redução do risco de contaminação. A escolha do tipo de seringa e de calibre da agulha vai depender do tipo de imunobiológico, da via a ser utilizada para aplicação e da recomendação do laboratório produtor.

Alguns cuidados devem ser adotados pelo profissional no manuseio das seringas e agulhas. Todos eles devem ser seguidos pela equipe da saúde, tendo sempre, como base, as recomendações do fabricante e do PNI. Ao gestor, cabe acompanhar as inovações do mercado, buscando, além de produtos mais seguros, observar as normas e diretrizes do Programa Nacional de Imunizações e informar sua equipe sobre as inovações e novas recomendações no uso e manuseio dos insumos utilizados nas atividades de vacinação. 


\section{Caixa coletora para descarte de resíduos perfurocortantes e infectantes}

Em toda a atividade de vacinação e na rede de frio, diversos tipos de resíduos são gerados. Em relação aos resíduos cortantes ou perfurocortantes, como seringas e agulhas, os cuidados básicos estão relacionados com o acondicionamento desses insumos. Eles devem ser pré-acondicionados em recipiente rígido, resistente a ruptura e vazamentos, que contenha tampa e a simbologia de material infectante, a exemplo da caixa coletora de material perfurocortante apresentada na foto a seguir.

Foto 26 - Modelo de caixa e de suporte para caixa coletora de material perfurocortante e infectante

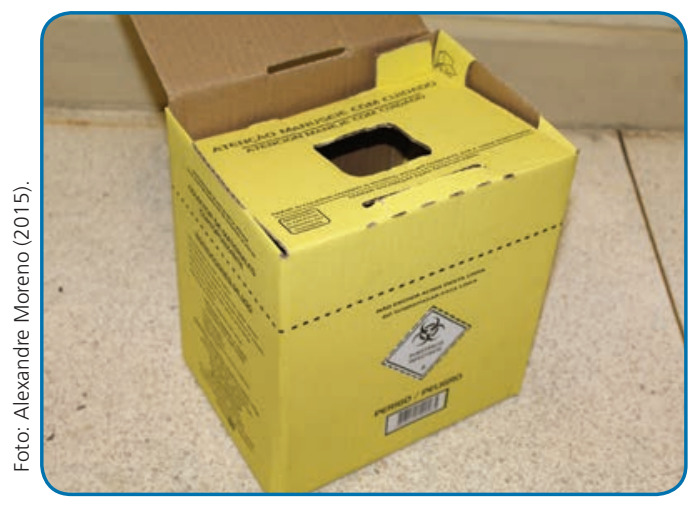

Os materiais perfurocortantes devem ser especialmente:

* acondicionados separadamente, logo após o uso, no local de sua geração;

depositados na caixa coletora, até que esta atinja 2/3 de sua capacidade. Ao atingir esse percentual, a caixa deve ser descartada, porque caixas cheias podem causar acidentes.

Ciente dos cuidados, é fundamental que, no planejamento para a aquisição desse tipo de material, o gestor considere aspectos como: o movimento da sala de vacina e a quantidade de lixo perfurocortante a ser descartado; o destino das caixas após sua utilização; e a capacidade das caixas coletoras. Levando em consideração tais aspectos, o planejamento garantirá a disponibilidade desse insumo, possibilitando o acondicionamento dos perfurocortantes de forma correta, e garantindo, para toda a equipe, segurança no manejo e na utilização.

\section{Considerações finais}

Entendemos que a discussão sobre gestão da rede de frio de imunobiológicos envolve um conjunto de diversos procedimentos, em que cada ator tem importância e papel de destaque. Nenhum deles é mais ou menos importante, e todos os trabalhadores devem atuar de forma planejada, articulada e integrada, como elos de uma rede, da rede de frio!

As atividades de armazenamento, manuseio, distribuição e transporte dos imunobiológicos são de grande importância e complexidade, exigindo

O manejo, a segregação, a coleta, o tratamento, o transporte e a destinação final dos resíduos da rede de frio merecem atenção especial e serão discutidos no capítulo seguinte.

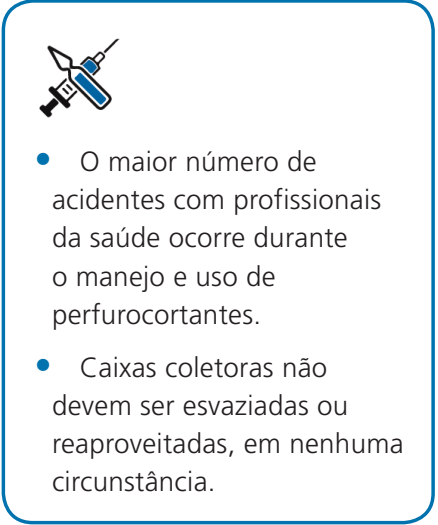


Para mais informações sobre o curso de formação de especialista em rede de frio de imunobiológicos, oferecido pela Escola Politécnica Joaquim Venâncio/Fiocruz/MS, acesse http:// www.epsjv.fiocruz.br/. comprometimento da equipe e a presença do profissional técnico responsável, conforme legislação pertinente. Segundo o artigo 11, da Medida Provisória n. 2.190-34, de 23 de agosto de 2001 (BRASIL, 2001), as distribuidoras de medicamentos devem manter, obrigatoriamente, a assistência de técnico responsável farmacêutico, devidamente inscrito no Conselho Regional de Farmácia, durante o funcionamento do estabelecimento (BRASIL, 1973), norma que deve ser também cumprida na rede de frio de imunobiológicos, pois a dispensação de imunobiológicos é compreendida como dispensação de medicamento.

Além do farmacêutico, outros profissionais são importantes e fazem parte da equipe da rede de frio, como enfermeiro e auxiliar de enfermagem; auxiliar de serviços gerais; auxiliar de expedição; apoio administrativo; motorista; almoxarife; armazenista; profissionais da importação, carga e descarga; operadores de empilhadeira e, mais recentemente incorporado à equipe, o especialista de rede de frio. Trata-se de um profissional atuante na central de RF e que, mediante uma formação específica, se torna especialista em gestão de rede de frio de imunobiológicos, apto para a gestão das centrais de armazenamento e distribuição dos imunobiológicos. Esse profissional deve e pode auxiliar o farmacêutico na gestão desses locais.

Seja qual for o gestor da central de rede de frio, todas as atividades desenvolvidas irão requerer um conjunto de procedimentos técnicos e administrativos com o objetivo de assegurar a qualidade dos insumos (imunobiológicos), por meio de condições adequadas de recebimento, armazenagem, manuseio, controle eficaz de estoque e transporte. Uma forma de garantir o cumprimento dos procedimentos é o gestor, ou especialista da rede de frio, descrever e registrar, formalmente, todas as atribuições e responsabilidades profissionais da equipe e fazer que sejam compreendidas por todos.

Cientes de que todos os trabalhadores exercem papel essencial no bom funcionamento da rede de frio, é importante que os gestores identifiquem suas necessidades de educação permanente e promovam oportunidades para sua qualificação. Para isso, o recurso orçamentário anual deve ser planejado e aprovado em valor suficiente e, da mesma forma, o quantitativo da equipe deve ser compatível com o bom andamento das atividades.

Nessa perspectiva, a Política Nacional de Desenvolvimento de Pessoal da Administração Pública Federal ratifica a relevância da melhoria continuada da eficiência, eficácia e qualidade dos serviços públicos prestados, assim como o desenvolvimento permanente do pessoal, a adequação das competências requeridas, a divulgação e o gerenciamento das ações 
de capacitação. Toda a equipe deve ser qualificada em procedimentos da rede de frio de imunobiológicos e em boas práticas de armazenamento, distribuição e transporte, de maneira a deter o conhecimento geral do contexto no qual está inserida e garantir a qualidade das atividades desenvolvidas.

Buscamos, neste capítulo, demonstrar os processos envolvidos na gestão da rede de frio, a partir da experiência da Cenadi, destacando suas etapas fundamentais, reforçando o papel do planejamento na gestão da RF, bem como a importância da medição e do controle da temperatura dos imunobiológicos, em todas as etapas e instâncias. Ressaltamos, especialmente, a responsabilidade dos trabalhadores das centrais de armazenamento na manutenção da temperatura e na eficiência da RF, enfatizando a necessidade de serem implementados cursos de formação e de educação continuada, a fim de propiciar uma atuação crítica e eficaz dos profissionais.

Ao escolher esse tipo de abordagem, nossa intenção é, principalmente, destacar a amplitude e complexidade do trabalho na rede de frio, para que você, trabalhador da imunização, rede de frio, ou da saúde, em geral, identifique sua posição nesse contexto e sua contribuição para o sucesso das ações de imunizações, fundamentais para a garantia do direito de todos os indivíduos receberem vacina com qualidade e capacidade de conferir proteção. É essa consciência que impulsiona você, trabalhador da rede de frio, a cumprir seus deveres profissionais e, especialmente, de cidadão.

A gestão eficiente e qualificada e o apoio dos órgãos competentes são instrumentos essenciais para fortalecer a perspectiva de um sistema de saúde público, universal, que, em vez de atender ao usuário do SUS como um "cliente" à procura de um produto ou serviço, seja humanizado, acolhedor para todos, sem distinção, e ciente da sua obrigação de cumprir o preceito constitucional de que o acesso à saúde é um direito do cidadão e dever do Estado.

\section{Referências}

AGÊNCIA NACIONAL DE VIGILÂNCIA SANITÁRIA (Brasil). Consulta pública n. 81, de 29 de agosto de 2007. Dispõe sobre a criação do vocabulário controlado de embalagens de medicamentos. Diário Oficial da União, Brasília, DF, 3 set. 2007.

AGÊNCIA NACIONAL DE VIGILÂNCIA SANITÁRIA (Brasil). Resolução da Diretoria Colegiada RDC n. 11, de 16 de fevereiro de 2012. Dispõe sobre o funcionamento de laboratórios analíticos que realizam análises em produtos sujeitos à vigilância sanitária e dá outras providências. Diário Oficial da União, Brasília, DF, 22 fev. 2012. Seção 1, p. 23. 
AGÊNCIA NACIONAL DE VIGILÂNCIA SANITÁRIA (Brasil). Vocabulário controlado de formas farmacêuticas, vias de administração e embalagens de medicamentos. Brasília, DF, 2011.

ANACleto, A. M. C. Temperatura e sua medição. Porto: Universidade do Porto, 2007.

ASSOCIAÇÃO BRASILEIRA DE NORMAS TÉCNICAS. NBR 5462:1994: confiabilidade e mantenabilidade. Rio de Janeiro, 1994. p. 37.

BRANCO FILHO, G. Dicionário de termos técnicos de manutenção e confiabilidade. Rio de Janeiro: Ciência Moderna, 2000.

BRASIL. Decreto n. 7.508, de 28 de junho de 2011. Regulamenta a Lei n. 8.080, de 19 de setembro de 1990, para dispor sobre a organização do Sistema Único de Saúde (SUS), o planejamento da saúde, a assistência à saúde e a articulação interfederativa, e dá outras providências. Diário Oficial da União, Brasília, DF, 29 jun. 2011

BRASIL. Lei n. 5.991, de 17 de dezembro de 1973. Dispõe sobre o Controle Sanitário do Comércio de Drogas, Medicamentos, Insumos Farmacêuticos e Correlatos, e dá outras providências. Diário Oficial da União, Brasília, DF, 19 dez. 1973.

BRASIL. Lei n. 6.360, de 23 de setembro de 1976. Dispõe sobre a vigilância sanitária a que ficam sujeitos os medicamentos, as drogas, os insumos farmacêuticos e correlatos, cosméticos, saneantes e outros produtos, e dá outras providências. Diário Oficial da União, Brasília, DF, 24 set. 1976.

BRASIL. Lei n. 8.080, de 19 de setembro de 1990. Dispõe sobre as condições para a promoção, proteção e recuperação da saúde, a organização e o funcionamento dos serviços correspondentes e dá outras providências. Diário Oficial da União, Brasília, DF, 20 set. 1990.

BRASIL. Lei n. 8.142, de 28 de dezembro de 1990. Dispõe sobre a participação da comunidade na gestão do Sistema Único de Saúde (SUS) e sobre as transferências intergovernamentais de recursos financeiros na área da saúde e dá outras providências. Diário Oficial da União, Brasília, DF, 31 dez. 1990

BRASIL. Medida Provisória n. 2.190-34, de 23 de agosto de 2001. Diário Oficial da União, Brasília, DF, 24 ago. 2001.

BRASIL. Ministério da Saúde. Portaria n. 3.252, de 22 de dezembro de 2009. Aprova as diretrizes para execução e financiamento das ações em vigilância em saúde pela união, estados, Distrito Federal e municípios e dá outras providências. Diário Oficial da União, Brasília, DF, 23 dez. 2009. Revogada pela Portaria n. GM/MS n. 1.378, de 9 de julho de 2103.

BRASIL. Ministério da Saúde. Secretaria de Vigilância em Saúde. Departamento de Vigilância das Doenças Transmissíveis. Manual de rede de frio do Programa Nacional de Imunizações. 4. ed. Brasília, DF, 2013. Disponível em: <http://portalsaude.saude.gov.br/images/pdf/2014/julho/03/ manual-rede-frio.pdf>. Acesso em: 20 abr. 2014.

BRASIL. Ministério da Saúde. Secretaria de Vigilância em Saúde. Departamento de Vigilância Epidemiológica. Informe técnico $12^{a}$ campanha nacional de vacinação do idoso. Brasília, DF, abr. 2010. 
BRASIL. Ministério do Trabalho e Emprego. Norma regulamentadora NR 6: equipamento de proteção individual: EPI. Brasília, DF, 2010.

BRASIL. Ministério do Trabalho e Emprego. Portaria n. 3.214, de 8 de junho de 1978. Aprova as Normas Regulamentadoras (NR) do Capítulo V, Título II, da Consolidação das Leis do Trabalho, relativas a Segurança e Medicina do Trabalho. Diário Oficial da União, Brasília, DF, 6 jul. 1978.

COLMAN, J. Confiabilidade metrológica de equipamentos da cadeia de frio para produtos hemoterápicos. Rio de Janeiro: Pontifícia Universidade Católica do Rio de Janeiro, set. 2011.

DAMACENO, R. J. Excelência em gestão na saúde. Banas Qualidade, n. 207, p. 38-47, ago. 2009.

INMETRO. Vocabulário internacional de metrologia: conceitos fundamentais e gerais e termos associados (VIM 2008). Rio de Janeiro, 2008.

MARTINELLO, B. F. et al. Transporte de medicamentos. Revista do Conselho Regional de Farmácia, Florianópolis, ano 3, n. 9, p-30-32, 2013.

MEINDL, P.; CHOPRA, S. Gestão da cadeia de suprimentos: estratégia, planejamento e operações. 4. ed. São Paulo: Pearson Education, 2011.

ORGANIZAÇÃO MUNDIAL DA SAÚDE. Termoestabilidade das vacinas. Genebra, 1998.

ORGANIZAÇÃO PAN-AMERICANA DE SAÚDE. Cadena de frio: curso de gerencia para el manejo efectivo del Programa Ampliado de Immunización (PAI): módulo 3. [S.I.], 2006.

PUBLIC HEALTH AGENCY OF CANADA. National vaccine storage and handling guidelines for immunization providers. Ottawa, 2007.

SILVA JUNIOR, J. B. 40 anos do Programa Nacional de Imunizações: uma conquista da saúde pública brasileira. Epidemiologia e serviços de saúde, Brasília, DF, v. 22, n. 1, p. 7-8, mar. 2013.

WORLD HEALTH ORGANIZATION. Guia para seleção e aquisição de equipamentos e acessórios. Geneva, 2002.

WORLD HEALTH ORGANIZATION. Manual on the management, maintenance and use of blood cold chain equipment. Geneva, 2005.

WORLD HEALTH ORGANIZATION. PQS devices catalogue: pre-qualified equipment for the Expanded Programme on Immunization (EPI). Geneva, 2013.

WORD HEALTH ORGANIZATION. Temperatura sensitivity of vaccines. Geneva, 2006.

XAVIER, J. N. Manutenção: tipos e tendências. Belo Horizonte: Tecém, 2000. Disponível em: <http:// tecem.com.br/site/downloads/artigos/tendencia.pdf>. Acesso em: 3 ago. 2016. 


\section{Anexo A - Protocolo de recebimento de insumos}

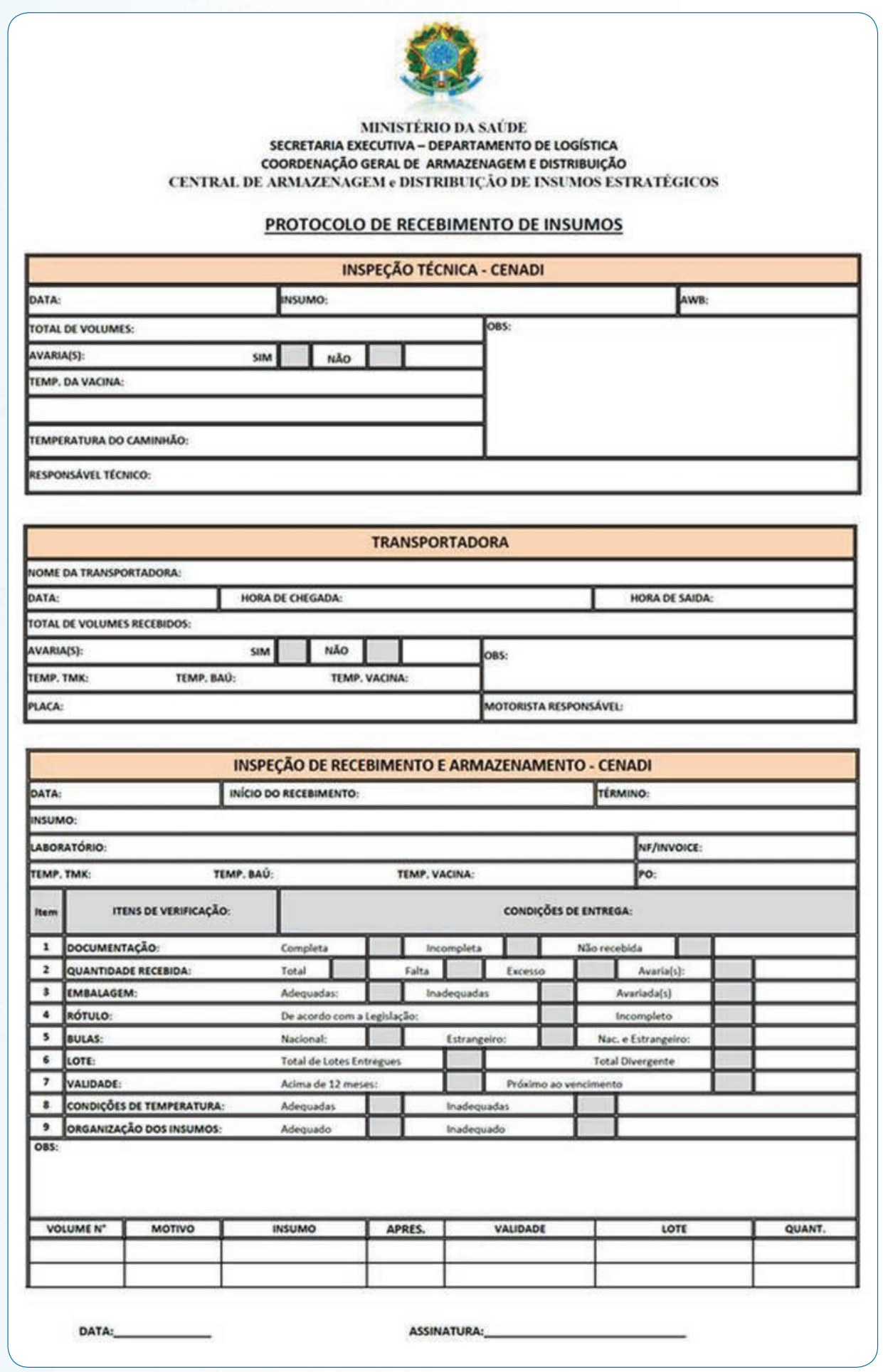




\section{Anexo B - Ata de recebimento de vacina}

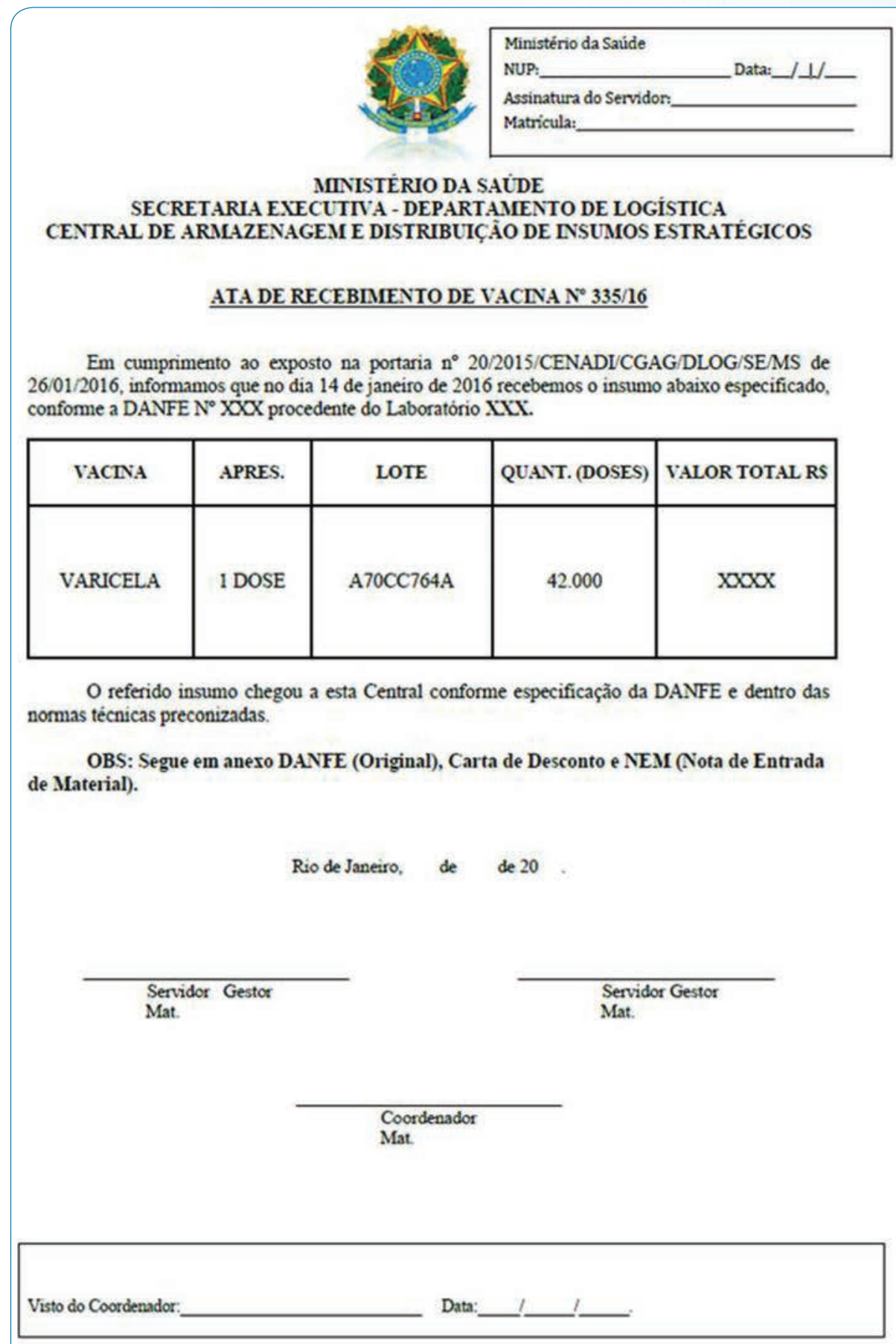




\section{Anexo C - Guia de entrada de imunobiológicos (GEI)}

MINISTÉRIODA SAÛDE

SECRETARIA EXECUIIVA

Departamento de Logistica - DELOG

Coordenaçāo Geral de Armazenagem e Distribuiçăo - CGAD

Central Nacional de Armaz. e Distr. de Insumos - CENADI

Setor de Recebimento e Armazenagem

GUIA DE ENTRADA

RECEBEMOS

$\mathrm{Em}$,

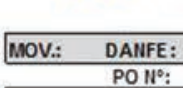

\begin{tabular}{|c|c|c|c|c|c|c|c|c|}
\hline \multirow{2}{*}{ IMSUMO } & \multirow{2}{*}{ LOTE } & \multirow{2}{*}{ VALIDADE } & \multicolumn{3}{|c|}{ LOCAUZAÇÃO } & \multirow{2}{*}{ QUANT. } & \multirow{2}{*}{ VALOR } & \multirow{2}{*}{$\begin{array}{l}\text { CONT. } \\
\text { QUALD }\end{array}$} \\
\hline & & & BL. & SET. & PAL & & & \\
\hline & & & & & & & & \\
\hline & & & & & & & & \\
\hline & & & & & & & & \\
\hline & & & & & & & & \\
\hline & & & & & & & & \\
\hline & & & & & & & & \\
\hline & & & & & & & & \\
\hline & & & & & & & & \\
\hline & & & & & & & & \\
\hline & & & & & & & & \\
\hline & & & & & & & & \\
\hline & & & & & & & & \\
\hline & & & LRE & 1DO: & & & & \\
\hline
\end{tabular}

Ooservaça:

… 


\section{Anexo D - Nota de fornecimento de material (NFM)}

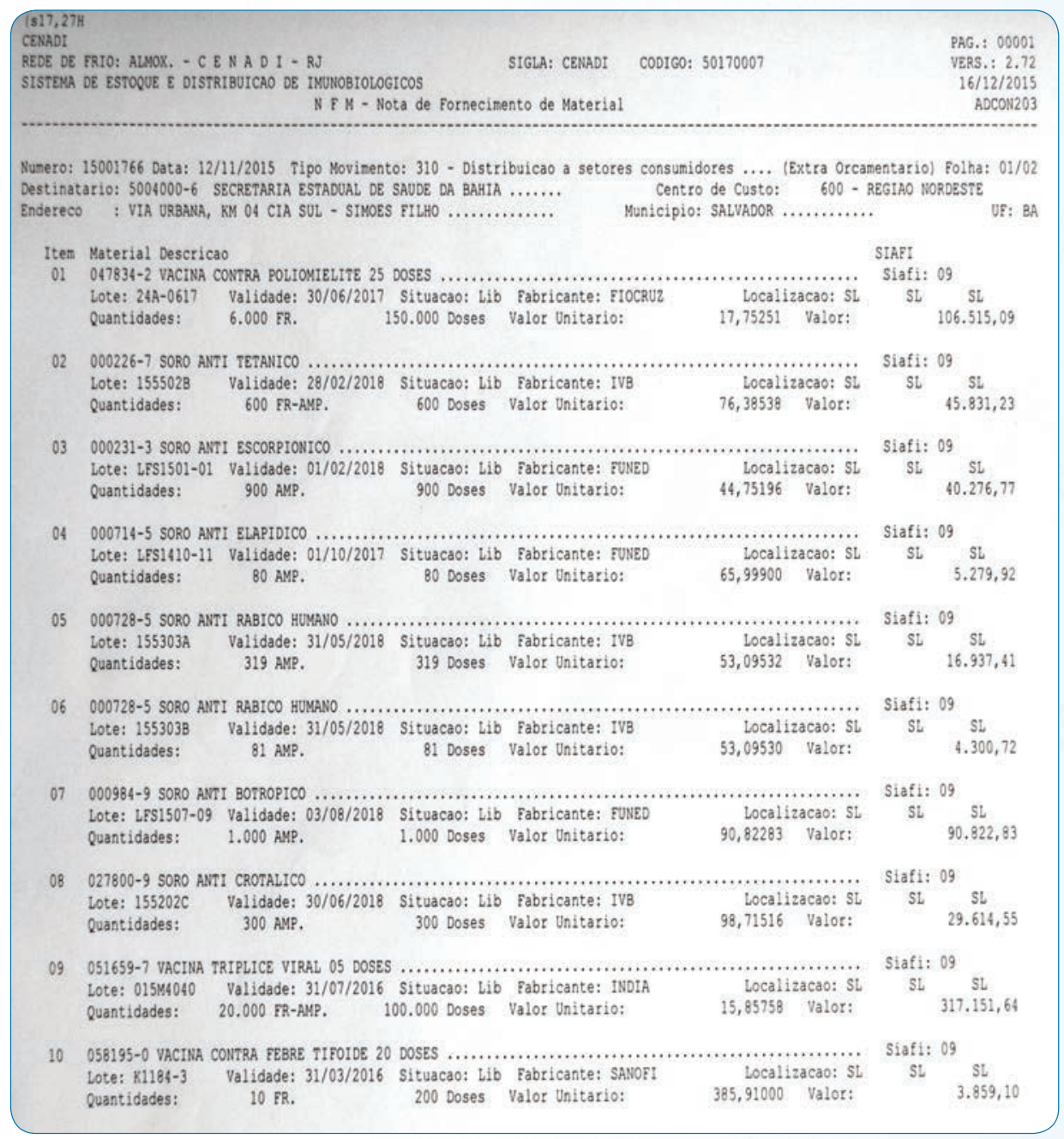




\title{
Anexo E - Detalhamento da carga
}

\author{
MINISTÉRIO DA SAÚDE \\ SECRETARIA EXECUTIVA - DEPARTAMENTO DE LOGISTICA \\ COORDENACุÃO GERAL DE ARMAZENAGEM E DISTRIBUIÇÃO \\ Central de Armaz. e Distr. de Insumos Estratégicos
}

UF: SÃO PAULO

\begin{tabular}{|c|c|c|c|}
\hline $\begin{array}{l}\text { CAIXA } \\
\text { NÚMERO }\end{array}$ & $\begin{array}{l}\text { VACINAS/SOROS/ } \\
\text { DILUENTES }\end{array}$ & LOTE & $\begin{array}{l}\text { QUANT. } \\
\text { FRASCOS }\end{array}$ \\
\hline $001 / 050$ & Vacina pentavalente & $137 \mathrm{Q} 4004 \mathrm{~B}$ & $50 \mathrm{cx} / 2400$ \\
\hline $051 / 073$ & Vacina triplice viral & $014 \mathrm{~N} 3009 \mathrm{~A}$ & $23 \mathrm{cx} / 2100$ \\
\hline 074 & 71 & $\pi$ & 331 \\
\hline 074 & 71 & $014 \mathrm{~N} 3009 \mathrm{~B}$ & 1369 \\
\hline 074 & Vacina dupla adulto & 024P4033BE & 300 \\
\hline 075 & II & $\pi$ & 2100 \\
\hline $076 / 085$ & "II & 024P4033AE & $10 \mathrm{cx} / 2100$ \\
\hline $086 / 087$ & Imunoglobulina antirrabica & $09047131 \mathrm{~L}$ & $2 \mathrm{cx} / 200$ \\
\hline 088 & $\pi$ & 11 & 100 \\
\hline 088 & $\begin{array}{l}\text { Imunoglobulina humana anti- } \\
\text { bepatite B-180 }\end{array}$ & F03136133 & 166 \\
\hline 089 & $\|$ & $\pi$ & 390 \\
\hline 090 & Soro antibotrópico & LFS1507.09 & 500 \\
\hline 091 & II & II & 200 \\
\hline 091 & Soro antiescorpiónico & LFS1501-01 & 100 \\
\hline 091 & Soro antielapidico & LFS1410-11 & 50 \\
\hline 091 & Imunoglobulina antivaricela zoster & $280 V_{14028}$ & 228 \\
\hline 112 & $\pi$ & II & 720 \\
\hline
\end{tabular}

DATA: 07/12/2015 HORA: 11:00 TOTALDE VOLUMES: 112

N.F.M. $15001855 / 15001857$ TEMPPOSITIVA: $2^{\circ} \mathrm{C}$ TEMP.NEGATIVA: $40^{\circ} \mathrm{C}$

ICE FOAM: $180 \quad$ BOBNA (GEL): $\underline{1127 \mathrm{~N}}$

ASS: 


\section{Anexo F - Comprovante de recebimento de insumos}

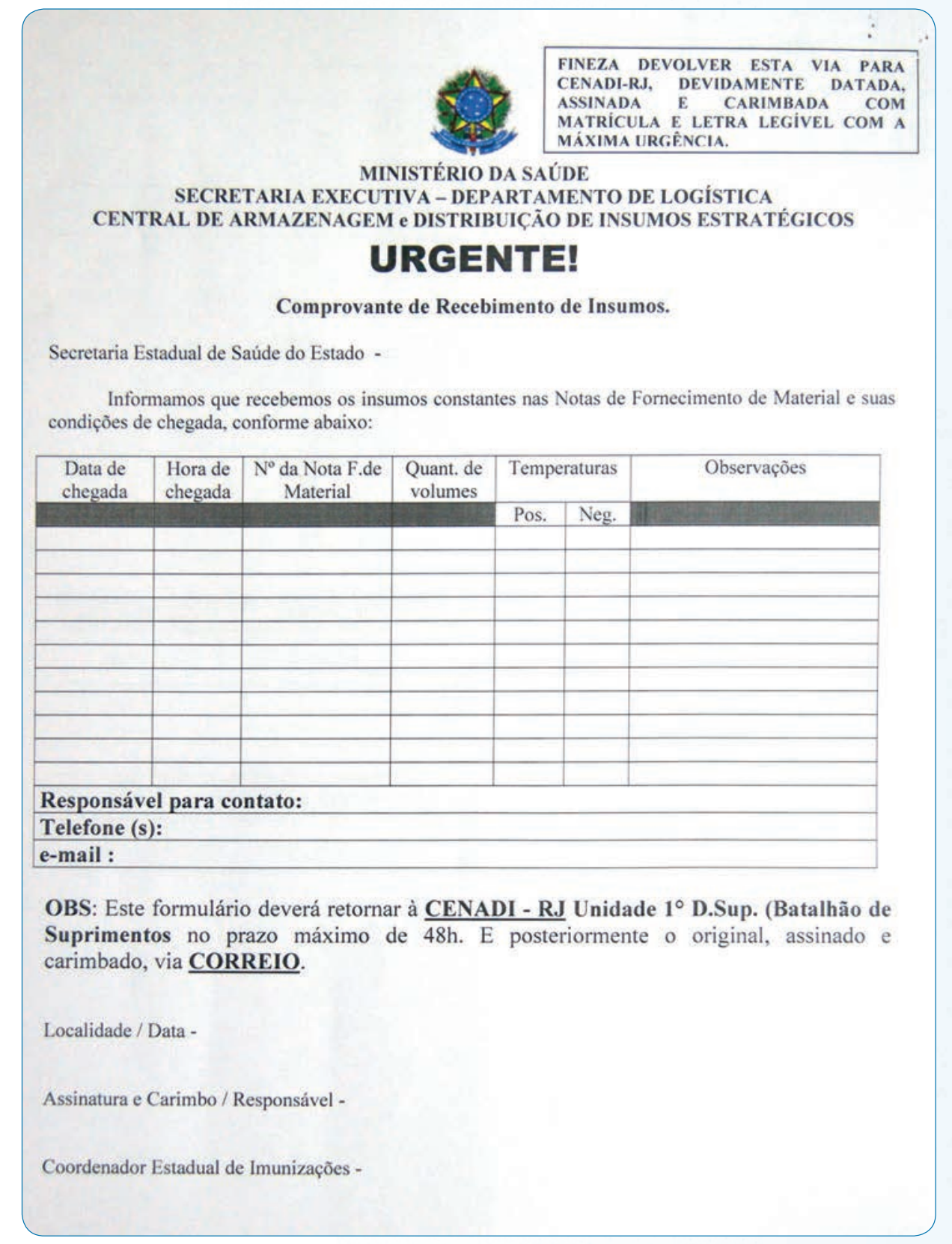




\section{Anexo G - Cuidados com seringas e agulhas}

1. Guardar o material na embalagem original, em local limpo e seco.

2. Lavar as mãos com água e sabão antes do manuseio.

3. Manusear o material em campo limpo.

4. Verificar o prazo de validade e se a embalagem está íntegra.

5. Abrir a embalagem na direção do êmbolo para a agulha, evitando contaminação.

6. Descartar as seringas e agulhas em recipientes apropriados, resistentes e de parede rígida, sem reinserir as agulhas nos protetores, após o uso, para evitar acidentes. Usar sempre as caixas coletoras apropriadas. 


\section{Gerenciamento de resíduos na rede de frio}

Cristiane Pereira de Barros e Walquíria Gonçalves dos Santos Teles

Desde que o mundo é mundo, todos nós produzimos resíduos diariamente, seja na higienização pessoal, alimentação, no trabalho, ou até mesmo em uma simples atividade de lazer. Podemos destacar um exemplo: ao assistirmos a uma sessão no cinema, daquela deliciosa pipoca será gerado um resíduo, ou seja, o saco vazio que deverá ser descartado no lixo. Você já parou para pensar qual a importância do destino final desse resíduo para o bem-estar da comunidade?

Existem várias definições para o termo resíduo. Considerando sua etimologia, a palavra se origina no latim residuum, que significa

Etimologia é o estudo da origem e evolução das palavras. resto, restante. Aquilo que resta. O que fica das substâncias submetidas à ação de vários agentes físicos ou químicos (resíduos industriais, nucleares, sólidos urbanos, dos serviços de saúde) (RESÍDUO, 2013).

Assim como em todos os processos da atividade humana, as atividades desenvolvidas nas diversas instâncias da rede de frio/PNI, e em todos os processos de trabalho para a manutenção dessa rede, geram resíduos. Podemos citar, como exemplo, o imunobiológico, cuja composição pode conter microrganismos vivos ou atenuados; se descartado de maneira inadequada, pode contaminar o homem e o meio ambiente. Portanto, é importante gerenciar esse resíduo, a fim de assegurar o seu destino final de forma correta.

Para que os resíduos sejam gerenciados de maneira adequada, contamos com órgãos federais que regulamentam as políticas de gerenciamento dos resíduos oriundos dos serviços de saúde, em todo o país, entre eles: a Agência Nacional de Vigilância Sanitária (Anvisa), do Ministério da Saúde; o Conselho Nacional do Meio Ambiente (Conama), do Ministério 
Descarte é a fase de manejo interno em que os resíduos são desprezados em recipientes adequados a cada grupo, conforme sua classificação.

Disposição final é uma fase do manejo externo referente ao destino dos resíduos que não têm mais serventia. Normalmente, esse destino é o aterro sanitário ou a vala séptica, com exceção da disposição final dos rejeitos radioativos, que deve ser feita em instalação especial denominada repositório. do Meio Ambiente. É importante ressaltar que estados, municípios e Distrito Federal, com o apoio dos órgãos federais, também podem estabelecer normas de caráter complementar, a fim de adequá-las às especificidades locais. Neste capítulo, abordaremos os itens dessas regulamentações relacionados às atividades desenvolvidas na rede de frio.

\section{Arcabouço legal para o gerenciamento de resíduos}

O arcabouço legal para o gerenciamento de resíduos dos serviços de saúde é constituído de normatizações atuais existentes no Brasil que regulamentam o gerenciamento dos resíduos em saúde. Vale lembrar que essas normas sofrem constantes atualizações, considerando os avanços técnicos e científicos, assim como as necessidades da comunidade. Como exemplo, citamos as atuais seringas utilizadas nos serviços de saúde. Anteriormente, eram de vidro e reutilizáveis. Hoje, fabricadas com plástico descartável, geram, diariamente, uma quantidade maior de resíduos; em consequência, o estabelecimento de normas para o descarte seguro se tornou essencial.

Apresentamos, a seguir, algumas referências que normatizam o gerenciamento de resíduos em saúde, aplicáveis ao processo de trabalho na rede de frio.

\section{Resolução n. 358/2005}

Publicada em abril de 2005, pelo Conselho Nacional do Meio Ambiente (Conama), do Ministério do Meio Ambiente, a Resolução n. 358/2005 dispõe sobre o tratamento e a disposição final dos resíduos dos serviços de saúde (CONSELHO NACIONAL DO MEIO AMBIENTE, 2005). Destacamos, a seguir, trechos da resolução que se aplicam à rede de frio.

$\mathrm{O}$ inciso $\mathrm{X}$ do art. $2^{\circ}$ conceitua resíduos de serviços de saúde (RSS) como detritos ou materiais desprezíveis, resultantes de atividades exercidas dentro de estabelecimentos de saúde e que podem apresentar contaminação biológica, química ou radioativa. São todos aqueles que, por suas características, necessitam de processos diferenciados em seu manejo, exigindo ou não tratamento prévio à sua disposição final (CONSELHO NACIONAL DO MEIO AMBIENTE, 2005). 


\section{Classificação dos resíduos de serviços de saúde (RSS)}

Segundo o Anexo I da Resolução n. 358/2005 do Conama, os RSS são classificados em grupos, segundo a contaminação:

1. Grupo A: formado por resíduos biológicos que, por suas características de maior virulência, infectividade e concentração de patógenos, apresentam risco potencial à saúde pública e ao meio ambiente.

2. Grupo B: constituído por resíduos químicos que, por sua toxicidade (incluindo a mutagenicidade e genotoxidade), corrosividade, inflamabilidade e reatividade, apresentam risco potencial à saúde pública e ao meio ambiente.

3. Grupo C: incorpora rejeitos radioativos, ou seja, resíduos contaminados com radionuclídeos ou outro elemento radioativo, em quantidades superiores aos limites de isenção especificados na norma CNEN-NE-6.02, referente ao licenciamento de instalações radioativas.

4. Grupo D: inclui resíduos comuns, com características semelhantes às dos resíduos domésticos.

5. Grupo E: agrupa os materiais perfurocortantes ou escarificantes, tais como: lâminas de barbear, agulhas, escalpes, ampolas de vidro, brocas, limas endodônticas, pontas diamantadas, lâminas de bisturi, lancetas; tubos capilares; micropipetas; lâminas e lamínulas; espátulas; e todos os utensílios de vidro quebrados no laboratório (pipetas, tubos de coleta sanguínea e placas de Petri) e similares.

Foto 1 - Exemplo de resíduo do subgrupo A1: vacina febre amarela

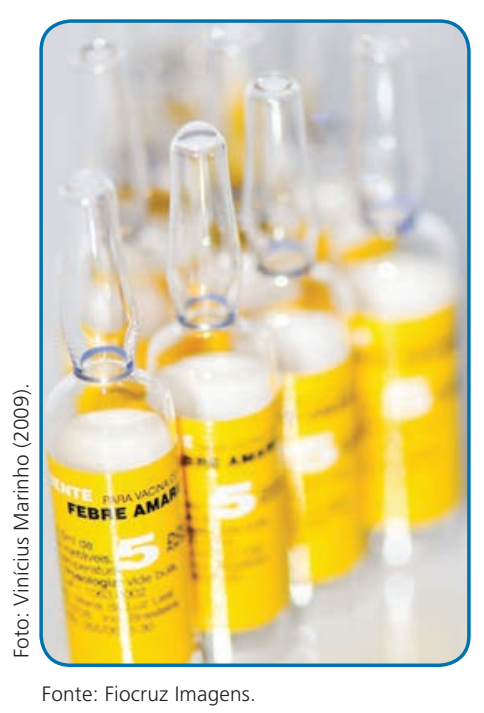

Os resíduos gerados na rede de frio estão classificados nos Grupos A, subgrupo Al, Grupo D e Grupo E, que detalharemos a seguir.

燐 O subgrupo Al é composto de culturas e estoques de microrganismos; resíduos de fabricação de produtos biológicos, exceto os hemoderivados; descarte de vacinas de microrganismos vivos ou atenuados; meios de cultura e instrumentais utilizados para transferência, inoculação ou misturas de culturas; resíduos de laboratórios de manipulação genética. Podemos citar, como exemplo, o frasco da vacina febre amarela, que, em sua composição, contém vírus vivo atenuado, podendo, no manejo inadequado, contaminar o 
Reciclagem é o conjunto de ações que realiza o reprocessamento dos resíduos e recuperação da parte para fabricação de novos produtos, evitando que sejam lançados no meio ambiente.

Aterro sanitário é uma obra de engenharia destinada a receber os resíduos no solo, sem risco de contaminação das águas subterrâneas. É dotado de obras de saneamento e controle ambiental, tais como drenos e canalizações que permitem a captação, o desvio e o destino adequados de gases e percolados (também conhecido como chorume: líquido produzido pela compressão e decomposição do lixo).

meio ambiente. Neste grupo, os resíduos gerados constituem risco de infecção por causa da possível presença de agentes biológicos.

\section{Para refletir}

Em sua prática, como acontece o descarte de resíduos do subgrupo A1? Você obteve orientações para realizar essa atividade?

* Grupo D incorpora resíduos que não apresentam riscos biológico, químico ou radiológico à saúde ou ao meio ambiente; podem ser equiparados aos resíduos domiciliares. Portanto, não necessitam de tratamento prévio para o descarte. Quando não forem passíveis de reutilização, recuperação ou reciclagem, devem ser encaminhados para o aterro sanitário de resíduo sólido urbano, devidamente licenciado pelo órgão ambiental competente. Podemos citar como exemplo: resíduos de varrição, os provenientes das áreas administrativas, caixas de poliuretano e/ou poliestireno expandido (isopor), resto de fita crepe, papel usado, copos usados, resto de alimentos etc.

Fotos 2 e 3 - Exemplos de resíduos do Grupo D: caixas de poliuretano e copos descartáveis

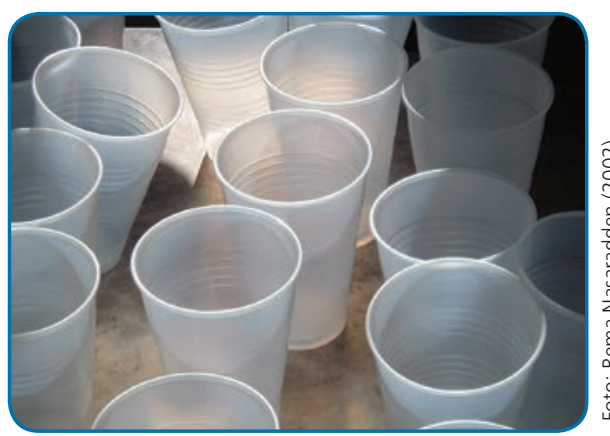

Fonte: Freelmages.com.

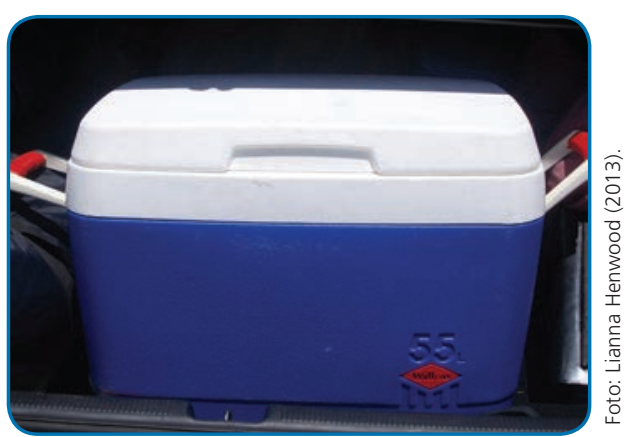

Fonte: Wikimedia Commons
Materiais perfurocortantes são objetos pontiagudos ou que apresentam fios de corte capazes de causar perfurações.
粰O Grupo E é constituído de materiais perfurocortantes ou escarificantes, tais como: lâminas de barbear, agulhas, escalpes, ampolas de vidro, brocas, limas endodônticas, pontas diamantadas, lâminas de bisturi, lancetas; tubos capilares; micropipetas; lâminas e lamínulas; espátulas; e todos os utensílios de vidro
Foto 4 - Exemplos de resíduos do Grupo E: seringa e ampola

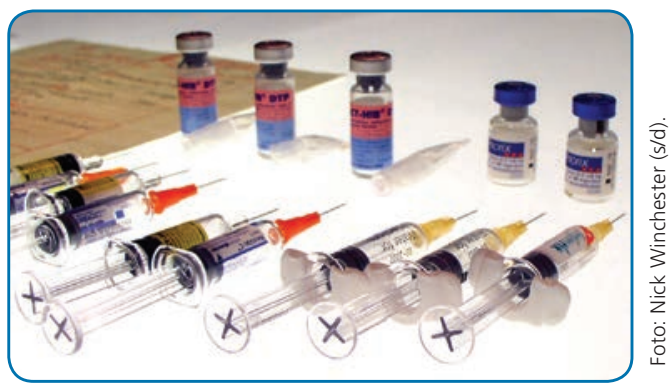

Fonte: Freelmages.com. 
quebrados no laboratório (pipetas, tubos de coleta sanguínea e placas de Petri) e similares.

\section{Para refletir}

Na sua rotina de trabalho, como acontece o descarte de resíduos do Grupo E? Você obteve orientações para realizar essa atividade?

É importante obter orientações técnicas para proceder adequadamente ao descarte de resíduos, evitando contaminação da natureza e de outras pessoas, bem como possíveis acidentes e danos ao meio ambiente. Para isso, recomendamos a leitura da Resolução n. 358/2005, do Conama.

\section{Resolução da Diretoria Colegiada (RDC) n. 306/2004, Resolução do Conama n. 275/2001 e Nota técnica da Anvisa n. 002/2011}

Publicada pela Agência Nacional de Vigilância Sanitária (Anvisa), a RDC n. 306/2004 dispõe sobre o regulamento técnico para o gerenciamento de resíduos de serviços de saúde, com o objetivo de preservar a saúde pública e a qualidade do meio ambiente, considerando os princípios da biossegurança, as medidas técnicas, administrativas e as normativas para prevenir acidentes. O gerenciamento de resíduos também conta com diretrizes na Resolução do Conama n. 275/2001 e na Nota técnica n. 002/2011, da Anvisa. Aqui, descreveremos as etapas do gerenciamento de resíduos na cadeia de frio para que você possa identificar a sua inserção no processo, como também suas responsabilidades.

Considerando que a rede de frio é um gerador de diversos resíduos em saúde, segundo a RDC n. 306/ 2004, compete à própria rede elaborar um plano de gerenciamento de resíduos de serviços de saúde (RSS), conhecido também como PGRSS (AGÊNCIA NACIONAL DE VIGILÂNCIA SANITÁRIA, 2004). Esse documento deve ser compatível com a legislação vigente e fará parte do processo de licenciamento ambiental, em conformidade com a Resolução Conama n. 237/1997. Importa destacar que ele deve ser adequado à realidade local, atender aos critérios técnicos e potencializar a capacidade dos recursos disponíveis.
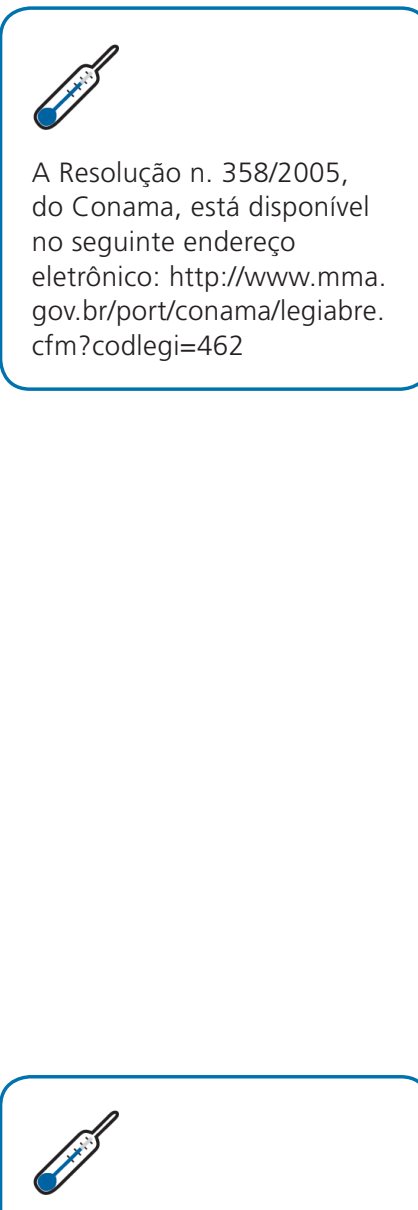

Você pode acessar a RDC n. 306/2004 pelo endereço eletrônico http://goo.gl/p94fVS 
Segregação é a separação dos resíduos, conforme sua classificação, no momento e local de geração.
Manejo dos Resíduos dos Serviços de Saúde (RSS) é a ação de gerenciar os resíduos em seus aspectos intra e extraestabelecimento, desde a geração até a disposição final.

Para acessar o Manual de rede de frio do Programa Nacional de Imunizações, visite http:// bvsms.saude.gov.br/bvs/ publicacoes/manual_rede_ frio4ed.pdf
No caso das bobinas reutilizáveis, o conteúdo interno de gel celulose é uma substância atóxica; por isso, pode ser descartado na rede de esgoto local, antes do acondicionamento da bobina para a reciclagem.
Todos os profissionais que trabalham na cadeia de frio, mesmo os que atuam temporariamente ou que não estejam diretamente envolvidos nas atividades de gerenciamento de resíduos, devem conhecer como funciona o sistema adotado para o gerenciamento de RSS. Por exemplo, a prática de segregação de resíduos, os conhecimentos sobre símbolos, expressões, padrões de cores adotados, localização dos abrigos de resíduos, entre outros fatores, indispensáveis à completa integração ao PGRSS.

O PGRSS deve ter como base as características dos resíduos gerados no serviço e deve estabelecer diretrizes de manejo dos Resíduos dos Serviços de Saúde (RSS). O processo de manejo dos RSS ocorrerá de acordo com sua classificação, que, no caso da rede de frio, refere-se aos Grupos Al, D e E.

O manejo adequado inclui as seguintes etapas: segregação, acondicionamento, identificação, transporte interno, armazenamento temporário, tratamento, armazenamento externo, coleta e transporte externos. Todas merecem especial atenção, tanto em face dos riscos sanitários envolvidos quanto das normas legais vigentes no país. A seguir, apresentamos as etapas conforme referenciado no Manual de rede de frio do Programa Nacional de Imunizações (BRASIL, 2013).

1.Segregação: consiste na separação dos resíduos no momento e local de sua geração, de acordo com as características físicas, químicas, biológicas e radioativas, o estado físico e os riscos envolvidos.

2. Acondicionamento: consiste no ato de embalar os resíduos segregados em sacos ou recipientes que evitem vazamentos e resistam às ações de punctura e ruptura (furos e rasgos). A capacidade dos recipientes de acondicionamento deve ser compatível com a geração diária de cada tipo de resíduo.

\section{Especificidades da rede de frio}

- Os materiais perfurocortantes, como seringas agulhadas e frascos de vacina quebrados, classificados no Grupo $E$, deverão ser acondicionados em recipientes resistentes (caixa coletora de perfurocortante), que atendam aos parâmetros referenciados na NBR ABNT n. 13.853:1997 (ASSOCIAÇÃO BRASILEIRA DE NORMAS TÉCNICAS, 1997). 


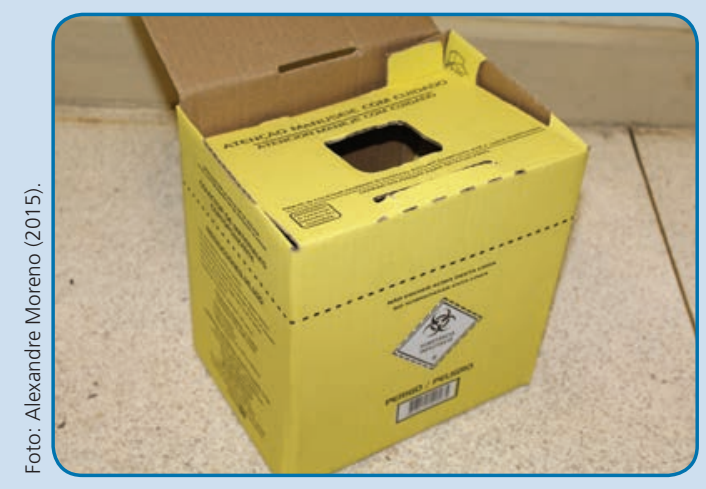

- As campanhas de vacinação realizadas em todo país, a vacinação extramuro ou as intensificações geram resíduos, como as seringas utilizadas e os frascos de vacina. Esses resíduos são gerados em ambiente fora da estrutura do serviço de saúde; portanto, quando não puderem ser submetidos ao tratamento nos locais de geração, como a autoclavagem, devem ser segregados, acondicionados para serem encaminhados à unidade de tratamento de referência.

Há políticas que incentivam a reciclagem de resíduos sólidos no país. No caso da rede de frio, resíduos recicláveis são: de poliuretano e/ou poliestireno expandido (isopor), bobinas reutilizáveis, papéis e derivados. O Conama aprovou a Resolução n. 275/2001, que define um sistema de cores de fácil visualização, com validade em todo o território nacional, para segregação e acondicionamento categorizado dos resíduos. A definição dessas cores foi inspirada em formas de codificação adotadas internacionalmente para identificação dos recipientes e transportadores usados na coleta seletiva.

Quadro 1 - Padrão de cores definido pelo Conama, Resolução n. 275/2001, para acondicionar resíduos segregados

\begin{tabular}{|c|c|}
\hline AZUL & Papel/Papelão \\
\hline VERMELHO & Plástico \\
\hline VERDE & Vidro \\
\hline AMARELO & Metal \\
\hline PRETO & Madeira \\
\hline LARANJA & Resíduos perigosos \\
\hline BRANCO & Resíduos ambulatoriais e de serviços de saúde \\
\hline ROXO & Resíduos radioativos \\
\hline MARROM & Resíduos orgânicos \\
\hline CINZA & Resíduo geral não reciclável ou misturado, ou contaminado não \\
& passível de separação \\
\hline
\end{tabular}

Fonte: Elaborado de acordo com a RDC n. 275/2001 (CONSELHO NACIONAL DO MEIO AMBIENTE, 2001). 
Não há restrição quanto ao uso de adesivos para identificação dos sacos e recipientes de acondicionamento de resíduos, desde que seja garantida a sua resistência aos processos normais de manuseio.
Com base na Resolução Conama RDC n. 275/2001, o acondicionamento para reciclagem deve estar de acordo com as orientações dos serviços locais de limpeza urbana (CONSELHO NACIONAL DO MEIO AMBIENTE, 2001). São utilizados sacos impermeáveis, contidos em recipientes, mantidos em abrigos de guarda devidamente identificados, usando os códigos de cores, suas correspondentes nomeações e símbolos do tipo de material reciclável.

3. Identificação: consiste em um conjunto de medidas que permite o reconhecimento dos resíduos contidos nos sacos ou recipientes, fornecendo informações para seu correto manejo. Os sacos de acondicionamento, os recipientes de coleta e transporte, internos e externos, e os locais de armazenamento devem ser identificados de maneira a propiciar fácil visualização, de forma indelével, utilizando-se símbolos, cores e frases, atendendo aos parâmetros vigentes referenciados na norma da Associação Brasileira de Normas Técnicas, NBR 12.810: 2016. Além disso, deve atender, também, às exigências relacionadas à identificação de conteúdos e ao risco específico de cada grupo de resíduos.

Quadro 2 - Padrão de símbolos adotados para identificar os resíduos segregados, definidos pela ABNT

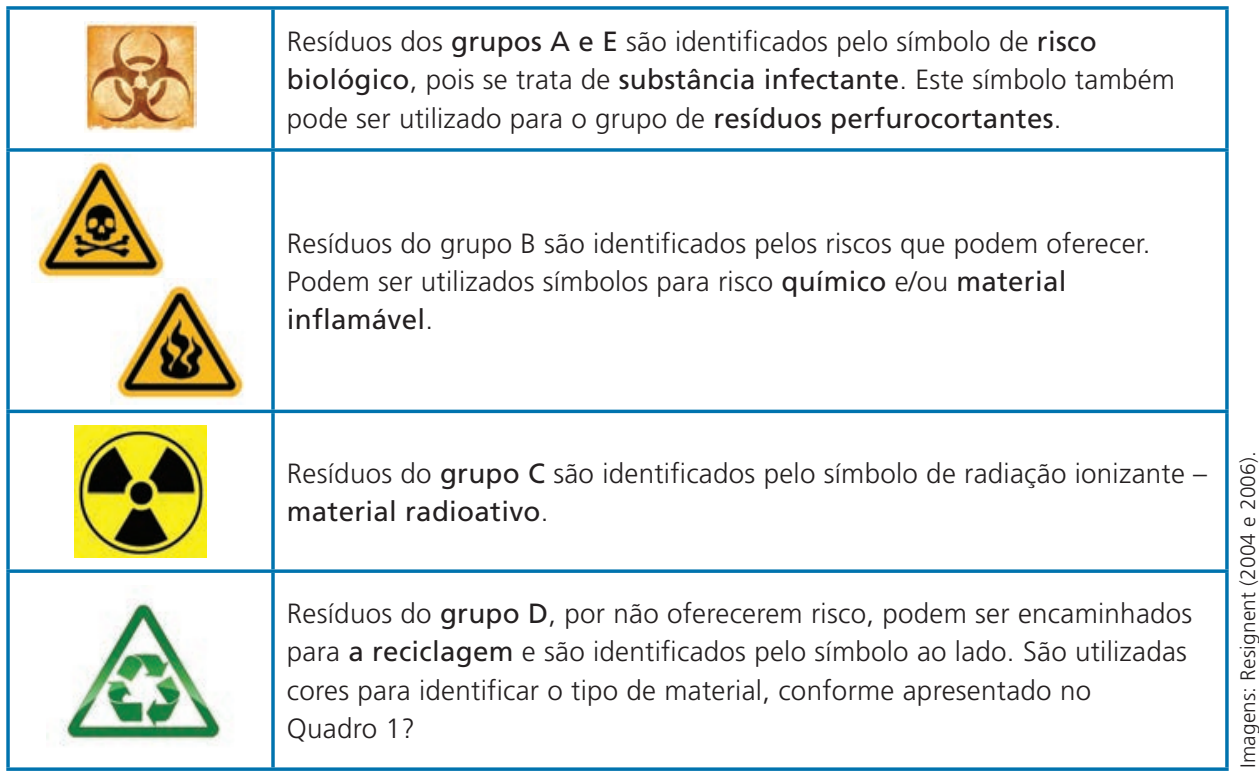

Fonte das Imagens: Freelmages.com.

4. Transporte interno: consiste no translado dos resíduos dos pontos de geração até o local destinado ao armazenamento temporário ou ao armazenamento externo, com a finalidade de apresentação para a coleta. 
Foto 5 - Exemplos de transporte interno dos resíduos até o local de armazenamento temporário

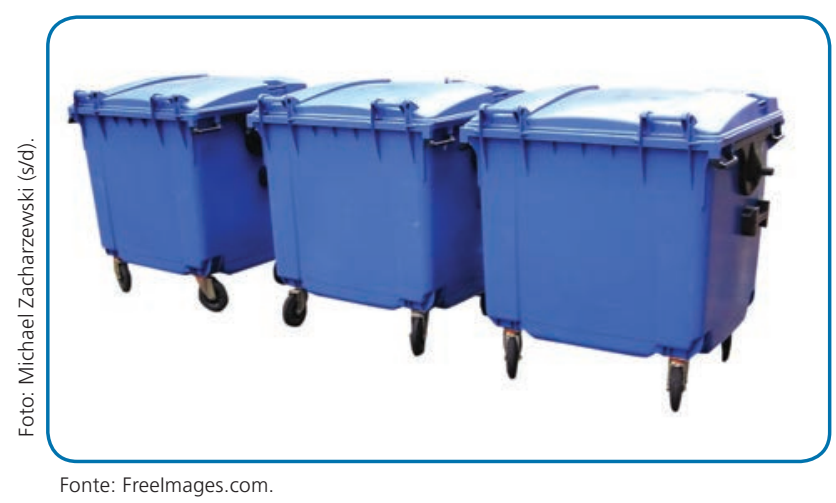

5. Armazenamento temporário: consiste na guarda temporária dos recipientes contendo os resíduos já acondicionados, em local próximo aos pontos de geração. Não poderá ser feito armazenamento temporário com disposição direta dos sacos sobre o piso. É obrigatória a conservação dos resíduos em recipientes de acondicionamento. Esses podem ser dispensados, se a distância justificar. Pisos e paredes deverão ser laváveis e resistentes ao tráfego dos recipientes coletores. Deve ter ponto de iluminação artificial e área para armazenamento de, no mínimo, dois recipientes coletores, para o posterior translado até a área de armazenamento externo. Se contar com sala exclusiva, esta deve ser identificada como sala de resíduos. No armazenamento temporário, não é permitida a retirada dos sacos de RSS de dentro dos recipientes ali posicionados.

6. Tratamento: consiste na aplicação de método, técnica ou processo que modifique as características dos riscos inerentes aos resíduos, reduzindo ou eliminando o risco de contaminação, de acidentes ocupacionais ou de dano ao meio ambiente.

Sobre o tratamento na rede de frio, contamos com a Nota técnica n. 002/2011, da Agência Nacional de Vigilância Sanitária (Anvisa), que, de acordo com a Resolução Anvisa, RDC n. 306/2004, orienta sobre o tratamento de resíduos resultantes de atividades de vacinação com microrganismos vivos ou atenuados. As orientações instruem que os seguintes resíduos devem ser submetidos a um tratamento prévio à disposição final: frascos de vacinas com expiração do prazo de validade, com conteúdo inutilizado, vazios ou com restos do produto.

O processo de tratamento prévio indicado é a autoclavação por vapor saturado sob pressão. A autoclave a ser utilizada para esse procedimento deve ser exclusiva, ou seja, não pode ser compartilhada com

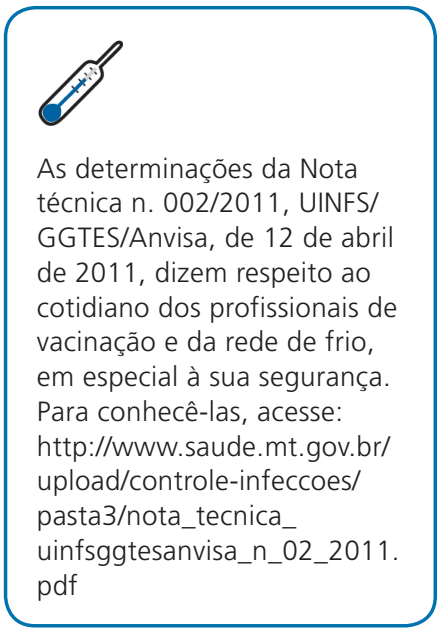

Autoclave é um equipamento utilizado para esterilizar materiais contaminados por meio de vapor de água, durante um período determinado, com o objetivo de destruir os agentes patogênicos (FIOCRUZ, 2004). 
A autoclavação poderá ser feita por meio de contratação de empresa habilitada para esse serviço, ou de aquisição da autoclave para realização do tratamento. Caso seja feita a aquisição do equipamento, sua localização poderá ser na própria unidade de saúde, na central de distribuição de vacinas do PNI ou mesmo em alguns centros regionais do estado, para facilitar a logística.
Incineração é o tratamento com queima de resíduos sólidos ou líquidos químicos até a redução a cinzas, utilizando equipamentos que produzem altas temperaturas, com padrões de emissões atmosféricas controlados. outros serviços. Essa exclusividade, na ocorrência de algum acidente e consequente contaminação do equipamento, evita que seja necessário limpar e descontaminar a autoclave, o que acarreta custo financeiro e interrompe o uso do equipamento.

\section{Importante!}

Os resíduos provenientes das atividades de vacinação, como frascos de imunobiológicos, vacinas com prazo de validade expirado, materiais perfurocortantes etc., devem ser devidamente tratados, acondicionados e identificados para serem encaminhados ao processamento final. Todos os profissionais da saúde precisam conhecer esse processo para garantir o tratamento adequado dos resíduos, pois são corresponsáveis por ele.

Após o tratamento prévio, os resíduos dos serviços de saúde dos Grupos A e E devem ser acondicionados em saco branco leitoso. A coleta desse lixo é feita pelo município, e o transporte, em veículos (caminhões) específicos e adequados para essa finalidade. O lixo é enviado diretamente para o aterro sanitário autorizado, onde passa por processo de incineração.

7. Armazenamento externo: consiste na guarda dos recipientes de resíduos até a realização da etapa de coleta externa, em ambiente exclusivo e com acesso facilitado aos veículos coletores, não sendo permitida a manutenção dos sacos de RSS fora dos recipientes ali estacionados.

Figura 1 - Exemplos de estrutura adequada para a guarda dos resíduos acondicionados até a coleta externa

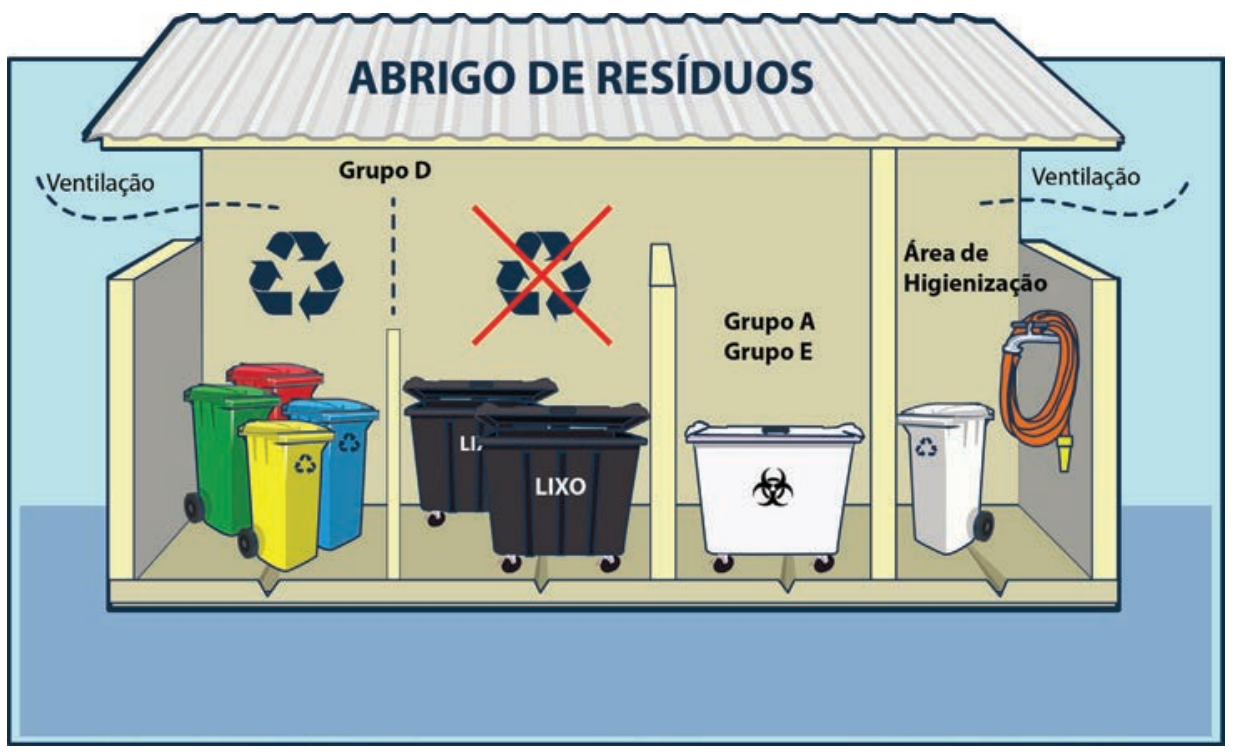


8. Coleta e transporte externos: consistem na remoção dos RSS do abrigo de resíduos até a unidade de tratamento ou disposição final, utilizando-se uma técnica que garanta a preservação das condições de acondicionamento e a integridade dos trabalhadores, da população e do meio ambiente, devendo estar de acordo com as orientações dos órgãos de limpeza urbana, assim como da Resolução Conama n. 358/2005. A coleta e o transporte externos dos resíduos de serviços de saúde devem ser realizados de acordo com as normas NBR n. 12.810 e NBR n. 14.652, da ABNT (ASSOCIAÇÃO BRASILEIRA DE NORMAS TÉCNICAS, 2016, 2013).

Figura 2 - Transporte adequada para coleta de resíduos infectantes (Grupo A e E)

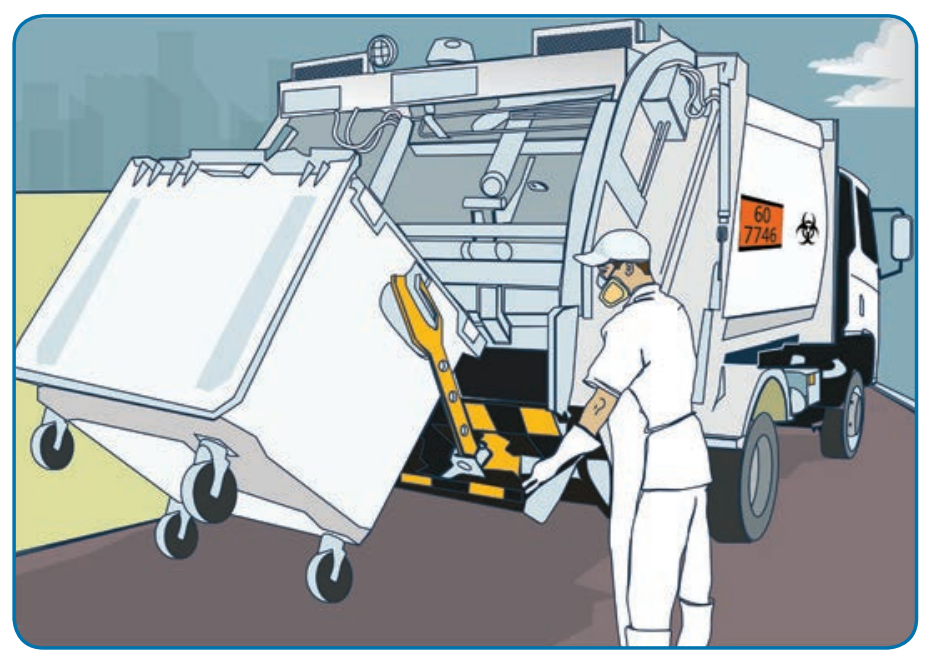

\section{Considerações finais}

Podemos compreender, no fim deste capítulo, que o gerenciamento de resíduos de serviços de saúde (GRSS) é entendido como o conjunto de ações de gestão planejadas, implantadas e implementadas com bases técnico-científicas, normativas e legais. Tem como objetivo minimizar a produção de resíduos gerados e proporcionar seu encaminhamento seguro, de forma eficiente, visando à proteção dos trabalhadores, à preservação da saúde pública, dos recursos naturais e do meio ambiente.

Destaque-se que são os serviços de saúde os responsáveis pelo correto gerenciamento de todos os RSS por eles gerados, desde o momento de sua produção até o destino final. É um processo que necessita ser eficiente, e, para isso, os trabalhadores precisam conhecer os diversos tipos de resíduos existentes. O manejo, a segregação, a coleta, o tratamento, o transporte e a destinação final desses resíduos merecem espe-
As NBR n. 12.810 e 14.652 não se encontram disponíveis para consulta na internet. Verifique, em seu serviço, se há exemplares disponíveis, caso deseje aprofundar seus estudos. 
cial atenção tanto em face dos riscos sanitários envolvidos, em relação ao trabalhador da saúde e à população, quanto das normas legais vigentes no nosso país. É por tudo isso que você, trabalhador da saúde, é tão importante nesse processo.

\section{Referências}

AGÊNCIA NACIONAL DE VIGILÂNCIA SANITÁRIA (Brasil). Nota técnica n. 002, de 12 de abril de 2011. Tratamento de resíduos resultantes de atividades de vacinação com microrganismos vivos ou atenuados. Brasília, DF, 2011. Disponível em: <http://www.saude.mt.gov.br/upload/controleinfeccoes/pasta3/nota_tecnica_uinfsggtesanvisa_n_02_2011.pdf >. Acesso em: 3 ago. 2016.

AGÊNCIA NACIONAL DE VIGILÂNCIA SANITÁRIA (Brasil). Resolução da Diretoria Colegiada RDC n. 306, de 7 de dezembro de 2004. Dispõe sobre o Regulamento Técnico para o gerenciamento de resíduos de serviços de saúde. Diário Oficial da União, Brasília, DF, 10 dez. 2004. Seção 1, p. 49.

ASSOCIAÇÃO BRASILEIRA DE NORMAS TÉCNICAS. NBR 12.810:2016: resíduos de serviçOs de saúde: gerenciamento extraestabelecimento: requisitos. Rio de Janeiro, 2016.

ASSOCIAÇÃO BRASILEIRA DE NORMAS TÉCNICAS. NBR 13.853:1997: coletores para resíduos de serviços de saúde perfurantes ou cortantes: requisitos e métodos de ensaio. Rio de Janeiro, 1997.

ASSOCIAÇÃO BRASILEIRA DE NORMAS TÉCNICAS. NBR 14.652:2013: implementos rodoviários: coletor-transportador de resíduos de serviços de saúde: requisitos de construção e inspeção. Rio de Janeiro, 2013.

BRASIL. Ministério da Saúde. Secretaria de Vigilância em Saúde. Departamento de Vigilância das Doenças Transmissíveis. Manual de rede de frio do Programa Nacional de Imunizações. 4. ed. Brasília, DF, 2013. Disponível em: <http://portalsaude.saude.gov.br/images/pdf/2014/julho/03/ manual-rede-frio.pdf>. Acesso em: 20 abr. 2014.

CONSELHO NACIONAL DO MEIO AMBIENTE (Brasil). Resolução n. 358, de 29 de abril de 2005. Dispõe sobre o tratamento e a disposição final dos resíduos dos serviços de saúde e dá outras providências. Diário Oficial da União, Brasília, DF, 4 maio 2005. Seção 1, p. 63-65.

CONSELHO NACIONAL DO MEIO AMBIENTE (Brasil). Resolução n. 275, de 25 de abril de 2001. Estabelece o código de cores para os diferentes tipos de resíduos, a ser adotado na identificação de coletores e transportadores, bem como nas campanhas informativas para a coleta seletiva. Diário Oficial da União, Brasília, DF, 19 jun. 2001. Seção 1, p. 80.

FIOCRUZ. Glossário em biossegurança. Rio de Janeiro: Escola Nacional de Saúde Pública Sérgio Arouca/Fiocruz, 2004. Disponível em: <http://www.fiocruz.br/biosseguranca/Bis/StartBIS.htm>. Acesso em: 18 set. 2016.

RESÍDUO. In: DICIONÁRIO Priberam da língua portuguesa. Porto: Priberam, 2013. Disponível em: <https://www.priberam.pt/dlpo/resíduos>. Acesso em: 3 ago. 2016. 

em saúde e a rede de frio de imunobiológicos

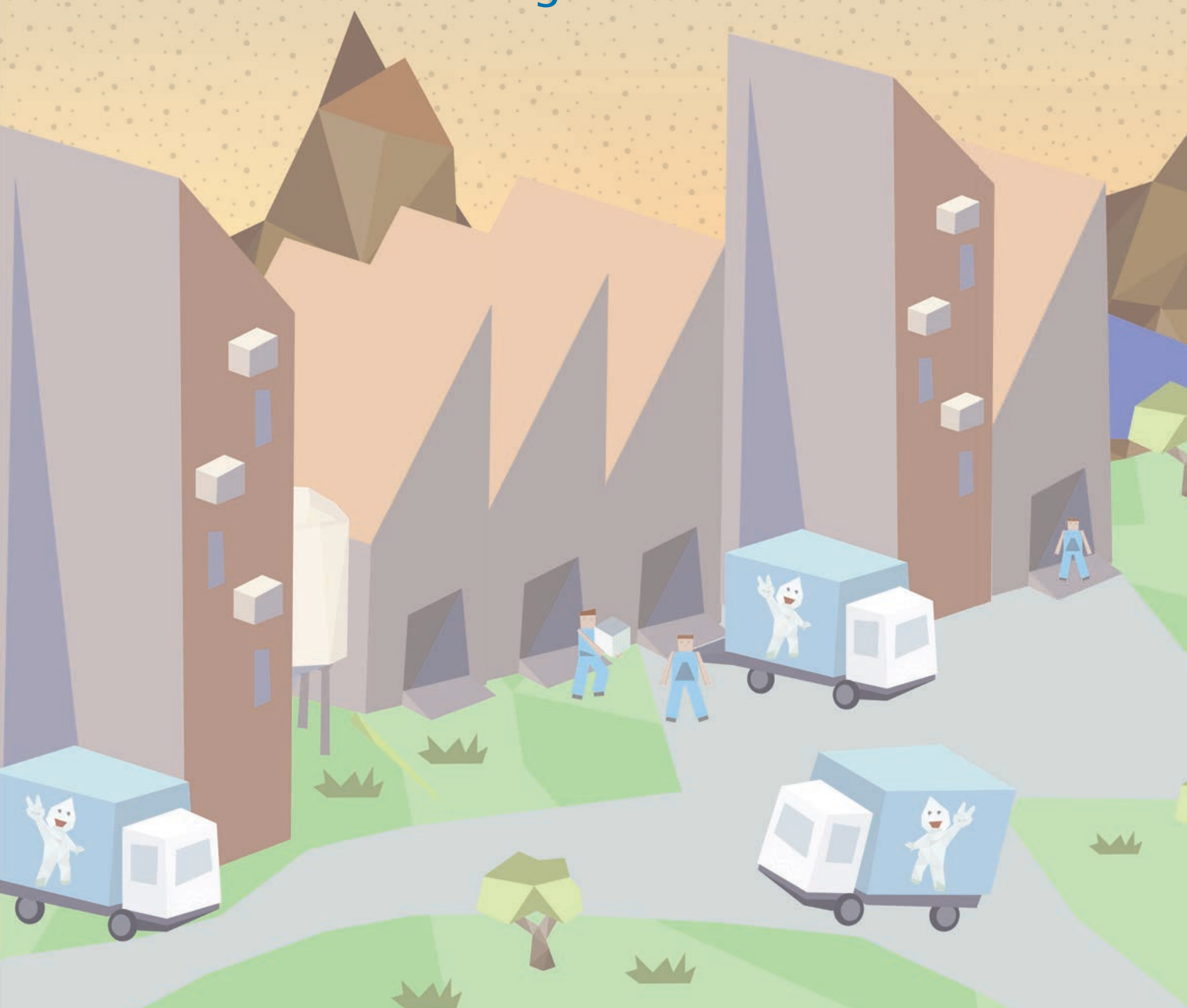





\title{
10. Organização do trabalho
}

\author{
Marcello de Moura Coutinho e Valéria Cristina Gomes de Castro
}

O trabalhador da rede de frio (RF) de imunobiológicos atua, diariamente, em uma série de ações e procedimentos que fazem parte do seu processo de trabalho. No entanto, é fundamental ressaltar que o trabalho na RF, especificamente, e o trabalho em saúde, de maneira mais ampla, são entendidos de forma muito mais complexa. É a compreensão dessa complexidade que permite uma prática não alienante e não alienada do trabalhador, uma atuação que constrói novas realidades e reflete sobre elas.

Não existe atividade humana da qual se possa excluir toda intervenção intelectual, não se pode separar o homo faber do homo sapiens. Em suma, todo homem, fora de sua profissão, desenvolve uma atividade intelectual qualquer, ou seja, é um "filósofo", um artista, um homem de gosto, participa de uma concepção do mundo, possui uma linha consciente de conduta moral, contribui assim, para manter ou para modificar uma concepção do mundo, isto é, para promover novas maneiras de pensar (GRAMSCI, 1979, p. 8).

Neste capítulo, debatemos os conceitos de trabalho e processo de trabalho, as diferentes formas que o trabalho assume na sociedade e sua organização na atualidade, buscando relacioná-los às especificidades do setor de saúde, em especial, da rede de frio de imunobiológicos.

\section{Trabalho e sociedade}

Antes de tudo, o trabalho é um processo de que participam o homem e a natureza, processo em que o ser humano com sua própria ação impulsiona, regula e controla seu intercâmbio material com a natureza. Defronta-se com a natureza como

Homo faber - considera-se, do ponto evolutivo, a superação do homo sapiens, no sentido em que conjuga a razão e a produção de ferramentas, ou seja, trabalho intelectual e manual. Na definição relativa ao verbete do Dicionário de Filosofia Nicolas Abbagnano (2007, p. 156): "é a definição de homem feita por Bergson, que viu na inteligência, característica fundamental do homem, a

faculdade de fabricar instrumentos inorganizados." 
uma de suas forças. Põe em movimento as forças naturais de seu corpo, braços e pernas, cabeça e mãos, a fim de apropriar-se dos recursos da natureza, imprimindo-lhes forma útil à vida humana. Atuando assim sobre a natureza externa e modificando-a, ao mesmo tempo modifica sua própria natureza (MARX, 2005).

O capitalismo superou o feudalismo, um sistema socioeconômico baseado na posse da terra, tendo o senhor feudal, os nobres e o clero como integrantes da classe social dominante e os servos/camponeses como dominados.
O trabalho humano assume diferentes formas, dependendo da organização societária em que se encontra. Distingue-se do trabalho realizado por outros animais, pois, através dele, o homem se transforma e transforma a realidade, uma condição necessária em qualquer tempo histórico. O trabalho, porém, assume formas específicas em diferentes modos de produção (primitivo, escravista, feudal e capitalista).

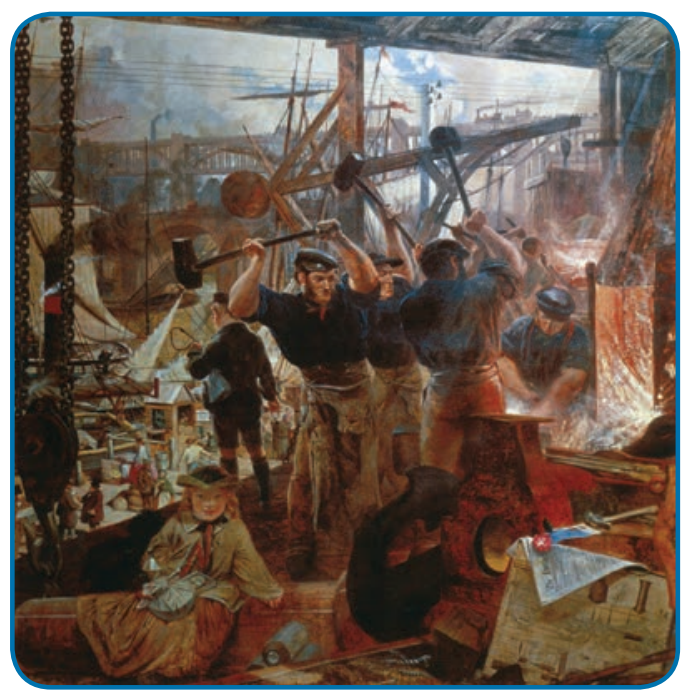

Ferro e Carvão, de William Bell Scott (1811-1890).

O capitalismo é um sistema socioeconômico surgido nos séculos XV e XVI, a partir da expansão marítima europeia (capitalismo mercantil/comercial), mas que se consolidou com a Revolução Industrial iniciada na Inglaterra, entre os séculos XVIII e XIX, substituindo, mundialmente, o trabalho artesanal pelo trabalho assalariado com o uso de máquinas. Fonte: Wikimedia Commons
Com o advento do sistema capitalista, houve a ascensão da burguesia (patrões/empregadores) - a classe que domina e detém os meios de produção (empresas, fábricas, máquinas e infraestrutura) - e a criação do proletariado (trabalhadores) - a classe que precisa vender a sua força de trabalho para sobreviver e se reproduzir, constituindo, portanto, a classe trabalhadora. Essas duas classes surgidas no âmbito do capitalismo não possuem os mesmos interesses, já que os que pertencem à burguesia acumulam capital e riqueza com base na exploração do trabalho do proletariado.

Na sociedade contemporânea, o trabalho tem sofrido muitas transformações. Características próprias da forma de trabalho predominante na sociedade industrial vêm sendo substituídas por um tipo de trabalho em que o uso da tecnologia é cada vez mais necessário. Postos de trabalho vêm sendo substituídos por tecnologias, e novas relações têm sido estabelecidas, reconfigurando a forma de organização predominante até então. Não se exige mais do trabalhador apenas o conhecimento do seu ofício, mas também maior flexibilidade para assumir diferentes tarefas, a fim de suprir a demanda proveniente da diminuição de postos de trabalho e garantir o lucro das empresas.

\section{Para refletir}

Como as mudanças tecnológicas afetam seu trabalho? 
Também na saúde observamos muitos avanços tecnológicos: novas vacinas, medicamentos, recursos diagnósticos e outras mudanças que exigem do trabalhador diferentes conhecimentos.

Os avanços do século XXI têm sido marcados por transformações significativas no mundo do trabalho; o desemprego estrutural e o acirramento da acumulação de capital, em nível mundial, se efetivam em novas formas de organização do trabalho, com base em três grandes eixos:

落 novas tecnologias;

novas formas de produção do trabalho;

novas formas de gerenciamento.

Outra tendência mundial é a feminilização, ou seja, o aumento, no mercado de trabalho, da atuação feminina, a qual representa, hoje, mais de $40 \%$ da força de trabalho em países avançados. A classe trabalhadora vem se constituindo por uma grande parcela de trabalhadores informais, com vínculos "precarizados", subcontratados e trabalhadores on-line.

Para alguns autores das ciências humanas, o amadurecimento de um novo regime de acumulação pós-fordista no Brasil tem possibilitado o surgimento de novas formas de trabalho, como os call centers (centrais de telemarketing). Em geral, esses espaços atraem um amplo contingente de trabalhadores jovens, especialmente mulheres e negros, em busca de uma primeira oportunidade no mercado formal de trabalho, constituindo-se, assim, o "precariado". Isso porque esse setor da economia tem remunerações baixíssimas, jornadas extremamente desgastantes de trabalho, não possui regulamentação e normas de salubridade, submetendo seus trabalhadores a constante pressão, o que leva a alta rotatividade e inúmeros problemas ligados à saúde do trabalhador, tais como depressão, perda auditiva induzida por ruído e distúrbios osteomusculares relacionados ao trabalho (Dort).
Acumulação pós-fordista significa, por exemplo, redução de estoques, rápido descarte programado de produtos como a televisão e o computador, assim como a flexibilização dos direitos trabalhistas. 
Figura 1 - Novas formas de trabalho: central de telemarketing

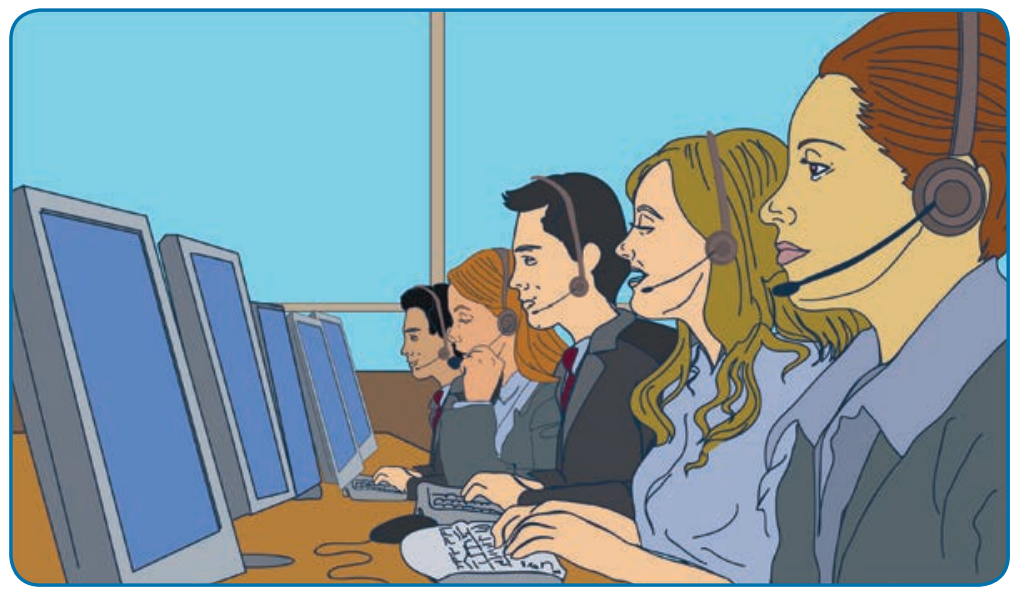

Segundo Ricardo Antunes e Giovanni Alves (2004, p. 355),

A classe trabalhadora no século XXI, em plena era da globalização, é mais fragmentada, mais heterogênea e ainda mais diversificada. Pode-se constatar, neste processo, uma perda significativa de direitos e de sentidos, em sintonia com o caráter destrutivo do capital vigente. O sistema de metabolismo, sob controle do capital, tornou o trabalho ainda mais precarizado, por meio das formas de subempregado, desempregado, intensificando os níveis de exploração para aqueles que trabalham.

Para refletir

Como são os contratos de trabalho no lugar em que você exerce a sua atividade profissional? Quais são as formas de vínculo empregatício dos trabalhadores?

O processo de trabalho é compreendido como a forma pela qual o homem transforma os objetos, utilizando instrumentos, a fim de alcançar um objetivo. São três os principais componentes do processo de trabalho:

* a atividade adequada a um fim, isto é, o próprio trabalho;

o objeto de trabalho, ou seja, a matéria a que se aplica o trabalho;

os instrumentos ou meios de trabalho.

Estabelecendo uma aproximação com a organização da rede de frio de imunobiológicos, podemos considerar que os trabalhadores atuam a partir de uma mesma finalidade, que seria possibilitar o acesso da 
população a vacinas, a fim de promover o controle e a erradicação de doenças imunopreveníveis. Para essa finalidade, utilizam diversos instrumentos de trabalho, como computadores, seringas, geladeiras, caixas, gelo, empilhadeiras de mão, paletes, entre outros.

Foto 1 - Trabalhador aplicando vacina que chegou à sala de vacina depois de passar por todas as instâncias da rede de frio

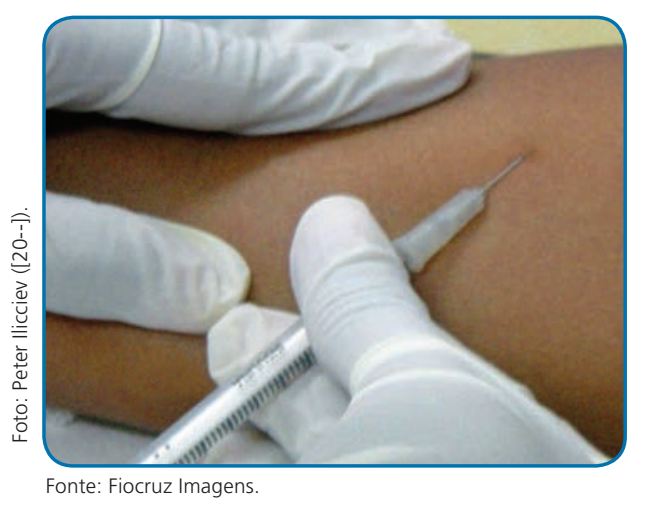

O trabalho em saúde pode ser compreendido como uma área não produtora direta de mercadorias, porém inserido em um contexto de mercado, no qual o uso da tecnologia e o consumo de produtos estão diretamente relacionados. Refere-se a uma divisão técnica do trabalho, em que atuam trabalhadores com diversas formações profissionais e diferentes concepções técnicas e éticas sobre o seu trabalho.

Embora, no trabalho em saúde, o resultado final a ser alcançado não seja a produção direta de mercadoria, como em outros setores, algumas categorias de análises do trabalho em geral são úteis para compreendermos a organização da atividade laborativa no setor de saúde. Diversos autores do campo da saúde coletiva se preocuparam em conceituar o processo de trabalho em saúde, entre eles destacamos Marina Peduzzi e Lilia Schraiber (2009), de acordo com o trecho a seguir.

O conceito Processo de Trabalho em Saúde diz respeito à dimensão microscópica do cotidiano do trabalho em saúde, ou seja, à prática dos trabalhadores/profissionais de saúde inseridos no dia-a-dia da produção e consumo de serviços de saúde. Contudo, é necessário compreender que nesse processo de trabalho cotidiano está reproduzida toda a dinâmica do trabalho humano, o que torna necessário introduzir alguns aspectos centrais do trabalho que é a grande categoria de análise da qual deriva o conceito de processo de trabalho em saúde (PEDUZZI; SCHRAIBER, 2009, p. 323, grifo nosso).

Podemos considerar, então, que o trabalho em saúde possui diversas dimensões:

* na relação direta do trabalhador com seu ato produtivo;

* na integração com outros trabalhadores e usuários dos serviços; e

nas questões relativas à vinculação do trabalho no contexto em que este se insere, envolvendo contradições e conflitos. 


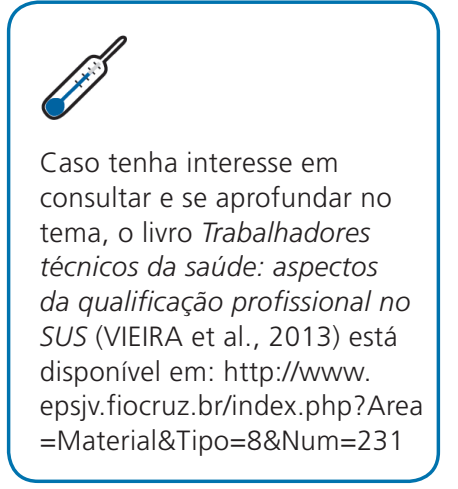

Fotos 2, 3 e 4 - O processo de trabalho em saúde envolve diferentes etapas e muitas tecnologias

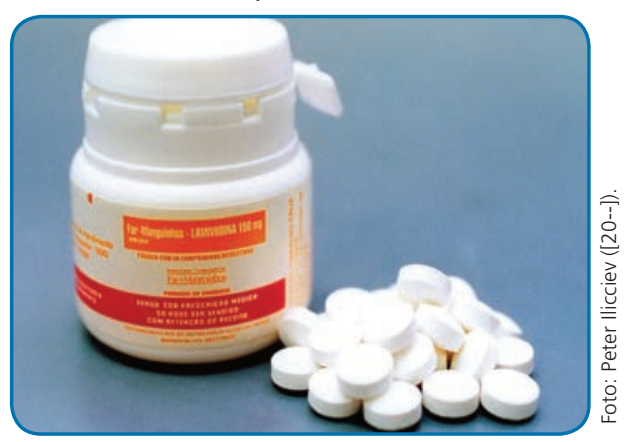

Fonte: Fiocruz Imagens.
Com o aumento do desemprego no setor industrial a partir de 2012, grande parte de trabalhadores, antes empregados formalmente naquele setor, passou a compor a força de trabalho precarizada em outras áreas, como a da saúde, que recebeu um grande contingente de trabalhadores nas áreas técnica e administrativa, inclusive em cargos comissionados nas administrações municipais.

O livro Trabalhadores técnicos da saúde: aspectos da qualificação profissional no SUS (VIEIRA et al., 2013), da Escola Politécnica de Saúde Joaquim Venâncio, apresenta uma análise de aspectos extremamente relevantes sobre a qualificação dos trabalhadores técnicos da saúde no Brasil; ao apresentarem e analisarem os dados sobre o setor, os autores afirmam que, a despeito das oscilações econômicas pelas quais passou o país, houve uma expansão nessa área, embora sem uma correlata adequação sobre as condições de trabalho e formação profissional. Em reforço a essa afirmativa, destacamos o trecho a seguir:

Os dados apresentados [ao longo do livro] permitem afirmar que durante a última década, a despeito das oscilações da economia brasileira, os postos de trabalho em saúde apresentaram um movimento de expansão que consolidou um sistema de saúde dualizado, com uma ligeira superioridade numérica do setor público. É importante destacar que, embora cada vez mais relevante em termos econômicos e sociais, essa expansão vem sendo marcada tanto no âmbito público quanto no privado pela deterioração das condições de trabalho e pela diminuição da proteção jurídica do trabalho (VIEIRA et al., 2013).

\section{Para refletir}

Você está conseguindo relacionar as questões estudadas até agora com a realidade do seu trabalho? 
Nas imagens, é possível perceber o emprego de alta tecnologia na saúde. Em consequência, principalmente, do avanço tecnológico, diversas profissões foram sendo incorporadas a esse setor, gerando novas especializações (arquitetura hospitalar, direito em saúde, mecatrônica, biomedicina, entre outras). Embora haja crescimento dos postos de trabalho formais, as mudanças relativas aos aspectos estruturais do trabalho, tais como a flexibilização e a precarização dos vínculos, passaram a compor fortemente o processo de trabalho em saúde no Brasil nos últimos anos (esta discussão será retomada no próximo capítulo, “Organizações públicas e o processo de trabalho em saúde").

A consolidação do SUS como um sistema que amplia direitos sociais possibilitou, também, discussões relativas a vinculação e regulamentação dos trabalhadores que atuam no sistema. Com a regionalização dos serviços, ocorre menos contratação de pessoal nas esferas federal e estadual, e há aumento do número de trabalhadores com vínculo municipal. As mudanças ocorridas com a municipalização dos serviços de saúde não foram acompanhadas, no entanto, por novas regulamentações a respeito da administração de pessoal, forçando a convivência, no mesmo espaço, de trabalhadores com carga horária, vínculos e salários diferenciados.

A Norma Operacional Básica de Recursos Humanos do SUS (NOB/ RH-SUS) (CONSELHO NACIONAL DE SAÚDE, 2005) foi uma tentativa de definir princípios e diretrizes para o setor, objetivando maior valorização profissional e regularização das relações de trabalho em saúde. No entanto, pouco se avançou nesse sentido, sendo a diversidade de vínculos, salários e outros direitos ainda muito frequente em todo o território nacional. Observa-se retração da tendência de regulamentação do trabalho no SUS, avançando para a precarização e terceirização dos vínculos trabalhistas, apesar das estratégias promovidas pelo Ministério da Saúde, como a criação da Secretaria da Gestão do Trabalho e Educação, em 2003, e outras ações ao longo da última década. Muito há ainda para ser feito no sentido de regulamentação das relações de trabalho no SUS.

\section{Processo de trabalho na rede de frio de imunobiológicos}

O que, comumente, é denominado apenas como "rede de frio" compreende uma série de atividades de diferentes profissionais, que envolve armazenamento, conservação, manuseio, distribuição e transporte de imunobiológicos do Programa Nacional de Imunizações (PNI).
Os termos flexibilização e precarização têm sido utilizados para designar o processo de produção ao qual os trabalhadores estão submetidos no sistema capitalista, em que há diversas formas de contratação e salários diferenciados para a realização de atividades semelhantes. Essa multiplicidade de formas de contratação difere da padronização fordista e tem sido chamada de flexibilização. E, geralmente, implica também perdas de direitos do trabalhador, sendo denominada, portanto, de precarização do trabalho. 
No Brasil, o termo "rede de frio" se refere ao setor público de saúde, embora a administração de vacinas também ocorra na rede privada (na qual encontramos apenas o elo entre produtores, distribuidores e clínicas).
Todas essas etapas, como discutido em outros capítulos, devem garantir as condições adequadas de refrigeração, desde o laboratório produtor até o momento em que a vacina é administrada, se fazendo necessária, ainda, uma articulação com outras políticas de saúde e ações intersetoriais, além do diálogo com a sociedade. Segundo o documento comemorativo dos 40 anos do programa, o futuro do PNI aponta para a necessidade de se avançar sobre diferentes questões:

Ao se olhar o PNI no futuro, torna-se imprescindivel vê-lo concretamente a partir de um longo espectro de questões: (i) no contexto da atenção à saúde como uma ação da atenção básica; (ii) no compromisso de incorporação com novas vacinas e novos grupos populacionais; (iii) na clareza de que vacinação segura envolve o compromisso com a eficiência e qualidade com os diferentes componentes da atividade; (iv) no compromisso com a investigação e análise dos eventos adversos associados à vacinação; (v) no investimento e capacitação dos profissionais envolvidos; (vi) na busca incessante por resultados que representem impacto real na situação das doenças imunopreveníveis sob vigilância (BRASIL, 2013, p. 88).

$\mathrm{Na}$ rede de serviços que envolvem o PNI, encontramos profissionais da enfermagem, administrativos, biólogos, médicos, entre outros, que atuam na relação direta com o usuário dos serviços, como na aplicação de vacinas, mas também diretamente na produção e distribuição desses imunobiológicos.

Fotos 5, 6 e 7 - Processos de trabalho na rede de frio de imunobiológicos
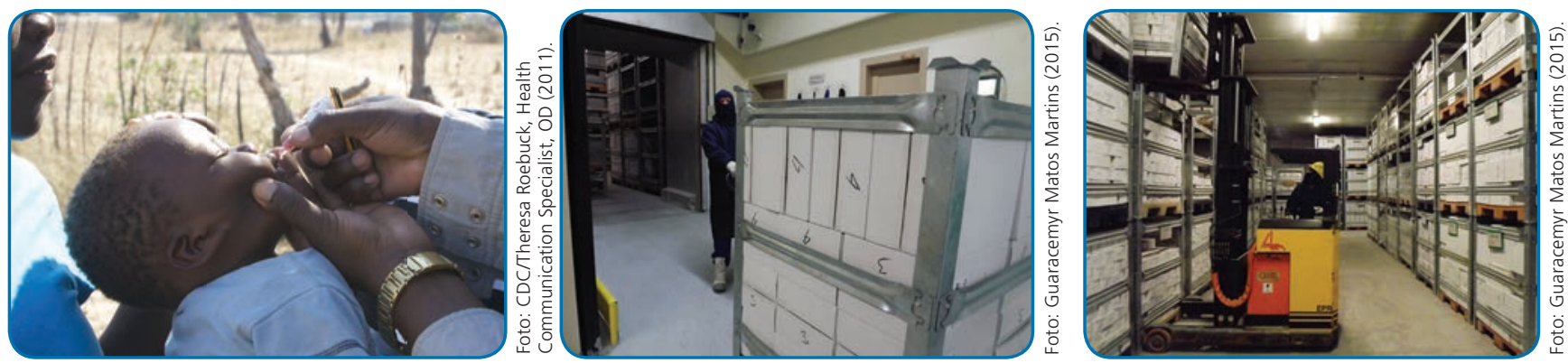

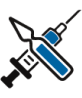

É muito importante que os trabalhadores que atuam na rede de frio de imunobiológicos conheçam os aspectos dos processos de trabalho envolvidos até as salas de vacina, no nível local!
A organização do trabalho na rede de frio de imunobiológicos é, de fato, em rede: compreende um complexo de ligações entre instâncias nacionais, estaduais e municipais, com centrais de abastecimento e distribuição nacional e regionalizadas, além das salas de vacinação, localizadas nas unidades de saúde.

Muitas atividades desenvolvidas na rede de frio de imunobiológicos exigem do trabalhador conhecimentos técnicos variados, além da compreensão de questões éticas e culturais da sociedade. Em algumas áreas, 
é o trabalho administrativo que predomina e, em outras, os conhecimentos técnicos da enfermagem. No entanto, a formação integral desse trabalhador é essencial, pois, na prática, todo esse conjunto de saberes está relacionado à imunização.

A principal característica desse processo de trabalho é compor diferentes profissionais para realizar a:

gestão das vacinas, que exigem controle constante de temperatura e tempo de armazenagem;

*atuação direta com os usuários e o conhecimento de técnicas de aplicação de vacinas; e,

orientação ao cuidado e o planejamento do controle vacinal.

Embora cada tipo de profissional atue em uma parte da rede, podemos considerar que todos, de uma maneira ou outra, realizam a gestão desses imunobiológicos. Isso não se constitui vantagem para esse trabalhador, visto que, ao se analisar a atividade exercida, o que se observa, de modo geral, é pouco reconhecimento e fragilidade na forma de contratação. Essa fragilidade se expressa tanto no aspecto relativo ao vínculo empregatício e à regulamentação profissional, como ao salarial e às condições de trabalho, apesar da enorme responsabilidade que assumem em sua prática. É o que podemos observar no texto a seguir, em que se discute a qualificação profissional dos técnicos administrativos na saúde:

Observa-se, no exercício dessa função, uma grande variedade de atividades e uma significativa instabilidade no emprego relacionada às mudanças políticas que se manifestam nas modalidades e número da contratação de pessoal. Ou seja, a cada novo mandato muda-se o contingente de trabalhadores contratados, por se tratar, em muitos casos, de cargos comissionados e de outras formas precárias de contratação de força de trabalho (CASTRO et al., 2013, p. 154).

Como o próprio nome diz, os trabalhadores da rede de frio fazem parte de uma grande rede. Para tanto, é fundamental compreender que cada ponto deve estar plenamente conectado para que os princípios do SUS sejam assegurados e o usuário possa contar com o imunobiológico de qualidade. Nesse sentido, vale a pena conhecer a proposta do trabalho em equipe na saúde e, em particular, na rede de frio.

\section{O trabalho em equipe na rede de frio}

Observe atentamente a Figura 2. O que lhe parece? É possível relacionar o que aprendeu sobre o processo de trabalho em saúde com a imagem? 
Figura 2 - Trabalhando em equipe

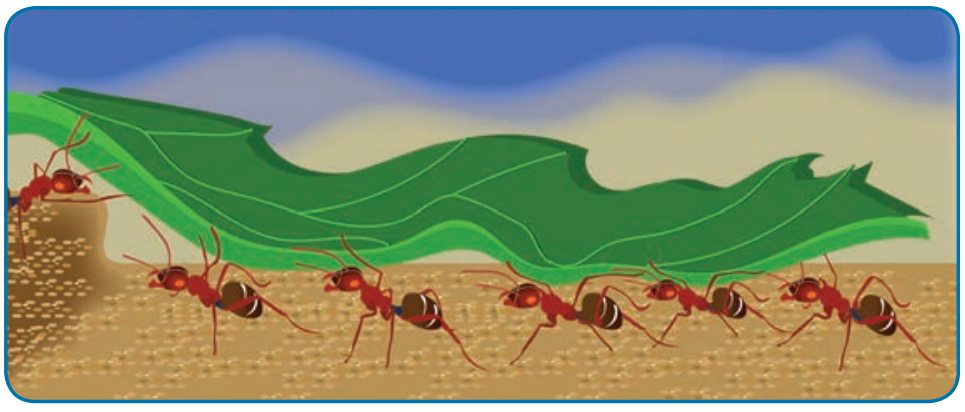

As formigas se comunicam, geralmente, por uma química chamada feromonas; esses sinais de mensagens são mais desenvolvidos na espécie das formigas que em outros grupos. Como as formigas passam a vida em contato com o solo, elas deixam uma trilha de feromônio, que pode ser seguida por outras (FORMIGA, 2013).

Nós, também, estabelecemos muitas formas de comunicação. No caso do processo de trabalho da rede de frio, a notificação de eventos adversos de vacinas é muito importante para melhorar a qualidade dos serviços prestados à população. Apesar da organização da rede e do enorme número de trabalhadores da saúde e de outras áreas (como de transporte de cargas, por exemplo) envolvidos na distribuição de imunobiológicos, problemas acontecem e precisam ser comunicados, a fim de se contribuir para o planejamento estratégico das ações de imunização e integração da rede.

\section{Considerações finais}

Para finalizar este capítulo, sistematizamos alguns dos pontos com base em nossa experiência docente e atuação no SUS, a fim de contribuir para o debate sobre o processo de trabalho na rede de frio de imunobiológicos:

* Podemos observar que há uma prática de articulação entre os trabalhadores dos diferentes serviços que integram essa rede, porém essa articulação ocorre mais na resolução de problemas práticos, sendo necessária ainda maior reflexão sobre todo mecanismo e complexidade que compõem o sistema.

Os trabalhadores percebem a importância do seu trabalho, sendo que a proximidade com o usuário é um fator gerador de maior cobrança na resolução de problemas, causando estresse, muitas vezes. No entanto, naqueles serviços em que essa relação não ocorre, carecem do retorno e do reconhecimento da importância de seu trabalho por parte daqueles que o utilizam. O estresse está relacionado, geralmente, ao processo de trabalho e execução de prazos e normas.

* diversidade de vínculos de trabalho (estatutários, Consolidação das Leis Trabalhistas [CLT] e outros) pode gerar conflitos em relação à gestão, relacionados principalmente a desigualdades salariais, condições de trabalho e possibilidades de liberação, no horário de trabalho, para realização de cursos de aperfeiçoamento profissional. 
Tal diversidade está ligada às diferenças políticas e regionais no Brasil. As diferentes condições de trabalho e de realidades nem sempre são modificáveis pelos esforços de manuais e protocolos implementados pelos níveis nacional e estadual, na organização do Programa Nacional de Imunizações.

Esperamos ter contribuído para a reflexão sobre a organização do trabalho em nossa sociedade e a importância daqueles que atuam na complexa organização de distribuição de imunobiológicos no Brasil e, também, em outros países. Atuar nessa rede exige muita responsabilidade e compromisso com o trabalho, a fim de fortalecer, por meio do PNI, o reconhecimento das ações de vigilância em saúde e de todo o SUS, como um sistema universal e equânime.

\section{Referências}

ANTUNES, R.; ALVES, G. As mutações no mundo do trabalho na era da mundialização do capital. Educação e Sociedade, Campinas, v. 25, n. 87, p. 335-351, 2004.

BRASIL. Ministério da Saúde. Secretaria de Vigilância em Saúde. Departamento de Vigilância das Doenças Transmissíveis. 40 anos do Programa Nacional de Imunizações. Brasília, DF, 2013.

CASTRO, V. et al. Regulamentação e história dos trabalhadores administrativos na gestão da saúde. In: MOROSINI, M. V. G. C. et al. (Org.). Trabalhadores técnicos em saúde: aspectos da qualificação profissional no SUS. Rio de Janeiro: Fiocruz/Escola Politécnica de Saúde Joaquim Venâncio, 2013.

CONSELHO NACIONAL DE SAÚDE (Brasil). Princípios e diretrizes para a gestão do trabalho no SUS (NOB/RH-SUS). 3. ed. rev. atual. Brasília, DF, 2005.

DICIONÁRIO de filosofia Nicolas Abbagnano. 5. ed. São Paulo: Martins Fontes, 2007.

FORMIGA. In: WIKIPEDIA: a enciclopédia livre. [S.I.], 2013. Disponível em: <pt.wikipedia.org/wiki/ Formiga>. Acesso em: 5 ago. 2016.

GRAMSCI, A. Os intelectuais e a organização da cultura. Rio de Janeiro: Civilização Brasileira, 1979.

MARX, K. Processo de trabalho e processo de produção de mais-valia. In: MARX, K. O capital. [S.I.]: Marxists Internet Archive, 2005. v. 1, parte 3, cap. 7. Disponível em: <https://www.marxists.org/ portugues/marx/1867/ocapital-v1/vol1cap07.htm>. Acesso em: 22 nov. 2013.

PEDUZZI, M.; SCHRAIBER, L. Processo de trabalho em saúde. In: PEREIRA, I. B.; LIMA, J. C. F. (Org.). Dicionário de educação profissional em saúde. Rio de Janeiro: Fiocruz/Escola Politécnica de Saúde Joaquim Venâncio, 2009. p. 320-326.

VIEIRA, M. et al. Dinâmica da formação técnica e da ocupação de postos de trabalhos em saúde: Brasil Anos 2000. In: MOROSINI, M. V. G. C. et al. (Org.). Trabalhadores técnicos em saúde: aspectos da qualificação profissional no SUS. Rio de Janeiro: Fiocruz/Escola Politécnica de Saúde Joaquim Venâncio, 2013. 



\section{Organizações públicas e o processo de trabalho em saúde}

Marcello de Moura Coutinho, Maria Luiza Silva Cunha

A discussão do trabalho na saúde engloba, necessariamente, uma análise do contexto organizacional do trabalho e suas relações com o Sistema Único de Saúde (SUS). Nos últimos anos, diferentes autores (AZEVEDO; BRAGA NETO; SÁ, 2002; LIMA, 1996) têm apontado para a crise com que nos deparamos no setor de saúde, em geral, e na gestão das organizações públicas, em particular, que se relaciona com diferentes aspectos, entre eles, governabilidade, resolutividade e eficiência.

Essa crise tem várias causas, em distintos níveis (LIMA, 1996):

* No nível estrutural, pode ser apontada, entre outras, a histórica fragilidade da política de saúde, que se expressa, na atualidade, pelos entraves político-institucionais observados na implementação do SUS.

慗No nível organizacional, existem diferentes elementos relacionados à formação de profissionais e gestores, à insuficiência de planejamento e à baixa clareza dos objetivos, à escassez de recursos financeiros. Há, ainda, aqueles relacionados ao trabalho, como a divisão inadequada e a insuficiência de mecanismos de coordenação e integração, elementos estes que integram os sistemas de direção e modelos de gestão de uma organização de saúde.

*⿻ nóvel individual, estão os aspectos relacionados à qualidade do atendimento ao usuário e às condições de trabalho.

A seguir, vamos apresentar os elementos presentes no nível organizacional, com base em algumas teorias que fundamentam o trabalho na gestão em saúde. Com esse estudo, esperamos que você aprofunde e amplie seus conhecimentos sobre as organizações públicas de saúde,
Eficiência trata de como fazer, não do que fazer. Quando se fala em eficiência, está se tratando de produtividade, de fazer mais com o mínimo de recursos possíveis. 
suas características e determinações, bem como sobre o tema do trabalho em equipe e a educação em saúde, na direção da transformação pretendida pelo fortalecimento da política de saúde prevista no SUS.

\section{Caracterização de uma organização pública de saúde}

No dicionário, o termo organização é definido como "s.f. Ato ou efeito de organizar (-se). I Modo por que um ser vivo é organizado. / Associação ou instituição com objetivos definidos. / Organismo". (FERREIRA, 1977).

Assim, organização tanto pode ser entendida como a forma pela qual o trabalho é organizado em uma instância ou um serviço de saúde (por exemplo, os procedimentos de solicitação, o processo de compra, o armazenamento de imunobiológicos, como no caso da Cenadi), ou como a própria instância ou serviço, em que o conceito de organização se confunde com o de instituição.

Veja alguns exemplos de organizações.

Figura 1- Unidade básica de saúde (UBS)

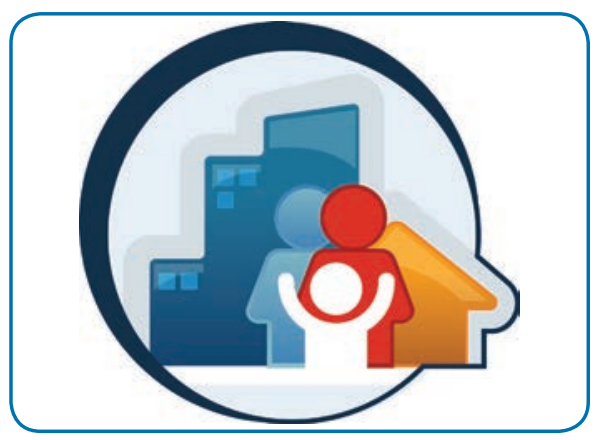

Figura 2 - Hospital

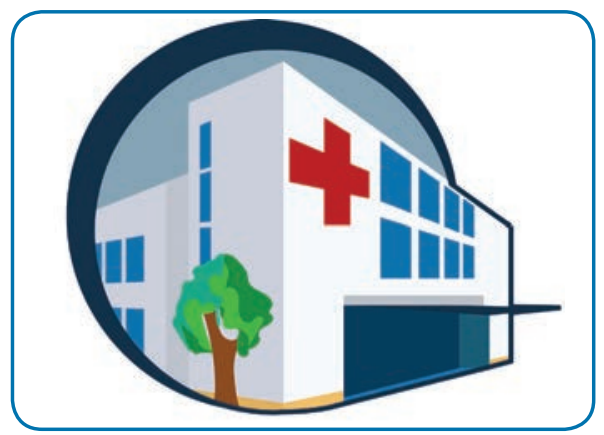

Foto 1 - Cenadi

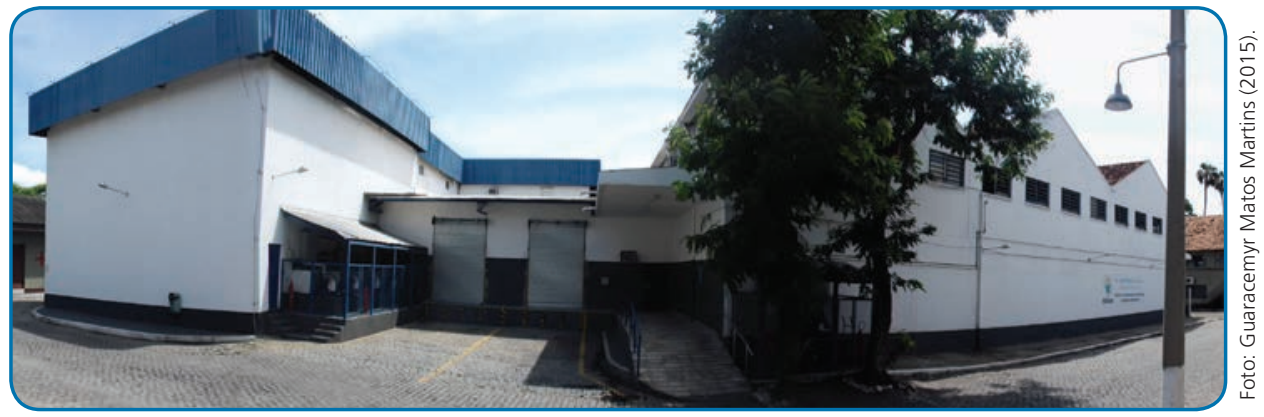

As organizações são compreendidas a partir de diferentes perspectivas que se relacionam aos fatores que as condicionam. 


\section{Fatores inerentes à organização}

- A tecnologia, compreendida como o processo de trabalho, ou seja, o conhecimento, as técnicas, os instrumentos e as ações que são utilizadas numa organização para transformar insumos em produtos.

- A estrutura, que representa a divisão do trabalho e a coordenação e integração do trabalho dividido (inclui o processo de departamentalização e a definição dos mecanismos de coordenação - a hierarquia, com a consequente distribuição da autoridade).

- Os objetivos, entendidos como estados futuros desejados, que definem o escopo das ações organizacionais para dentro e para fora, devendo conter duas dimensões, uma relacionada à intenção e outra, à ação.

- O poder, compreendido como a capacidade de influenciar, que só ocorre numa relação social.

- O ambiente, compreendido como fonte de insumo e receptor dos produtos organizacionais, que incorpora tanto uma dimensão mais geral - os aspectos políticos, legais, demográficos, ecológicos, sociais, econômicos, tecnológicos, culturais etc. - quanto uma dimensão mais específica - os fornecedores, os clientes, os concorrentes e as agências regulamentadoras etc.

Fonte: Lima (1996).

Todos esses fatores se apresentam, de forma diferenciada, entre várias organizações e entre momentos históricos distintos de uma mesma organização. Eles nos ajudam a entender nosso trabalho e como ele é produto das determinações presentes nas organizações. Por exemplo, o organograma de uma unidade de saúde ou setor representa a estrutura e favorece a identificação da departamentalização, da hierarquia, da distribuição de autoridade e das relações de poder.

\section{Para refletir}

Considerando os fatores apresentados, reflita sobre a organização na qual você se insere. Como se estrutura? Existe um organograma da unidade de saúde ou setor em que você trabalha? Como é feita a divisão do trabalho? Como acontece o processo decisório? Quem participa desse processo?

As organizações foram analisadas segundo diferentes teorias e abordagens. Uma delas adota um conjunto de metáforas para interpretar as organizações com base em imagens de máquinas, organismos vivos, 
Morgan (1996) destaca que a metáfora é usada "sempre que tentamos compreender um elemento da nossa experiência em face de outro. Assim, a metáfora prossegue por meio de afirmações implícitas ou explícitas de que A é (ou parece) B. Quando se diz que 'o homem é um leão' usa-se a imagem do leão para chamar a atenção dos aspectos do homem parecidos com o leão. A metáfora enquadra a nossa compreensão do homem de forma específica, ainda que parcial" (MORGAN, 1996, p. 16). culturas, sistemas políticos, prisões psíquicas, fluxos e transformações e, também, como instrumentos de dominação. A utilização das diferentes metáforas permite, segundo o autor, a compreensão da organização como fenômeno complexo, ambíguo e paradoxal (MORGAN, 1996). Vamos, a seguir, discutir um pouco sobre uma dessas metáforas, que se faz bastante presente nas organizações do ponto de vista histórico e ainda marca os processos de trabalho nos dias atuais.

\section{A imagem das organizações como máquinas}

Nas organizações compreendidas como máquinas, as partes possuem um papel claramente definido no funcionamento do todo. A organização é pensada como a interligação das diferentes partes que a compõem, de forma mecânica.

Tal modo de funcionamento tem repercussões na vida organizacional, caracterizada pela rotina e exigência de precisão, assim como na vida dos trabalhadores, em que se espera que se comportem como se fossem partes de máquinas.

Você conhece alguma organização assim? Televendas seria um exemplo? Ela ainda está presente nos dias atuais?
Foto 2 - Linha de montagem em uma fábrica da Ford (1913) - um modo de fazer ainda significativamente presente nos dias atuais

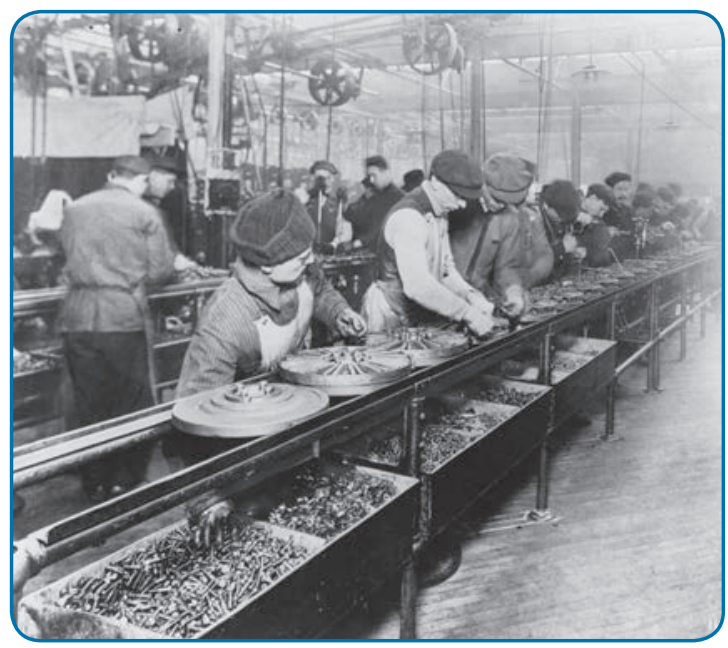

Fonte: Wikimedia Commons.
A resposta para as duas últimas perguntas é sim. Essa concepção encontra-se bastante disseminada ainda nos dias atuais e pode ser exemplificada pelo trabalho de produção em massa em uma fábrica, nas cadeias de "refeições rápidas" ou mesmo em atividades como a dos assistentes de vendas, cujos comportamento e respostas na interação com os clientes são fortemente padronizados e determinados previamente.

A origem dessa concepção remonta à invenção e à proliferação das máquinas e ao seu uso, predominantemente na indústria, e à consequente necessidade de adaptação das organizações às suas exigências. Essa ampliação do uso das máquinas no processo de trabalho se deu em um momento histórico que envolveu transformações sociais e econômicas significativas, a Revolução Industrial.

No contexto da Europa e da América do Norte, a Revolução Industrial suscitou mudanças nas organizações em direção a maior burocratização, "rotinização" e divisão do trabalho. Esta última tornou-se cada vez maior e intensivamente especializada, representando, por um lado, 
maior controle e eficiência por parte dos fabricantes e, por outro, perda de liberdade de ação e submissão às normas e rotinas de produção por parte dos trabalhadores.

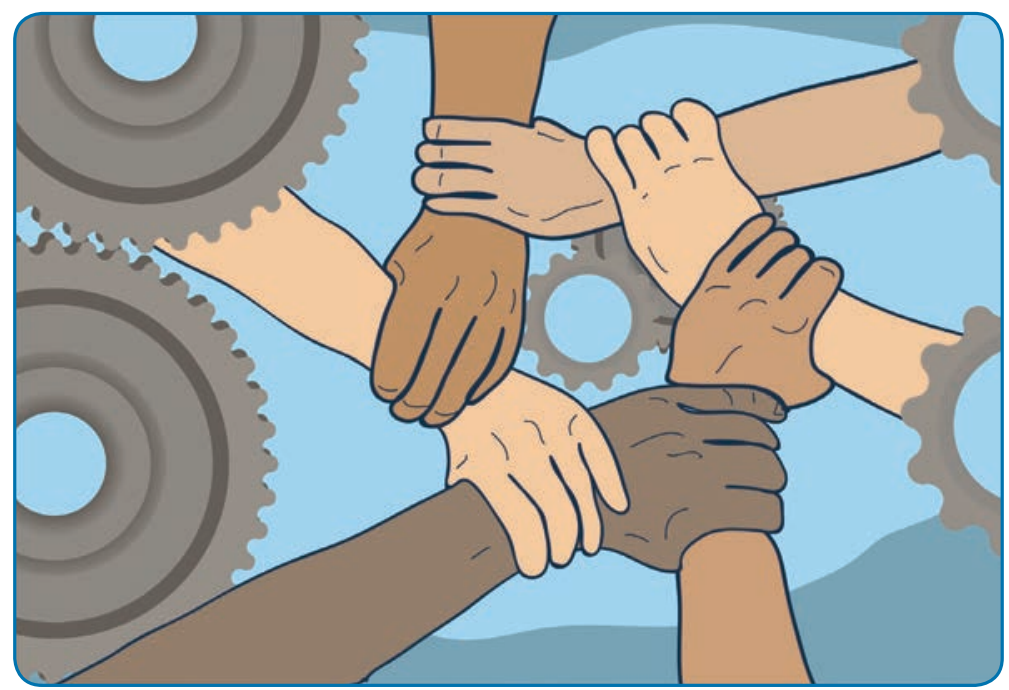

Os trabalhadores, assim como as peças, eram vistos como parte da engrenagem. Essa percepção está contida na expressão "recursos humanos".

Como foi formulada a concepção de organização ao longo do tempo? Essa visão mecanizada se estendeu a outros processos de trabalho?

No início do século XX, uma teoria de organização e de administração foi formulada considerando diferentes contribuições. A mais significativa se referia às conclusões do sociólogo alemão Max Weber (18641920); este afirmava que, ao "rotinizar" os processos de administração, as formas burocráticas exerciam, na produção, o mesmo papel que as máquinas.

Outra contribuição significativa foi dada por um grupo de teóricos e profissionais em administração, da América do Norte e da Europa, que embasou o que atualmente é conhecido como "a teoria da administração clássica" e "administração científica". Eles defendiam fortemente a burocratização, em oposição a Weber, influenciando, em grande medida, o pensamento presente até os dias atuais.

Como a forma mecanicista interfere nas organizações de saúde?

Para o setor de saúde, pensar as organizações de forma mecanicista, produzidas unicamente a partir de processos racionais e técnicos, tem consequências importantes. Tal perspectiva envolve a subvalorização dos aspectos humanos e a baixa capacidade de abordar os fatores
Para Weber, a primeira definição compreensível de burocracia caracteriza-a como uma forma de organização que enfatiza a precisão, a rapidez, a clareza, a regularidade, a confiabilidade e a eficiência, atingidas através da criação de divisão de tarefas fixas, supervisão hierárquica, regras detalhadas e regulamentos (MORGAN, 1996, p. 26). 
envolvidos em sua complexidade, levando a um trabalho sem significação tanto para os trabalhadores como para os usuários. Ou seja, em grande medida, a perspectiva mecanicista influenciou e continua influenciando o trabalho em saúde.

Atualmente, consideram-se, entretanto, formas diferenciadas de conceber o trabalho, que podem ser identificados na história e no conceito de trabalho em equipe, que abordaremos a seguir.

\section{O trabalho em equipe}

Em nossos dias, o trabalho em equipe é considerado como um dos elementos centrais para a gestão dos serviços e do cuidado à saúde. O trabalho em equipe é um conceito que tem uma origem histórica e que se transforma a partir da segunda metade do século XX.

Abordaremos o desenvolvimento histórico e o conceito do trabalho em equipe a seguir, mas, antes, propomos algumas questões para reflexão sobre o seu processo de trabalho.

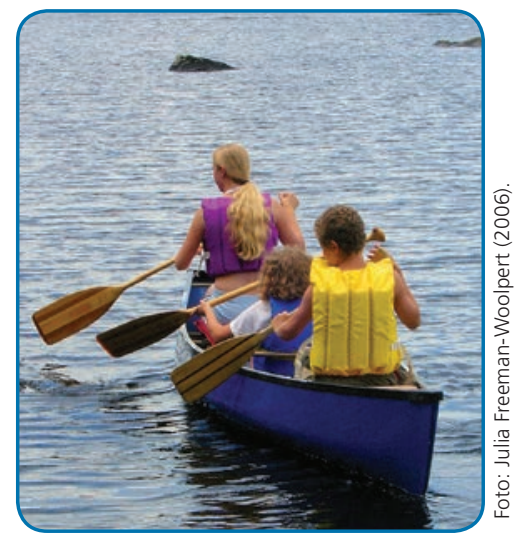

O trabalho em equipe, assim como uma travessia, pressupõe que os envolvidos atuem em conjunto e com objetivos comuns.

Fonte: Freelmages.com.

\section{Para refletir}

Com quem você desenvolve o seu trabalho? Quem faz parte da sua equipe? Como é a relação entre os integrantes da equipe? O seu processo de trabalho considera a interação das ações entre os diferentes participantes? Como é feita a comunicação entre os integrantes da equipe?

\section{Uma breve história do trabalho em equipe}

Atualmente, é comum as pessoas perceberem o trabalho em saúde como atividade de uma equipe. Mas, algumas ainda relacionam esse trabalho fortemente à figura do médico. A seguir, vamos entender um pouco mais sobre os motivos dessas percepções.

O trabalho em equipe surge no contexto de emergência da medicina preventiva, nos Estados Unidos, na década de 1950. Naquela ocasião, o papel do médico sofreu uma reformulação; ele passou a não ter mais a 
responsabilidade exclusiva pelos cuidados em saúde e assumiu a função de liderar o trabalho realizado por uma equipe multiprofissional. Buscava-se uma integração entre a medicina preventiva e as demais especialidades, conforme a compreensão ampliada do conceito de saúde, que considerava, além dos aspectos biológicos, os aspectos psíquicos e sociais. Tais referências conceituais foram retomadas na década de 1960, pela medicina comunitária, e serviram de base, nos anos 1970, para os programas de extensão de cobertura ocorridos em nosso país (PEDUZZI, 2009).

A compreensão da determinação social da saúde levou a uma correspondente busca de reorientação do modelo assistencial, que passou a se voltar para o alcance da atenção integral à saúde. Para tal, esse novo modelo previa a articulação de ações de promoção, prevenção, recuperação e reabilitação da saúde, a serem realizadas por profissionais da saúde de diferentes áreas, mediante o trabalho em equipe multiprofissional. No entanto, ainda mantinha a centralidade do trabalho médico (PEDUZZI, 2009).

Outra vertente explicativa do surgimento do trabalho em equipe, na saúde, se refere à busca pela reorganização dos processos de trabalho, de forma a fazer frente aos crescentes custos da atenção médica. Estes foram acarretados para o sistema pela incorporação de novas tecnologias, pelo aumento da necessidade de aquisição de produtos industrializados e pela ampliação da população atendida (PEDUZZI, 2009).

\section{O trabalho em equipe}

- Parte da busca por maior eficiência da atenção médica, prevista em uma visão economicista.

- Incorpora a concepção ampliada de saúde e um modelo baseado na atenção integral.

Os conceitos de interdisciplinaridade e transdisciplinaridade foram importantes para a formulação da definição do trabalho em equipe, compreendido como trabalho de um coletivo, tal como se apresenta nas definições atuais.

Mas como foi o desenvolvimento da concepção do trabalho em equipe ao longo do século XX?

A partir dos anos 1970, a perspectiva de organização do sistema se voltou para as necessidades de saúde de populações concretas, inseridas em espaços de vida complexos e dinâmicos, compreendidos, posteriormente, pelo conceito de território. As concepções de adstrição de clientela, de responsabilidade sanitária, descentralização, hierarquização,
A determinação social da saúde e os modelos assistenciais foram abordados, respectivamente, no Capítulo 1, "Um pouco de história: evolução das concepções de saúde, doença e cuidado", e no Capítulo 2, "Políticas públicas de saúde e a organização do SUS", do livro Rede de Frio: fundamentos para a compreensão do trabalho (SILVA; FLAUZINO; GONDIM, 2016). 
Os princípios do SUS foram abordados no Capítulo 2, "Políticas públicas de saúde e a organização do SUS", do livro Rede de Frio: fundamentos para a compreensão do trabalho (SILVA; FLAUZINO; GONDIM, 2016). regionalização e participação comunitária desencadearam uma necessidade de revisão do trabalho em saúde, visando efetivar tais princípios organizativos pretendidos para o sistema público, que foi instituído alguns anos depois.

Tal perspectiva levou a um processo de substituição das equipes constituídas por médicos e atendentes por uma progressiva incorporação de profissionais de outras áreas, conformando equipes que consideravam a atuação multiprofissional. Estas, entretanto, caracterizavam-se pelo predomínio de profissionais de nível superior.

Considerado como um elemento estratégico voltado à superação da fragmentação da assistência, o trabalho em equipe é enfatizado a partir dos anos 1980. A $8^{\text {a }}$ Conferência Nacional de Saúde, de 1986, incorporou, na política prevista de recursos humanos, o conceito de equipe de saúde como unidade produtiva do trabalho em saúde (PEDUZZI, 2009).

Na década de 1990, a busca pela implementação do SUS levou ao aprofundamento das discussões a respeito dos seus princípios doutrinários, entre eles o da integralidade da atenção.

A integralidade pressupõe a capacidade de assegurar aos indivíduos o direito à atenção à saúde, dos níveis mais simples aos mais complexos, da atenção curativa à preventiva, bem como a compreensão do indivíduo em sua totalidade e dos indivíduos/coletividades em suas singularidades (BRASIL, 1990).

A noção de integralidade expressa, em suas diferentes dimensões, o componente reorientador do modelo de atenção à saúde, estando fortemente relacionada às diretrizes de universalização do acesso e equidade. Ela fortalece a perspectiva do trabalho em equipe no período inicial de implantação do SUS. Outro marco do SUS foi a constituição do Programa Saúde da Família, como estratégia governamental, e a formação de equipes compostas por médicos, enfermeiros, técnicos de enfermagem e agentes comunitários, em 1994.

O trabalho em equipe se inclui na perspectiva do trabalho em saúde que reconhece a determinação social da saúde e os múltiplos aspectos envolvidos (educacionais, econômicos, históricos, biológicos, sociais, culturais, simbólicos, entre outros), os quais demonstram a complexidade desse campo.

Nas concepções mais recentes, o trabalho em saúde não se refere apenas a um indivíduo ou a um grupo profissional. Assim, 
o "trabalho em saúde" é sempre realizado por um trabalhador coletivo. Não há trabalhador de saúde que dê conta sozinho do mundo das necessidades de saúde, o objeto real do "trabalho em saúde". Os trabalhadores universitários, técnicos e auxiliares são fundamentais para que o trabalho de um dê sentido ao trabalho do outro, na direção da verdadeira finalidade do "trabalho em saúde": cuidar do usuário, o portador efetivo das necessidades de saúde (MERHY; FRANCO, 2009, p. 281).

Ao longo dos anos, entretanto, a reversão do modelo biomédico não foi um processo automático. No que se refere ao trabalho em equipe, o desenho previsto na atuação multiprofissional nem sempre garantia a pretendida integração das práticas e saberes. A atuação especializada, tornada hegemônica por meio da organização disciplinar do conhecimento, persistia no fazer cotidiano dos serviços. Frequentemente, os diferentes profissionais compartilhavam o mesmo local de trabalho, mas mantinham lógicas distintas de atendimento, com pouca comunicação e integração.

\section{O conceito de trabalho em equipe}

Neste capítulo, destacamos que, ao longo do tempo, o trabalho em saúde sofreu transformações. Chamamos a sua atenção, contudo, para o fato de que diferentes perspectivas sobre o trabalho em saúde convivem, em um mesmo período, com um processo muitas vezes de disputa. No que se refere à concepção de trabalho em equipe, isso não é diferente. Assim, em nossos dias convivem concepções de trabalho em equipe que o entendem como:

暽 Um fazer coletivo e articulado, ou seja, “uma modalidade de trabalho coletivo que é construído por meio da relação recíproca, de dupla mão, entre as múltiplas intervenções técnicas e a interação dos profissionais de diferentes áreas, configurando, através da comunicação, a articulação das ações e a cooperação" (PEDUZZI, 2009, p. 273).

* A mera coexistência, em um mesmo setor, serviço ou unidade, de diferentes profissionais.

Com base nessas perspectivas, o trabalho em equipe pode ser classificado em dois tipos, que se referem a duas modalidades de equipe (PEDUZZI, 2001), conforme a Figura 3.
Relembrando, o modelo biomédico é centrado na atenção especializada e em procedimentos individuais. Seu local de atenção mais expressivo se referia aos hospitais.

Hegemônica refere-se à supremacia, à preponderância, ao poder político e econômico. 
Figura 3 - Tipologia do trabalho em equipe

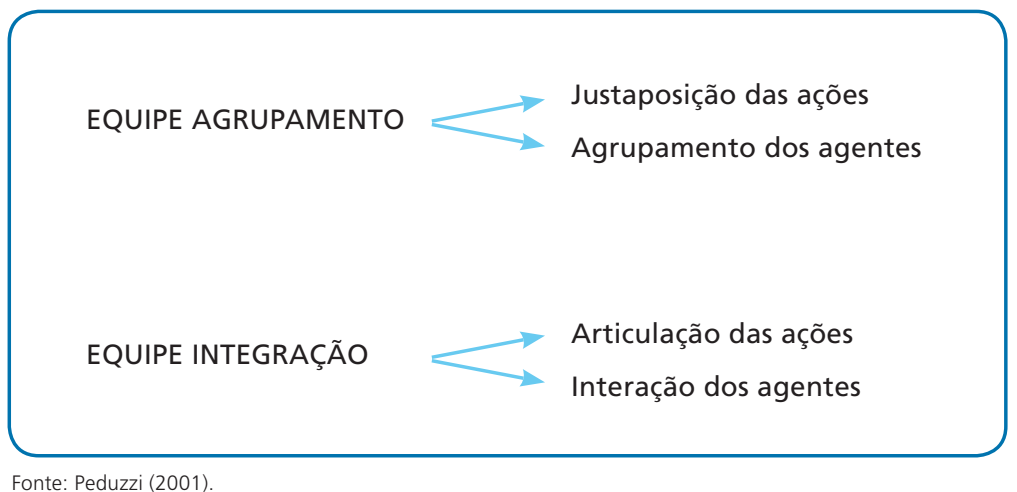

Fonte: Peduzzi (2001)

\section{Para refletir}

Pense, agora, no seu trabalho na rede de frio de imunobiológicos.

Quem faz parte da sua equipe? Como se dá a relação entre os integrantes da equipe? Você percebe que as ações realizadas pelos diferentes trabalhadores se encontram articuladas ou justapostas? Que consequências isso tem para o funcionamento da rede? E para o SUS?

Apesar da distinção realizada em relação à equipe agrupamento e à equipe integração, existem identidades entre as duas. Estas se referem à existência, em ambas, das "diferenças técnicas dos trabalhos especializados e a desigualdade do valor atribuído a esses distintos trabalhos, operando a passagem da especialidade técnica para a hierarquia de trabalhos, o que torna a recomposição e a integração diversas do somatório técnico" (PEDUZZI, 2001, p. 106). Outros aspectos em comum consideram as tensões entre as diversas formas de conceber e exercer a autonomia técnica e de organização dos trabalhos especializados.

Em outras palavras, o processo de trabalho em saúde envolve profissionais que exercem autonomia técnica, esta concebida como a possibilidade de julgamento e tomada de decisão frente às necessidades de saúde dos usuários. O grau de autonomia, entretanto, está condicionado pela maior ou menor autoridade técnica e por dimensões políticas e ideológicas, relativas às diferentes inserções sociais dos profissionais em questão (PEDUZZI, 2001). 


\section{Relações de trabalho: autonomia, responsabilidade e processo gerencial}

Conforme mencionado, o trabalho em saúde envolve a autonomia dos profissionais, mas o que pensamos sobre o conceito de autonomia?

Apresentamos, a seguir, a contribuição de Campos (2002) que, ao enfocar as profissões de nível superior e a sua atuação na clínica e na saúde coletiva, possibilita uma discussão fértil sobre tal concepção. O autor discute a questão da autonomia profissional e do paradoxo entre esta e a atribuição institucional de responsabilidade. Apresenta, ainda, uma reflexão importante para a compreensão do tema trabalho em saúde. Segundo esse autor, devem-se considerar os trabalhadores da saúde em uma dupla dimensão. Uma que se refere à sua capacidade de produção do sistema, como sujeito, e a outra, pela sua condição de objeto produzido por fatores culturais, pelo conhecimento disciplinar, pelo mercado, entre outros. Significa que:

os trabalhadores de saúde operam com relativo grau de autonomia, apesar dos constrangimentos a que estão sempre submetidos. Em consequência, o grau de alienação dos trabalhadores em relação ao objetivo (missão), objeto e meios de trabalho dos sistemas de saúde pode variar conforme a conjuntura e conforme a sua própria atuação como atores sociais que são. A alienação não é um dado exclusivamente estrutural (CAMPOS, 2002, p. 242).

A alienação dos trabalhadores em saúde pode ser verificada pelo grau de afastamento destes do movimento de defesa da vida. Considerada como princípio ético, a defesa da vida contrapõe-se a práticas cada vez mais frequentes na atualidade, norteadas pelos interesses mercadológicos, pelas normas burocráticas, pelo corporativismo e pela organização parcelar do trabalho em saúde. Em relação ao último, Campos (2002) estabelece que a fixação do profissional a determinada etapa de certo projeto terapêutico produz alienação.

Como, então, podem-se superar tais práticas e o processo de alienação do trabalhador ao realizar o trabalho em saúde? Não existem respostas simples para problemas complexos, mas veremos, a seguir, que tal condição pode e deve ser alcançada no âmbito do trabalho em saúde, no SUS.

Vamos enfatizar aqui o tema da obra, que se refere ao reconhecimento tanto do trabalhador da saúde quanto do usuário e da sociedade acerca do resultado do seu trabalho. A obra é uma das condições necessárias para a realização profissional e existencial dos profissionais da saúde.
O paradoxo existente entre autonomia profissional e atribuição institucional de responsabilidade, identificado nas análises acerca da atuação de profissionais de nível superior, diz respeito, por exemplo, à perspectiva médico-centrada e ao modelo biomédico, que entram em choque com a política de humanização do SUS e não respeitam os direitos do paciente (usuário). Além disso, limitam ou até mesmo inviabilizam o trabalho em equipe, quando os profissionais de nível superior desconsideram os saberes de outros, por exemplo, os do agente comunitário de saúde.

Organização parcelar do trabalho refere-se a fragmentação e especialização do trabalho, modelo taylorista, em que cada trabalhador domina e realiza apenas uma parte do trabalho. 
Através dela, o trabalhador, em sua condição de sujeito, não apenas atua de forma criativa, mas se responsabiliza pela produção final da saúde, tanto no que se refere à recuperação individual como à promoção da saúde de uma coletividade (CAMPOS, 2002).

O trabalho em saúde prevê, assim, a aproximação dos trabalhadores com o resultado do seu trabalho, levando a reconhecimento, valorização, desalienação e, consequentemente, maior satisfação profissional.

Campos prevê maneiras de implementar a diretriz da obra, entre elas, a criação de mecanismos que permitam o envolvimento de todos os participantes de uma equipe com a elaboração de novas maneiras de se fazer uma instituição funcionar. Tornar a reinvenção uma possibilidade cotidiana e garantir a participação da maioria nesses processos são maneiras de implicar trabalhadores com as instituições e com os pacientes. Neste sentido, a Gestão Colegiada de serviços de saúde pode servir como um dispositivo desalienante. Um modo de comprometer trabalhadores com a missão e com os projetos institucionais (CAMPOS, 2002, p. 235).

Outro desafio apontado à gestão é lidar com a especialização do trabalho sem, contudo, conduzi-lo a ações fragmentadas entre os profissionais da saúde. Com relação a esse ponto, o autor propõe a aplicação dos conceitos de Campo e de Núcleo. Núcleo corresponde ao conjunto de conhecimentos e responsabilidades referentes a uma profissão ou especialidade, o que diferenciaria os membros de uma equipe, e Campo, os saberes e responsabilidades compartilhados. Pertencem ao Campo os conhecimentos referentes às noções gerais da política de saúde, da organização de modelos de atenção e do processo de trabalho, assim como o saber básico sobre o processo saúde-doença e conhecimentos relativos à epidemiologia, ao funcionamento corporal, ao vínculo profissional-paciente e regras gerais de prevenção e promoção à saúde (CAMPOS, 2002).

Campos (2002) afirma que os médicos buscam extrema especialização, ou seja, ao se especializarem, vão perdendo progressivamente a perspectiva global da medicina. O que poderia minimizar esse efeito seria, então, uma formação que privilegiasse a polivalência, para propiciar uma visão mais holística, em cada clínica médica.
No interior das equipes, a possibilidade de negociação das definições de Campo e Núcleo de Competência e Responsabilidade possibilita maior autonomia para os profissionais e equipes e a atribuição de responsabilidades de forma clara. A respeito desses pontos, o autor prevê uma abertura no paradoxo entre autonomia e definição de responsabilidade, assim como entre polivalência e especialização (CAMPOS, 2002).

A seguir, abordamos alguns aspectos importantes relacionados ao trabalho em saúde nas organizações. 


\section{Mediação de conflitos nas relações de trabalho}

A adoção do trabalho em equipe não implica, necessariamente, na existência de consenso. Os diferentes participantes do trabalho em saúde possuem pontos de vista, experiências de vida e de trabalho, valores, interesses, controle de recursos (entre eles, financeiros, administrativos, de conhecimento e de poder) e formações diferentes, que, muitas vezes, entram em conflito. Tais divergências e a existência de conflito não devem ser negadas ou "abafadas", mas, sim, entendidas como inerentes às relações de trabalho, como objeto da gestão em saúde e como possibilidade de aprendizagem, crescimento e transformação.

\section{Posicionamento ético}

Os crescentes custos do setor de saúde, relacionados com o envelhecimento populacional, o predomínio de condições crônicas e, cada vez mais, com intensa incorporação tecnológica, se colocam como importantes aspectos para a capacidade de manutenção de sistemas públicos e universais de saúde, como o SUS.

A escassez de recursos coloca desafios éticos, considerando a necessidade de racionamento dos serviços de saúde e o estabelecimento de prioridade de intervenções relativas a diferentes ações e serviços voltados aos indivíduos e coletivos. Tal perspectiva envolve a tomada de decisão baseada no conceito de equidade. Equidade e iniquidade envolvem juízos de valor. São “conceitos políticos que expressam um compromisso moral com a justiça social" (ESCOREL, 2009, p. 205).

\section{Relações de respeito e confiança}

O processo de trabalho em saúde envolve o estabelecimento de relações, seja entre trabalhadores, gestores, usuários, outros atores sociais etc. Por isso, o reconhecimento do outro e o respeito às suas diferenças são a base para a construção da confiança e da produção do cuidado e da saúde. Tais relações são mediadas, entretanto, pela comunicação, conforme os quadrinhos a seguir. 

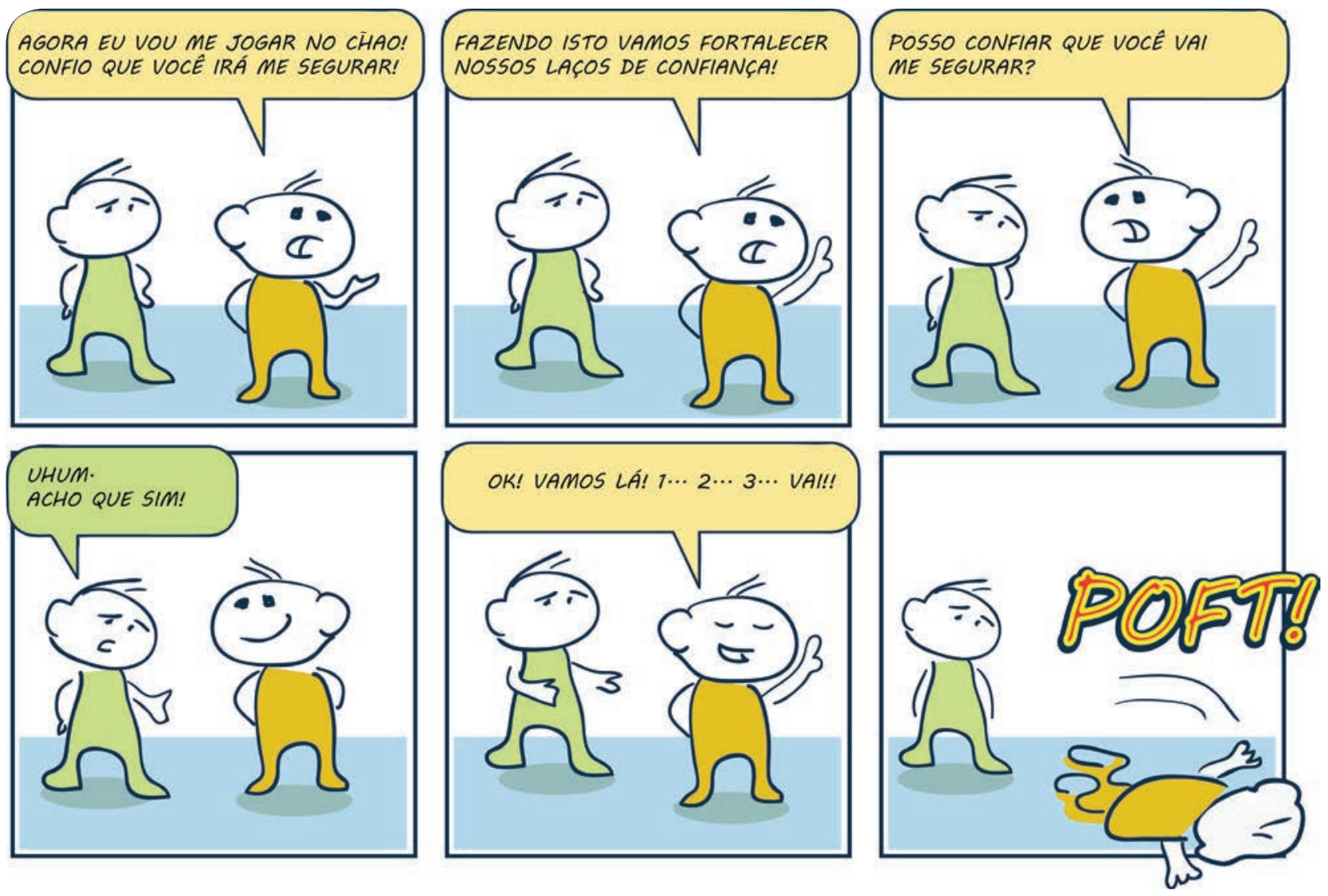

\section{Para refletir}

O que você refletiu a partir dos quadrinhos? Pode-se apreender que confiança é construída na relação entre as pessoas; mas, qual é o papel da comunicação? E como pensar essas relações de respeito e confiança na rede de frio de imunobiológicos? Que papel você acredita que elas têm? Seriam tão importantes quanto os insumos, os equipamentos e o número suficiente de trabalhadores para que a rede funcione?

\section{Educação e saúde}

Em nossos dias, existem diversas expressões que relacionam educação e saúde. Apesar de, muitas vezes, serem usadas com o mesmo significado, essas expressões designam coisas muito diferentes e partem de variadas concepções de saúde, educação e sociedade. 
O Ministério da Saúde (BRASIL, 2009) propôs um glossário para facilitar a identificação das diferenças contidas nas diversas perspectivas de educação:

Educação continuada, fem. Processo de aquisição sequencial e acumulativa de informações técnico-científicas pelo trabalhador, por meio de escolarização formal, de vivências, de experiências laborais e de participação no âmbito institucional ou fora dele.

Educação em saúde, fem. 1 - Processo educativo de construção de conhecimentos em saúde que visa à apropriação temática pela população, e não à profissionalização ou à carreira na saúde. 2 - Conjunto de práticas do setor que contribui para aumentar a autonomia das pessoas no seu cuidado e no debate com os profissionais e os gestores a fim de alcançar uma atenção à saúde de acordo com suas necessidades.

Notas: i) A educação em saúde potencializa o exercício do controle social sobre as políticas e os serviços de saúde para que esses respondam às necessidades da população. ii) A educação em saúde deve contribuir para o incentivo à gestão social da saúde. Ver Educação popular em saúde.

Educação na saúde, fem. Produção e sistematização de conhecimentos relativos à formação e ao desenvolvimento para a atuação em saúde, envolvendo práticas de ensino, diretrizes didáticas e orientação curricular.

Educação permanente em saúde, fem. Ações educativas embasadas na problematização do processo de trabalho em saúde e que tenham como objetivo a transformação das práticas profissionais e da própria organização do trabalho, tomando como referência as necessidades de saúde das pessoas e das populações, a reorganização da gestão setorial e a ampliação dos laços da formação com o exercício do controle social em saúde.

Educação popular em saúde, fem. Ações educativas que têm como objetivo promover, na sociedade civil, a educação em saúde, mediante inclusão social e promoção da autonomia das populações na participação em saúde.

Fonte: Brasil (2009, p. 22-23)

\section{Para refletir}

Qual perspectiva de educação, sistematizada pelo Ministério da Saúde (BRASIL, 2009), é mais frequente em sua realidade de trabalho? Como as perspectivas educativas (BRASIL, 2009) podem contribuir para o trabalho em saúde, na rede de frio de imunobiológicos?

Vamos tomar um exemplo que considera a divisão social do trabalho. Muitas vezes, as oportunidades de formação e desenvolvimento são mais frequentes, quando não exclusivas, para os profissionais de nível superior e consideram a lógica parcelar do trabalho e o conhecimento 
especializado. Quem já ouviu falar nos famosos treinamentos para segmentos profissionais específicos, como médicos, enfermeiros e farmacêuticos?

Com a Resolução n. 353/2003 (CONSELHO NACIONAL DE SAÚDE, 2003) e a Portaria MS/GM n. 198/2004 (BRASIL, 2004), uma nova perspectiva de formação e desenvolvimento de trabalhadores foi adotada pelo SUS. Trata-se da Educação Permanente em Saúde, tomada não apenas como estratégia didática, mas como uma opção político-pedagógica, direcionada para equipes e voltada para o contexto de trabalho.

A educação permanente é um direito do trabalhador e contribui sensivelmente para o aperfeiçoamento do SUS, em razão de ser realizada com e para o trabalhador da saúde, a partir de experiências vivenciadas no cotidiano do trabalho.

\section{Concluindo...}

No âmbito do SUS, as organizações de saúde devem superar a concepção mecanicista, caracterizada pelo trabalho fragmentado e parcelar, e considerar as múltiplas dimensões envolvidas no trabalho em saúde. Entre elas, a dimensão relacional e ética, a busca pela defesa da vida e efetivação da cidadania e o trabalho coletivo, o qual pressupõe forte interação e comunicação.

\section{Considerações finais}

Em que medida seu trabalho incorpora a concepção de trabalho em equipe, que envolve forte interação e comunicação? Que ações podem ser pensadas para viabilizá-la em seu processo de trabalho? Que importância tem essa forma de organização quando pensamos em processos de trabalho que envolvem produção, distribuição, abastecimento e administração de imunobiológicos e outros insumos estratégicos na rede de frio de imunobiológicos?

Essas questões representam algumas das reflexões que buscamos trazer para você neste capítulo. Nosso caminhar até aqui foi extenso, mas esperamos que tenha contribuído para o aprofundamento dos seus saberes e a incorporação de novos conhecimentos. Se agora você é capaz de compreender o que são as organizações, como elas se constituíram e se modificaram ao longo da história, como influenciaram e influenciam o trabalho em saúde (incluindo o trabalho em equipe), teremos dado um passo significativo na formação pretendida. 


\section{Referências}

AZEVEDO, Creuza da Silva; BRAGA NETO, Francisco Campos; SÁ, Marilene de Castilho. Indivíduo e a mudança nas organizações de saúde: contribuições da psicossociologia. Cadernos de Saúde Pública, Rio de Janeiro, v. 18, n. 1, p. 235-247, jan./fev. 2002.

BRASIL. Lei n. 8.080, de 19 de setembro de 1990. Dispõe sobre as condições para a promoção, proteção e recuperação da saúde, a organização e o funcionamento dos serviços correspondentes e dá outras providências. Diário Oficial da União, Brasília, DF, 20 set. 1990.

BRASIL. Ministério da Saúde. Portaria n. 198, de 13 de fevereiro de 2004. Diário Oficial da União, Brasília, DF, 16 fev. 2004. Seção 1, p. 37.

BRASIL. Ministério da Saúde. Secretaria de Gestão do Trabalho e da Educação na Saúde. Glossário temático: gestão do trabalho e da educação na saúde. Brasília, DF, 2009.

CAMPOS, G. W. S. Subjetividade e administração de pessoal: considerações sobre modos de gerenciar trabalho em equipes de saúde. In: MERHY, E. E.; ONOCKO, R. (Org.). Agir em saúde: um desafio para o público. 2. ed. São Paulo: Hucitec, 2002.

CONSELHO NACIONAL DE SAÚDE (Brasil). Resolução n. 333. Aprova as diretrizes para criação, reformulação, estruturação e funcionamento dos Conselhos de Saúde. Diário Oficial da União, Brasília, DF, 4 dez. 2003. Seção 1, p. 57.

ESCOREL, S. Equidade em saúde. In: PEREIRA, I. B.; LIMA, J. C. F. (Org.). Dicionário de educação profissional em saúde. Rio de Janeiro: Fiocruz/Escola Politécnica de Saúde Joaquim Venâncio, 2009 Disponível em: <http://www.epsjv.fiocruz.br/dicionario/verbetes/equsau.html>. Acesso em: 4 ago. 2016.

FERREIRA, A. B. H. Minidicionário Aurélio. Rio de Janeiro: Nova Fronteira, 1977.

LIMA, S. M. L. O contrato de gestão e a conformação de modelos gerenciais para as organizações hospitalares públicas. Revista de Administração Pública, Rio de Janeiro, v. 30, n. 5, p. 101-138, set./ out. 1996.

MERHY, E. E.; FRANCO, T. Trabalho em saúde. In: PEREIRA, I. B.; LIMA, J. C. F. (Org.). Dicionário de educação profissional em saúde. Rio de Janeiro: Fiocruz/Escola Politécnica de Saúde Joaquim Venâncio, 2009. Disponível em: <http://www.epsjv.fiocruz.br/dicionario/verbetes/trasau.html>. Acesso em: 4 ago. 2016.

MORGAN, G. Imagens da organização. São Paulo: Atlas, 1996.

PEDUZZI, M. Equipe multiprofissional de saúde: conceito e tipologia. Revista de Saúde Pública, São Paulo, v. 35, n. 1, p. 103-109, 2001.

PEDUZZI, M. Trabalho em equipe. In: PEREIRA, I. B.; LIMA, J. C. F. (Org.). Dicionário de educação profissional em saúde. Rio de Janeiro: Fiocruz/Escola Politécnica de Saúde Joaquim Venâncio, 2009. Disponível em: <http://www.epsjv.fiocruz.br/dicionario/verbetes/traequ.html>. Acesso em: 4 ago. 2016. 
PEDUZZI, M.; SCHRAIBER, L. Processo de trabalho em saúde. In: In: PEREIRA, I. B.; LIMA, J. C. F. (Org.). Dicionário de educação profissional em saúde. Rio de Janeiro: Fiocruz/Escola Politécnica de Saúde Joaquim Venâncio, 2009. Disponível em: <http://www.epsjv.fiocruz.br/dicionario/verbetes/ protrasau.html>. Acesso em: 13 dez. 2013.

SILVA, M. N.; FLAUZINO, R. F.; GONDIM, G. M. M. (Org.). Rede de frio: fundamentos para a compreensão do trabalho. Rio de Janeiro: Ed. Fiocruz, 2016. 


\section{Saúde e segurança do trabalhador na rede de frio de imunobiológicos}

Irai Borges de Freitas, Katia Butter Leão de Freitas, Marcello de Moura Coutinho e Sarita de Oliveira Ferreira Lopes

A atuação do trabalhador é ponto central nos processos que envolvem o adequado funcionamento da rede de frio de imunobiológicos e, em consequência, na manutenção da qualidade das vacinas que chegam à população. Sua atuação depende de inúmeros fatores, tais como dos insumos e equipamentos, de formação para desempenho das atividades, da organização do processo de trabalho e, certamente, da sua saúde.

Neste capítulo, desejamos compartilhar ideias sobre o campo da saúde e segurança do trabalhador. Apresentamos, brevemente, um pouco do histórico conceitual desse campo, bem como alguns instrumentos legais relacionados a ele, além de estratégias de análise dos ambientes de trabalho, como o mapa de risco e sua relação com a rede de frio de imunobiológicos.

\section{Saúde: muito além da ausência de doença}

O famoso modelo Dahlgren e Whitehead demonstra que o estado de saúde vai muito além da ausência de doença: ele é afetado por um conjunto de fatores individuais, biológicos, ambientais, sociais, políticos, econômicos. Esse conceito ampliado de saúde diz respeito às condições de vida das pessoas, ou, como se diz, formalmente, são as condições de bem-estar físico, mental e social.

Os determinantes e condicionantes da saúde foram definidos pela Lei Orgânica da Saúde n. 8.080/90, no seu parágrafo 3, do artigo $2^{\circ}$ :

Os níveis de saúde expressam a organização social e econômica do país, tendo a saúde como determinantes e condicionantes, entre outros, a alimentação, a moradia, o saneamento
O modelo da determinação social da saúde, cunhado por Dahlgren e Whitehead, foi apresentado no Capítulo 1, "Um pouco de história: evolução das concepções de saúde, doença e cuidado", do livro Rede de Frio: fundamentos para a compreensão do trabalho (SILVA; FLAUZINO; GONDIM, 2016).

Lei procede do latim lex, que significa regra, norma. Trata-se de uma norma ou um conjunto de normas concebido por um poder soberano para regular a conduta social e impor sanções a quem não a cumpre. 
A função das leis é controlar os comportamentos e ações dos indivíduos de acordo com os princípios daquela sociedade. Em geral, as ações puníveis por lei são ponderadas pelos cidadãos antes de serem praticadas.
Positivista refere-se a uma corrente de pensamento sociológico e filosófico que pressupõe uma hierarquia de saberes, na qual a ciência está acima dos demais saberes. básico, o meio ambiente, o trabalho, a renda, a educação, a atividade física, o transporte, o lazer e o acesso aos bens e serviços essenciais (BRASIL, 1990b, grifo nosso).

A terceirização, no contexto da precarização, acompanhada da intensificação e do aumento da jornada de trabalho, com acúmulo de funções; a maior exposição a fatores de risco para a saúde; o descumprimento de regulamentos de proteção à saúde e segurança do trabalhador; o rebaixamento dos níveis salariais e o aumento da instabilidade no emprego... Esses são alguns dos fatores que fazem parte de processos de trabalho contemporâneos. Se considerarmos o conceito ampliado de saúde, pode-se perceber que eles têm grande impacto sobre os trabalhadores, os quais, frequentemente, desenvolvem estresse, contaminação e fadiga mental/psíquica, as chamadas "dores relacionadas ao trabalho", isto é, lesões por esforços repetitivos (LER) e distúrbios osteomoleculares relacionados ao trabalho (Dort).

Esse contexto também pode se apresentar na rede de frio, principalmente no tocante aos trabalhadores técnicos de nível médio. Determinados períodos como os de campanha de vacinação, possivelmente, aumentam os níveis de estresse e fadiga, os quais constituem alguns dos fatores desencadeadores de LER/Dort. Já o trabalho repetitivo de empilhamento de paletes e a exposição frequente à variação extrema de temperatura nas câmaras frias, quando não controlados corretamente, podem gerar, por exemplo, dores musculares e doenças alérgicas respiratórias, respectivamente.

Com base no conceito ampliado de saúde, seus determinantes e nas questões específicas que o conceito implica na produção do trabalho e suas implicações para o trabalhador, podemos refletir mais especificamente sobre práticas de saúde e saúde do trabalhador.

\section{Saúde do trabalhador: um pouco de sua história}

Essa história tem três grandes momentos ou visões - medicina do trabalho, saúde ocupacional e saúde do trabalhador.

Na medicina do trabalho, o enfoque é dado à doença, tendo surgido como uma especialidade médica na Inglaterra, na primeira metade do século XIX, com a Revolução Industrial. O Brasil assumiu o mesmo pressuposto positivista da onipotência da medicina, ou seja, a ideia de que apenas a medicina científica é adequada para compreender o processo saúde-doença, desconsiderando o saber popular, por exemplo. 
Cabe destacar que a medicina do trabalho estava limitada à ação médica, devendo cuidar da adaptação física dos trabalhadores, atuando com foco nos modelos de produção taylorista e fordista, em que o trabalhador é visto como uma "máquina de produção", mais uma engrenagem que deve ser "consertada", sob pena de perda da margem de lucro por parte do dono da fábrica.

A medicina do trabalho, para estudiosos como Mendes \& Dias (1991, p. 342), está intimamente relacionada ao exercício direto do controle da força de trabalho. Os autores justificam tal afirmativa considerando que:

a medicina do trabalho se constituiu, fundamentalmente, como uma atividade médica, sendo praticada nos locais de trabalho (empresas, instituições públicas etc.);

* sua principal motivação era
Foto 1 - O trabalho na indústria

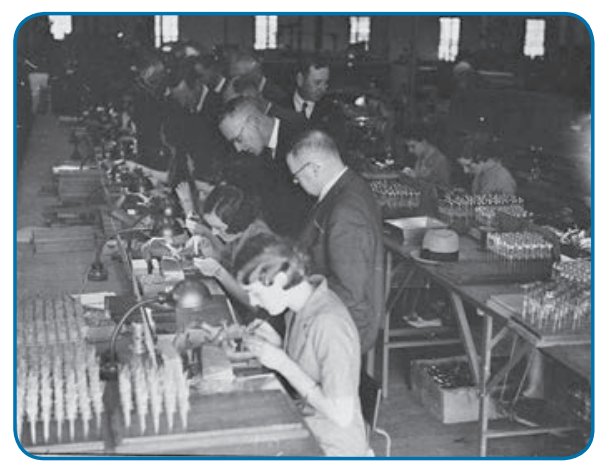

A medicina do trabalho era voltada para a manutenção do trabalhador "funcionando" em seu posto de trabalho, de forma a não atrapalhar a produção da indústria. Fonte: Wikimedia Commons. contribuir para o estabelecimento e a manutenção do nível mais elevado possível de bem-estar físico e mental dos trabalhadores (perspectiva de adequação ao trabalho).

A origem da medicina do trabalho e seu desenvolvimento, portanto, estão articulados à necessidade de máxima produtividade. Tanto a perspectiva de adaptação ao trabalho quanto a ideia de manutenção da saúde da força de trabalho refletem as influências da medicina científica e da fisiologia, assim como das ciências da administração, quando nos lembramos dos princípios do taylorismo-fordismo.

\section{Para refletir}

Com base nessas ideias, você identifica alguma semelhança com seu trabalho nos dias atuais?

Os processos de trabalho foram se transformando e se intensificando desde a Segunda Guerra Mundial. O esforço industrial começou a exigir, progressivamente, de algumas categorias profissionais, um trabalho extremamente árduo, o que acabou gerando inúmeras doenças ou até mesmo mortes, em decorrência de inúmeros acidentes de trabalho.

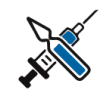

Não podemos nos esquecer de que, no referido período, o trabalho era extremamente extenuante! As jornadas de trabalho eram de 12, 14 e até 16 horas, em condições insalubres, aumentando significativamente as possibilidades de contágio de doenças, inclusive nos alojamentos próximos às fábricas, onde se amontoavam os trabalhadores.
Como teria dito Henry Ford: "O corpo médico é a seção da minha fábrica que mais dá lucro" (OLIVEIRA; TEIXEIRA, 1984, p. 181). Não é à toa que a medicina do trabalho continua até hoje... 


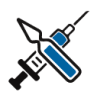

A medicina do trabalho foi superada historicamente pela saúde ocupacional, mas, ainda assim, continua tendo seu lugar nos processos de trabalho contemporâneos.
Tal quadro começou a preocupar muito os empregadores, ávidos por uma mão de obra produtiva, e também as companhias de seguro, as quais estavam arcando com o pagamento de indenizações de altos valores por incapacidades provocadas pelo trabalho. Aliada a isso, a tecnologia industrial avançou consideravelmente, adotando novos processos, equipamentos e a síntese de novos produtos químicos. Ao mesmo tempo, estava havendo o rearranjo de uma nova divisão internacional do trabalho.

Com isso, a medicina do trabalho perdeu espaço, em virtude da impotência de intervir sobre os problemas de saúde causados pelos novos processos de produção, assim como cresceram a insatisfação e o questionamento dos trabalhadores e empregadores. Os empregadores estavam sendo mais onerados pelos custos diretos e indiretos dos agravos à saúde de seus empregados. E qual foi a solução dada?

A solução foi a saúde ocupacional, na lógica da atuação médica direcionada ao trabalhador, pela "intervenção sobre o ambiente" com instrumental oferecido por outras disciplinas e profissões. Isso porque a saúde ocupacional manteve a centralidade do médico do trabalho na identificação de problemas de saúde do trabalhador. Além disso, o contexto do seu surgimento foi o período Pós-Segunda Guerra Mundial, época de esforço para a reconstrução dos países com base na produção industrial.

Também herdeira da racionalidade científica, mas baseada em uma atuação multiprofissional, e não só no profissional médico, a saúde ocupacional surgiu usando a estratégia de intervir nos locais de trabalho, com a finalidade de controlar os riscos nesses ambientes. Ela ganha importância pelo alicerce que as escolas de saúde pública e universidades dos Estados Unidos da América (EUA) forneceram, com os estudos sobre problemas de saúde ocupacional e enfoque ambiental, principalmente na metade do século XX.

No Brasil, a adoção e o desenvolvimento da saúde ocupacional ocorreram tardiamente, em três vertentes, as quais podem ser sintetizadas da seguinte forma:

* Acadêmica: desenvolvimento de centros de ensino e pesquisa, com destaque para a área de saúde ocupacional do Departamento de Saúde Ambiental da Universidade Estadual de São Paulo (USP).

* Institucional: cuja marca mais característica foi a criação da Fundação Jorge Duprat Figueiredo de Segurança e Medicina do Trabalho (Fundacentro), versão nacional dos modelos de institutos de saúde ocupacional que surgiram na década de 1950 pelo mundo. 


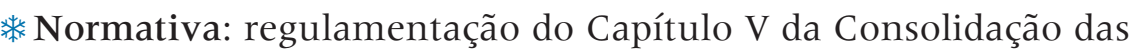
Leis do Trabalho (CLT), principalmente nas normas relativas à obrigatoriedade de equipes técnicas multidisciplinares nos locais de trabalho. Sobre essa vertente, cabe destacar que a avaliação quantitativa de riscos ambientais pela adoção de "limites de tolerância" é explicitada, principalmente, pelas Normas Regulamentadoras de Segurança e Saúde no Trabalho n. 7 e n. 15.

A respeito da vertente normativa, é importante salientar que as chamadas Normas Regulamentadoras (NRs) foram publicadas inicialmente pelo Ministério do Trabalho e Emprego (MTE), pela Portaria n. 3.214/78 (totalizando $28 \mathrm{NRs}$ ), estabelecendo os requisitos técnicos e legais sobre os aspectos mínimos de segurança e saúde ocupacional (SSO).

As NRs relativas a segurança e saúde ocupacional, desde 1978, são de observância obrigatória para qualquer empresa ou instituição que tenha trabalhadores regidos pela Consolidação das Leis do Trabalho (CLT), incluindo empresas privadas e públicas, órgãos públicos da administração direta e indireta, bem como órgãos dos poderes Legislativo e Judiciário.

| Mas será que cabe alguma obrigação ao trabalhador?

Sim, o trabalhador deve seguir os requisitos técnicos e legais, além dos procedimentos escritos e boas práticas estabelecidas e comunicadas pelo empregador. Vale a pena ficar atento às seguintes obrigações:

* cumprir as disposições legais e regulamentares sobre segurança e saúde ocupacional, inclusive as ordens de serviço expedidas pelo empregador;

* usar o equipamento de proteção individual (EPI), o equipamento de proteção coletiva (EPC) e métodos de trabalho fornecidos e estabelecidos pelo empregador;

* submeter-se aos exames médicos estabelecidos no Programa de Controle Médico de Saúde Ocupacional (PCMSO) da empresa;

*aborar com o local de aplicação das NRs.

No caso dos trabalhadores da rede de frio, em especial aqueles que trabalham nas câmaras frias das centrais de distribuição, o Manual do Programa de Imunização (BRASIL, 2013, p. 75) estabelece os seguintes equipamentos de proteção individual (Foto 2 - EPI da rede de frio de imunobiológicos de uso obrigatório):

栔 touca balaclava (touca ninja de lã);

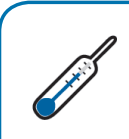

São 36 Normas

Regulamentadoras de

Segurança e Saúde no

Trabalho, que podem ser

acessadas pelo link:http://

trabalho.gov.br/index.php/

seguranca-e-saude-no-

trabalho/normatizacao/normasregulamentadoras

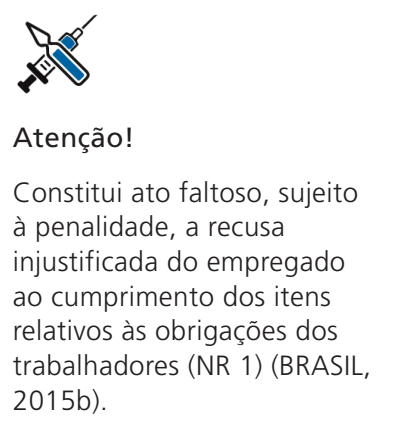

Atenção!

Constitui ato faltoso, sujeito à penalidade, a recusa injustificada do empregado ao cumprimento dos itens trabalhadores (NR 1) (BRASIL, 2015b) 
* japona longa 7/8 com capuz de náilon;

*alça em lona de náilon;

跘 meias em malha de algodão (não alérgica);

luva de pelica; e

* calçado de segurança (bota de cano alto para câmara fria, forrada com lã e solado em PVC).

Vale ressaltar que o empregador também tem a responsabilidade de garantir a qualidade dos EPIs e EPCs e substituí-los periodicamente, evitando sua deterioração, o que nem sempre é observado, inclusive na rede de frio. A não observância nesse caso pode contribuir e/ou gerar incapacidade parcial ou integral do trabalhador.

Como a saúde ocupacional perdeu seu espaço para a saúde do trabalhador?

Figura 14 - Vivitrum cum intius ex non hos bon nihil virtiae.

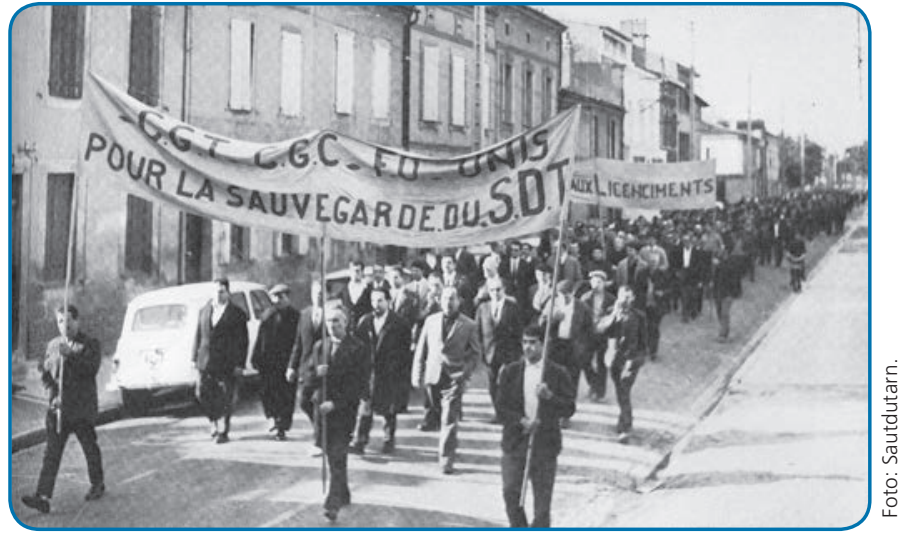

O ano de 1968 foi o mais intenso da década de 1960. Nele, a população da França se reuniu no maior protesto da história (foto); Praga se rebelou contra os desmandos da União Soviética; Martin Luther King e Robert Kennedy foram assassinados nos EUA; a ditadura endureceu suas ações no Brasil, acarretando maior repressão, inúmeras prisões e algumas mortes, como a do estudante Edson Luís.

Fonte: Wikimedia Commons.
Foto 2 - EPI da rede de frio de imunobiológicos de uso obrigatório

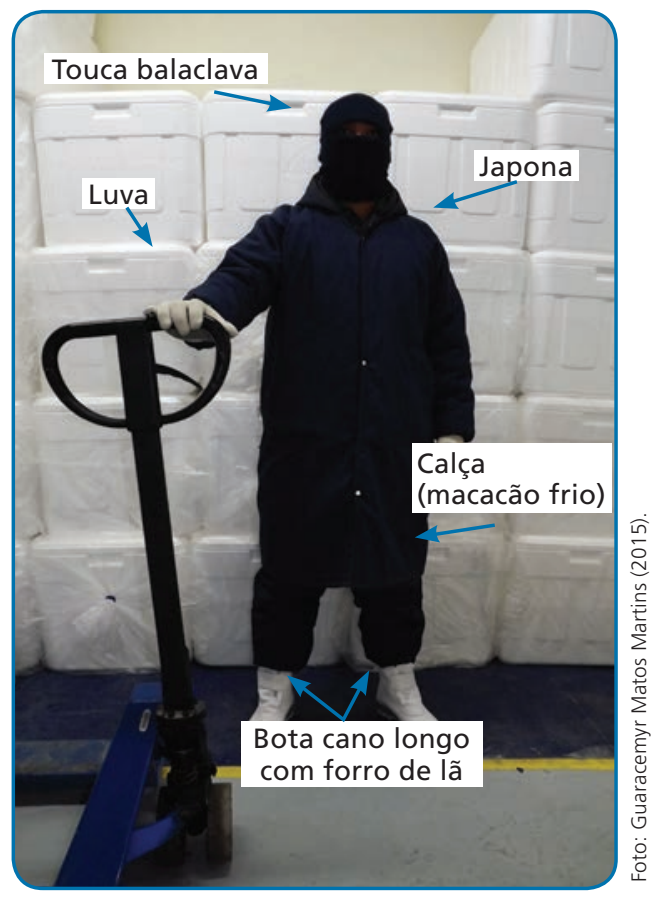

Chegamos aos anos 1960, época do "é proibido proibir", momento de caminhar e cantar Soyloco por ti, America (Gilberto Gil, Torquato Neto e José Carlos Capinan). O chamado "Maio francês" ocorreu em 1968, e a juventude da época, em todo o mundo, passou a questionar o sentido da vida, o uso do corpo, os padrões comportamentais e os valores religiosos e tradicionalistas. O trabalho também sofreu questionamentos, no que diz respeito ao seu lado sagrado e místico, cultivado no pensamento cristão e capitalista. E daí? Você perguntaria como um jovem da época.

Tentando responder, podemos afirmar que todo esse contexto histórico-político, esse momento de utopias, inclusive a socialista (uma sociedade sem propriedade privada, 
onde tudo é de todos), levou à seguinte consideração: quando será a vez de os trabalhadores participarem como protagonistas das questões de saúde e segurança do trabalho, e não mais apenas como "máquinas a serem consertadas"? Mais do que ninguém, são os trabalhadores que sabem efetivamente onde o "calo aperta".

Além das questões anteriormente citadas, havia um conjunto de fatores que possibilitou a constatação de que a saúde ocupacional, desenvolvida, também, para atender à necessidade da produção, não conseguiu atingir seus objetivos. Dentre esses fatores, destacam-se:

* manutenção da saúde ocupacional no âmbito do trabalho, em detrimento do setor de saúde, assim como do referencial mecanicista da medicina do trabalho;

* a não concretização do apelo à interdisciplinaridade, ou seja, as atividades apenas se justapuseram de modo desarticulado e foram dificultadas pelas lutas corporativas;

o ritmo da transformação dos processos de trabalho não ter acompanhado a capacitação de recursos humanos, a produção de conhecimento e de tecnologia de intervenção;

* continuação da abordagem dos trabalhadores como "objeto" das ações de saúde, apesar de enfocar a questão no coletivo dos trabalhadores.

Vale afirmar, então, que a saúde do trabalhador recebeu forte influência do pensamento que defende o conceito ampliado de saúde, superando a saúde ocupacional. E começou a ganhar força a partir dos anos de 1960-1970, com a "teoria da determinação social do processo saúde-doença", na qual as condições de trabalho têm papel importante.

A saúde do trabalhador surge, portanto, por volta dos anos 1970, caracterizada pela expressão das necessidades dos trabalhadores e dos empregadores. Como campo da saúde pública, deve ter o trabalhador como sujeito ativo nas transformações, nos processos de trabalho e na sociedade. Considerando as experiências singulares da saúde do trabalhador, podemos afirmar que é de caráter conflitante e de embates.

\section{Saúde do trabalhador no Brasil}

No Brasil, a saúde do trabalhador tem como aliados os preceitos da Reforma Sanitária, ao propor uma nova visão na saúde, na segurança e no trabalho. Ganha força especialmente em 1986, com a realização da $8^{a}$ Conferência Nacional de Saúde e da $1^{\text {a }}$ Conferência Nacional de Saúde dos Trabalhadores, provocando mudanças na Constituição Federal de 1988. 


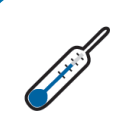

A Lei n. 8.213, de 24/7/1991, está disponível em:

http://www.planalto.gov.br/ ccivil_03/leis//8213cons.htm
Legalmente, a CAT está embasada no artigo 169 da Consolidação das Leis do Trabalho (CLT).
Com a regulamentação da chamada Lei Orgânica da Saúde (LOS) - Leis Federais n. 8.080 e n. 8.142, de 1990 -, a saúde do trabalhador conquistou definitivamente expressão legal nas áreas da saúde, da previdência social e do trabalho. Vale citar o entendimento de saúde do trabalhador presente na Lei Orgânica n. 8.080, artigo $6^{\circ}, \S 3^{\circ}$, no que se refere ao campo de atuação do SUS:

[...] um conjunto de atividades que se destina, através das ações de vigilância epidemiológica e vigilância sanitária, à promoção e proteção da saúde dos trabalhadores, assim como visa à recuperação e reabilitação da saúde dos trabalhadores submetidos aos riscos e agravos advindos das condições de trabalho (BRASIL, 1990, p. 3).

Para compreender a saúde do trabalhador, temos que conhecer os aspectos legais relacionados ao SUS, assim como as vigilâncias sanitárias e epidemiológica, assuntos discutidos em capítulos anteriores. A Constituição Federal Brasileira, no artigo 200, inciso II, estabelece a competência do SUS para "executar as ações de vigilância sanitária e epidemiológica, bem como as de saúde do trabalhador" (BRASIL, 1988).

A Lei n. 8.213, de 24/7/1991, Lei de Planos de Benefícios da Previdência Social, sinaliza para uma relação entre a saúde do trabalhador e a previdência social ao demonstrar o acidente de trabalho como aspecto determinante para a saúde do trabalhador. Define o acidente do trabalho em seu artigo 19:

Acidente do trabalho é o que ocorre pelo exercício do trabalho a serviço da empresa ou pelo exercício do trabalho dos segurados referidos no inciso VII do art. 11 desta lei, provocando lesão corporal ou perturbação funcional que cause a morte ou a perda ou redução, permanente ou temporária, da capacidade para o trabalho (BRASIL, 1991).

Além da definição de acidente de trabalho, a Lei Federal n. 8.213/91 determina que, sempre que houver esse tipo de ocorrência, com afastamento ou não do trabalhador, as empresas serão obrigadas a emitir a Comunicação de Acidente de Trabalho (CAT), idealmente até o primeiro dia útil após o acidente.

Emitir uma CAT nos remete à necessidade de promover a prevenção de acidentes de trabalho por meio de: ações de capacitação e de informações aos trabalhadores, identificação dos locais de riscos aos trabalhadores e indicação da necessidade de medidas de correção, colaborando, desse modo, para a elaboração do Mapa ou Mapeamento de Riscos, abordado mais adiante. 
Vale lembrar que é considerado acidente de trabalho ou de trajeto também aquele que ocorre no deslocamento residência-local de trabalhoresidência. No caso da rede de frio, os acidentes mais comuns estão relacionados aos movimentos repetitivos na lida com computador, empilhamento, câmaras frias e sala de vacinação.

Figura 1 - Formulário para comunicação de acidente de trabalho (CAT)

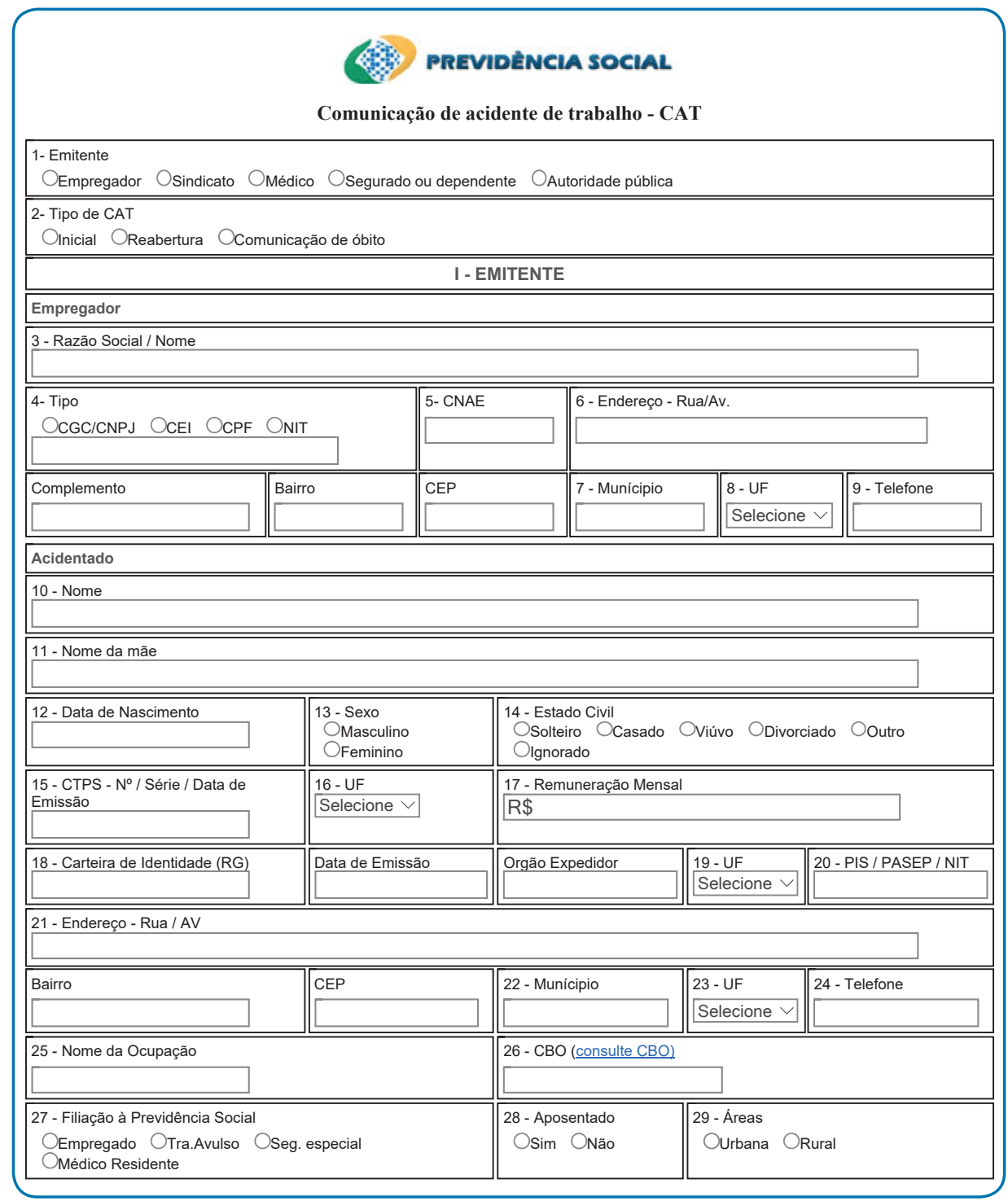

Fonte: Ministério do Trabalho e Previdência Social (BRASIL, 2016). 
Figura 1 - Formulário para comunicação de acidente de trabalho (CAT) (cont.)

\begin{tabular}{|c|c|c|c|c|}
\hline \multicolumn{5}{|c|}{ Acidente ou Doença } \\
\hline \multirow[t]{2}{*}{$\begin{array}{l}30 \text { - Data de } \\
\text { Acidente }\end{array}$} & 31 - Hora do Acidente & $\begin{array}{l}\text { 32- Após quantas horas de } \\
\text { trabalho? }\end{array}$ & \multirow{2}{*}{\begin{tabular}{|c|}
33 - Tipo \\
OTipico \\
ODoença \\
OTrajeto \\
\end{tabular}} & \multirow{2}{*}{$\begin{array}{l}34 \text { - Houve } \\
\text { afastamento? } \\
\text { Osim } \\
\text { ONão }\end{array}$} \\
\hline & & & & \\
\hline \multirow{2}{*}{$\begin{array}{l}35 \text { - Último dia } \\
\text { trabalhado }\end{array}$} & \multirow{2}{*}{$\begin{array}{l}36 \text { - Local do } \\
\text { acidente }\end{array}$} & \multirow{2}{*}{$\begin{array}{l}37 \text { - Especificação do local do } \\
\text { acidente }\end{array}$} & \multirow[t]{2}{*}{38 - CGC / CNPJ } & $39-$ UF \\
\hline & & & & Selecione $v$ \\
\hline \multicolumn{2}{|c|}{40 - Munícipio do local do acidente } & 41 - Parte do corpo & \multicolumn{2}{|l|}{42 - Agente causador } \\
\hline \multicolumn{2}{|c|}{$\begin{array}{l}43 \text { - Descrição da situação geradora do acidente ou } \\
\text { doença }\end{array}$} & \multicolumn{2}{|l|}{$\begin{array}{l}44 \text { - Houve registro policial? } \\
\text { OSim } \\
\text { ONão }\end{array}$} & \\
\hline & & \multicolumn{2}{|l|}{$\begin{array}{l}45 \text { - Houve morte? } \\
\text { Osim } \\
\text { ONão }\end{array}$} & \\
\hline
\end{tabular}

Para saber mais sobre a CAT, acesse: http://goo.gl/yF4uJT.
É essencial frisar que a CAT também tem caráter legal, pois gera informações para o controle estatístico e epidemiológico junto aos órgãos federais, com garantia de assistência acidentária ao empregado junto ao Instituto Nacional de Seguridade Social (INSS) ou, se necessário, uma aposentadoria por invalidez.

Segundo o Anuário Estatístico da Previdência Social (AEPS) de 2014, elaborado pelo Ministério da Previdência Social (BRASIL, 2015a):

* 2009 a 2014, houve um crescimento de 15,6 milhões de contribuintes ao RGPS (Regime Geral de Previdência Social).

704,1 mil acidentes do trabalho foram registrados no INSS em 2014. Em relação a 2013, houve um decréscimo de 2,9\%.

o número de acidentes registrados com CAT diminuiu em 0,82\% de 2013 para 2014. Desse total, os acidentes típicos representaram $76,55 \%$; os de trajeto, 20,67\%; e as doenças do trabalho, $2,79 \%$. As pessoas do sexo masculino representam $71,85 \%$ e, as do sexo feminino, 28,14\% nos acidentes típicos; $61,48 \%$ e 38,52\%, nos de trajeto; e $57,01 \%$ e $42,99 \%$, nas doenças do trabalho.

O maior setor em número de acidentes de trabalho foi o de comércio e reparação de veículos automotores (95.659 registros), seguidos pelo setor de saúde e serviços sociais, com 66.302 acidentes. Na saúde, o mais preocupante é que as atividades de atendimento hospitalar (exceto pronto-socorro e unidades para atendimento a urgências) e as de atenção ambulatorial, executadas por médicos e odontólogos, assim como os serviços de administração de hospitais vêm apresentando, desde 2009, um aumento de acidentes. 


\section{Saúde do trabalhador e vigilância}

Neste momento de nossa análise, é oportuno relembrar que saúde do trabalhador é, também, um campo da vigilância em saúde. Para muitos autores, como Lacaz (2007), a saúde do trabalhador nasceu, academicamente, da saúde coletiva com o objetivo central de conhecer e intervir nas relações entre trabalho e saúde-doença, tendo como referência principal o surgimento de um novo ator social: a classe operária.

A perspectiva adotada foi aquela que considera o trabalho como organizador da vida social, como espaço de dominação e submissão do trabalhador pelo capital, mas igualmente de resistência, de constituição e do fazer histórico-político. Podemos afirmar que, nesse contexto, surge uma postura proativa do trabalhador, de não tutela, frente às relações sociais de produção. No caso da rede de frio de imunobiológicos, isso ocorre quando, por exemplo, os trabalhadores assumem protagonismo no planejamento, na gestão e transformação dos processos de trabalho em que estão inseridos.

A postura proativa, de protagonismo no planejamento, na gestão e transformação dos processos de trabalho, é confirmada pela primeira experiência bem-sucedida de que se tem notícia a respeito. Trata-se dos denominados "Modelo Operário Italiano" ou "Mapa de Risco ou Mapeamento de Riscos", abordados mais adiante. Por enquanto, cabe informar que sua origem é o Movimento Operário Italiano (MOI), objetivando tornar possível, por parte dos trabalhadores, a identificação dos fatores de risco (ocupacionais/ambientais) e as condições de trabalho. Isso ocorreu, inicialmente, nas fábricas italianas, posteriormente estendeu-se ao redor do mundo e a quaisquer ambientes de trabalho, inclusive aos da rede de frio de imunobiológicos. Atualmente, de forma didática, os riscos podem ser classificados de acordo com a NR 5 - Cipa (Quadro 1).

Quadro 1 - Classificação dos principais riscos ocupacionais em grupos, de acordo com sua natureza e padronização das cores

\begin{tabular}{|l|l|l|l|l|}
\hline $\begin{array}{l}\text { Grupo 1 } \\
\text { Riscos Físicos }\end{array}$ & $\begin{array}{l}\text { Grupo 2 } \\
\text { Riscos Químicos }\end{array}$ & $\begin{array}{l}\text { Grupo 3 } \\
\text { Riscos Biológicos }\end{array}$ & $\begin{array}{l}\text { Grupo 4 } \\
\text { Riscos Ergonômicos }\end{array}$ & $\begin{array}{l}\text { Grupo 5iscos de Acidentes ou } \\
\text { Mecânicos }\end{array}$ \\
\hline Ruídos & Poeiras & Vírus & Esforço físico intenso & $\begin{array}{l}\text { Arranjo físico } \\
\text { inadequado }\end{array}$ \\
\hline Vibrações & Fumos & Bactérias & $\begin{array}{l}\text { Levantamento e } \\
\text { transporte manual de } \\
\text { cargas }\end{array}$ & $\begin{array}{l}\text { Máquinas e } \\
\text { equipamentos sem } \\
\text { proteção }\end{array}$ \\
\hline Radiações ionizantes & Névoas & Protozoários & $\begin{array}{l}\text { Exigência de postura } \\
\text { inadequada }\end{array}$ & $\begin{array}{l}\text { Ferramentas inadequadas } \\
\text { ou defeituosas }\end{array}$ \\
\hline
\end{tabular}


Quadro 1 - Classificação dos principais riscos ocupacionais em grupos, de acordo com sua natureza e padronização das cores (cont.)

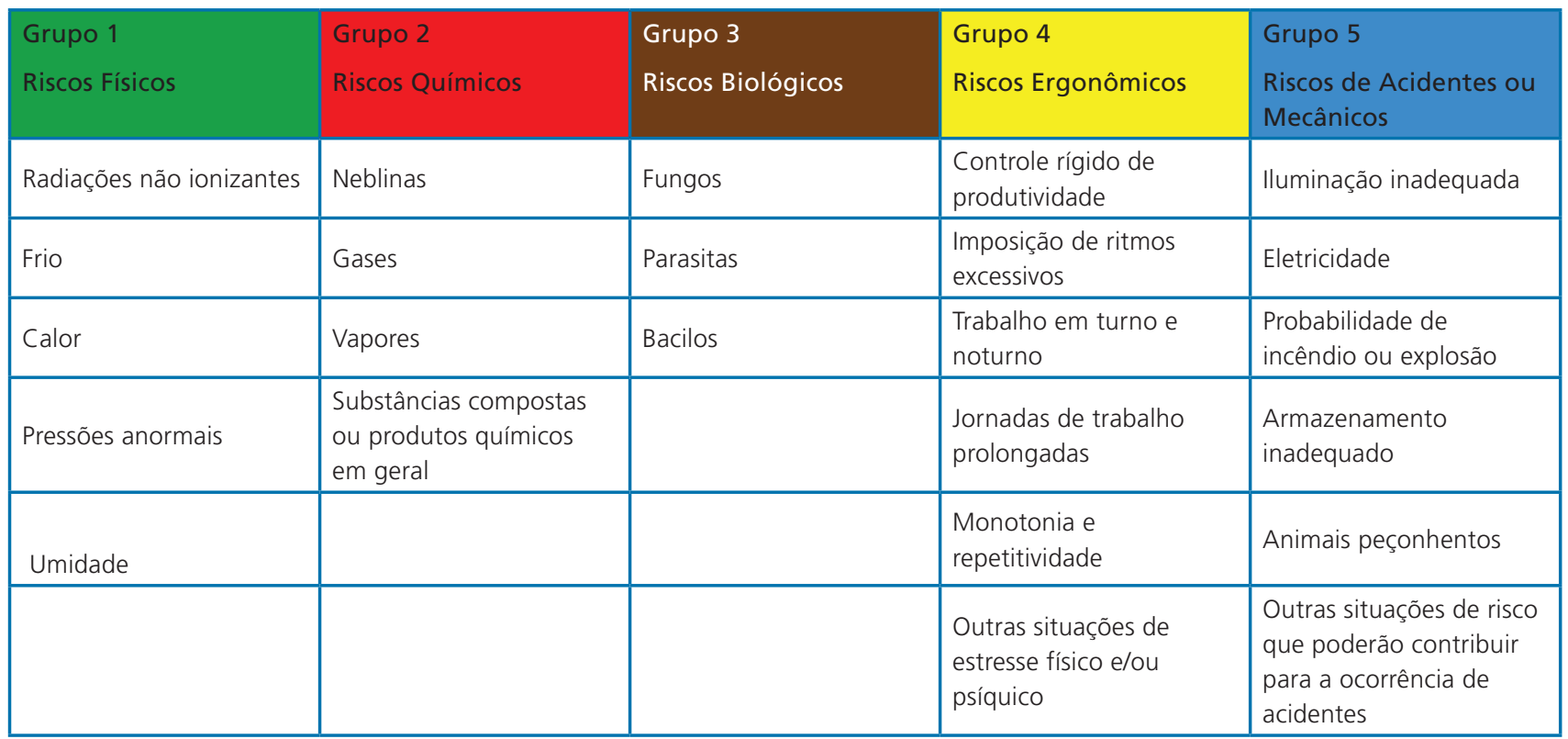

Fonte: Adaptado de Araújo (2002, p. 150).

Aspectos relativos a ergonomia e ambiência são tratados no próximo capítulo, trazendo exemplos relacionados ao trabalho na rede de frio de imunobiológicos.
Ao pensar nos riscos existentes relacionados às atividades de trabalho realizadas na rede de frio de imunobiológicos, podemos citar alguns exemplos: riscos físicos - as câmaras frias; riscos químicos - as vacinas; riscos biológicos - sangue; riscos ergonô- micos - estresses na relação com a chefia e demais trabalhadores; utilização de empilhadeiras, paletes e mobiliários inadequados (que propiciam posturas e posições incorretas); locais adaptados com más condições de iluminação, ventilaFoto 3 - Trabalhador em laboratório

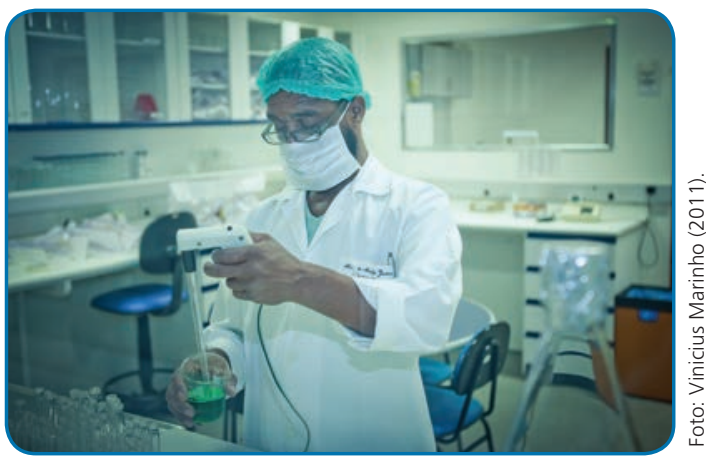

O trabalho pode expor o trabalhador a riscos químicos, físicos, biológicos, ergonômicos e mecânicos. Nesta foto, que mostra um trabalhador dentro de um laboratório, há possibilidade de risco físico de exposição à radiação, risco químico pela manipulação de reagentes, ergonômico pelo esforço repetitivo, de pipetagem, dentre outros.

Fonte: Fiocruz Imagens. ção e de conforto para os trabalhadores; riscos de acidentes ou mecânicos - equipamentos e mobiliários defeituosos das unidades de saúde.

Esses fatores de risco devem ser identificados, analisados e compreendidos sempre no contexto específico de cada processo de trabalho; não devem ser assimilados de modo estanque e fragmentado! 
Feita a observação sobre os fatores de risco, cabe destacar que a saúde do trabalhador está devidamente regulamentada, sendo atualmente uma realidade, uma política nacional, por meio da Portaria n. 1.823, de 23 de agosto de 2012 (BRASIL, 2012).

\section{Norma Regulamentadora 32 - NR 32}

A partir do entendimento de que todo trabalhador da rede de frio de imunobiológicos faz parte do setor de saúde, torna-se importante conhecer a NR 32, que trata da segurança e saúde no trabalho em estabelecimentos de saúde. A NR 32 faz parte de um conjunto de normas brasileiras, do Ministério do Trabalho e Emprego (MTE), Portaria n. 485, de 2005, publicada no Diário Oficial da União em 16/1 1/2005. Foi elaborada por uma Comissão Tripartite Permanente Nacional (CTPN) e, sempre que houver necessidade, deverá ser atualizada e aperfeiçoada.

A NR 32 surgiu pela necessidade, detectada por entidades representantes dos trabalhadores, de serem normatizadas questões problemáticas que envolvam os serviços de saúde, de acordo com a atividade e os riscos ocupacionais, tais como: uso de calçados fechados, coleta de sangue, uso de adornos, dentre outros.

A NR 32 não é a única legislação para proteção do profissional de saúde, mas é a primeira norma regulamentadora federal no mundo específica para a área de saúde. Abarca uma complexidade de pontos como questões de segurança e saúde no trabalho, que se referem aos riscos biológicos, químicos, radiações ionizantes, manutenção de máquinas e equipamentos, resíduos, condições de conforto por ocasião das refeições, lavanderias e limpeza e conservação, dentre outros.

Ao ler a NR 32 (BRASIL, 2005), observam-se três eixos norteadores:

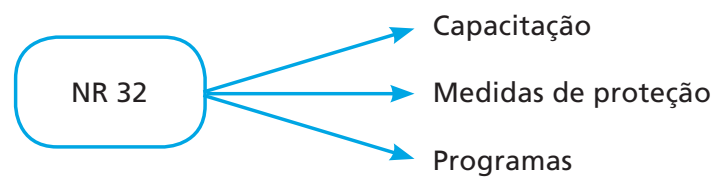

A NR 32 favorece a interação entre os trabalhadores, reconhecendo a necessidade de diálogo entre os profissionais e a segurança do trabalho. Também ressalta a necessidade do uso de equipamento de proteção individual, o chamado EPI, abordado no próximo capítulo, valoriza a educação permanente, assim como o registro dos riscos e avaliações, possibilitando a maior conscientização dos profissionais em relação aos riscos relacionados ao ambiente e à atividade de trabalho.

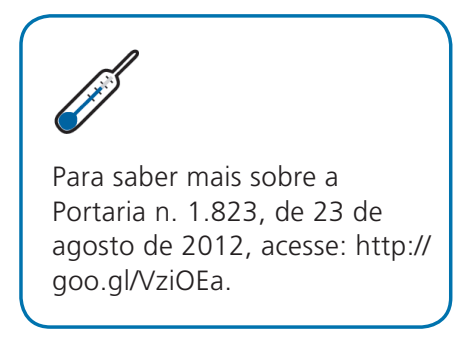

Comissão Tripartite Permanente Nacional é uma comissão composta por representantes das três partes envolvidas - trabalhadores, governo e empregadores. É paritária, porque tem número proporcional de representantes por segmento, e é permanente, porque não há prazo para a sua extinção. 
Biossegurança é o conjunto de ações voltadas para prevenção, proteção do trabalhador, minimização de perigos inerentes às atividades de pesquisa, produção, ensino, desenvolvimento tecnológico e prestação de serviços, visando à saúde do homem, dos animais, à preservação do meio ambiente e à qualidade dos resultados. Esse foco de atenção retorna ao ambiente ocupacional e amplia-se para a proteção ambiental e a qualidade.
Essa norma apresenta o conceito de serviços de saúde, no qual fica claro que a responsabilidade é solidária entre empregadores e trabalhadores. Trata, ainda, de temas relacionados à biossegurança, abordada no próximo capítulo, reafirmando a necessidade da abertura da CAT, mesmo não havendo afastamento do trabalhador, e aborda o trabalho com perfurocortantes (a agulha de vacinação, por exemplo).

É extremamente importante que o trabalhador não só conheça as normas, mas também esteja atento ao cumprimento destas em seu local de trabalho, sob pena de causar danos a sua saúde e a dos demais trabalhadores.

Entretanto, é sabido que a maioria dos trabalhadores ainda possui vínculo precário, não recebendo o EPI adequado às atividades que desenvolvem. Desse modo, acabam expostos a inúmeros fatores de risco, gerando insatisfações e conflitos no ambiente de trabalho. Infelizmente, essa situação também ocorre na rede de frio de imunobiológicos. São frequentes as reclamações quanto à baixa qualidade das luvas, às alergias respiratórias geradas pelo entra e sai nas câmaras frias e aos cortes provocados pelo manuseio dos imunobiológicos (frascos de vidro), entre outros.

Desse modo, percebemos que o campo da saúde do trabalhador possui vital importância para os trabalhadores da rede de frio de imunobiológicos, quando pensamos em suas condições de trabalho. O conhecimento de seu histórico, de seu marco legal e de suas ferramentas constitui uma forma de garantir melhores condições de trabalho. Defendemos que os trabalhadores devem tomar para si a responsabilidade não só de conhecer todas as questões que envolvem seu trabalho, mas também de, coletivamente, buscar intervir e transformar suas próprias condições laborais e da sociedade.

\section{Mapa ou mapeamento de riscos ocupacionais/ambientais}

Conforme mencionado anteriormente, o mapa ou o mapeamento de riscos surgiu no seio do MOI, no final da década de 1960 e início da década de 1970, mais precisamente na Federazione dei Lavoratori Metalmeccanici (FLM), que, na época, desenvolveu um modelo próprio de atuação na investigação, no planejamento e controle das condições de trabalho pelos próprios trabalhadores. Essa experiência foi retratada no livro clássico de Ivar Oddonne et al. (1986), Ambiente de trabalho: a luta dos trabalhadores pela saúde. 
O mais interessante é que o mapa de riscos (expressão que está mais disseminada) é uma produção intelectual e política, fruto do saber dos trabalhadores italianos organizados. Dessa forma, foram valorizados o conhecimento e a experiência de todos os trabalhadores, sem delegação aos "especialistas" (técnicos em segurança do trabalho, por exemplo).

O mapa de riscos se disseminou por todo o mundo, chegando ao Brasil no início da década de 1980. Autores como Mattos e Freitas (1994) apontam a existência de duas versões quanto à sua introdução no Brasil. A primeira atribui tal feito às áreas sindical e acadêmica, por meio de David Capistrano, Mário Gawryzewski, Hélio Baís Martins Filho e do Departamento Intersindical de Estudos em Saúde e Ambiente de Trabalho (Diesat). A outra versão atribui à Fundação Jorge Duprat Figueiredo de Segurança e Medicina do Trabalho (Fundacentro).

Mas, o que é, de fato, o mapa de riscos, como é feito? Serve para a rede de frio de imunobiológicos?

Podemos afirmar que é uma representação gráfica, feita a partir de um levantamento das condições de trabalho em determinado local ou setor de trabalho, na qual os fatores de riscos devem ser identificados pelos próprios trabalhadores.

Figura 2 - Mapa de riscos

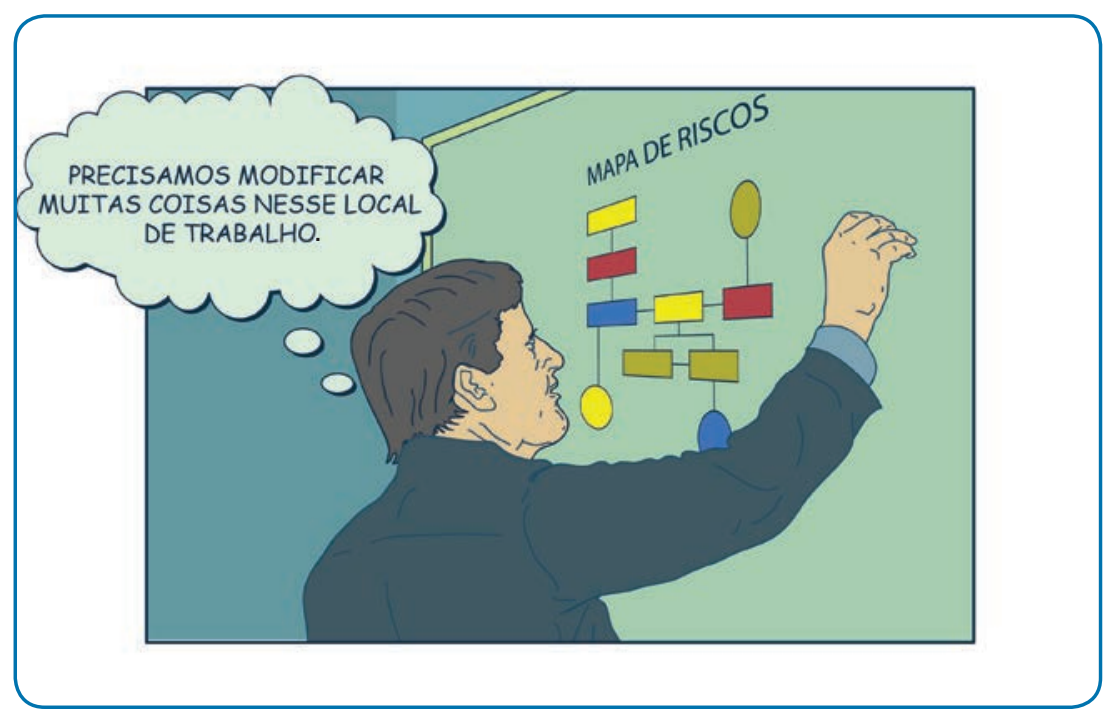

A elaboração dos mapas de riscos ocupacionais/ambientais é competência formal dos membros da Comissão Interna de Prevenção de Acidentes (Cipa), conforme orientações contidas no anexo IV da NR-5, Portaria n. 25, do Ministério do Trabalho e Emprego, de 29/12/1994, e tem como objetivos: 
a) reunir, no local de trabalho, as informações necessárias para estabelecer o diagnóstico da situação de segurança e saúde no trabalho;

b) possibilitar, durante sua elaboração, a troca e divulgação de informações entre os trabalhadores, bem como estimular sua participação nas atividades de prevenção.

De todo modo, cabe destacar que não são apenas os representantes da Cipa que têm responsabilidade sobre o mapa de riscos. Todos os trabalhadores devem atuar em sua elaboração e cobrar de sua empresa ou instituição de trabalho as soluções para os problemas identificados, pois está em jogo a melhoria das condições de trabalho e, em última instância, a sua própria vida!

Como se constrói um mapa de riscos?

$1^{\circ}$ Passo: Agendar a visita com o responsável do setor, explicando o que será feito, os objetivos, a metodologia, os trabalhadores participantes, e marcar dia e horário para o início da elaboração do mapa de riscos.

$2^{\circ}$ Passo: Compreender o processo de trabalho do local a ser analisado: ou seja, os setores/seções, o que são e como produzem; para quem e quanto produzem; conhecer o quantitativo de trabalhadores, o sexo, a idade, os treinamentos existentes relacionados a segurança e saúde, as jornadas de trabalho desses trabalhadores; as atividades executadas; o ambiente; e listar todas as matérias-primas e os demais insumos (equipamentos, tipo de alimentação das máquinas etc.) envolvidos no processo produtivo.

$3^{\circ}$ Passo: Identificar todos os riscos existentes no local analisado com base na tabela de classificação de riscos elaborada pela NR 5 - Comissão Interna de Prevenção de Acidentes (Cipa).

$4^{\circ}$ Passo: Identificar as medidas preventivas realizadas e sua eficácia considerando: as medidas de proteção coletiva e individual; a organização do trabalho; higiene e conforto.

$5^{\circ}$ Passo: Identificar os indicadores de saúde, ou seja, as queixas de maior incidência entre os trabalhadores expostos aos mesmos riscos; a ocorrência dos acidentes de trabalho; as doenças dos trabalhadores diagnosticadas e as causas mais comuns do absenteísmo.

$6^{\circ}$ Passo: Conhecer os levantamentos ambientais já realizados no local.

$7^{\circ}$ Passo: Elaborar o mapa de riscos, com base no leiaute da empresa, utilizando círculos para indicar os seguintes dados: 
* O grupo a que pertence o risco, de acordo com a cor padronizada da tabela de classificação de riscos da NR 5: Grupo 1 - Verde; Grupo 2 Vermelha; Grupo 3 - Marrom; Grupo 4 - Amarela e Grupo 5 - Azul.

O número de trabalhadores que estão expostos ao risco deve ser indicado no centro do círculo.

* especificação do agente pode ser escrita dentro do círculo ou descrita em legenda (por exemplo, risco químico - vacinas; risco ergonômico - transporte de caixas).

* A intensidade do risco, ou seja, se é pequeno, médio ou grande, representada por círculos, de acordo com a percepção dos trabalhadores, conforme a Figura 3:

Figura 3 - Representação gráfica da intensidade dos riscos

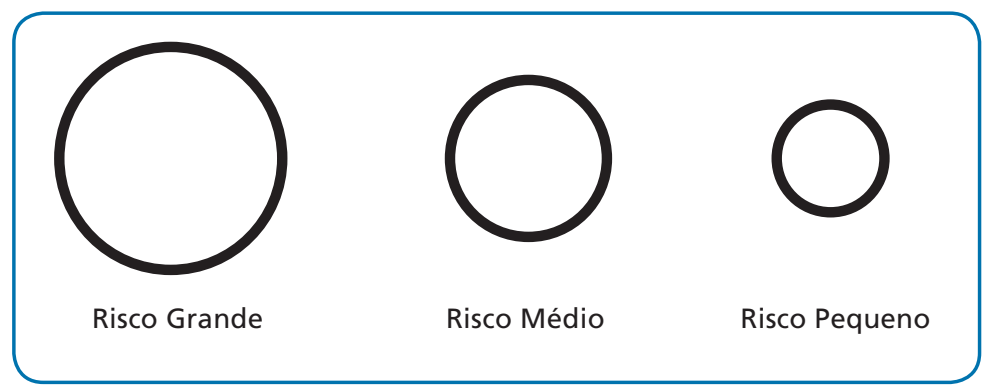

Após ser aprovado pela Cipa, o mapa de riscos de toda a empresa ou setorial deverá ser fixado em local visível e de fácil acesso aos trabalhadores.

Concluindo, a elaboração do mapa de riscos é um trabalho de equipe, exige diálogo entre os participantes e observação apurada para se perceber, com exatidão, os riscos presentes no ambiente. 
Figura 4 - Mapa de riscos do térreo de um posto de saúde

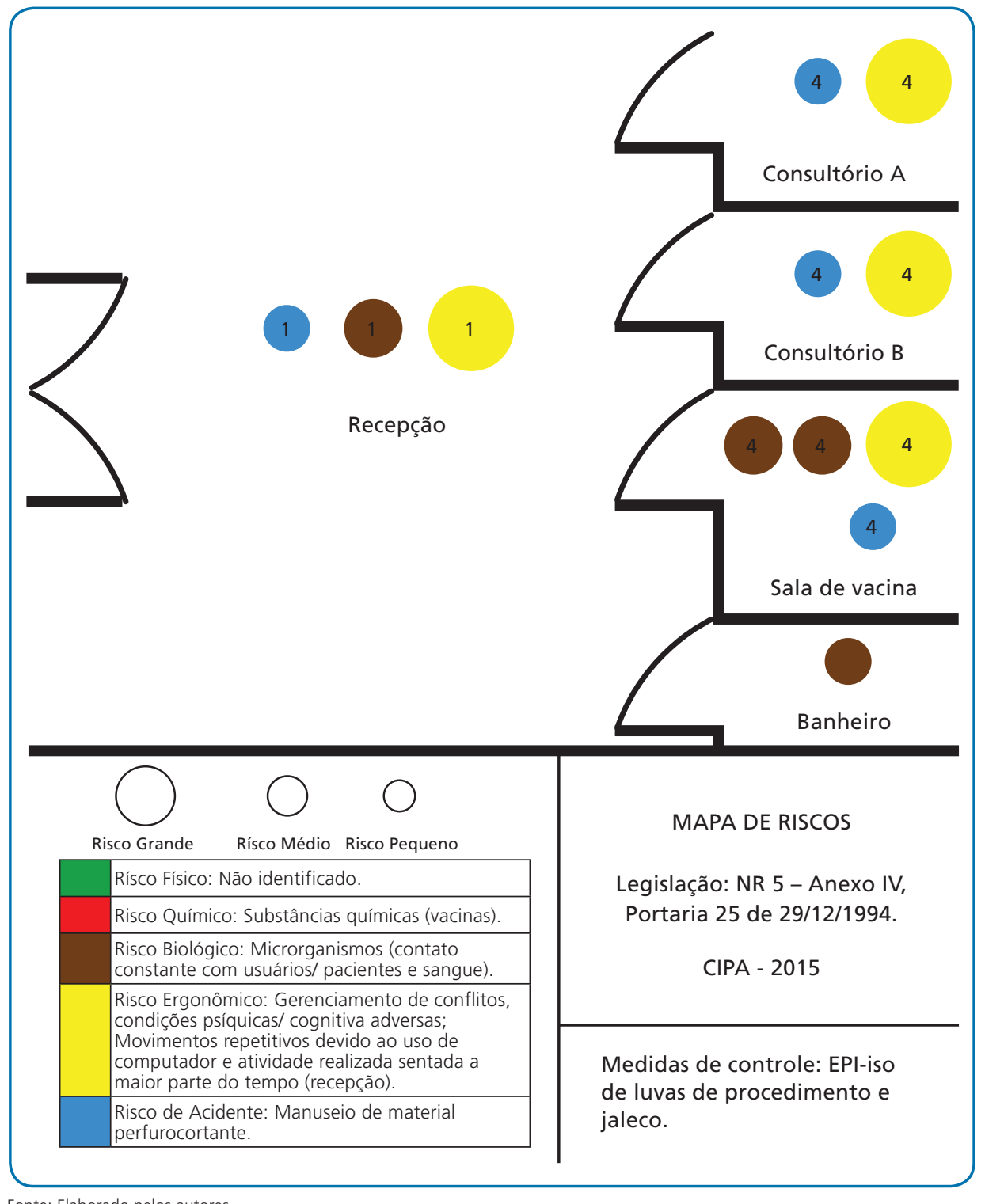

Fonte: Elaborado pelos autores.

Agora que você já viu o que é e como se faz, de forma geral, um mapa ou mapeamento de riscos, que tal tentar fazê-lo em seu ambiente de trabalho? Dissemine a ideia! Ajude a mobilizar os seus companheiros de trabalho e mãos à obra. E não se esqueça de registrar como foi a experiência! O registro pode ser útil para outros trabalhadores. 


\section{Para refletir}

Com base nas explanações apresentadas neste capítulo e nos demais sobre o campo da saúde do trabalhador, reflita sobre os fatores de risco existentes nas imagens a seguir, relativas a processos de trabalho da rede de frio de imunobiológicos, comparando-os com os do seu ambiente de trabalho.

Foto 4 - Atividade da rede de frio de imunobiológicos

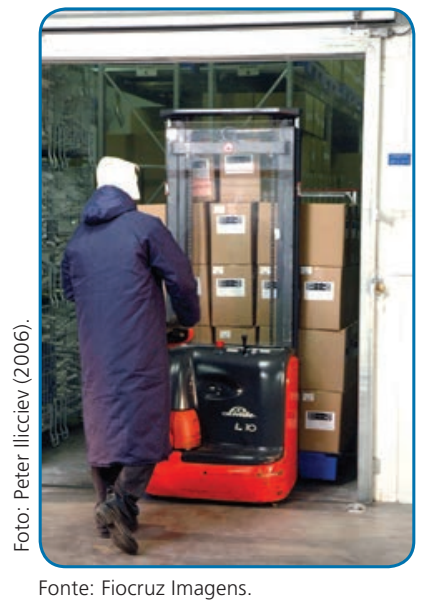

Figura 5 - Atividade da rede de frio de imunobiológicos

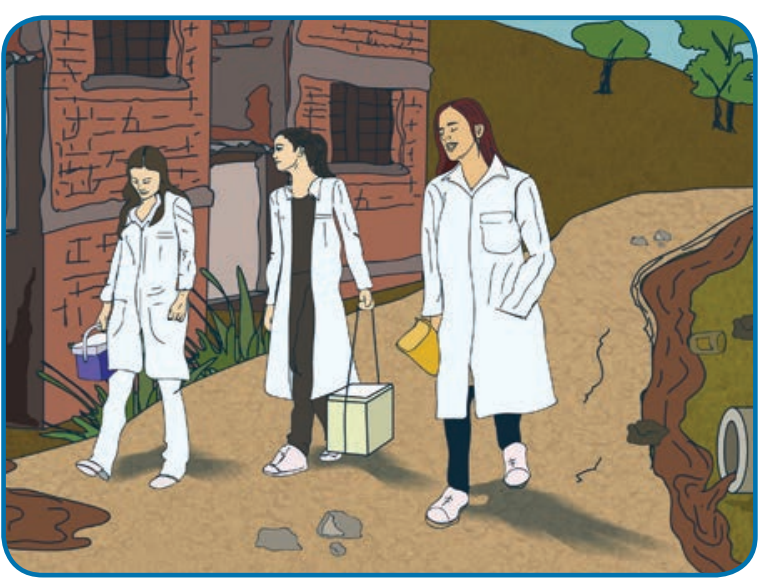

\section{Considerações finais}

O objetivo deste capítulo foi introduzir reflexões relacionadas à saúde do trabalhador, trazendo um pouco do seu contexto histórico-conceitual, partindo da medicina do trabalho, passando pela saúde ocupacional até chegar à saúde do trabalhador propriamente dita.

Retomamos o conceito ampliado de saúde e a questão dos determinantes sociais da saúde, de forma a fundamentar o argumento de que a saúde do trabalhador é algo muito mais amplo do que somente o fato de ele estar atuando adequadamente e garantindo a produção esperada. Há questões de saúde física e saúde mental envolvidas que implicam um olhar mais abrangente e atento para esse trabalhador, e elas são registradas em instrumentos legais como aqueles que apresentamos.

Conhecer esses instrumentos e desenvolver estratégias para promover a saúde do trabalhador são ações fundamentais devidas não apenas ao empregador, por ser seu dever legal, mas, também, ao trabalhador, que, empoderado por esses conhecimentos, deve exigir adequação das suas condições de trabalho aos parâmetros necessários para garantir sua saúde. 
Para empregadores e trabalhadores, o mapa de riscos traz uma grande contribuição, pois proporciona um espaço de diálogo e troca de diferentes visões para construção de um pacto comum de atenção às questões de saúde e segurança de um local de trabalho.

\section{Referências}

ARAÚJO, Giovanni Moraes de. Normas regulamentadoras comentadas. 3. ed. rev. ampl. e atual. Rio de Janeiro: [s.n.], 2002.

BRASIL (Constituição, 1988). Constituição da República Federativa do Brasil. Brasília, DF: Senado Federal, 1988.

BRASIL. Lei n. 8.042, de 28 de dezembro de 1990. Dispõe sobre a participação da comunidade na gestão do Sistema Único de Saúde (SUS) e sobre as transferências intergovernamentais de recursos financeiros na área da saúde e dá outras providências. Diário Oficial da União, Brasília, DF, 31 dez. 1990a.

BRASIL. Lei n. 8.080, de 19 de setembro de 1990. Dispõe sobre as condições para a promoção, proteção e recuperação da saúde, a organização e o funcionamento dos serviços correspondentes e dá outras providências. Diário Oficial da União, Brasília, DF, 20 set. 1990b.

BRASIL. Lei n. 8.213, de 24 de julho de 1991. Dispõe sobre os Planos de Benefícios da Previdência Social e dá outras providências. Diário Oficial da União, Brasília, DF, 25 jul. 1991. Disponível em: <http://www.planalto.gov.br/ccivil_03/leis//8213cons.htm>. Acesso em: 4 ago. 2016.

BRASIL. Ministério da Saúde. Portaria n. 1.823, de 23 de agosto de 2012. Institui a Política Nacional de Saúde do Trabalhador e da Trabalhadora. Diário Oficial da União, Brasília, DF, 24 ago. 2012. Seção 1, p. 46.

BRASIL. Ministério da Saúde. Secretaria de Vigilância em Saúde. Departamento de Vigilância das Doenças Transmissíveis. Manual de rede de frio do Programa Nacional de Imunizações. 4. ed. Brasília, DF, 2013.

BRASIL. Ministério da Previdência Social. Anuário estatístico da Previdência Social. Brasília, DF, jul. 2015a. Disponível em: <http://www.previdencia.gov.br/dados-abertos/aeat-2013/estatisticas-deacidentes-do-trabalho-2013/>. Acesso em: 24 nov. 2015.

BRASIL. Ministério do Trabalho. Normas regulamentadoras. Brasília, DF, 2015b. Disponível em: <http://trabalho.gov.br/index.php/seguranca-e-saude-no-trabalho/normatizacao/normasregulamentadoras>. Acesso em: 20 set. 2016.

BRASIL. Ministério do Trabalho e Previdência Social. Comunicação de acidente de trabalho, CAT. Brasília, DF, [2016]. Disponível em: <http://www.previdencia.gov.br/servicos-ao-cidadao/todos-osservicos/comunicacao-de-acidente-de-trabalho/>. Acesso em: 22 jun. 2017.

BRASIL. Ministério do Trabalho e Emprego. Portaria n. 485, de 11 de novembro de 2005. Aprova a Norma Regulamentadora n. 32 (Segurança e Saúde no Trabalho em Estabelecimentos de Saúde). Diário Oficial da União, Brasília, DF, 16 nov. 2005. 
BRASIL. Ministério do Trabalho e Emprego. Portaria n. 25, de 29 de dezembro de 1994. Diário Oficial da União, Brasília, DF, 30 de dezembro de 1994.

LACAZ, F. A. C. The workers' health field: reclaiming knowledge and practices in the interface between work and health. Cadernos de Saúde Pública, Rio de Janeiro, v. 23, n. 4, p. 757-766, 2007. Disponível em: <http://www.scielo.br/pdf/csp/v23n4/02.pdf>. Acesso em: 20 set. 2016.

MATTOS, U. A. O.; FREITAS, N. B. B. Mapa de risco no Brasil: as limitações da aplicabilidade de um modelo operário. Cadernos de Saúde Pública, Rio de Janeiro, v. 10, n. 2, p. 251- 258, abr./jun., 1994.

MENDES, R.; DIAS, E. C. Da medicina do trabalho à saúde do trabalhador. Revista de Saúde Pública, São Paulo, v. 25, n. 5, p. 341-349, 1991.

ODDONNE, Ivar et al. Ambiente de trabalho: a luta dos trabalhadores pela saúde. São Paulo: Hucitec, 1986.

SILVA, M. N.; FLAUZINO, R. F.; GONDIM, G. M. M. (Org.). Rede de frio: fundamentos para a compreensão do trabalho. Rio de Janeiro: Ed. Fiocruz, 2016.

TEIXEIRA, S. M.; OLIVEIRA, J. A. Medicina de grupo: a medicina e a fábrica. In: GUIMARÃES, R. F. N. (Org.). Saúde e medicina no Brasil: contribuição para um debate. 5. ed. Rio de Janeiro: Graal, 1984. 



\section{Arquitetura, ambiência, ergonomia e saúde nos locais de trabalho}

Irai Borges de Freitas, Katia Butter Leão de Freitas

e Sarita de Oliveira Ferreira Lopes

O conceito ampliado de saúde e as reflexões sobre saúde do trabalhador reforçam nosso entendimento de que são necessárias contribuições de diversas áreas para se promover a saúde no trabalho.

Mas quais são essas áreas? Qual a relação da arquitetura e da ambiência com a ergonomia para a saúde dos trabalhadores da rede de frio de imunobiológicos?

À luz de alguns conceitos utilizados pela arquitetura, como o de espaço construído, ambiência, e dos preceitos da ergonomia, ciência que se baseia em muitas disciplinas como a fisiologia, biomecânica, antropometria, psicologia, dentre outras, vamos, juntos, ao longo deste capítulo, buscar respostas para essas indagações.

\section{Arquitetura e o desmembramento didático do espaço construído}

A arquitetura utiliza, com muita frequência, a expressão espaço construído, mas o que é isso? Para maior entendimento, apresentamos alguns conceitos fundamentais, tais como espaço, lugar e não lugar.

Quando as quatro fachadas de um edifício constituem uma caixa, denominamos de espaço (ZEVI, 1996 apud ALVES, 2007, p. 2). Esse conceito se complementa quando o espaço se concentra na "distância entre dois pontos, ou a área ou volume entre limites determinados" (FERREIRA, 1975, p. 562). O espaço só se torna lugar com a presença do ser humano, e o tempo é um elemento que diferencia o espaço de lugar (ZEVI, 1996 apud ALVES, 2007). 
Como poderíamos exemplificar o não lugar? São rodoviárias, aeroportos, supermercados, locais onde apenas estamos de passagem.
Para saber mais sobre desmembramento do espaço construído, leia "Constituição da ambiência hospitalar a partir da gestão de coletivos", de Silva, Freitas e Freitas (2009), no livro Iniciação científica na educação profissional em saúde: articulando trabalho, ciência e cultura.
Então, todo espaço pode se tornar um lugar? Sim, e quanto mais tempo se habita um lugar, mais nos identificamos com ele (TUAN, 1983 apud ALVES, 2007). Já, o "não lugar" apresenta uma ideia contrária à do lugar, ou seja, é quando não existe uma identidade, um relacionamento ou uma história em um dado espaço (AUGÉ, 1994 apud ALVES, 2007).

Partindo do pressuposto de que os espaços devem ser organizados para contemplar as necessidades daqueles que os utilizam, e de acordo com as atividades que serão ali realizadas, entende-se que sua organização é passível de projeção, construção e habitação para, assim, se tornar um espaço construído.

E qual a finalidade do espaço construído? É proteger o ser humano contra elementos naturais, como a chuva, o vento, o calor, o frio e também de outros animais (AMOS RAPPORT apud CHING, 2006).

Diante dos conceitos apresentados, como você percebe a sua relação com seu espaço de trabalho? Seria um espaço, lugar ou não lugar? Nosso espaço de trabalho é, sem dúvida, um lugar, que pode ter nosso porta-retratos sobre a mesa, um armário para guardar nossos pertences, onde compartilhamos horas trabalhando em equipe. Portanto, há uma identificação de mão dupla com o ambiente onde você trabalha, pois, ao mesmo tempo em que você o identifica com seus pertences, o mesmo ocorre em relação à sua equipe de trabalho, às cores etc.

Ao realizar o desmembramento do espaço construído, Freitas e Lopes (2008) apresentam o seguinte ensaio: espaço edificado, espaço instalado e espaço ocupado. Vale ressaltar que a presente abordagem não tem a pretensão de limitar o desmembramento do espaço construído aos três momentos apresentados pelos referidos autores.

\section{Espaço edificado}

O espaço edificado se caracteriza pela atividade criadora, expressa pelo processo de se projetar, considerando as etapas de trabalho que compreendem o programa, os estudos preliminares, o anteprojeto e o projeto executivo (SILVA, 1983 apud CUNHA, 2006).

Atividade criadora é o momento em que a equipe multidisciplinar se reúne para definir as tipologias, a setorização e a organização dos espaços (leiaute), dentre outros, mediante as demandas previamente indicadas. 
Ao se pensar em criar um novo ambiente para atender às necessidades de trabalho na rede de frio de imunobiológicos, os especialistas (arquitetos, engenheiros, ergonomistas, enfermeiros, gestores, auxiliares em geral, economistas e quantos mais estiverem disponíveis para compor uma equipe multidisciplinar) devem se reunir e dialogar sobre as características desse novo ambiente, tais como: fluxos de trabalho, mobiliário, equipamentos, acessibilidade, local para armazenamento, recebimento e distribuição. Enfim, tudo que diz respeito à atividade a ser realizada naquele espaço edificado.

Portanto, é nesse momento que, de acordo com a demanda, escolhe-se a tipologia (vertical e/ou horizontal), com algumas diferentes formas arquitetônicas. Segundo o arquiteto Góes (2004), a tipologia vertical se apresenta como torre simples, torre dupla, torre radial e bloco, lâminas verticais e monólito vertical; e a tipologia horizontal apresenta pente e pavilhão, lâminas isoladas articuladas, pátio expandido, pátio compacto e monólito horizontal.

Figura 1 - Tipologias mais usadas no projeto do edifício hospitalar

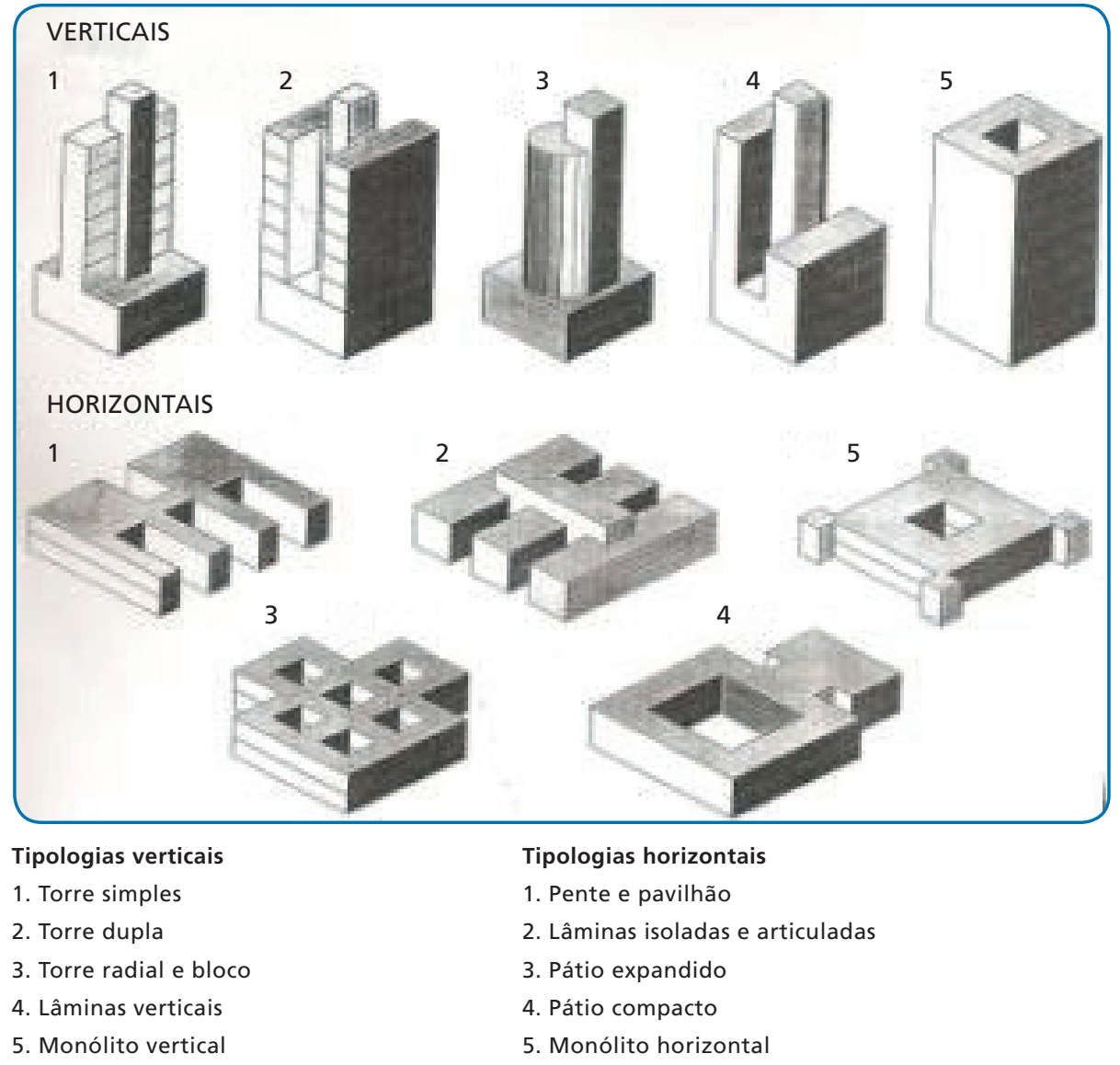


Existem alguns critérios recomendados para o projeto de construção das edificações. Podemos destacar alguns:

* custos: refere-se ao gasto econômico que representa a fabricação de um produto ou a prestação de um serviço;

* localização: se a edificação será localizada em área apropriada para o desenvolvimento do trabalho proposto;

* acessibilidade: se é de fácil acesso aos trabalhadores e usuários em geral;

* tamanho do terreno: se o terreno possui área suficiente para acomodar as instalações atuais e futuras;

sustentabilidade: o projeto deve minimizar os impactos ambientais e utilizar materiais ecologicamente corretos, com a finalidade de preservar a qualidade de vida dos usuários e não comprometer a das gerações futuras;

* conforto ambiental:

- lumínico - observar o curso aparente do Sol de forma a aproveitar ao máximo a iluminação natural,

- térmico - explorar a ventilação natural predominante usando a climatização artificial como complemento,

- acústico - não projetar as portas e janelas da edificação na direção das fontes externas de ruído. Na impossibilidade, atenuar com barreiras acústicas, que podem ser de madeira, vidro, concreto, entre outros materiais.

\section{Para refletir}

O seu local de trabalho está em conformidade com os critérios recomendados para espaços edificados? Se não, como amenizar os efeitos adversos ao bem-estar dos profissionais?

\section{Espaço instalado}

O espaço instalado se caracteriza pela atividade técnica. Mas o que compõe essa atividade?

A atividade técnica consiste em instalar fisicamente os sistemas elétrico, hidráulico e mecânico, considerando-os funcionais, de forma a se adequarem à atividade fim do espaço (AZEVEDO NETO, 2004). 
Foto 1 - Sala com alguns elementos humanizadores

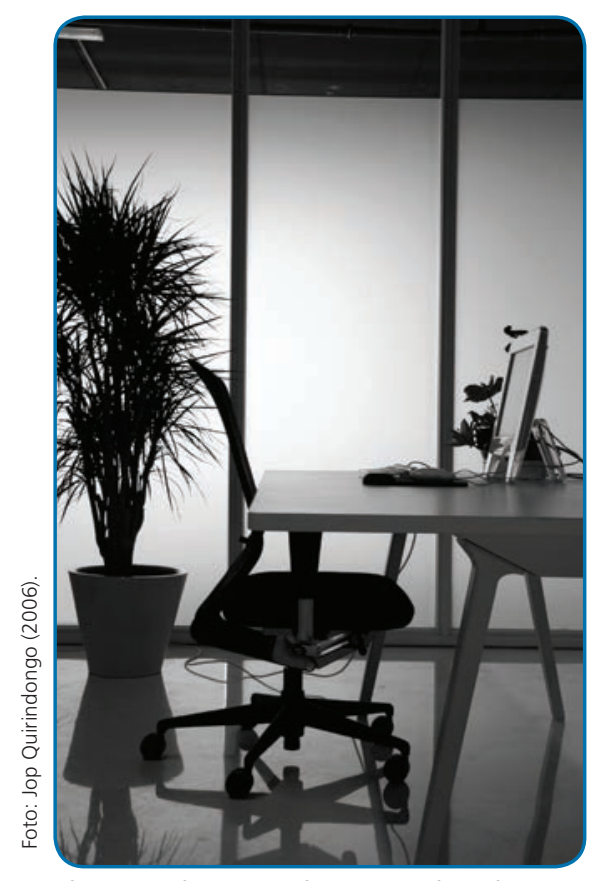

Elementos humanizadores como luz, cheiro, plantas, cores, entre outros, contribuem para criar um ambiente acolhedor e resolutivo.

Fonte: Freelmages.com.
A utilização dos componentes dos sistemas funcionais possibilita que o espaço físico seja favorecido pela ambiência por meio dos diversos elementos potencializadores da humanização espacial, tais como luz, cheiro, cor, paisagismo, arte, entre outros.

Tendo em vista a humanização dos espaços da rede de frio de imunobiológicos, onde não haja necessidade de temperatura específica (por exemplo, a câmara fria), devemos buscar o conforto térmico através de aparelhos infladores (pegando o ar externo e colocando no ambiente interno), climatizadores (condicionando a temperatura do ambiente interno) e exaustores (retirando o ar do ambiente interno e jogando-o para o ambiente externo). Esse processo favorece a minimização e/ou a eliminação de odores existentes nos ambientes e, também, uma temperatura confortável aos usuários do ambiente.

\section{Espaço ocupado}

O arquiteto Távora (2007) compreende que o espaço ocupado deverá ser o resultado da inteligência artística do ser humano, que contempla uma harmonia envolvida de sensibilidade, consciência e integração. Portanto, entende-se que espaço ocupado caracteriza-se pela atividade humana.

Aqui consideramos a atividade humana toda ação realizada pelo e para o ser humano, com o objetivo de capacitar, acolher e cuidar de quem cuida. Visa três aspectos: a promoção da saúde, o atendimento ao usuário do sistema de saúde e a saúde do trabalhador.

Quando falamos em promoção da saúde, não podemos esquecer dois documentos importantes: a Carta de Ottawa (1986) e a Carta do Caribe (1993). Ambas se referem à promoção da saúde, entendendo que o ser humano deve e pode ter maior controle sobre sua saúde para melhorá-la. Com efeito, podemos afirmar que a promoção da saúde vai além 
da assistência médica, e que o serviço de saúde deve ser um elemento minimizador das patologias e dos agravos da saúde da população, considerando que a saúde das pessoas deve ser um recurso para a sua sobrevivência.

O atendimento ao usuário do sistema de saúde ocorre no espaço ocupado, pois é nele que acontecem as interações entre os usuários e os profissionais da saúde. Essas interações são potencializadas pela ambiência, que irá proporcionar tratamento ao espaço projetado, observando, com maiores detalhes, as subjetividades de seus atores e as objetividades das legislações, com foco na confortabilidade e na privacidade, criando espaços identitários com aspectos relacionados às suas práticas diárias.

Por subjetividade, entendemos os desejos e as necessidades de cada trabalhador, e por objetividade, as legislações vigentes. Portanto, o equilíbrio entre subjetividades e objetividades é fundamental para que o trabalhador se reconheça nesse espaço, sentindo-se acolhido, gerando um espaço identitário sustentável, promovendo o atendimento humanizado, acolhedor e resolutivo.

Para saber mais sobre gestão participativa, indicamos:

- Saúde paidéia, de Gastão Wagner de Souza Campos. 3 ed. São Paulo: Hucitec, 2007

- Um método para análise e co-gestão de coletivos, de Gastão Wagner de Souza Campos. São Paulo: Hucitec, 2000.
O olhar para a saúde do trabalhador considera o cuidar de quem cuida, observando que o trabalhador participa ativamente dos problemas e das soluções relativos aos processos de trabalho, buscando o consenso coletivo. A questão do espaço construído também influi nesses processos de trabalho.

Mas, afinal, como a divisão didática do espaço construído pode contribuir para a gestão na rede de frio de imunobiológicos?

Quando os trabalhadores conhecem as características dos espaços mencionados, estamos potencializando uma gestão participativa dos serviços de saúde, pois eles poderão auxiliar no gerenciamento, atuando de forma analítica, crítica e transformadora, nos possíveis problemas existentes no trabalho.

\section{Você sabia?}

A gestão participativa pode ser, também, denominada de cogestão, que se utiliza do Método de Roda para as tomadas de decisão, pois valoriza a participação e a integração dos trabalhadores. O Método de Roda se caracteriza como espaço democrático, que busca contemplar as necessidades do coletivo de trabalhadores, por meio da escuta, do diálogo e do consenso das ações propostas, para solucionar os problemas existentes. 
Veja um exemplo do uso da divisão didática do espaço construído na compreensão e na solução de um problema.

O problema: a sala de vacina de uma rede de frio de imunobiológicos apresenta problemas para manter a temperatura do meio ambiente externo ao freezer entre $19^{\circ} \mathrm{C}$ e $21^{\circ} \mathrm{C}$.

\section{O uso dos conceitos:}

- ao se buscar as características do espaço edificado, o trabalhador deverá conhecer o projeto que foi executado para avaliar sua adequação, considerando o coeficiente de isolamento térmico em relação ao dimensionamento da sala de vacina recomendado pelas legislações pertinentes;

- no espaço instalado, o trabalhador poderá observar a existência de sobrecarga nas máquinas e equipamentos de refrigeração ocasionados pelo fato anterior;

- o espaço ocupado é onde iremos perceber as consequências, ou seja, a ocorrência de constantes oscilações da temperatura no interior da sala de vacina, que poderá comprometer a qualidade das vacinas armazenadas, trazendo, com isso, um possível estresse aos trabalhadores, pois vivenciarão situações de tensão. Toda essa conjuntura poderá refletir na saúde desses profissionais nos âmbitos físico, cognitivo e organizacional.

\section{Ambiência}

A ambiência é fundamental no espaço instalado da edificação e faz parte da Política Nacional de Humanização do Ministério da Saúde.

A ambiência na saúde refere-se

[...] ao tratamento dado ao espaço físico entendido como espaço social, profissional e de relações interpessoais que deve proporcionar atenção acolhedora, resolutiva e humana. [...] Vai-se além da composição técnica, simples e formal dos ambientes, passando a considerar as situações que são construídas (BRASIL, 2010, p. 5).

\section{Importante}

A ambiência deve ter origem na fase do planejamento do edifício de saúde, ou seja, no espaço edificado.

Já a efetivação da ambiência ocorre no espaço instalado, com a utilização dos elementos humanizadores apresentados pela cartilha Ambiência, do 


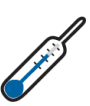

O material sobre ambiência, produzido pelo Ministério da Saúde, encontra-se disponível em http://bvsms. saude.gov.br/bvs/publicacoes/ ambiencia_2ed.pdf

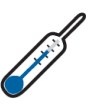

Para saber mais sobre o conceito de morfologia, indicamos o Dicionário visual de arquitetura, de Francis D. K. Ching. Tradução Julio Fischer. 4. tir. São Paulo: Martins Fontes, 2006.
Ministério da Saúde (BRASIL, 2010). É no espaço ocupado que ocorrerá o desfrute da ambiência, entendendo que os seus benefícios influenciarão diretamente na promoção da saúde, no atendimento ao usuário do SUS e na saúde do trabalhador.

Para compreender o que representa a ambiência na rede de frio de imunobiológicos, é necessário conhecer os elementos humanizadores do espaço construído, apresentados na cartilha Ambiência (BRASIL, 2010). São eles: 1. Morfologia, 2. Luz, 3. Cheiro, 4. Som, 5. Sinestesia, 6. Arte, 7. Cor, 8. Tratamento das áreas externas, 9. Privacidade e individualidade, 10. Confortabilidade.

\section{Morfologia}

Como você descreve as dimensões, as formas e os volumes existentes no seu espaço de trabalho? E as características desse espaço? Ele é público ou privado? Quantas pessoas o utilizam? Quais equipamentos são necessários e em que período do dia são utilizados?

Esses pontos deverão ser considerados para que os espaços sejam acolhedores, funcionais e propícios aos processos de produzir saúde. A estética também deverá ser considerada, favorecendo um ambiente agradável.

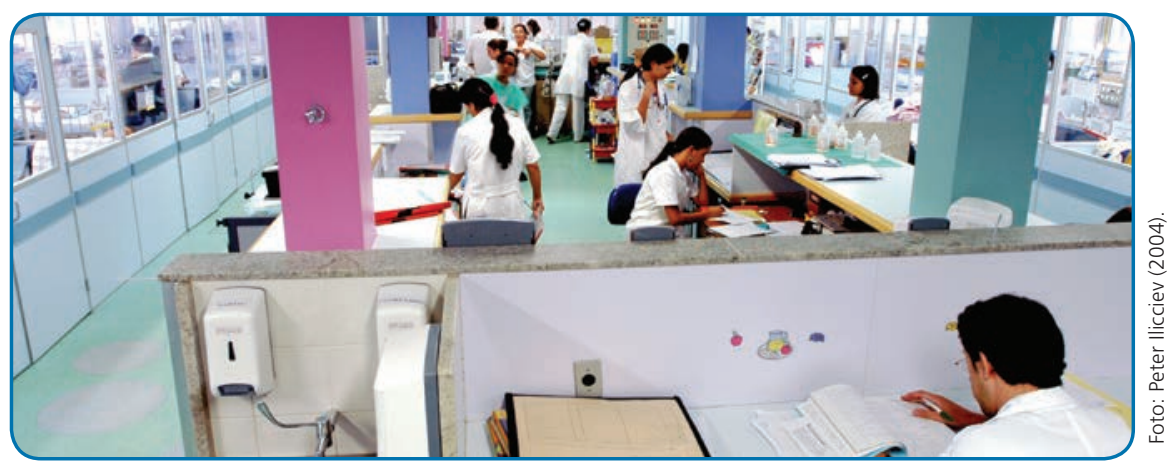

Morfologia no ambiente de trabalho. Formas, dimensões e volumes de um espaço podem contribuir ou não para o ambiente ser percebido pelas pessoas como agradável.

\section{Luz}

Você percebe alguma influência da luz no processo saúde-doença?

Sabe-se que o seu uso adequado poderá favorecer a realização das atividades e o conforto dos usuários e que, quando utilizada inadequadamente, poderá contribuir para a fadiga e acuidade visual e afetar o desempenho no trabalho, além de trazer outros desconfortos. 
É fácil perceber que, cada vez mais, as edificações se utilizam de iluminação artificial. Existem vários tipos de sistema tecnológico de iluminação como: geral ou de fundo, localizada ou de tarefa, combinada, emergência, segurança e decorativa. Vejamos o que são:

* A iluminação geral ou de fundo pretende garantir um iluminamento homogêneo no espaço. É aquela que, geralmente, se localiza no teto das áreas, mas, dependendo do projeto, pode ser instalada lateralmente nas paredes, desde que garanta um iluminamento bem distribuído e sem sombras.

* A localizada ou de tarefa direciona o iluminamento para o campo do posto de trabalho. Por exemplo, a utilização de luminária pendente próximo ao local em que o trabalhador realiza as tarefas.

* A iluminação combinada é solicitada quando surge a necessidade de complementação da iluminação geral com focos de luz localizada. Uma mesa de trabalho iluminada com uma luminária e também com a iluminação geral existente no ambiente é um exemplo.

A de emergência deverá ser acionada em processo manual ou automático, no caso de falta de fornecimento de energia, sempre que ocorrer a necessidade de resoluções rápidas e de evacuação.

* A de segurança diz respeito à sinalização das saídas de emergência, de extintores de incêndio e de outra qualquer voltada para a segurança do prédio.

* No caso da iluminação decorativa, o objetivo é explorar as sombras de um objeto, como um quadro de arte, por exemplo.

As fotos a seguir demonstram alguns sistemas de iluminação típicos em áreas de trabalho. A iluminação no local de trabalho deve ser bem planejada, considerando o plano de trabalho em que será realizada a tarefa. Ressaltamos que a luz natural deverá ser valorizada nas edificações, face aos benefícios ao ser humano, aos custos, além de prover a sustentabilidade.

Foto 2 - Sistema de iluminação geral

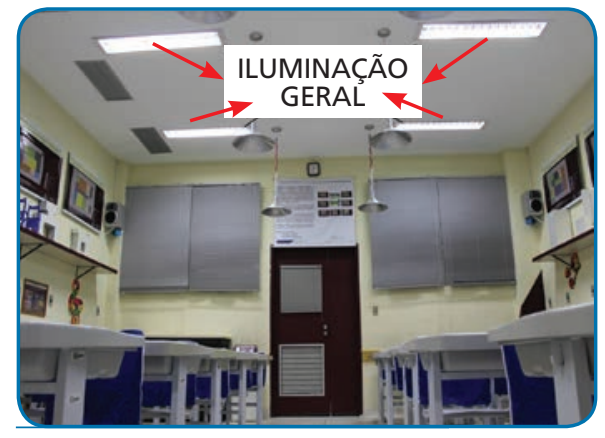

Foto 3 - Sistema de iluminação combinada

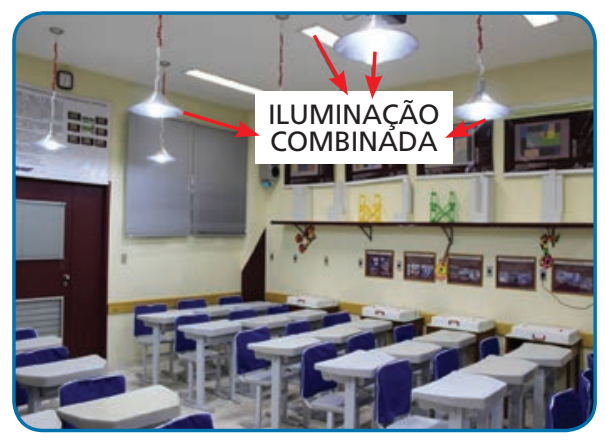

Foto 4 - Sistema de iluminação localizada

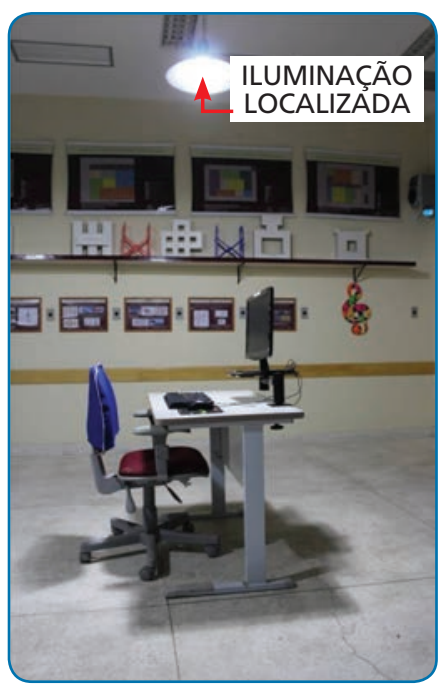


Sheds são telhados ou parte desses em forma de "dentes de serra", com um dos planos em vidro para favorecer a captação da iluminação natural. Podem ser utilizados em fábricas, galpões e hospitais.

Brises-soleil é um dispositivo arquitetônico, localizado na fachada da edificação, para impedir a incidência de radiação solar para o seu interior, porém permitindo a entrada da ventilação natural.

Cobogós são blocos decorativos vazados, feitos geralmente de concreto ou de cerâmica, que favorecem o aproveitamento da iluminação e a ventilação natural.

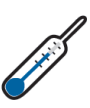

Para saber mais sobre ventilação interior e exterior da edificação, leia:

Eficiência energética na arquitetura, de Roberto Lamberts, Luciano Dutra, Fernando Oscar Ruttkay Pereira. São Paulo: PW, 1997.

Ventilação natural das habitações, de Eustáquio Toledo. Coord. da publicação brasileira por Alexandre Toledo. Maceió: Edufal, 1999.

\section{Cheiro}

Não conseguimos visualizar o cheiro, porém o sentimos, e ele exerce influência sobre o estado de bem-estar dos usuários de um espaço. Quais são as fontes de odores nos ambientes de saúde?

Os odores existentes nos ambientes são provenientes de diversas fontes como: banheiros, substâncias químicas, cozinhas, entre outros. Por isso, a renovação de ar deverá ser constante, e a preocupação com a qualidade do ar interior merece atenção.

O projeto de uma edificação deverá considerar a forma arquitetônica adequada para o aproveitamento dos ventos predominantes, que poderão influenciar diretamente na sua ventilação interior e exterior. Também contribuirão para a renovação do ar ambiental interno a utilização de recursos como exaustores, sheds, chaminés, janelas, brises-soleil, cobogós, entre outros. Os ambientes ventilados são fundamentais para o conforto, a satisfação, a saúde e o desempenho dos trabalhadores.

Figura 2 - Traçado urbano em Marrakesh aproveitando os ventos predominantes

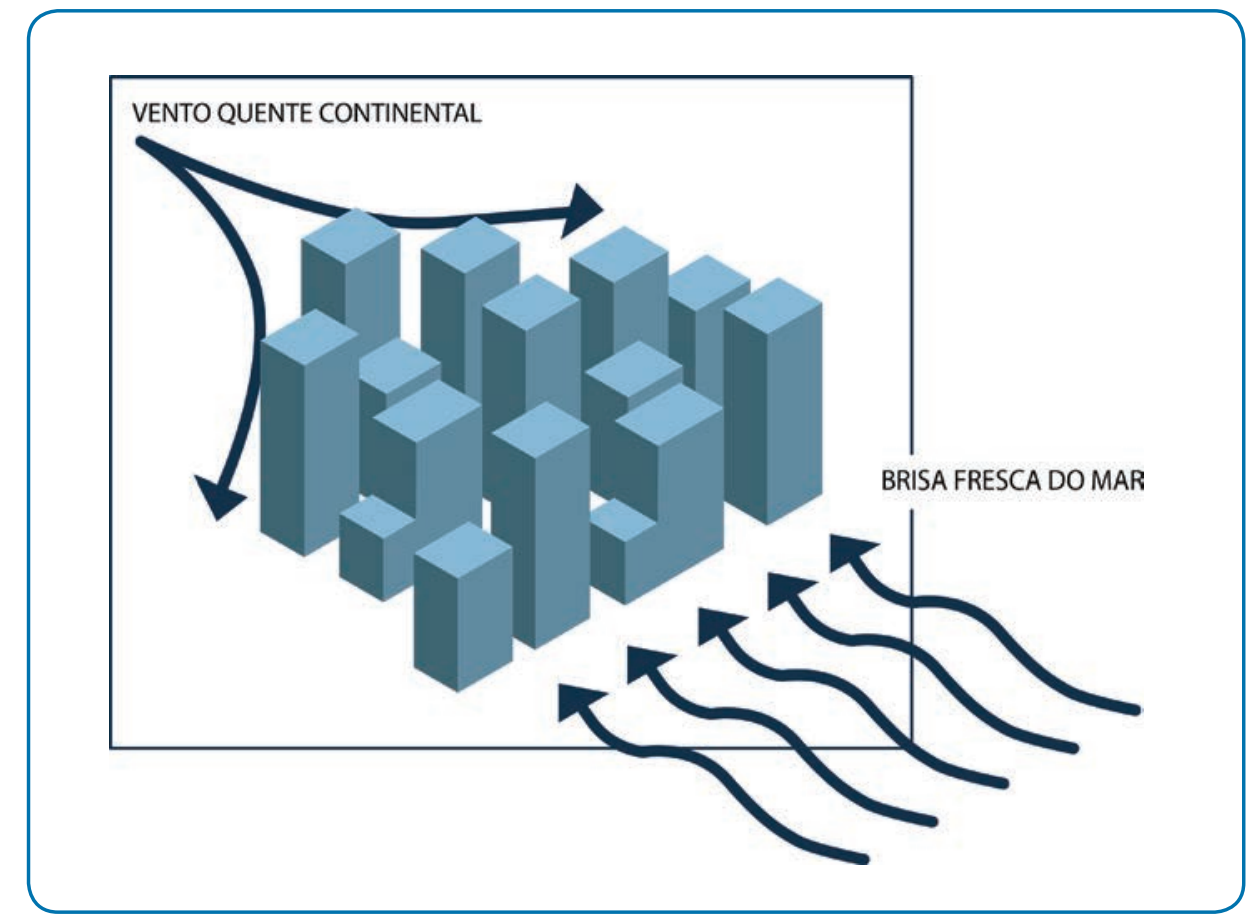

Fonte: Adaptado de Lamberts, Dutra e Pereira (1997, p. 52). 


\section{Som}

Existe diferença entre som e ruído?

O som é o resultado audível de uma vibração, e o ruído é uma vibração indesejável; ambos são subjetivos e, portanto, devem ser considerados nos espaços. O conhecimento das fontes de ruído é necessário ao se buscar soluções para minimizá-lo ou, se possível, eliminá-lo, objetivando garantir a confortabilidade dos usuários do espaço.

A música é uma alternativa para harmonização do ambiente; ela não deve ser usada para atenuar um ruído, pois os dois se somarão, ocasionando um ruído de maior intensidade.

\section{Sinestesia}

Percebemos os diferentes espaços existentes nas edificações usando nossos sentidos: visão, olfato, tato, audição e sentido térmico; portanto, destaca-se aqui a subjetividade sensorial do reconhecimento do espaço, através do contato com as superfícies e texturas existentes.
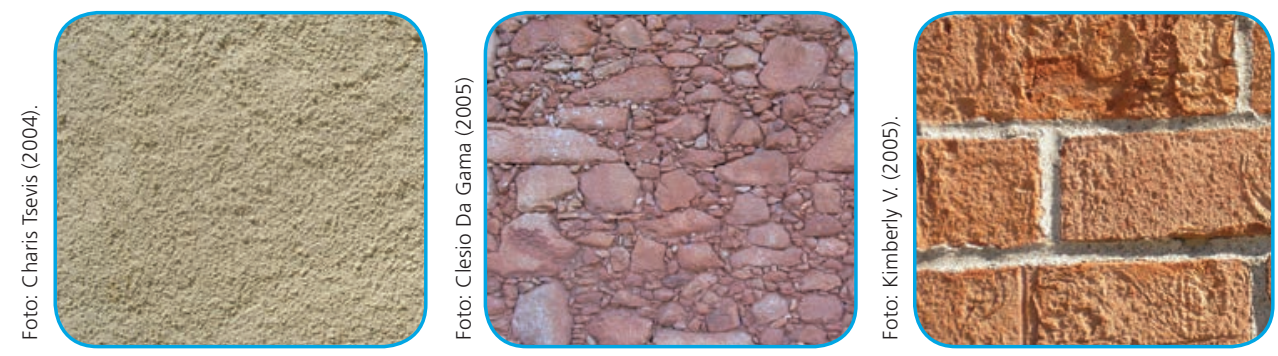

Diferentes texturas. Diferentes espaços podem ser identificados pelos tipos de superfícies e texturas que apresentam.

\section{Arte}

É um aspecto fundamental na interação entre os espaços e os sujeitos, pois transmite sensações e expressa a cultura local. Por isso, a participação dos sujeitos no processo de decoração do ambiente se faz importante. O prazer do ser humano pode ser representado por meio da arte, pois essa exterioriza as emoções das experiências de vida de uma pessoa.

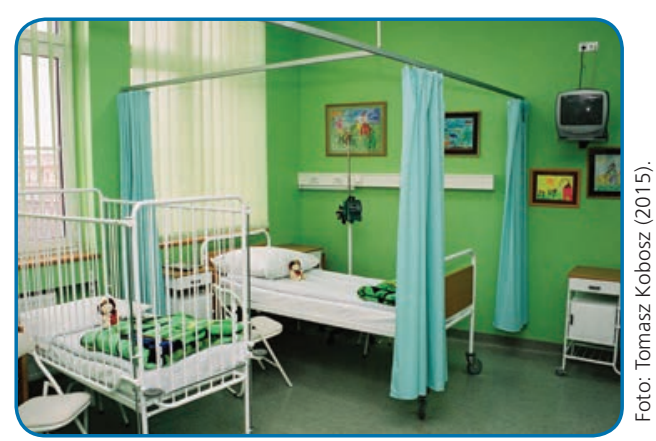

A arte inserida no ambiente. $\mathrm{O}$ uso da arte como potencializadora nas percepções e sensações humanas. O uso de cores e pequenos quadros na parede buscam despertar sensações mais leves para este quarto de um hospital pediátrico.
Para saber mais sobre os níveis de ruído no ambiente de trabalho, consulte:

- Norma RegulamentadoraNR 15, do Ministério do Trabalho e Emprego (MTE), disponível em: http://trabalho. gov.br/index.php/segurancae-saude-no-trabalho/ normatizacao/normasregulamentadoras

- Sistemas de controle das condições ambientais de conforto, de Tadeu Almeida de Oliveira e Otto Toledo Ribas. Brasília, DF: Ministério da Saúde, 1995.

- Ergonomia: projeto e produção, de Itiro lida.2. ed. rev. e ampl. São Paulo: Edgard Blücher, 2005.

Se quiser conhecer mais sobre diferentes espaços, superfícies e textura, consulte a obra de Jun Okamoto intitulada Percepção ambiental e comportamento: visão holística da percepção ambiental na arquitetura e na construção. São Paulo: Mackenzie, 2002.

Para saber mais sobre arte e espaços de saúde, leia Apostila do Programa de Educação de Jovens e Adultos: ensino médio, de Márcia Cristina Mendes Lopes. Rio de Janeiro: Fiocruz, 2002. Disciplina de Educação Artística. Laboratório de Manutenção em Equipamentos MédicoHospitalares-Fiocruz. 


\section{Cor}

A arquitetura, ao se preocuparem fazer uma edificação, se propõe, também, a humanizá-la, trazendo os elementos da natureza (iluminação, ventilação, cor etc.) para compor o ambiente. A ambiência, ao se preocupar em compor espaços agradáveis, recomenda a combinação de cores harmoniosas. Seu uso deve também ser planejado, pois a prática de uma só cor em todo o ambiente pode transmitir monotonia e/ou melancolia. Já a utilização inadequada de diversas cores pode criar uma atmosfera confusa no ambiente.

De acordo com a cartilha Ambiência (BRASIL, 2010, p. 9), "as cores estimulam nossos sentidos e podem nos encorajar ao relaxamento, ao trabalho, ao divertimento ou ao movimento", além de proporcionarem beleza ao ambiente.

Para saber mais sobre cores no ambiente, leia $A$ influência da luz e da cor em salas de espera e corredores hospitalares, de Marilice Costa Costi. Porto Alegre: EDIPUCRS, 2002.

Figura 3 - Percepção do espaço cromático

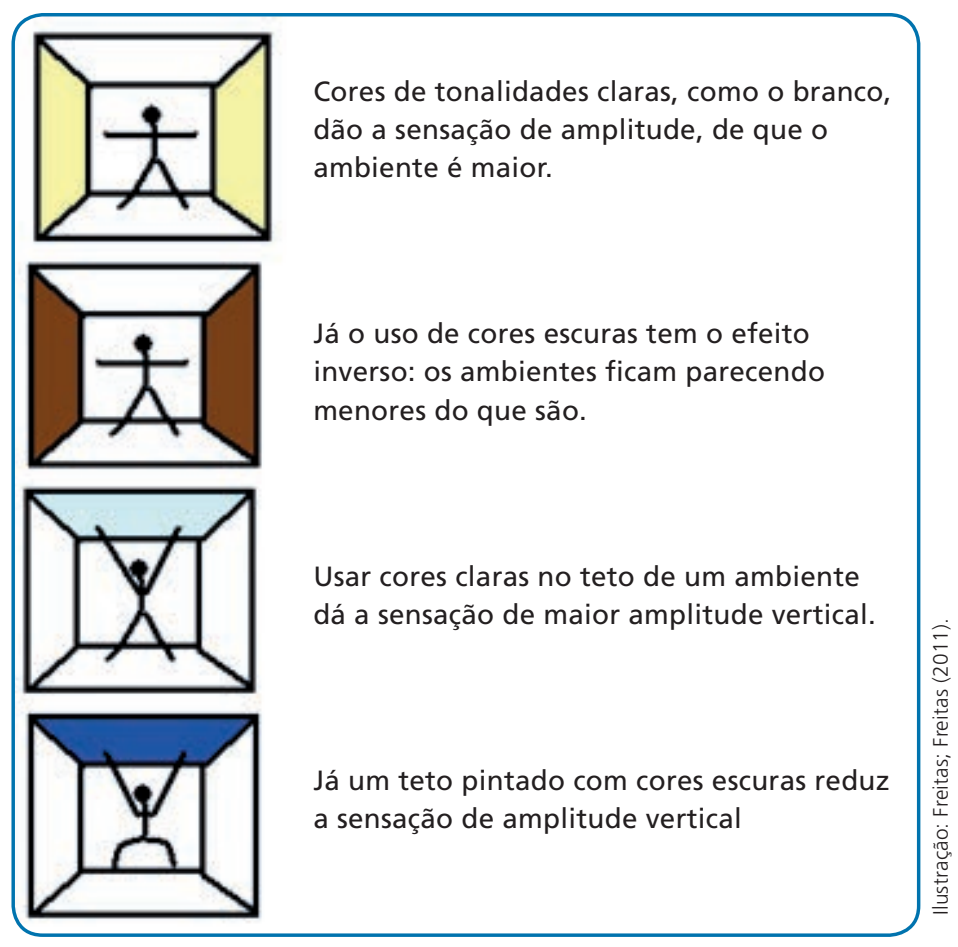

\section{Tratamento das áreas externas}

O tratamento das áreas externas (paisagismo vegetal, bancos, vasos com plantas, pergolados etc.) não é apenas a construção de um jardim, mas sim o uso estratégico de vegetação e ornamentações de forma a criar sombras para a edificação, temperaturas e ambientes mais acolhedores. 


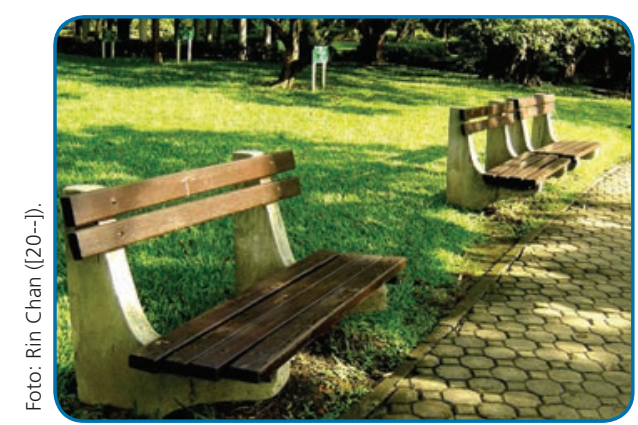

Área externa acolhedora para os usuários. Local com sombra e assentos para convívio e interação.
As áreas externas têm grande importância para a humanização dos ambientes de saúde, pois podem ser utilizadas como lugar de espera ou de descanso dos usuários. Localizam-se na entrada, na saída e ao redor das edificações e podem promover uma área de convívio.

\section{Privacidade e individualidade}

Já parou para refletir sobre a importância da sua privacidade e individualidade no trabalho?

A privacidade abrange a intimidade do usuário, por meio da utilização de objetos que permitam a interação entre ele e o ambiente, como, por exemplo, armários para a guarda de seus pertences e divisórias de espaços. A individualidade compreende que cada usuário é singular, oriundo de culturas diferentes. A arquitetura se propõe a criar espaços que respeitem essas diferenças.
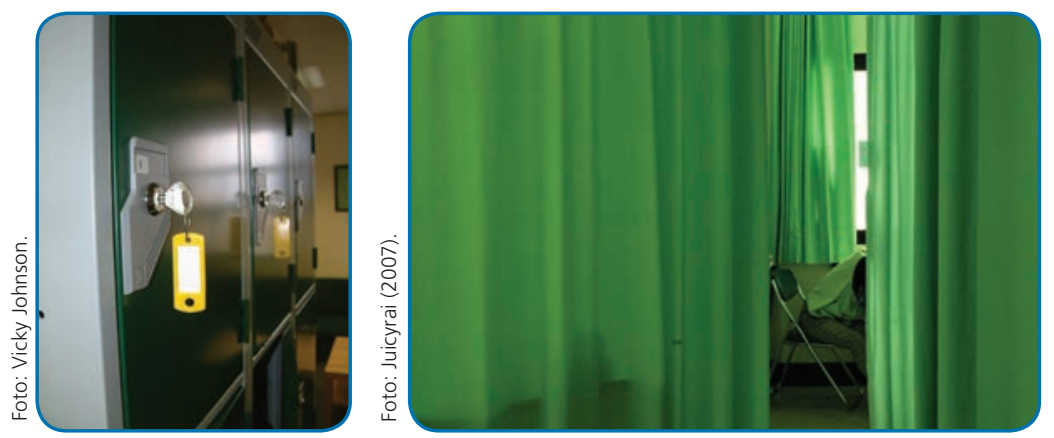

Exemplos de privacidade e individualidade. A disponibilização de armários para os trabalhadores guardarem seus pertences e de cortinas para os atendimentos na unidade de saúde são estratégias para resguardar, minimamente, a privacidade das pessoas.

Fonte: Freelmages.com. | Fonte: Flickr.

\section{Confortabilidade}

Sob o ponto de vista da ambiência, é a inclusão da acessibilidade aos usuários por meio de rampas, corrimãos, piso podotátil, entre outros. Mas não se limita a esse entendimento. Considerando a sala de vacina, é importante que o usuário se sinta inserido e acolhido pelo conjunto de características do ambiente, para que ele possa se identificar culturalmente, sem perder suas referências.

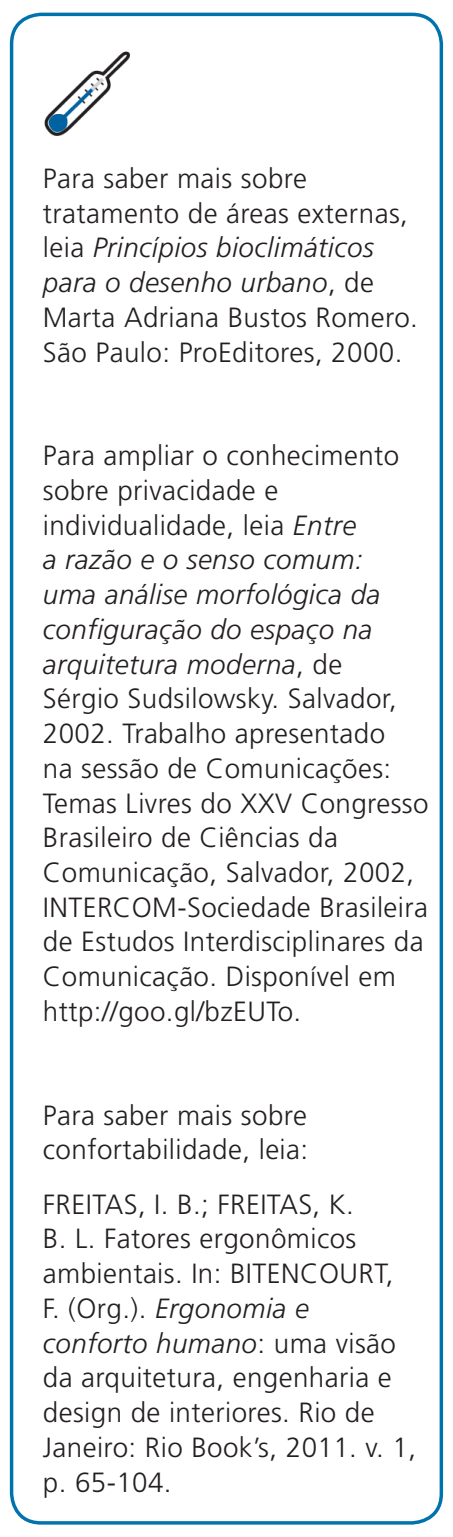

Para saber mais sobre tratamento de áreas externas, Principios bioclimáticos Marta Adriana Bustos Romero. São Paulo: ProEditores, 2000.

Para ampliar o conhecimento sobre privacidade e individualidade, leia Entre a razão e o senso comum: Sérgio Sudsilowsky. Salvador, 2002. Trabalho apresentado na sessão de Comunicações: Brasileiro de Ciências da Comunicação, Salvador, 2002, de Estudos Interdisciplinares da Comunicação. Disponível em http://goo.gl/bzEUTo.

Para saber mais sobre FREITAS, I. B.; FREITAS, K. B. L. Fatores ergonômicos ambientais. In: BITENCOURT, F. (Org.). Ergonomia e conforto humano: uma visão quitetura, engenhari Janeiro: Rio Book's, 2011. v. 1 p. 65-104. 


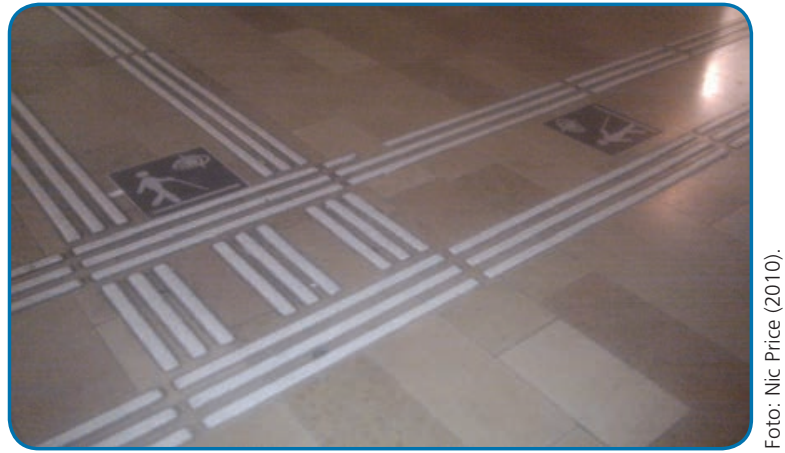

Exemplo de piso podotátil. Este tipo de piso auxilia na orientação do caminhar de um deficiente visual. Fonte: Flickr.

\section{Para refletir}

Vamos a um desafio? Pense no seu local de trabalho e reflita sobre os elementos humanizadores lá presentes. Como você avalia a presença destes na sua relação com o local de trabalho?

\section{Ergonomia}

Entendemos que a arquitetura deve buscar, na ambiência, as subjetividades dos usuários e, também, seguir a legislação vigente (normas, leis, decretos etc.). Agora vamos compreender o que é e o que a ergonomia tem em comum com a arquitetura e a ambiência.

A palavra ergonomia deriva dos radicais gregos ergon ou ergos, que significa trabalho, e nomos, que significa normas, regras, leis naturais. É uma ciência e tem a atividade de trabalho como ponto central de compreensão e de transformação.

A ergonomia tem um campo de aplicação muito amplo, porque abarca conhecimentos de diversas áreas, tais como fisiologia, biomecânica, antropometria, psicologia, arquitetura etc. De uma forma ou de outra, está presente em todos os locais de trabalho e tem como objetivo principal adaptar o trabalho ao trabalhador. Portanto, é fundamental a sua existência nos diversos espaços construídos, em consonância com a ambiência e com a arquitetura, pois, como já mencionado, ambas têm influência no bem-estar e na produtividade do trabalhador.

Quando a ergonomia deu os seus primeiros passos?

Considera-se que os ensinamentos da ergonomia estão presentes desde a Pré-História, quando o primeiro homem escolheu uma pedra mais 
adequada às mãos e aos movimentos para usá-la como uma arma, na caça e na pesca; para sobreviver, usou seus saberes práticos a fim de facilitar suas tarefas, criando ferramentas que contemplassem suas necessidades. Portanto, esses atos podem ser entendidos como ações simples do tipo ergonômico.

Pode-se afirmar que a ergonomia nasceu, "oficialmente", em 12 de julho de 1949, na Inglaterra, em uma reunião entre pesquisadores e cientistas que buscavam formalizar esse novo olhar interdisciplinar da ciência (IIDA, 2005).

\section{É interessante saber que...}

A Segunda Guerra Mundial (1939-1945) é marcada pela ergonomia, sobretudo no campo da aviação, pois era necessário criar novos modos de informação por meio de formas, cores e materiais diferentes, que possibilitassem aos pilotos manejar melhor e mais facilmente as aeronaves, além de poderem se organizar, evitar erros e minimizar acidentes e incidentes.

O interesse por esse conhecimento se destacou, principalmente, na Inglaterra e nos Estados Unidos. Em 1949, na Inglaterra, o engenheiro e psicólogo Murrel (1908-1984) criou a primeira Associação Científica de Ergonomia (Ergonomics Research Society), com característica multidisciplinar.

Tal conhecimento se espalhou pelo mundo. Nos Estados Unidos, em 1957, foi criada a Human Factors Society, e, então, outros países, principalmente os industrializados, propagaram a ergonomia. Já em 1963, na França, foi criada a Société d'Ergonomie de Langue Française (Self) (LAVILLE apud FALZON, 2007). Em 1961, foi fundada, em Estocolmo, a Internacional Ergonomics Association (Associação Internacional de Ergonomia).
Incidente é qualquer situação que surge inesperadamente no local de trabalho, com potencial de causar lesão, dano ou prejuízo. Difere do acidente, que resulta em alguém ferido ou na promoção de danos à propriedade. Por exemplo, se alguém deixa vazar água no piso de um estabelecimento mas não prejudica ninguém e nem causa danos às instalações, isso pode ser caracterizado como um incidente. Se alguém escorregar na poça de água, cair e sofrer um prejuízo (fratura, lesão etc.), dizemos que houve um acidente.

Os conceitos de acidente e incidente são discutidos no capítulo seguinte deste livro, que trata da biossegurança e da prevenção de incêndios.

No Brasil, a ergonomia se destaca a partir da década de 1970, com a influência da ergonomia da atividade, desenvolvida nos países de língua francesa e difundida pelo professor e ergonomista Alain Wisner (1923-2004). Sua prática tem como característica uma aproximação muito íntima com o campo de trabalho para se compreender a atividade e transformá-la. Busca identificar as lacunas existentes entre o trabalho real (a atividade realizada) e o trabalho prescrito (a tarefa), considerando, também, os diversos fatores presentes nos ambientes de trabalho, como iluminação, ventilação, acústica, organização espacial (leiaute), estresse, entre outros. 


\section{Exemplo de distinção entre trabalho real e trabalho prescrito na rede de frio de imunobiológicos}

Pensemos sobre a tarefa de monitorar a temperatura dos equipamentos de refrigeração existentes na sala de vacinação.

A prescrição determina que a leitura deve ser realizada diariamente, no início da jornada de trabalho da manhã, da tarde e no fim do dia, registrando-se as temperaturas em formulário próprio. Caso não exista formulário fornecido por gráfica, mas somente na versão digital, o trabalho real pode obrigar o trabalhador a ligar o computador, imprimir o formulário e, se não houver tinta suficiente no cartucho de impressão, esse mesmo trabalhador deve pedir a alguém o produto para que possa trocá-lo e, por fim, imprimir o formulário a ser utilizado nas leituras das temperaturas. Todas essas ações demandam tempo e somam na carga de trabalho diária do profissional.

Nesse exemplo, é possível identificar as diferenças existentes entre trabalho real e trabalho prescrito. Por mais que se busque padronizar os procedimentos, ainda existirão diferenças no modo operacional de se realizar o trabalho, pois ele sempre exigirá uma forma diferente de ser efetuado.

Outro ponto importante a ressaltar é que a ergonomia se apresenta em consonância com a perspectiva da saúde do trabalhador e se afasta de uma visão restrita, simplista e seguidora de normas prescritas.

Não existe uma única definição para ergonomia. De forma mais detalhada, a Associação Brasileira de Ergonomia (Abergo), em 1998, a definiu como:

[...] a disciplina científica que trata da compreensão das interações entre os seres humanos e outros elementos de um sistema, e a profissão que aplica teorias, princípios, dados e métodos, a projetos que visam otimizar o bem-estar humano e a performance global dos sistemas. A Ergonomia visa adequar sistemas de trabalho às características das pessoas que nele operam. Nos projetos de sistemas de produção a Ergonomia faz convergir os aspectos de Segurança, Desempenho e de Qualidade de Vida, através de sua metodologia específica, a Análise Ergonômica do Trabalho (ABERGO, 1988 apud RIO; PIRES, 2001, p. 31). 
Para a Associação Internacional de Ergonomia (International Ergonomics Association-IEA),

Ergonomia (ou Fatores Humanos) é a disciplina científica que estuda as interações entre os seres humanos e outros elementos do sistema, e a profissão que aplica teorias, princípios, dados e métodos, a projetos que visem otimizar o bem-estar humano e o desempenho global de sistemas (IEA, 2000 apud IIDA, 2005, p. 2, grifos do autor).

\section{Você sabia?}

A identificação dos fatores de risco ergonômico bem como dos possíveis danos à saúde relacionados ao processo de trabalho e à organização do trabalho é fundamental para que se possam elaborar programas de segurança e medidas de prevenção, além de contribuir para a redução dos acidentes de trabalho e das doenças ocupacionais.

O desenvolvimento da ergonomia envolve, de maneira determinante, os setores/áreas de recursos humanos, segurança do trabalho e medicina do trabalho, incluindo, fundamentalmente, a direção da instituição, caracterizando-se, assim, como um processo interdisciplinar. A participação do diretor se destaca: é ela que determina a organização do trabalho ao definir os organogramas, fluxogramas de processos, tarefas, horários, turnos, arranjo físico, tecnologia, automação, metas produtivas, capacidade de produção, índice de produtividade, modelo de gestão, entre outros.

Já o envolvimento do setor de recursos humanos se destaca pela determinação da política de pessoal na contratação dos funcionários: os níveis de escolaridade e capacitação, tipos de contrato, categorias profissionais, níveis hierárquicos, qualificações, política de remuneração, entre outros. Portanto, define o perfil dos trabalhadores.

A aplicação da Norma Regulamentadora do Trabalho 17 (NR 17-Ergonomia) está diretamente relacionada à segurança no trabalho e à medicina ocupacional, por meio do Serviço Especializado em Engenharia de Segurança e em Medicina do Trabalho (SESMT). O serviço tem como principal finalidade a promoção da saúde e a proteção da integridade do trabalhador, no local em que trabalha, aplicando as legislações pertinentes ao trabalho; esclarecendo os empregados acerca dos riscos existentes no ambiente de trabalho; promovendo ações para neutralizá-los ou eliminá-los; prevenindo acidentes de trabalho e doenças ocupacionais.

Os trabalhadores da rede frio de imunobiológicos estão expostos a riscos ergonômicos ao realizar suas atividades? 
Segundo o Ministério da Saúde (BRASIL, 1999), dentre as possíveis doenças ocupacionais relacionadas com os riscos ergonômicos existentes no trabalho da rede de frio de imunobiológicos, podemos citar: artroses, dorsalgias, cervicalgias, sinovites, tenossinovites, bursites.

Atualmente, percebemos que existe uma ocorrência crescente de problemas ergonômicos relacionados a projetos de máquinas, equipamentos, ferramentas, mobiliário e de postos de trabalho. Tal fato ainda é agravado pelas inadequações relacionadas à organização do trabalho; portanto, se faz necessária a adaptação ergonômica dos postos de trabalho.

São exemplos de riscos ergonômicos:

* esforço físico intenso,

釉 levantamento e transporte manual de carga,

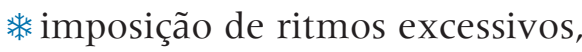

*⿻ controle rígido de produtividade,

trabalho em turnos,

粰 trabalho noturno,

* jornadas prolongadas de trabalho,

monotonia,

蒋 repetitividade,

outras situações causadoras de estresse físico e/ou psíquico.

Quando for solicitada a solução de um problema complexo relacionado à ergonomia nos locais de trabalho, a Análise Ergonômica do Trabalho (AET), metodologia obrigatória contemplada na NR 17, deverá ser realizada por um profissional específico, denominado ergonomista.

A AET pode contribuir na análise das causas de um acidente e das doenças ocupacionais, sempre que isso contemplar o estudo dos aspectos físicos, ambientais, organizacionais e cognitivos correspondentes ao trabalho. De uma maneira geral, a AET possibilita:

* Contemplar informações que auxiliam na construção do perfil de saúde dos trabalhadores: o perfil de saúde demonstra o somatório das informações relacionadas aos riscos ergonômicos da atividade de trabalho e dos hábitos referentes ao estilo de vida dos trabalhadores. Possibilita a elaboração de programas de saúde, voltados à qualidade de vida no trabalho, reduzindo o absenteísmo, melhorando a produtividade, prevenindo riscos e doenças ocupacionais, orientando sobre hábitos saudáveis e aconselhando mudanças comportamentais. 


\section{Para refletir}

Você já participou de algum programa realizado no seu local de trabalho que buscasse levantar o perfil de saúde dos trabalhadores? Se afirmativo, teve conhecimento dos resultados?

* Elaborar o Programa de Controle Médico da Saúde Ocupacional (PCMSO-NR7) e o Programa de Prevenção de Riscos Ambientais (PPRA-NR9): o PCMSO é um instrumental clínico e epidemiológico que busca rastrear, prevenir e diagnosticar precocemente possíveis agravos à saúde dos trabalhadores, relacionados ao trabalho. O PPRA busca o controle da ocorrência de riscos ambientais (riscos físicos, químicos, biológicos, ergonômicos e de acidentes) existentes no local de trabalho, considerando a proteção do meio ambiente e dos recursos naturais. Ambos objetivam a proteção, a promoção e a preservação da saúde dos trabalhadores.

\section{Para refletir}

O PCMSO estabelece exames periódicos a serem realizados pelos trabalhadores, conforme os riscos existentes nas atividades de trabalho, para conhecer e tratar os possíveis danos à saúde.

Você já realizou exames periódicos neste ano? Já teve a oportunidade de saber se existe PPRA no local em que trabalha? Se não, procure informações sobre o programa nos setores de recursos humanos ou de segurança do trabalho.

\section{* Fornecer subsídios para a diminuição da alíquota do Seguro} de Acidente do Trabalho (SAT): a AET, ao identificar os riscos ergonômicos e propor as recomendações a serem cumpridas, estará contribuindo para a redução de acidentes e doenças ocupacionais e, consequentemente, reduzirá o valor da alíquota do SAT.

* Fornecer subsídios para a elaboração de contraprova pela empresa referente ao Nexo Técnico Epidemiológico junto à Previdência Social: a AET pode responder a uma contestação de um benefício acidentário junto ao INSS, ao demonstrar a relação entre o agravo apresentado pelo trabalhador e a atividade de trabalho. Faz isso por meio de estudo ergonômico realizado no posto de trabalho, vinculando ou não a existência de patologias possíveis à atividade laboral. A AET é, portanto, fundamental para esclarecer essas questões junto à Previdência Social.
O PCMSO é analisado com mais detalhes no próximo capítulo, relativo à biossegurança.

O acidente de trabalho não é um evento desejável para o profissional nem para a empresa. Além de interferir na saúde do trabalhador e na produção da organização, gera custos ao empregador e/ou ao Estado.

Para saber mais sobre o Nexo
Técnico Epidemiológico junto à
Previdência Social, acesse:
http://www.previdencia.gov.
br/a-previdencia/saude-e-
seguranca-do-trabalhador/
politicas-de-prevencao/
nexo-tecnico-epidemiologico-
previdenciario-ntep/




\section{Domínios da ergonomia}

Até agora mencionamos três domínios da ergonomia: física, cognitiva e organizacional, mas o que significam e como podemos relacioná-los com o trabalho da rede de frio de imunobiológicos? A seguir, cada domínio traz a sua definição para um melhor entendimento.

\section{Ergonomia física}

Tem o foco voltado às características humanas anatômicas, antropométricas, fisiológicas e biomecânicas e como elas se relacionam com as exigências de ordem física, que incluem:

* posturas,

manuseios de materiais,

movimentos repetitivos,

distúrbios musculoesqueléticos relacionados ao trabalho,

* desenho da disposição do mobiliário,

*áquinas e equipamentos necessários à atividade de trabalho (leiaute),

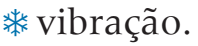

\section{Ergonomia física na rede de frio de imunobiológicos}

- Ao chegarem à Cenadi, as vacinas são armazenadas em câmara fria com temperaturas específicas para, depois, serem distribuídas aos locais de destino. Para que essas ações ocorram, é necessário que o trabalhador realize a atividade de levantamento, transporte e descarga de materiais. De acordo com o espaço disponível, essas atividades poderão ser facilitadas com a utilização de aparelhos mecânicos e/ou eletromecânicos (paleteira, vagões, empilhadeiras, entre outros), minimizando, assim, o esforço físico realizado pelos trabalhadores.

- Em algumas salas de vacinação, a ausência de maca ocasiona a adoção de posturas forçadas, como flexão de tronco, para que se possa vacinar a criança no colo da mãe, sentada na cadeira. 


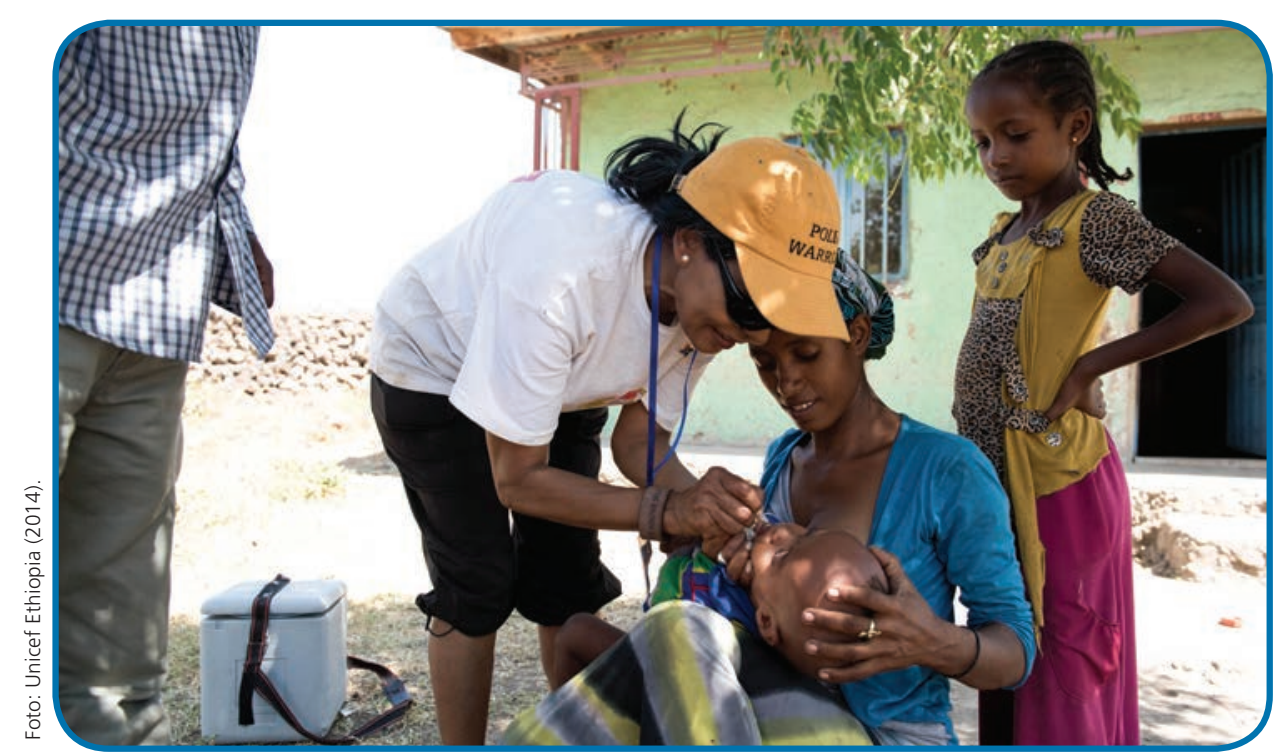

Atividade de vacinação em uma comunidade. Destaca-se a ergonomia física no que se refere ao deslocamento de grandes distâncias; transporte e carregamento individual das caixas térmicas contendo as vacinas, além de posturas desfavoráveis, como flexionar o tronco e/ou agachar para possibilitar a aplicação da vacina.

Fonte: Flickr.

A figura, a seguir, demonstra as melhores posturas a serem adotadas no carregamento de peso.

Figura 4 - Postura adequada para carregamento de peso

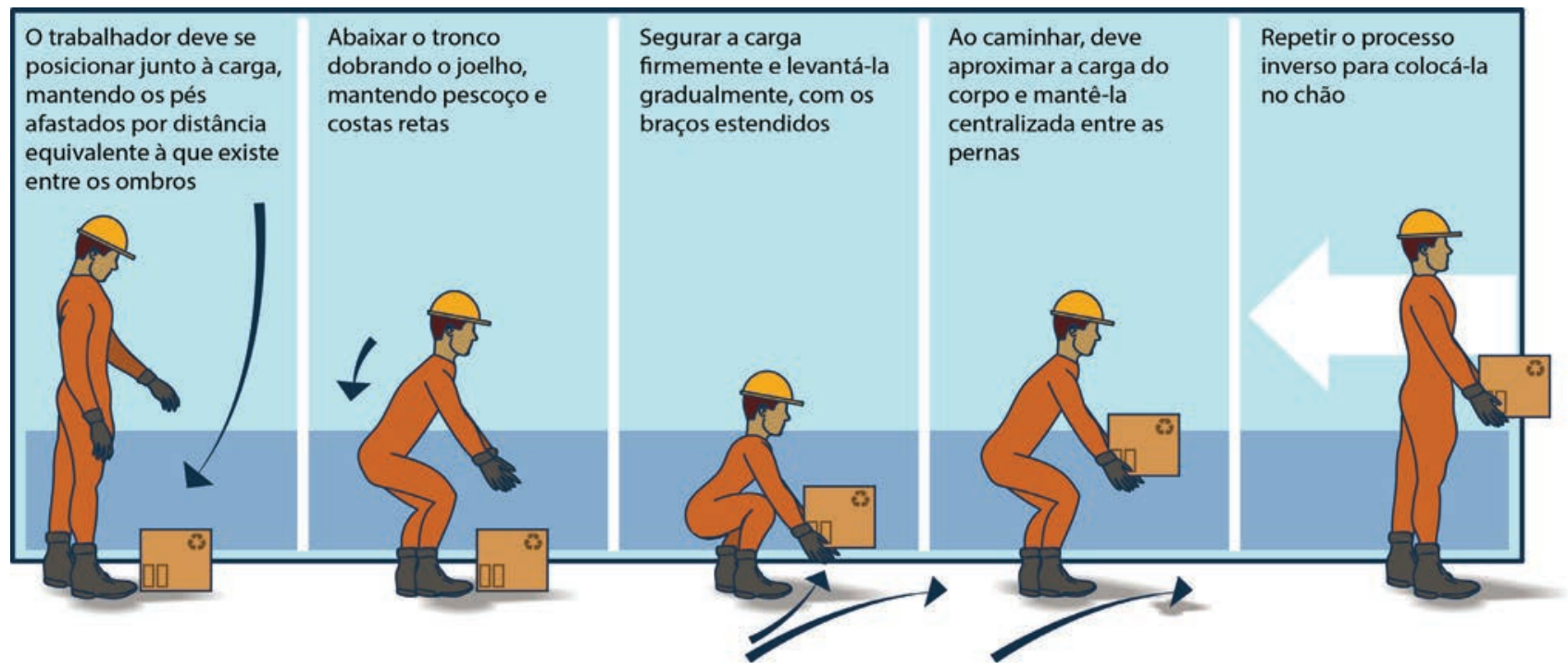

Os quadros a seguir compilam algumas informações com base nos preceitos da ergonomia física, em algumas atividades (trabalho real) realizadas na Cenadi. Essas informações podem auxiliar os gestores 


\section{a determinar o controle dos riscos ergonômicos e também promover ações em prol da segurança e da saúde dos trabalhadores.}

Quadro 1 - Ergonomia física na rede de frio de imunobiológicos

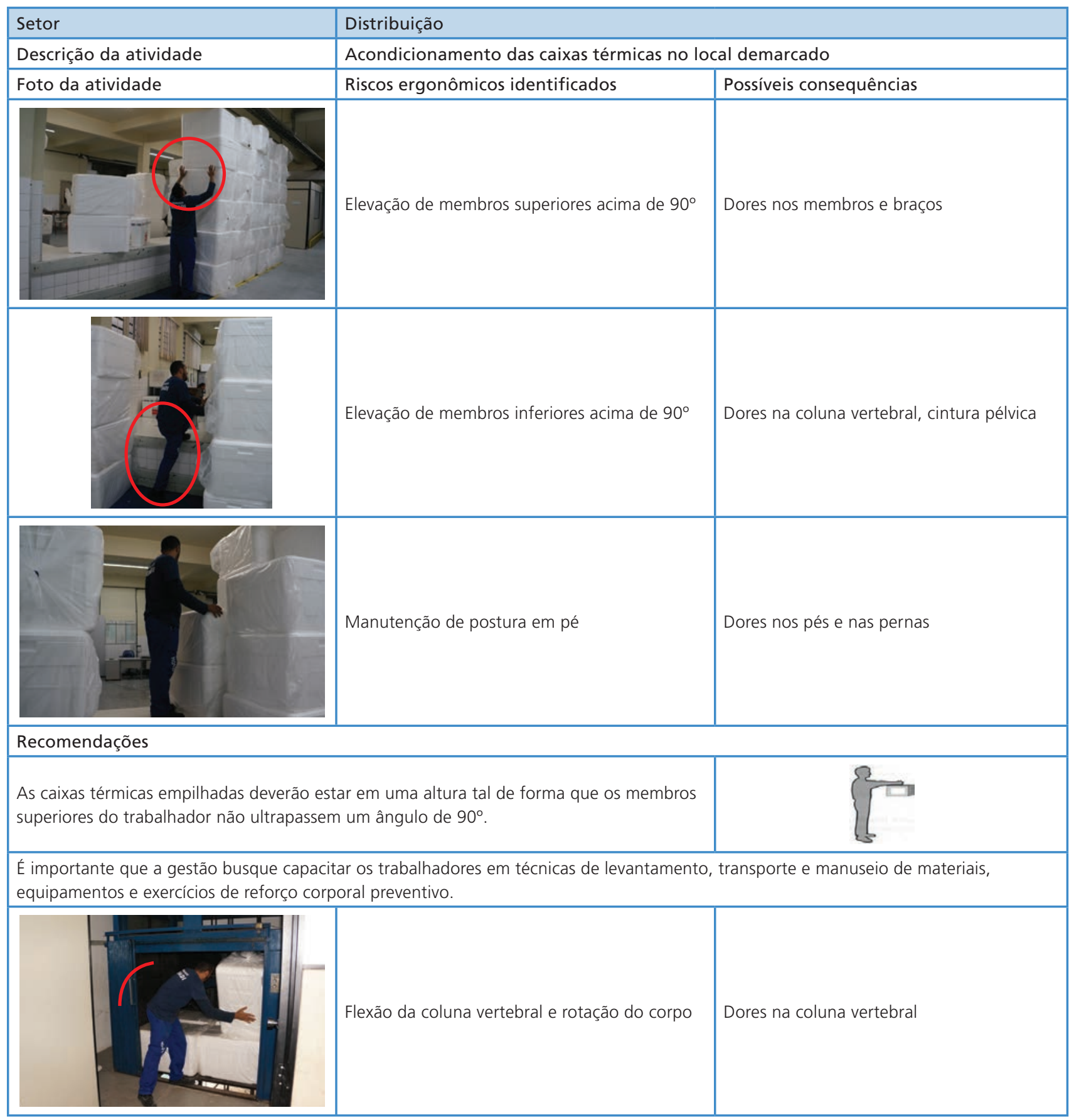


Quadro 1 - Ergonomia física na rede de frio de imunobiológicos (cont.)

\begin{tabular}{|c|c|c|}
\hline Setor & \multicolumn{2}{|l|}{ Distribuição } \\
\hline Descrição da atividade & \multicolumn{2}{|c|}{ Acondicionamento das caixas térmicas no local demarcado } \\
\hline Foto da atividade & Riscos ergonômicos identificados & Possíveis consequências \\
\hline & Transporte de carga com desnível de piso & Dores na coluna vertebral \\
\hline & Esforço físico & Dores na coluna vertebral \\
\hline \multicolumn{3}{|l|}{ Recomendações } \\
\hline \multicolumn{3}{|c|}{$\begin{array}{l}\text { É importante que a gestão busque capacitar os trabalhadores em técnicas de levantamento, transporte e manuseio de materiais, } \\
\text { equipamentos e exercícios de reforço corporal preventivo. }\end{array}$} \\
\hline & Esforço físico & $\begin{array}{l}\text { Dores na coluna vertebral, ombros, braços, } \\
\text { antebraços e punhos }\end{array}$ \\
\hline \multicolumn{3}{|l|}{ Recomendações } \\
\hline \multicolumn{3}{|c|}{$\begin{array}{l}\text { É importante que a gestão busque capacitar os trabalhadores em técnicas de levantamento, transporte e manuseio de materiais, } \\
\text { equipamentos e exercícios de reforço corporal preventivo. }\end{array}$} \\
\hline
\end{tabular}

\section{Ergonomia cognitiva}

Refere-se à demanda por processos mentais, tais como: percepção, memória, raciocínio e resposta motora. Abrange a carga de trabalho mental, tomada de decisão, interação homem-máquina, estresse, vigilância e desempenho de habilidades e capacitação.

\section{Ergonomia cognitiva na rede de frio de imunobiológicos}

- Para serem distribuídas, muitas vezes as vacinas são transportadas por via aérea. O cancelamento e/ou o atraso dos voos provocam uma preocupação (estresse) referente a diversos aspectos: a manutenção da 
temperatura para atender às condições técnicas de qualidade, a extensão do horário diário de trabalho, a reorganização do espaço fisco para armazenagem, entre outros.

- Quando na sala de vacinação há um número insuficiente de trabalhadores para vacinar um grande número de pessoas, isso gera estresse, pois ocasiona cansaço e preocupação em realizar um bom atendimento e com menor tempo de espera.

A seguir, um exemplo referente à ergonomia cognitiva do trabalho efetuado na Cenadi. Observa-se que a atividade de empilhamento de paletes solicita do trabalhador uma carga mental que exige conhecimento, precisão e destreza.

Quadro 2 - Ergonomia cognitiva na rede de frio

\begin{tabular}{|c|c|c|}
\hline \multirow{2}{*}{$\begin{array}{l}\text { Setor } \\
\text { Descrição da atividade }\end{array}$} & \multicolumn{2}{|l|}{ Câmara fria } \\
\hline & \multicolumn{2}{|c|}{ Empilhar os paletes com caixas de imunobiológicos } \\
\hline Foto da atividade & Riscos ergonômicos identificados & Possíveis consequências \\
\hline & Exigência de atenção e habilidade & Estresse \\
\hline \multicolumn{3}{|l|}{ Recomendações } \\
\hline
\end{tabular}

\section{Ergonomia organizacional}

Está relacionada com a otimização do sistema sociotécnico, incluindo suas estruturas organizacionais, políticas e de processos. Tópicos pertinentes incluem (IIDA, 2005, p. 3):

comunicações,

projeto de trabalho, 
* programação do trabalho em grupo,

* projeto participativo,

trabalho cooperativo,

cultura organizacional,

燐 organizações em rede,

teletrabalho,

* gestão da qualidade.

\section{Ergonomia organizacional na rede de frio de imunobiológicos}

- Antes de usar a paleteira, o trabalhador deverá ter recebido capacitação adequada às características tecnológicas do equipamento. Uma rota deverá ser previamente determinada para garantir a segurança do trabalhador e do ambiente.

- A caderneta de vacinação é uma forma de o indivíduo controlar e informar as vacinas já realizadas e aquelas a realizar. Quando o indivíduo vai ao posto de saúde querendo se vacinar e não apresenta o cartão de vacinação, recebe todas as vacinas referentes à sua idade, conforme orientação do Programa Nacional de Imunizações, do Ministério da Saúde. A ausência de um sistema único informatizado com todos os dados dos indivíduos dificulta o acesso às informações e pode aumentar o custo/ desperdício de doses repetidas de vacinas.

Em todo planejamento é fundamental que ocorra a interação entre os trabalhadores e os gestores. A ausência dessa relação pode ocasionar a ocorrência de riscos ergonômicos organizacionais.

O Quadro 3 apresenta algumas situações ou atividades de trabalho na rede de frio e suas possíveis consequências, quando não planejadas ou planejadas incorretamente.

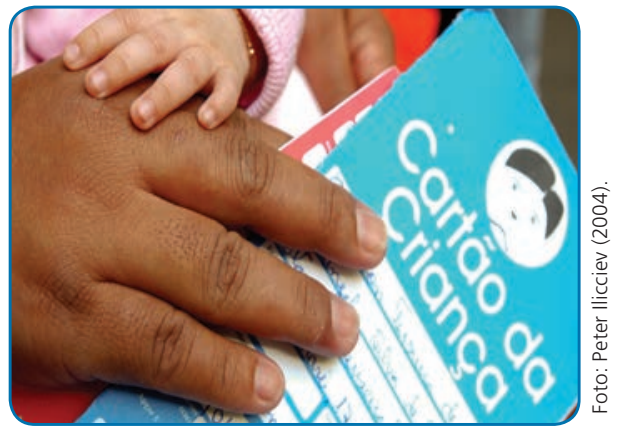

O cartão de vacinação é, atualmente, o documento utilizado para identificação e informação da situação das vacinas aplicadas. Fonte: Fiocruz imagens. 
Quadro 3 - Ergonomia organizacional na rede de frio

\begin{tabular}{|l|l|}
\hline Situações ou atividades de trabalho & $\begin{array}{l}\text { Possíveis consequências do planejamento } \\
\text { ou da realização incorreta }\end{array}$ \\
\hline Manutenção dos maquinários & Parada ou atraso da produção \\
\hline Compra de caixas térmicas & $\begin{array}{l}\text { Impossibilidade de acondicionamento dos } \\
\text { imunobiológicos }\end{array}$ \\
\hline Reuniões periódicas com as chefias & Insatisfação dos trabalhadores, erros etc. \\
\hline Acúmulo de tarefas & Estresse, fadiga, erros etc. \\
\hline Ritmo de trabalho acelerado & Estresse, fadiga, erros etc. \\
\hline $\begin{array}{l}\text { Uso de equipamento de proteção individual de } \\
\text { má qualidade }\end{array}$ & Desconforto, incidentes, acidentes etc. \\
\hline
\end{tabular}

A ergonomia organizacional deve valorizar uma cultura em que prevaleça o diálogo, os projetos em equipe, a escuta do trabalhador, fazendo- o ser participativo para alcançar a gestão pela qualidade.

\section{Para refletir}

Agora que você conhece um pouco mais sobre ergonomia, consegue perceber sua importância para o bom desempenho do trabalho e para sua saúde, como trabalhador?

Refletindo sobre o seu ambiente de trabalho, como você avalia as questões ergonômicas físicas, cognitivas e organizacionais?

\section{Classificação da ergonomia}

Iida (2005) classifica a ergonomia de acordo com o momento de sua utilização. Diversos autores como Orselli (2008), Freitas, Freitas e Lopes (2009) comungam da mesma classificação, conforme descrito a seguir.

\section{Ergonomia de concepção}

Ocorre na fase da elaboração do projeto da edificação, do mobiliário, do produto, da máquina, do ambiente ou do sistema. Prevê as probabilidades de futuras modificações e, geralmente, segue as normas exigidas pela legislação.

\section{Ergonomia de correção}

Atua na modificação do que já existe, quando se constata a necessidade de corrigir problemas de segurança, fadiga excessiva, doenças dos trabalhadores, espaço físico, condições ambientais inadequadas, quantidade e qualidade da produção. Envolve custos elevados, quando exige substituição de máquinas ou materiais. 
Pode atuar, por exemplo, na correção de posturas dos trabalhadores, colocação de dispositivos de segurança, modificações na iluminação, exaustão e ventilação, entre outras.

\section{Ergonomia de conscientização}

Busca, por meio da capacitação individual e/ou coletiva, desenvolver nos trabalhadores a capacidade de identificar e corrigir os problemas existentes no trabalho, além de ensiná-los a maneira mais adequada de utilização dos diversos componentes presentes em suas atividades.

\section{Ergonomia de participação}

Objetiva encontrar soluções ergonômicas junto aos trabalhadores e consumidores. A participação ativa de todos os implicados no problema envolve singularidades que, aparentemente, não se fazem perceber pelos analistas ou projetistas.

\section{Importante!}

É fundamental que o gestor da rede de frio de imunobiológicos se aproprie das contribuições da ergonomia, especialmente nos momentos de concepção, correção, conscientização e participação, porque é sua atribuição recomendar a implantação de ações ergonômicas que protejam a saúde do trabalhador.

Para finalizar nosso tema, vale ressaltar que não existe um modelo que contemple todas as situações de trabalho, mas o Manual de Aplicação da NR 17 apresenta as etapas mínimas que deverão ser contempladas numa AET, assim como o seu Anexo II (BRASIL, 2002).

\section{Considerações finais}

Como vimos no decorrer do capítulo, existe uma forte relação entre a tríade arquitetura-ambiência-ergonomia e a saúde e segurança dos trabalhadores. A arquitetura, ao projetar as edificações, poderá se utilizar dos elementos humanizadores da ambiência para criar espaços construídos seguros, saudáveis e acolhedores. Os conhecimentos da ergonomia irão, certamente, contribuir para um projeto arquitetônico humanizado, que compreende e acolhe as necessidades dos trabalhadores no exercício de suas atividades, nos aspectos físico, cognitivo e organizacional.

Os processos de trabalho na rede de frio de imunobiológicos, dentre as diversas caraterísticas que apresentam, necessitam de espaços arquitetônicos harmonizados com a ambiência, conforme as legislações vigentes 
(objetividade), e as subjetividades de todos que utilizam determinado ambiente. As diversas atividades realizadas nessa rede demandam movimentos que exigem, dos trabalhadores, a adoção de posturas com potenciais danos à saúde; nessas horas, valem os conhecimentos da ergonomia, que, ao compreender os riscos, propõe mudanças para garantir segurança e bem-estar aos profissionais.

Porém, todas essas questões só serão contempladas se houver uma gestão participativa que escute e valorize as experiências singulares dos trabalhadores, expressas por eles próprios, inclusive durante a construção, ou reconstrução, do mapa/mapeamento de riscos.

Por essas razões, é importante que você, trabalhador da rede de frio, analise seu espaço de trabalho e busque, junto à gestão, a mudança dos aspectos que demandam melhoria para alcançar uma boa ergonomia.

\section{Referências}

ALVES, L. A. dos R. O conceito de lugar. Arquitextos, ano 8, ago. 2007. Disponível em: <www. portalvitruvius>. Acesso em: 18 ago. 2013.

AZEVEDO NETO, F. P. B. Desenvolvimento de tecnologia de gestão para ambientes hospitalares, o caso do Instituto Fernandes Figueira-Fiocruz. Dissertação (Mestrado Profissional em Ciência e Tecnologia em Saúde) - Escola Nacional de Saúde Pública Sergio Arouca, Fiocruz, 2004.

BRASIL. Ministério da Saúde. Secretaria de Atenção à Saúde. Departamento de Ações Programáticas e Estratégicas. Lista de doenças relacionadas ao trabalho: Portaria n. 1.339/GM, de 18 de novembro de 1999. 2. ed. Brasília, DF, 2008.

BRASIL. Ministério da Saúde. Secretaria de Atenção à Saúde. Núcleo Técnico da Política Nacional de Humanização. Ambiência. 2. ed. Brasília, DF, 2010.

BRASIL. Ministério do Trabalho e Emprego. Manual de aplicação da Norma Regulamentadora NR 17. Brasília, DF, 2002.

BRASIL. Ministério do Trabalho e Emprego. NR 17: ergonomia: Portaria MTPS n. 3.751, de 23 de novembro de 1990. Diário Oficial da União, Brasília, DF, 26 nov. $1990 b$.

BRASIL. Ministério do Trabalho e Previdência Social. NR-15: atividades e operações insalubres: Portaria MTB n. 3.214, de 9 de junho de 1978. Diário Oficial da União, Brasília, DF, 6 jul. 1978.

CAMPOS, G. W. de S. Saúde paidéia. 3. ed. São Paulo: Hucitec, 2007.

CAMPOS, G. W. de S. Um método para análise e co-gestão de coletivos. São Paulo: Hucitec, 2000.

CARTA de Ottawa: Primeira Conferência Internacional sobre Promoção da Saúde. [S.I.]: Blog Opas, 1986. Disponível em: <www.opas.org.br/promoção/upload Arq/Ottawa.pdf>. Acesso em: 10 jun. 2013. 
CARTA do Caribe para a Promoção da Saúde. Assinada na I Conferência de Promoção da Saúde do Caribe, Trinidad e Tobago, em 4 de junho de 1993. Disponível em: <http://www.saudeemmovimento. com.br/conteudos/conteudo_frame.asp?cod_noticia=203>. Acesso em: 22 set. 2016.

CHING, Francis D. K. Dicionário visual de arquitetura. Tradução Julio Fischer. 4. tir. São Paulo: Martins Fontes, 2006.

COSTI, M. C. A influência da luz e da cor em salas de espera e corredores hospitalares. Porto Alegre: EDIPUCRS, 2002.

CUNHA, E. G. da (Org.). Elementos de arquitetura de climatização natural: método projetual buscando a eficiência nas edificações. Porto Alegre: Masquatro, 2006.

FALZON, P. Natureza, objetivos e conhecimentos da ergonomia: elementos de uma análise cognitiva da prática. In: FALZON, P. (Ed.). Ergonomia. São Paulo: Edgard Blücher, 2007.

FERREIRA, A. B. H. Novo dicionário da língua portuguesa. Rio de Janeiro: Nova Fronteira, 1975.

FREITAS, I. B.; FREITAS, K. B. L. Fatores ergonômicos ambientais. In: BITENCOURT, F. (Org.). Ergonomia e conforto humano: uma visão da arquitetura, engenharia e design de interiores. Rio de Janeiro: Rio Book's, 2011. v. 1, p. 65-104.

FREITAS, I. B.; FREITAS, K. B. L.; LOPES, S. O. F. Ergonomia. In: COSTA, M. A. F; COSTA, M. F. B. (Org.). Biossegurança geral: para cursos técnicos da área de saúde. Rio de Janeiro: Publit, 2009.

GÓES, R. de. Manual prático de arquitetura hospitalar. São Paulo: Edgard Blücher, 2004. p.43.

IIDA, I. Ergonomia: projeto e produção. 2. ed. rev. e ampl. São Paulo: Edgard Blücher, 2005.

LAMBERTS, R.; DUTRA, L.; PEREIRA, F. O. R. Eficiência energética na arquitetura. São Paulo: PW, 1997.

LOPES, M. C. M. Apostila do Programa de Educação de Jovens e Adultos: ensino médio. Disciplina de Educação Artística. Laboratório de Manutenção em Equipamentos Médico-Hospitalares-Fiocruz. Rio de Janeiro: Fiocruz, 2002.

OLIVEIRA, T. A.; RIBAS, O. R. Sistemas de controle das condições ambientais de conforto. Brasília, DF: Ministério da Saúde, 1995.

OKAMOTO, J. Percepção ambiental e comportamento: visão holística da percepção ambiental na arquitetura e na construção. São Paulo: Mackenzie, 2002.

ORSELLI, O. T. A ergonomia de conscientização e o comitê de ergonomia. São Paulo: Mundo Ergonomia, 2008. Disponível em: <http://www. mundoergonomia.com.br/website/artigo.asp?cod=1 847\&idi=1\&moe=74\&id=15229 . . Acesso em: 4 jul. 2011.

RIO, R. P.; PIRES, L. Ergonomia: fundamentos da prática ergonômica. 3. ed. São Paulo: LTr, 2001. 
ROMERO, M. A. B. Princípios bioclimáticos para o desenho urbano. 2. ed. São Paulo: ProEditores, 2000.

SILVA, A. C.; FREITAS, I. B.; FREITAS, K. B. L. Constituição da ambiência hospitalar a partir da gestão de coletivos. In: MONKEN, M.; DANTAS, A. V. (Org.). Iniciação científica na educação profissional em saúde: articulando trabalho, ciência e cultura, v. 5. Rio de Janeiro: Fiocruz/Escola Politécnica de Saúde Joaquim Venâncio, 2009. p. 13-41.

TÁVORA, F. Da organização dos espaços. Porto: FAUP, 2007.

TOLEDO, E. Ventilação natural das habitações. Maceió: Edufal, 1999.

SUDSILOWSKY, S. Entre a razão e o senso comum: uma análise morfológica da configuração do espaço na arquitetura moderna (Trabalho apresentado na sessão de Comunicações: Temas Livres do XXV Congresso Brasileiro de Ciências da Comunicação). Salvador, 2002. 


\section{Noções gerais sobre biossegurança e a questão do incêndio}

Paulo Roberto de Carvalho e Marcello de Moura Coutinho

O planeta Terra vem se transformando rapidamente, e isso se deve ao acelerado crescimento dos países, sustentado pelo avanço da ciência e da tecnologia. Não resta dúvida que o progresso pode beneficiar a sociedade, pois, até pouco tempo, vários bens não estavam disponíveis, tendo em vista o alto custo da produção. A produção de novos medicamentos, produtos químicos e de vacinas, em geral, assim como de diversos insumos utilizados na rede de frio de imunobiológicos é oriunda da descoberta de novas tecnologias.

Outro exemplo de novas pesquisas, materiais e tecnologias na rede de frio é a variedade de embalagens térmicas. Essas embalagens são produzidas com material térmico do tipo poliuretano ou poliestireno expandido, por exemplo, o isopor. Certamente, enquanto um profissional responsável pela organização das caixas térmicas, que vão garantir a manutenção da temperatura de conservação dos imunobiológicos, está envolvido nessa atividade, as indústrias do ramo das embalagens térmicas também estão realizando pesquisas de outros materiais que serão capazes de oferecer proteção ainda maior no transporte de produtos perecíveis, num futuro próximo.

O fato de a ciência e a tecnologia se desenvolverem aceleradamente remete às instituições de saúde e às demais que desenvolvem atividades correlatas a responsabilidade de se prepararem para acompanhar esse desenvolvimento. Enquanto alicerces primordiais de uma instituição, os trabalhadores e as equipes multiprofissionais precisam ser eficazmente formados e capacitados, de forma a contribuir com resultados confiáveis e de qualidade. 


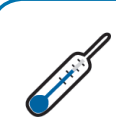

Neste capítulo, são apresentados aspectos mais gerais sobre a biossegurança, com a finalidade de introduzir essa questão. Orientações mais específicas quanto aos procedimentos no âmbito da rede de frio de imunobiológicos podem ser encontradas no Manual do PNI, disponível em: http://bvsms. saude.gov.br/bvs/publicacoes/ manual_rede_frio4ed.pdf
Organismos geneticamente modificados (OGM) são aqueles cujo material genético foi alterado através de técnicas de engenharia genética. Podem ser desenvolvidos apenas para fins de pesquisa ou, como é o caso de milho e soja, por exemplo, para melhorias que otimizam a produção desses alimentos, maximizando os lucros com as safras.
Os trabalhadores menos experientes e sem formação adequada apresentam maior dificuldade para reconhecer situações perigosas do que os mais experientes e capacitados. Além disso, podem também não estar cientes das responsabilidades exigidas para os cargos que ocupam, bem como do direito de questionar se as atividades a serem executadas são potencialmente perigosas.

Com o objetivo de lhe proporcionar uma reflexão sobre os riscos à sua saúde e à segurança no trabalho, neste capítulo discutimos pontos relacionados à biossegurança, como seus aspectos éticos, boas práticas e qualidade. Além disso, apresentamos também algumas noções gerais sobre a questão do incêndio.

\section{Biossegurança}

A biossegurança está diretamente ligada à vida, pois, etimologicamente, o significado da palavra é compreendido por dois componentes: a raiz grega bio, cujo significado é vida, e "segurança", que exprime a qualidade ou condição de estar seguro, livre de danos e perigos eventuais (COSTA; COSTA, 2010; HOUAISS; VILLAR, 2009).

Retomando a discussão iniciada no capítulo anterior, segundo a Anvisa, biossegurança Figura 1 - Símbolo internacional de biossegurança

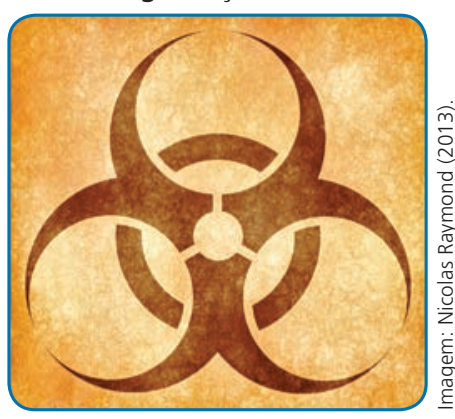

Fonte: Freelmages.com refere-se à "condição de segurança alcançada por um conjunto de ações destinadas a prevenir, controlar, reduzir ou eliminar riscos inerentes às atividades que possam comprometer a saúde humana, animal e o meio ambiente" (AGÊNCIA NACIONAL DE VIGILÂNCIA SANITÁRIA, 2016).

No Brasil, a biossegurança se insere em dois momentos distintos.

O primeiro é sustentado pela Lei n. 11.105, de 24 de março de 2005, que estabelece normas de segurança e mecanismos de fiscalização para a manipulação e comercialização de organismos geneticamente modificados (OGM) e seus derivados, além das pesquisas com célulastronco embrionárias.

Num segundo momento, a biossegurança se faz presente nos locais de trabalho em que os OGM não estão presentes, ou seja, em ambientes em que os agentes ocupacionais se fazem presentes - como é o caso da rede de frio de imunobiológicos. A legislação referente a esse segundo momento é a NR 32, que trata da segurança e saúde do trabalho em 
estabelecimentos de saúde, aprovada pela Portaria n. 485, do Ministério do Trabalho e Emprego, de 4 de novembro de 2005.

A biossegurança também abrange outras questões importantes nos dias atuais, como as relacionadas aos impactos ambientais (CARVALHO, 2008; COSTA; COSTA, 2010).

Para que executem as atividades sob suas responsabilidades de forma segura, isto é, sem que se exponham às adversidades potencialmente presentes no ambiente de trabalho, é essencial um esforço da instituição para formação dos profissionais. Conceitos e preceitos de biossegurança deverão compor o conteúdo programático de programas de capacitação em prevenção de acidentes, tendo em vista sua relação direta com as necessidades cotidianas dos profissionais em diversos setores da vida, em especial no ambiente de trabalho.

Isso demandará da instituição mais do que a transmissão de informações para a execução da tarefa. Uma instituição deverá ser gestora e promotora de saberes fundamentais e necessários para as práticas seguras. Gerir conhecimentos em prevenção de acidentes é relevante para que uma instituição garanta a integridade do seu quadro funcional, bem como de suas instalações.

\section{Para refletir}

No seu entendimento, quais setores da sua instituição merecem ser analisados no que tange à prevenção de acidentes? Existem pontos evidentes, capazes de gerar situações de alta complexidade, mas que não são observados pela maioria dos profissionais? Qual o seu comportamento frente às situações complexas e quais suas atitudes em relação a isso?

O ensino da biossegurança no ambiente de trabalho, por exemplo, abre possibilidades para reflexões, tendo em vista ser um campo de estudo que vai ao encontro das necessidades do trabalhador em geral, principalmente daquele que desempenha atividades profissionais em condições potencialmente adversas. Nesse contexto se enquadra a rede de frio de imunobiológicos, que engloba atividades relacionadas a armazenamento, conservação, manipulação, distribuição e transporte de imunobiológicos do PNI.
No que se refere à capacitação do quadro funcional, e aqui incluise a biossegurança, essa deverá ser abrangente sob todos os aspectos e adaptada ao nível de conhecimento do pessoal. 


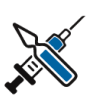

\section{Atenção!}

O contato do gelo seco com a água poderá aumentar a sublimação do dióxido de carbono, acarretando o aumento de asfixia.

No que tange à proteção dos equipamentos, $\mathrm{O} \mathrm{CO}_{2} \mathrm{em}$ contato com a umidade produz o ácido carbônico, capaz de corroer alguns metais.

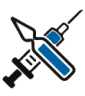

No tocante à biossegurança, os agentes ocupacionais são classificados em cinco grupos, conforme tratamos no Capítulo 12,"Saúde e segurança do trabalhador na rede de frio de imunobiológicos":

Grupo 1- Agentes químicos; Grupo 2- Agentes físicos; Grupo 3- Agentes biológicos; Grupo 4- Agentes ergonômicos; e Grupo 5-Agentes mecânicos.

\section{Exemplo de situação envolvendo biossegurança na rede de frio}

Na área de armazenamento e transporte de imunobiológicos, o gelo seco é frequentemente utilizado. Ele é composto de dióxido de carbono $\left(\mathrm{CO}_{2}\right)$, um gás de alta densidade e inodoro, que se mantém sólido a baixas temperaturas mas, em temperatura ambiente, volta ao estado gasoso.

À medida que o gelo seco sublima (passa do estado sólido para o gasoso), o $\mathrm{CO}_{2}$ é liberado e fica disponível no ar, de forma que podemos respirá-lo. Quando as concentrações de dióxido de carbono são extremas (superior a 20\%) em espaços confinados ou inadequadamente ventilados, pode ocorrer a anóxia (ausência de oxigênio no ar), que se traduz na possibilidade de acidentes graves e prejuízo para a saúde dos trabalhadores. Em alguns casos, a vítima não percebe o processo da asfixia. Demais sintomas podem incluir perda de consciência e de funções motoras, aumento da taxa de respiração ou aceleramento dos batimentos cardíacos. Danos ao sistema nervoso não estão descartados.

Além disso, o gelo seco apresenta a propriedade de gerar queimaduras quando entra em contato com a pele. Esse contato direto, sem a devida proteção, pode ocasionar o congelamento dos lábios. Em elevadas concentrações é capaz de produzir dores de cabeça, sonolência, vertigem, excitação, extrema salivação, vômitos e inconsciência.

Algumas medidas de segurança deverão ser adotadas, tendo em vista a periculosidade da exposição ao material: obrigatoriedade do uso de luvas isolantes, protetor para os olhos, pinças e vestimentas adequadas. No que concerne ao ambiente onde é manipulado o gelo seco, esse deverá ser dotado de sistema de ventilação eficaz, de modo a não permitir que o oxigênio do ar seja deslocado na zona de respiração dos trabalhadores.

Essa diversidade de atividades favorece a possibilidade de serem gerados acidentes e danos à saúde do trabalhador, em especial quando os profissionais estão submetidos a esforços repetitivos, movimentação de cargas, exposição a baixas temperaturas, ruídos e aos demais agentes ocupacionais, somados a uma potencial ausência de treinamento e capacitação.

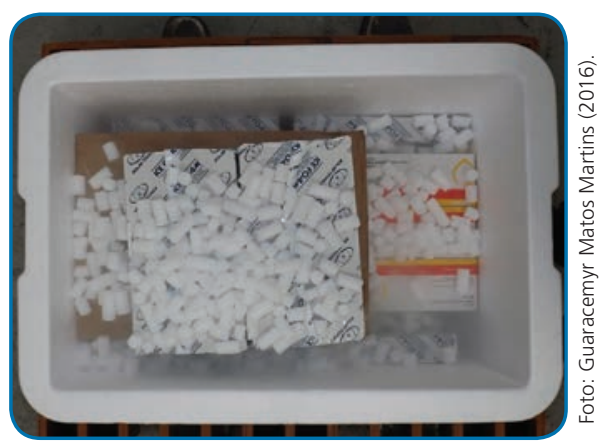

Gelo seco.

Salas de vacinas são locais em que os cuidados referentes à biossegurança também devem ser observados. A não observância das normas de biossegurança, assim como imperícia, ausência de instruções sobre 
o emprego de práticas seguras, ausência ou uso inadequado do EPI são alguns dos fatores capazes de contribuir para a geração de acidentes. Acidentes com material perfurocortante, em especial envolvendo as seringas contendo vacinas, os cortes nas mãos derivados de ampolas de vidro e a potencial projeção de material nos olhos desprotegidos são agravados, principalmente, quando os acidentados menosprezam a situação e não percebem o risco, demorando a relatar os acidentes e procurar o serviço de saúde (MACÊDO; FREIRE; ANDRADE, 2013; SILVA et al., 2010).

Com o objetivo de minimizar as situações de risco potencial para os trabalhadores durante as suas atividades na rede de frio, há regras de segurança e de prevenção. O Ministério do Trabalho e Emprego (MTE), a partir da Norma Regulamentadora n. 06, estabelece o uso obrigatório de equipamentos de proteção individual (EPIs). Segundo essa norma, EPI é "todo dispositivo ou produto, de uso individual, utilizado pelo trabalhador, destinado à proteção de riscos suscetíveis de ameaçar a segurança e a saúde no trabalho" (Norma Regulamentadora n. 06) (BRASIL, 2015).

Segundo a NR 32, a todo trabalhador de saúde deve ser fornecida, gratuitamente, pelo PNI, imunização ativa contra tétano, difteria, hepatite $B$ e ao que foi estabelecido no PCMSO. Sempre que houver vacinas eficazes contra outros fatores biológicos aos quais os trabalhadores estão ou poderão estar expostos, o empregador deve fornecê-las gratuitamente (BRASIL, 2015).

De acordo com as instruções preconizadas pela NR 32, os trabalhadores que exercem atividades em serviços de saúde, bem como aqueles que exercem atividades de promoção e assistência à saúde, igualmente os trabalhadores que exercem funções em salas de vacinação, estarão potencialmente protegidos se utilizarem adequadamente os EPIs e EPCs (SILVA et al., 2010).

Os EPIs mais utilizados na rede de frio de imunobiológicos são apresentados na Figura 2. Eles se destinam à proteção contra o frio intenso das câmaras frias, onde são armazenados os imunobiológicos nas centrais de distribuição.

Quando não são adotadas medidas de controle, a exposição aos agentes ocupacionais presentes nos locais de trabalho pode produzir danos aos trabalhadores e, também, comprometer a produtividade da instituição. São capazes de afetar a saúde do trabalhador a curto, médio e longo prazos, gerando lesões e doenças variadas. Complexidades variadas estão

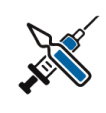

Você não poderá, em nenhum momento, reencapar agulhas, nem tentar retirá-las da seringa com as mãos. Todo o conjunto formado pela seringa e pela agulha deverá ser descartado em caixas adequadas.
A NR 32 foi abordada no Capítulo 12, "Saúde e segurança do trabalhador na rede de frio de imunobiológicos", deste livro.
Relembrando o que foi mencionado no capítulo anterior, os incidentes, em geral, não causam danos, e a integridade do profissional é mantida. Já os acidentes, dependendo do tipo e da magnitude, são capazes de gerar vítimas, em muitas situações, afastando o acidentado temporária ou permanentemente de suas funções. 
Figura 2 - EPI da rede de frio de imunobiológicos de uso obrigatório

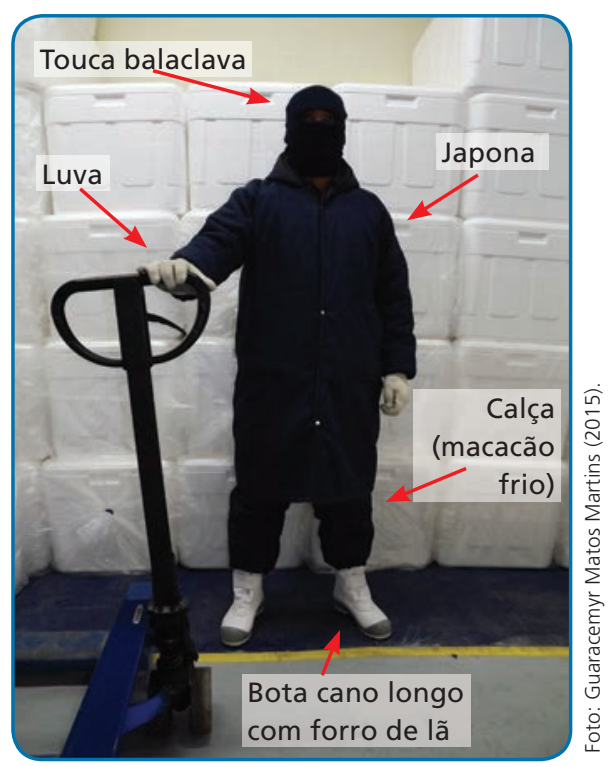

presentes, em grande parte, nos locais de trabalho e, se somadas à ausência de informações e de conhecimentos acerca das medidas preventivas por parte dos profissionais, potencializam a geração de incidentes e de acidentes, muitas vezes de grande porte.

\section{Para refletir}

Faça uma análise minuciosa do seu ambiente de trabalho. Você identifica eventos capazes de gerar potenciais situações adversas? Esses eventos estão associados a um único tipo de agente ocupacional ou a um somatório de agentes? Que medidas você percebe como capazes de mitigar ou eliminar a situação?

A biossegurança é algo dinâmico, vai além do entendimento dos conceitos inerentes ao tema e da aplicação e do atendimento às normas de prevenção e controle nos ambientes de trabalho. Além da capacidade de compreensão e execução, os indivíduos carecem de uma adequada e consistente formação educacional que os faça hábeis para identificar, minimizar, controlar e eliminar situações capazes de abalar a integridade física e/ou afetá-los por alguma doença que os afastem temporária ou definitivamente de suas atividades (BONIS; COSTA, 2009). Além disso, a instituição deverá dispor de toda a estrutura necessária para detectar, analisar e corrigir falhas, bem como propor planos de treinamento e capacitação diferenciados. Planos de intervenção imediata para mitigar, eliminar ou administrar incidentes ou acidentes deverão estar disponíveis.

\section{Aspectos comportamentais e éticos}

A palavra ética é derivada do grego ethos, que significa aquilo que pertence ao caráter, ou seja, ao modo de ser de uma pessoa.

Uma definição de ética foi apresentada no Capítulo 10, "Organização do trabalho", deste livro.
A formação do trabalhador da rede de frio de imunobiológicos requer não só a inclusão de conhecimentos inerentes às atividades rotineiras, mas de outros que estimulem a capacidade cognitiva, a aquisição de saberes e novas competências e ampliem a autonomia do profissional. Nessa proposta de formação, aspectos comportamentais e éticos se somam e há troca de informações, resultando dessa permuta ações de promoção da qualidade de vida no trabalho.

Num ambiente de trabalho, o êxito na obtenção de resultados confiáveis e o sucesso profissional estão diretamente relacionados ao grau de conhecimento do trabalhador e às relações interpessoais. Desse modo, no mundo atual, ações que estimulem esse trabalhador a aprender a 
conhecer (ou seja, tomar posse dos instrumentos da compreensão); a aprender a fazer, para ser capaz de tomar decisões; a aprender a viver, para participar e cooperar; e a aprender a ser são inquestionavelmente relevantes (OS QUATRO..., 1996).

A questão ética exercida no ambiente de trabalho está intrinsecamente relacionada à formação moral do indivíduo. O conjunto de valores morais e princípios que norteia a conduta do ser humano na sociedade faz parte da ética. Num sentido mais amplo, a ética está intrinsecamente relacionada ao exame dos hábitos do homem e do seu caráter, em geral. Vários elementos compõem os princípios éticos, conforme apresentados na Figura 3.

Figura 3 - Ética

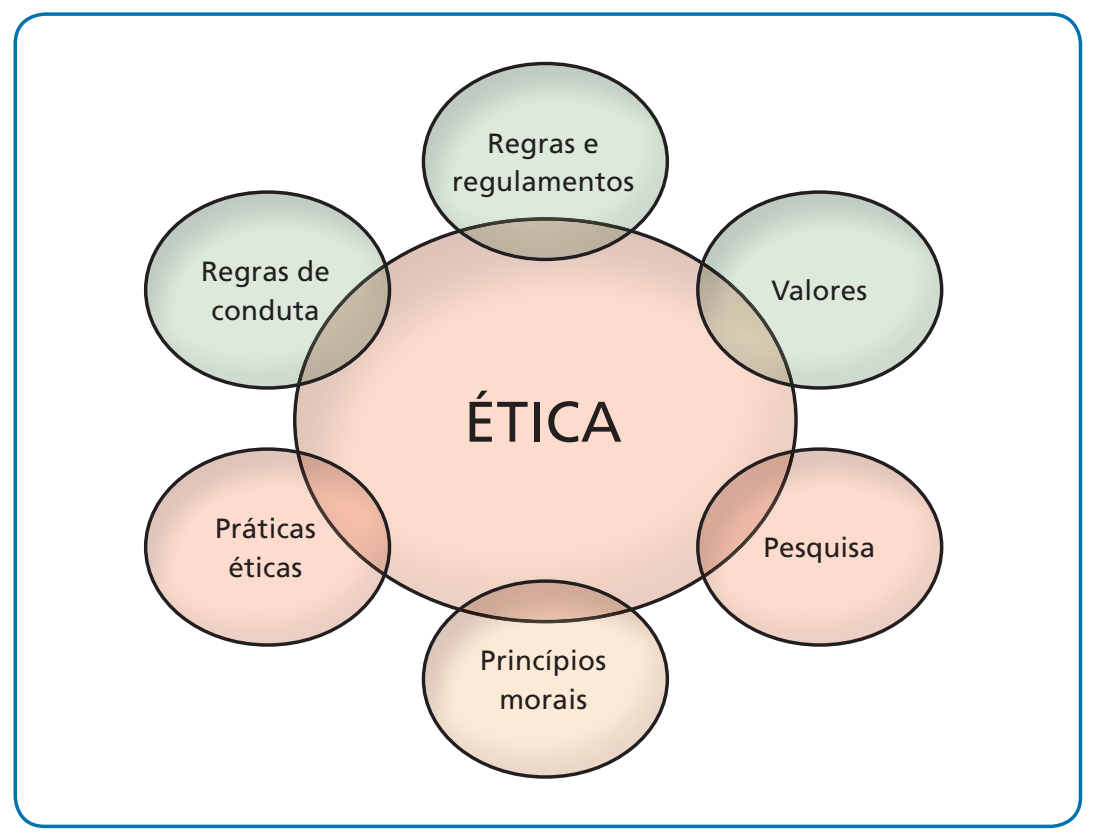

Fonte: Adaptado de http://carleton.ca/psychology.

A conduta ética aplicada ao trabalho merece reflexão, tendo em vista que, raramente, o homem trabalha sozinho, pois faz parte de uma coletividade de trabalhadores que são obrigados a conviver por várias horas, dias, meses e anos. O viver bem em comunidade no trabalho remete ao respeito ao próximo, ao cumprimento das diretrizes da instituição, ao trabalho de acordo com as normas e os protocolos estabelecidos, a saber receber instruções, incumbências e cumprir prazos, bem como à observância dos preceitos de programas de prevenção em vigor.

Os princípios éticos e os princípios de biossegurança estão amplamente alinhados. O limite entre eles pode ser muito tênue e, às vezes, classi- 
Bullying é um termo da língua inglesa (bully significa valentão) que se refere a todas as formas de atitudes agressivas, verbais ou físicas, intencionais e repetitivas, que ocorrem sem motivação evidente e são exercidas por um ou mais indivíduos com o objetivo de intimidar ou agredir outra pessoa que não tem possibilidade ou capacidade de se defender, sendo realizadas dentro de uma relação desigual de forças ou poder e causando dor e angústia.

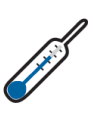

Para saber mais sobre práticas éticas, leia Boas práticas químicas em biossegurança, de Paulo Roberto Carvalho. 2. ed. Rio de Janeiro: Interciência, 2013. ficado de acordo com as concepções das partes envolvidas. As áreas de competências para a prática da ética em biossegurança no ambiente de trabalho incluem: o cumprimento da legislação, assim como a utilização de equipamentos de proteção individual e coletiva.

Os princípios éticos associados à biossegurança facultam aos trabalhadores a responsabilidade de exercer suas atribuições observando uma série de atitudes, que nem sempre estão descritas nos códigos de todas as profissões. No entanto, apesar da ausência de informações descritas, isso não livra os profissionais do cumprimento do bom senso e dos deveres. Qualquer que seja a categoria profissional, o conjunto de princípios e regras de conduta é fundamental para regular o exercício da profissão. A opção por uma profissão é livre, mas, após a sua escolha, o indivíduo assume a responsabilidade de buscar, atualizar e complementar saberes, para que, no desenvolvimento das atividades, essas não resultem em constrangimentos, malefícios, danos à comunidade de trabalhadores e à instituição.

A biossegurança está intrinsecamente relacionada à vida das pessoas - social, profissional e eticamente. Os indivíduos inseridos em qualquer ambiente de trabalho não podem perder a dimensão de que a prática da biossegurança se sustenta por um conjunto de conceitos, preceitos e atitudes ético-profissionais. Somado a isso, aquele que está à frente de uma atividade profissional é responsável pela sua integridade física, bem como a dos seus pares e do patrimônio da instituição, de uma forma geral. Assim, a revisão da conduta pessoal, por parte do trabalhador, e a atualização dos conhecimentos técnicos relacionados aos aspectos éticos, legais e normativos são imprescindíveis.

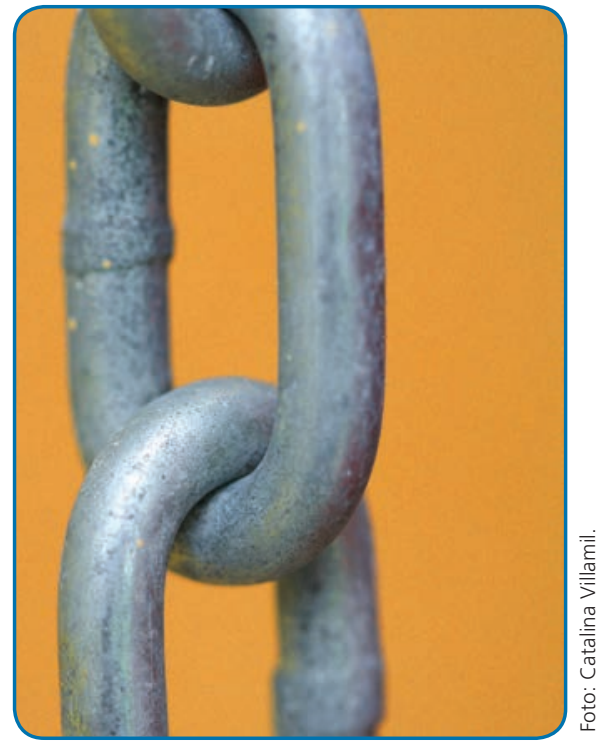

Educação, respeito, honestidade, sigilo das informações, interlocução e cooperação entre os trabalhadores, independentemente do grau hierárquico, propiciam um ambiente saudável. A interlocução entre os atores são elos de uma corrente de atitudes éticas. Fonte: Freelmages.com.
Atos e atitudes que infringem os preceitos éticos, tais como assédio moral, sexual, bullying, cyberbullying, não poderão ser tolerados no ambiente de trabalho, bem como as ofensas e violências físicas. 
No que tange às tarefas programadas e relacionadas ao trabalho, essas deverão ser executadas atendendo a normas e protocolos estabelecidos. O reconhecimento, por parte do profissional, do seu limite de conhecimento deverá ser informado de modo que as atividades sejam realizadas por pessoal qualificado. Um profissional desqualificado à frente de uma tarefa poderá gerar uma situação extremamente grave, com exposição dele próprio, da coletividade de profissionais e das instalações prediais.

\section{Biossegurança no âmbito das boas práticas}

Como os profissionais passam cerca de $1 / 3$ de sua vida à frente de atividades, desempenhando papéis importantes, na maioria dos locais de trabalho, é necessário que esse profissional goze de bem-estar físico, mental e social. Além disso, é importante reconhecer que os ambientes de trabalho inseridos em edifícios saudáveis são capazes de ofertar conforto ao profissional e, ainda, de contribuir para um ambiente ecologicamente equilibrado.

Um edifício saudável é uma construção cujo desenho arquitetônico ofereça as condições técnicas ideais para a segurança de seus ocupantes, além de promover a qualidade ambiental. A qualidade do ar interior (QAI) está entre as muitas questões a serem observadas a fim de se evitar os impactos adversos sobre o bem-estar e a saúde dos ocupantes.

Uma variedade de compostos potencialmente perigosos presentes nos ambientes e derivados das emissões dos materiais de construção, de equipamentos e demais produtos específicos às atividades desenvolvidas é capaz de prejudicar a saúde das pessoas que ali estão inseridas. A poluição atribuída a microrganismos, proveniente de espécies de bactérias e de fungos, merece atenção, não devendo ser negligenciada (AGÊNCIA PORTUGUESA DO AMBIENTE, 2009).

O objetivo principal da adoção das boas práticas no ambiente de trabalho é a garantia de que, no desenvolvimento das atividades, não ocorrerão eventos estranhos às práticas corretas. A observância dos requisitos operacionais, de segurança e de qualidade é fundamental para garantir o bom andamento das atividades e o cumprimento das metas.

Uma boa prática importante é, como já dissemos, a formação dos profissionais. Os trabalhadores novatos e os estagiários deverão receber atenção diferenciada para não se expor, desnecessariamente, aos agentes ocupacionais. A eles serão garantidas as orientações e informações pertinentes para a execução das tarefas.
No mundo do trabalho, profissionais motivados, qualificados e, acima de tudo, saudáveis são essenciais para o sucesso de uma instituição.

Edifícios saudáveis podem ser dotados de comodidades como academias, creches, local para descanso e demais instalações que contribuam para o bem-estar.

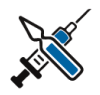

A umidade e a ventilação deficientes são capazes de contribuir para o desenvolvimento de agentes biológicos, potenciais causadores de doenças. 
Metodologias do trabalho, demais informações específicas e princípios de segurança deverão estar descritos em protocolos, preferencialmente nos Procedimentos Operacionais Padronizados (POP) ou manuais, que devem ficar à disposição de todos, sem distinção.

\section{Procedimentos Operacionais Padronizados (POP)}

POP se caracteriza por instruções escritas que visam à uniformidade de uma função específica. Um POP adequadamente elaborado pode ser usado para satisfazer os requisitos especificados de conformidade relativos a um produto, processo, sistema, uma pessoa ou um organismo.

A conformidade está relacionada a processos que deverão gerar resultado satisfatório, ou seja, que atendam a determinado requisito estabelecido por normas, regulamentos e preceitos.

O POP é um tipo de documento recomendado para os procedimentos que representam potenciais riscos para a saúde e a segurança do trabalhador.

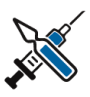

As atividades e os treinamentos referentes à prevenção de acidentes deverão ser igualitários, para todo o conjunto de trabalhadores, sem distinção. Em termos de segurança, a parceria entre empregados e empregadores é mutuamente benéfica, pois incentiva ambas as partes a assumirem suas responsabilidades quanto à implantação de programas de saúde.

Auditoria é o exame analítico de uma empresa ou instituição. O papel da auditoria interna é fornecer uma garantia independente de que a gestão de riscos de uma organização, a governança e os processos de controles internos estão funcionando de forma eficaz.
O trabalhador deverá ser orientado a seguir o POP referente à sua atividade, o qual deve ser atualizado, caso haja alterações nos procedimentos. Além disso, atividades voltadas à prevenção de acidentes e às práticas seguras serão desenvolvidas sempre que forem necessárias, como parte da formação do profissional.

O planejamento de atividades, elucidando todas as dúvidas dos trabalhadores, também faz parte das recomendações de boas práticas. Também é indicada a realização de auditorias que visem à observância:

* do cumprimento das normas (como as coisas estão sendo feitas);

* da valorização do trabalho (se o que é importante está sendo realizado);

*a compatibilidade social (profissionais se ajudando mutuamente para cumprir metas e evitar acidentes);

* do suporte organizacional (políticas de segurança, procedimentos corretos, comunicação efetiva, incentivos etc.);

* da análise do ambiente de trabalho (senso de comunidade, visão compartilhada, cooperação entre os pares etc.), a fim de corrigir as não conformidades.

No que tange à elaboração de programas de saúde abrangentes com foco na biossegurança, as instituições poderão buscar parcerias com outras instituições, fornecedores de produtos, de equipamentos, de materiais e demais organizações de comprovada experiência no tema. 
Alguns fatores deverão ser considerados nos ambientes de trabalho para garantir que as ações de biossegurança sejam efetivamente garantidas, dentre os quais se destacam:

avaliação dos perigos no ambiente de trabalho, da saúde dos profissionais, bem como dos gestores e demais membros da administração superior da instituição;

* promoção de ações de treinamento em saúde; de exames admissionais e periódicos e de vacinação para todos os membros da coletividade de profissionais;

* realização de seminários com sessões educacionais que estimulem melhorias de comportamento do quadro funcional em relação à saúde;

* programas de orientação e apoio aos profissionais das áreas de manutenção, projetos e engenharia para atender aos requisitos inerentes às normas de biossegurança, no que diz respeito a instalações, leiaute etc.

\section{Qualidade no trabalho no contexto da biossegurança}

Qualidade nos resultados é o que se espera na maioria das atividades profissionais. O desempenho e a obtenção de resultados confiáveis estão atrelados a vários fatores, em especial, à cultura organizacional, aos programas de gestão, às condições ambientais, à valorização dos

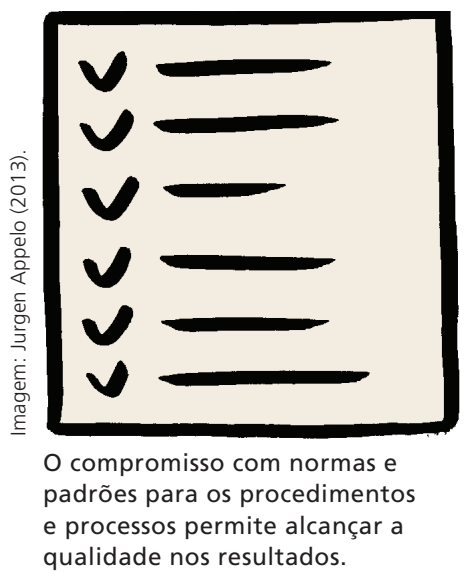
recursos humanos, às seguranças patrimonial e pessoal, além de investimento para a melhoria contínua dos processos.

Em um processo, a qualidade refere-se a uma medida de excelência ou uma condição da construção de algo livre de defeitos, deficiências e variações significativas. É provocada pelo compromisso rigoroso e consistente com o cumprimento de normas que permitam atingir a uniformidade de um produto, de modo a satisfazer as necessidades explícitas ou implícitas.
As necessidades explícitas referem-se àquelas que são percebidas pelo cliente, isto é, aquilo que o cliente procura encontrar em um produto, por exemplo, que as fotos do seu novo celular apresentem níveis de qualidade excelentes.
Para que seja atingido um grau de excelência, é fundamental atender a vários requisitos específicos, a fim de analisar o desempenho, eliminar os conflitos, implantar melhorias e alcançar resultados eficazes. 
As necessidades explícitas referem-se àquelas que são percebidas pelo cliente, isto é, aquilo que o cliente procura encontrar em um produto, por exemplo, que as fotos do seu novo celular apresentem níveis de qualidade excelentes.

As necessidades implícitas são aquelas que não estão claras para o cliente. Quando um produto é pensado para ser produzido, todas as necessidades deverão ser contempladas, pois o cliente, em um dado momento, as perceberá. Grosso modo é o que acontece, por exemplo, com o uso dos softwares processadores de textos, em que, aos poucos, o usuário descobre funções como o Ctrl $+C$; Ctrl $+V_{i}$ C $\operatorname{crl}+$ T etc., que ele não sabia que existiam, mas que atendem às suas necessidades de agilidade.

As inter-relações entre a qualidade esperada nos experimentos científicos, nas análises laboratoriais, na produção de fármacos e imunobiológicos e a biossegurança e as boas práticas laboratoriais são muito intensas. A implantação das técnicas de qualidade nos procedimentos de biossegurança é vital para garantir controles eficazes, padronização dos sistemas de prevenção e manutenção da reputação da instituição. Somando-se a isso, alguns benefícios poderão ser usufruídos a partir da implantação da prática de qualidade em biossegurança.

Programas de qualidade em biossegurança, baseados em estratégias e planos bem definidos, são capazes de melhorar as condições de trabalho e atender às legislações no que tange à segurança dos trabalhadores e aos potenciais impactos ao meio ambiente. Permitem, ainda, reduzir custos por meio da revisão dos protocolos de trabalho e de processos de compras de produtos, equipamentos e materiais em geral.

\section{Para refletir}

No seu local de trabalho existem normas e protocolos que visem manter a qualidade nos processos realizados? Eles são de conhecimento do conjunto de trabalhadores? São seguidos? Têm funcionado? O que você sugeriria de melhorias?

A implantação de sistemas de certificação e de gestão da qualidade permite a realização de auditorias, que são necessárias para averiguar o cumprimento das disposições planejadas e/ou estabelecidas previamente e se essas estão em conformidade ou não com os objetivos esperados.

A família ISO 9000, de normas internacionais, é considerada uma ferramenta capaz de auxiliar no desenvolvimento de planos para a implan- 
tação da biossegurança, com foco na qualidade. As normas ISO se aplicam a campos distintos, como materiais, produtos, processos e serviços. A utilização adaptada dessas normas serve de base para a elaboração de planos de prevenção, pois contribui na organização das áreas de trabalho, em geral, aponta para a necessidade de planejamento, identifica a necessidade de investimento na capacitação do quadro funcional, além de estabelecer padrões de qualidade (COSTA, 2000; INTERNATIONAL ORGANIZATION FOR STANDARDIZATION, 2013).

\section{ISO}

A International Organization for Standardization (Organização Internacional para Normalização) é a maior desenvolvedora mundial de normas internacionais. A sigla ISO é uma referência à palavra grega iso, que significa igualdade. A organização foi fundada em 1947 e está localizada em Genebra, Suíça. Já publicou mais de 19.500 normas internacionais, abrangendo quase todos os aspectos da tecnologia e de negócios. As normas internacionais são o estado da arte das especificações para produtos, serviços e boas práticas, ajudando a tornar as indústrias e instituições em geral mais eficientes e eficazes. Desenvolvidas por meio de consenso global, elas ajudam a quebrar as barreiras ao comércio internacional.

A atenção aos padrões de qualidade nos processos também é uma preocupação da rede de frio de imunobiológicos. De acordo com o Manual do PNI, a aferição da qualidade está relacionada ao aumento da garantia da qualidade e segurança na conservação, no armazenamento e na distribuição dos imunobiológicos (BRASIL, 2013).

\section{Noções gerais sobre a questão do incêndio}

A questão da segurança contra incêndios é de grande relevância, uma vez que o fogo é uma séria ameaça para qualquer unidade de trabalho, principalmente aquelas que empregam materiais de fácil combustão, inflamáveis, e apresentam um quadro funcional desprovido das informações necessárias para a prevenção e as respostas às emergências.

As causas mais comuns de incêndios em instalações comerciais, industriais, instituições científicas e hospitalares são o não cumprimento das regras de prevenção e a não implementação dos cuidados básicos de manutenção de equipamentos e das instalações prediais. Casos de incêndios originados de atos criminosos, pela ação de vandalismo ou pela proximidade às comunidades carentes, onde não existe a conscientização da população para a prevenção, não estão de todo descartados.

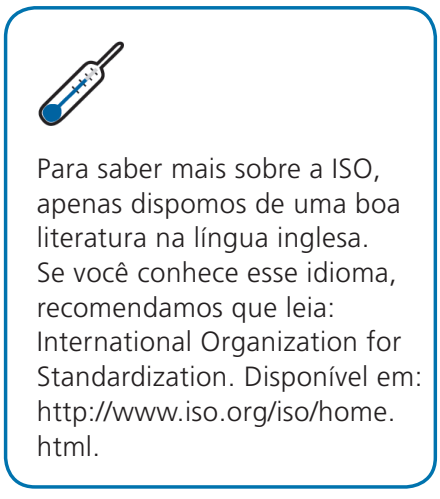

Para saber mais sobre a ISO, apenas dispomos de uma boa literatura na língua inglesa. Se você conhece esse idioma, recomendamos que leia: International Organization for Standardization. Disponível em: html.

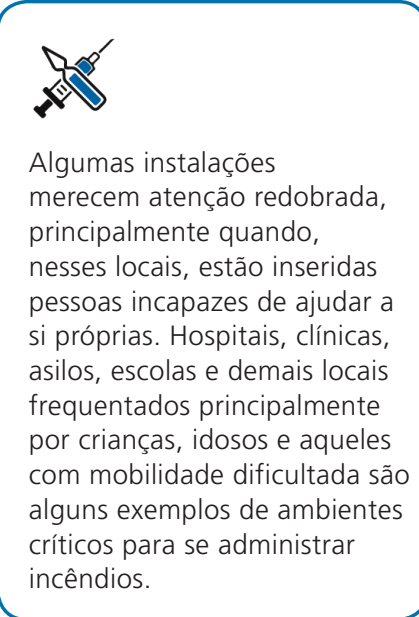


Gás é um dos quatro estados fundamentais da matéria (sendo os outros: sólidos, líquidos e o plasma). O que distingue um gás de líquidos e de sólidos é a grande separação das partículas.

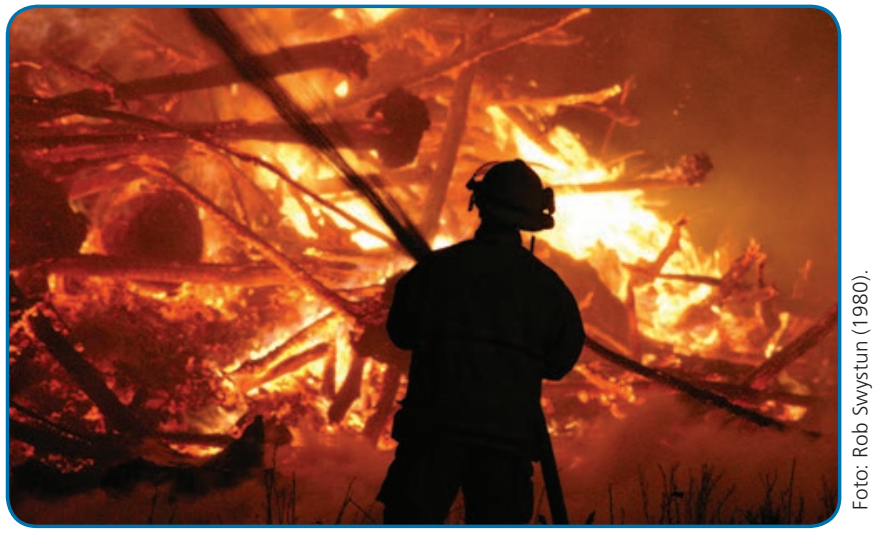

Incêndios podem destruir completamente o espaço de uma instituição. A melhor solução é preveni-los.

Equipamentos defeituosos ou utilizados indevidamente são potenciais fontes geradoras de incêndios, bem como sistemas de iluminação e ventilação, instalações elétricas sobrecarregadas, improvisadas e fora do padrão. Tubulações de gases industriais, gás liquefeito de petróleo (GLP) e gás natural, se não mantidas adequadamente, também são fontes geradoras e alimentadoras de incêndios. As causas, as circunstâncias e a extensão da propagação do fogo variam de acordo com o tipo de atividade executada (CARVALHO, 2013).

A prevenção contra incêndios em locais de armazenamento de materiais combustíveis, tais como isopor, papelão, madeira, papel etc., necessita de atenção reforçada, em virtude do rápido consumo desses materiais pelo fogo.

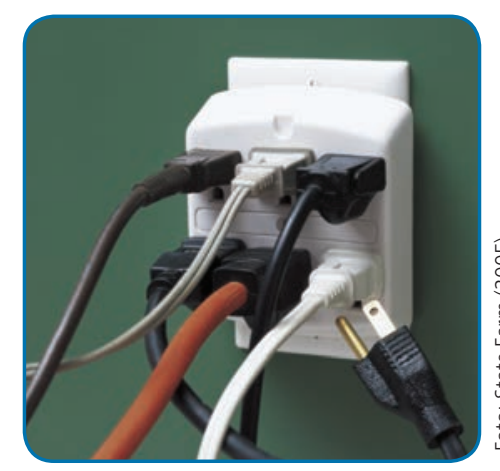

O uso inadequado das tomadas elétricas pode provocar sobrecarga, gerando potencial risco de incêndios.
As instalações onde se promovem o armazenamento e a distribuição de imunobiológicos necessitam da implementação de planos de prevenção contra incêndios, de modo que a integridade física de seus ocupantes esteja garantida.

Saídas de emergência e adoção de rotas de fuga são importantes, além do treinamento para o uso correto desses elementos de segurança. As rotas de fuga são meios estruturais, tais como: escadas de segurança, iluminação de emergência, área de refúgio devidamente sinalizada. As rotas de fuga, desobstruídas e seguras, devem ser capazes de assegurar a saída em qualquer ponto da edificação até o ponto de encontro estabelecido, sem que seja necessária a ajuda de terceiros (RODRIGUES et al., 2014). 
Figura 4 - Triângulo do fogo

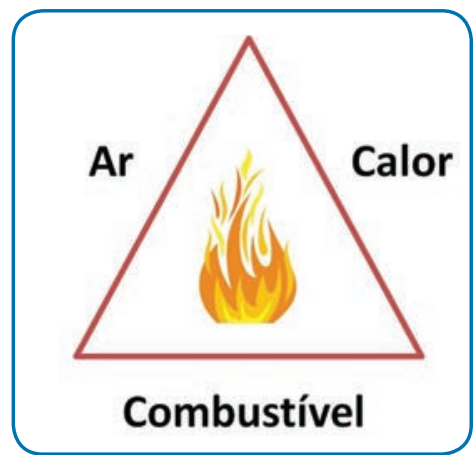

Fonte: Ícone do fogo: sundeiparora (s/d).
O primeiro passo para iniciar uma reflexão sobre controle e prevenção de incêndios é entender como, de fato, eles acontecem. Nos incêndios, três elementos importantes são necessários para o fogo prosperar e se espalhar nos ambientes. O combustível que queima, o ar que alimenta o fogo pela ação do oxigênio, e o calor que permite que o fogo continue queimando. Esses três elementos formam o Triângulo do fogo (Figura 4).

\section{Definições importantes para a configuração do triângulo do fogo}

Para controlar o fogo, pelo menos um dos lados do triângulo deverá ser removido. Para melhor entendimento sobre a questão da configuração do triângulo do fogo, algumas definições são importantes.

\section{Combustível}

Refere-se a qualquer material que possa ser queimado. Líquidos como solvente de tintas, gasolina, tintas em geral à base de óleo estão incluídos nessa categoria, uma vez que lançam gases que podem facilmente inflamar e começar um fogo, sob as condições certas. Tanques que armazenam gases (propano) são outra forma de material combustível. Vazamento de combustível das empilhadeiras movidas a gás liquefeito de petróleo (GLP), quando esses veículos não recebem os cuidados necessários no que tange à movimentação e à manutenção, pode ser considerado um fator relevante para a geração de princípios de incêndios.

Os materiais combustíveis mais comuns são madeira, borracha, tecido e alguns plásticos. Quando aquecidos a determinada temperatura, podem alcançar seu ponto de ignição.

Os combustíveis são classificados quanto:

*o estado físico, em sólidos, líquidos e gasosos. São materiais que queimam em profundidade e extensão e deixam resíduos.

*à volatilidade, em:

- voláteis: aqueles que não necessitam de aquecimento para desprender vapores inflamáveis, ou seja, emanam esses vapores à temperatura ambiente. São denominados produtos leves. Exemplos: gasolina, éter, tolueno etc.;

Inflamar é o que ocorre com materiais inflamáveis, ou seja, que podem facilmente pegar fogo. Um bom exemplo são os líquidos altamente inflamáveis, como álcool, éteres, cetonas e ésteres. É aconselhável mantê-los longe do fogo e de eletricidade.

Ponto de ignição é a temperatura mínima na qual os gases desprendidos dos elementos combustíveis entram em combustão apenas pelo contato com o oxigênio do ar, independentemente de qualquer fonte de calor.

A classificação quanto à volatilidade se aplica a combustíveis líquidos. 
- não voláteis: aqueles que necessitam de aquecimento para desprender vapores inflamáveis. São denominados produtos pesados. Exemplo: óleo combustível (diesel).

Quando o combustível é removido, o fogo se extingue. Esse processo de remoção pode ser realizado por meio da queima controlada ou da eliminação física do combustível, com estrita observância às normas de segurança. Caso o fogo esteja fora de controle, a retirada do material combustível deverá ser realizada por pessoal treinado (brigada de incêndio), ou pelos bombeiros e equipes bem supervisionadas.

\section{$\operatorname{Ar}$ (comburente)}

O ar atmosférico é composto por um conjunto de gases em proporções diferentes. Dentre eles, está o oxigênio $\left(\mathrm{O}_{2}\right)$ que respiramos e que atua como comburente em processos de queima, em volume de cerca de 20,93\%.

Quando o ar é removido, o fogo se extingue pela falta de oxigênio. Normalmente, a remoção do ar se faz por abafamento das chamas; para tal, se lança mão dos extintores de espuma, de dióxido de carbono $\left(\mathrm{CO}_{2}\right)$ ou de pó químico seco (PQS). Esses compostos funcionam como um cobertor de abafamento, isolando os combustíveis do oxigênio do ar, diminuindo a concentração do comburente e, consequentemente, inibindo o processo de combustão. No Quadro 1, é apresentada a concentração de oxigênio no ar para que ocorra a combustão.

Quadro 1 - Condições favoráveis para que ocorra a combustão

\begin{tabular}{|l|l|}
\hline Concentração de oxigênio (\%) & Combustão \\
\hline De 0 a 8 & Não ocorre \\
\hline De 8 a 13 & Lenta \\
\hline De 13 a 21 & Viva \\
\hline
\end{tabular}

Fonte: Boas práticas químicas em biossegurança (CARVALHO, 2013).

\section{Calor}

Vapor, muitos líquidos, sólidos e combustíveis inflamáveis são de natureza volátil, ou seja, evaporam rapidamente e estão continuamente emitindo vapores. A taxa de evaporação varia muito de um líquido para outro e aumenta com a temperatura.
A remoção do calor, ou o resfriamento de um incêndio, é a forma mais comum para a extinção do fogo. Um combustível entrará em combustão, espontaneamente, quando os seus vapores atingirem a temperatura de ignição. Essa temperatura é um fator determinante na fixação das normas de segurança para produtos voláteis, como petróleo, óleo diesel e óleo combustível lubrificante.

Na maioria das extinções de incêndios, a água é o elemento primordial utilizado para resfriamento do calor gerado pelo fogo. Esse calor transforma a água em vapor, permitindo, com isso, que o calor seja retirado. A água é capaz de agir para abafar as chamas e sufocar o fogo. Produtos 
químicos podem ser adicionados à água para melhorar a capacidade de remoção de calor ou melhorar a manutenção da integridade do combustível não consumido.

No caso de incêndios nas unidades de trabalho, tais como estabelecimentos de saúde, instituições de ensino e de pesquisa, indústrias, residências, meios de transporte e demais instalações em que se concentram pessoas e matérias combustíveis, os métodos de transmissão ocorrem por três meios - irradiação, condução e convecção.
Irradiação, condução e convecção são conceitos trabalhados neste livro, no Capítulo 7, "Refrigeração e equipamentos da rede de frio".

Figura 5 - Formas de transmissão de calor

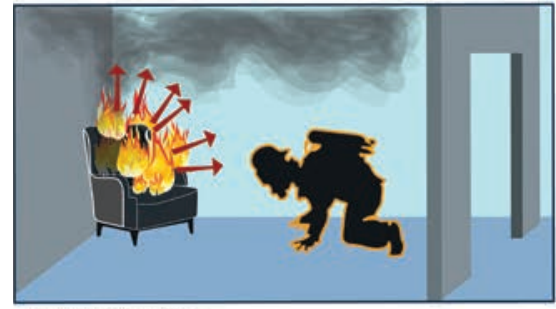

IRRADIAÇÃO

É a forma de transmissão de calor por meio de ondas caloríficas que atravessam o ar, irradiadas do corpo em chamas.

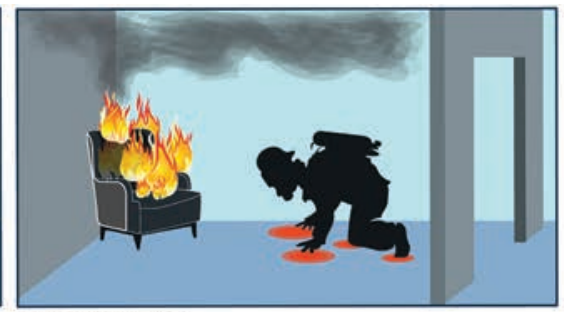

CONDUÇÃO

É a forma de transmissão de calor que se processa de um elemento a outro, de molécula a molécula.

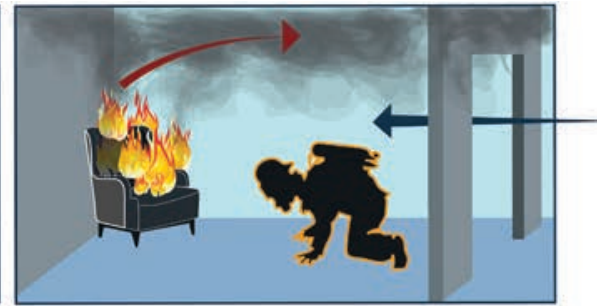

\section{CONVECÇÃO}

É a forma de transmissão de calor através da circulação de um meio transmissor gasoso ou líquido.

\section{Classes de incêndios e agentes extintores}

Existem quatro classes principais de incêndios no Brasil, conforme ilustra o Quadro 2.

Quadro 2 - Classes de incêndios

\begin{tabular}{|l|l|}
\hline & $\begin{array}{l}\text { São aqueles que envolvem materiais combustíveis comuns, como } \\
\text { madeira, papel, papelão, plástico, tecido e a maioria dos tipos de lixo. } \\
\text { Extintor de água é muito eficaz para a extinção desse tipo de incêndio, } \\
\text { no entanto, dependendo da área de trabalho (por exemplo, hospitais), } \\
\text { esses tipos de extintores não são facilmente encontrados, o que remete } \\
\text { ao uso de extintor de PQS. }\end{array}$ \\
\hline $\begin{array}{l}\text { São aqueles que envolvem líquidos inflamáveis, gases, óleos, tintas e } \\
\text { graxas. Para esse tipo de fogo, o recomendado é o extintor de CO, ou PQS. } \\
\text { A água não deve ser utilizada para incêndios dessa classe, tendo em vista } \\
\text { que líquidos inflamáveis e água são incompatíveis em caso de incêndios. }\end{array}$ \\
\hline $\begin{array}{l}\text { São aqueles que envolvem equipamentos elétricos de um modo geral, } \\
\text { quadros elétricos, motores elétricos etc. Para esse tipo de fogo, o } \\
\text { recomendado é o extintor de CO, ou extintores com carga de produtos } \\
\text { químicos secos e específicos. A água não deve ser utilizada para } \\
\text { incêndios dessa classe. O inconveniente de se utilizar PQS e demais } \\
\text { produtos químicos secos é que deixam nos equipamentos resíduos } \\
\text { difíceis de serem removidos. }\end{array}$ \\
\hline $\begin{array}{l}\text { São aqueles que envolvem metais combustíveis (pirofóricos), tais como } \\
\text { magnésio ou sódio. A água pode reagir com o sódio e outros metais } \\
\text { alcalinos explosivamente, portanto não use água! Os extintores de } \\
\text { CO não são capazes de conter um incêndio da Classe D, portanto } \\
\text { devem ser utilizados somente extintores do tipo PQS. }\end{array}$ \\
\hline
\end{tabular}

Fonte: Norma 9.443:2002 (ASSOCIAÇÃO BRASILEIRA DE NORMAS TÉCNICAS, 2002).

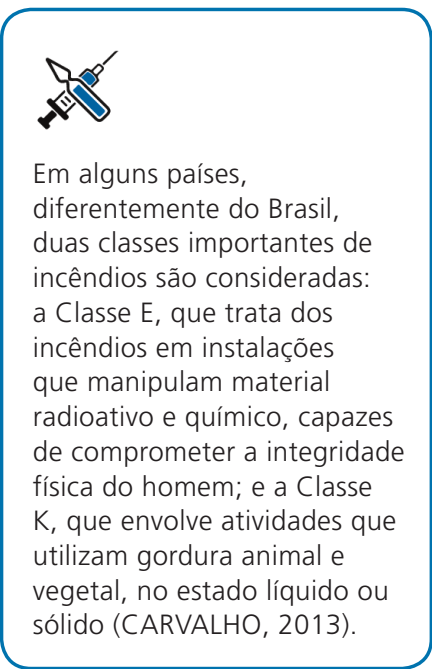


Indicações para o uso dos vários tipos de extintor, mencionados no Quadro 3, são apresentadas a seguir.

Quadro 3 - Agentes extintores

\begin{tabular}{|l|l|}
\hline Tipo de extintor & Finalidades \\
\hline PÓ QUÍMICO & $\begin{array}{l}\text { São ideais para uso em ambientes em que existe a possibilidade da geração } \\
\text { de múltiplos tipos de incêndios e oferecem uma excelente proteção geral. } \\
\text { Os extintores PQS são a única solução eficaz para incêndios envolvendo } \\
\text { gases inflamáveis. }\end{array}$ \\
\hline ESPUMA & $\begin{array}{l}\text { São ideais para uso em incêndios que envolvem materiais combustíveis sólidos } \\
\text { e são altamente eficazes em incêndios de líquidos inflamáveis. A camada } \\
\text { de espuma aplicada por esses extintores ajuda a evitar a reignição após a } \\
\text { extinção do fogo. }\end{array}$ \\
\hline $\begin{array}{l}\text { DIÓXIDO DE } \\
\text { CARBONO }\end{array}$ & $\begin{array}{l}\text { Extintores de CO } \mathrm{CO}_{2} \text { são adequados para uso em incêndios de líquidos } \\
\text { inflamáveis e são extremamente eficazes na extinção de incêndios envolvendo } \\
\text { equipamentos elétricos. O CO, é também um dos agentes de extintor mais } \\
\text { limpo e não deixa nenhum resíduo quando utilizado na extinção do fogo. }\end{array}$ \\
\hline ÁGUA & $\begin{array}{l}\text { São adequados para utilização em ambientes que contêm materiais combustíveis } \\
\text { sólidos, tais como madeira, papel e têxteis. É importante lembrar que a água } \\
\text { conduz eletricidade e não deve ser utilizada em equipamentos elétricos. }\end{array}$ \\
\hline
\end{tabular}

\section{Recomendações para o uso de extintores}

Algumas regras devem ser observadas e cumpridas, obrigatoriamente, no que tange ao uso dos extintores de incêndio:

1.Para que um extintor de incêndio seja utilizado, é necessária a obediência estrita a normas brasileiras ou regulamentos técnicos do Instituto Nacional de Metrologia e Qualidade Industrial (Inmetro).

2. Os extintores devem ser submetidos, mensalmente, a rigorosa vistoria, quando são examinados aspecto externo, lacres, manômetros (se pressurizados) e se os bicos de aspersão e as válvulas de alívio não apresentam obstrução.

3. As informações inerentes ao extintor devem estar disponíveis na etiqueta de identificação, presa, obrigatoriamente, ao corpo do extintor, onde constam a data em que foi submetido à recarga, a próxima data para recarga e o número de identificação. Essa etiqueta deve ser protegida ao máximo, para não ser danificada, e as informações, perdidas.

4. Os extintores de pressão injetada devem ser submetidos à pesagem, de preferência semestralmente, para que seja garantida a totalidade da recarga, que não deverá ter perda acima de 10\% do peso original. No caso de perda de peso, o cilindro deve ser submetido à recarga.

5. Os extintores de espuma devem ser inspecionados e recarregados anualmente. 
6. Quanto à localização dos extintores, eles devem ser colocados em locais de fácil visualização, de fácil acesso e, preferencialmente, em um ponto cujo acesso não seja dificultado pelo fogo, em caso de incêndio.

7. Os locais destinados aos extintores devem ser identificados de acordo com as normas vigentes. No piso, o local deve ser identificado por pintura de um quadrado de, no mínimo, $1 \mathrm{~m}^{2}$, na cor vermelha. Essa área deve estar livre de qualquer obstrução.

\section{Como utilizar um extintor de forma segura}

Para manejar um extintor de forma eficiente e segura, há alguns passos a serem seguidos:

1. Segurar o extintor firmemente, puxar e rodar, concomitantemente, o pino de segurança.

Atenção: esse pino garante a segurança para que o extintor não seja acionado acidentalmente.

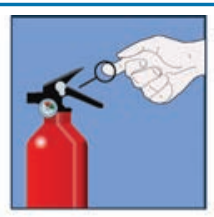

2. Aponte o bico do extintor em direção à base do fogo.

Atenção: mantenha uma distância de, pelo menos, 8 metros do fogo. Observe a direção do vento. Se o vento estiver soprando em sua direção, mude a posição em relação ao fogo.

3. Pressione a alça para descarregar o extintor.

Atenção: peça ajuda e tenha outros extintores nas proximidades, pois, dependendo do tipo de extintor, a carga do componente poderá não ser suficiente. Caso não consiga debelar as chamas, saia do local e chame o Corpo de Bombeiros.

4. Varrer o bocal de trás para frente e de lado a lado até que as chamas sejam extintas.

Atenção: fique atento, pois as chamas podem voltar a acender!
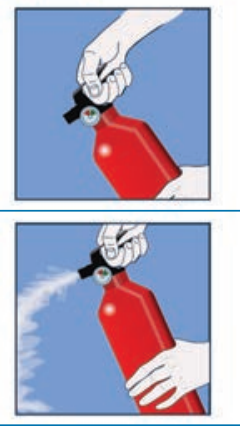

\section{Considerações finais}

Falar em biossegurança significa procurar cuidar da vida de forma ética. Para tanto, os ambientes de trabalho da rede de frio de imunobiológicos devem estar em condições adequadas, assim como os trabalhadores, gestores e usuários devem conhecer as chamadas "boas práticas da biossegurança". Por isso, há extrema necessidade de educação permanente dos trabalhadores para que eles possam acompanhar o avanço tecnológico e realizar o trabalho de forma preventiva e resolutiva. 
O mesmo entendimento pode ser aplicado, também, à questão do incêndio, pois tem íntima relação com a biossegurança. É muito importante ter conhecimentos gerais que possam auxiliar na redução das possibilidades de geração de incêndio.

Portanto, é fundamental estar atento às normas e às boas práticas que garantem não só a sua segurança, mas a de todos que dependem do seu trabalho. Lembre que o aprendizado deve ser contínuo, com a finalidade de garantir a qualidade necessária para a prestação de serviços, no tocante à rede de frio de imunobiológicos.

\section{Referências}

AGÊNCIA NACIONAL DE VIGILÂNCIA SANITÁRIA (Brasil). Biossegurança. Brasília, DF, 2016. Disponível em: <http://goo.gl/L6zta0>. Acesso em 5 ago. 2016.

AGÊNCIA PORTUGUESA DO AMBIENTE. Responsabilidade ambiental. [Lisboa], 2009. Disponível em: $<$ http://www.apambiente.pt/index.php?ref=17\&subref=157>. Acesso em: 23 set. 2016.

ASSOCIAÇÃO BRASILEIRA DE NORMAS TÉCNICAS. ABNT NBR 9.443: extintor de incêndio. Rio de Janeiro, 2002.

BONIS, M.; COSTA, M. A. F. Ética da alteridade nas relações entre biossegurança em saúde e bioética. Revista Ciências \& Cognição, Rio de Janeiro, v. 14, 2009.

BRASIL. Lei n. 11.105, de 24 de março de 2005. Regulamenta os incisos II, IV e $V$ do $\S 1^{\circ}$ do art. 225 da Constituição Federal, estabelece normas de segurança e mecanismos de fiscalização de atividades que envolvam organismos geneticamente modificados - OGM e seus derivados, cria o Conselho Nacional de Biossegurança - CNBS, reestrutura a Comissão Técnica Nacional de Biossegurança - CTNBio, dispõe sobre a Política Nacional de Biossegurança - PNB, revoga a Lei n. 8.974, de 5 de janeiro de 1995, e a Medida Provisória n. 2.191-9, de 23 de agosto de 2001, e os arts. $5^{\circ}, 6^{\circ}, 7^{\circ}, 8^{\circ}, 9^{\circ}, 10$ e 16 da Lei n. 10.814 , de 15 de dezembro de 2003 , e dá outras providências. Diário Oficial da União, Brasília, DF, 24 mar. 2005. Disponível em: <http://www. planalto.gov.br/ccivil_03/_ato2004-2006/2005/lei/l11105.htm>. Acesso em: 24 out. 2016.

BRASIL. Ministério da Saúde. Secretaria de Vigilância em Saúde. Departamento de Vigilância das Doenças Transmissíveis. Manual de rede de frio do Programa Nacional de Imunizações. 4. ed. Brasília, DF, 2013.

BRASIL. Ministério do Trabalho. Normas regulamentadoras. Brasília, DF, 2015. Disponível em: <http://trabalho.gov.br/index.php/seguranca-e-saude-no-trabalho/normatizacao/normasregulamentadoras>. Acesso em: 20 set. 2016.

CARVALHO, P. R. O olhar docente sobre a biossegurança no ensino de ciências: um estudo em escolas da rede pública do Rio de Janeiro. Tese (Doutorado) - Instituto Oswaldo Cruz, Rio de Janeiro, 2008.

CARVALHO, P. R. Boas práticas químicas em biossegurança. 2. ed. Rio de Janeiro: Interciência, 2013. 
COSTA, M. A. F. Qualidade em biossegurança. Rio de Janeiro: Qualitymark, 2000.

COSTA, M. A. F.; COSTA, M. F. B. Entendendo a biossegurança: epistemologia e competências para a área da saúde. Rio de Janeiro: Publit, 2010.

HOUAISS, A.; VILLAR, M. S. Dicionário Houaiss da língua portuguesa. Rio de Janeiro: Objetiva, 2009.

INTERNATIONAL ORGANIZATION FOR STANDARDIZATION. What is ISO? Geneva, 2016. Disponível em: <http://www.iso.org/iso/home.html >Acesso em: out. 2013.

MACÊDO, L.; FREIRE, S. M.; ANDRADE, J. A. Acidentes ocupacionais com BCG em salas de vacina do estado da Bahia. Revista Baiana de Saúde Pública, Salvador, v. 37, n. 1, p. 222-235, 2013.

OS QUATRO pilares da educação. In: DELORS, Jacques et al. Educação: um tesouro a descobrir: relatório para a UNESCO da Comissão Internacional sobre Educação para o século XXI. São Paulo: Cortez, 1996. Disponível em: <http://dhnet.org.br/dados/relatorios/a_pdf/r_unesco_educ_tesouro_ descobrir.pdf>. Acesso em: 23 set. 2016.

PGB CONSULTORIA E ASSESSORIA. ISO 9000: gestão da qualidade. São Paulo, [201-]. Disponível em: <http://www.pgpconsultoria.com.br/servicos_iso9000.php>. Acesso: em mar. 2014.

RODRIGUES, R. S. C. et al. Incêndio em edificações hospitalares: conhecimento dos profissionais de enfermagem sobre prevenção, combate e escape. Revista Eletrônica de Enfermagem, v. 16, n. 2, 30 jul. 2014.

SILVA, T. R. et al. Acidente com material perfurocortante entre profissionais de enfermagem de um hospital universitário. Revista Gaúcha de Enfermagem, Porto Alegre, v. 31, n. 4, p. 615-622, 2010. 
Formato: $205 \times 260 \mathrm{~mm}$

Tipografia: Meridien LT Std e Frutiger Lt Std

Papel do Miolo: Offset $90 \mathrm{~g} / \mathrm{m}^{2}$

Papel e Acabamento Capa: Papel Cartão supremo 250g/m²

Ctp Digital: Walprint Gráfica e Editora

Impressão e acabamento: Walprint Gráfica e Editora

Rio de Janeiro, julho de 2017. 
Rede de Frio: gestão, especificidades e atividades versa sobre o complexo sistema logístico adotado pela rede de frio de imunobiológico e implementado por equipes com perfis profissionais diversificados, nos níveis nacional, regional, estadual, municipal e local, com a finalidade de garantir a eficácia e a qualidade dos imunobiológicos oferecidos aos cidadãos.

O livro analisa, sob a ótica do planejamento, da gestão e dos processos de trabalho, os caminhos percorridos pelas vacinas dos laboratórios fabricantes até as comunidades longínquas, de difícil acesso, ressaltando as condições requeridas para a manutenção da sua integridade e a observância das normas de manuseio dos imunobiológicos. Oferece uma visão completa de como opera, passo a passo, a rede de frio do Programa Nacional de Imunizações no país, em diferentes realidades sociopolíticas, econômicas e culturais.

Publicada pela Editora Fiocruz, em parceria com a Escola Nacional de Saúde Pública Sergio Arouca/Coordenação de Desenvolvimento Educacional e Educação a Distância (ENSP/CDEAD), a obra, por sua especificidade e aprofundamento, é leitura recomendada para todos os profissionais de saúde da cadeia de frio e da sala de imunizações do Brasil.

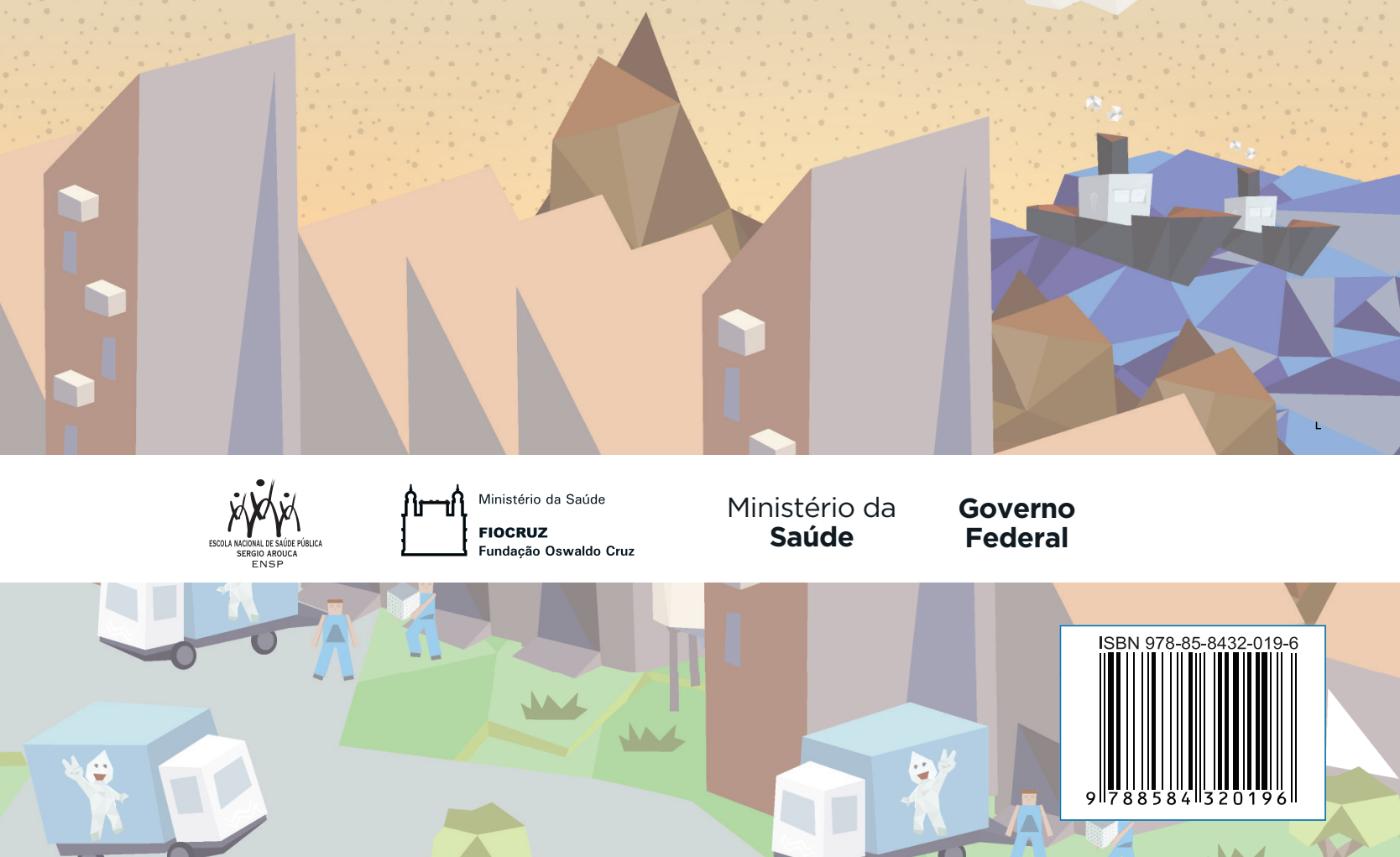

